\title{
EVALUATION AND DEMONSTRATION OF DECENTRALIZED SPACE AND WATER HEATING \\ VERSUS CENTRALIZED SERVICES FOR NEW \\ AND REHABILITATED MULTIFAMILY BUILDINGS
}

Final Report

Prepared for

THE NEW YORK STATE

ENERGY RESEARCH AND DEVELOPMENT AUTHORITY

Project Manager

Norine H. Karins

Prepared by

FOSTER-MILLER, INC.

350 Second Avenue

Waltham, MA 02154-1196

Project Manager

Paul Belkus

STEVEN WINTER ASSOCIATES, INC.

50 Washington Street

Norwalk, CT 06854

Project Manager

Adrian Tuluca

NATIONAL CONFERENCE OF STATES

ON BUILDING CODES AND STANDARDS

505 Huntman Park Drive, Suite 210

Herndon, VA 22070

1794-EEED-BES-92

Energy Authority

Report 93-8

June 1993

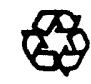




\section{NOTICE}

This report was prepared by Foster-Miller, Inc. in the course of performing work contracter for and sponsored by the New York State Energy Research and Development Authority (hereafter the "Energy Authority"). The opinions expressed in this report do not necessarily reflect those of the Energy Authority or the State of New York and reference to any specific product, service, process or method does not necessarily constitute an implied or expressed recommendation or endorsement of same. Further, the Energy Authority, the State of New York and the contractor make no warranties $\mathrm{Ci}$ representations, expressed or implied, as to the fitness for particular purpose, merchantability of any product, apparatus or service or the usefulness, completeness or accuracy of any processes, methods or other information contained, described, disclosed or referred to in this report. The Energy Authority, the State of New York and the contractor make no representation that the use of any product, apparatus, process, method or other information will not infringe privately owned rights and will assume no liability for any loss, injury, or damage resulting from, or occurring in connection with, the use of information contained, described, disclosed, or referred to in this report.

First Printing: June 1993 


\section{ABSTRACT AND KEY WORDS}

\section{ABSTRACT}

The general objective of this research was aimed at developing sufficient technical and economic know-how to convince the building and design communities of the appropriateness and energy advantages of decentralized space and water heating for multifamily buildings. Two main goals were established to guide this research. First, the research sought to determine the cost-benefit advantages of decentralized space and water heating versus centralized systems for multifamily applications based on innovative gas piping and appliance technologies. The second goal was to ensure that this information is made available to the design community.

To achieve the two main goals of this research project, eight specific tasks were performed :

- Conduct a review of extant literature and research on comparisons between centralized versus decentralized space and water heating in multifamily dwellings.

- Analyze energy requirements and potential for savings as a result of technical innovations applicable to decentralized gas-fired space and water heating systems for three prototypical multifamily dwellings.

- Characterize the multifamily building stock in the State of New York. Determine which types of multifamily buildings are most likely to benefit from innovations in decentralized space and water heating systems.

- Investigate the regulatory barriers in the State of New York to the use of innovative technology for new gas piping and decentralized gas-fired space and water heating systems in multifamily dwellings.

- Develop strategies for overcoming the identified institutional barriers or for promoting the adoption of new gas piping systems and appliance technologies.

- Conduct a survey to identify emerging technologies for gas piping. gas metering, gas utilization equipment, and appliance vents for rehabilitated and newly constructed multifamily buildings.

- Conduct a survey to identify innovative construction technologies for chaseways, appliance venting, fire protection, insulation, and other affected areas of rehabilitated and newly constructed multifamily buildings.

- Document the results of the research in a comprehensive final report. This is the vehicle for information transfer to the design community. 
Several surveys, literature reviews, assessments, and analyses were conducted to achieve the project goals.

The resuits of the research clearly indicate that there exists a sizable new and retrofit multifamily market for decentralized space and water heating systems in the State of New York. Furthermore, substantial energy savings are achlevable in multifamily buildings solely as a result of the decentralized heating configurations. Also, shifting the responsibility for heating costs to tenants alone results in energy savings.

Potential energy savings can range from 6 to 77 percent.

However, institutional constraints could affect the implementation of new gas piping systems and appliance technologies. More spectfically, there exists potential code barriers to the acceptance of corrugated stainless steel tubing (CSST) gas piping systems and duel integrated appliances (DIAs) in multifamily buildings. The constraints focus on the use of elevated gas pressures, the use of circulating potable water for heating or cooling, and the actual approval or installation of the tubing material (CSST). A great deal of work will be required to inform and educate the affected parties before acceptance and use of the technologies is achieved.

The technology survey, which identified emerging gas technologies that are considered innovative relative to conventional approaches that are in use today, concluded: 1) there are commercially avallable small residential meters that could be used for multifamily new and rehabilitated construction projects in the State of New York; 2) a combination of rigid steel pipe (vertical riser) and/or semirigid tubing (CSST or copper tubing) operated at elevated pressure (up to $5 \mathrm{psi)}$ ) offer the most advanced technologies that will result in the lowest total installed costs for multifamily new and rehabilitated buildings; and 3 ) combination space and water heating systems require a Category I vent because the water heater portion of the system produces combustion products. However, no other special materials or installation practices are required for the vent systems of combination space and water heating systems.

\section{KEY WORDS}

Interior gas distribution

Decentralized space and water heating systems

Duel integrated appliances

Corrugated stainless steel tubing
Energy use by buildings

Muiti-attribute analysis

Energy savings

Multifamily buildings 


\section{ACKNOWLEDGMENTS}

Foster-Miller, Inc. acknowledges the valuable contributions made to this research from two subcontractors. Without their contributions and efforts, this research project could not have been successfully completed. The research plan was developed around a team approach and the following members are gratefully recognized.

Mr. Adrian Tuluca - Steven Winter Associates. Mr. Tuluca conducted the economic/ energy assessment. This study analyzed the energy requirements and potential savings as a result of technical innovations applicable to decentralized gas-fired space and water heating systems for multifamily dwellings. The study also characterized the multifamily bullding stock in the State of New York.

Ms. Kate McQueen - National Conference of States on Bullding Codes and Standards. Ms. McQueen provided an assessment of the codes and standards that address institutional concerns associated with avallable technologies for decentralized gas applications in multifamily buildings in the State of New York. 


\section{TABLE OF CONTENTS}

Section

SUMMARY

INTRODUCTION

Goals and Objectives

ECONOMIC AND ENERGY ASSESSMENT

Analysis of Opportunities for Decentralized Space Heating/Domestic

Hot Water Heating in the State of New York

MAA Tables with Statistics on Multifamily Homes

Tables Containing Only Heuristic Information ...........................2-8

Multiple Attribute Analysis ............................................... 2-8

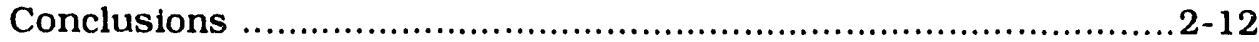

Energy Simulation ............................................................. 2-15

Building Prototypes ......................................................... 2-15

Building Geometry ........................................................... 2-18

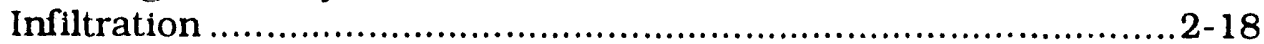

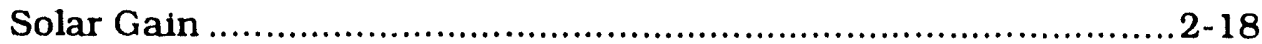

Operating Assumptions ................................................. 2-19

Integral Loads ........................................................... 2-19

Domestic Hot Water Loads Methodology ................................ 2-19

HVAC System ...............................................................2 1

Results of Simulations ................................................................ 1

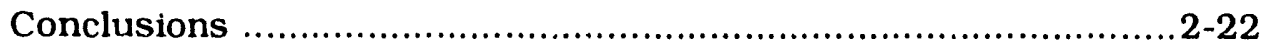

Recommendations ..........................................................2-24

Central Versus Decentralized Heating in Multifamily Buildings,

A Literature Review .........................................................2-25

Executive Summary ....................................................25

Methods to Save Heating/DHW Energy Through Tenant Control

and Decentralized Equipment ..........................................2-25

Conclusions .....................................................................2-30

Recommendations ............................................................ 2-31

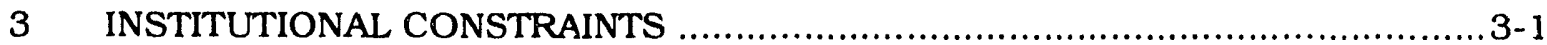

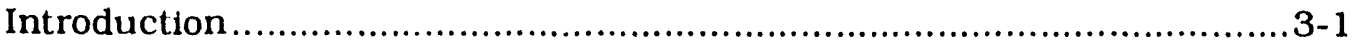

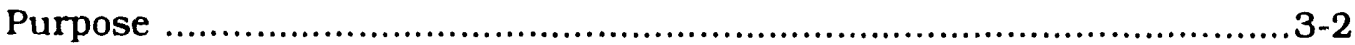

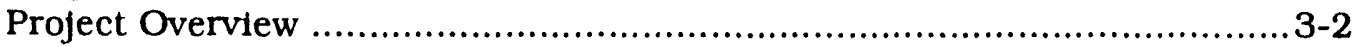

Task 1 - Review of Available Technologies ................................3-3

Task 2 - Identification of Code Issues ........................................3-4

Task 3 - Review of Building Construction Regulations .................3-5

Task 4 - Development of Strategies .......................................3-23

Insights by Issues .......................................................

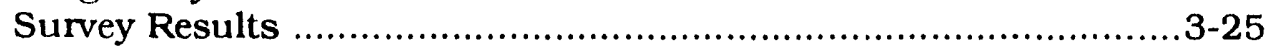

Strategies .....................................................................

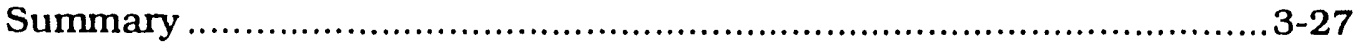

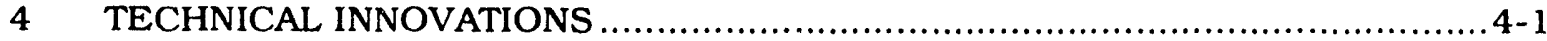

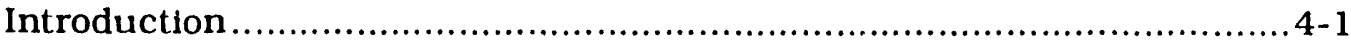

Category One - Technologies that Affect Energy Distribution/ Utilization Equipment 
Category Two - Technologies that Affect the Bullding Structure ............4-3

Metering .............................................................................4 4-4

Automatic Meter Reading Systems .......................................4-5

Compact Gas Meters .......................................................4-9

GRI Program ............................................................... 4-9

GRI Projects Now Underway on Near-Term Compact Meters .........4-11

Gas Piping Technologies ......................................................... 4-12

Piping and Tubing Systems .................................................4-12

Distribution Networks .................................................4-25

Piping System Accessories ................................................4-32

Space and Water Heating Systems ...........................................4-45

Mor-Flo Industries, Inc. ...............................................4-49

Rheem Manufacturing Company ........................................4-54

Apollo Hydro Heat ..........................................................4-56

First Co. - Aqua Thermaire ............................................. 4-60

Comparison of Dual Integrated Systems ......................................4-60

Benefits of Dual Integrated Systems .............................................4-64

Appliance Venting ................................................................4-66

Construction Practices ...............................................................4-70

Installation Assumptions and Limitations ..................................4-70

Limitations ....................................................................4 4-71

List of Drawings .............................................................. 4-72

Summary ........................................................................... 42

Conclustons ...................................................................... 47

5 SUMMARY AND CONCLUSIONS …......................................................

Retrofit of Pre-1970 Multifamily Bulldings ................................... 5-1

New Multifamily Buildings ......................................................5 5-2

Energy Assessment ...............................................................

Institutional Constraints ......................................................... 5-3

Technical Innovations ............................................................. 5-4

APPENDIX A Criteria for Assigning Wetghting Factors and Opportunity Ratings .....A-1 APPENDIX B Multiple Attribute Analysis for Decentralized Heating in Existing Multifamily Bullding Stock in New York State ........................ B-1

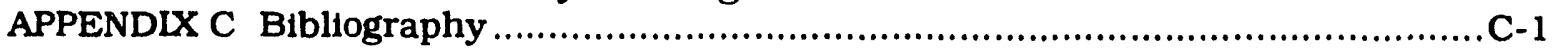

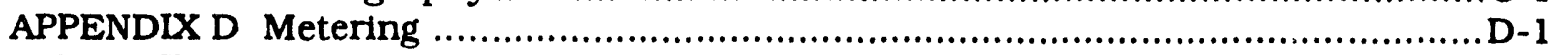

APPENDIX E Gas Piping Technologies ..................................................

APPENDIX F Combination Space and Water Heating Systems .............................. F-1

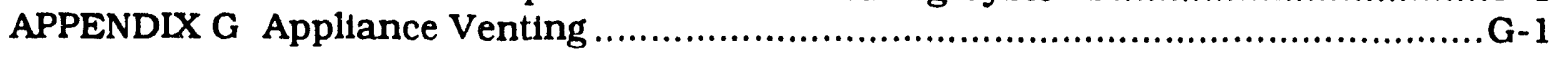




\section{FIGURES}

4-1 Metretek Automatic Meter Reading System ................................... 4-8

4-2 Commercially Available Small Residential Gas Meters ......................... 4-12

4-3 Vertical Riser .......................................................................... 4-14

4-4 SAE 45-Degree Flare Fitting with Tube Attached .................................. 4-2 1

4 5 Thermoplastic-Lined Welded Tubing Concept .................................4-22

4-6 Gas Distribution Network - Typical Residential-Commercial Building ...... 4-26

4-7 Gas Distribution Network with Submeter Room Located in

Parking Garage ............................................................4 4-28

4-8 Gas Distribution Network with Submeter Room on Each Floor ..............4-29

4-9 Gas Distribution Network with Submeter Room on Every Other Floor ......4-30

4-10 Gas Distribution Network with Electronic Submetering ......................4-31

4-11 British Gas Mark II Built-In Meter Box ...............................................4-32

4-12 British Gas Concealed Meter Box .................................................4-33

4-13 British Gas Semi-Concealed Meter Box .....................................4-33

4-14 R.W. Lyall Flush Mounted Manifold Box ....................................4-34

4-15 Foster-Miller Striker Plate Designs .......................................4-36

4-16 Striker Plate Installed to Protect CSST ........................................4-36

4-17 Gas Tubing Installed in Baseboard Channel ................................. 4-37

4-18 British Gas Tubing and Micropoint Gas Outlet Installation Using

Baseboard Channel ...............................................................4-38

4-19 M.B. Sturgis Advanced Convenience Gas Outlet ............................ 4-40

4-20 Special Gas Outlet Enclosure for Concealed Joints ............................4-43

4-21 Standard Gas Outlet Wall Mounting Method ................................4-44

4-22 Combination Space and Water Heating System ................................4-47

4-23 Combination Spacer and Water Heating Systems ..............................4-50

4-24 Proper Sizing Procedure for a Combo System ...............................4-51

4-25 Summary of Mor-Flo Appliances for Dual Use ..................................4-52

4-26 Mor-Flo's Polaris Water Heater .................................................... 4-53

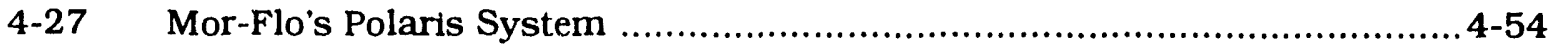

4-28 Mor-Flo's Integra System ........................................................... 4-55

4-29 Rheem's EnergyMate System .................................................. 4-57

4-30 Apollo's Hydro Heat System .................................................... 4-59

4-31 First Co.'s Aqua Therm System .................................................... 4-61

4-32 ANSI Categorization Criteria per ANSI Z223.1-1988 ….........................4-68

4-33 Gas Pipe Penetration through Exterior Wall of Wood Studs and Siding .... 4-73

4-34 Flexible Tubing Run through Wood Frame Construction ......................4-74

4-35 Flexible Tubing Run through Wood Trusses at Attic Floor .......................4-75

4-36 Flexible Tubing Run through Wood Truss Floors ...............................4-76

4-37 Gas Pipe Penetration through Exterior Wall of Brick Veneer on Metal Studs .................................................................47

4-38 Flexible Tubing Run through Stud Partition Wall ................................4-78

4-39 Flexible Tubing Run through Steel Stud Partition ..............................4-79

4-40 Gas Pipe Penetration through Brick and Block Cavity Wall .......................4-80

4-41 Multiple Gas Lines Penetrating through Fire Wall ...............................4-80

4-42 Gas Riser and Tubing Runs through Concrete Slab .............................4-81

4-43 Gas Line Penetration through Poured Concrete Slab at Roof .................... 4-82

4-44 Gas Pipe Penetration through Hollow Core Concrete Slab at Roof .............4-83

4-45 Gas Pipe Penetration Detail through Hollow Core Concrete Roof Slab ...... 4-84 
4-46 Flexible Tubing Run through Concrete Roof Slab and

Steel Joist Framing ......................................................... 4-85

4-47 Gas Pipe Penetration through Roof with Hung Ceiling ....................... 4-86 


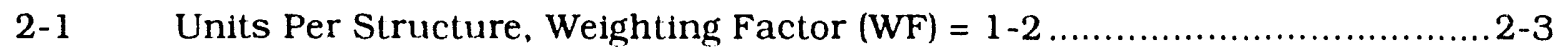

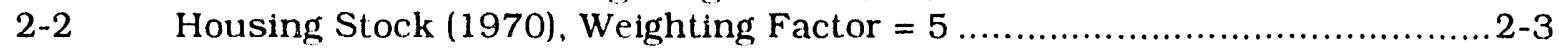

2-3 Existing Heating Fuel Replacement Potential ...................................... 2-4

2-4 Existing Heating System Replacement Potential ..............................2-5

2-5 Floors Per Structure in New York State, Weighting Factor $=5 \ldots \ldots \ldots \ldots \ldots \ldots .2-6$

2-6 Number of Units Grouped According to Number of Floors,

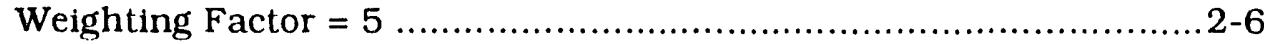

2-7 Gas Availability, Existing Housing Stock, Weighting Factor $=5 \ldots \ldots \ldots \ldots \ldots \ldots .6$

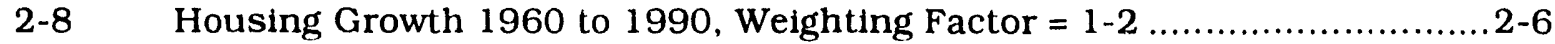

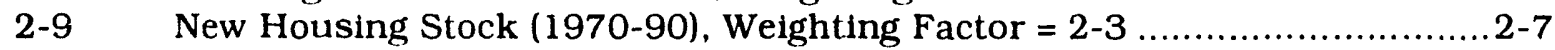

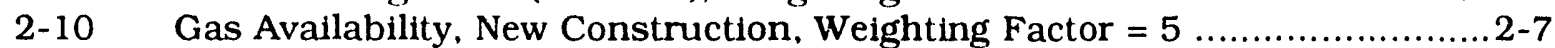

2-11 Total Stock of Multifamily Units in the State of New York .......................2-7

2-12 Normalized Scores for the Segmentation by Number of Apartments .........2-10

2-13 Normalized Scored for Full Type and Heating System Type ...................2-11

2-14 Classification of Pre-1970 Multifamily Bulldings in New York City by

Number of Units and Building Height ...................................2-13

2-15 Characteristics of Pre-1940 Prototype ....................................... 16

2-15 Characteristics of Post-1980 Prototype ......................................... 2-17

2-17 Estimated Average Annual Internal Loads Per Multifamily Apartment Unit ...................................................................... 2-20

2-18 Energy and Cost of Multifamily Units for Heating and DHW ..................2-21

2-19 Change in Energy Use and Energy Cost Between Central and DIA Systems .............................................................2-22

2-20 Pre-1940 Building Natural Gas Consumption for Space Heating and DHW ..................................................................2-23

2-21 Post-1980 Building Natural Gas Consumption for Space Heating and DHW ...................................................................2-24

2-22 Energy Savings in the Palermini and Hewitt (1991) Study ......................2-28

2-23 Summary of Energy Savings Achieved by Shifting Responsibility of Heating Costs to Tenants of Multifamily Bulldings .....................2-31

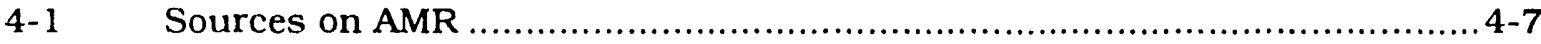

4-2 Target Specifications for Near-Term Meters ................................ 4-10

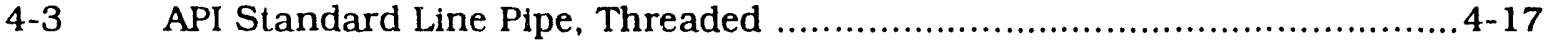

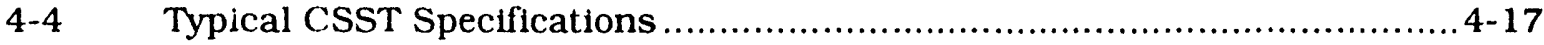

4-5 Results from Piping Field Tests Installation Labor and Cost Comparison .4-19

4-6 Copper Tubing Dimensional Specifications ....................................4-20

4-7 Summary of Composite Tubing Products ..................................... 4-24

4-8 Minimum Efficiency Levels and Effective Dates for Gas Appliances Covered by NAECA .....................................................4-46

4-9 Summary of Rheem Appliances for Dual Use .............................. 4-56

4-10 Summary of State Appliances for Dual Use .................................4-58

4-11 Water Heater Matrix for Dual Integrated Systems .............................. 4-62

4-12 Air Handler Matrix for Dual Integrated Systems ...............................4-63

4-13 Types of Applications for Dual Integrated Systems ........................... 4-65

4-14 Installed Costs for Dual Integrated Systems ................................. 4-66

5-1 Estimate of Number of Floors versus Number of Units .......................... $5-2$ 


\section{SUMMARY}

This research project has determined the cost-benefit advantages of clecentralized space and water heating versus centralized systems for multifamily applications based on innovative gas piping and appliance technologies. A complete review was performed to assess the energy requirements and potential for savings as a result of technical innovations applicable to decentralized gas-fired space and water heating systems for multifamily dwellings in the State of New York. The review included the characterization of the multifamily building stock in the Siate of New York to determine which types of multifamily buildings are most likely to benefit from innovations in decentralized space and water heating systems.

For the retrofit multifamily market, the analysis concluded that buildings with 10 to 49 apartments and buildings with 50 or more apartments represent the largest segment of the multifamily market in the State of New York (over 70 percent). Another segment with a high potential is defined by low-rise (one to three floors) buildings with three to nine apartments, that have gas-fired hydronic heating. Buildings with over 10 units are appropriate for decentralized heating/domestic hot water systems, provided they are less than 4 stories high and either have gas heating or the economies of fuel switching are attractive. Seventy-five to eighty percent of these buildings use fuel oil. Regarding new multifamily buildings, the largest market segment, when defined solely by the number of units in New York State, currently appears to be that with 50 or more apartments.

Finally, the assessment indicated that substantial energy savings are achievable in multifamily buildings solely as a result of the conversion to a decentraiized configuration. The savings range from 11 to 15 percent for the pre-1940 building types, and from 7 to 17 percent for the post-1980 building types. However, the heating energy cost increases for dual-integrated appliance (DIA) systems. In the Consolidated Edison and Brooklyn Union Gas service territories, the increase ranges from 42 to 53 percent for pre-1940 building types, and 59 to 83 percent for post-1980 building types. The cost increases are a result of the high gas rate for the first few therms, and to the service charges assessed on each apartment. This rate structure constitutes a significant institutional impediment. 
The literature review of decentralized versus centralized heating systems revealed (through several studies) that shifting the responsibility for heating costs to tenants results in energy savings. Furthermore, based on those studies, energy savings ranged from 6 to 77 percent.

Institutional constraints that may affect the implementation of new gas piping systems and appliance technologies were investigated and identified, and strategies to overcome them were developed. The potential code barriers to the acceptance of corrugated stainless steel tubing (CSST) gas piping systems and DIAs in multifamily buildings focused on the use of elevated gas pressures, the use of circulating potable water for heating or cooling, and the actual approval or installation of the tubing material (CSST).

From the informal survey of professionals with an interest in these applications, the National Conference of States on Building Codes and Standards (NCSBCS) found that several issues of concern presented in Section 3 are fairly pervasive throughout the State of New York. These included but were not limited to: concerns about gas pressures over $0.5 \mathrm{psig}$ inside a residential structure, the use of potable water for space heating, and the sack of a long-term safety record for CSST, despite its listings. In conclusion, a great deal of work will be required to inform and educate the affected parties before acceptance and use of these technologies is achieved. Strategies for overcoming the restriction on using potable water for space heating and elevated gas pressures in multifamily buildings were developed.

A technology survey was conducted by Foster-Muler to identify emerging gas technologies that are considered innovative relative to conventional approaches that are in use in New York State today. Areas of investigation included metering. gas piping, space and water heating systems, and appliance venting. A second survey was conducted by Steven Winter Associates (SWA) to identify installation methods for gas piping located in chaseways, fire protected areas, and other affected areas of rehabilitated and newly constructed multifamily buildings. The results of the SWA survey were documented by the development of 15 construction drawings showing details of flexible tubing and rigid piping installation techniques needed for the implementation of this recently developed technology. 
Three of the most significant conclusions drawn from the survey are:

- There are commercially available small residential meters that could be used effectively for multifamily new and rehabilitated construction projects in the State of New York. These downsized meters, which are 40 percent smaller than existing meters of the same flow capacity, can save valuable space in submetering closets. Several compact gas meters are under development, but are not commercially avallable and are still a few years from commercial availability.

- A combination of rigid steel pipe (vertical riser) and/or semirigid tubing (CSST or copper tubing) operated at elevated pressure (up to 5 psi) offers the most advanced technology that will result in the lowest total installed costs for multifamily new and rehabilitated buildings.

- Combination space and water heating systems require a Category I vent jecause the water heater portion of the system produces combustion products. However, no special materials or installation practices are required for the vent systems of combination space and water heating systems. 


\section{Section 1 \\ INTRODUCTION}

The primary objective of this research was aimed at developing sufficient technical and economic know-how to convince the butlding and design communities of the appropriateness and energy advantages of decentralized space and water heating for multifamily buildings. Several recent political and technical events have made this project especially timely. Renewed concerns for energy independence and efficiency are lending new impetus to utilizing natural gas as the residential fuel of choice. New methods and requirements for appliance venting and gas piping are affecting the costs of installing gats service. New combustion-gas space and water heating, heating/air conditioning, and space heating only equipment all require new evaluations in light of current econornic conditions.

More cost-effective use of natural gas specifically, but also energy for space and water heating, in general, will have economic benefits to the citizens of the State of New York. In particular, occupants of multifamily buildings, who do not have any say in the space/water heating fuel, are left to pay the bill for the decisions of others. The number of citizens living in multifamily buildings in New York represents a significant proportion of the total state population. It is essential that this large population be given some future options regarding the use of more cost-effective energy alternatives.

\section{GOALS AND O13JECTIVES}

There were two main goals established and achieved through this research. First, the research sought: to determine the cost-benefit advantages of decentralized space and water heating versus centralized systems for multifamily applications based on innovative gas piping and appliance technologies. The second goal was to ensure that this information. is made available to the design community.

In order to achieve these goals, nine specific tasks were developed, eight of which were performed:

- Task 1: Conduct a review of extant literature and research on comparisons between centralized versus decentralized space and water heating in multifamily dwellings. 
- Task 2: Analyzt energy requirements and potential for savings as a result of technical innovations applicable to decentralized gas-fired space and water heating systems for three prototypical multifamily dwellings.

- Task 3: Characterize the multifamily building stock in the State of New York. Determine which types of multifamily buildings are most likely to benefit from innovations in decentralized space and water heating systems.

- Task 4.: Investigate the regulatory barriers in the State of New York to the use of innovative technology, for new gas piping and decentralized gas-fired space and water heating systems, in multifamily dwellings.

- Task 5: Develop strategies for overcoming the identified institutional barriers or for promoting the adoption of new gas piping systems and appliance technologies.

- Task 6: Conduct a survey to identify emerging technologies for gas piping, gas metering, gas utilization equipment and appliance vents for rehabilitated and newly constructed multifamily buildings.

- Tasik 7: Conduct a survey to identify innovative construction methods and technologies for chaseways, appliance venting, fire protection, insulatioii, and other affected areas of rehabilitated and newly constructed multifamily buildings.

- Task 8: Provide demonstrable verification of the predicted results based on the engineering/market studies.

- Task 9: Document the results of the research in a comprehensive final report. Thts is the vehicle for information transfer to the design community.

All but Task 8 were successfully completed in this research project. A demonstration was originally proposed by Foster-Miller in conjunction with a piping study sponsored by Brooklyn Union Gas (BUG). Unfortunately, BUG had to cancel the piping study, which forced the Energy Authority and Foster-Miller to delete the demonstration task from this research project.

The economic/energy assessment is reported in Section 2. The economic assessment evaluates the opportunities for decentralized space and water heating systems in the New York State multifamily housing stock. The energy assessment focuses on the energy savings associated with natural gas and water heating equipment in two multifamily building types. Section 3 investigates and identifies institutional barriers and develops an action plan for the adoption of new gas piping systems and appliance technologies. Section 4 presents and discusses technical innovations. Emerging 
technologies are identified that are considered innovative to conventional approaches that are currently in use in New York State today. Section 5 contains conclusions and recommendations based on the reported research. 


\section{Section 2 \\ ECONOMIC AND ENERGY ASSESSMENT}

\section{ANALYSIS OF OPPORTUNITIES FOR DECENTRALIZED SPACE HEATING/ DOMESTIC HOT WATER HEATING IN NEW YORK STATE}

This section represents one component of the research effort to evaluate the opportunities for decentralized space and water heating systems in the New York State multifamily housing stock. Steven Winter Associates, Inc. (SWA) performed a multiple attribute analysis (MAA) to detect the characteristics of multifamily housing that could most benefit from decentralized heating/domestic hot water (DHW).

The MAA can help reach decisions on the merit of different options when attributes (features) of these options are not easily quantifiable and directly comparable. This project, in particular, addresses the potential for installing decentralized heating/DHW in different types of multifamily housing. As shown below, the potential is determined by an interplay of several attributes (features) of each housing type: how many apartments there are per building, how many stories there are per bullding, how old the building is, what type of fuel it uses, what type of heating system it has, etc.

Some of these attributes are easily quantifiable (e.g., the total of New York State apartments that are located in buildings composed of 3-4 apartments, 5-9 apartments, 10-49 apartments and over 50 apartments). Other attributes are more difficult to quantify because data are scarce (e.g., total of New York State apartments that are located in buildings with 1-3 stories and with over 50 apartments). Each attribute has a different weight (importance) in deciding whether the decentralized heating/DHW system is feasible. The number of stories in a bulding, for instance, is very important; the number of apartments in a bullding is not. Very important and not important have different meanings in different contexts. The MAA offers a unifying framework for the evaluation of all attributes, with both quantitative and qualitative aspects.

The first step in the MAA was to collect data on the housing stock and on its evolution. The following sources yielded usable information on number of units, number of floors, age, fuel, heating system, and type of ownership: 
- Bureau of the Census, U.S. Department of Commerce

- U.S. Department of Housing and Urban Development

- New York State Division of Housing and Community Renewal

- New York City Department of Housing Preservation and Development

- New York City Housing Authority

- F.W. Dodge, National Information Services.

The housing stock (past, current and future) was then examined from several perspectives.

- Ownership

- Number of units per structure

- Housing stock as of 1970

- Housing growth $1960-1990$

- Newer housing stock (1970 - 1990)

- Number of units grouped according to the number of floors per bullding

- Heating fuel used in units

- Heating system used in units.

Specifically, each analysis created a table where the housing stock was classified according to the total number of units extant in bulldings (refer to Tables 2-1 to 2-10):

- 3-4 apartments

- 5-9 apartments

- 10-49 apartments

- 50 or more apartments.

This breakdown roughly corresponds to the following:

- Attached housing (3-4 apartments)

- 1-3 story detached walkups (5-9 apartments) 
Table 2-1. Units Per Structure, Weighting Factor $=1-2$

\begin{tabular}{|c|c|}
\hline $\begin{array}{c}\text { Units in } \\
\text { Structure }\end{array}$ & $\begin{array}{c}\text { Potential } \\
\text { Opportunity Rating }\end{array}$ \\
\hline $3-4$ & 5 \\
$5-9$ & 3 \\
$0-4 \underline{\underline{a}}$ & 5 \\
$50>$ & 3 \\
\hline
\end{tabular}

Table 2-2. Housing Stock (1970), Weighting Factor $=5$

\begin{tabular}{|c|c|c|}
\hline $\begin{array}{c}\text { Units in } \\
\text { Structure }\end{array}$ & 1970 Stock & $\begin{array}{c}\text { Potential } \\
\text { Opportunity } \\
\text { Rating }\end{array}$ \\
\hline $3-4$ & 340,190 & 3 \\
$5-9$ & 300,099 & 3 \\
$10-49$ & 907,128 & 5 \\
$50>$ & 821,976 & 5 \\
\hline
\end{tabular}

- 1-3 story buildings without elevator (10-49 apartments)

- Buildings that could have more than 3 stories (50 or more apartments).

The separation between these categories is not sharp. Some 40 apartment buildings could have more than 3 stories and, therefore, an elevator, especially in an urban environment. On the other hand, buildings with more than 50 apartments could have 2-3 stories, especially in a suburban area.

Table 2-11 segments the housing stock according to ownership. The percentage of owner-occupied units has been increasing steadily since 1950, but still accounted for only 10 percent of the multifamily building stock in 1980. Data for 1990 is not available yet; it is expected by 1993 .

The great majority of published housing statistics either refers only to renter-occupied units or does not differentiate between the two categories. For this reason, the remainder of the MAA is conducted on renter-occupied units.

\section{MAA Tables with Statistics on Multifamily Homes}

Tables 2-2, 2-3, 2-4, 2-6, 2-8, and 2-9 present analyses by number of apartments in a building. (For the other tables see Heuristic Information section below.) These tables also contain two additional values: a weighting factor (WF) for each table, and a potential opportunity rating (ORT) for each building configuration (3-4 apartments, 5-9 apartments, etc.) A WF of 5 signifies that the table contains data of high importance 
Table 2-3. Existing Heating Fuel Replacement Potential (1980)

\begin{tabular}{|c|c|c|}
\hline Units in Structure & Heating Fuel Used in Units & $\begin{array}{c}\text { Potential } \\
\text { Opportunity Rating }\end{array}$ \\
\hline & Oll (WF - 2-3) & \\
\hline $3-4$ & 161,677 & 2 \\
\hline $5-9$ & 158,086 & 2 \\
\hline $10-49$ & 535,082 & 4 \\
\hline \multirow[t]{2}{*}{$50>$} & 701,346 & 5 \\
\hline & Gas (WF = 5) & \\
\hline $3-4$ & 173,396 & 2 \\
\hline $5-9$ & 115,216 & 2 \\
\hline $10-49$ & 196,299 & 2 \\
\hline \multirow[t]{2}{*}{$50>$} & 205,476 & 2 \\
\hline & Electricity $(\mathrm{WF}=2)$ & \\
\hline $3-4$ & 21,136 & 1 \\
\hline $5-9$ & 25,051 & 1 \\
\hline $10-49$ & 44,679 & 1 \\
\hline \multirow[t]{2}{*}{$50>$} & 72,246 & 1 \\
\hline & LPG $(W F=4)$ & \\
\hline $3-4$ & 6,986 & 1 \\
\hline $5-9$ & 5,229 & 1 \\
\hline $10-49$ & 9,977 & 1 \\
\hline \multirow[t]{2}{*}{$50>$} & 7,866 & 1 \\
\hline & Other $(W F=n / a)$ & \\
\hline $3-4$ & 2,144 & $\mathrm{n} / \mathrm{a}$ \\
\hline $5-9$ & 3,102 & $\mathrm{n} / \mathrm{a}$ \\
\hline $10-49$ & 13,319 & $\mathrm{n} / \mathrm{a}$ \\
\hline \multirow[t]{2}{*}{$50>$} & 19,232 & $\mathrm{n} / \mathrm{a}$ \\
\hline & All Systems (WF = n/a) & \\
\hline $3-4$ & 365,339 & $\mathbf{n} / \mathbf{a}$ \\
\hline $5-9$ & 306,684 & $\mathrm{n} / \mathrm{a}$ \\
\hline $10-49$ & 799,356 & $\mathrm{n} / \mathrm{a}$ \\
\hline $50>$ & $1,006,166$ & $\mathrm{n} / \mathrm{a}$ \\
\hline
\end{tabular}


Table 2-4. Existing Heating System Replacement Potential (1980)

\begin{tabular}{|c|c|c|}
\hline Units in Structure & $\begin{array}{c}\text { Heating System Used in } \\
\text { Units }\end{array}$ & $\begin{array}{l}\text { Potenitial } \\
\text { Opportunity in Units }\end{array}$ \\
\hline & $\begin{array}{c}\text { Steam or Hot Water System } \\
\text { with Piping }(W F=5)\end{array}$ & \\
\hline $3-4$ & 241,064 & 2 \\
\hline $5-9$ & 221,864 & 2 \\
\hline $10-49$ & 671,632 & 5 \\
\hline \multirow[t]{2}{*}{$50>$} & 801,076 & 5 \\
\hline & $\begin{array}{l}\text { Central Warm Air Ducted } \\
\text { System (WF }=3-4)\end{array}$ & \\
\hline $3-4$ & 66,162 & 1 \\
\hline $5-9$ & 43,240 & 1 \\
\hline $10-49$ & 61,670 & 1 \\
\hline \multirow[t]{2}{*}{$50>$} & 120,703 & 1 \\
\hline & $\begin{array}{l}\text { Built-In Electric Units (WF } \\
=2 \text { ) }\end{array}$ & \\
\hline $3-4$ & 16,044 & 1 \\
\hline $5-9$ & 19,346 & 1 \\
\hline $10-49$ & 33,985 & 1 \\
\hline \multirow[t]{2}{*}{$50>$} & 50,615 & 1 \\
\hline & $\begin{array}{l}\text { Floor, Wall or Pipeless } \\
\text { Furnace (WF }=n / a)\end{array}$ & \\
\hline $3-4$ & 4.777 & $\mathrm{n} / \mathrm{a}$ \\
\hline $5-9$ & 3,128 & $\mathrm{n} / \mathrm{a}$ \\
\hline $10-49$ & 6,610 & $\mathrm{n} / \mathrm{a}$ \\
\hline \multirow[t]{2}{*}{$50>$} & 7,714 & $\mathrm{n} / \mathrm{a}$ \\
\hline & Other Means $(\mathrm{WF}=1)$ & \\
\hline $3-4$ & 37,292 & 1 \\
\hline $5-9$ & 19,106 & 1 \\
\hline $10-49$ & 26,228 & 1 \\
\hline $50>$ & 23,068 & 1 \\
\hline
\end{tabular}


Table 2-5. Floors Per Structure in New York State, Weighting Factor $=\mathbf{b}$

\begin{tabular}{|c|c|}
\hline $\begin{array}{c}\text { No. of } \\
\text { Floors }\end{array}$ & $\begin{array}{c}\text { Potential } \\
\text { Opportunity } \\
\text { Rating }\end{array}$ \\
\hline $1-3$ & 5 \\
$\begin{array}{c}4 \text { and } \\
\text { above }\end{array}$ & $2-3$ \\
\hline
\end{tabular}

Table 2-6. Number of Units Grouped According to Number of Floors, Weighting Factor $=5$

\begin{tabular}{|c|c|c|}
\hline $\begin{array}{c}\text { No. of } \\
\text { Floors }\end{array}$ & $\begin{array}{c}\text { Percentage of } \\
\text { Construction } \\
1986-1990(\%)\end{array}$ & $\begin{array}{c}\text { Potential } \\
\text { Opportunity } \\
\text { Rating }\end{array}$ \\
\hline $\begin{array}{c}1-3 \text { floors } \\
4 \text { and } \\
\text { above }\end{array}$ & $74-84$ & 5 \\
\hline
\end{tabular}

Table 2-7. Gas Avallabllity, Bzisting Housing Stock, Weighting Factor $=5$

\begin{tabular}{|l|c|}
\hline \multicolumn{1}{|c|}{ Gas Avallability } & $\begin{array}{c}\text { Potential } \\
\text { Opportunity Rating }\end{array}$ \\
\hline Gas used already on premises & 5 \\
Gas not used on premises, but avallable on street & $3-4$ \\
Gas not avallable in neighborhood & 1 \\
\hline
\end{tabular}

Table 2-8. Housing Growth 1960 to 1990, Welghting Factor $=1-2$

\begin{tabular}{|c|c|c|c|c|c|}
\hline & \multicolumn{6}{|c|}{ 10 Year Percent Growth in Multifamily Housing Stock by } \\
Comparison to Previous Decade & $\begin{array}{c}\text { Potential } \\
\text { Opportunity } \\
\text { Rating }\end{array}$ \\
\hline $\begin{array}{c}\text { Units in } \\
\text { Structure }\end{array}$ & $1950-60$ & $1960-70$ & $1970-80$ & $1980-90$ & \\
\hline $3-4$ & -11.5 & 6.0 & 7.5 & 35 & 5 \\
$5-9$ & -7.8 & -3.2 & 2.35 & 20 & 5 \\
$10-49$ & 4.3 & 3.0 & -11.7 & 13.5 & 4 \\
$50>$ & 58.3 & 30.5 & 22.5 & 11.26 & 1 \\
\hline
\end{tabular}


Table 2-9. New Housing Stock (1970-90), Weighting Factor $=2$-3

\begin{tabular}{|c|c|c|c|c|}
\hline \multirow{2}{*}{$\begin{array}{c}\text { Units in } \\
\text { Structure }\end{array}$} & \multicolumn{2}{|c|}{$\begin{array}{c}\text { Apartments } \\
\text { Multifamily Housing Stock In }\end{array}$} & $\begin{array}{c}\text { Less than } 20 \\
\text { Years } \\
\text { Old }\end{array}$ & $\begin{array}{c}\text { Potential } \\
\text { Opportunity } \\
\text { Rating }\end{array}$ \\
\cline { 2 - 3 } $3-4$ & 1970 & 1990 & 153,748 & 4 \\
$5-9$ & 340,190 & 493,938 & 68.693 & 2 \\
$10-49$ & 300,099 & 368,792 & 1,755 & 1 \\
$50>$ & 807,128 & 908,883 & 298,126 & 5 \\
\hline
\end{tabular}

Table 2-10. Gas Availability, New Construction, Weighting Factor $=5$

\begin{tabular}{|l|c|}
\hline \multicolumn{1}{|c|}{ Gas Availability } & $\begin{array}{c}\text { Potential } \\
\text { Opportunity } \\
\text { Rating }\end{array}$ \\
\hline Gas used already on premises & $\mathrm{n} / \mathrm{a}$ \\
$\begin{array}{l}\text { Gas not used on premises, but } \\
\text { available on street }\end{array}$ & $3-4$ \\
$\begin{array}{l}\text { Gas not available in } \\
\text { neighborhood }\end{array}$ & 1 \\
\hline
\end{tabular}

Table 2-11. Total Stock of Multifamily Units in the State of New York (Renter and Owner Occupied, 1950 to 1990)

\begin{tabular}{|c|c|c|c|c|}
\hline \multirow{2}{*}{ Year } & $\begin{array}{c}\text { Renter-Occupied } \\
\text { Units }\end{array}$ & Number of Units & Percent of Total & $\begin{array}{c}\text { Owner-Occupled } \\
\text { Total Number of } \\
\text { Units (3 or more } \\
\text { in a structure) }\end{array}$ \\
\cline { 3 - 4 } 1950 & $1,940,712$ & 123,332 & 6.0 & $2,064,044$ \\
1960 & $2,141,358$ & 159,299 & 6.9 & $2,300,657$ \\
1970 & $2,369,393$ & 219,118 & 8.5 & $2,588,511$ \\
1980 & $2,480,189$ & 285,545 & 10.3 & $2,765,734$ \\
1990 & $2,891,715$ & n/a & n/a & n/a \\
\hline
\end{tabular}


in deciding whether the distributed gas heating/DHW has an opportunity for application in New York State. A WF of 1 indicates that the table is of little consequence to the market potential of this heating/DHW system.

Within each table, the bullding configurations (3-4 apartments, 5-9 apartments, etc.) were assigned ratings on a scale of 1 to 5 . A rating of 5 means that, based solely on the information provided by that specific table, the bullding configuration has the highest potential to receive distributed gas DHW/heating in the State of New York.

In some instances, the WF and the ORT are defined by ranges, rather than by unique values, to reflect the uncertainty in the experience-based rating process. The multiple-attribute analysis, described later, explores all combinations of values in these pages.

For reasons behind the selection of valv ss for WF and ORT, please refer to "Criteria for Assigning WFs and Opportunity Rations" of Appendix A.

\section{Tables Containinc Onle Feuristic Information}

Several MAA Tables 2-1, 2-5, 2-7, and 2-10)contain only information derived from experience (heuristic). For example, Table 2-5 assigns an ORT of 5 for buildings with 1-3 floors, and an ORT range of 2-3 for bulldings with 4 or more floors. This is because bulldings with elevators require a higher investment to accommodate distributed heating/DHW (chases, rigid gas conduits, possible flue venting), present substantial building code barriers, and are perceived by most designers as inappropriate for systems that bring gas to each apartment. These heuristic tables are important because they bring into the MAA analysis factors that are not captured by housing statistics, but are nonetheless essential in the decision process that determines whether or not distributed heating/DHW is specified.

\section{Multiple Attribute Analysis}

The information first presented in Tables 2-1 to 2-10 is re-organized in Appendix $B$ in a multi-tiered system as Tables $11 \mathrm{~A}$ through $18 \mathrm{~A}$, and $11 \mathrm{~B}$ through $14 \mathrm{~B}$. The " $\mathrm{A}$ " Tables (11A, 12A, etc.) address the older housing stock (built before 1970), which is a prime candidate for heating system replacement. The "B" Tables (11B, 12B, etc.) are concerned with relatively new and future construction. 
MAA on Existing Housing Stock. Within the A tables, three parallel analyses are undertaken: The first analysis (rows 1-4) examines the opportunity for distributed heating/DHW systems in each of four building configurations: 3-4 units, 5-9 units, 10-49 units, and 50 and more units. The second analysis (rows 5 and 6) examines the opportunity for distributed heating/DHW systems according to the number of floors in a building. The third analysis (row 7) investigates the effect of gas availability.

The three analyses are combined, qualitatively, in the next subsection of this report. Numerical relationships between the three analyses could not be established because of lack of statistical data.

The MAA mechanism is simple. Each row corresponds to one table, or to a portion of one of the Tables 2-1 to 2-10. Each row is associated with the WF previously assigned in Tables 2-1 to 2-10. The columns are organized according to the classification criteria used to differentiate the housing stock (number of units per building, number of floors per building, etc.) The intersection of a row and a column contains the ORT previously assigned in Tables 2-1 to 2-10. The WF is multiplied by the ORT and the result of the multiplication is squared and entered under the heading "attribute score."

For example, within the first analysis, Table $11 \mathrm{~A}$ has $\mathrm{WF}=5$ for row 2 , HOUSING STOCK (1970). This, as explained for Table 2-2, signifies that the number of old multifamily units is an important indicator since these units are very likely to undergo heating system renovation. The ORT for buildings with 3-4 units is 3 . This rating was assigned in Table 2-2 according to the relative number of units in buildings with 3-4 apartments. Since the largest number of such units existed in buildings with over 50 apartments, that category recelved a rating of 5. Proportionately, the 3-4 apartment category received a rating of 3 .

The attribute score is $(5 \times 5)^{2}=225$. The highest score points to the highest likelihood for applications. The squaring is used to magnify differences between entries and. therefore, to penalize the entries with a low rating. Since the 3-4 unit configuration has a mediocre rating $(\mathrm{ORT}=3)$ in an important indicator $(\mathrm{WF}=5)$, this configuration compares poorly with others that have received a higher ORT. It can be seen that the 
category with 10-49 units and the category with over 50 units have scores about three times higher than the category with 3-4 units (625 versus 225).

Each table has subtotals and totals of the scores, which are then normalized on a scale of 1 to 10. A normalized score of 10 indicates highest opportunity. For example, the first analysis (rows 1-4) of Table 11 A yields the following normalized scores for the segmentation by number of apartments shown in Table 2-12.

These scores indicate that, in absence of information about number of stories and gas avallabilty, the greatest market potential for distributed heating/DHW systems exdsts in buildings with 10 or more apartments.

Another set of normalized scores, shown in Table 2-13, refers to fuel type and existing heating system type. The scores show that, in general, those pre-1970 bulldings with oll or gas fuel and hydronic systems have by far the greatest potential for distributed heating/DHW retrofit. An examination of the MAA table also yields information beyond the normalized scores.

The subtotals for rows $3 a+4 a$ and $3 b+4 a$ show that, for pre-1970 bulldings with $3-49$ units, the gas-fired, hydronic systems present a higher application potential then oilfired hydronic systems. For bulldings with 50 and more apartments, the calculated potential is the same (725) because, while extsting gas supply gives an advantage to gas systems, more buildings use oll-fired bollers.

The second analysis of Table 11A for pre-1970 bulldings shows a clear preference for low-rise buildings. (The total normalized score is 10.00 for 1-3 floors and 1.60 for 4and-above floors.) The third analysis of Table $11 \mathrm{~A}$ for pre-1970 bulldings shows a

Table 2-12. Normalized Scores for the Segmentation by Number of Apartments

\begin{tabular}{|l|c|c|c|c|}
\hline \multicolumn{5}{|c|}{ Number of Apartments/Buildings } \\
\hline & 3 to 4 & 5 to 9 & 10 to 49 & 50 and more \\
\hline $\begin{array}{l}\text { Total normalized } \\
\text { scores }\end{array}$ & 3.35 & 3.35 & 9.87 & 10.00 \\
\hline
\end{tabular}


Table 2-13. Normalized Scores for Full Type and Heating System Type

\begin{tabular}{|l|c|}
\hline \multicolumn{1}{|c|}{ Attribute } & $\begin{array}{c}\text { Total } \\
\text { Normalized } \\
\text { Score }\end{array}$ \\
\hline Existing Heating Fuel Replacement Potential & \\
a. Oil & \\
b. Gas & 4.90 \\
c. Electricity & 10.00 \\
d. LPG & 0.40 \\
Existing Heating System Replacement Potential & 1.60 \\
a. Hydronic piping & \\
b. Warm air ducts & 10.00 \\
c. Electric units & 0.25 \\
d. Other & 0.11 \\
& 0.03 \\
\hline
\end{tabular}

high preference for gas available in the building (normalized score of 10), a modest potential for the situation where gas is available on street but not in the building (normalized score of 3.6), and practically no chance for the situation where gas is not available on-street. Similar analyses are carried in Tables 12A through 24A, with variations in WFs and ORTs.

MAA on Newer and Future Housing. Tables 11B through 14B coritain the MAA on new multifamily housing. The first analysis examines the housing growth patterns and the post-1970 housing stock. While the high growth rate is clearly established in 3-4 and 5-9 apartrient building categories (row 8), the existing post-1970 stock (row 9) still has a preponderance of buildings with 50 units and above. The buildings with over 50 apartments grew at a slow rate between 1970 and 1990, but this rate is measured with respect to a large existing base. As a resuli, buildings in the 50 or more apartment category accounted ior more apartments than all other building categories combined. Overall, the near-term potential appears to be in two categories: buildings with 3-4 apartments (high growth rate, modest stock less than 20 years old), and buildings with 50 or more apartments (low growth rate, but very high stock less than 20 years old). The same analysis on number of floors applies as for retrofit: walk-up buildings ( $1-3$ floors) retaln a substantial advantage. Finally, gas avallability to the project is essential. 


\section{Conclusions}

An examination of all MAA tables shows the results to have little sensittvity to the reasonable changes in WFs and ORTs. The following conclusions comment on the numerical results and draw inferences across the three analyses of each table.

It should be noted that energy and fuel cost savings are discussed separately in the Energy Sinnulations section since the amount of data available did not permit generalizations.

Retrofit of Pre-1970 Multifomlle Bulldings. The following conclusions apply to pre1970 multifamily buildings:

1. The bulldings with $10-49$ apartments and the bulldings with 50 or more apartments have by far the highest number of units in the State of New York (over 70 percent). For this reason, they recelve the highest normalized scores (9.6 to 10 versus 3.24 to 3.74 for the 3-4 and 5-9 apartment buildings).

This large potential can be realized only in buildings with 1-3 stories. The statistical data avallable for the State of New York do not correlate between number of stories and number of apartments in a bullding.

Vendor information on decentralized heating/DHW systems installed in the Northeast shows that low-rlse bulldings with a large number of units exist and offer good opportunities. It is not possible to ascertain whether, state-wide or even region-wide, such bulldings are found in large numbers. The only information that relates the number of apartments per bullding to the number of stories per bullding was found for New York City. In New York City, relattvely few units are located in low-rlse, 50 or more apartment bulldings (see No. 3 below). However, New York City is not representative of suburban conditions.

2. The next tier is formed by bulldings with 3-9 apartments. They constitute close to 30 percent of the pre-1970 multifamily housing stock and are overwhelmingly bullt with 1-3 stories. This market, although smaller, is clearly tdentifled by the extant data as being approprlate for decentralized heating/ DHW system conversions.

3. While the issue of number of floors versus number of apartments could not be resolved at the New York State level, inferences could be drawn on pre-1970 multifamily stock in New York City based on The Estumation of Building Stocks and Thetr Charactertstics in Urban Areas: An Investigation of Emptrical Regularttles by Project, by Barclay G. James, Donald M. Manson, John E. Mulford and Mark A. Chain of Cornell University (1976).

Calculations based on the Cornell study show that the New York City multifamily stock can be classifled as shown in Table 2-14. 
Table 2-14. Classification of Pre-1970

Multifamily Buildings in New York City by

Number of Units and Building Height

\begin{tabular}{|c|c|c|}
\hline \multirow{2}{*}{$\begin{array}{c}\text { Number of Units } \\
\text { per Building }\end{array}$} & $\begin{array}{c}\text { Percent of Total No. Units } \\
\text { (\%) }\end{array}$ & $\begin{array}{c}4 \text { a. d above } \\
(\%)\end{array}$ \\
\hline $3-4$ & 18 & 1 \\
$5-9$ & 2 & 9 \\
$10-49$ & 1 & 18 \\
$50>$ & 2 & 49 \\
Total units & 23 & 77 \\
\hline
\end{tabular}

These percentages cannot be applied to the entire State of New York, given the unique characteristics of New York City. Also, the data are 13 years old, and the process of demolition/reconstruction has proceeded at a relatively brisk pace during the 1980 s.

However, for New York City alone, it can be reasonably stated that buildings with 3-4 apartments offer the clear, dominant opportunity for dual-integrated appliance (DIA) applications (18 percent) of total pre-1970 apartment stock with 1-3 stories. The 1-3 story apartment stock of all the other building types combined is smaller by a factor of 3 to 4 .

4. Gas availability is essential for the feasibility of a heating/DHW system retrofit. Gas availability on-premises is preferred to gas avallability on-street. Two caveats apply:

- If the building would convert to gas anyway (e.g., to avoid repairing the oll tank), then there is no particular disadvantage, from the perspective of decentralized systems, if gas is available on-street but not on-premises.

- The first cost of bringing gas from street to building is more important for small buildings (e.g., 3-4 apartments). However, some utilities fully pay for the gas line to the building, so this criterion may not always be relevant.

5. A building subject to gut rehabilitation or major HVAC work is more likely than others to be a candidate for decentralized heating/DHW systems.

6. In any renovation except gut rehabilitation, buildings with hydronic heating systems are by far the most attractive for conversion.

7. Those buildings already using gas for heating are much more likely to be converted to the decentralized system. (In all analyses. gas heating scores 
either 9 or 10; oil scores in 50 percent of the analyses 5, and in the other 50 percent scores 10 . depending on WFs.)

However, bulldings using oil can also be good candidates since they form about 65 percent of the pre-1970 housing stock. Their preponderance is 75 to 80 percent among bulldings with 10-49 apartments and 50 or more apartments. so converstons in this particular market segment are heavlly dependent on the economics of fuel switch. The gas/oil breakdown is relatively equal in the 3-4 and 5-9 apartment bulldings.

8. Although not analyzed numerically in the MAA, codes and customary practice need to be discussed. Both present obstacles to the implementation of decentralized heating/DHW systems. Both impact greatly all mid-and highrise bulldings. Both impact the last bulldings with 1-3 floors. Actually, all experience to date on heating/DHW installations has been in low-rise bulldings.

9. Energy use and energy cost need also be discussed, even though the MAA could not address it. The section titled Central Versus Decentralized Heating in Muitifamily Buildings, A Literature Review, shows that substantial heating/ DHW savings (6 -77 percent) can be achleved via energy use metering on an apartment-by-apartment basis, and/or via decentralized equipment. DOE$2.1 \mathrm{D}$ energy simulations by SWA indicate savings of 7 to 17 percent due solely to decentralized equipment, in absence of any occupant behavior changes (such as thermostat setback).

The range is wide enough to recommend site monitoring for obtaining more information and further computer analyses. The extant energy data, within its limitations, indicates that older housing stock has the highest potential for energy use savings.

These energy use savings may not translate in energy cost savings, unless utility rates are changed. The computer simulations for Manhattan and Brooklyn show that, because of a high cost of gas for the first few therms, the decentralized heating/DHW systems save energy but result in an increase in fuel cost.

Summary. The segment with a clear, high potential is defined by lou-rise (1-3 floors) bulldings with 3-9 apartments that have gas-fired hydronic heating. The potential is clear since all conditions are met by large numbers of multifamily units.

- The great majority of bulldings with 3-9 apartments have 1-3 stories (90 percent assumed).

- About 69 percent of bulldings with 3-9 apartments use hydronic heating.

The buildings with 3-9 apartments contain over 640,000 units, or about 27 percent of the New York State multifamily stock built before 1970. At a minimum, 170,000 units satisfy the above conditions.

Buildings with over 10 units can be even more appropriate for decentralized heating/DHW systems, provided they are less than 4 stories high and that 
either (a) they have gas heating or (b) the economics of fuel switching are attractive, since 75 to 80 percent of these buildings use oil fuel. In most instances ( 83 percent), the buildings with 10 or more units use hydronic heating.

A numerical estimate of the multifamily housing segment satisfying the above conditions cannot be made since a correlation between number of floors and number of units does not exist.

New Multifamily Buildings. The following apply to new multifamily buildings:

1. The largest market for new multifamily buildings, when defined solely by the number of units in New York State, appears to be for buildings with 50 or more apartments. Over the past 30 years, this market has been flattening out. The 3-9 apartment buildings experienced a fivefold growth rate, and the 10-49 apartment buildings close to a fourfold growth rate by comparison to the 50 or more apartment category. Therefore, in the more distant future, the smaller buildings may present higher opportunity if the trend persists.

2. As with existing buildings, the 1-3 story segment is a clear favorite. The per unit first cost advantage when compared to taller bulldings should be somewhat smaller since it is much less expensive to destgn a gas network from the beginning rather than to retrofit it, and since taller buildings are more heavily affected by the cost of retrofit.

3. Gas availability is a determining factor.

4. The same building code and customary practice considerations apply as in retrofit situations (see No. 8 above).

5. The same considerations for energy use and cost apply as in retrofit situations (see No. 9 above).

\section{ENERGY SIMULATION}

SWA undertook DOE-2.1D simulations to estimate the decease in heating/DHW energy use when a decentralized system replaces a central system in multifamily buildings.

\section{Building Prototypes}

Two multifamily building types were selected from a previous Gas Research Institute (GRI) study conducted by Lawrence Berkeley Laboratory (LBL): Multifamily Heating and Cooling Requirements: Assumption, Methods, and Summary Results, prepared by R.L. Ritschard and Y.J. Huang. In that study. the buildings are Identified as Building 3 and Building 4, and were developed based on the 1980-1982 residential energy consumption survey of Energy Information Administration. For the purpose of this 
work, the buildings are designated as pre-1940 and post-1980. Tables 2-15 and 2-16 summarize the major characteristics of each multifamily prototype.

The DOE 2.1 input for New York State bulldings, created by LBL for GRI, was used as the starting point for the development of each multifamily building model in this study. Therefore, the description of the bullding prototypes is substantially similar to the one in the GRI 1989 study by Ritschard and Huang. Portions of the LBL description (pages 2-6) of the prototypes are repeated or paraphrased in this paper because numerous references to the document would have resulted in a text that is difficult to follow. Also, the prototypes modeled in this study differ to some extent from those described in the LBL report:

Table 2-15. Characteristics of Pre-1940 Prototype

\begin{tabular}{|l|l|}
\hline \multicolumn{1}{|c|}{ Parameter } & Specification \\
\hline Year built & Pre-1940 \\
No. of units /floor & 10 \\
No. of floors & 4 and 10 \\
Unit floor area (ft 2 )* & 675 \\
Envelope & \\
No. of windows/unit & 4 \\
Glazing type & Single \\
Average window size (ft 2 ) & 15.52 \\
No. of sliding glass doors/unit & None \\
Average sliding door stze (ft2) & N/A \\
Glazing area (\%) & 9.2 \\
Exterior wall facade & Brick \\
Wall insulation & None \\
Ceiling insulation & None \\
& \\
Operations & 70 \\
Heat set point (F) & 64 \\
Heating night setback & \\
1 1 p.m. - 7 a.m (F) & 78 \\
Cooling set point (F) & \\
Other characteristics & \\
Number of occupants & 1.25 \\
Cooking fuel type & Gas \\
Domestic hot water fuel type & Gas \\
Sensible internal loads (Btu/day) & 30,846 \\
Latent internal loads (Btu/day) & 7.088 \\
& \\
\hline *Average floor area per dwelling unit is conditioned \\
floor space only. & \\
\hline
\end{tabular}


Table 2-16. Characteristics of Post-1980 Prototype

\begin{tabular}{|l|l|}
\hline \multicolumn{1}{|c|}{ Parameter } & Specification \\
\hline Year built & $1980 \mathrm{~s}$ \\
No. of units/floor & 10 \\
No. of floors & 4 and 10 \\
Unit floor area (ft 2 )* & 920 \\
Envelope & \\
No. of windows/unit & 4 \\
Glazing type & Double \\
Average window size (ft 2 ) & 12.2 \\
No. of sliding glass doors/unit & None \\
Average sliding door size (ft2) & 20.0 \\
Glazing area including sliding door (\%) & 14.0 \\
Exterior wall facade & Brick \\
Wall insulation & $\mathrm{R}-13$ \\
Ceiling insulation & $\mathrm{R}-30$ \\
& \\
Operations & 70 \\
Heating set point for apartments (F) & 64 \\
Heating night setback for apartments & \\
11 p.m - 7 a.m. (F) & 64 \\
Heating set point for corridors (F) & 78 \\
Cooling set point for apartments (F) & 82 \\
Cooling set point for corridors (F) & \\
& \\
Other characteristics & 2.07 \\
Number of occupants & Gas \\
Cooking fuel type & 41,034 \\
Domestic hot water fuel type & 9,276 \\
Sensible internal loads (Btu/day) & \\
Latent internal loads (Btu/day) & \\
\hline *Average floor area per dwelling unit is conditioned \\
floor space only. & \\
& \\
\hline
\end{tabular}

- Glazing area in the post-1980 prototype is 14 percent rather than 5 percent (typo in LBL study).

- No shading by adjacent buildings was simulated.

- The HVAC system was changed to hot water baseboard and direct expansion (DX) through-the-wall air conditioners.

- A decentralized system was also modeled.

Each building type has 40 or 100 units. Each building floor has 10 family units. Each building type is modeled either with central boller or with decentralized heating/ 
DHW units (also called dual integrated appliances or DIA). Fin-tube baseboards deliver heat into each zone (apartment or common area) of the bulldings.

When a central boller is used, it provides DHW and hot water for space heat in each unit of the bullding and in each common space. When DIA units are used, they are installed in each family unit and also in the common spaces. Each DIA unit provides DHW and hot water for space heating.

\section{Building Geometry}

Many adjoining apartment units have the same thermal characteristics (e.g., center units that are neither located on the first floor nor on the last floor). In such cases, one unit was modeled and assigned a multiplier to compute the combined effect of all units of this type.

sits differing in their heat flow characteristics were modeled separately. These include ground floor units, top floor units, and end-units on all floors. Common spaces such as stairwells, hallways and basements were modeled as separate zones. Common spaces were assumed to be air-conditioned.

\section{Infiltration}

Air infiltration is simulated with the Sherman-Grimsrud model. This model receives as input the leakage area of the bullding.

For the pre-1940 bullding the average fractional leakage area of 0.00050 (total leakage area/floor area) was assumed. For the post-1980 bullding, tighter construction with an average fractional area of 0.00035 was assumed.

\section{Solar Gain}

The solar gain of a bullding depends on the orientation of the windows and walls, and on shading by nearby bulldings and trees. In this study, a bullding that represents a statistical average was modeled. An average building orientation was created by apportioning the amount of walls, windows and doors equally in the four cardinal directions. The glass shading of 0.80 was used during the winter and 0.60 during the summer. No shading from other buildings was assumed. 


\section{Operating Assumptions}

During the heating season, the apartment units were assumed to maintain $70^{\circ} \mathrm{F}$ during the day, with setback to $64^{\circ} \mathrm{F}$ between 11 p.m. and 7 a.m. During the cooling season, the temperature was maintained at $78^{\circ} \mathrm{F}$ for all hours.

Window venting was permitted in winter when indoor temperatures rose above $78^{\circ} \mathrm{F}$. During the cooling season, windows were assumed to be open until the indoor temperature reached $72^{\circ} \mathrm{F}$, if the following criteria were met: 1) the outdoor temperature was lower than indoor temperatures; 2) the outdoor temperature was not higher than $78^{\circ} \mathrm{F} ; 3$ ) the enthalpy of outdoor air was less than that of indoor air; and 4) the cooling load that hour could be met totally through window venting. The windows were assumed to retain until 7 a.m. the same status they had at $11 \mathrm{p} . \mathrm{m}$. (i.e., open or closed) unless indoor temperatures dropped to below the heating setpoint.

Lobbies, stairwells, hallways, and basements were modeled as separately heated and cooled zones. Basements were simulated as unconditioned zones. The other common spaces had heating and cooling set points of $64^{\circ} \mathrm{F}$ and $82^{\circ} \mathrm{F}$, respectively.

\section{Internal Loads}

The internal load assumptions are listed in Table 2-17. The hourly distribution of internal loads was based on the profile developed by the California Energy Commission (CEC) for si.igle-family residences. This profile includes heat gain from hot water standby losses. For central systems, the water heater standby losses were assigned to the basement. Because of their smaller surface-to-volume ratio. central boilers are assumed to have standby losses per unit that decrease proportionally to NApt 1/3, where NApt is the number of apartments in the building.

\section{Domestic Hot Water Loads Methodology}

Energy use for heating water is a function of variables including water storage temperature, inlet and outlet temperatures, air temperatures, and the rate of usage of hot water. To calculate the annual hot water load per apartment, the following methodology was used: 
Table 2-17. Estimated Average Annual Internal Loads

Per Multifamily Apartment Unit

\begin{tabular}{|c|c|c|}
\hline End Use & $\begin{array}{l}\text { Sensible Heat Load Per Unit } \\
\text { (Btu/day) }\end{array}$ & $\begin{array}{l}\text { Latent Heat } \\
\text { Load Per Unit } \\
\text { (Btu/day) }\end{array}$ \\
\hline Occupants & $2700 \times$ NOCC* & $2140 \times$ NOCC \\
\hline DHW standby & 5480 & \\
\hline DHW use & $5639 \times \mathrm{NOCC}$ & $539 \times$ NOCC \\
\hline Television & 1244 & \\
\hline Refrigerator & 10520 & \\
\hline Electric range (if exist) & 7480 & 3740 \\
\hline Lighting & $8.42 \times \mathrm{SF}^{* *}$ & \\
\hline Miscellaneous & $1870^{* *}$ & \\
\hline Totals per unit & $\begin{array}{l}21114+3239 \times \mathrm{NOCC}+8.42 \times \\
\mathrm{SF}=5480 \text { (for units } \mathrm{w} / \text { indirect } \\
\mathrm{DHW} \text { only) }\end{array}$ & $\begin{array}{l}3740+2679 x \\
\text { NOCC }\end{array}$ \\
\hline $\begin{array}{l}\text { DHW standby in basement (for } \\
\text { apts. w/central DHW only) }\end{array}$ & $8220 / N$ Apt $1 / 3^{* *}$ & \\
\hline Dryer in basement & 560 & \\
\hline
\end{tabular}

load $=$ NOCCxWxCpx $\left(T_{T}-T_{M}\right)$

Where $\quad$ NOCC $=$ Number of occupants per unit

$\mathrm{W}=$ Average dally hot water consumption (based on $18.5 \mathrm{gal} / \mathrm{day} /$ person)

$\mathrm{C}_{\mathrm{p}}=$ Energy required per gallon heated $\left(8.33 \mathrm{Btu} / \mathrm{gal} /{ }^{\circ} \mathrm{F}\right)$

$\mathrm{T}_{\mathrm{T}}=$ Tank set temperature $\left(120^{\circ} \mathrm{F}\right)$

$T_{M}=$ City water main temperature $\left(50^{\circ} \mathrm{F}\right)$

The DHW load includes the heat necessary to raise the temperature from the main to the tank temperature of $120^{\circ} \mathrm{F}$. The effects of burner efficiency and standby losses are not considered in the calculation of water heating loads, but standby losses are included in the interloads assumptions (Table 2-17). 


\section{HVAC System}

Each apartment was cooled by wall air conditioning units. The common areas were cooled by a central forced air packaged system.

The heating in all the apartment units was provided by hot water baseboards. Hot water was produced by either a gas-fired central boiler or by DIA units. The basement of the building was unconditioned.

\section{RESULTS OF SIMULATIONS}

Tables 2-18 and 2-19 show a summary of the detalled results of the DOE-2.1D simulations listed in Tables 2-20 and 2-21.

Note that, because of the gas rate structure, the DIA units save energy in every case yet incur a higher energy cost. This discrepancy is major. Energy savings range from 7 to 17 percent. Cost increases range from 42 to 83 percent. The gas rate structures of Consolidated Edison and BUG are given in Appendix S.

Table 2-18. Energy and Cost of Multifamily Units for Heating and DHW

\begin{tabular}{|l|c|c|c|c|c|c|}
\hline & Central & DIA & Central & DIA & Central & DIA \\
\cline { 2 - 7 } $\begin{array}{c}\text { Building } \\
\text { Type }\end{array}$ & $\begin{array}{c}\text { Energy } \\
\text { use } \\
\text { (therms) }\end{array}$ & $\begin{array}{c}\text { Energy } \\
\text { use } \\
\text { (therms) }\end{array}$ & $\begin{array}{c}\text { ConEd } \\
\text { cost (\$) }\end{array}$ & $\begin{array}{c}\text { ConEd } \\
\text { cost (\$) }\end{array}$ & $\begin{array}{c}\text { BUG cost } \\
\text { (\$) }\end{array}$ & $\begin{array}{c}\text { BUG cost } \\
(\$)\end{array}$ \\
\hline $\begin{array}{l}\text { Pre-1940, } \\
40 \text { unit }\end{array}$ & 11,702 & 10,399 & 7,731 & 11,308 & 8,299 & 11,789 \\
$\begin{array}{l}\text { Pre-1940, } \\
100 \text { unit } \\
\text { Post-1980, } \\
40 \text { unit }\end{array}$ & 26,545 & 22,603 & 16,723 & 25,660 & 18,487 & 26,693 \\
$\begin{array}{l}\text { Post-1980, } \\
100 \text { unit }\end{array}$ & 15,488 & 15,488 & 12,244 & 20,482 & 13,160 & 20,938 \\
\hline
\end{tabular}


Table 2-19. Change in Energy Use and Energy Cost Between Central and DIA Systems

\begin{tabular}{|c|c|c|c|c|c|c|}
\hline & Central & DIA & Central & DIA & Central & DIA \\
\hline $\begin{array}{l}\text { Building } \\
\text { Type }\end{array}$ & $\begin{array}{l}\text { Energy } \\
\text { use } \\
\text { (therms) }\end{array}$ & $\begin{array}{l}\text { Energy } \\
\text { use } \\
\text { (therms) }\end{array}$ & $\begin{array}{l}\text { ConEd } \\
\text { cost (\$) }\end{array}$ & $\begin{array}{l}\text { ConEd } \\
\text { cost (\$) }\end{array}$ & $\underset{\text { (\$) }}{\text { BUG cost }}$ & $\begin{array}{l}\text { BUG cost } \\
\text { (\$) }\end{array}$ \\
\hline $\begin{array}{l}\text { Pre-1940, } \\
40 \text { unit }\end{array}$ & 11,702 & 10,399 & 7,731 & 11,308 & 8,299 & 11.789 \\
\hline $\begin{array}{l}\text { Pre- } 1=40, \\
100 \text { l=1t }\end{array}$ & 26.545 & 22,603 & 16,723 & 25.660 & 18,487 & 26,693 \\
\hline $\begin{array}{l}\text { Post-1980, } \\
40 \text { unit }\end{array}$ & 6,715 & 6,272 & 4,510 & 8,242 & 4,873 & 8,434 \\
\hline $\begin{array}{l}\text { Post-1980, } \\
100 \text { unit }\end{array}$ & 15,488 & 15,488 & 12,244 & 20.482 & 13,160 & 20.938 \\
\hline
\end{tabular}

\section{Conclustons}

The energy savings achievable solely as a result of the decentralized configurations are substantial. Savings range from 11 to 15 percent for the pre-1940 prototypes, and from 7 to 17 percent for the post-1980 prototypes.

Higher percent savings are achieved for 10-story and greater buildings. The variation in savings from 4-story to 10-story can be explained as follows: In a 10-story building, the center apartments, in aggregate, account for a higher percentage of the fuel use. These apartments have low heating loads. As a result, solar gains can often reduce the heating loads considerably. Decentralized units can more efficiently follow such load fluctuations than central systems.

The heating energy cost increases for DLA systems. In the Consolidated Edison and BUG service territories, the increase ranges from 42 to 53 percent for pre-1940 prototypes, and from 59 to 83 percent for post 1980 prototypes.

The cost increases are due to the high gas rate charge for the first few therms, and to the service charges assessed on each apartment. This rate structure constitutes a significant institutional impediment. 
Table 2-20. Pre-1940 Building Natural Gas Consumption for Space Heating and DHW (therm)

\begin{tabular}{|c|c|c|c|c|c|c|c|c|}
\hline \multirow[b]{2}{*}{ Unit Type } & \multicolumn{4}{|c|}{40 Family Unit } & \multicolumn{4}{|c|}{100 Family Unit } \\
\hline & $\begin{array}{l}\text { Central } \\
\text { System }\end{array}$ & $\begin{array}{l}\text { Individ- } \\
\text { ual } \\
\text { System }\end{array}$ & $\begin{array}{l}\text { Multi- } \\
\text { plier }\end{array}$ & Total & $\begin{array}{l}\text { Central } \\
\text { System }\end{array}$ & $\begin{array}{l}\text { Individ- } \\
\text { ual } \\
\text { System }\end{array}$ & $\begin{array}{l}\text { Multi- } \\
\text { plier }\end{array}$ & Total \\
\hline $\begin{array}{l}40 \text { family } \\
\text { unit } \\
100 \text { family } \\
\text { unit }\end{array}$ & 11,702 & & & & 26,545 & & & \\
\hline $\begin{array}{l}\text { End unit } \\
\text { ground }\end{array}$ & & 253 & 4 & 1,012 & & 253 & 4 & 1,012 \\
\hline $\begin{array}{l}\text { End unit } \\
\text { middle }\end{array}$ & & 231 & 8 & 1,848 & & 231 & 32 & 7.392 \\
\hline $\begin{array}{l}\text { End unit } \\
\text { top }\end{array}$ & & 423 & 4 & 1,692 & & 423 & 4 & 1,692 \\
\hline $\begin{array}{l}\text { Mid unit } \\
\text { ground }\end{array}$ & & 208 & 6 & 1,248 & & 208 & 6 & 1,248 \\
\hline $\begin{array}{l}\text { Mid unit } \\
\text { middle }\end{array}$ & & 185 & 12 & 2,220 & & 185 & 48 & 8,880 \\
\hline $\begin{array}{l}\text { Mid unit } \\
\text { top }\end{array}$ & & 389 & 6 & 2,334 & & 389 & 6 & 2,334 \\
\hline Hallway & & 45 & 1 & 45 & & 45 & 1 & 45 \\
\hline $\begin{array}{l}\text { Total } \\
\text { building }\end{array}$ & 11,702 & & & 10,399 & 26,545 & & & 22,603 \\
\hline \multirow[b]{2}{*}{ Savings \% } & \multicolumn{4}{|c|}{$\frac{11,702-10,399}{11,702} \times 100$} & \multicolumn{4}{|c|}{$\frac{26.545-22.603}{26.545} \times 100$} \\
\hline & \multicolumn{4}{|c|}{11.13} & \multicolumn{4}{|c|}{14.85} \\
\hline
\end{tabular}

Note: Changes due to user behavior will yield savings above those noted in this report. Specifically, the users could: a) lower the space heating thermostat settings; b) extend the period of thermostat setback; and c) reduce hot water use. The literature review has shown that aggregate DIA/behavior savings can reach in the 30 to 70 percent range. 
Table 2-2;1. Post-1980 Building Natural Gas Consumption for Space Heating and DHW (theirm)

\begin{tabular}{|c|c|c|c|c|c|c|c|c|}
\hline \multirow[b]{2}{*}{ Unit Type } & \multicolumn{4}{|c|}{40 Family Unit } & \multicolumn{4}{|c|}{100 Family Unit } \\
\hline & $\begin{array}{l}\text { Central } \\
\text { System }\end{array}$ & $\begin{array}{l}\text { Individ- } \\
\text { ual } \\
\text { System }\end{array}$ & $\begin{array}{l}\text { Mult1- } \\
\text { plier }\end{array}$ & Total & $\begin{array}{l}\text { Central } \\
\text { System }\end{array}$ & $\begin{array}{l}\text { Individ- } \\
\text { ual } \\
\text { System }\end{array}$ & $\begin{array}{c}\text { Multi- } \\
\text { plier }\end{array}$ & Total \\
\hline $\begin{array}{l}40 \text { family } \\
\text { unit } \\
100 \text { family } \\
\text { unit }\end{array}$ & 6,715 & & & & 18,758 & & & \\
\hline $\begin{array}{l}\text { End unit } \\
\text { ground }\end{array}$ & & 186 & 4 & 744 & & 186 & 4 & 744 \\
\hline $\begin{array}{l}\text { End unit } \\
\text { middle }\end{array}$ & & 162 & 8 & 1,296 & & 162 & 32 & 5,184 \\
\hline $\begin{array}{l}\text { End unit } \\
\text { top }\end{array}$ & & 149 & 4 & 596 & & 149 & 4 & 596 \\
\hline $\begin{array}{l}\text { Mid unit } \\
\text { ground }\end{array}$ & & 172 & 6 & 1,032 & & 172 & 6 & 1,032 \\
\hline $\begin{array}{l}\text { Mid unit } \\
\text { middle }\end{array}$ & & 148 & 12 & 1,776 & & 148 & 48 & 7,104 \\
\hline $\begin{array}{l}\text { Mid unit } \\
\text { top }\end{array}$ & & 138 & 6 & 828 & & 138 & 6 & 828 \\
\hline $\begin{array}{l}\text { Total } \\
\text { building }\end{array}$ & 6,715 & & & & 18,758 & & & \\
\hline Savings \% & & $\begin{array}{c}6.715-6.2 \\
6.715 \\
6.6\end{array}$ & $72 \times 1$ & & & $\begin{array}{r}18.758-15 \\
18.75 \\
17.43\end{array}$ & $\frac{488}{8} \times$ & 100 \\
\hline
\end{tabular}

\section{Recommendations}

DOE-2.1 can only simulate hourly energy use steps, while the bollers might cycle on/ off more often. It is recommended that monitoring be undertaken to verify the range of savings found in this work. It is also recommended that gas utilities be encouraged to set separate pricing structures for DIA installations. 


\section{CEPVTRAL VERSUS DECENTRALIZED HEATING IN MULTIFAMIIY BUILDINGS, A LITERATURE REVIEW}

The literature review was undertaken by SWA to investigate differences between ce $e_{1, i}$ ralized versus decentralized space and water heating in multifamily dwellings.

\section{Executive Summary}

General studies undertaken during the 1970 s and 1980 s on multifamily tenantoccupied buildings showed that energy was saved by shifting responsibility for heating costs from landlords to tenants. Three main strategies are used to this end: 1) allucation of common heatirg bill to tenants; 2) submetering of the apartments and; 3 ) $r$, lacement of central boilers with individu 'systems, one per apartment.

Five to twenty percent savings in heating energy consumption was documented when master-metered properties were converted to individual metering. However, little testing and analysis was performed on the advantages of using individual systems for space conditioning and DHW instead of a central system for the entire bullding.

A preliminary study by Bohac, et al. (1990) has shown 13 to 19 percent savings by irıstalling new individual heating/DHW systems in place of older central systems. A study by Palermini and Hewitt (1991) has shown savings of 69 to 77 peicent by replacing a central gas system with individual space-heating gas units, and also by weatherizing the apartments.

The authors could not find any comparisons of decentralized (individual) systems and centralized systems with the same annual fuel utilization efficiency (AFUE). The data avallable do not support a determination of sa ' $n g s$ due solely to more efficient operation of distributed equipment (as differentiated from savings due to modified tenant behavior as a result of direct billing).

\section{Methods to Save Heating/DHW Fnerey throurh Tenant Control and Decentralized Equipment}

The following subsections review savings obtained in heating the space and/or the DHW of multifamily buildings by making the tenants directly responsible for heating/ DHW co:ts and by installing decentralized equipment. Although this Energy Authority project specifically investigates the seasonal efficiency of decentralized 
heating/DHW systems, other methods that solely affect the behavior of tenants are also relevant since decentralized heating/DHW systems can be controlled by tenants and, therefore are likely to result in modification of tenant behavior.

Three metilods are reviewed based on results from licerature:

- Billing allocation

- Indtvidual metering

- Decentralized systems.

Decentralized systems in turn, are separated in two groups:

- Decentralized heating systems

- Decentralized heating/DHW systems.

This review also discusses the relevance of the savings achlevable with the first two techniques on decentralized heating/DHW systems and makes recommendations for the remainder of the Energy Authority's study.

Residential Utility Billing Allocation. As an energy conservation tool, the effectiveness of energy cost allocation to tenants of multifamily housing was shown to vary substantially. The most common method involves allocation of master-metered energy costs using proportional division based on the relative floor areas of the Individual units. A 1980 study performed by the University of Colorado, and an update published in 1983, found that billing by formula allocation, while eastly administered, ylelded savings of only 6 percent on average for space heating and DHW heating (McClelland 1980). This effect may diminish over time and even become negative in the long term, the study predicted. Tenants who realize that their energy bills are not noticeably affected by their individual conservation efforts may reduce those efforts or abandon them altogether (Scott 1991).

Metering. The energy savings obtained by converting a master-metered property to individual meters, submeters, or individual consumption monitors vary over a wide range. Reductions in the use of gas for space and water heating were shown to average 14 percent, ranging from a low of 5 percent to a high of 20 percent, in the McClelland (1983) study. 
A study of 20 multifamily properties, each with 90 units or more, located in the Denver area and in Colorado Springs, CO, reports significant energy savings due to allocation of central boiler fuel cost based on monitored use of heating systems (Scott 1991). Reductions in gas consumption were achieved in all units and range from about 2 percent to almost 66 percent for the post-conversion predicted use, as compared with the pre-conversion predicted use. Leaving out results for two properties that registered unusually high savings, the average reduction in predicted gas use was over 18 percent (Scott 1991).

Another study on an apartment complex in Milwaukee, WI (Maher 1991), showed savings of 20 percent in heating season gas consumption and 13 percent in summer season gas consumption. The savings resulted from converting a 204-unit apartment complex from a billing system that included gas costs in the base rent, to a billing system that separated rent from gas costs, and that billed gas directly to the residents. The conversion involved the installation of a Btu metering and allocation system.

Individual Heating Units. A few studies have compared central systems and individual systems for space conditioning and DHW in new multifamily buildings. Palermini and Hewitt (1991) conducted a study of 37 multifamily buildings in Portland, OR. These buildings: a) had been converted from central-boiler heating systems to individual tenant-metered heating systems; or b) had installed secondary metering systems on the central-boiler system to allocate the heating costs to each tenant. Thirty-one buildings had undergone conversion of the heating system from a central boller to individual heating systems in each apartment. Of these buldings, 22 were converted from an oil- or gas-fired central boiler to electric resistance heating systems. Eight of the remaining bulldings were converted from a gas-fired boiler system to individual gas space-heating units in each apartment. The buildings that were converted to individual systems contain a total of 661 apartments.

Of the 37 buildings studied, only 7 were included in the final analysis. The others had insufficient data, significant data gaps, or poor data fit to the analysis methodology. The savings are shown in Table 2-22. The two shaded rows are of most interest for the Energy Authority's project since they compare central gas systems to individual gas systems. 
Table 2-22. Energy Savings in the Palermini and Hewitt (1991) Study

\begin{tabular}{|c|c|c|c|c|}
\hline $\begin{array}{l}\text { Apartment } \\
\text { Building }\end{array}$ & Type of Modification & Pre-NAC* & Post-NAC* & $\begin{array}{l}\text { Energy } \\
\text { Savings } \\
(\%)\end{array}$ \\
\hline 1 & $\begin{array}{l}\text { Central oil to individual electric } \\
\text { conversion }\end{array}$ & $95,878 \mathrm{kWh}$ & $68,787 \mathrm{kWh}$ & 28 \\
\hline 2 & $\begin{array}{l}\text { Central oil to individual electric } \\
\text { conversion }\end{array}$ & $60,371 \mathrm{kWh}$ & $43,644 \mathrm{kWh}$ & 28 \\
\hline & 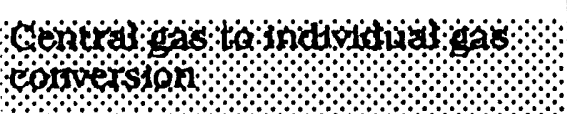 & की & की & mos \\
\hline & o & onsthisths & molstoms & 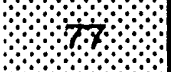 \\
\hline & & & 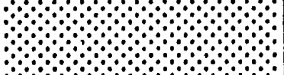 & \\
\hline 5 & $\begin{array}{l}\text { Central gas with allocation } \\
\text { systems added }\end{array}$ & 10,253 therms & 9,789 therms & 6 \\
\hline 6 & $\begin{array}{l}\text { Central gas with allocation } \\
\text { systems added }\end{array}$ & 9,659 therms & 8,387 therms & 13 \\
\hline 7 & $\begin{array}{l}\text { Central gas with allocation } \\
\text { systems added }\end{array}$ & 18,170 therms & 12,868 therms & 29 \\
\hline
\end{tabular}

The energy savings for the bulldings that were converted to individual apartment heating were substantial. However, these savings were likely to result from several interactive effects, including the replacement of the old heating system with a more efficient system; the increased control the tenant could now exercise over the heating system, which resulted in a lower average interior temperature; and the savings attributable to weatherization. The study showed 28 percent energy savings due to the conversion of central oil bollers to individual electric baseboard systems. Most important for the Energy Authority project, Palermini and Hewitt found 69 to 77 percent energy savings in those apartments that underwent the conversion of the central gas-heating system to individual gas-heating systems.

Byrene and Fay (1989) compared central and individual systems for space conditioning and DHW in new multifamily bulldings. The two types of systems were simulated with DOE 2.1C in prototypical apartment bulldings in Chicago and Atlanta. 
The bulldings were equipped with: a) central chiller and gas-fired boller, with fourpipe fan coils in each apartment; or b) packaged terminal air conditioners.

The bullding energy consumption for Chicago was reported to be 899 million Btu per year (MBtu/year) for packed terminal alr conditioners (PTAC), $857 \mathrm{BMtu} /$ year for PTAC system with night temperature setback, and 1,300 MBtu/year for four-pipe fan coil system. This translates into heating and cooling savings for the PTAC systems of over 30 percent.

For Atlanta, the building energy consumption was reported to be $442 \mathrm{MBtu} / \mathrm{year}$ for PTAC, $421 \mathrm{MBtu} /$ year for PTAC with night temperature setback, and $560 \mathrm{MBtu} / \mathrm{year}$ for the four-pipe fan coll system. This translates into heating and cooling savings for PTAC systems of over 20 percent.

The study also showed that if the bullding had less than $5 i$ apartments and was located in Chicago, the PTAC system had lower life-cycle cost than the four-pipe fan coil system. Similarly in Atlanta, a bullding with less than $\mathbf{3 0}$ apartments had lower life-cycle cost for the PTAC system than for the central system.

Combination Space/Water-Heating Srstems, Gas-fired domestic water heaters are increasingly used as combination space-heating/DHW systems for apartments and single-family homes. A study by Talbert et al. (1992) showed that conventional gasfired water heaters are capable of meeting both DHW and space heating loads even during peak winter design conditions when the components of the combination systems are properly sized. It is important that some oversizing be designed into combination systems, in terms of the ratio of water heater output to the fan/coil heating capacity. This ratio should be at least 1.2 , as discussed in Pietsch and Talbert (1989).

An interim report by Bohac et al. (1990) compared Type II dual integrated appliances (DIA) with central heating systems. The dual integrated appliance is defined as a unit that provides both DHW and space heat to a bullding. The Type II DIA unit is a water heater that has the primary function of supplying DHW, but includes a separate heating coll and pump for producing space heat. The study examined five multifamily apartments that were located in a 2-story, 8 apartment bullding erected in the early 1980s. The apartments had either 2 or 3 bedrooms. 
The savings of the Type II DIA systems were determined by comparing their measiied gas use to the gas use of the existing central system. This analysis, which employed the PRISM method, is more accurate for an entire year of data. However, the systems were monitored only from February 1990 to November 1991 and require further heating season monitoring to obtain a full year of data. The normalized annual consumption of four units for the February/November pertod ranged from 592 to 870 hundred of cubic feet per year (ccf/year) and represented savings from 13 to 19 percent. There was a 17 percent increase in the energy use of one unit, which was most likely due to the change in occupants that occurred shortly after the system was installed.

It is important to note that the individual heating/DHW systems, with AFUE of 76 percent or higher, were compared to furnaces with AFUE of 60.2 percent. Further analysis will compare the combined elergy use of the DIA systems to central units with the same AFUE.

\section{Concinsione}

Several studies show that shifting the responsibility for heating costs to tenants results in energy savings. Table 2-23 summarizes results from these studies.

Table 2-23 lists savings ranging from 6 to 77 percent. Only three studies have compared central heating systems with decentralized heating (Palermini and Hewitt, Bohac et al., and Byrene and Fay).

None of these studies breaks down the savings obtained through change in tenant behavior due to direct billing versus savings obtained through more efficient operation by decentralized equipment. Furthermore, the savings reported by metering studies are of the same order of magnitude with the savings reported by studies where the central heating system was replaced with decentralized heating equipment. Therefore, It is not possible to assess the contribution of decentralized equipment only. (Note: The Palermini and Hewitt study did report very high savings for decentralized equipment, but these savings also included the effect of weatherization.)

Finally, all studies were performed on different types of multifamily units and in different climates. This compounds the problem of comparing the results and 
Table 2-23. Summary of Energy Savings Achieved by Shifting Responsibility of Heating Costs to Tenants of Multifamily Buildings

\begin{tabular}{|c|c|c|c|c|}
\hline Study & Building Type & Year & Type & $\begin{array}{l}\text { Savings } \\
(\%)\end{array}$ \\
\hline $\begin{array}{l}\text { Palermini } \mathrm{D} \text {. } \\
\text { and Hewitt } \mathrm{D} \text {. }\end{array}$ & Multifamily building & 1991 & $\begin{array}{l}\text { 1) Central oil to } \\
\text { individual electric } \\
\text { conv. } \\
\text { 2) Central gas to } \\
\text { individual gas conv. } \\
\text { 3) Central gas with } \\
\text { allocation system } \\
\text { added }\end{array}$ & $\begin{array}{r}69-77 \\
6-29\end{array}$ \\
\hline Scott W.L. & $\begin{array}{l}\text { Multifamily buildings } 90 \\
\text { units or more each. Low- } \\
\text { nse } 4 \text { stories or less and } \\
\text { high-rise } 10 \text { stories or } \\
\text { more }\end{array}$ & 1991 & Metering & 19 \\
\hline Bohac, et al. & $\begin{array}{l}\text { Multifamily building } \\
\text { single and } 2 \text {-story }\end{array}$ & 1990 & $\begin{array}{l}\text { Decentralized } \\
\text { heating DHW }\end{array}$ & $13-19$ \\
\hline Byrene and Fay & $\begin{array}{l}\text { Multifamily building 3- } \\
\text { story }\end{array}$ & 1989 & $\begin{array}{l}\text { Computer modeling } \\
\text { (DOE 2.1C) }\end{array}$ & 20 \\
\hline McClelland, L. & Multifamily buildings & 1983 & Metering & 14 \\
\hline
\end{tabular}

reinforces the fact that extant data do not support any conclusions on the energysaving effect of decentralized heating equipment in and by itself, without contribution from tenant behavior.

\section{Recommendations}

In view of the scant information on the energy use and seasonal efficiency of distributed heating/DHW units, the originally planned monitoring in the Energy Authority project would have provided important data. Specifically, the tests performed in the other studies have addressed the total energy savings obtained; a) through cost allocation; b) through individual metering; or c) through replacement of a central system with individual units. However, these tests did not differentiate between reductions as a result of the psychological effect of direct billing and reductions as a result of more efficient operation of distributed equipment under partload conditions. Unless such equipment-related reductions are documented and found 
to be significant, there would be little incentive to provide decentralized heating rather than individual metering. The original Energy Authority project, which included a demonstration, attempted, among other goals, to provide information on the energy use of indtvidual heating/DHW units. 


\section{Section 3 \\ INSTITUTIONAL CONSTRAINTS}

\section{INTRODUCTION}

The National Conference of States on Building Codes and Standards (NCSBCS) conducted the institutional constraints investigation. The development, application, and installation of new technologies in new and existing buildings is affected by codes, standards and regulations. For the State of New York, multifamily building energy research and development is critical to advance the level of energy efficiency in these structures. Advances in energy research and development can reduce utility costs and energy consumption for the state as well as for owners and renters of these buildings.

Energy-saving strategies include development of more energy-efficient appliances and energy delivery and billing systems. In the latter strategy, those who pay directly for their utility bills have a financial incentive to reduce consumption. In the former strategy, decentralized appliances and systems that make users directly responsible for their energy use are now more efficient than in the past; larger and more centralized systems had historically been more energy efficient than smaller, individual units. In either case, bullding construction regulations will impact the acceptance and application of any technology.

Beginning with work by the U. S. Department of Housing and Urban Development in the mid-1960s, there have been considerable efforts devoted to the issues of individual and master metering of energy use and the efficiency and economics of individual and central systems. These issues were actively studied and debated by the American Society of Heating, Refrigerating and Air Conditioning Engineers (ASHRAE) and utility companies until the mid-1980s. With new emphasis on energy conservation and more efficient and less centralized appliances, the opportunity for reductions in gas consumption can be revisited.

This opportunity is made even more viable with new technologies in gas piping and metering. However, bullding health and life safety must take precedence over energy savings. This means that state and local building codes and ordinances and gas utility regulations that regulate construction or gas installations in New York State must be satisfied before any technology can be readily approved for use. The 
development of technologies that do not satisfy the requirements or intent of these documents may never be marketable.

\section{PURPOSE}

This section investigates the regulatory barriers in New York State to using innovative technology for decentralized gas-fired space and water heating. The administrative criteria in the state and local construction codes and utlity regulations and directives that will impact use of this innovative technology are also identified.

After the barriers presented by code limitations were identified, analysis of these regulatory criteria was carried out to provide insight into the application of the criteria. The potential impact of code requirements was delineated. Informal discussions with fire and code officials, utility representatives, and other interested parties, formed the basis for development of strategies for overcoming these barriers or for promoting the use of the technologies.

\section{PROJECT OVERVIEW}

In the development and application of decentralized gas systems in multifamily buildings, building construction regulations can either be a hindrance or a help. This Investigation focuses on a review of New York State and local codes and utllity regulations to identify issues that may arise with the application of these gas systems. The resulting identification of issues and assessment of the impacts of codes, standards and regulations lead to a series of recommendations and strategles to overcome the barriers or limitations.

The tasks necessary to determine the feasibility of decentralized gas applications in multifamily buildings from a regulatory perspective include the following:

- Task 1: Reviewing the avallable technologies.

- Task 2: Identifying issues upon which the codes and standards and utility directives will have an impact.

- Task 3: Reviewing the state and local codes and utility regulations for each of the technologies identified in Task 1 for prohibitions or limitations.

- Task 4: Recommending strategies for the successful use of the decentralized gas technology. 
As part of Task 4, it is critical to communicate with those individuals with some interest in the implementation and enforcement of codes and regulations. Therefore, an integral part of the task has been to informally canvas various code officials, gas utility representatives, insurance company officials, and people in the trades. This contact has elicited opinions on the acceptance of the new technologies, the code enforcement implications, and the potential support or resistance that might be expected from various interested parties.

\section{Task 1 - Review of Available Technologies}

NCSBCS received product literature on innovative gas piping and appliance technologies for decentralized applications in multifamily buildings from Foster-Miller and Steven Winter Associates. A review of this literature defined the two areas of technology critical to this project: dual integrated appliances (DIAs) and corrugated stainless steel tubing (CSST).

DIAs (also known as combo units in the industry) are space and domestic water heating systems that typically utilize domestic hot water heaters (DHWH) as the single heat source. Hot water generated by the DHWH is circulated through a heating coil in an air handler. A fan circulates air over the heating coil and moves the heated air into an air duct system that distributes it into the space for comfort heating. A circulating pump and the fan motor are activated by a room thermostat upon a call for heating. After the hot water passes through the heating coil, it is re-introduced to the DHWH tank to be reheated and avallable for domestic hot water use. A mixing valve is used to maintain a pre-set domestic hot water temperature. Valves are installed that allow the heating coll to be isolated and flushed, so that water stagnation will not occur.

CSST, American Gas Association (AGA) design-certified for use in fuel gas piping systems, utilizes semirigid corrugated tubing made of 304 stainless steel. The corrugated tubing is covered with a polyethylene (PE) or polyvinyl chloride (PVC) coating, approximately $0.025 \mathrm{in}$. $(0.63 \mathrm{~mm})$ thick. The purpose of the coating is twofold: to protect it against household chemicals and abrasion, and to reduce friction while snaking it through stud walls and floor joists. Special mechanical fittings are provided to interconnect the tubing with other components within the overall gas piping system. It is currently supplied in coils of 100 to $250 \mathrm{ft}$ in length and is manufactured in four different sizes: $3 / 8,1 / 2,3 / 4$, and $1 \mathrm{in}$. internal diameters (ID). Larger sizes, up to $1-1 / 2$ in. ID, may be available in the future. 


\section{Task 2-Identification of Code Insues}

After reviewing the product literature, NCSBCS listed all the possible building and mechanical issues that applied to the innovative technologies (DIAs and CSST) as contained in building construction regulations. It must be noted that not all the issues identified as having a potential impact in the use of these technologies will necessarlly be covered in the bullding codes.

The issues identifled are :

A. Pre-equipment issues (gas distribution system)

1. Structural requirements

2. Configuration of gas supply system

3. Inspection/enforcement responstbility

4. Gas meters

5. Gas valves

6. Gas regulators

7. Piping/tubing

a. Joint and support requirements

b. Installation requirements

c. Sizing/design/pressure limits

B. Equipment issues

1. Performance efficiencies

2. Controls

3. Component venting requirements

4. Equipment sizing

5. Enclosures/locations

6. Installation/service

C. Post-equipment issues

1. Combustion air 


\section{Venting/chimneys/flues}

3. Other issues

\section{Task 3-Review of Bullding Construction Regulations}

Subsequent to the delineation of the applicable issues that might impact the acceptance of DIAs and CSST, NCSBCS conducted a review of the codes and regulations in New York that apply to multifamily buildings. The documents reviewed include the following:

- The New York State Uniform Fire Prevention and Bullding Code, mandatory in all jurisdictions except New York City.

- The New York State Energy Conservation Construction Code, mandatory throughout the state.

- The New York State Multiple Dwelling Law, mandatory in cities with a population of 350,000 or more.

- The New York State Multiple Residence Law, mandatory in municipalities with less than 350,000 population.

- The Building Code of the City of New York.

- Any local amendments to the State Uniform Fire Prevention and Bullding Code for Albany, Buffalo, Rochester and Syracuse (local jurisdictions are permitted to amend the state building code, with state approval, to provide more stringent requirements).

- Any relevant regulations of the 12 major gas utility companies.

The summaries of code criteria by issue found in all the reviewed documents are found in the following matrices. Note that not all the issues identified are covered in the codes. In addition, a review of the State Multiple Residence Laws found no references to the issues identified; therefore, these documents are not included in the matrices. The major city amendments were reviewed and also found to not apply to the issues identified. The gas utility companies all use the National Fuel Gas Code (NFGC), 1988 edition; a review of the relevant issues in the NFGC is included in the matrices. The New York State Uniform Fire Prevention and Bullding Code references the 1984 edition of NFGC, and the New York City Building Code references the 1974 edition. The major difference between these editions is that only the 1988 edition recognizes CSST. The number that appears in parenthesis after the text indicates the relevant section in the code. 
New York State Uniform Fire Prevention and Building Code

A. Pre-equipment issues

1. Structural requirements

2. Configuration of gas supply system

3. Inspection/enforcement responsibility

4. Gas meters

5. Gas valves

6. Gas regulators
Hazardous piping not allowed in exits, stairways, or hoistways. (850.11)

Gas pipe must not be installed in cinderfill or other corrosive material unless protected. (1001.1(c))

Fuel gas piping and equipment must not be located in ducts, chutes, chimneys. flues, hoistways, stairways, or exits. (1001.1(e))

Buildings having service $>1$ psig must have exterior wall openings below grade within $10 \mathrm{ft}$ of gas pipe made airtight. (1001.5b)

Fuel gas and piping system requirements per NFPA 54-84. ((B-1001.1), 850, 610, and RS38-12 in 1250.3)

Must be located in dry, well-ventilated. readily accessible area, free from steam or chemical fumes, protected from extreme heat. Must be located as near as practicable to point of entry of gas service. Meter's location protected from damage. not in spaces designed for storage oi flammable products, and away from bottom of stairway. (1 163.2(d), 1001.3(a))

Gas service piping lines must have accessible means for shutting of gas supply to bullding. Additional means must comply with State Public Service Commission regulations. (1001.2(a). $1163.2(\mathrm{a}))$

An easily accessible shut-off valve or cock must be provided in close proximity and upstream of each gas outlet or appliance connection. (1001.2(b), 1163.2(c))

Locate to be protected from damage and away from bottom of stairway. (B-1001.3) 
New York State Uniform Fire Prevention and Building Code

\section{Piping/tubing}

a. Joint and support requirements

b. Ins,tallation requirements

c. Sizing/design/pressure limits

B. Equipment issues

1. Performance efficiencies

2. Controls

3. Component venting requirements

4. Equipment sizing
Cleanouts must be provided where contaminants may collect. (1001.1(d))

Fuel supply connections to equipment must be made with pipe or tubing of solid metal or means of generally accepted methods. (B-1000.2e)

Gas systems must be designed and installed to supply sufficient gas to meet maximum demands of installed gas appliances. (1001.1(f))

Fuel gas piping system must be of approved material resistant to the corrosive effects of gases conveyed by them. (1001.1(b))

Service connections supplying gas at a pressure $>1$ psig must have device to reduce pressure to $\leq 0.5 \mathrm{psig}$ prior to entering meter, except where system designed for higher pressures. (1001.5(a))

Hot water supply systems must be provided with safety devices arranged to relieve hazardous pressure and excessive temperatures. (902.6(a))

An approved combustion pressure/temperature relief valve may be used on equipment with storage capacity $\leq 120 \mathrm{gal}$, and hourly input $\leq 100 \mathrm{~K} \mathrm{Btu} / \mathrm{hr}$. (902.6(d))

Safety controls will prevent overheating and operation of pilots and burners during conditions of overheat or excessive pressure. $(1000.2(j)(1)(2)(1)(i 1)($ iv) $)$ 
New York State Uniform Fire Prevention and Bullding Code

5. Enclosures/locations

6. Installation/service

C. Post equipment issues

1. Combustion air

2. Venting/chimneys/flues

3. Other issues
Do not install so equipment is potential hazard to occupants. (B-1000.2d4)

When in, on, or adjacent to combustible materials, limit surface temperature to such materials to $175^{\circ} \mathrm{F}$. (B-1000.2f)

Provide direct fired heat-producing equipment and its enclosure with air for combustion and ventilation. When $\geq 250,000 \mathrm{Btu} / \mathrm{hr}$ rated capacity, provide via fixed openings to the exterior. (B1005.6)

Connect to suitable chimney, flue, or gas vent unless of the direct vent type with combustion air inlet directly to the exterior. (B-1000.2h)

Connectors to chimneys or gas vents in $>1$ story not allowed. Equipment in different tenancies cannot be connected to the same flue.

Terminate gas vents $\geq 2 \mathrm{ft}$ above point within $10 \mathrm{ft}$ and $\geq 15 \mathrm{ft}$ horzontal to windows or other extertor opening higher than and $\leq 30 \mathrm{ft}$ above the opening. For masonry and metal chimneys, provide $\geq 20$ $\mathrm{ft}$ vertical clearance, $\geq 3 \mathrm{ft}$ above highest roof point where flue passes and $\geq 2 \mathrm{ft}$ above point within $10 \mathrm{ft}$ (B-1005.6)

Locate integral venting system outlet per applicable appllance standard. (B-1005.6) 
A. Pre-equipment issues

1. Structural requirements

2. Configuration of gas supply system

3. Inspection/enforcement responsibility

4. Gas meters

5. Gas valves

6. Gas regulators

7. Piping/tubing

a. Joint and support requirements

b. Installation requirements

c. Sizing/design/pressure limits

B. Equipment issues

1. Performance efficiencies

2. Controls
All joints and openings in building envelope must be caulked, gasketed, weather-stripped, or otherwise sealed. (7813.4(b))

Governmental entity that is responsible for administration and enforcernent of Building Construction Code or the Fire Prevention and Building Construction Code within municipality. (7810.9(a))

Separate valve must be provided to permit burning off the energy supplied to the main burner or burners of gas-fired equipment. (7813.34(d)(2))

Gas-fired water heaters (U.S. DOE covered) must meet the following performance (efficiency) requirements. Energy factor, overall heating efficiency $\geq 0.62-0.0019 \mathrm{v}(\mathrm{v}=$ storage volume in gallons).

Each separate dwelling unit must have open thermostat capabile of automatically adjusting the space temperature set point. (7813.13(a) and (b))

Thermostat must have a $5^{\circ} \mathrm{F}$ dead band between full heating and full cooling. (7813.13(b)) 


\begin{tabular}{l|l} 
& $\begin{array}{l}\text { New York State Energy Conservation } \\
\text { Construction Code }\end{array}$ \\
\hline 2. Controls (continued) & $\begin{array}{l}\text { Service water heating systems must be } \\
\text { equipped with automatic temperature } \\
\text { controls capable of adjusting from the } \\
\text { lowest to the highest temperature settings } \\
\text { for the intended use. (7813.34) }\end{array}$ \\
3. Component venting requirements & $\begin{array}{l}\text { In accordance with generally accepted } \\
\text { engineering practice. (7813.12(b)) }\end{array}$ \\
4. Equipment sizing & \\
5. Enclosures/locations & \\
6. Installation/service & \\
C. Post-equipment issues & \\
1. Combustion air & \\
2. Venting/chimneys/flues &
\end{tabular}


New York City Building Code

A. Pre-equipment issues

1. Structural requirements

2. Configuration of gas supply system

Tubing $\leq 4 \mathrm{in}$. may pass through fire resistance rated construction if area around penetration is $\leq 1 / 2$ in. and packed with noncombustible materials. ([1600.8] 27-903, 27-343, Article 5)

Gas pipe shafts cannot be located in stairways, must be sealed to prevent gas leakage, conform to high hazard requirements, be vented to open air at top. (RS16 P115.8)

3. Inspection/enforcement responsibility

New gas distribution systems must be approved/inspected by Department of Buildings according to code. ([1606.4] 27 922(d), [1606.1] 27-919)

4. Gas meters

5. Gas valves

\section{Gas regulators}

Locate as near as practical to point of service entrance. Locate in cellar or basement unless permitted by commissioner. Location must be clean and dry, free of refuse and steam. protected from extreme heat and cold, readily accessible for reading and inspection, and properly ventilated. Do not locate multiple dwelling meters in boller rooms or public hall above lowest story. (P1 15.6(b))

Per ANSI Z2 1.15-1979 and Addenda Z21.15a-1981, Z21.15b-1984 (manually operated gas valves). Provide on supply side of meter and any service regulator. (P1 15.2(a))

Install emergency shutoff in gas pipe outside building. (P1 15.5(a))

Regulator must reduce supply pressures $>0.5 \mathrm{psig}$ to $\leq 0.5 \mathrm{psig}$ except where higher pressures are permitted. [RS16, P1 15.4]

When located inside building, regulators must vent directly to outside air. Pipe is sized according to utility requirements. Gas vents must be identified by suitable markings on outlet. (P1 15.4(b)) 
New York City Bullding Code

7. Piping/tubing

a. Joint and support requirements

Provide per NFPA 54-74 when system operates at $\leq 1 / 2 \mathrm{psig}$. Do not use screwed foints on pipe $>4 \mathrm{ln}$. dia. (P115.7(a))

Butt weld all welded pipe $>3$ psig inside buildings and subject to controlled inspection. (P115.7(k))

b. Installation requirements

c. Sizing/design/pressure limits

Provide service piping per serving utility (P115.8(a)). Provide gas distribution per NFPA 54-74. (P115.8(g) and (k))

Limit to $1 / 2$ psig within buildings except $\leq 3 \mathrm{psig}$ for commercial, industrial and other large areas. (P1 15.3)

May use $>10$ psig when piping in 3-hr walls and partitions and 2-hr floor and cellings. (P115.8(n))

May use $>15$ psig when in 3-hr rating, fire protection provided, gas detection system alarm, gas pipe shafts are not for stairways, compressors are located in separate rooms, and other safeguards provided. (P1 15.8(n))

Size per NFPA 54-74 and provide $\geq 3 / 4$ in. outlet to gas ranges. (P115.9)

Provide per NFPA 54-74 when system operates at $\leq 1 / 2$ psig except:

- Plastic pipe and tubing cannot be used

- Provide materials per serving utility

- Limit primary stress to 20 percent of piping yleld strength (P1 15.7(a))

When system $>1.2$ psig, provide per ANSI B31.2-1968. (P115.7(a))

Gas pipe must be sized in accordance with ANSI Z223.1-1974, RS16 P115.9. Size per NFPA 54-74 and provide $\geq 3 / 4$ in. outlet to gas ranges. (P115.9) 
B. Equipment issues

1. Performance efficiencies

2. Controls

3. Component venting requirements

4. Equipment sizing

5. Enclosures/locations
Floor-mounted combustion or heating equipment to be mounted on noncombustible construction, or combustible construction if protected as required in RS-14-17. Equipment tested to standards listed in RS-14 to be installed at clearances determined by such test. ([C26-1406.1] 27-804, [C261407.1] 27-805, RS-14-17)

Air handling equipment to be located in separate compartment having a fire resistance rating not less than $1 \mathrm{hr}$ (not applicable to fans $\leq 1,000 \mathrm{cfm})$. (RS-13, 2 5.3)

Clearances for water heaters top, sides, back 6 in., front 18 in. [Reference Standard RS 14-15]

All fans on roof or floor, other than on grade, must be mounted on vibration isolators. ([C26-1208.3 27-770(b))

Insulation on surfaces of heat-producing equipment must be of noncombustible materials. $(1000.2(j)(2))$

Hot water heating systems must be provided with expansion tanks or other means to allow for the expansion of water in the system. $(1000.2(\mathrm{k}))$

Low-capacity heater rooms not required to be enclosed. When enclosed, enclosure must have 3/4-hr fire resistance rating, and interior finish must provide at least 10 minutes of fire protection to combustible members. Where serving one dwelling unit, openings in one interior wall are allowed without opening protective. $(739.4(f)(3))$ 


5. Enclosures/locations (continued)

6. Installation/service

C. Post-equipment issues

1. Combustion air
Heat-producing equipment must be mounted on noncombustible floor construction, or protected combustible floor protection, must be installed with sufficient clearance from adjacent combustible materials to prevent ignition. If celling above reaches temperature in excess of $175^{\circ} \mathrm{F}$, must be protected for $3 \mathrm{ft}$ on all sides of equipment by noncombustible material providing at least $10 \mathrm{~min}$ of fire protection, except if celling is of noncombustible construction and has a fire resistance rating with at least $3 / 4 \mathrm{hr}$. $(717.3(3)(1))$

Fuel-burning heat-producing equipment on levels having habitable space, walls, floor and ceiling $\leq 3 \mathrm{ft}$ from the equipment must have $3 / 4 \mathrm{hr}$ fire resistance rating. and interior finish providing at least 10 min of fire protection to combustible members. Protection not required when test made to generally accepted standards show that heat-producing equipment will not create a fire hazard or heat adjacent. materials $>175^{\circ} \mathrm{F}$. When doors are provided for enclosures, they must be selfclosing or finished on interlor with noncombustible material. (717.3(e)(2))

Fuel-burning water heaters may not be located in sleeping, bath or tollet rooms. (1000.2(d)(2))

Fuel-burning equipment may not be hazard to occupants in event of accidental contact. (1000.2(d))

Air intakes and exhausts cannot be located to interfere with other openings, interfere unreasonably with occupants and general public, or create a fire or health hazard. $(27-776(d))$

When mechanical ventilation supplies combustion air, interlock with burner. $(27-807(d))$ 
New York City Bullding Code

1. Combustion air (continued)

1. Combustion air (continued)

2. Venting/chimneys/flues
Heat-producing equipment within enclosure must be provided with adequate air for complete combustion at rated gross output and ventilation to prevent heat accumulation. Ventilating systems must have adequate openings for intake and exhaust. Intake air must come from an uncontaminated source. $(1000.2(\mathrm{~g})(1)$. 1004.2(b)(3))

Rooms having fuel-burning equipment with combined gross capacities $\leq 250 \mathrm{~K}$ $\mathrm{Btu} / \mathrm{hr}$. must have openings to the exterior, or fixed openings to be spaced open to the exterior. $(1000.2(\mathrm{~g})(2))$

Gas-fired space heating equipment must connect to suitable chimney flue or gas vent, except equipment having integral vent systems (intake and exhaust connected to exterior are not required to be connected to chimneys, flues, or gas vents). (1000.2(h)(2) and (4))

When gas vent is permitted, a permanent sign containing type of equipment that may be connected to gas vent must be located where gas vent passes through wall or ceiling. (1000.2(h)(6))

Equipment requiring mechanical draft must be interlocked to shut off fuel supply when vent system is in operation.

$(1000.2(\mathrm{~g})(5))$

Extend chimneys for low temperature appliances $\geq 3 \mathrm{ft}$ above highest construction and $\geq$ height of highest construction within $2 \times$ free area (sq. in.). (27-859)

May use Type B-W vents with multistory installations. $(27-884(\mathrm{~b}))$

Unless Type B or B-W vents used, cannot use a common vent to serve equipment on $>1$ floor. $(27-884(d))$

Extend gas vents as for chimneys above except $2 \mathrm{ft}$ rather than $3 \mathrm{ft}$. $\quad(27-888)$ 
2. Venting/chimneys/flues (continued)

2. Venting/chimneys/flues (continued)

3. Other issues
Masonry and factory-bullt chimneys, gas vents, and supports must be structurally safe, secure, smoketight, noncombustible, and resistant to flue gas deterioration. (1005.1(a))

Masonry chimneys, except approved prefabricated chimneys, must have noncombustible foundations. (1005.1(c))

Flue lines must be resistant to flue gas deterioration. (1005.1(d))

Metal chimneys must be sufficiently separated from bullding construction to prevent potential hazard. (1005.1(e))

Openings for connectors must have means of easy connection without restriction of flue. (1005.1(f))

No chimney or gas vent must have connections in more than 1 story of a building. (1005.2(a))

Fuel-burning equipment located in different tenancies must not be connected to same flue. (1005.2(b))

Chimneys, gas vents, or other draftproducing devices installed on fuelburning equipment must provide sufficient draft to develop the rated output of the connected equipment. (1005.3(a))

Gas-fired equipment operating in natural draft and connected to a chimney or gas vent must have draft hood (except prohibited on incinerators). (1005.3(b))

No supply water piping must be directly connected to drainage system. $(902.2(d)(1))$

Water used for process heating or cooling, etc., cannot be re-introduced to potable water supply. (902.2(d)(2))

Flush valves directly connected to potable water supply must be equipped with vacuum breaker. (902.2(d)(3))

No cross connection of potable water supplies that may contaminate, pollute, or render water unpotable. ([1601.3] 27-

908) 
A. Pre-equipment issues

1. Structural requirements

2. Configuration of gas supply system

3. Inspection/enforcement responsibility

4. Gas meters

5. Gas valves
Installation of gas piping may not cause structural stresses within building components to exceed allowable limits. (3.3.1(a))

Structural members may not pass through gas utilization equipment operating $\geq 500^{\circ} \mathrm{F}$. Structural members passing through equipment operating $\leq 500^{\circ} \mathrm{F}$ must be of noncombustible material. (5.1.8)

Gas systems supplying separate users on the same premises may not be interconnected after the meters or regulators when meters are not provided. (2.3.1)

Must be located in areas protected from temperature extremes, accessible for reading, replacement, service. Must be 3 $\mathrm{ft}$ from source of ignition. (2.7.2)

Meter must be adequately supported.

(2.7.3)

Piping of multiple meter installations must be permanently marked designating areas served. (2.7.5)

Accessible gas shutoff valve must be placed upstream of each pressure regulator. When two regulators installed in series in a single line, second valve not required at the second regulator. $(3.10 .1)$

Main gas shutoff valves controlling several gas piping systems must be readily accessible for operation and protected from physical damage. Must be identified to system. (3.10.2(a))

In multiple tenant buildings supplied by master meter, or one service regulator with no meter, or when meters or service regulators not readily accessible from the equipment locations, individual shutoff valve for each apartment or tenant line must be provided at conventent point of general accessibility. (3.10.2(b)) 
5. Gas valves (contınued)

All gas utilization equipment connected to piping system must have approved manual shutoff valve installed within $6 \mathrm{ft}$ of equipment served. When connector used, the valve must be installed upstream of connector. Union or flanged connection must be installed downstream of valve to permit removal of control. (5.5.4)

6. Gas regulators

When gas sunply pressure is greater than that required by equipment or varies beyond design pressure limits, gas line pressure regulator or gas equipment regulator, as applicable, must be installed.

Adequately sized independent gas regulator venting to outside of building must be provided when location of regulator may cause a hazard due to ruptured diaphragm. Multiple regulators require separate vents, except if authority housing jurisdiction (AHJ) approves manifolding vent lines per accepted engineering practices to minimize back pressure in diaphragm fallure. (2.8.4(1))

Regulators complying with ANSI Z21.18 may be used without a vent to outside if regulator and vent limiting means are installed in ventllated location. (2.8.4)

Regulators may not be vented to equipment flues or exhaust systems. (2.8.4(A)(4))

Over-pressure protection devices not required on systems operating $\leq 60 \mathrm{psig}$.

7. Piping/tubing

Materials and components must conform to nationally recognized standards or specifications or be approved by AHJ. Materials not covered by standards must be tested to ensure suitability and safety for proposed service, recommended by manufacturers for service intended. (2.6.1)

Corrugated stainless steel conduit must be tested and listed as to compliance with construction, installation, and performance requirements for use in interior gas piping systems. ((AGA-1-87) 2.6.3(d)) 
a. Joint and support requirements

b. Installation requirements
Piping must be installed in substantial and workmanlike manner with adequate hanger supports or brackets. Must be installed to prevent undue stress and loads on connected equipment. (3.3.6)

When installing concealed gas piping, unions, tubing fittings, running threads, right and left couplings, bushings and swing joints made by a combination of fitungs must not be used.

Reconnection of tubing in a concealed space is prohibited. (3.4.6)

Pipe slopes of not less than $1 / 4$ in. per 15 $\mathrm{ft}$ required, unless using dry gas. (3.3.2. 3.3.3)

Gas piping may be installed in accessible above-ceiling spaces, whether or not such places are used as a plenum. Valves may not be installed in such spaces. (3.3.4)

Gas piping may not be run through a circulating air duct, clothes chute, chimney or gas vent, ventllating duct, dumbwaiter, or elevator shaft. Does not apply to combustion or ventilation air ducts. (3.3.4)

Concealed gas piping must not be located in solid partitions. (3.4.3)

Tubing may not run horizontally in hollow walls or partitions unless protected for full concealed length against physical damage. Tubing may run vertically inside hollow walls or partitions along its entire length if a steel striker barrier of not less than 0.0508 -in. thick or equal is installed between the tubing and the finished wall and extends at least 4 in. beyond concealed penetrations of plates and firestops, and tubing is not rigidly secured. (The preceding provisions do not apply to tubing that pierces walls, floors, or partitions.) (3.4.4) 


\section{b. Installation requirements (continued)}

c. Sizing/design/pressure limits

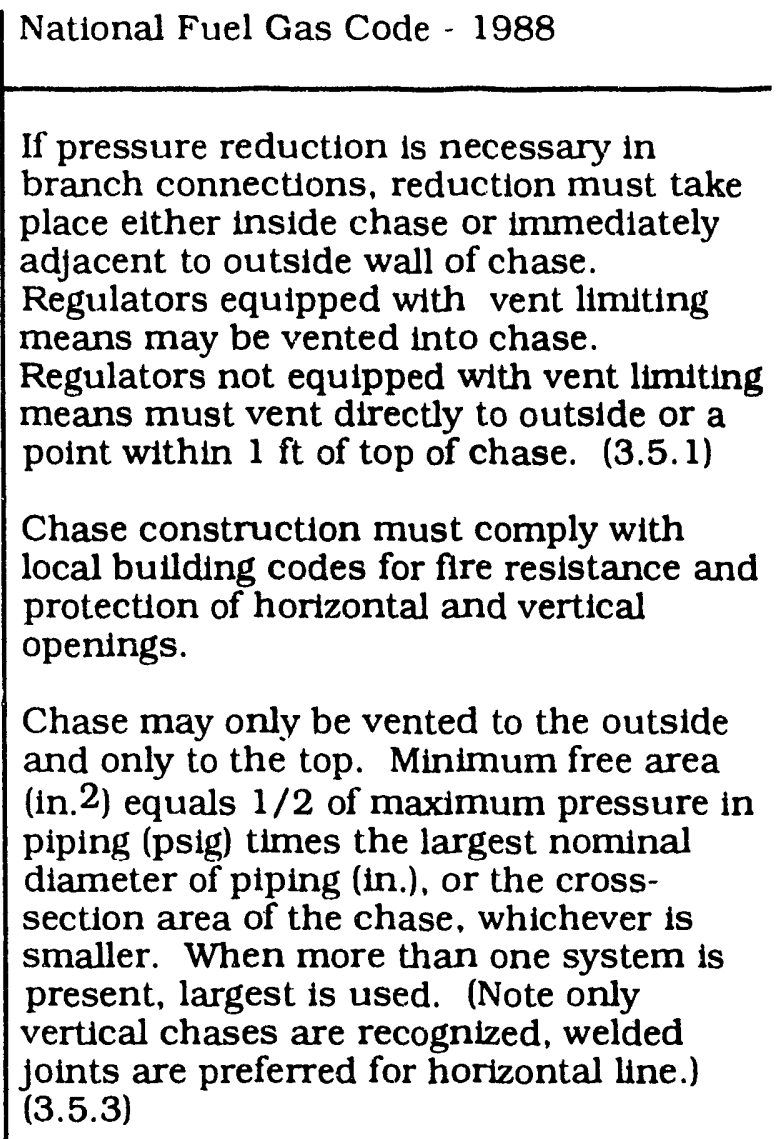

Chase may only be vented to the outside and only to the top. Minimum free area (in.2) equals $1 / 2$ of maximum pressure in piping (psig) times the largest nominal diameter of piping (in.), or the crosssection area of the chase, whichever is smaller. When more than one system is present, largest is used. (Note only vertical chases are recognized, welded joints are preferred for horizontal line.) (3.5.3)

Bends in metallic piping must be made only with bending equipment and procedures especially intended for that purpose. All bends must be smooth and free from buckling, cracks, or other evidence of mechanical damage. Pipe may not be bent through an arch of more than $90 \mathrm{deg}$. Inside radius of a bend must be $\geq 6$ times the pipe outer diameter (OD) (3.6.1)

Each above-ground portion of gas pipe system upstream from equipment shut-off valve must be electrically continuous and bonded to any grounding electrode as defined in National Electrical Code.

Gas pipe may not be used as a grounding electrode. (3.14(a) and (b))

Gas system must be sized to adequately supply gas to the gas utilizing equipment. Procedure for sizing NFGG NFPA-54, ANSI Z223.1 Appendix C.

System sized to provide adequate pressure at equipment. (2.4.4) 
c. Sizing/design/pressure limits (continued)

\section{B. Equipment issues}

\section{Controls}

3. Component venting requirements
Maximum pressure in system inside building $\leq 5$ psig, unless approved by $\mathrm{AHJ}$ and system is welded or piping is located in ventilated chase, or enclosed to protect against gas accumulation, or piping is located inside buildings not in habitable areas. (2.5.1)

Gas/air mixtures maximum pressure 10 psig. (2.5.2)

Gas appliance presisure regula: ors requiring access to atmosphere for operation must have vent piping to outdoors or, if regulator is an integral part of the equipment, to the combustion chamber at the pilot, unless equipped with a vent limiting means to limit escape of gas from vent due to diaphragm fallure. (5.1.19(a))

Vent limiting means must be employed on listed gas appliance regulators only.

\section{(5.1.19(b))}

Regulators must not be vented to equipment flue or exhaust system. (5.1.19(d))

Any combination of gas utilization equipment, attachments, or devices used together in anv manner must comply with the standards that apply to the individual equipment. (5.1.21)

Water heater installations must be provided with over-pressure and overtemperature protection by an approved device constructed, listed, and installed in accordance with its listing and manufacturer's instructions.

Equipment must be installed to allow for adequate circulation of air for combustion, ventilation, and dilution of flue gases from within the building. When normal infiltration does not provide the necessary air, outside air must be introduced. (This does not apply to direct vent equipment.) (5.3.1(a) through (d)) 


3. Component venting requirements
4. Equipment sizing
5. Enclosures/location

6. Installation/service

C. Post-equipment issues

1. Combustion air

2. Venting/chimneys/flues

3. Other issues
Equipment located in confined spaces using all alr from indoors must have two permanent openings communicating directly with additional room/rooms of sufficient volume that the combined volume of all space meets criteria for unconfined space. Each of the openings must have a free area of 1 sq. in. per $1,000 \mathrm{Btu} / \mathrm{hr}$ of input of equipment or minimum of $\geq 100$ sq. in. Openings must be $12 \mathrm{in}$. from top and $12 \mathrm{in}$. from bottom of enclosure. (5.3.3(a))

Equipment in confined space using all air from outdoors must have two permanent openings communicating directly or through ducts with the outside. Each opening must have a free area of $1 \mathrm{sq}$. in. per 4,000 Btu of input of equipment.

When communicating through vertical duct openings, clearance must be 1 sq. in. per 4,000 Btu/hr input of appliance.

When communicating through horizontal ducts, free area must be $2.000 \mathrm{Btu} / \mathrm{hr}$ of input of equipment.

Water heaters, with the exception of those having direct vent systems, must not be installed in bathrooms, bedrooms, or any occupled rooms normally kept closed.

(6.29.1)

Listed water heaters must be installed in accordance with their listing and

manufacturer's instructions. (6.29.3(a))

Requirements do not apply to direct vent equipment. (5.3.1.a) NFGC cites different requirements for combustion air from inside the building and air from outside. (5.3.3)

All gas utilization equipment must be connected to venting systems, with some exceptions. (7.2.1) 


\section{Task 4 - Development of Strategies}

With the information obtained from the first three tasks, NCSBCS analyzed the regulatory criteria to provide insights into the application of the criteria and the potential impacts of code requirements. Such insights were a necessary component of the development of strategies for accepted use of the technology.

\section{Insights by Issues}

A. Pre-equipment

1. Tubing run in hollow walls during retrofit requires protection from physical damage.

2. Higher operating pressures ( $>0.5 \mathrm{psig})$ require testing at minimum $90 \mathrm{psig}$ for $1 \mathrm{hr}$.

3. Meter placement in New York City in other than basement areas must be approved by the building commissioner and service utility.

4. Multiple regulators require separate venting unless the authority having jurisdiction approves manifolding of vent lines.

5. In New York City, no piping of gas at $>0.5$ psig may be run in a building unless commercial or industrial.

6. In New York City, gas systems $\geq 0.5 \mathrm{psig}$ in commercial and industrial use may be installed with commissioner approval. No mention of approval available for elevated pressures in residential buildings.

7. In New York State code, gas systems $>0.5$ psig require regulators to reduce pressure to $\geq 0.5$ psig unless the system is designed for higher pressures.

8. New York City requires gas systems to be sized per NFPA 54-74. New York State requires systems to be sized to meet maximum demand.

9. Both New York City and New York State reference NFPA 54-84 and -74, respectively, for gas piping/tubing. CSST is not mentioned as an acceptable metallic tubing in either NFPA 54 edition.

10. Pressure reductions for branch connections must take place either inside the chase or immediately adjacent to the outside wall of the chase. Pressure regulator (with vent limiting means) venting may be into the chase. Regulators without vent limiting means must vent to the outside.

B. Equipment

1. DIA equipment efficiencles conform to State Energy Code and U.S. DOE requirements. 
C. Post equipment

1. State Energy Code requires caulking and sealing of all construction joints, which may constitute "unusually tight construction." Combustion alr requirements for DIAs may be affected.

2. New York City prohibits water used for process heating, cooling, etc. from being re-introduced to potable water supply.

As an integral part of the strategy-development effort (Task 4), NCSBCS initiated informal telephone contact with a number of individuals having a professlonal interest in code adoption and enforcement, the acceptance of new technologies, and the fire and life safety implications of gas installations. This survey was undertaken with existing contacts of NCSBCS in New York State to elicit opinions and ideas about possible code changes or innovative technologies. The rationale for this informal assessment of perceptions among code officials and other interested parties was to enable NCSBCS to provide realistic strategies for technology acceptance - to stay within the realm of what is possible.

The entities that were contacted for this survey work include the following:

- Officials from the New York City Fire Marshal's Office, the New York City Department of Buildings, and the New York City Fire Prevention Bureau

- The town engineer and the fire marshal in Eastchester, NY

- Officials from Suffolk County fire and bullding departments

- Representatives from Brooklyn Union Gas Company, Central Hudson Gas and Electric Corporation, Corning Natural Gas Corporation, and the New York Public Service Commission

- Representatives from Metropolitan Life Insurance Company and State Farm Insurance

- A spokesman for Local 2 of the Plumbers Union (operating in Manhattan and the Bronx)

- An official in the New York State Energy Office

- An official in the New York State Housing and Building Codes Bureau. 


\section{Surver Results}

The fire marshals all indicated a concern over gas pressures over 0.5 psig inside a residential structure. Their concerns increased when they found pressures were to be in a relatively new type of gas distribution tubing. The fire prevention community relates CSST performance to that of typical flexible gas connectors, and all relayed negative experiences with them. They voiced strong opposition to the prospect of code changes that would allow CSST and higher gas pressures. No opposition was voiced concerning DLAs.

Code officials generally accepted the concept of DLAs. No contact felt that water heaters in DIAs should meet ASME boiler requirements. Most code officials indicated that once restrictive language was removed from the code, that they had no problem with accepting DIAs.

Opinions on CSST differed appreciably. New York City code officials felt that CSST was not a proven safe product, despite listings, etc. An “if it isn't broke, don't fix it" attitude prevailed. The use of typical steel piping methods for gas distribution systems was preferred, and any mention of code changes to allow CSST was frowned upon. The use of $\geq 0.5 \mathrm{psig}$ gas pressures was not favored.

State code officials were not as negative regarding CSST applications and generally indicated that if a product was listed for its intended use by a nationally recognized listing agency, they had no major opposition to its implementation. State code officials noted that adoption of NFPA 54-1988 by reference would provide necessary language to allow CSST. State code officials voiced no negative opinions on DIAs.

Gas utility representatives all have positive comments regarding DIAs. Energy savings were their primary considerations. Opinions and comments on CSST applications all appeared to center on elevated gas pressures in the systems. The concerns over CSST applications ranged from possibilities of punctures during construction to meter and regulator applications. Most utility representatives indicated that new metering technology would be favorably reviewed if it assisted DIA and CSST application. The utilities also would look at innovative meter and regulator placement and be willing to adjust utility metering on regulator requirements for certain applications on an individual basis. Certain unique system configurations would be reviewed for 
approval if requested. Some utility representatives have been very active in attempting to gain city- and state-wide acceptance of DIAs and CSST.

Insurance company representatives contacted did not appear to have any specific knowledge or concerns about CSST or DIAs. The only concern of the two companies contacted was that the bullding meet all applicable codes and regulations. If a building meets code, the insurance company saw no need for additional surcharges due to DIAs or CSST at this time.

The New York State Energy Office had no comments regarding CSST. The use of DIAS received favorable comments. Efficiency ratings for DIAs may be included in the energy code at a later date.

The Office of Uniform Fire Prevention and Building Code had no comment on DLAs. Discussion on CSST and elevated gas pressures was apprehensive. Code changes necessary to allow CSST and higher residential gas pressures were not anticipated. A generally negative view of CSST exists, and appears to be supported by bad experience with flexible gas connector malfunction and associated problems.

The plumbing trade union had no comment or experience with DIAs. The union official voiced strong negative opinions on CSST. Construction problems were cited. The union also recognizes that CSST systems are not as labor intensive as standard gas systems and therefore affect union plumbers financially. The union official also noted that special additional training myst.be supplied for the correct installation of CSST. It was felt that this training may not be readily avalable, and CSST systems may be installed with sub-standard workmanship.

\section{Strategies}

The use of potable water for space heating restriction appears to be the greatest regulatory drawback for DIAs. The informal survey revealed that some officials feel that the possibility of the occurrence of Legionnatres' disease is unusually high with DIAs. This may or may not be a legitimate concern. The opposition, however, must be researched and extensive testing to prove or disprove these assertions should be referenced. If the concern is disproved, then code amendments should be undertaken to allow the use of DIAs. If the concern is proven valid, use of only those DIAs that do 
not use the potable water for space heating should be promoted. There does not appear to be any other major code restrictions to the use of DIAs. Typical construction practices that would apply to any gas heating and hot water generator would equally apply to DIA applications.

The use of CSST in multifamily dwellings appears to have several regulatory barriers. First, the use of elevated gas pressures (above $0.5 \mathrm{psig}$ ) in residential applications does not appear to be generally acceptable in the fire prevention, code official, or utility communities. Extensive research, testing, and experience information must be transmitted to the three groups in order to change current opinions and positions on elevated gas pressure applications. Second, the use of CSST remains a very controversial subject. Local fire officials and state code officials must be exposed to more positive information about CSST.

Dialogue must begin with the plumbing trade unions to begin to resolve the philosophical problems with CSST installations. As a technology of the future, CSST must be shown to installers as a positive opportunity -one that promotes more rehabilitation of existing structures, thereby saving or providing jobs.

If hybrid systems (combination CSST and steel pipe) are designed that will not require more than 0.5 psig operating pressures, the acceptance of CSST would be facilitated.

The adoption by New York City and the State of New York of NFPA 54-1988 will provide the necessary code language to allow CSST implementation. The less-thanpositive views of those contacted who would have some direct influence on code changes does not appear to facilitate general acceptance of CSST for gas distribution systems in multifamily residences. The availability and proliferation of educational materials about the use and safety of CSST must occur before general acceptance will occur.

\section{SUMMARY}

The purpose of this investigation was to identify and delineate the institutional constraints to the use of innovative technologies in decentralized gas space and water heating applications in multifamily buildings. The potential code barriers to the acceptance of DIAs and CSST in this residential setting relate primarily to the use of 
elevated gas pressures, the use of circulating potable water for heating or cooling, and the actual approval or installation of the tubing material.

From the informal survey of professionals with an interest in these applications, NCSBCS found that areas of concern mentioned in the previous paragraph are fairly pervastve throughout the state. A great deal of work will be required to inform and educate the affected parties before acceptance and use of the technologies is achieved. 


\section{Section 4 \\ TECHNICAL INNOVATIONS}

\section{INTRODUCTION}

The technical innovations survey was not performed to conceive advanced technologies for the distribution of natural gas within multifamily buildings, but rather to identify emerging technologies that are considered innovative relative to conventional approaches that are in use in New York State today. Furthermore, the information complled in this section was used as input for the Economic/Energy Assessment (Section 2) and the Institutional Constraints (Section 3) of this research project.

The objectives of the survey were to:

- Identify emerging technologies for gas piping, gas metering, gas utilization equipment and appliance vents for use in rehabilitated and newly constructed multifamily buildings

- Identify installation methods for gas piping located in chaseways, fire protected areas, and other affected areas of rehabilitated and newly constructed multifamily buildings.

The technical innovations surveyed were categorized as:

- Technologies that affect energy distribution/utilization equipment

- Technologies that affect the bullding structure.

The first category includes all of the gas piping hardware and equipment necessary to efficiently transport and consume natural gas from the utility meter to the decentralized space and water heating equipment. The second category addresses available building construction practices necessary to facilitate the implementation of the technologies identified in the first category. 


\section{CATEGORY ONE - TECHNOLOGIES THAT AFFECT ENERGY DISTRIBUTION/ UTILIZATION EQUIPMENT}

The following technologies were considered in the survey:

- Metering: Gas Research Institute (GRI) and others have developed advanced, compact, and intelligent meters, some of which will be commercialized in the near future. These and other metering technologies uncovered in the survey were reviewed for applicabllity to the New York State building market.

- Gas piping technologies: Foster-Miller has been involved in developing/ evaluating advanced gas piping systems for GRI, gas utilities and gas piping manufacturers since 1983. Foster-Miller's experience puts it in a position to assess the gas piping tech nology needs of the building market in New York State, and to offer several alternatives. Although the project was focused on corrugated stainless steel tubing systems, macro-composite tubing systems (KITEC and MEPLA PIPE) were also considered, as well as modified copper tubing.

- Space and water heating systems: A review of combined space and water heating systems was conducted to identify commercially avallable units. These included the Apollo-Hydro Heat, First Co. - Aqua Thermalre, and Mor-Flo Industries, Inc. - Polaris.

- Appliance venting: New developments in appliance venting, such as the new method of characterization that has led to new vent sizing tables, were reviewed for applicability to the combined space and water heating systems.

Common appliance and multi-story venting were also investigated by performing a literature search and discussions with key industry organizations, such as the Gas Appliance Manufacturers Association (GAMA), AGA and GRI.

This survey was conducted by extracting technical information from a number of industry sources that included:

- Foster-Miller's research files

- American Gas Association

- American Gas Association Laboratories

- Gas Appliance Manufacturing Association

- Gas utilities

- Manufacturers of gas decentralized space and heating systems

- Manufacturers of gas piping products and associated hardware. 


\section{CATEGORY TWO - TECHNOLOGIES THAT AFFECT THE BUILDING STRUCTURE}

Installation methods for gas piping located in chaseways, fire protected areas, and other affected areas of rehabilitated and newly constructed multifamily buildings were surveyed. The information was collected from builders/developers who tend to use innovative technologies. The search focused on demonstration projects which are most likely to incorporate technical advances. Organizations that were contacted included:

- Trade associations

- Institute of Heating and Air Conditioning Industries

- Mechanical Contractors Associations

- National Association of Plumbing, Heating, and Cooling Contractors

- Mechanical Contractors Association

- General Building Contractors Association

- Industry organizations

- Gas Research Institute

- American Gas Association

- Gas Appliance Manufacturing Association

- Federal and state energy offices

- U.S. DOE

- New York State Energy Office

- New York State Energy Research and Development Authority

- Washington State Energy Office

- California Energy Commission

- Minnesota Energy Office

- Colorado Energy Office

- Massachusetts Energy Office

- Pennsylvania Energy Office 
- Utilities

- Brooklyn Union Gas

- Yankee Gas

- Bonneville Power Authority

- Major construction companies

- TIshman

- Turner.

\section{METERING}

Two technology areas related to metering are needed to promote the development of new gas distribution technology for multifamily bulldings. They are:

- Automatic meter reading (AMR) systems

- Compact gas meters.

Although metering technology as applied to residential and commercial applications by the gas industry is essentlally unchanged since the turn of the century, the collection, transfer, and processing of the flow data have undergone dramatic changes. The diaphragm type gas meter is still the overwhelming choice by gas utilities for residential, commercial and, to a large extent, industrial applications. It is a timeproven device that is accurate over large flow ranges and reliable over its long service life of 20 years. Coupled with the fact that it is also a low-cost item. it is hard to find a suttable replacement. However, by current standards it has two distinct drawbacks: its relatively large size and how it measures (1.e., flow based on "volume" instead of "mass" or "energy").

There are several gas meter technologies currently under investigation and/or development by GRI and others. These include:

- Small diaphragm meter (developed by Battelle/National Meter)

- Digital electronic flowmeter (developed by Select Corporation)

- Microcomputer-controlled N-type diaphragm gas meter (developed in Japan and referred to as the intelligent gas meter) 
- Domestic compact turbine meter (currently under development in Japan)

- Fluidic flowmeter (developed by Japan)

- Fluidic flowmeter (developed by Illinois Institute of Technology/Alnor Instrument Co.)

- Ultrasonic meter (currently under development by British Gas).

None of these non-diaphragm types have been commercialized to the point where they can be given serious consideration as replacements for the diaphragm meter. But like many other technological innovations, once they are introduced into the market, a switchover is likely to take place. However, it will probably be several years before any of these new gas metering technologies find a place in the market that serves the residential industry. The following subsections are an appreciation of what is needed more than what is currently avallable. By identifying the current needs and trends, technology developers may be enticed to follow with the necessary (and acceptable) hardware and software. The realities of the marketplace will determine if new meters are introduced to the gas industry.

\section{Automatic Meter Reading Systems}

By far the biggest change in metering has been in the development of AMR technology. The use of remote terminal units (RTUs) on the gas transmission and distribution pipelines for control, monitoring, and enhanced safety has opened up the field for new applications. AMR promises to help solve several problems for the gas utilities regarding residential/commercial meter reading:

- Inacressible meters

- Estimated billings

- Injuries to utility field personnel

- Customer property damage

- Customer complaints and security concerns.

There are several different types of AMR systems available on the market today. They substantially vary in operating procedure, technology, and cost. Most AMR systems consist of three components: 
- An electronic field unit

- A communications link

- A host computer and software system.

Some of them use the public telephone network (PTN) as the communications link, while others use RF (radio frequency) to transmit stored data. Also, systems that use PTN are either inbound or outbound. Inbound systems are programmed to send data from the user to the host computer as often as desired. For the outbound system, the host computer systematically calls each customer for data. Each has advantages and disadvantages. For example, the outbound system requires a utility to keep a database of all of its customers' current phone numbers. Table 4-1 provides a current listing of avallable AMR systems.

A simple diaphragm meter can be easily adapted with an RTU for signal transmission regarding real-time or cumulative gas flow data. Figure 4-1 gives an example of one such product. This was first done for large industrial customers to monitor gas volume flow and provide current usage rates for both the utllity and customer. Now several companies have developed AMR systems that can read thousands of meters almost instantly.

How does this apply to multifamily buildings? First, if the building is submetered with each tenant having a meter, the data could be routed via signal cable to a central computer in the building for transmission directly to the local utility via a gateway and telephone wires. An alternative for utilities that still use meter readers would be to collect the information and route it to a central location in the bullding where all services (electric, gas, water, etc.) could be accessed by the appropriate service personnel. There are even automated collection systerns on the market (one example is ACCESSplus) that not only read the gas, electric, and water meters, but phone the utility as well.

Most of the electronic devices for these meters will include an integrator that converts flow rate on a volume basis to accumulated volume as a function of time. They will, however, correct actual flow rates to flows and volumes at standard conditions. Also, the readout unit can be located any place the owner/developer desires. Bllling will be accomplished by interrogating the mete: ria remote computer control. 
Table 4-1. Sources on AMR

Here is a partial listing of the manufacturers of automated meter reading (AMR) equipment and the type of systems they specialize in. AMR also has its own trade association, the Automatic Meter Reading Association, P.O. Box 500, Westwood, NJ 07675. For information, call Stan Kulp at (201) 666-0902.

Alpha Omega Technology, Inc., 1279 Route 46, Parsippany, NJ 07054, (201) 334-4321. Remote-based.

American Meter, 13500 Philmont Ave., Philadelphia, PA 19116, (215) 673-2100. Radioand remote-based.

Badger Meter Inc., 4545 W. Brown Deer Road, P.O. Box 23099, Milwaukee, WI 53223. (414) 355-0400. Telephone-, radio- and remote-based.

Computer Metering Corp., 450 7th Ave., New York, NY 10123, (212) 279-7215.

Telephone- and remote-based.

Datamatic Inc., 2121 North Glenville Dr., Richardson. TX 75082, (214) 234-5000.

Radio- and remote-based.

Digitec Telecom Inc., 11 Indell L.a., Brampton, Ont., Canada L6T 3Y3, (416) 791-0333. Telephone-based.

EnScan Inc., 11095 Viking Drive, Suite 220, Eden Prairie, MN 55344, (800) 433-7323. Radio-based.

Equimeter Inc., 805 Liberty Road, P.O. Box 528, DuBois, PA 15801. (814) 375-8363. Telephone- and remote-based.

Hexagram Inc., 23905 Mercantile, Cleveland, $\mathrm{OH} 44122$, (216) 464-1057. Remotebased.

Husky Computers Inc., 13921 ICOT Blvd., Clearwater, FL 34620, (813) 530-4141. Telephone- and remote-based.

IMAC Systems, P.O. Box 1605. Tullytown, PA 19007.

International Teldata Corp., 5910 Bowcroft St., Los Angeles, CA 90016, (213) 842-8044. Telephone-based.

Iris Systems Inc., 123 Bannatyne Ave., Winnipeg, Man., Canada R3B OR3, (204) 947 9064. Radio-based.

Itron Inc., East 15616 Euclid Avenue, P.O. Box 15288, Spokane, WA 99216, (800) 635-

5461. Telephone-, radio- and remote-based.

Metering Services Inc., 50 Chesinut Ridge Rd., Montvale, NJ 07645, (201) 930-9200.

Telephone-based.

Metretek Inc., P.O. Box 280, Melbourne, FL 32902-0280, (800) 327-8559. Telephonebased.

Metscan Inc., 1450 Rochester St., Lima, NY 14485, (716) 624-9384. Telephone-based.

RioTronics, 6841 S. Yosemite, Englewood, CO 80112 , (303) 73-2600. Telephone-based.

Radix Corp., 4855 Wiley Post Way, Salt Lake City, UT 841 16, (800) 367-9256. Remotehased.

Schlumberger/Neptune Information Systems, 3155 orthwoods Parkway, Norcross, GA 30071 , (404) 446-1991. Telephone-based.

Sparton Technology Inc., c/o RذS Marketing Department, 4901 Rockaway Blvd., Rio Rancho, NM 87124 , (505) 892-5300. Telephone-based.

Syscon Corp., 3990 Sherman St., San Dieģ,o, CA 92110 , (619) 296-0085. Remote-based

Versa-Link Inc., 7379 Washington Ave. S., Edina, MN 55435, (612) 944-4001.

Telephone-based.

Reference snirre: American 6as, Marcl 1991 


\section{METRSTEK Application Notes}

\section{造解}
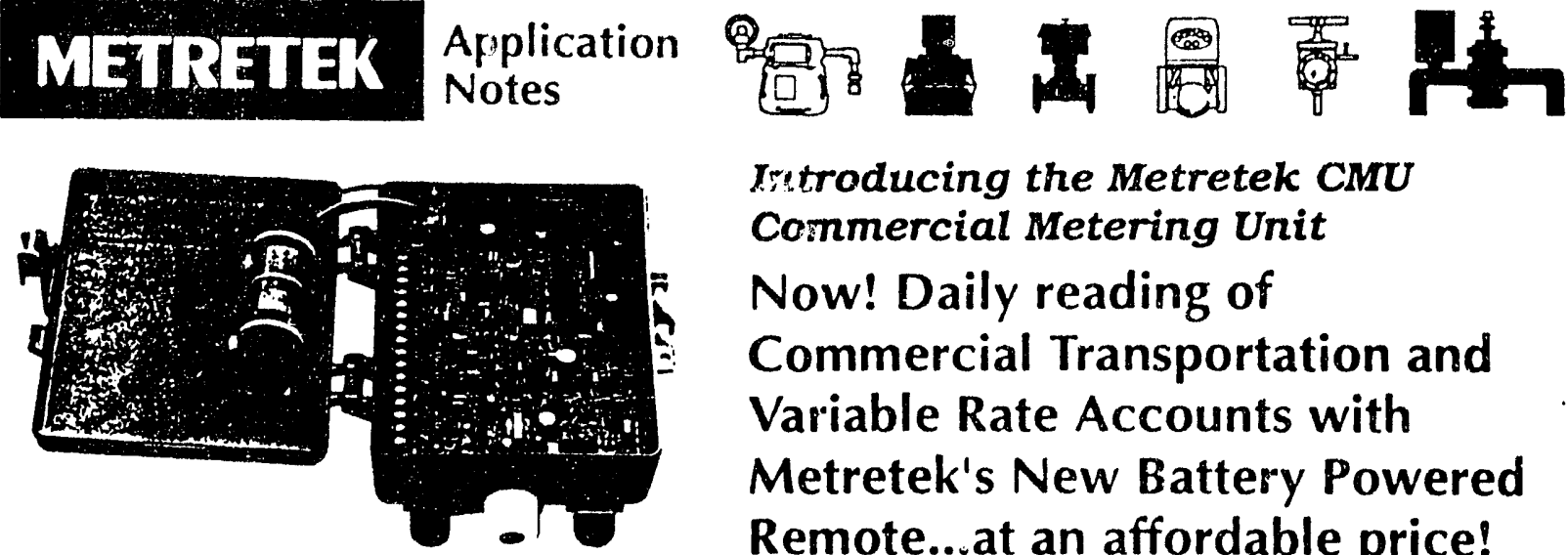

\section{Jitroducing the Metretek CMU Commercial Metering Unit Now! Daily reading of Commercial Transportation and Variable Rate Accounts with Metretek's New Battery Powered Remote...at an affordable price!}
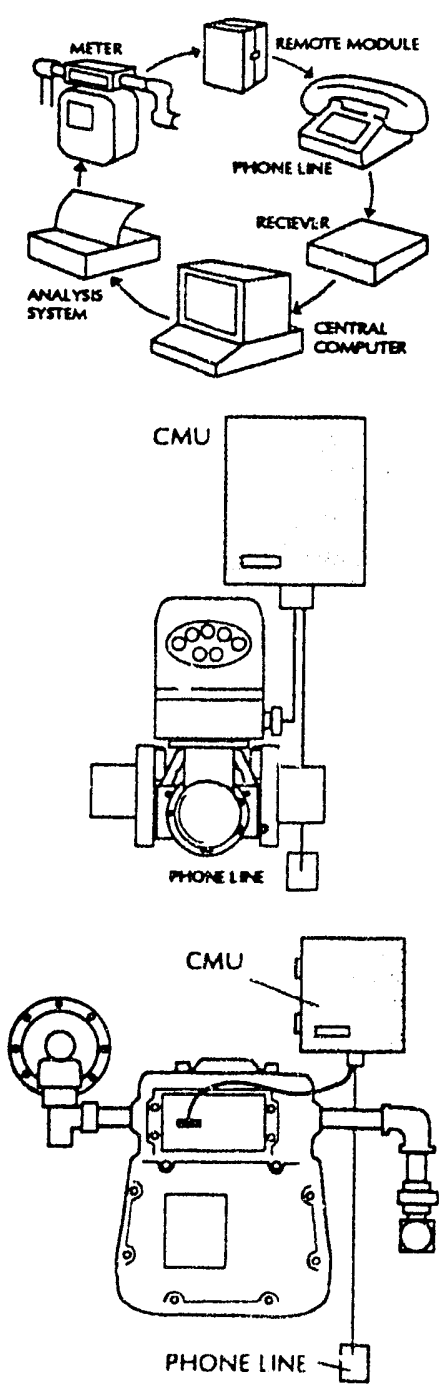

The Commercial Metering Unit (CMU) is a low cost and accurate meter reading device that offers needed telemetry for commercial and light industrial applications. The CMU is a microprocessor based, battery powered module that accepts and stores consumption pulse data from rotary and positive-displacement meters. It can report consumption and alarm information to the utility's central computer via the customer's exdsting telephone line. With its patented communications protocol, the CMU operates in a transparent mode always giving the customer priority over telephone access. Feasibility checking capability enables the CMU to Immediately notify the utility when a predetermined level of consumption has been reached. providing significant benefits in monitoring transportation and variable rate accounts. The CMU's lexible. system oriented design makes it appropriate for most volume applications.

Some Important Benefits of Installing Metretek's Automatic Commercial Meter Reading System are:

$\square$ Provides gas consumption information for commercial volume accourits

Accelerated cash flow from same day billing capability

Immediately notifies the utility when predefined consumption levels are reached

Provides ce isumption profling on a daily basis

Mounts on existing meter sets

Battery powered operation for 5 years on a daily reporting schedule

optional UL listed-nonincendive module for use in Class 1 Group D Division 2 hazardous locations 


\section{Compact Gas Meters}

One of the primary design objectives for all of the advanced gas meters currently under development is size reduction. Because of the high per-square-foot cost to construct multifamily buildings, developers have indicated a need to minimize the amount of space on each floor required for service areas. Compact gas meters will substantially reduce the total area required for gas meter rooms while enhancing the overall installation appearance. They will also facilitate ease of installation and maintenance.

Smaller and smarter gas meter sets will soon be seen that:

- Provide better customer service and greater installation flexibility, particularly for multifamily installations

- Meet the demand for a more aesthetic appearance

- Lower overall customer and utility costs

- Compensate for pressure and temperature.

These benefits are applicable both to new construction and to renovations of single family, multifamily and commercial buildings.

Present meter sets - consisting of the riser that brings gas from the service line, service valve, pressure regulator, meter, and pipe fittings - are rather bulky and can be unsightly assemblies in some applications. For single-family homes, a smaller meter set would reduce the problem of space limitations, making more options available for its location, including wall mounting and free standing, without violating aesthetic sensibllities. In multifamily buildings, separate gas metering for individual apartments is becoming more common. With present meter sizes, a 10 meter two-tier manifold installation can take up to $25 \mathrm{ft}^{2}$ of wall space. Compact meters would substantially reduce this space requirement.

\section{GRI Proqrarn}

A July 1989 workshop sponsored by GRI and attended by gas industry personnel concluded that a compact meter R\&D program could have two najor objectives: 
- A meter available in the near-term that would be suitable for multifamily buildings as well as single family attached dwellings requiring service line upgrades

- An advanced meter for the longer term that would provide additional features, such as remote shutoff and compensation for gas composition, and be suitable for a broader range of applications.

A March 1990 workshop conducted for GRI by Arthur D. Little, Inc. set target specifications for the near-term compact meter and possible specifications for an advanced meter (see Table 4-2). Generally, a major difference in a design that contributes to the compactness of the meter set will be to introduce the gas at the

Table 4-2. Target Specifications for Near-Term Meters

\begin{tabular}{|c|c|}
\hline & Near-Term Meter \\
\hline Size & $\begin{array}{l}200 \mathrm{cu} . \text { in. } \\
3 \text { in. } D \times 6.5 \text { in. } H \times 10 \text { in. W }\end{array}$ \\
\hline Weight & $10 \mathrm{lb}$ or less \\
\hline Minimum registrable flow & $0.5 \mathrm{cf} / \mathrm{hr}$ \\
\hline Totalizing accuracy & \\
\hline $\begin{array}{l}\text { Pllot flow to } 20 \mathrm{cf} / \mathrm{hr} \\
20 \text { to } 200 \mathrm{cf} / \mathrm{hr}\end{array}$ & $\begin{array}{l} \pm 20 \% \\
\pm 1 \%\end{array}$ \\
\hline Accuracy & $\pm 2 \%$ over 20 years \\
\hline Piping orientation & $\begin{array}{l}\text { Bottom inlet, top outlet; side outlet } \\
\text { as possible alternative }\end{array}$ \\
\hline Maximum pressure drop & 1 in. wc \\
\hline Pressure rating & 5 psig \\
\hline Pressure compensation & Desirable \\
\hline $\begin{array}{l}\text { Temperature } \\
\text { compensation } \\
\text { Service life }\end{array}$ & $\begin{array}{l}\text { Optional } \\
20 \text { to } 40 \text { years }\end{array}$ \\
\hline Calibration interval & 20 years \\
\hline Readout & Totalizing \\
\hline Remote reading capability & Yes \\
\hline Battery life & 7-year minimum \\
\hline
\end{tabular}


bottom of the set and take it out of the set at the top. Because of their method of operation, available meters have both inlet and nutlet at the top. A more compact design and other changes will result in a near-term meter size of about 200 in.3 or less compared with 750 in. 3 for available meters.

In 1991, GRI began initial work on three compact meter concepts: a convoluteddiaphragm positive-displacement meter (Battelle Memorial Institute and National Meter Co.), an electronic positive-displacement meter (Select Corp.), and a fluidicoscillator meter (Illinois Institute of Technology and Alnor Instrument Co.). In mid1992, GRI chose the first concept for further development and possible commercialization by 1994. Other meter designs from foreign organizations are also being evaluated.

\section{GRI Prolects Now Underway on Near-Term Compact Meters}

The following GRI projects are now underway:

Fluidic-oscillator gas meter

Contractor: Illinois Institute of Technology

Participating manufacturer: Alnor Instrument Co.

Description: Meter operates by measuring the fluctuating pressures created by an oscillating pair of vortices. It will be small enough to fit between house wall studs, has no moving gear mechanisms to wear with time, and is a digital device easily adaptable to digital electronic circuitry and to automatic meter reading. By counting the number of oscillation cycles, it can be used as a totalizing flowmeter, giving total gas usage. Nonlinearities are adjusted in the meter's software. Size: less than 50 in. ${ }^{3}$; weight: less than 3 $\mathrm{lb}$; accuracy: 1 percent above $15 \mathrm{cf} / \mathrm{hr}$. Life of D-size lithium battery estimated to be at least 5 years.

Electronic positive-displacement meter

Contractor: Select Corporation

Description: New positive-displacement concept employs undulating, waveshaped polyester membrane housed in rigid polymer chamber. Membrane traps discrete volumes of gas and moves them through length of chamber in pulses; each pulse causes a signal in a piezoelectric element. Microprocessor converts signal into volumetric flow and records cumulative volume in memory. Meter adaptable to remote reading. Accuracy within \pm 0.5 percent down to $2 \mathrm{cf} / \mathrm{hr}$. Potential power sources: lithium battery, telephone hook-up, photocell, household current. Size: 36 in. ${ }^{3}$, suitable for stud mounting; weight: less than $1.5 \mathrm{lb}$. 
Convoluted-Diaphragm Posittve Displacement Meter

Contractor: Battelle Memorial Institute

Participating manufacturer: National Meter

Description: Four-chamber, convoluted-diaphragm device uses highly reliable sliding valve principles of current gas meters. Similar accuracy and reliability are anticipated. Temperature compensated. Compatible with avallable remote and automatic meter reading devices and callbration equipment. Size: 200 in. ${ }^{3}$, weight: 6 to $7 \mathrm{lb}$. Totalizing accuracy $< \pm 10$ percent from pllot to $20 \mathrm{cf} / \mathrm{hr} ; \pm 0.5$ percent from 20 to $250 \mathrm{cf} / \mathrm{hr}$.

Although there may not be a truly compact gas meter commercially avallable at this time, there are two commercially available, small, lightweight residential meters that represent a major improvement over existing models. The dimensions for these two products are shown in Figure 4-2. The Westinghouse G2 meter weighs approximately $7 \mathrm{lb}$ and is 40 percent smaller than conventional models of the same capacity. The Schlumberger SL-250 is slightly larger than the Westinghouse G2 meter, and weighs $7.5 \mathrm{lb}$. Appendix A contains manufacturer's literature on each meter.

\section{GAS PIPING TEChNOLOGIES}

\section{Piping and Tubing Systems}

Currently, steel pipe (both threaded and welded) is the most commonly used material for gas piping systems in multifamily butldings. This is a time-proven system that is considered by the gas industry to be both safe and reliable. To a much lesser extent, copper tubing is used either as a replacement for steel pipe or to supplement it. In the last few years, some plumbing contractors have taken a closer look at the benefits
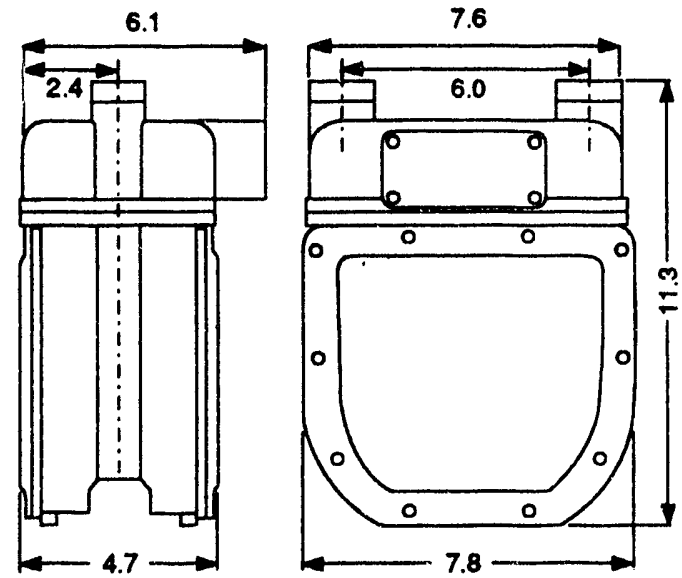

WESTINGHOUSE-ABB CQ QAS METER

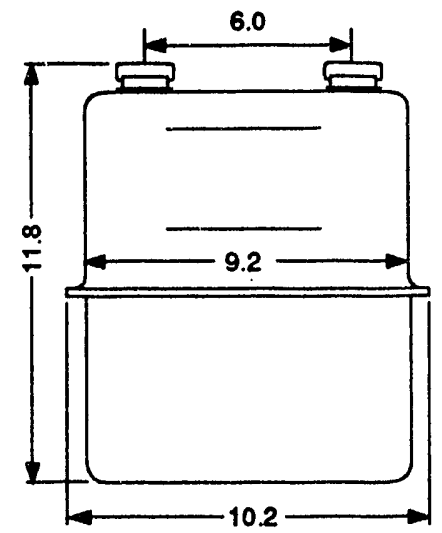

DIMENSIONS IN INCHES

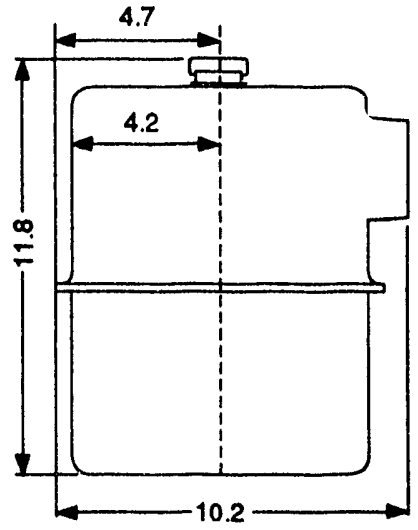

105-NYS-8416-1

SCHLUMBERGER SL-250 GAS METER

Figure 4-2. Commercially Available Small Residential Gas Meters 
of installing copper tubing gas piping systems in residential and commercial buildings. Primarily, the benefits are economics and ease of installation.

Within the last 7 years, a new product classified as semirigid tubing consisting of CSST has been developed, code approved (in many areas of the United States) and commercialized by two manufacturers. Additionally. two advanced gas piping technologies, one that is in the development stage (modified copper tubing) and one that is in the evaluation stage (macro composite tubing) are avallable for consideration. This subsection will discuss these conventional, new, and advanced gas piping systems for application to rehabilitated and newly constructed multifamily buildings.

Steel Pipe Srstems, In large multifamily bulldings, the gas piping system usually consists of two distinct portions: vertical and horizontal piping. The portion of the gas piping system in a large building that distributes gas to each floor is referred to as the "vertical riser." All gas codes require that the vertical riser be constructed from Schedule 40 steel pipe. If the building is to have decentralized gas metering, a few gas utilities have assumed responsibility for the design, installation, and maintenance of the vertical riser. Figure 4-3 shows an engineering sketch of a typical vertical riser for an 8-story building.

The NFGC, NFPA 54, 1988 allows threaded fittings to be used on steel pipe sizes up to and including 4 in. Larger pipe sizes must be connected via welded joints. Most vertical risers are sized for pipe larger than 4 in. because the systems are typically designed for low-pressure service (7 in. of water). Some of the other model codes and/ or utllity practices are more restrictive and require welded joints for pipe sizes larger than $2-1 / 2$ in.

Steel Pipe. The NFGC allows steel, wrought-iron, nodular (ductile) iron, copper, brass, and aluminum alloy pipe. However, the most commonly used material for above-ground interior gas piping in the United States is Schedule 40 steel pipe (black and hot-dipped, zinc-coated steel pipe). On a material cost basis, this is the most economical code-approved pipe. Installation costs for steel pipe are typically higher than for certain alternatives such as copper tubing or the corrugated stainless steel tubing. Physical specifications of Schedule 40 steel pipe are listed in Table 4-3. 


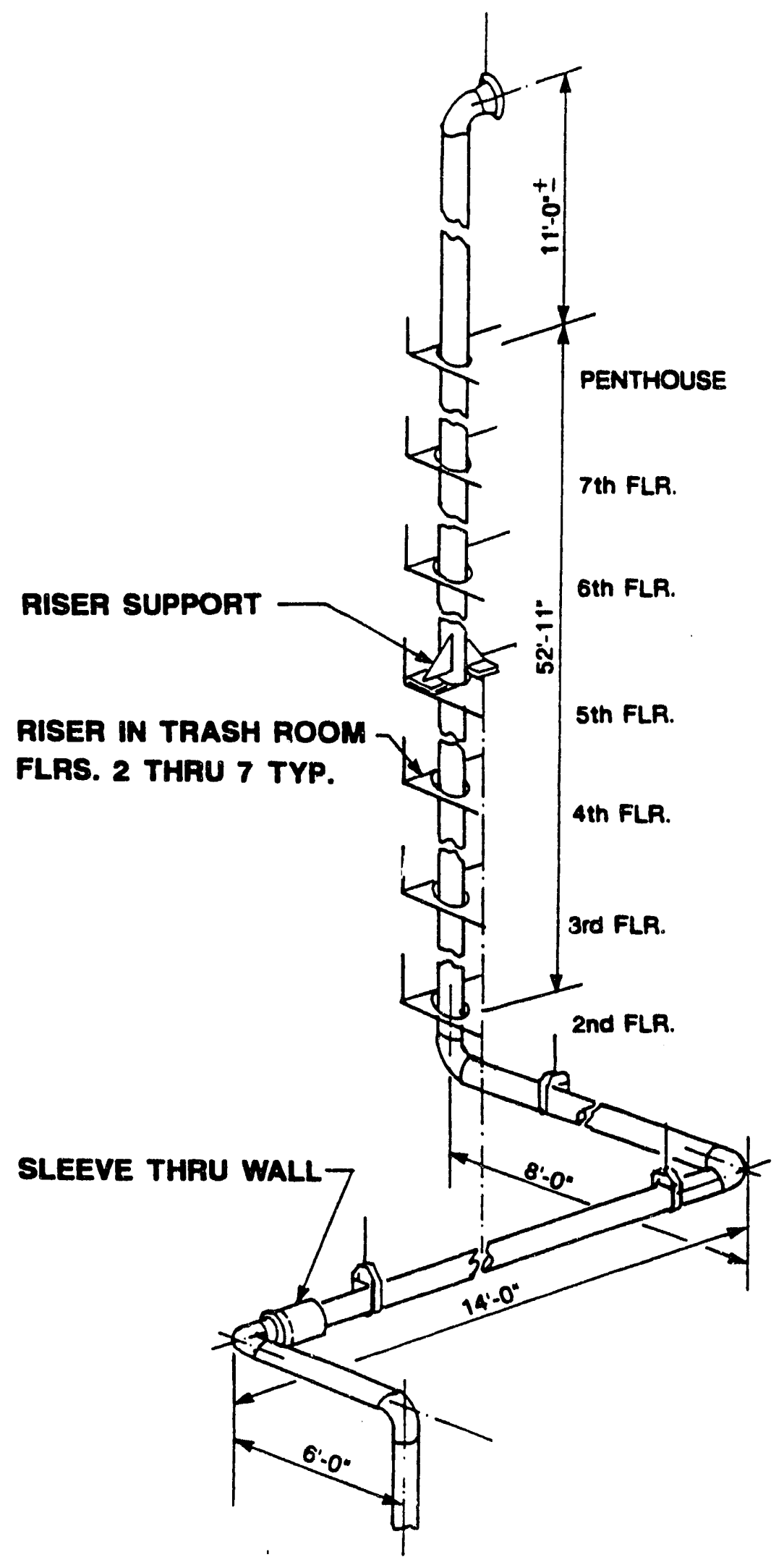

Figure 4-3. Vertical Riser 
Table 4-3. API Standard Line Pipe, Threaded

(All weights and dimenaions are nominal. National Tube Division. United States Steel Corp.)

\begin{tabular}{|c|c|c|c|c|c|c|c|c|c|c|c|c|}
\hline \multirow[b]{2}{*}{ Bise, in. } & \multicolumn{2}{|c|}{$\begin{array}{l}\text { Weight per } \\
\text { ft. lb }\end{array}$} & \multirow[b]{2}{*}{ 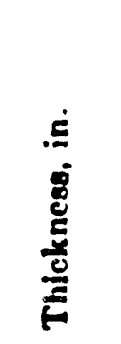 } & \multicolumn{2}{|c|}{ Dinmeter, in. } & \multirow[b]{2}{*}{ 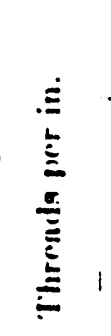 } & \multicolumn{3}{|c|}{ Couplings } & \multicolumn{3}{|c|}{ Test pressure," poi } \\
\hline & 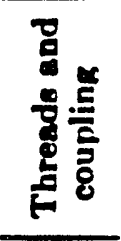 & $\begin{array}{l}\bar{E} \\
\frac{E}{a} \\
\frac{E}{a}\end{array}$ & & O.D. & I.D. & & $\begin{array}{l}\dot{\Xi} \\
\overline{\overline{\bar{x}}} \\
\dot{\bar{E}}\end{array}$ & O.D. & $\begin{array}{l}\equiv \\
\overline{\bar{\alpha}} \\
\vdots \\
\vdots\end{array}$ & 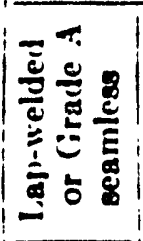 & 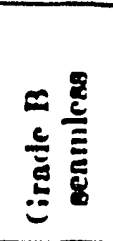 & 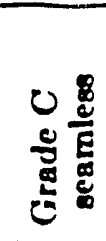 \\
\hline $\begin{array}{l}\frac{1}{1} \\
13 \\
3 \\
1 / 2 \\
x\end{array}$ & $\begin{array}{l}0.25 \\
0.43 \\
0.57 \\
0.86 \\
1.14\end{array}$ & $\begin{array}{l}0.24 \\
0.42 \\
0.57 \\
0.85 \\
1.13\end{array}$ & $\begin{array}{l}0.068 \\
0.088 \\
0.091 \\
0.109 \\
0.113\end{array}$ & $\begin{array}{l}0.405 \\
0.540 \\
0.675 \\
0.840 \\
1.050\end{array}$ & $\begin{array}{l}0.269 \\
0.364 \\
0.493 \\
0.622 \\
0.824\end{array}$ & $\begin{array}{l}27 \\
18 \\
18 \\
14 \\
14\end{array}$ & $\begin{array}{l}1460 \\
148 \\
138 \\
218 \\
248\end{array}$ & $\begin{array}{l}0.563 \\
0.719 \\
0.875 \\
1.063 \\
1.313\end{array}$ & $\begin{array}{l}0.04 \\
0.09 \\
0.13 \\
0.24 \\
0.34\end{array}$ & $\begin{array}{l}700 \\
700 \\
700 \\
700 \\
700\end{array}$ & $\begin{array}{l}700 \\
700 \\
700 \\
700 \\
700\end{array}$ & $\begin{array}{l}700 \\
700 \\
700 \\
700 \\
700\end{array}$ \\
\hline $\begin{array}{l}1 \\
136 \\
13 / 2 \\
2 \\
213\end{array}$ & $\begin{array}{l}1.70 \\
2.30 \\
2.75 \\
3.75 \\
5.90\end{array}$ & $\begin{array}{l}1.68 \\
2.27 \\
2.72 \\
3.65 \\
5.79\end{array}$ & $\begin{array}{l}0.133 \\
0.140 \\
0.145 \\
0.154 \\
0.203\end{array}$ & $\begin{array}{l}1.315 \\
1.660 \\
1.900 \\
2.375 \\
2.875\end{array}$ & $\begin{array}{l}1.049 \\
1.380 \\
1.610 \\
2.067 \\
2.469\end{array}$ & $\begin{array}{l}112 / 2 \\
1112 \\
1122 \\
11 ! 2 \\
8\end{array}$ & $\begin{array}{l}238 \\
23: 4 \\
23: 4 \\
31 / 4 \\
4 ! 8\end{array}$ & $\begin{array}{l}1.576 \\
2.054 \\
2.200 \\
2.875 \\
3.375\end{array}$ & $\begin{array}{l}0.54 \\
1.03 \\
1.17 \\
2.13 \\
3.27\end{array}$ & $\begin{array}{l}700 \\
1.000 \\
1.000 \\
1.000 \\
1.000\end{array}$ & $\begin{array}{r}700 \\
1.100 \\
1.100 \\
1.100 \\
1.100\end{array}$ & $\begin{array}{l}700 \\
1.300 \\
1.300 \\
1.300 \\
1.300\end{array}$ \\
\hline $\begin{array}{l}3 \\
31 / 2 \\
4 \\
5 \\
6\end{array}$ & $\begin{array}{r}7.70 \\
9.25 \\
11.00 \\
15.00 \\
19.45\end{array}$ & $\begin{array}{r}7.58 \\
9.11 \\
10.79 \\
14.62 \\
18.97\end{array}$ & $\begin{array}{l}0.216 \\
0.226 \\
0.237 \\
0.258 \\
0.280\end{array}$ & $\begin{array}{l}3.500 \\
4.000 \\
4.500 \\
5.563 \\
6.625\end{array}$ & $\begin{array}{l}3.068 \\
3.548 \\
4.026 \\
5.047 \\
6.065\end{array}$ & $\begin{array}{l}8 \\
8 \\
8 \\
8 \\
8\end{array}$ & $\begin{array}{l}41 / 4 \\
42 / 8 \\
4128 \\
458 \\
478\end{array}$ & $\begin{array}{l}4.000 \\
4.625 \\
5.200 \\
6.296 \\
7.390\end{array}$ & $\begin{array}{r}4.09 \\
5.92 \\
7.59 \\
9.98 \\
12.92\end{array}$ & $\begin{array}{l}1.000 \\
1.200 \\
1.200 \\
1.200 \\
1.200\end{array}$ & $\begin{array}{l}1.100 \\
1.300 \\
1.300 \\
1.300 \\
1.300\end{array}$ & $\begin{array}{l}1.300 \\
1.600 \\
1.600 \\
1.600 \\
1.600\end{array}$ \\
\hline $\begin{array}{l}8 \\
8 \\
10 \\
10 \\
10\end{array}$ & $\begin{array}{l}25.55 \\
29.35 \\
32.75 \\
35.75 \\
41.85\end{array}$ & $\begin{array}{l}24.70 \\
28.55 \\
31.20 \\
34.24 \\
40.48\end{array}$ & $\begin{array}{l}0.277 \\
0.322 \\
0.279 \\
0.307 \\
0.365\end{array}$ & $\begin{array}{r}8.625 \\
8.625 \\
10.750 \\
10.750 \\
10.750\end{array}$ & $\begin{array}{l}8.071 \\
7.981^{\prime} \\
10.192 \\
10.136 \\
10.020\end{array}$ & $\begin{array}{l}8 \\
8 \\
8 \\
8 \\
8\end{array}$ & $\begin{array}{l}51 / 4 \\
51 / 4 \\
52 / 4 \\
52 / 4 \\
53 / 4\end{array}$ & $\begin{array}{r}9.625 \\
9.625 \\
11.750 \\
11.750 \\
11.750\end{array}$ & $\begin{array}{l}23.18 \\
23.18 \\
31.55 \\
31.55 \\
31.55\end{array}$ & $\begin{array}{l}1.200 \\
1.200 \\
1.000 \\
1.000 \\
1.000\end{array}$ & $\begin{array}{l}1.300 \\
1.300 \\
1.200 \\
1.200 \\
1.200\end{array}$ & $\begin{array}{l}1.600 \\
1.600 \\
1.400 \\
1.400 \\
1.400\end{array}$ \\
\hline $\begin{array}{l}12 \\
12 \\
14 \text { O.D. } \\
15 \text { O.D. }\end{array}$ & $\begin{array}{l}45.45 \\
51.15 \\
57.00 \\
61.15\end{array}$ & $\begin{array}{l}43.77 \\
49.56 \\
54.57 \\
58.57\end{array}$ & $\begin{array}{l}0.330 \\
0.375 \\
0.375 \\
0.375\end{array}$ & $\begin{array}{l}12.750 \\
12.750 \\
14.000 \\
15.000\end{array}$ & $\begin{array}{l}12.090 \\
12.000 \\
13.250 \\
14.250\end{array}$ & $\begin{array}{l}8 \\
8 \\
8 \\
8\end{array}$ & $\begin{array}{l}63 \% \\
61 \% \\
62 \% \\
65 \%\end{array}$ & $\begin{array}{l}1 / 4.000 \\
1 / 4.000 \\
1 / 5.000 \\
116.000\end{array}$ & $\begin{array}{l}49.27 \\
49.27 \\
45.83 \\
51.26\end{array}$ & $\begin{array}{r}1.000 \\
1.000 \\
950 \\
900\end{array}$ & $\begin{array}{l}1.200 \\
1.200 \\
1.100 \\
1.000\end{array}$ & $\begin{array}{l}1.400 \\
1.400 \\
1.400 \\
1.400\end{array}$ \\
\hline $\begin{array}{l}16 \text { O.D. } \\
17 \text { O.D. } \\
18 \text { O.D. } \\
20 \text { O.D. }\end{array}$ & $\begin{array}{l}65.30 \\
73.20 \\
81.20 \\
90.00\end{array}$ & $\begin{array}{l}62.58 \\
69.70 \\
76.84 \\
85.58\end{array}$ & $\begin{array}{l}0.375 \\
0.393 \\
0.409 \\
0.409\end{array}$ & $\begin{array}{l}\mid 16.000 \\
\mid 17.000 \\
\mid 18.000 \\
\mid 20.000\end{array}$ & $\begin{array}{l}15.250 \\
16.214 \\
17.182 \\
19.182\end{array}$ & $\begin{array}{l}8 \\
8 \\
8 \\
8\end{array}$ & $\begin{array}{l}62 / 4 \\
7 \\
72 / 8 \\
79 / 8\end{array}$ & $\begin{array}{l}117.000 \\
118.000 \\
119.000 \\
121.000\end{array}$ & $\begin{array}{l}55.83 \\
61.67 \\
66.53 \\
79.37\end{array}$ & $\begin{array}{l}850 \\
850 \\
800 \\
750\end{array}$ & $\begin{array}{r}1.000 \\
950 \\
950 \\
850\end{array}$ & $\begin{array}{l}1.300 \\
1.200 \\
1.200 \\
1.100\end{array}$ \\
\hline
\end{tabular}

The permisaible variation in weight for any length of pipe is 10 percent above and $31 / 2$ percent below; but the carload weight ahall not be more than $1 \%$ percent under the calculated weight.

Furnished with threads and couplings and in random lengths, unlese otherwise ordered.

The weight per foot of pipe with threads and couplings is based on a length of $20 \mathrm{ft}$, including the coupling.

* Test pressure butt-welded pipe $1 / 8$ to $1 \mathrm{in} .=700 \mathrm{psi} ; 11 / 4$ to $3 \mathrm{in} .=800 \mathrm{pei}$. 
Steel pipe coated with epoxy, polyethylene, or PVC is used for underground and above-ground plumbing where corrosion protection is required. Coating thickness varies with the material used for corrosion protection. Coated pipe must meet ANSI/ ASTM A53 or A120 specifications for steel pipe. There is no reference in the NFGC for coated steel pipe. However, according to the NFGC Section 3.1.3: "Where appropriate (such as in contact with soll), piping shall be protected against corrosion in an approved manner."

Semiridd rubing sratems. The use of semirigid tubing for natural and LP gas distribution within residential and commercial bulldings has been going on for many years. Up to recent years, the tubing used was exclustvely copper. In 1988 , corrugated stainless steel tubing was introduced to the United States plumbing industry. Currently research has been started to develop/evaluate gas tubing products for use in the future (before the end of this century) to supplement the tubing products already avallable.

Cormugated Stainless steel Tubing, CSST is an acceptable code-listed material for natural gas piping systems in the NFGC, Standard Gas Code. Basic/National Mechanical Code and One- and Two-Family Dwelling Code. Currently, CSST is considered by many to be the optimum commercially avallable material for natural gas piping systems. Similar to copper tubing systems, CSST systems are usually designed to operate on elevated pressure ( 2 to $5 \mathrm{psi})$.

The design of corrugated stainless steel tubing used for gas piping is not too dissimilar to flexible appliance connectors used by the gas industry for over 30 years. The CSST is manufactured from 304 stainless and is constructed with annular corrugations. The number of convolutions per centimeter and the amplitude of each convolution are both much smaller than found on the appliance connector. Therefore, the CSST is much less flexdble and resilient than an appliance connector. However, CSST is only intended to be flexed once or twice during installation. Unlike the appliance connector, CSST is used netther as a vibration damper nor is it expected to be moved once installed. Table 4-4 shows typical dimensions for one brand of CiST used in the United States for interior distribution. Appendix E contains a brief description of the CSST systems currently offered by two manufacturers. 
Table 4-4. Typical CSST Specifications

\begin{tabular}{|l|c|c|c|c|c|c|}
\hline $\begin{array}{l}\text { Equivalent } \\
\text { Hydraulic diameter }\end{array}$ & EHD & 14 & 19 & 26 & 31 & \\
\hline Nominal diameter & $\mathrm{mm}$ & 10 & 15 & 20 & 25 & 32 \\
\hline Inside diameter (id) & $\mathrm{mm}$ & 11.5 & 15.0 & 20.0 & 25.0 & 32.0 \\
\hline Outside diameter (od) & $\mathrm{mm}$ & 14.2 & 18.4 & 24.9 & 30.8 & 38.8 \\
\hline Pitch/10 corrugations $(p)$ & $\mathrm{mm}$ & 34 & 38 & 50 & 60 & 70 \\
\hline Tube wall thickness $(t)$ & $\mathrm{mm}$ & 0.20 & 0.20 & 0.25 & 0.25 & 0.25 \\
\hline Coating thickness & $\mathrm{mm}$ & 0.6 & 0.6 & 0.6 & 0.6 & 0.6 \\
\hline O.D. of coating (oad) & $\mathrm{mm}$ & 15.4 & 19.6 & 26.1 & 32.0 & 40.0 \\
\hline Length (L) & $\mathrm{m}$ & 76.2 & 76.2 & 54.9 & 54.9 & \\
\hline
\end{tabular}

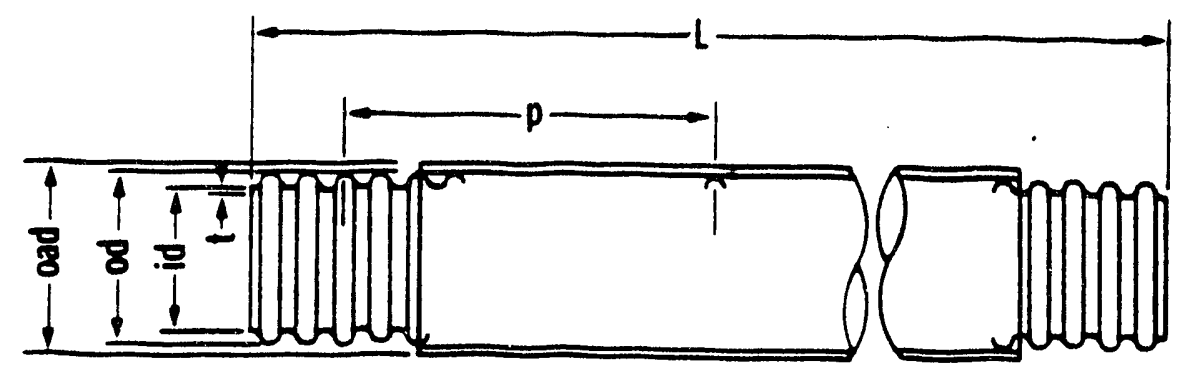

CSST is sold only as a system. The manufacturer must not only supply the tubing, but also the associated mechanical fittings, multiport manifolds, special mechanical protection shields and detailed installation instructions. In the United States, CSST systems must be design-certified by an independent testing organization and each component must be marked with specific information. The system is certified in accordance with the requirements of an ANSI Standard: ANSI/AGA LC-1 entitled American National Standard for Interior Fuel Gas Piping Systems Using Corrugated Stainless Steel Tubing. CSST is lightweight on a per "coil" basis and is extremely easy to install. It has excellent corrosion resistance characteristics and is protected by an outer covering of plastic. It can be easily bundled for multiple tubing runs and can be manufactured in almost any lengths required. CSST uses simple mechanical fittings for joining, requiring only hand tools for assembly. On a total system cost basis, CSST is not as cost-effective as copper tubing, but still less than steel pipe for many multifamily and commercial applications. CSST is currently avallable in four sizes; $3 /$ $8,1 / 2,3 / 4$ and 1 in. (ID). 
The use of corrugated tubing has several installation advantages over rigid steel pipe. In most installations there will be no intermediate joints between the manifold and appliance because the tubing is capable of being installed in one continuous run. This minimizes the number of potential leak sites and eliminates concealed joints. Because the tubing is bendable by hand, it can be installed more quickly and in areas that would be inaccessible to rigid pipe. This feature is especially critical in the retrofitting/remodeling of existing structures. The tubing installation requires only hand tools and, therefore, needs no heavy, electrically powered cutting/threading equipment and/or truck to carry and store piping and fitting inventories.

Because the tubing comes in coils and is lightweight, a tubing reel can be used to expedite the running of the service and appliance lines. This technique makes it possible, in some cases, for one plumber to install the entire system. The installation is insensitive to the construction materials and structural elements. The tubing can be installed through holes drilled in the wooden floor joists, through open spaces in trusses, strapped to the sides of a floor joist, or beneath the joists. It can be as easily rin through wooden wall studs as steel studs. Since most gas piping is field run, the added flexibility of the corrugated tubing allows the installer to seek the path of least resistance around existing obstacles, either in new construction or in remodeled structures. This eliminates the repetitive measuring, cutting, threading and joint assembly common with steel pipe systems.

Mechanical fittings are used to connect the tubing within the system. Compared to steel pipe, these connections are easier to assemble and can be completed in less time and for lower cost. The fittings are lightweight and small enough to be easily carried around in the plumber's belt pouch.

Extensive field assessments of current tubing/piping hardware and installation practices have been completed. The field tests included time and material studies in several different single-family, multifamily, and commercial buildings, including both new constriction, retrofitting and rehabilitation. In all tests buildings, both lowpressure steel pipe and hybrid pressure copper and corrugated tubing systems were designed and installed. The data were analyzed for both installation labor (job hours) and total cost (labor plus materials). The results, summarized in Table 4-5, have been calculated using a labor rate and material prices that have been found to reflect average costs in the United States. 
Table 4-5. Results from Piping Field Tests Installation

Labor and Cost Comparison*

\begin{tabular}{|c|c|c|}
\hline Building Type & $\begin{array}{l}\text { Percent Average } \\
\text { Labor Savings Over } \\
\text { Steel Pipe* }\end{array}$ & $\begin{array}{l}\text { Percent average } \\
\text { Total Installed Cost } \\
\text { Savings Over } \\
\text { Stel Pipe* }\end{array}$ \\
\hline $\begin{array}{l}\text { Single-family (all types): } \\
\text { detached/attached wood frame/new } \\
\text { construction }\end{array}$ & 30 to 50 & 15 to 40 \\
\hline $\begin{array}{l}\text { Multifamily low-rise: wood frame/new } \\
\text { construction }\end{array}$ & 10 to 70 & 10 to 40 \\
\hline $\begin{array}{l}\text { Multifamily high-rise: concrete and steel } \\
\text { frame/new construction }\end{array}$ & 40 to 65 & 30 to 40 \\
\hline Multifamily rehabilition & 70 to 80 & 50 to 60 \\
\hline Light commercial buildings: (all types) & & 30 to 60 \\
\hline
\end{tabular}

Results from the research clearly indicate that semirigid tubing systems operated at elevated pressure are both safe and reliable, and can be installed for less cost than conventional low-pressure steel piping systems. The tubing systems are easier to install for new construction and especially for rehabllitation projects. Many variations exist for the choice of system hardware, design approach, arrangement and installation practices.

Conventional Copper Tubing. Interior natural gas piping systems using copper tubing currently must comply with standard Type $\mathrm{K}$ or L, of the Standard Specification for Seamless Copper Water Tube, ANSI/ASTM B88. In February 1991, the ASTM B-5 Committee on Copper and Copper Alloys drafted a proposed ASTM Standard Specification for Seamless Copper Tube for Natural Gas and Propane Fuel Distribution Systems. If the proposed standard is adopted, it would replace the existing ANSI/ASTM B88 Standard for natural gas and propane fuel piping applications. Under the new standard, the tubing for natural gas and propane fuel applications would be designated Type G. No other type of copper tubing would be allowed for these applications. The most commonly used tubing sizes that provide the 
necessary handling/flexibility characteristics are $1 / 4,3 / 8$, and $1 / 2 \mathrm{in}$. nominal. Specifications of approved copper tubing for natural gas service are listed in Table 4-6.

The tubing is avallable in either hard-drawn 20-ft long straight sections, or soft-drawn (annealed) 25- to 50-ft colls. The soft-drawn copper tubing is typically preferred over hard-drawn copper tubing for intertor gas piping systems because it can be bent by hand and is avallable in long coil lengths.

Copper tubing is usually jointed with sllver-brazed or SAE 45-deg flare fittings when used in a natural gas piping system. A special tool is required to flare the tubing at each end. The same tool can flare several different tubing sizes. Figure 4-4 shows a typical flare fitting with tube attached. If the local code authority does not permit mechanical flare fittings, silver-brazed joints attached with a material having a melting point in excess of $1,000^{\circ} \mathrm{F}$ may be substituted. Common copper water pipe fittings are used in the gas piping system to connect tubing lengths.

Modifled Copper-Based Srgtems, Semirigid copper-tubing -based interior piping systems have been shown to be a safe, reliable and economical alternative to rigid steel pipe. In some areas of the United States, there has been concern expressed about the potential for internal corrosion of copper in this application. The GRI

Table 4-6. Copper Tubing Dimensional Specifications (American Brass Company)

\begin{tabular}{|c|c|c|c|c|c|}
\hline \multirow[b]{2}{*}{$\begin{array}{l}\text { Nominal } \\
\text { Size, in. }\end{array}$} & \multirow[b]{2}{*}{$\begin{array}{c}\text { OD in. } \\
\text { Types } \\
K, L\end{array}$} & \multicolumn{2}{|c|}{ ID in. } & \multicolumn{2}{|c|}{ Wall thickness, in. } \\
\hline & & $\begin{array}{c}\text { Type } \\
\mathrm{K}\end{array}$ & $\begin{array}{c}\text { Type } \\
\text { L }\end{array}$ & $\begin{array}{c}\text { Type } \\
\text { K }\end{array}$ & $\begin{array}{c}\text { Type } \\
\text { L }\end{array}$ \\
\hline $\begin{array}{l}3 / 8 \\
1 / 2 \\
3 / 8 \\
3 / 4 \\
1 \\
1-1 / 4 \\
1-1 / 2 \\
2 \\
2-1 / 2 \\
3 \\
3-1 / 2 \\
4 \\
5 \\
6 \\
8 \\
10 \\
12\end{array}$ & $\begin{array}{r}0.500 \\
0.625 \\
0.750 \\
0.875 \\
1.125 \\
1.375 \\
1.625 \\
2.125 \\
2.625 \\
3.125 \\
3.625 \\
4.125 \\
5.125 \\
6.125 \\
8.125 \\
10.125 \\
12.125\end{array}$ & $\begin{array}{r}0.402 \\
0.527 \\
0.652 \\
0.745 \\
0.995 \\
1.245 \\
1.481 \\
1.959 \\
2.435 \\
2.907 \\
3.385 \\
3.857 \\
4.805 \\
5.741 \\
7.583 \\
9.449 \\
11.315\end{array}$ & $\begin{array}{r}0.430 \\
0.545 \\
0.666 \\
0.785 \\
1.025 \\
1.265 \\
1.505 \\
1.985 \\
2.465 \\
2.945 \\
3.425 \\
3.905 \\
4.875 \\
5.845 \\
7.72 ! \\
9.625 \\
11.565\end{array}$ & $\begin{array}{l}0.049 \\
0.049 \\
0.049 \\
0.065 \\
0.065 \\
0.065 \\
0.072 \\
0.083 \\
0.095 \\
0.109 \\
0.120 \\
0.134 \\
0.160 \\
0.192 \\
0.271 \\
0.338 \\
0.405\end{array}$ & $\begin{array}{l}0.035 \\
0.040 \\
0.042 \\
0.045 \\
0.050 \\
0.055 \\
0.060 \\
0.070 \\
0.080 \\
0.090 \\
0.100 \\
0.110 \\
0.125 \\
0.140 \\
0.200 \\
0.250 \\
0.280\end{array}$ \\
\hline
\end{tabular}



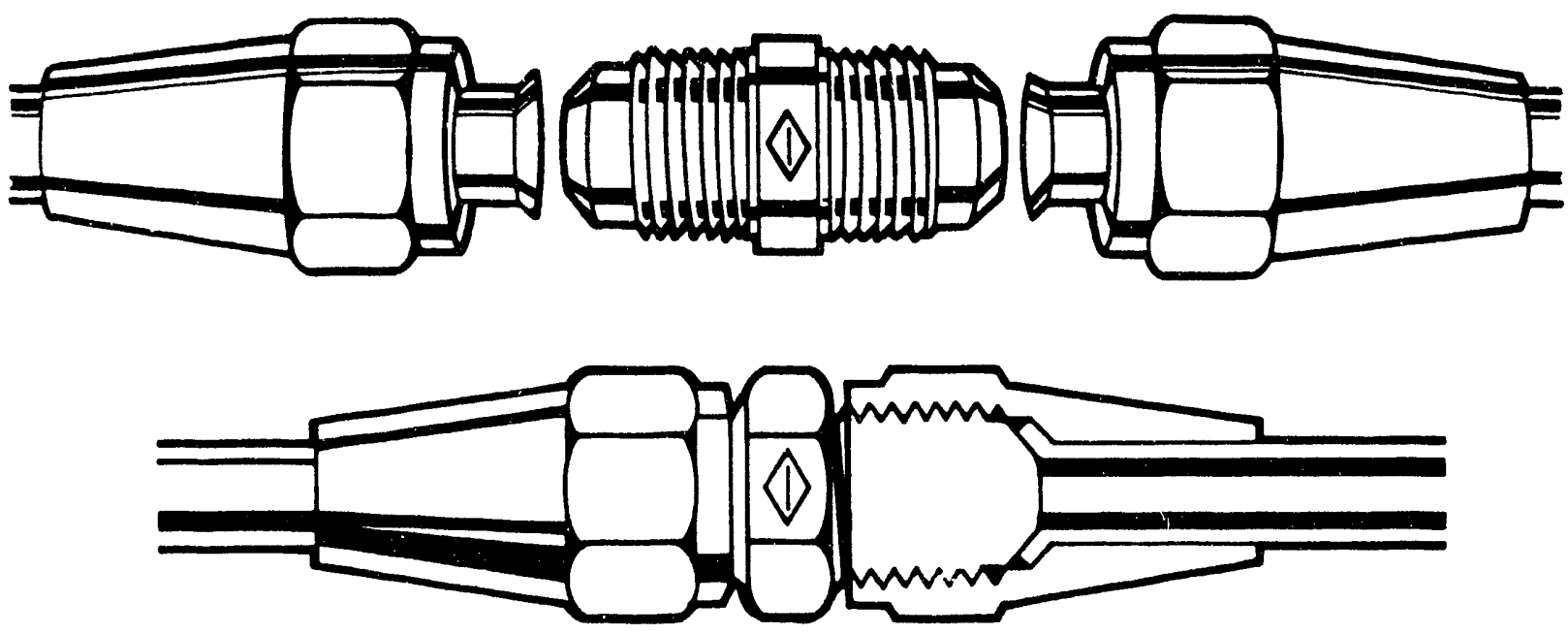

Figure 4-4. SAE 45-Degree Flare Fitting with Tube Attached (Imperial Eastman)

sponsored two related studies to address this concern. The first, performed by Southwest Research Institute (SwRI) was a study of the effects of natural gas constituents on copper corrosion.

The second, performed by Foster-Miller was the development of modified copper-based piping system concept for interior distribution of natural gas. The new system was to be highly resistant to internal corrosion and to have straightforward installation procedures. Also, the new system's total installed cost was to be equal to or less than alternate piping material systems.

Three general categories of tubing concepts were investigated: internally lined copper tubing, improved copper alloys, and corrugated copper alloy tubing. A series of laboratory experiments were performed on tubing and new joint fitting specimens to determine the feasibility of potential manufacturing processes, physical performance, and corrosion resistance, depending on the system concept and component type.

Three tubing concepts resulted from the preliminary development activities: a hypothetical polyethylene-lined welded tubing (Figure 4-5), a copper alloy tube having annular corrugations, and a cost-reduced version of existing state-of-the-art, tin-lined copper tubing. Feasibility calculations on the polyethylene-lined welded tubing concept indicated that a thin copper sheath can be welded around the thermoplastic liner without significant damage to the liner if done rapidly with low total energy input (electron beam welding). 
Copper alloys studied for possible use in corrugated tubing were alloy No. C61500 and C68800. The corrosion resistance of the various copper alloys was screened using the linear polarization resistance method. Following the screening tests, SwRI performed longer term corrosion tests in a severely contaminated environment on copper alloy No. C61500 and C68800, the tin-lined copper, and copper alloy No. C12200 (as a benchmark). Copper alloy No. C61500 and C68800 and the tin-lined specinens all had significantly lower corrosion rates than copper alloy No. C12200.

Composite Tubing, Recently, a number of multilayered composite tubing products have become commercially available, some of which are suitable for natural gas applications. These new tubing products are a combination of adhesively bonded. multilayer, plastic and metallic tubings. Although not quite as flexible as CSST, they do offer a new alternative to copper tubing and steel pipe. Some of them are priced close to copper tubing. They potentially offer thc most resistance to long-term corrosion effects, while at the same time can be more easily installed than steel pipe. Similar to CSST, their inherent flexible characteristic allows tubing movement to compensate for building movement under almost any conditions (e.g., earthquake, high winds, building settling).

Composite tubings are lightweight on a per-coil basis, and are connected via easy-toinstall mechanical fittings. They can be bundled and field run several hundred feet in

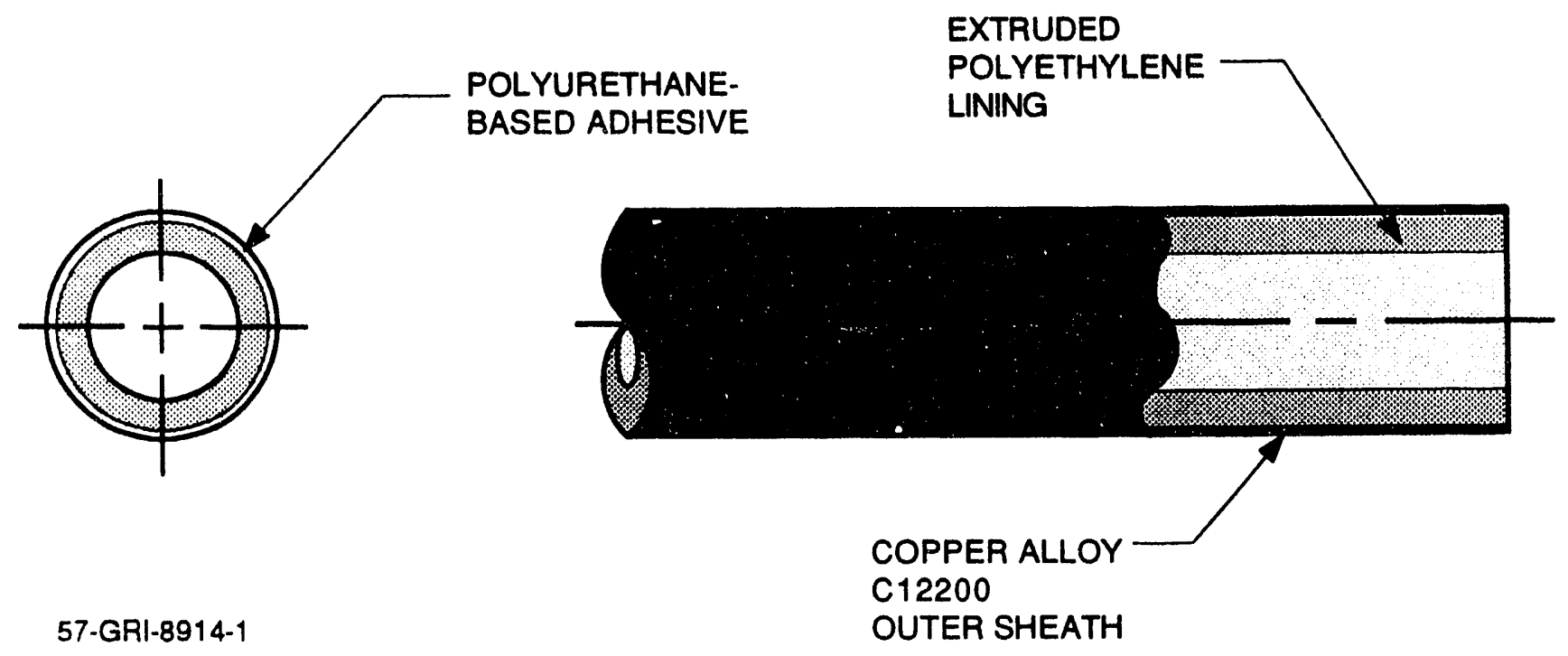

Figure 4-5. Thermoplastic-Lined Welded Tubing Concept 
chaseways with other services. Most manufacturers produce composite tubing products for several different applications. These currently include natural gas. hot water for underfloor heating, cold water for underfloor cooling, hot and cold water supply, compressed air/vacuum systems, solar heating, and electrical conduit (shielding) for electronics/telecommunications trunking. For produce demarcation. the composite tubings are manufactured in different colors. Conceivably, many services could be installed at the same time by fewer installers with tubing products from the same manufacturer. This scenario could lead to increased cost savings for both materials and labor for several different services combined.

Using a thin-wall aluminum tube as a center core, one version of the composite tubing product is designed as a sandwich arrangement. The aluminum tube is surrounded, both internally and externally, by a polymer (PE) jacket. Two commercially available products (MEPLA pipe and KITEC tubing) are undergoing laboratory evaluation. The driving issue for this approach is the cost of the metallic tubing alternatives. The cost of corrugated stainless steel is much higher than the cost of the composite tubing. thus making this approach more cost-effective on a first-cost basis.

Table 4-7 summarizes pertinent information for the two commercially available products. For each product, the thin-wall, seam-welded, aluminum tubing is laminated between two layers of polyethylene tubing. Two tubing sizes, 3/8 and 1/2 in., have been evaluated by Foster-Miller for each product. Also, each tubing product has specially designed fittings and installation tools for making connections to existing piping components. Each manufacturer has developed a piping system based on their tubing product, which includes all of the necessary hardware for a complete installation.

MEPLA Tubing. Of the two products evaluated, the MEPLA tubing is more robust. The overall wall thickness (in each size) is greater in the MEPLA products. This means the MEPLA tubing is stiffer (in all sizes) and more difficult to handle and install. The product specifications and configurations are described in Appendix E. The tubing comes with a complement of accessories, fittings, and assembly tools, and is supplied in three sizes $(16,20,25 \mathrm{~mm} O D)$.

The MEPLA tubing passed all of the mechanical tests and the thermal resistance tests for the tubing only. However, the MEPLA tubing joint failed at a temperature below 
Table 4-7. Summary of Composite Tubing Products

\begin{tabular}{|c|c|c|c|c|c|c|c|}
\hline \multicolumn{2}{|c|}{$\begin{array}{l}\text { Product } \\
\text { Name }\end{array}$} & Manufacturer & $\begin{array}{c}\text { Outer } \\
\text { Tubing } \\
\text { Material }\end{array}$ & $\begin{array}{l}\text { Inner } \\
\text { Tubing } \\
\text { Material }\end{array}$ & $\begin{array}{l}\text { Metal } \\
\text { Tubing } \\
\text { Material }\end{array}$ & $\begin{array}{l}\text { Min. } \\
\text { Oper. } \\
\text { Press } \\
\text { (psi) }\end{array}$ & $\begin{array}{c}\text { Coll } \\
\text { Length } \\
\text { (ft) }\end{array}$ \\
\hline \multicolumn{2}{|c|}{ MEPLA PIpe } & Fluid Air Energy & PE & PE & $\begin{array}{l}\text { Al } \\
\text { Al alloy }\end{array}$ & 88 & $\begin{array}{l}160 \\
320 \\
642\end{array}$ \\
\hline \multicolumn{2}{|l|}{$\begin{array}{l}\text { KITEC } \\
\text { Tubing }\end{array}$} & Kitechnology Ltd. & $\begin{array}{l}\text { XLPE } \\
\text { HDPE }\end{array}$ & $\begin{array}{l}\text { XLPE } \\
\text { HDPE }\end{array}$ & $\begin{array}{l}\mathrm{AL} \\
\mathrm{AL}\end{array}$ & 150 & $\begin{array}{l}500 \\
600\end{array}$ \\
\hline $\begin{array}{l}\text { PE } \\
\text { AL } \\
\text { XLPE } \\
\text { HDPE }\end{array}$ & $\begin{array}{l}- \\
- \\
-\end{array}$ & $\begin{array}{l}\text { lyethylene } \\
\text { uminum } \\
\text { oss-linked polyeth } \\
\text { gh-density polyeth }\end{array}$ & $\begin{array}{l}\text { lene } \\
\text { lene }\end{array}$ & & & & \\
\hline
\end{tabular}

$1000^{\circ} \mathrm{F}$. Furthermore, the MEPLA tubing was noticeably more difficult to install than the corrugated stainless steel tubing.

KITEC Trbinc. KITEC tubing is more flexible and comes in four sizes (14, 16, 20, 25 mm ID). The product specifications and configurations are also described in Appendix E. KITEC tubing also comes with a variety of accessories, fittings and installation tools.

Foster-Miller performance test results indicate that, except for the thermal resistance of the tubing/fitting joint and impact resistance, the KITEC tubing is essentially equal to the corrugated tubing. The requirements of the impact resistance tests can be met with a minor alteration to the present testing method. The installation of the KITEC tubing was rated equivalent to the corrugated tubing.

The fittings for both MEPLA and KITEC products must be redesigned for higher temperature resistance. This issue is being addressed by both manufacturers with assurances that the requirement can be met.

The economic analysis has shown the KITEC and MEPLA tubing systems to be significantly more cost-effective than all other systems studied, including steel pipe and corrugated stainicss steel tubing. For two types of commercial bulldings (multifamily low-rise and low-rise retain plaza) studied, the total installed cost of the 
KITEC system was 38 and 55 percent lower than the cost of the steel pipe system, respectively.

\section{Distribution Networks}

If gas piping systems are installed in multifamily buildings, they are often designed for low-pressure service applications. This requires much larger pipe sizes than would be required if higher pressures were used to distribute natural gas within the building. As an example, if gas operating pressure was increased from 1/4 psi (approximately 7 in. of water pressure) to 2 psi, an increase of eightfold, the gas-carrying capacity of the pipe would be increased 2.8 times. As a result of operating with increased pressure, there are large potential savings to be realized with reduced pipe sizes (both material and installation costs). Couple this with the potential savings using semirigid tubing and the total cost savings could be substantial compared to installing low-pressure all rigid steel pipe systems.

A hypothetical advanced gas distribution network could be described as follows. Gas is supplied via a main at a pressure up to $60 \mathrm{psi}$ and reduced to a lower pressure of 5 psi by a central regulator at the building entrance (see Figure 4-6). Portions of the hypothetical advanced gas distribution system would include corrugated stainless steel tubing. ANSI/AGA LC-1, 1991 Interior Fuel Gas Fiping Systems Using Corrugated Stainless Steel Tubing limits the operating pressure of the system to 5 psig. Total gas supplied to the building would be monitored by a conventional gas meter or advanced compact flowmeter. This portion of the piping system is the gas entrance header. From that point the gas would be distributed via a vertical riser(s) to various upper level floors (including the roof) and/or a horizontal header to common or retail use areas on the first floor level within the builiting. The size of these pipes would be in the range of 2 to $4 \mathrm{in}$. The vertical piping would require chaseways and engineered floor penetrations and support devices. The horizontal piping would also require engineered supports and wall penetrations.

On each floor, gas would be distrikuted via a subnetwork including a regulator to reduce the pressure from 5 to 2 psi, compact gas meters, and semirigid distribution piping to each unit. This portion of the piping system is the gas service header. The compact gas meters, required valves and hardware to connect the components could be installed in modular cubicles. Finally, the gas would be distributed within each 


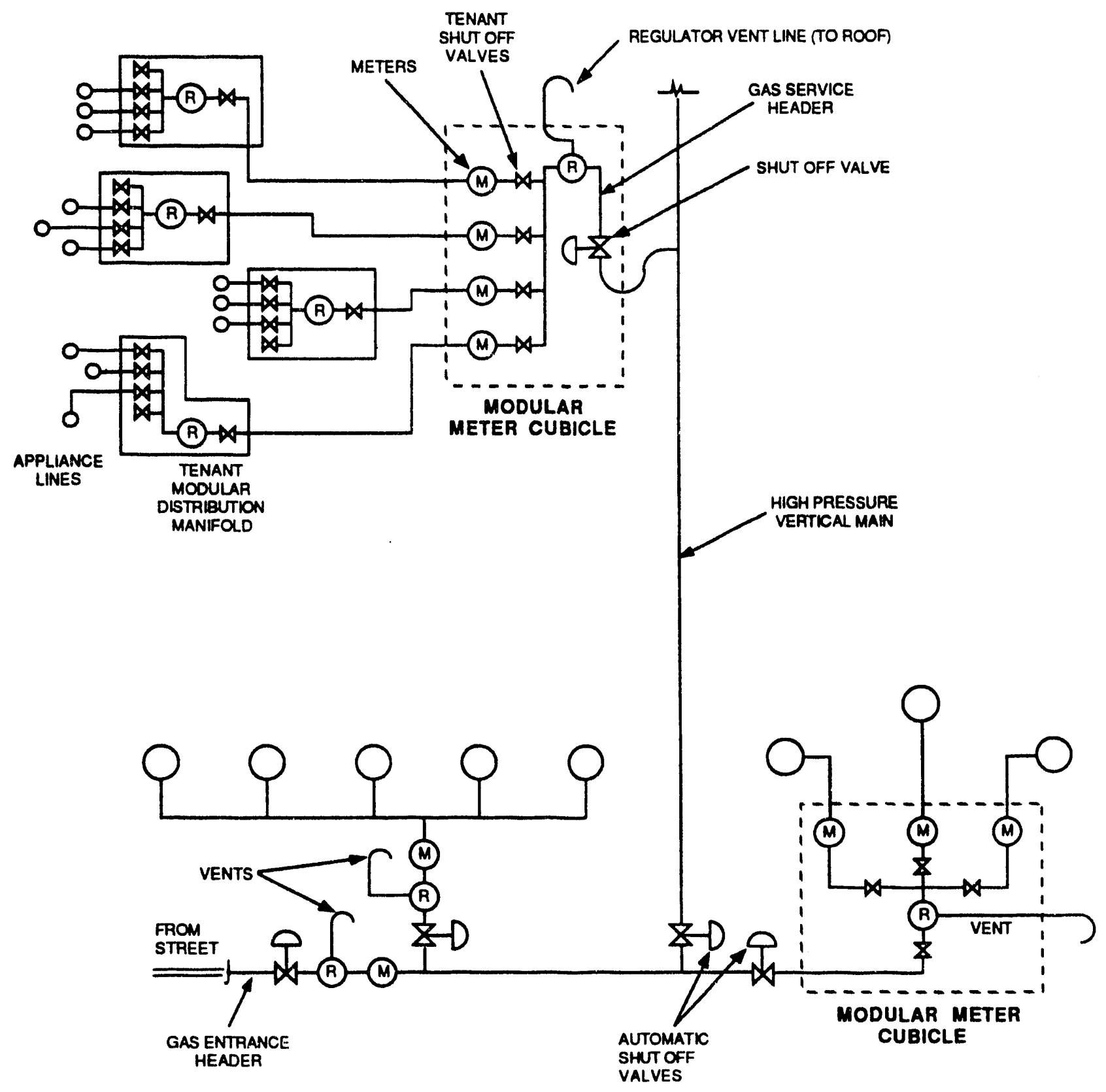

64-GRI-9204-3

Figure 4-6. Gas Distribution Network - Typical Residential-Commercial Building

tenant unit via the modular distribution manifold. This is essentially a second subnetwork that includes a regulator to reduce the pressure from 2 to $1 / 4$ psi and a multiport manifold for delivering the gas to the appliances or termination at a gas outlet. This approach should go a long way to streamline the design and installation of the piping system by making it highly compact and efficient from a fluid dynamic standpoint. To further enhance this approach, technology exists to integrate the 
advanced gas distribution network into the main control system of a fully automated building.

Foster-Miller, under contract to GRI, and a number of gas companies have done some experimenting with different designs for gas piping systems for multifamily buildings. Foster-Miller conducted a study in a 15-unit, 6-story condominium where the gas meters for each unit were located in a common meter room located in the underground garage of the building (see Figure 4-7). Significant total cost savings were shown by installing either a 2-psi all-CSST or copper tubing system compared to a low-pressure steel pipe system. The CSST was installed in two separate vertical bundles that were routed through chaseways specifically designated for building services.

Conversely, the experience of one gas company has shown that placing the meters at ground level for a decentralized system where each tenant has their own gas meter and distributing the gas via a copper tubing system only works for buildings with 3-4 stories, especially if there are more than two gas appliances per unit. Buildings with more than 4 stories may not benefit from meter groupings on the ground floor.

A second approach is to submeter on a floor-by -floor basis, as shown in Figure 4-8, or on every other floor, as shown in Figure 4-9. In this gas distribution network design the vertical riser and meter room piping up to the individual unit gas meters would be steel pipe. The riser would most likely have all welded joints, whereas the meter room manifold piping would probably have a combination of welded joints for the larger pipe sizes and screw thread joints for the smaller pipes sizes. CSST (or copper tubing) would be used to distribute the gas load downstream of the individual unit meters. Multiple pressures (5,2 and 1/4 psi) would be: used to distribute the gas throughout the entire gas distribution network, thereby minimizing the size of the piping for each section of the network.

A third approach, which is currently practiced in some areas of the United States, is called "electronic submetering." It is a time-based system rather than a capacity or volume based system and requires only one master meter at the entrance of the building (see Figure 4-10). The electronic submetering system records the amount of time an appliance gas valve is open in any particular unit. The time data over some predetermined period is accumulated for all appliances in a single unit. By 

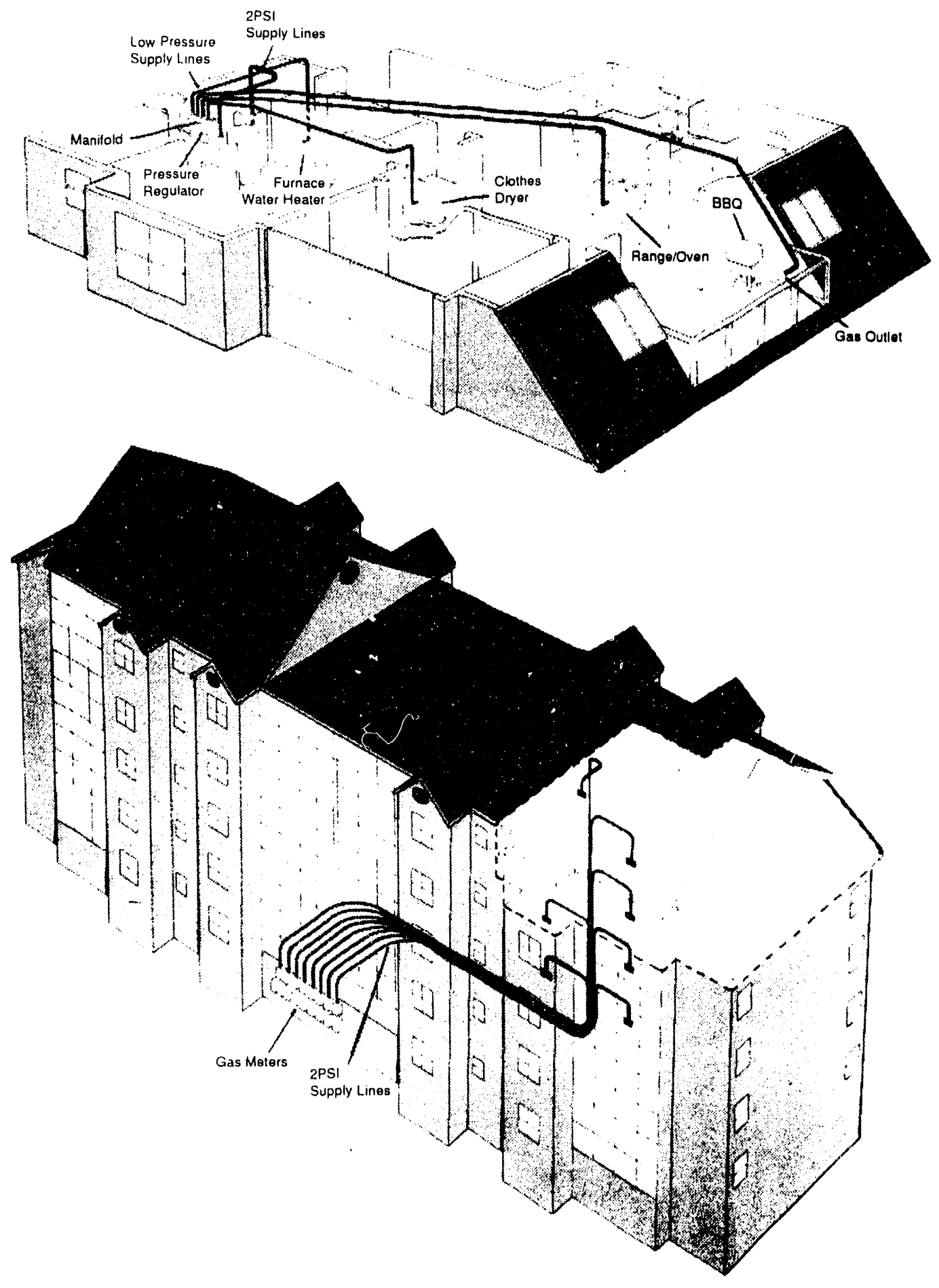

Figure 4-7. Gas Distribution Network with Submeter Room Located in Parking Garage 


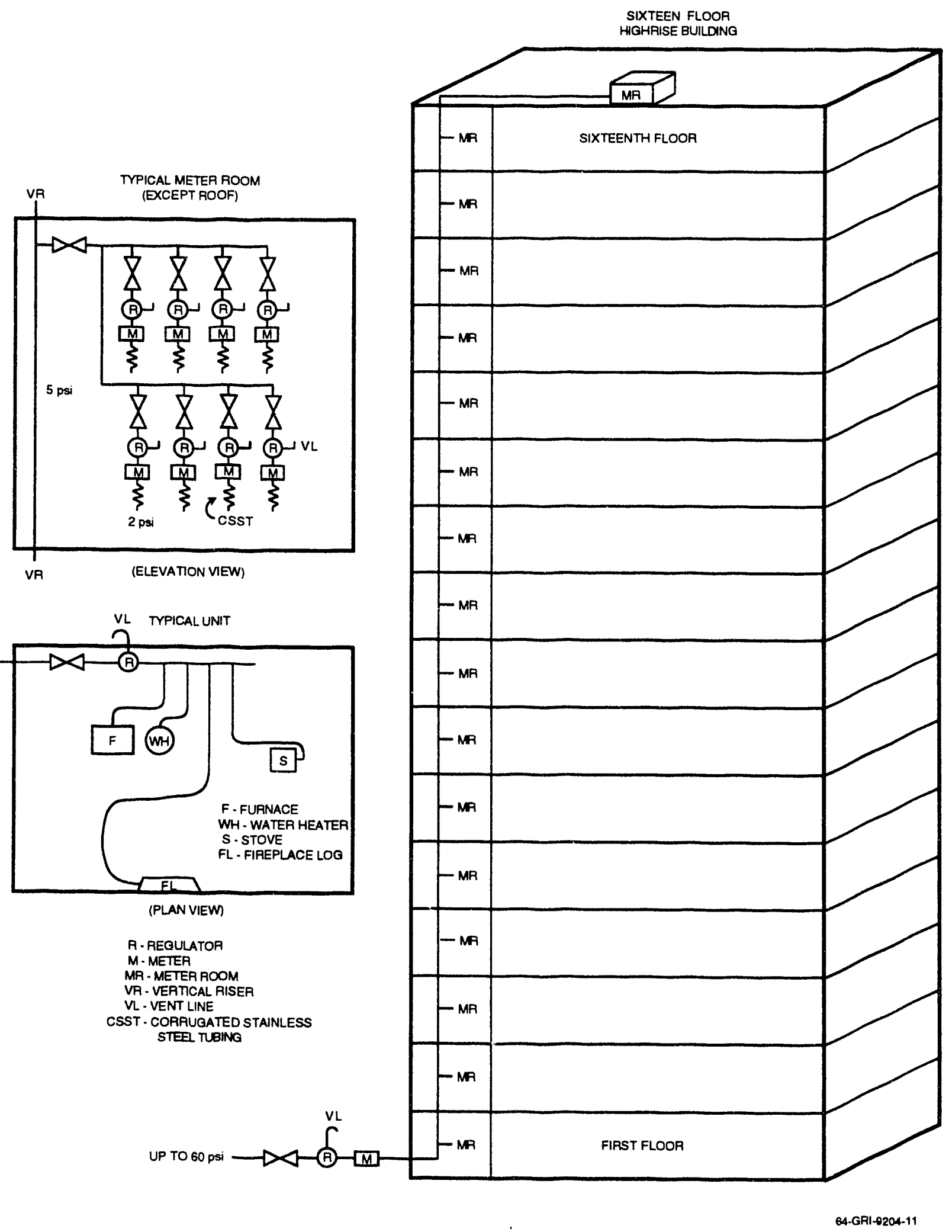

Figure 4-8. Gas Distribution Network with Submeter Room on Each Floor 


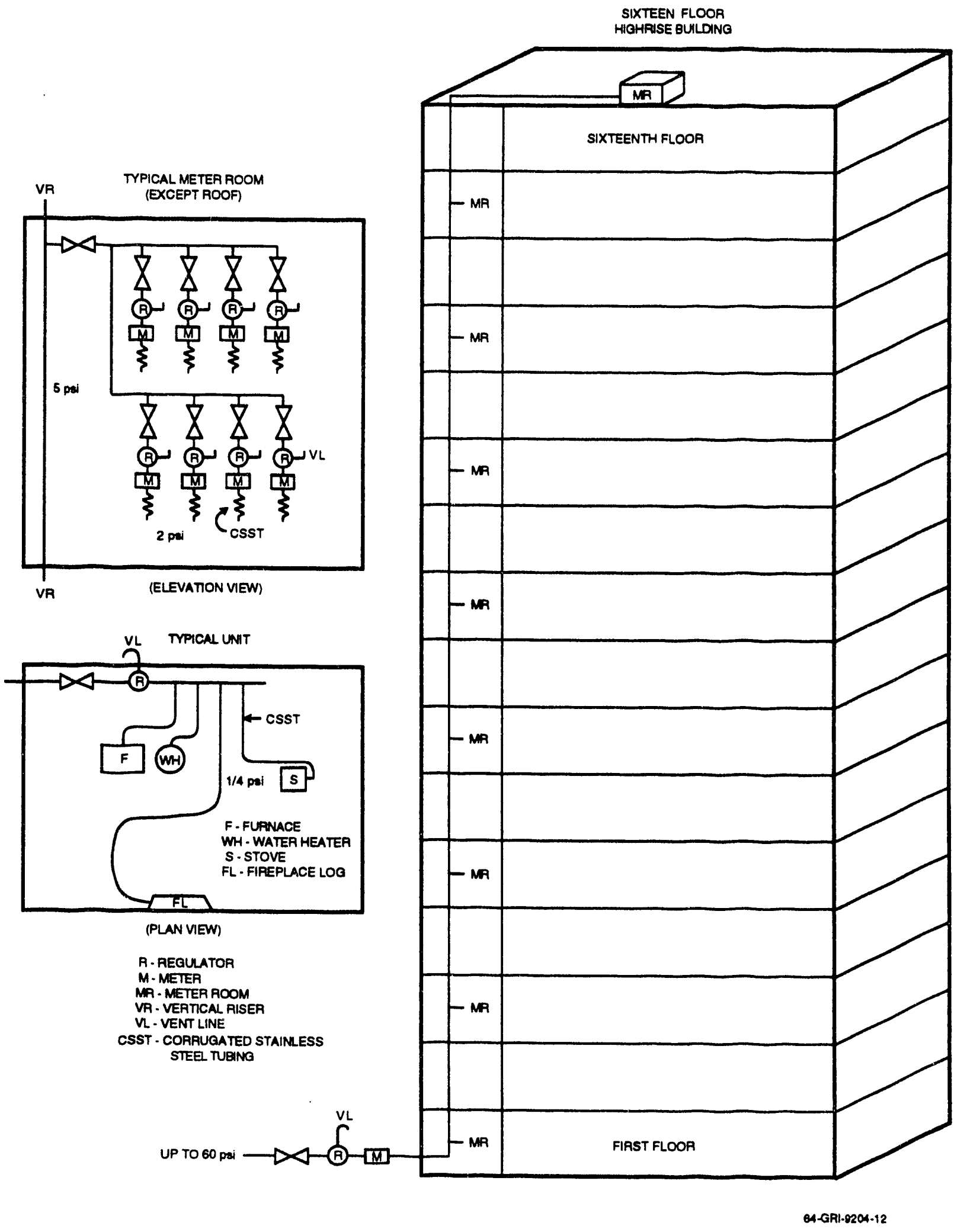

Figure 4-9. Gas Distribution Network with Submeter Room on Every Other Floor 

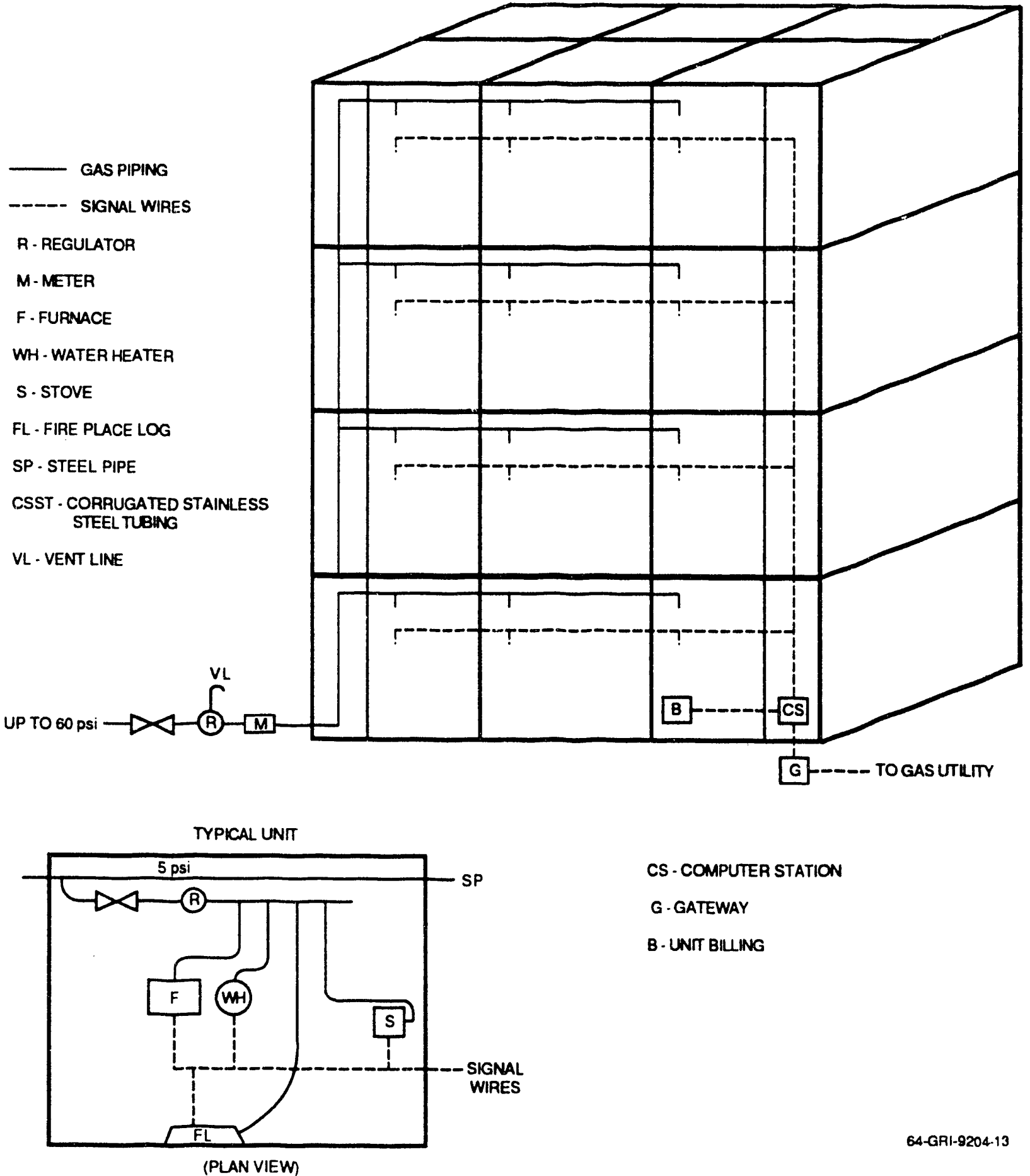

CS - COMPUTER STATION

G. GATEWAY

B. UNT BILING

Figure 4-10. Gas Distribution Network with Electronic Submetering 
proportioning the total amount of gas supplied to the building by the accumulated time data for each unit, the amount of gas supplied to each unit can be determined.

\section{Piping Srstem Accessorles}

The gas distribution network of the future for multifamily bulldings will require not only advanced piping, metering, and efficient network designs, but also innovative accessory hardware to complement the total system design. In this subsection four areas will be discussed regarding accessory hardware:

- Modular meter enclosures

- Modular manifold enclosures

- Striker plates, chaseways and baseboard channels

- Intermediate line regulators and venting.

Modular Meter Enclosures. There has not been much development in the United States in this accessory area. However, British Gas has ongoing research programs that have produced some products worth evaluating. The British Gas Mark II built-in meter box shown in Figure 4-11 is a good example of a well-thought-out product that is designed to architecturally integrate both electric and gas service in one area while maintaining physical separation. The gas meter box has a reduced surface area of 25 percent compared to its predecessor, which uses the same meter. As shown in the figure, the entrance and exdt plping is located near the front of the box for ease of installation .

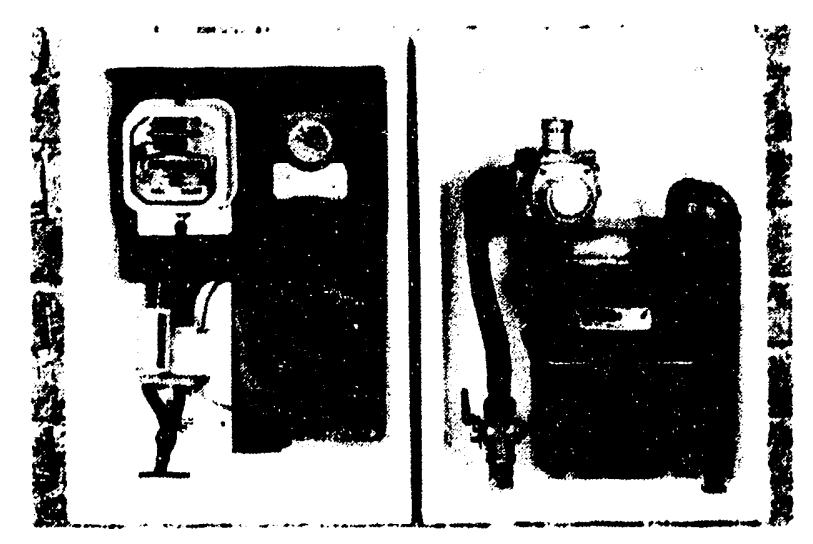

Figure 4-11. British Gas Mark II Bullt-In Meter Box 


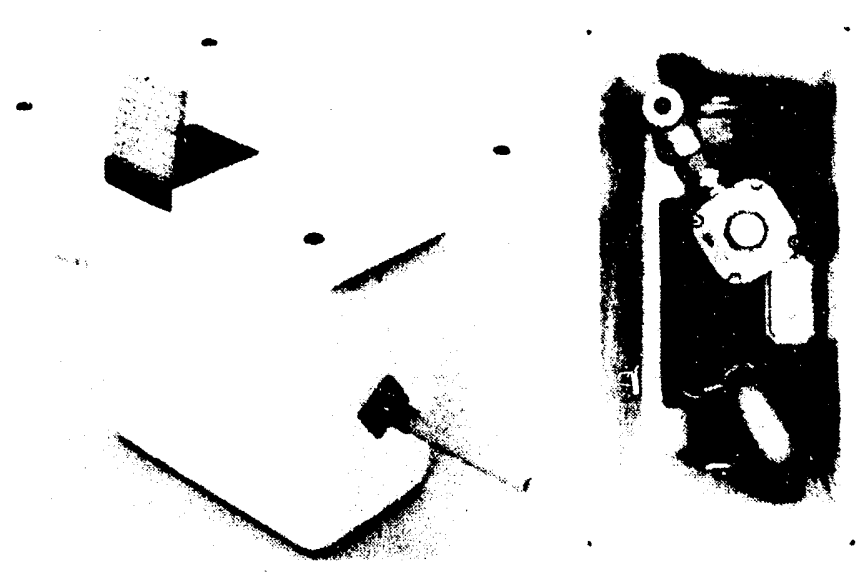

Figure 4-12. British Gas Concealed Meter Box

British Gas has also developed a concealed meter box for burial outside the building (see Figure 4-12). A meter box similar to this design may have applications in multifamily buildings where adequate floor depth is available for a recessed installation. The meter can be read through a viewing port that is designed into the cover. The cover provides a watertight seal but is removable for maintenance. The box and cover are composed of a tough glass-reinforced plastic.

British Gas has developed another version of the concealed meter box called the semiconcealed meter box (see Figure 4-13). This box extends 3 in. above the floor or ground and is intended to be installed adjacent to the property wall. Here again, with some minor design modifications, this box may be quite suitable for installing in multifamily buildings. The top is hinged, which allows the meter to be read and any maintenance to be performed.

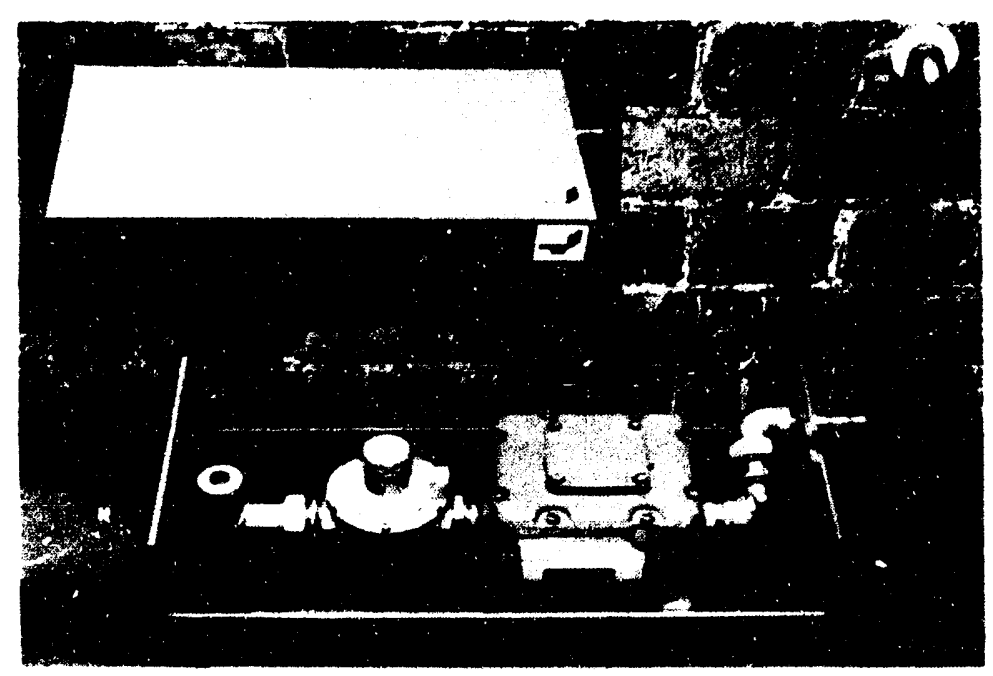

Figure 4-13. British Gas Semi-Concealed Meter Bor 
Modular Manifold Enclosures. Foster-Miller has identufied a need to facilitate the assembly and field installation of the distribution manifold required for hybrid pressure CSST systems. In response to this recommendation, R.W. Lyall has developed a new addition to the CSST system product line - a standardized, preassembled manifold box (see Figure 4-14). The primary benefit will be reduced liabor costs for the overall installation of the piping system.

The box is a prefabricated steel enclosure designed to be installed either between two standard wooden or metal wall studs or on a wall surface. The box includes a service shutoff valve, drip leg, a Maxitrol regulator (either a Model 325-3 or 325-5), a piping union (to facilitate regulator replacement), and a multiport, all welded construction
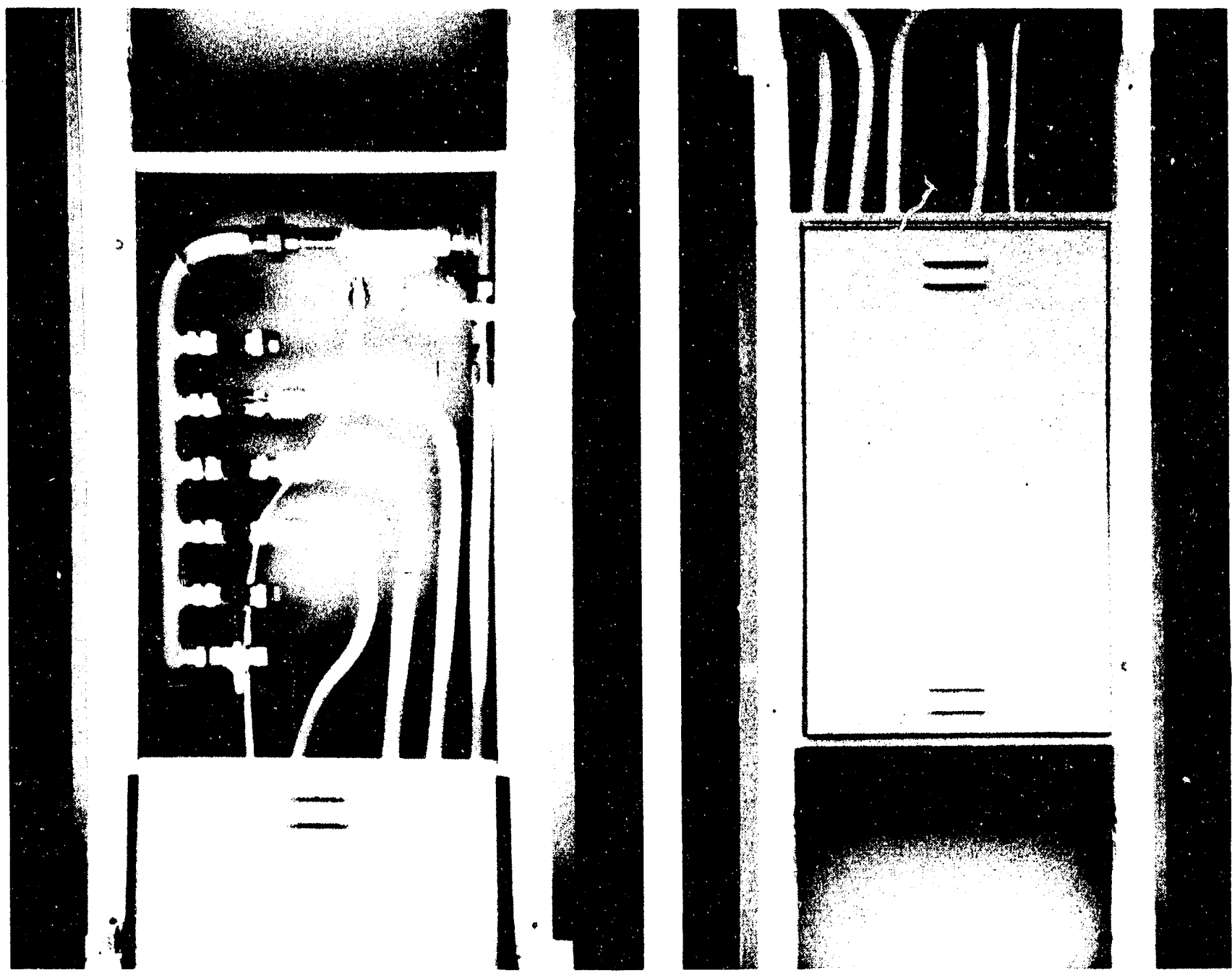

Figure 4-14. R.W. Lyall Flush-Mounted Manifold Box 
steel manifold. The entire assembly can be removed to allow the easy installation of the box between the studs. The front door panel is also removable, which permits easier access during tubing installation. The door can be specified for either right or left hand opening. The enclosure is also provided with knock-outs for 10 tubing runs. The box could also be easily modified for ceiling installation. This may better accommodate installation in multifamily buildings.

The manifold can be customized both in terms of the number and size of the ports. If more ports are needed, the closed end of the manifold riser is designed so that a crossover piping assembly can be retrofitted to add a manifold-only box between the adjacent wall studs. As an option, appliance shutoff valves can be installed at each manifold port to facilitate the servicing of the piping system and provide the consumer with some enhanced safety features. Each port can be numbered and recorded on a log sheet (located on the door) so that each gas appliance can be easil-r identified and isolated for service without disrupting the rest of the gas piping network. Saitiy information and important telephone numbers can also be provided on a notice located inside the box.

The entire manifold box, including tubing fittings, can be preassembled by apprentice -level personnel. Once assembled, each manifold system can be pre-inspected and pre-tested for leakage. Once the box is installed between the studs (or in the ceiling), the entire field operation is reduced to installing the service and appliance tubing and completing joint connections.

Early production units of the manifold box are being field evaluated and may be ready for market introduction in 1993. These manifold enclosures are expected to be a valuable addition to the CSST system, and with few design changes lend themselves to installation in all building types.

AGA -Certified Striker Plates. One of the key technical concerns addressed during the GRI research to develop the CSST system involved the need for and types of mechanical protection required for CSST. Under contract to GRI, Foster-Miller developed a series of metallic striker plates, shown in Figures 4-15 and 4-16, that effectively deal with the installation variations found in both wood and metal frame construction. The Foster-Miller approach to mechanical protection was incorporated into the NFGC, and a special performance test for striker plates has been included in 


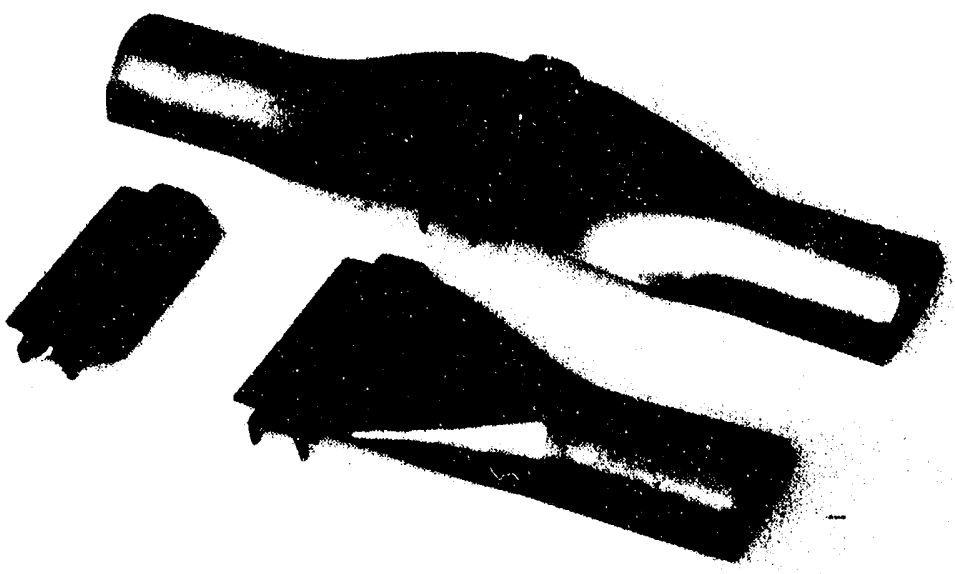

Figure 4-16. Foster-Miller Striker Plate Designs

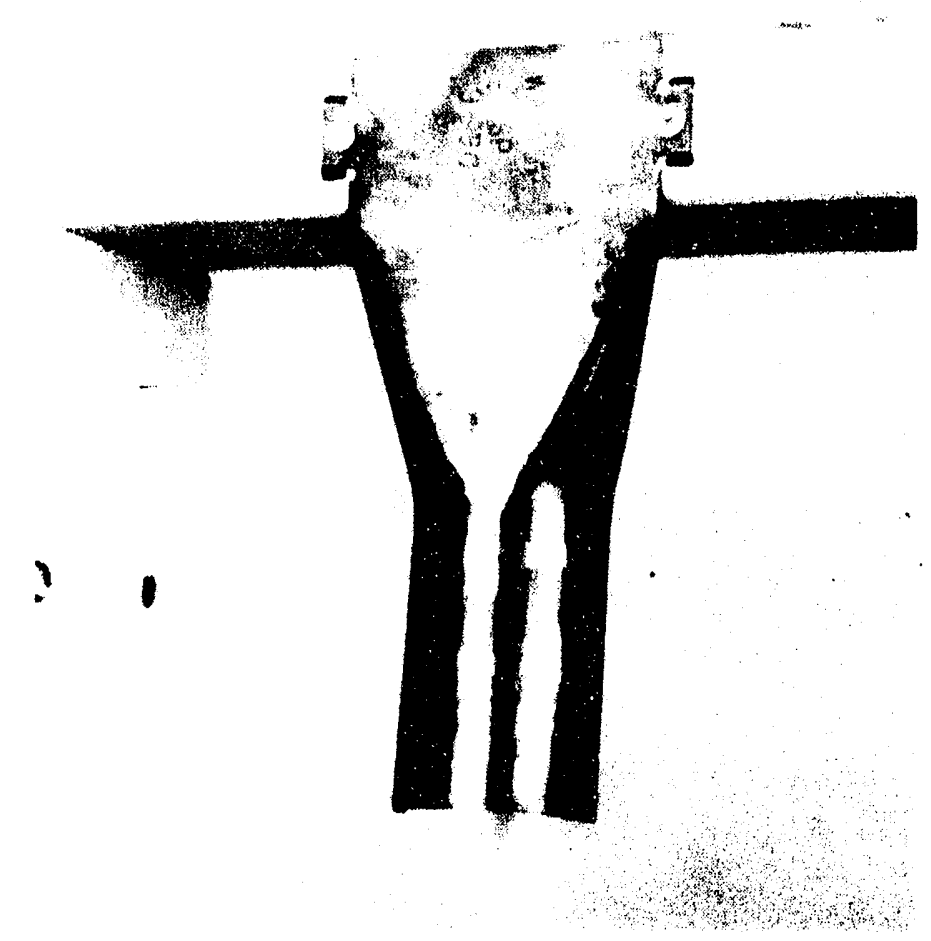

Figure 4-16. Striker Plate Installed to Protect CssT 
ANSI/AGA LC-1, 1991. With GRI approval, the striker plate designs were offered to all CSST manufacturers at no cost to encourage their voluntary adoption.

Chaseware and Baseboard Channels. Chaseways are an integral part of the design of some multifamily bulldings for running services between floors and along horkontal sections on each floor. These pathways are designed into some multifamily building for electric and water supply/drainage/fire suppression, but not necessarily for gas. It is important to minimize the size of gas piping to more easily accommodate already tight space requirements allowed for services requiring chaseways.

Baseboard channels usually located within rooms and offices are becoming more popular for running services such as electric power, communications, and data transmission. There is no reason why semirigid gas tubing cannot utilize the same pathways albeit separate compartments as these other services. This was demonstrated several years ago in the GRI single -family applications research house (see Figure 4-17). British Gas has also developed a system that uses baseboard channels, copper tubing, and special outlets to distribute gas within rooms/offices. Their system, called Micropoint, is shown in Figure 4-18.

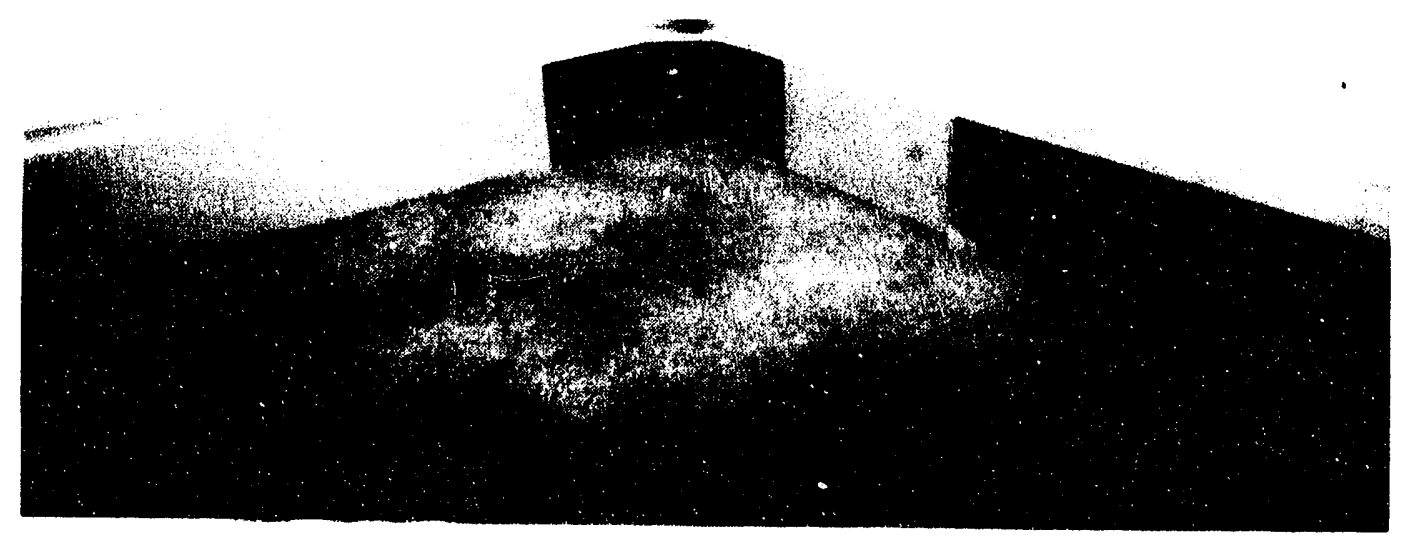

Figure 4-17. Gas Tublag Installed in Basoboard Channel 


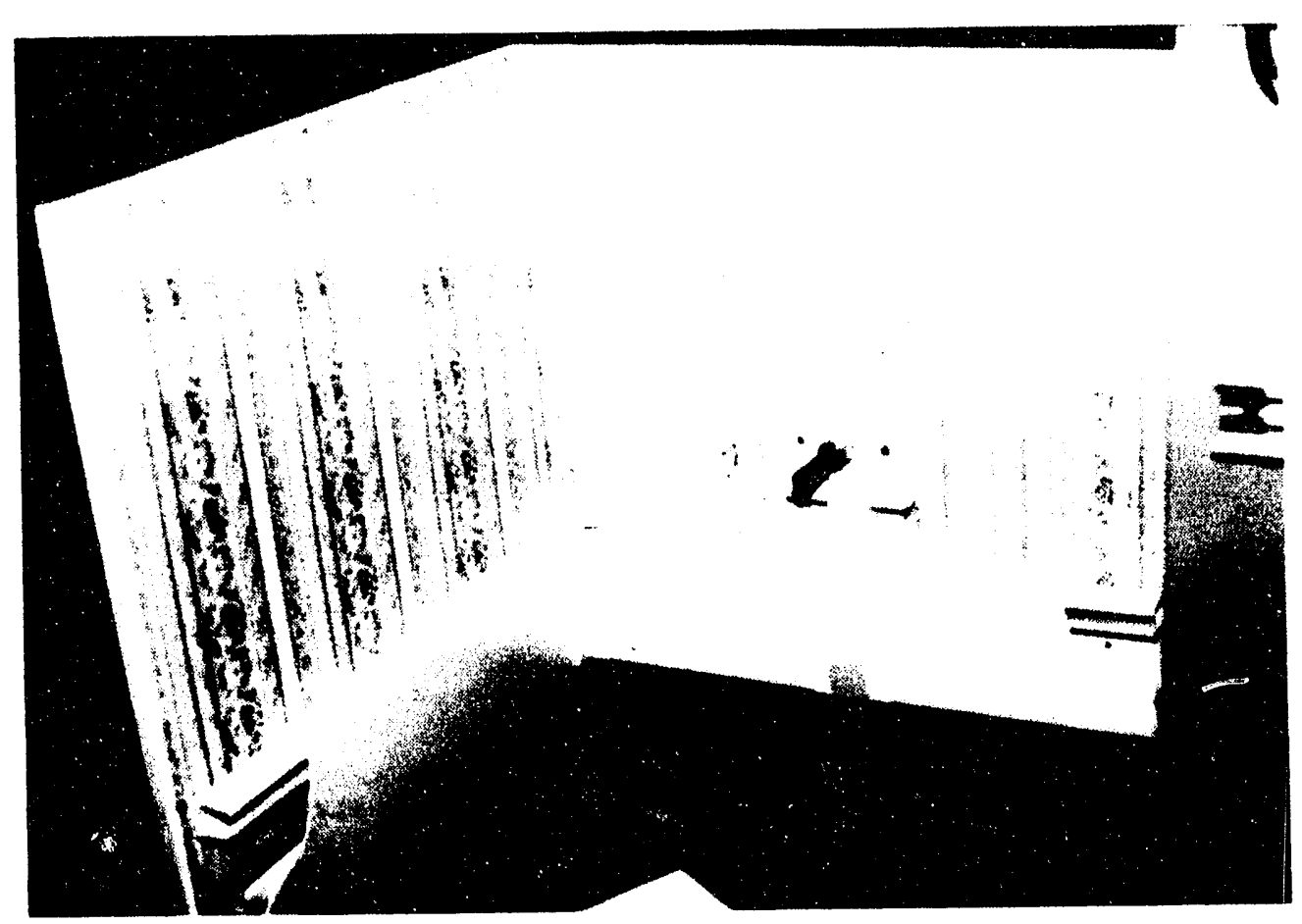

Figure 4-18. British Gas Tubing and Micropoint Gas Outlet Installation Using Baseboard Channel

Intermediate Line Regulators and Venting. There are no specific code prohibitions to installing line pressure regulators within buildings in addition to the service pressure regulator that reduces high street pressure (up to $60 \mathrm{psil}$ ) to lesser pressure $(1 / 2,2,5$, or $10 \mathrm{psi})$ for interior gas distribution. The issue for multifamily buildings is what are the operating requirements and acceptable locations for the intermediate line regulator? There are three important operating functions that can be required for this type of regulator which are:

- Overpressure protection

- Dead-end lock-up

- Full relief.

The NFGC, NFPA 54, 1988, states that overpressure protection of the interior piping system is not a requirement if the gas source is 60 psig or less and the service regulator is capable of dead-end lock-up. Dead-end lock-up is defined as limiting the downstream pressure under conditions of no-flow to 150 percent of the discharge pressure under normal flow conditions. In other words, if the normal operating pressure of the interior piping system is 7 in. of water, unfer no-flow conditions the 
downstream pressure could not rise to more than $10.5 \mathrm{in}$. of water. Most service regulators meet or exceed these specifications. However, some utllities still require an intermediate line regulator to have both dead-end lock-up and overpressure protection capabilities.

Regarding dead-end lock-up, the problem appears to be the time period. The regulator may pass the requirements of ANSI Z2 1.18, Gas Appliance Pressure regulators but not meet the more stringent requirements of a local gas utility. This has happened with one manufacturer's regulator. The utilities would apparently like to see no rise in pressure more than 150 percent or some other value of the set pressure for a period of time longer than that stated in ANSI Z21.18.

The overpressure protection issue is merely a matter of the gas utility wanting additional safety above that which is required by NFPA 54-1988 and, in some cases, their own local code. Overpressure protection devices, whether built into the line regulator or a separate component, add additional, unnecessary materials and labor cost to the installation of the gas distribution system. This will inhibit the development and hinder the commercialization of advanced gas distribution technology.

In addition to dead-end lock-up and overpressure protection, some utilities also require that intermediate line regulators have full-relief capability as well. First of all, NFPA 54-1988 does not require that line pressure regulators have a vent line. A vent limiting device is acceptable. However, many utilities/code officials have not accepted vent limiting devices.

For a line regulator to have full-relief capability means that a much larger vent pipe, up to 3/4 in.. may be required to satisfy the requirement. Also, NFPA 54-1988 allows, if approved by the authority having jurisdiction, vent lines to be manifolded in accordance with accepted engineering practices. It is questionable how many authorities having jurisdiction would allow manifolded vent lines. From a cost standpoint, it is crucial for the intermediate line regulator vent lines to be manifolded in multifamily buildings.

The location of the regulator within the building structure is also a controversial issue for many gas utilities. Questions arise such as can the regulator be installed above a 
suspended ceiling or even in a manifold box? The issue here is the degree of concealment that is acceptable that still allows the connections to be readily accessible for servicing as required by NFPA 54-1988. These issues need to be resolved before successful implementation of advanced gas distribution networks can be achieved.

Gas Outlets. Semirigid tubing systems provide the tenant with enhanced use operations that are not traditionally provided when using steel piping. Among these options is the decentralization of gas distribution within the multifamily building. Gas can be made avallable, with significantly less cost and difficulty, at many sites throughout the multifamily building, and not just in a utility area for the furnace and water heater. This network gives the tenant additional use options that currently are not being provided or that are being serviced by electricity.

GRI-sponsored research has led to the development of a prototype gas outlet as shown in Figure 4-19. Designed and manufactured by M.B. Sturgis, Inc., the device is engineered to meet the requirements for AGA Laboratory bench standard for gas

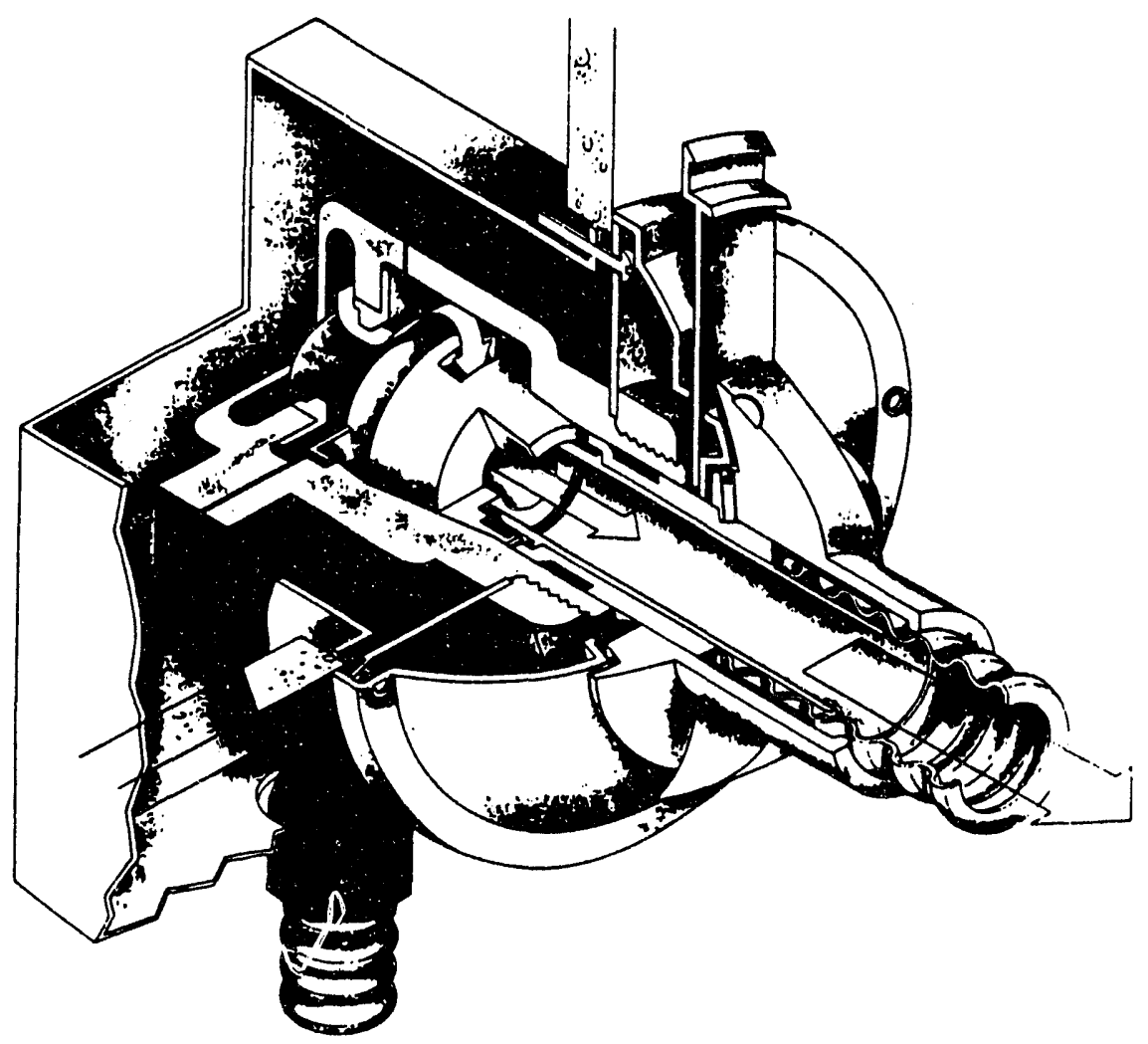

Figure 4-19. M.B. Sturgis Advanced Convenience Gas Outlet 
convenience outlets (AGA No. 7-90). Although the M.B. Sturgis outlet is still undergoing engineering evaluation and modifications, its features and operation can be described.

Outlet Features and Operation. The outlet is designed to be operated by inserting the connecting plug and then rotating the plug $90 \mathrm{deg}$ clockwise. The internal on/off vilve is activated as the plug is rotated. Gas flow is initiated only after the plug has rotated a minimum of $30 \mathrm{deg}$. In the connected position, with the gas flowing, the plug cannot be removed from the outlet. Bayonet tabs on the plug engage with corresponding grooves in the outlet body to prevent the removal of the plug by simply pulling on it. The primary on/off valve is a manually operated cone (tapered plug) valve that is activated by the combined effect of the insertion and rotation of the plug. A redundant secondary valve within the outlet is actuated by a cam system, which is activated by the movement of the back surface of the cone valve. This cram unseats a poppet valve, which permits the gas to flow into and through the cone valve and plug. To disconnect the plug from the outlet, the plug must be rotated 90 deg counterclockwise, which closes both the primary and secondary valves. The counterclockwise rotation also releases the locking tabs on the plug and allows the plug to be removed from the outlet with a small tug.

The outlet is designed to be assembled in two packages. The rough-in assembly is mounted on the wall stud before the wallboard is installed and is considered part of the rough-in gas piping installation. The rough-in assembly is pressure tested as part of the gas piping system. The finish assembly consists of the cover plate and wall trim, which are installed after the interior walls have been completed. The outlet is designed to be installed like an electric outlet and has built-in compensation for variation in the wall thickness. The outlet can be installed in any orientation, with the gas piping entering from the top, bottom or either side. The outlet can be used outdoors, but it must be installed in a weather-resistant enclosure.

The introduction of gas outlets into multifamily buildings is intended to encourage the use of portable countertop appliances. These types of appliances are expected to be lightweight and may require a more flexible connector than is currently sold for stoves and dryers. This ultra-flexibility is needed to prevent accidental tipping of the appliance caused by a non-compliant stiff connector. These will be critical applications because of the daily interaction with the consumer in $n n$ indoor 
environment. Entirely new technology that is more tolerant of abuse. extremely flextble (like wire), and fail-safe may be required and will be an important objective of ongoing GRI research. However, not all movable appliances need a highly flexible appliance connector. Freestanding range/oven units and clothes dryers could continue to get by with existing appliance connector technology but modified with the special gas outlet plug. Simllarly, outdoor use with such appliances as the barbecue grill can be met with existing products. Until the appliance connector issue is resolved, both in terms of the compatibllity and design needs, there could be a negative impact on both the market introduction and its growth.

Code Restriction. A complete evaluation of bullding standards and fuel gas codes used around the United States was conducted by the NCSBCS. In their report entitled, Code Assessment of Acceptabllity of Quick Connect/Disconnect Gas Outlets. NCSBCS summarized the results of soine informal industry surveys and technical investigations into the issues addressing the use of gas outlets inside buildings. The report highlighted two key areas: product standards and installation requirements. Most model codes in the United States list acceptable gas appliances or accessories by referencing the appropriate national scandard. Since the type of gas outlet being developed by GRI may require a new national standard, an interim standard is needed to get the outlet listed in the various model codes. To that end, an AGA bench standard has been developed entitled AGA Requirements for Gas Convenience Outlets, No. 7-90, dated $3 / 20 / 91$. The standard does not currently address the geometric compatibility issue raised earlier.

Codes and building standards deal mostly with installation issues involving equipment, piping, ducts, vents and system accessorles. Regarding gas outlets, most codes either allow quick connect/disconnect devices or they are sllent on the issue. When using quick connect devices, the codes require an accessible, upstream manual shut-off valve to be located close to the outlet. The M.B. Sturgis type of outlet internally incorporates the shut-off valve and is intended to be installed in concealed locations. Therefore, there is a need to modify code language to permit this type of device and installation method. The approach taken was to define a new category of quick connect devices called gas convenience outlets. The definition recommended is as follows: 
"Convenience Outlet, Gas. A permanently mounted hand operated device providing a means for connecting and disconnecting an appliance to the gas supply piping. The device includes an integral, manually operated gas valve with a non-displacement valve member so that disconnection can be accomplished only when the manually operated gas valve is in the closed position."

If this definition is adopted by the individual model codes, it will permit the M.B.

Sturgis-type outlet to be installed without an additional upstream shut-off valve. This language has been submitted to and approved by the NFGC Z223 for adoption in the 1992 reprinting.

The other code restriction, which will affect the installation of the convenience gas outlet, is the prohibition on the use of concealed tubing joints. This prohibition appears to be universal in those codes that permit the use of tubing for natural gas distribution within the house. To address this issue, two different approaches have been proposed. In the near term, when installing the gas outlet in concealed locations, the outlet must be installed inside an air-tight enclosure that includes the tubing fitting. Figure 4-20 depicts a prototype enclosure that permits the outlet to be

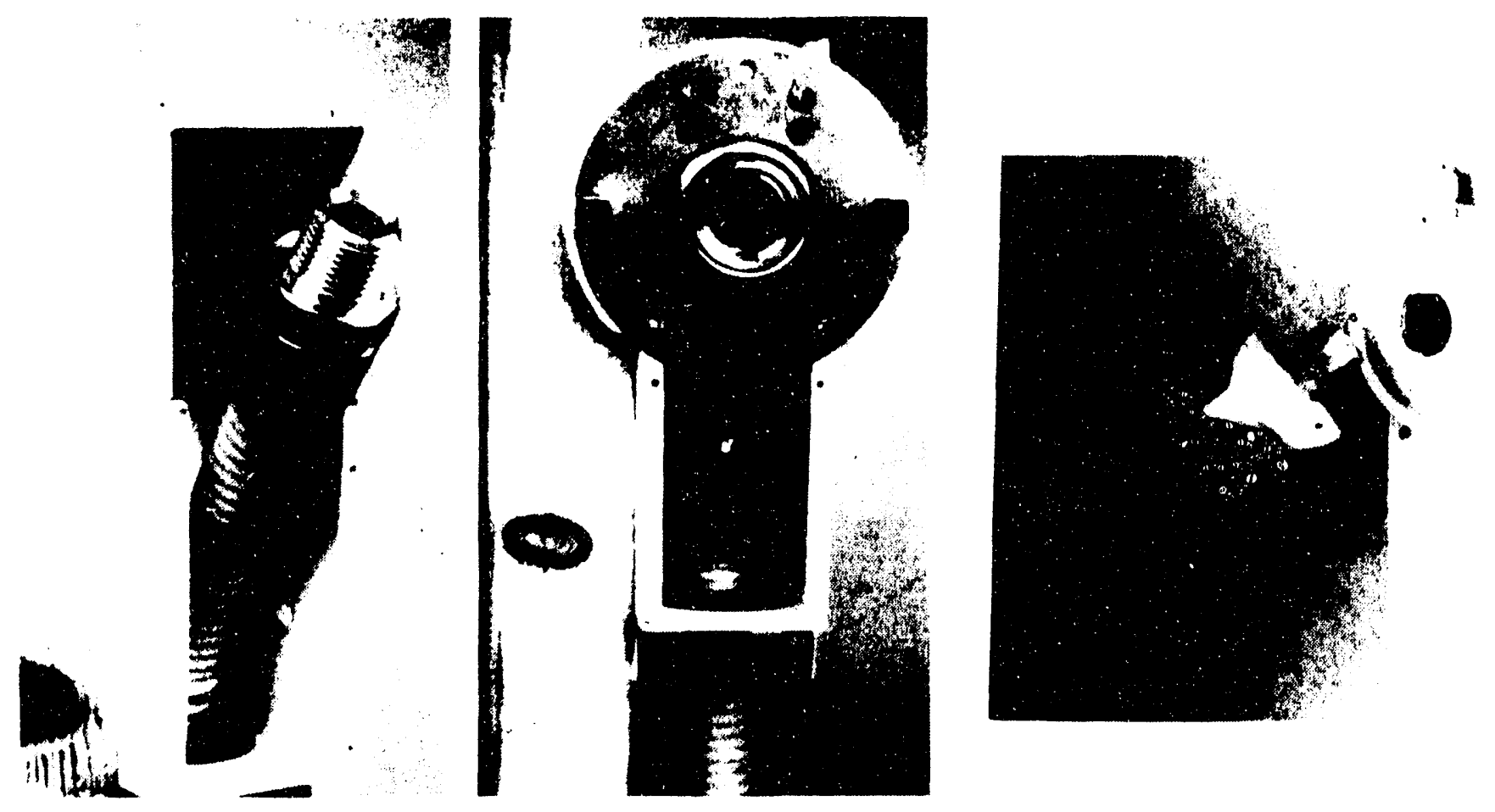

Figure 4-20. Special Gas Outlet Enclosure for Concealed Joints 
installed inside the plaster wall, while permitting access to the fitting. Should the joint leak, the escaping gas will vent into the room from inside the enclosure.

An alternative near-term approach is to mount the gas outlet on a steel pipe riser when the outlet is to be placed in a concealed location. The steel pipe should extend from the gas outlet to an area where an accessible transition from pipe to tubing can be accommodated. Since the prohtbition on concealed joints does not apply to steel pipe, no special enclosure would be needed for the outlet.

In the long term, it will be more cost-effective to install the outlet as shown in Figure 4-21. Using a simple, inexpensive plastic box, the outlet is easily nailed to the side of the wall stud like an electric switch or duplex outlet box. This does conceal the tubing joint behind the wallboard. However, Foster-Miller is currently developing some additional testing criteria that will permit the tubing joints to be qualified for use in concealed locations. Code language was submitted to the Z223 committee (NFGC) to permit the use of tubing joints when such joints are pre-qualified for such use by a recognized testing organization. This change has been accepted for inclusion in the 1992 reprinting of the code.

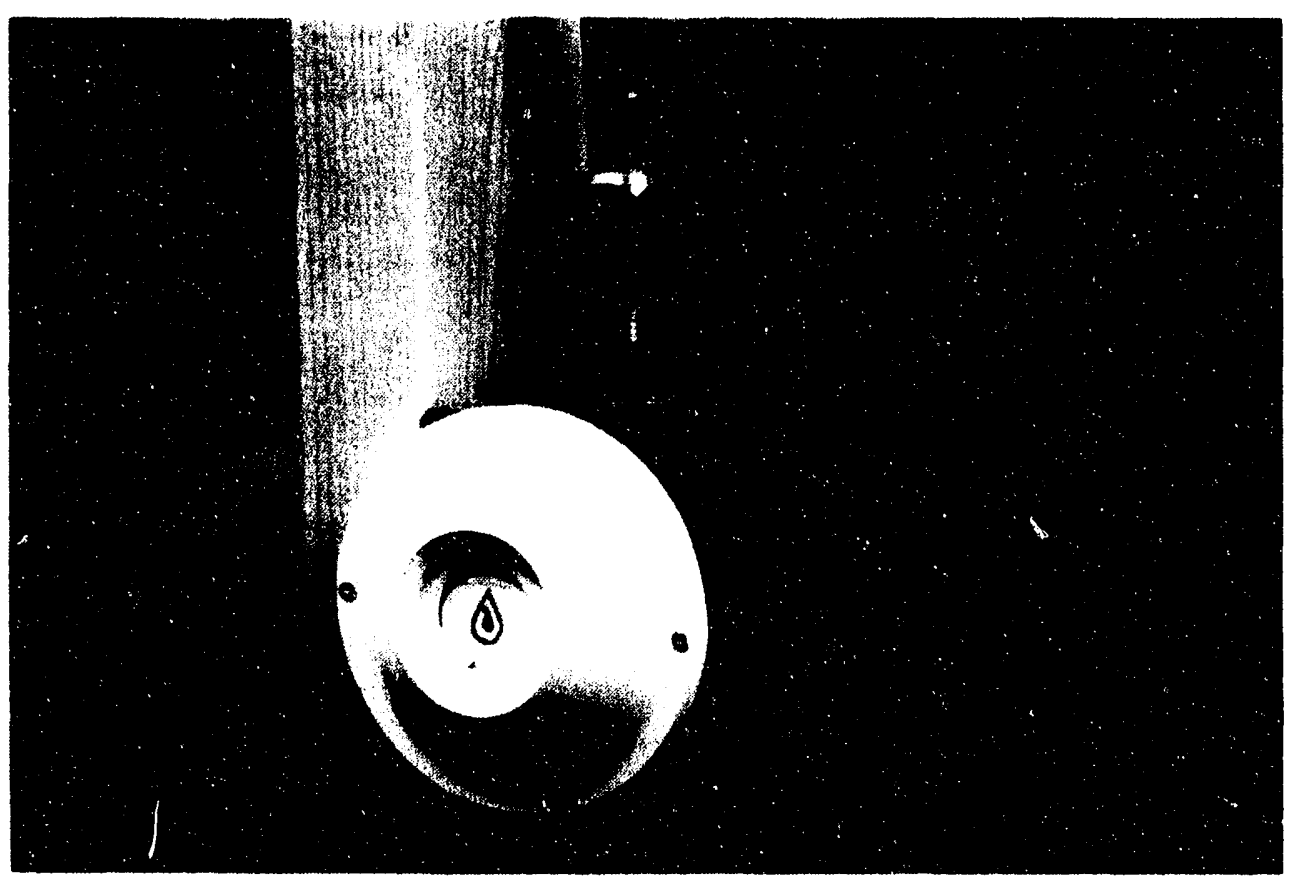

Figure 4-21. Standard Gas Outlet Wall Mounting Method 


\section{SPACE AND WATER HEATING SYSTEMS}

This is a critical period for the gas space and water heating appliance market. Public Law No. 100-12, which was passed in 1987, established that all new gas furnaces manufactured after January 1, 1992, must have as a minimum an AFUE of 78 percent. The law is part of the National Appliance Energy Conservation Act of 1987 (NAECA) and affects 14 classes of residential appliances, of which seven classes include gas appliances. The act requires that the Department of Energy set, review and raise minimum efficiency standards over the next 15 or 20 years. Any changes in minimum efficiency standards must be "technologically feasible" and "economically justified." The law applies to appliance installations in all states with few exceptions.

All gas water heaters manufactured after January 1, 1990, must have a minimum energy factor of 0.62 as shown in Table 4-8. The energy factor is a measure of the overall efficiency rating of the water heater. This has not presented major market problems for gas versus electric water heaters.

However, one class of gas furnaces has been devastated by the new standard. Conventional atmospherically vented furnaces cannot meet the new standard. The problem is the NAECA defines the AFUE for these appliances based on the assumption that the furnaces are installed indoors and all combustion air is supplied from the outside via ducts or grills. Any efficiency increases as a result of vent dampers are not included in the AFUE calculation. In 1991, these units accounted for approximately 65 percent of the market. The two remaining types of furnaces on the market are fanassisted combustion systems with AFUEs of 78 to 83 percent and full-condensing units with AFUEs of 90 to 95 percent. Both of these alternatives are significantly more expensive to purchase and install than the conventionally atmospherical vented furnaces. Only one manufacturer, Lennox, has been able to market a furnace with a 78 percent AFUE that can be conventionally vented.

This change in the appliance efficiency standards has been especially difficult for southern utllities since high-efficiency gas-fired heating systems cannot economically compete with electric heat pumps. The changes in the appliance efficiency standard have resulted in lower increased costs for the electric heat pump than for the equivalent gas-fired system. The answer to this problem for the southern utilities has been the hydro-heat system, which is commonly referred to as the combo or dual 


\section{Table 4-8. Minimum Efficiency Levels and Effective Dates for Gas Appliances Covered by NAECA}

\begin{tabular}{|c|c|c|}
\hline \multicolumn{3}{|c|}{$\begin{array}{l}\text { MINIMUM EFFCIENCY LEVELS } \\
\text { AND EFFECTIVE DATES FOR GAS APPLANCE } \\
\text { COVERED BY NAECA }\end{array}$} \\
\hline PRODUCT & $\begin{array}{l}\text { NAECA } \\
\text { MINIMUM }\end{array}$ & $\begin{array}{c}\text { EFFECTIVE } \\
\text { DATE }\end{array}$ \\
\hline FURNACES & \multirow{2}{*}{$78 \%$ AFUE } & \multirow{2}{*}{$\begin{array}{l}\text { Manuiactured } \\
\text { oner } 1 / 1 / 92\end{array}$} \\
\hline All input sizes & & \\
\hline $\begin{array}{l}\text { Mobile home } \\
\text { use only }\end{array}$ & $75 \%$ AFUE & $\begin{array}{l}\text { Monuiocrured } \\
\text { óner } 9 / 1 / 90\end{array}$ \\
\hline BOILERS & \multirow[b]{2}{*}{$80 \%$ AFUE } & \multirow[b]{2}{*}{$\begin{array}{l}\text { Manutacturea } \\
\text { oner i//192 }\end{array}$} \\
\hline $\begin{array}{l}\text { Bollers. } \\
\text { hol woter }\end{array}$ & & \\
\hline $\begin{array}{l}\text { Boilers. } \\
\text { steom }\end{array}$ & $75 \%$ AFUE & $\begin{array}{l}\text { M̈anuiocrured } \\
\text { oner } \mathrm{i} / 1 / 92\end{array}$ \\
\hline $\begin{array}{l}\text { WATER } \\
\text { HEATERS }\end{array}$ & \multirow{2}{*}{$\begin{array}{l}\text { Energy } \\
\text { lactor }=0.62 \\
(R S V=\times 0.0019)\end{array}$} & \multirow{2}{*}{$\begin{array}{l}\text { Manufactured } \\
\text { ofter } 1 / 1 / 90\end{array}$} \\
\hline Storoge & & \\
\hline Instantoneous & $\begin{array}{l}\text { Energy } \\
\text { lactor }=0.62\end{array}$ & $\begin{array}{l}\text { Monuroctured } \\
\text { after } 10 / 12 / 91\end{array}$ \\
\hline $\begin{array}{l}\text { SWMMMINo } \\
\text { POOL } \\
\text { HEATiRs }\end{array}$ & $\begin{array}{l}78 \% \\
\text { Thermal } \\
\text { Efficiency }\end{array}$ & $\begin{array}{l}\text { Manufoctured } \\
\text { ofter } 1 / 1 / 90\end{array}$ \\
\hline $\begin{array}{l}\text { RANGES } \\
\text { AND OVENS }\end{array}$ & $\begin{array}{l}\text { No constani } \\
\text { burning pilot } \\
\text { on modeis w/ } \\
\text { electric cord }\end{array}$ & $\begin{array}{l}\text { Manufoctured } \\
\text { ofter } 1 / 1 / 90\end{array}$ \\
\hline Divins & $\begin{array}{l}\text { No constant } \\
\text { burning pilot }\end{array}$ & $\begin{array}{l}\text { Monuractured } \\
\text { ofver } 1 / 1 / 88\end{array}$ \\
\hline
\end{tabular}

integrated system (DIS). These systems were developed in the 1970s. As depicted in Figure 4-22, combo systems basically consist of a gas water heater and air handler.

A dual integrated system is a simple system that utilizes a domestic hot water heater and an air handler to provide both space heating and potable hot water for residential applications. Optionally, air conditioning can be incorporated into the system. The integrated system utilizes a small circulation pump to draw hot water from the water heater and circulates it through a water-to-air heat exchanger in the air handler.

There the water loses 10 to $20^{\circ} \mathrm{F}$ before returning to the water heater to be reheated. A thermostat controls the operation of the circulating pump and the blower/motor in the air handler. Warm air is circulated into the home through a duct system. Cooling can be provided through the use of a split system, with an evaporator coll in the air handler and a remote condensing unit (optional items). 


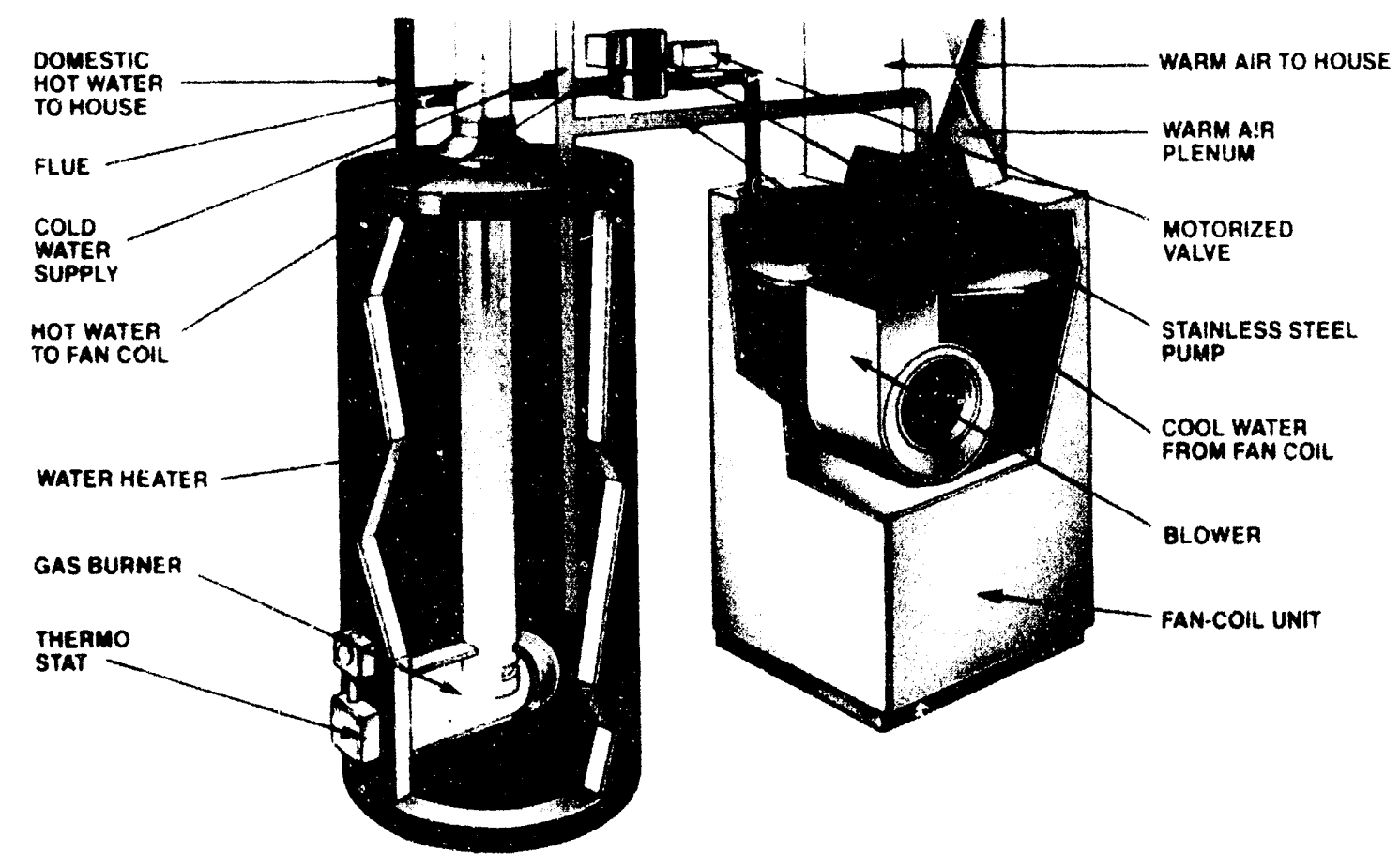

How do Gas

\section{Combo-Heaters work?}

The waller heallet uperalle lihe an! conicmumal water heater. When yode heall is

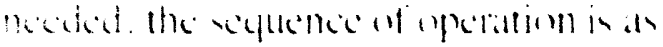
tillim,

1. How

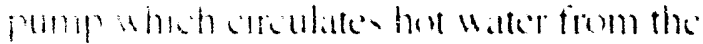

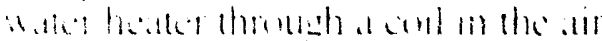
h.molin

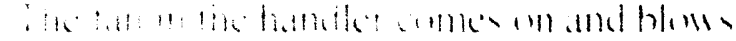

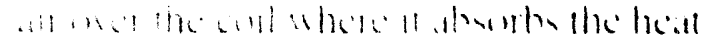

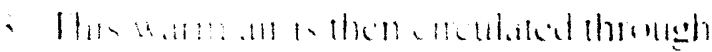

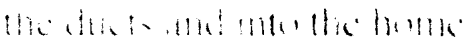

REFERENCE SOURCE: AMERICAN GAS ASSOCIATION

Figure 4-22. Combination Space and Water Heating System 
A typical integrated system includes:

- Water heater: A high-efficiency water heater is used to satisfy both hot water heating and space heating requirements.

- Air handler: The air handler may be one of several configurations, including a vertical unit for closet installation, a horizontal unit for celling installation, a wall unit for "between-the-studs" installation, or a duct coil for retrofit applications.

- Pump system: A small pump circulates hot water from the water heater to the hot water coil in the air handler. The pump may be integrally mounted in the air handler (Apollo and Rheem) or may be mounted in the piping (Mor-Flo and First Co.).

- Controls: The control system is relatively sirnple and includes typical controls such as a cooling/heating thermostat, pump and fan relays, and a $115 / 24 \mathrm{~V}$ transformer.

- Water piping: Water piping between the water heater and the air handler is field supplied. Water lines are typically $3 / 4$ in. nominal copper or approved plastic pipe. The lines should be insulated. In addition, check valves and service valves may be required though application varies by manufacturer.

- Condensing units: Split system condensing units are matched to the evaporator coll in the air handler. The outdoor condensing units may be manufactured by someone other than Apollo, Rheem, First, or Mor-Flo companies.

Dual integrated systems are efficient, competitively priced, space saving, easy to install and maintain, and extend the life of the water heater by increasing water circulation, which reduces sediment buildup and corrosion. Within the United States (including Alaska), approximately 375,000 units have been installed in starter homes and multifamily bulldings. If the water heater is properly sized, it works perfectly well in northern multifamily bulldings. However, three states including New York restrict or do not allow installation of combo units. The problem appears to be in the classification of the unit. Some state code officials have classified the water heater used in the combo unit as a boiler, thus requiring the water heater to comply with all applicable boller codes and standards. Since bollers are pressurized, they are designed to more rigorous standards than water heaters. All currently sold water heaters do not meet the boiler standards.

Since combination space and water heating appliances are an integrated system composed of components from several different manufacturers, a means to determine overall system efficiency was needed. To address this need, GRI sponsored research 
to develop an ASHRAE Standard, ANSI/ASHRAE 124P entitled Method of Testing for Rating Combination Space Heating/Water Heating Appliances. The research was conducted by Battelle and American Gas Association Laboratories. The standard covers electric, gas-fired and oil-fired combination space and water heating appliances up to $300,000 \mathrm{Btu} / \mathrm{hr}$ rated input. A draft of the proposed standard is currently out for public review and included in Appendix $F$. ASHr'AE published the standard in 1992.

Combination space and water heating systems offered by four manufacturers will be described that are referenced in an AGA brochure shown in Figure 4-23. They are:

- Polaris, Nautllus, and Integra: manufactured by Mor-Flo

- EnergyMate: manufactured by Rheem

- Aqua Therm System: manufactured by First Co.

- Hydro Heat System: manufactured by Apollo.

The key to choosing a combo system is to remember that if the water heater is too small the consumer may run out of hot water. Conversely, if the water heater is too large, the consumer will waste energy. AGA has published a Buyer's Guide on Efficient Gas Water Heating that can be used to properly size the combo system. Figure 4-24 provides a procedure for proper sizing.

\section{Mor-Flo Industries. Inc.}

Mor-Flo, incorporated in 1915, is an established manufacturer of a complete line of storage water heaters. They have been involved with integrated systems applications since 1985 when they made a commitment to market products to supply all the energy needed to heat homes, as well as hot water. Figure 4-25 summarzes their currently available mid- and high-efficiency systems. Appendix F contains manufacturers literature.

The Polaris system utilizes a specially designed water heater, which has a stainless steel tank, submerged combustion chamber, and power burner. It is a high efficiency (94 percent), condensing water heater that can be direct vented through an outside wall. Figures 4-26 and 4-27 show the Polaris system. 


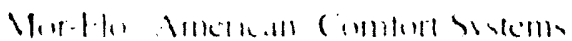

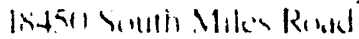

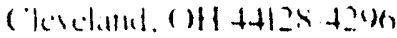
(2), $6(1,2-3)$

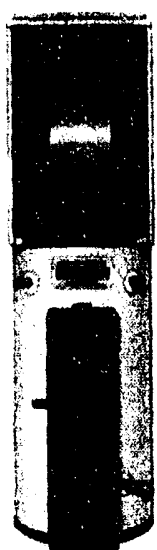

When lowng space is al a premium. chenes the Integrat he Mor-Flo. Jis the anls stacked Cias (inmbro-Heater and uxes atheut the sattlo flocer space as a standatrd waller healcer.

$\times 273$. Mohurk lanc

Dillas. $T \times 75227$

$1214,386-5751$

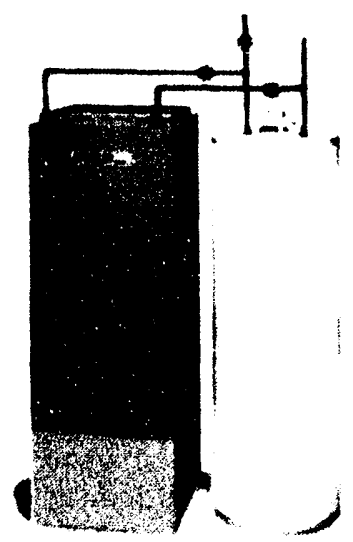

For added flexibility, select the Aqua Therm" System - a First Co. air handler that converts any properly sized water heater into a high efficiency Gas Combo-Heater.
Rheom Walter Healter Dmwan

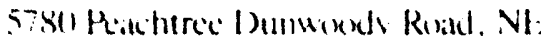
Nllantat. (iA 311342

Sece the lillow Payes under Watcer Heallers

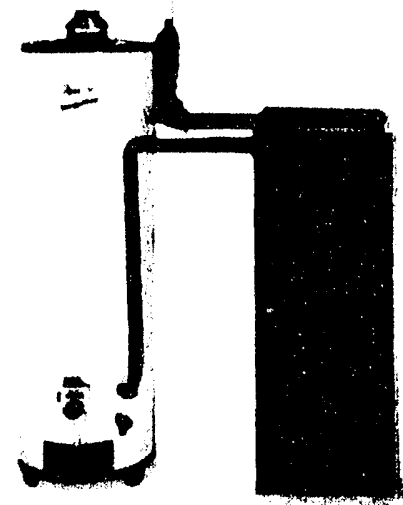

The Rheom Inergy Matc is a side-hy-side sstem that inleyrater Rheomi linergy Malle

Watcer Heater line with is Iancrey Mate ail handler for eptimum performance and encrey efficiency.

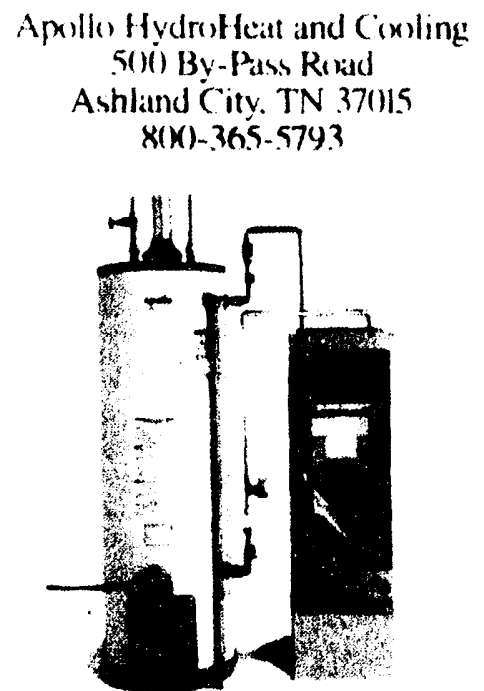

Apollo's HydroHeat System is available in vertical, horizontal, wall-mounted or ceiling-mounted configurations. With one-third as many parts as a heat pump, it is virtually maintenance free.

\section{Gas. Americąs best energy value.}

Figure 4-23. Combination Spacer and Water Heating Systems 


\section{PROPER SIZING}

A properly sized gas water heater will deliver all the hot water you wont wrien you need it

The best size for a water neater is determuned by its first hour raing. Starling with a full rank of hol water. the first hour rating is the maximum amount of hot water that con be supplied in a one-hour period

The Federal Trade Commission suggests the follow ing steps be used as a guide to correctly size a gas water heater.

- Determine the hour during which you use the most hot water

- Find each water use from Table No. I that will be needed during that hour

- From this table, list each water use that occurs during the hour of the day when your family uses the most hot water

- Total the estimated gallons needed. This tells you the peak water nealing capacity you will need

- Select a unit with a first-hour rating that is nearly equal to your estimated use since the first-nour rating includes the recovery rate, a smaller unit with a good recovery rate con outperform a larger unit with a lower recovery rate

\section{TABLE NO. 1}

MAJOR USES

ESTIMATED

OF HOT WATER

GALLONS OF HOT WATER PER USE

Clothes Washer

(warm/cold rinse)

$10-12$

Clothes Washer

(hot wash/cold rinse)

30

Shower

10-15 or 3 gallons per min.

Bath

15-20

Bathing an infant 2

Automatic dishwasher

$12-15$

Hand dishwoshing

Shaving

4

Hair shampoo

Food preparation

2

4

5

Hand and face washing 2

Housecleaning

\section{REFERENCE SOURCE: AGA BUYER'S GUIDE: EFFICIENT GAS WATER HEATING}

\section{Figure 4-24. Proper Sizing Procedure for a Combo System}

Mor-Flo does not manufacture the air handlers that are used in the Polaris system.

They are manufactured for Mor-Flo by First Co. under a nameplate agreement.

The Polaris water heater is limited to a single 36-gal, 100,000 Btu/hr input model that is ample for most jobs but may be cost prohibitive for some applications, particularly multifamily applications with their minimal heating requirements.

Mor-Flo has AGA certification on its Polaris water heater. The air handling units and pump modules have Underwriters Laboratory certification under First Co.

applications. 
Mor-Flo/American

National No.: (216) 663-7300, Gary Bosma

Polaris

$100,000 \mathrm{Btu} / \mathrm{hr}, 94$ percent AFUE, $34 \mathrm{gal}$, power burner, sealed standby loss $=1.2$

percent, energy factor about 0.90 , int. ignition, system cost (trade): $\$ 1,800$, installed cost $-\$ 2,400$, includes hot and cold coils and blower, does not include thermostat, piping, and vent pipe, cost for heater alone - $\$ 1,400$.

Nautilus

$38,000 / 40,000 \mathrm{Btu} / \mathrm{hr}, 85$ percent AFUE, $40 / 50 \mathrm{gal}$ atmosphertc, stack standby loss $=3.7 / 3.2$ percent $(40 / 50 \mathrm{gal})$, energy factor $=0.60 / 0.62$, heater cost: $40-\$ 260,50$ $\$ 320$

(10 year guarantee)

Integra

40,000 Btu/hr, 83 percent AFUE, $40 \mathrm{gal}$, induced draft, sealed modified Nautllus, int. Ignition, system cost: $\$ 950$, installed cost $-\$ 1,400 / 1,500$, includes hot $(28,000$ $\mathrm{Btu} / \mathrm{hr}$ ) and cold colls

(1.5 - 2 tons) and blower.

Note - all costs are trade prices as of March, 1992

\section{Figure 4-25. Summary of Mor-Flo Appliances for Dual Use}

Since the Integra system is a modified Nautilus system, only the Integra system will be discussed. For the Integra system, a power burner replaces the atmospheric burner found on the Nautllus. It is a mid-efficiency ( 83 percent), near-condensing water heater, quick connected to an air heater that results in an extremely compact unit. Figure 4-28 details the Integra system. As with the Polaris water heater, the Integra water heater incorporates sealed direct venting, which eliminates the need for inside air for combustion. The floor space required for the appliance is only 20-1/4 in. wide by 24-1/2 in. deep. Overall equipment space is reduced by 50 percent compared to a separate water heater and air handling unit.

The Integra system includes a 40-gal glass-lined water heater with a submerged combustion chamber. The 40,000-Btu/hr input makes the Integra system ideal for multifamily new construction and rehabilitation, as well as electric conversions. Mor- 


\section{Thermal Efficiency: +94 percent.}

Stainless steel tank assures long life. No anode rod or glass lining necessary.

Foam insulation with R-16 factor minimizes heat loss: meets

California Title 24 requirements.

Stainless steel coiled flue transfers heat from flue gases to the water resulting in $+94 \%$ efficiency.

Bullet -shaped submerged stainless steel combustion chamber elimi. nates conventional water heater heat loss. lime build-up and noise.

Burner generates intense heat that is forced through the combustion chamber and coiled flue by a powered combustion air blower.

Negative pressure gas valve main. tains uniform gas/air mixture for even. efficient combustion for a variety of inlet pipe applications.

Plastic vent pipes, which can be installed through the wall. serve as combustion arr inlet and flue gas outlet.

Other features/benefits:

- Sivid stati alentrom thermosiat desures prease cemperature comtrol

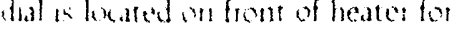
cidit sertume

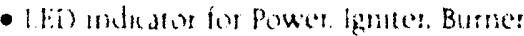

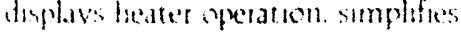

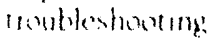

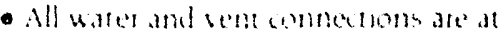

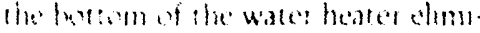
samprype and flue beat hess

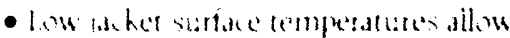

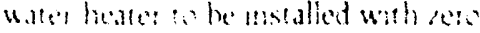

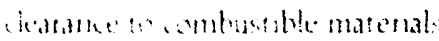

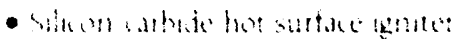

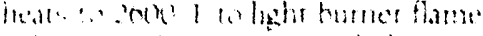

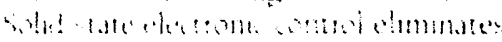

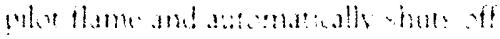

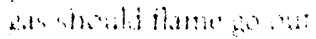

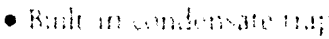

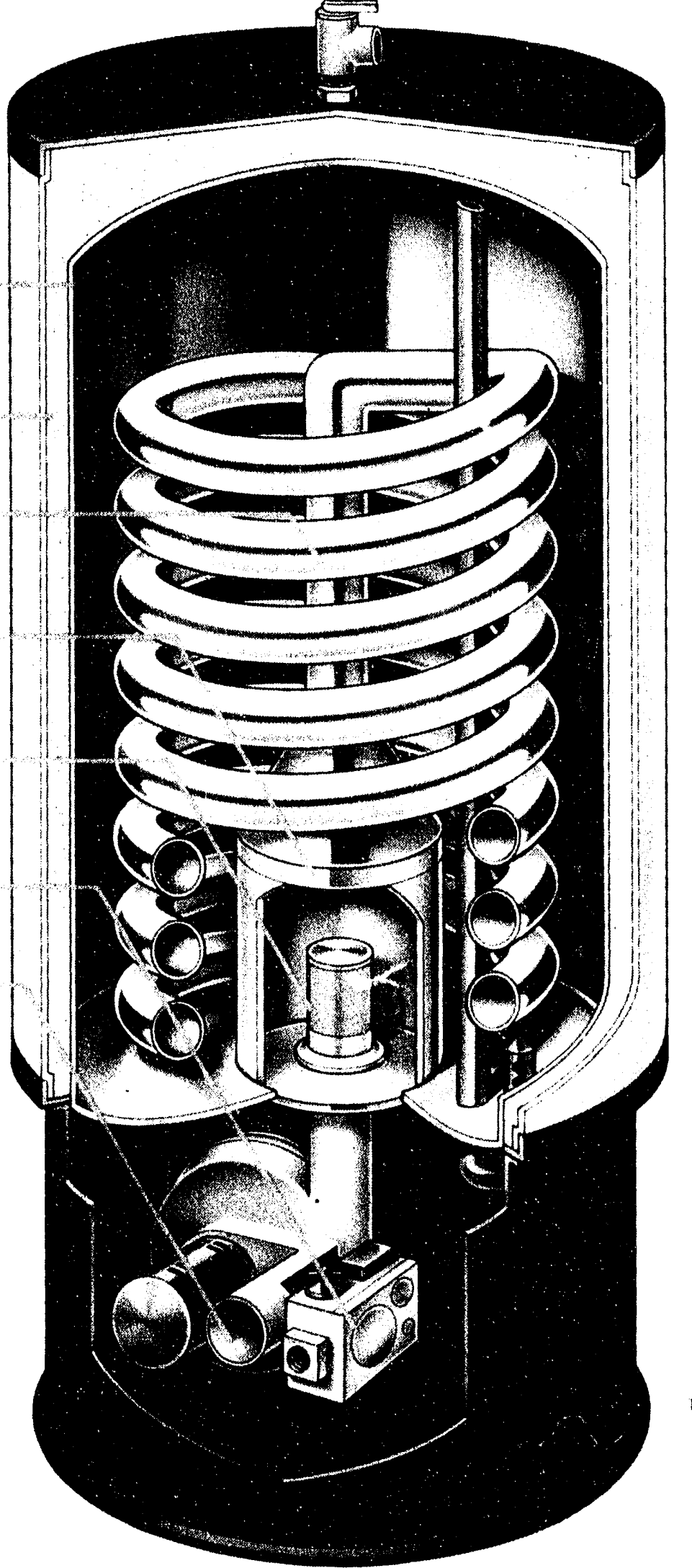

Figure 4-26. Mor-Flo's Polaris Water Heater 


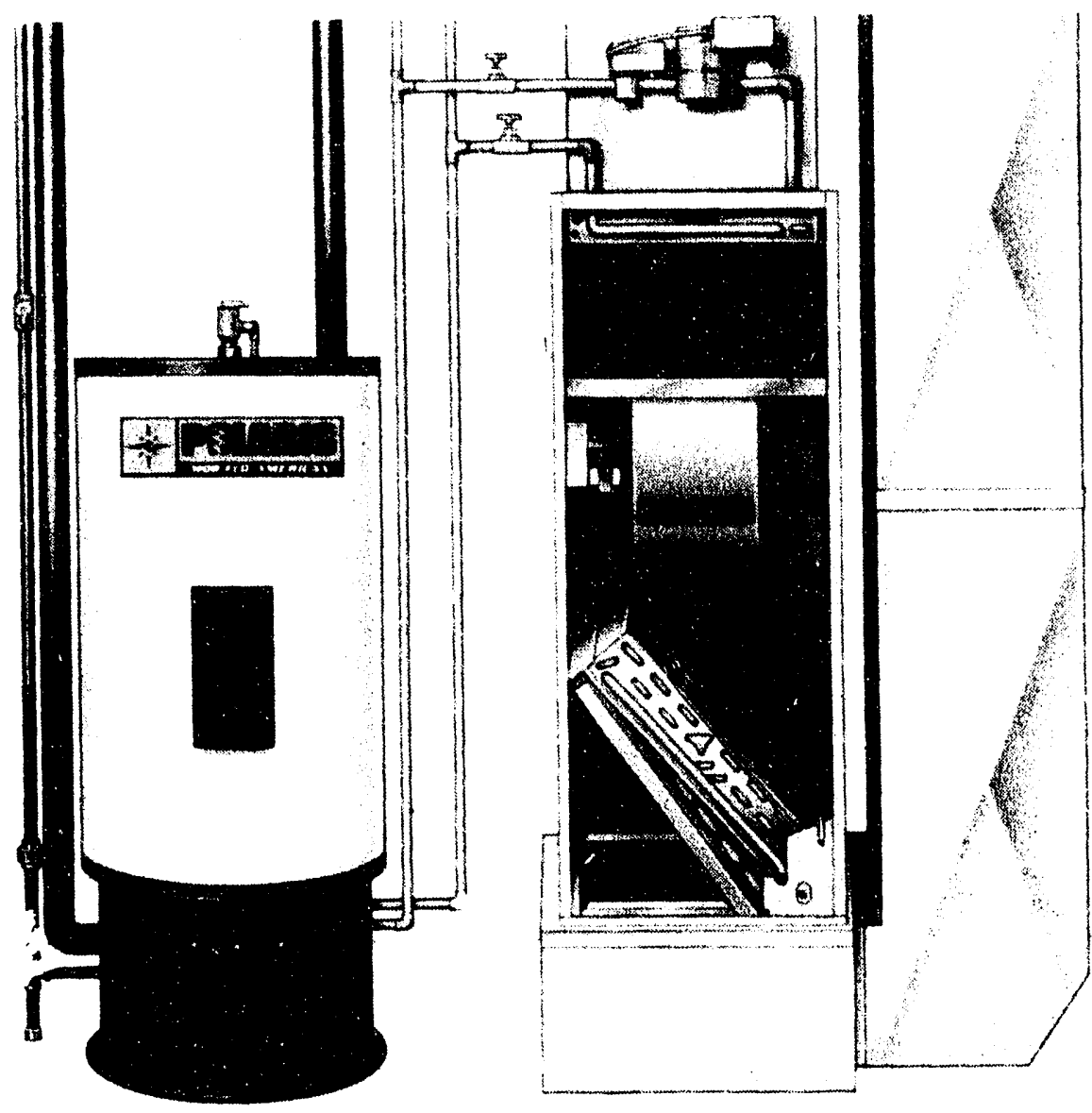

Mor-Flo/American

Comfort Systems

uthing a Polans water herter as a smgle energy soumes. will heat homes. the hot water used in those homes - and in any climate.

These relable and energy-efficiont sysicms. designed primanly for use with forced ar heatung. combine the polans with Mor-FloiAmerion Air Heaters

Compar collng. wall and closet An Heaters come: in space heatung capaciles of 14.000 Btw hr. and higher. In addinon. An Heaters are suppised with a DX cooling coul for su conditsoning during warmer moriths.

Figure 4-27. Mor-Flo's Polaris System

Flo has AGA certification on their Integra water heater. The air handling units and pump modules have Underwriters Laboratory certification under First Co. application.

\section{Rheem Manufacturing Company}

Rheem is also an established manufacturer of a complete line of storage water heaters and air handling units. Table 4-9 summarizes their current avallable water heaters used in their EnergyMate systems. Appendix F contains manufacturers literature on both Rheem water heaters and air handling units. The EnergyMate system utllizes a specially designed water heater that is glass-lined with an exclusive porcelain formula. Both conventional efficiency (76 percent) and mid-efficiency ( 80 percent) water heaters are supplied by the Rheem Water Heater Division for the EnergyMate system. The direct vent models have sealed combustion. Figure 4-29 shows the EnergyMate system. 


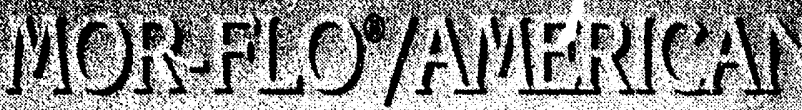

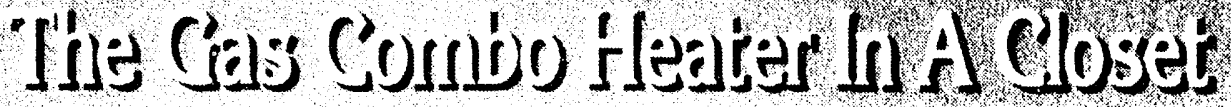

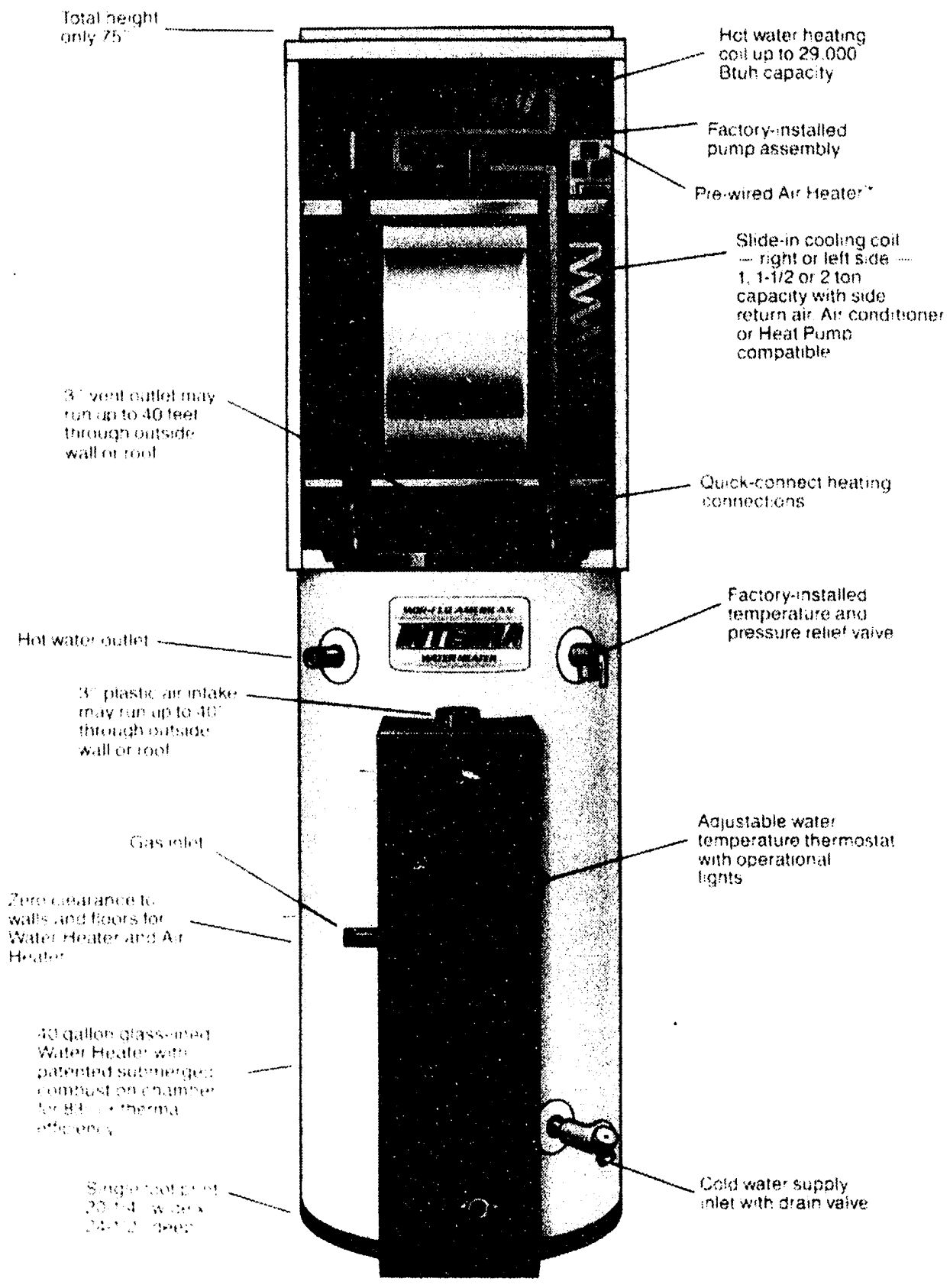

Figure 4-28. Mor-Flo's Integra System 
Table 4-9. Summary of Rheem Appliances for Dual Use

Rheem

National No.: (404) 256-5510, Roy Strong

EnergyMate (all atmospheric burners with side taps)

\begin{tabular}{|c|c|c|c|c|r|}
\hline Input & Storage & SS Eff & EF & Vent & Cost \\
\hline 38,000 & 40 & 76 & 0.56 & direct & 400 \\
40,000 & 50 & 76 & 0.54 & direct & 460 \\
40,000 & 40 & 80 & 0.62 & vertical & 310 \\
40,000 & 50 & 80 & 0.60 & vertical & 360 \\
57,500 & 40 & 80 & $0 . ? ?$ & vertical & 32 \\
75,500 & 62 & 80 & $0 . ? ?$ & vertical & 585 \\
40,000 & 40 & 76 & 0.55 & vertical & 280 \\
60,000 & 50 & 76 & 0.52 & vertical & 380 \\
\hline
\end{tabular}

The direct vent models are sealed combustion. The additional components to construct a complete system are being handled by their heating division. They are developing power vent models that will be both sealed combustion and using room air.

Note: All costs or trade prices as of March 1992.

The air handling unit is supplied by the Rheem Air Conditioning Division and includes a heavy duty circulating pump. The $800 \mathrm{cfm}$ unit can accommodate a cooling coll of 1-1/2- to 2-ton capacity, and the $1,200 \mathrm{cfm}$ unit can accommodate a cooling coil of 21/2-to 3-ton capacity.

The EnergyMate system offers a range of water heater capacities from 40 to $62 \mathrm{gal}$, with inputs ranging from 38,000 to $75,500 \mathrm{Btu} / \mathrm{hr}$, respectively. The EnergyMate systems are suitable for single and multifamily dwellings. The EnergyMate water heaters have AGA certification. The air handling units and pump modules have Underwriters Laboratory and Air-conditioning and Refrigeration Institute certification.

\section{Apollo Hydro Feat}

Apollo is probably the best known of the four major manufacturers. They have been In the business since 1979 and claim to have 100,000 units installed in 45 to 50 states. Several years ago, Apollo was acquired by State Industries, which strengthen their position and provided them with a water heater line designed specifically for the 


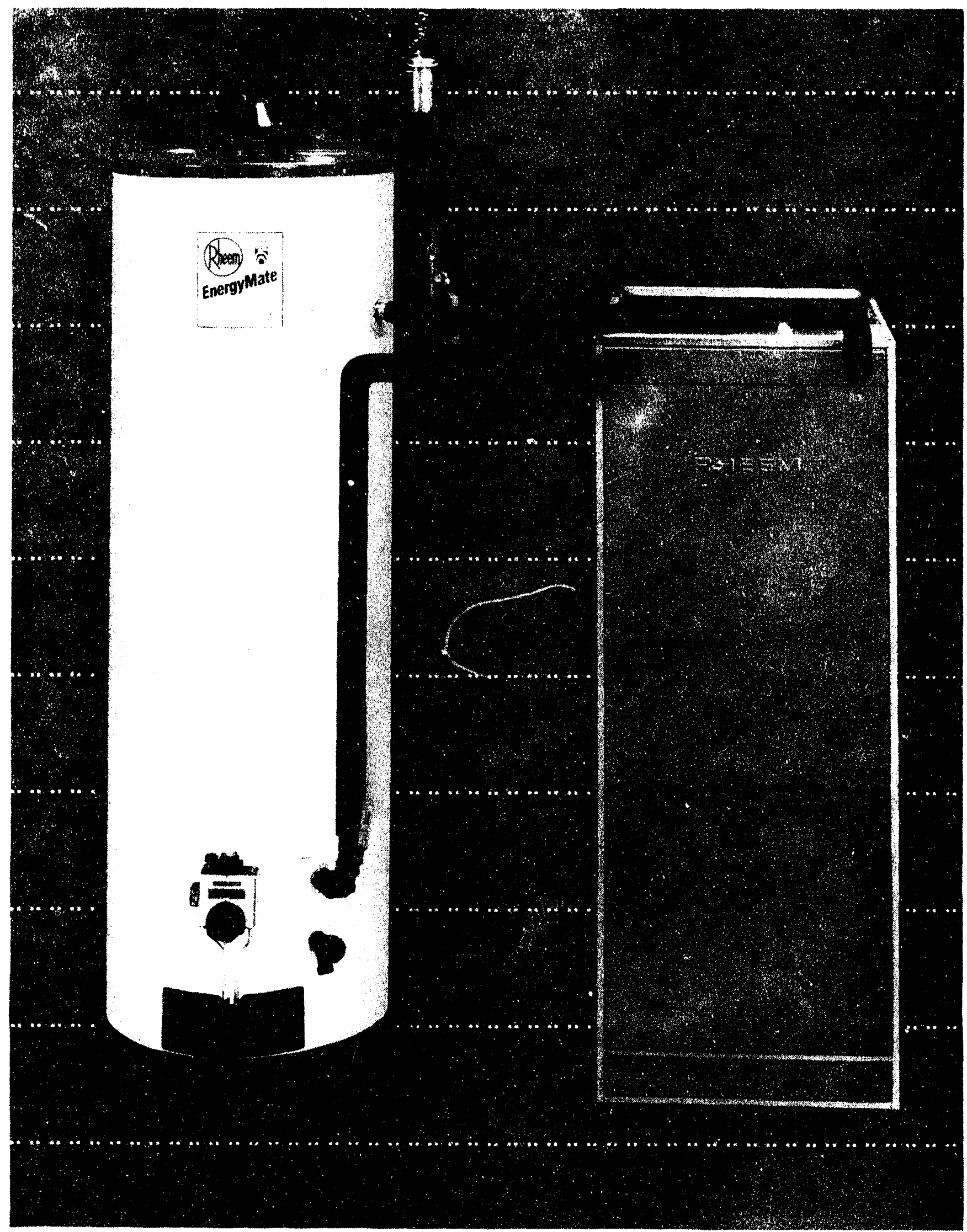

Figure 4-29. Rheem's EnergyMate System 
application. Table 4-10 summarizes the currently avallable water heaters used in their Apollo Hydro Heat system. Appendix F contains manufacturers literature.

They have engineered and packaged the air handler so as to include the pump and controls making for simple installation and single source responsibility. They have secured Underwriters Laboratory and vartous other approvals on the air handler package, including the circulator pump and controls. The water heater carries AGA certification. Figure 4-30 depicts Apollo's Hydro Heat System.

Table 4-10. Summary of State Appliances for Dual Use

State

National No.: 1-800-365-0024, Sonny Ferrel

Apollo Hydro Heat

\begin{tabular}{|c|c|c|c|c|c|}
\hline Input & Storage & SS Eff & EF & Vent & Cost \\
\hline 40.000 & 40 & 76 & $0 . ? ?$ & direct & \\
48,000 & 50 & 76 & $0 . ? ?$ & direct & \\
& & & & \\
40,000 & 40 & 85 & 0.61 & vertical & \\
40.000 & 50 & 85 & 0.58 & vertical & \\
55.000 & 75 & 80 & 0.49 & vertical & \\
40,000 & 40 & 76 & 0.57 & vertical & \\
52.500 & 40 & 76 & 0.54 & vertical & \\
52.500 & 50 & 76 & 0.52 & vertical & \\
65,000 & 50 & 76 & 0.52 & vertical & \\
75,100 & 75 & 76 & 0.48 & vertical & \\
\hline
\end{tabular}

System cost $(40,000,85$ percent $)=\$ 750$ for complete system; $\$ 50$ more for sealed combustion, does not include mixing valve.

They carry a line of air handlers (Hydro Heat) for vertical or horizontal installations with capacities from 16,700 to $41,500 \mathrm{Btu} / \mathrm{hr}$. The unit includes a water pump, twospeed direct drive blower, heating coll (a cooling coll can also be added), and relays.

All state heaters are approved for DIA (dual integrated appliance) use, efficiencles of 75 to 81 percent.

Note: All costs are trade prices as of March 1992. 
Since the earliest days of the Apollo Hydro Heat revolution, beginning in 1979, exceptionally low operating costs have been experienced by users of this combination water heating - space heating system.

This paper will answer many of the most often asked questions about the system.

\section{How does it work?}

Apollo uses a gas water heater to furnish heat to the space of a residence, as well as its domestic hot water. A simple recirculating loop of hot water is tapped off near the top of the heater and is circulated through a finned tube heat exchanger in an air handler or duct coil that furnishes warmed air to the space. The cooled water $\left(140^{\circ}\right.$ cooled to about $\left.120^{\circ}\right)$ is then returned to the water heater, near the bottom of the tank. Each Apollo air handler includes a circulating pump and controls, factory piped and wired. See Figure 1.

The Apollo water heater includes side tappings to provide the recirculating loop connections. When a conventional heater is used, special fittings including check valves are used at the hot and cold water connections.

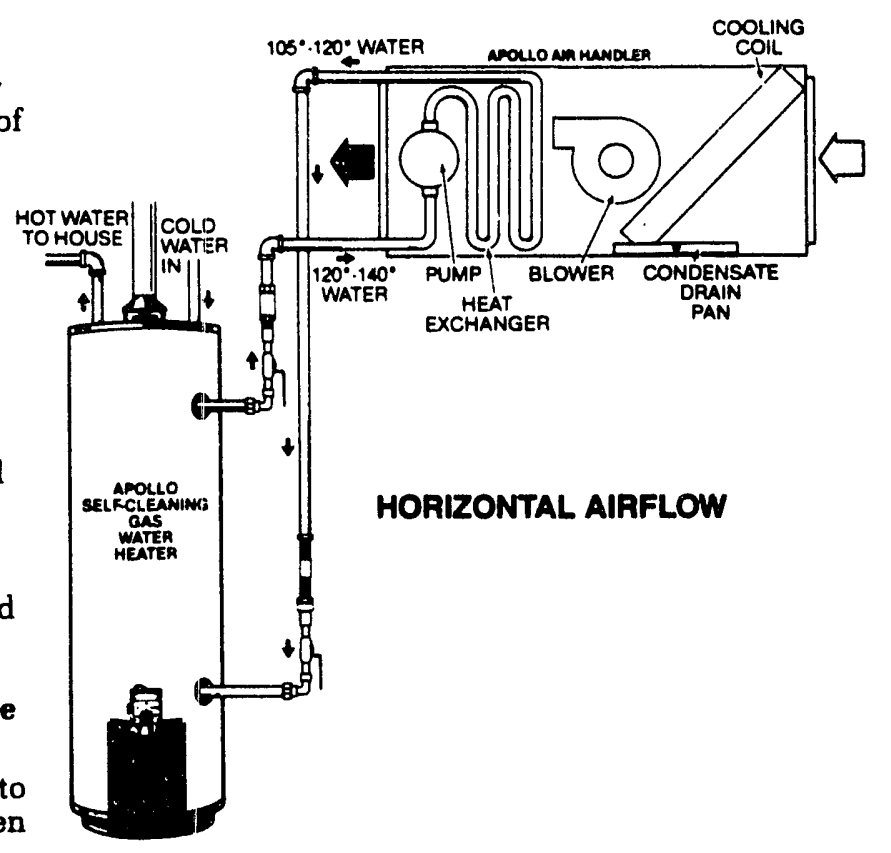

The control of the Apollo system is very simple. A conventional heating or heating/cooling thermostat is used. On a call for heat, the hot water circulator is energized through a relay, as is the blower motor. Hot water immediately begins circulating through the heat exchanger, and heats the air. Typical leaving air temperatures are $100-$ $105^{\circ}$. When the thermostat is satisfied, the pump and blower both stop.
FIG. 1

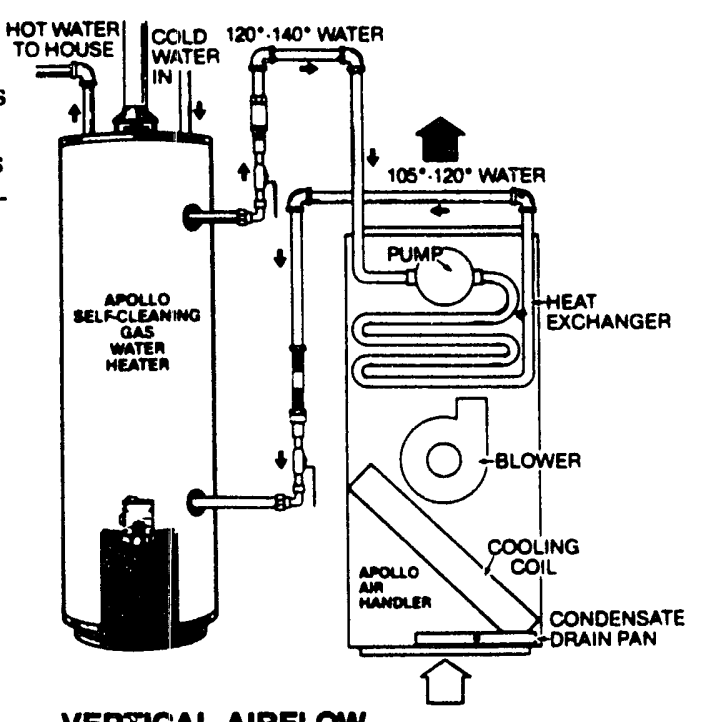

VERTICAL AIRFLOW 
Apollo offers considerable flexibility in sizes and Btu/hr input of their water heaters. In addition, they offer a direct vent model that can be installed with "zero clearance" so it can be placed in small places along outside walls.

\section{First Co. - Aqua Thermaire}

First Co. is relatively new in terms of integrated systems. However, they are a well established manufacturer with over 20 years experience manufacturing air handling units. Up untll 1986 they manufactured air handling units for Apollo under a name brand agreement, and they are manufacturing units for Mor-Flo under a similar agreement today.

First Co. is a substantial manufacturer and they offer considerable flexibility in air handler configurations and options. For integrated systems application, they have designed a flow control module with a pump and valve assembly that is piped and wired for simple field installation. The air handlers and flow control modules are Underwriters Laboratory certified as a system. Appendix F contains manufacturers literature.

First Co. does not manufacture or offer hot water heaters though many of the distributors handle various water heater product lines. Their position on water heaters is to tell the contractors to buy them from their best source and First Co. will provide assistance in putting the package together. Figure 4-31 shows First Co.'s Aqua Therm system.

\section{COMPARISON OF DUAL INTEGRATED STSTEMS}

The four manufacturers of dual integrated systems offer product lines with many similarities and differences. To further investigate these systems, two comparison matrices are provided in Tables 4-11 and 4-12. Table 4-11 compares each system based on its water heater, while Table 4-12 compares each system based on its air handler. Compared to the other four systems, the Mor-Flo Polaris system, has the highest natural gas input of $100,000 \mathrm{Btu} / \mathrm{hr}$ and the highest recovery efficiency of 94 percent. The two Mor-Flo systems (Polaris and Integra) also have power blowers for their combustion and vent systems. 


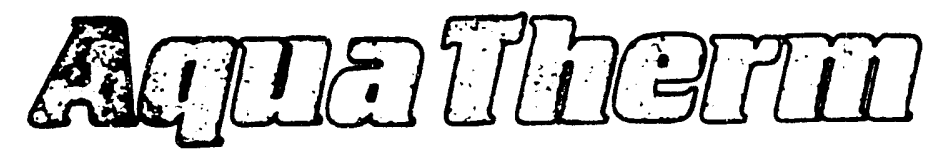

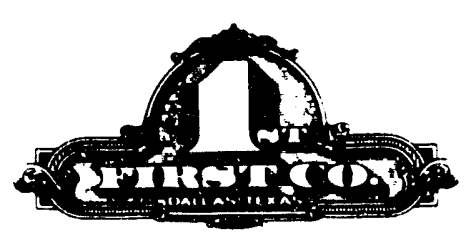

\section{INSTALLATION AND APPLICATION MANUAL FOR}

Hot WATER AIR HANDLERS

AND

ADD $O$ ON COILS

Catalog No. LAM591 (Replaces IAM990)

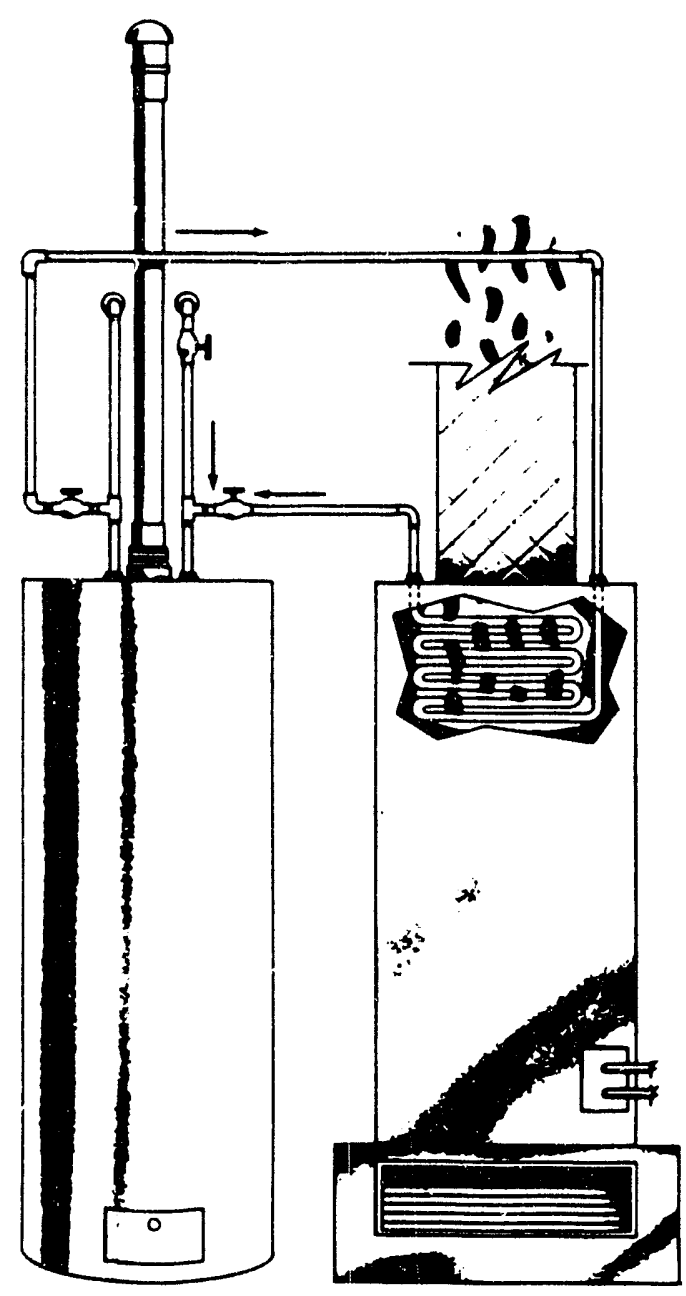

FIRS: CO. - 8273 MOBERLY LANE - DALLAS, TEXAS USA 75227-2388 - (214) 388-5751

Figure 4-31. First Co.'s Aqua Therm System 
Table 4-11. Water Heater Matrix for Dual Integrated Systems

\begin{tabular}{|c|c|c|c|c|c|}
\hline & $\begin{array}{c}\text { Mor-Flo/ } \\
\text { Polaris }\end{array}$ & $\begin{array}{c}\text { Mor-Flo/ } \\
\text { Integra }\end{array}$ & $\begin{array}{c}\text { Rheem/ } \\
\text { EnergyMate }\end{array}$ & $\begin{array}{c}\text { Apollo/ } \\
\text { Hydro Heat }\end{array}$ & $\begin{array}{l}\text { First Co./ } \\
\text { Aqua } \\
\text { Thermaire } \\
\end{array}$ \\
\hline Sizes (gal) & 34 & 40 & $40,50,62$ & $40,50,75$ & Do not \\
\hline $\begin{array}{l}\text { Input } \\
\text { Btu/hr }\end{array}$ & 100,000 & 40,000 & $\begin{array}{l}38,000 \\
75,500\end{array}$ & $\begin{array}{l}40,000- \\
75,000\end{array}$ & $\begin{array}{l}\text { line of water } \\
\text { heater units. } \\
\text { Approve } \\
\text { installation } \\
\text { with various } \\
\text { water heaters }\end{array}$ \\
\hline $\begin{array}{l}\text { Recovery } \\
\text { Efficiency }\end{array}$ & $94 \%$ & $83 \%$ & $76-85 \%$ & $75-85 \%$ & \\
\hline Tank & Stainless & $\begin{array}{l}\text { Re- } \\
\text { nitrogenized } \\
\text { steel }\end{array}$ & & $\begin{array}{l}\text { Steel, glass- } \\
\text { lined }\end{array}$ & \\
\hline $\begin{array}{l}\text { Tank } \\
\text { Insulation }\end{array}$ & Foam $R=16$ & $\begin{array}{l}\text { Polyurethan } \\
\text { e } R=8.33\end{array}$ & $\begin{array}{l}\text { Foam } R=9.4 \\
11.5 \\
R=6.3 \text { (direct } \\
\text { vent) }\end{array}$ & $\begin{array}{l}\text { Polyurethan } \\
\text { e } R=8.33\end{array}$ & \\
\hline Burner & $\begin{array}{l}\text { Stainless } \\
\text { Steel }\end{array}$ & Steel & $\begin{array}{l}\text { Glass-lined } \\
\text { steel }\end{array}$ & $\begin{array}{l}\text { Aluminized } \\
\text { steel }\end{array}$ & \\
\hline Ignition & $\begin{array}{l}\text { Electric, hot } \\
\text { surface }\end{array}$ & $\begin{array}{l}\text { Electric, hot } \\
\text { surface }\end{array}$ & $\begin{array}{l}\text { Standing } \\
\text { pllot }\end{array}$ & $\begin{array}{l}\text { Standing } \\
\text { pllot }\end{array}$ & \\
\hline Vent System & $\begin{array}{l}\text { Power } \\
\text { blower }\end{array}$ & $\begin{array}{l}\text { Power } \\
\text { blower }\end{array}$ & $\begin{array}{l}\text { Atmospheric } \\
\text {; vertical or } \\
\text { direct vent }\end{array}$ & $\begin{array}{l}\text { Atmospheric } \\
\text {; vertical or } \\
\text { direct vent }\end{array}$ & \\
\hline $\begin{array}{l}\text { Cathodic } \\
\text { Protection }\end{array}$ & Not required & $\begin{array}{l}\text { Powered } \\
\text { anode }\end{array}$ & Anode & Anode & \\
\hline Controls & $\begin{array}{l}\text { Thermostat } \\
\text { (electronic), } \\
\text { T\&P relief }\end{array}$ & $\begin{array}{l}\text { Thermostat } \\
\text { (electronic), } \\
\text { T\&P relief }\end{array}$ & $\begin{array}{l}\text { Thermostat, } \\
\text { T\&P relief }\end{array}$ & $\begin{array}{l}\text { Thermostat, } \\
\text { energy cutoff } \\
\text { ECO, T\&P } \\
\text { relief }\end{array}$ & \\
\hline Accessories & $\begin{array}{l}\text { LED } \\
\text { indicators }\end{array}$ & $\begin{array}{l}\text { LED } \\
\text { indicators }\end{array}$ & $\begin{array}{l}\text { Check } \\
\text { valves, ball } \\
\text { type service } \\
\text { valves and } \\
\text { di-electric } \\
\text { unions }\end{array}$ & $\begin{array}{l}\text { Check } \\
\text { valves, ball } \\
\text { type service } \\
\text { valves and } \\
\text { di-electric } \\
\text { unions }\end{array}$ & \\
\hline Warranty & $\begin{array}{l}\text { 10-year tank } \\
1 \text {-year parts }\end{array}$ & $\begin{array}{l}5 \text {-year tank } \\
1 \text {-year parts }\end{array}$ & $\begin{array}{l}\text { 5-year, tank } \\
\text { or parts }\end{array}$ & $\begin{array}{l}\text { 5-year, tank } \\
\text { or parts }\end{array}$ & \\
\hline $\begin{array}{l}\text { Code } \\
\text { Approvals }\end{array}$ & AGA certified & AGA certified & AGA certified & AGA certified & \\
\hline
\end{tabular}


Table 4-12. Air Handler Matrix for Dual Integrated Systems

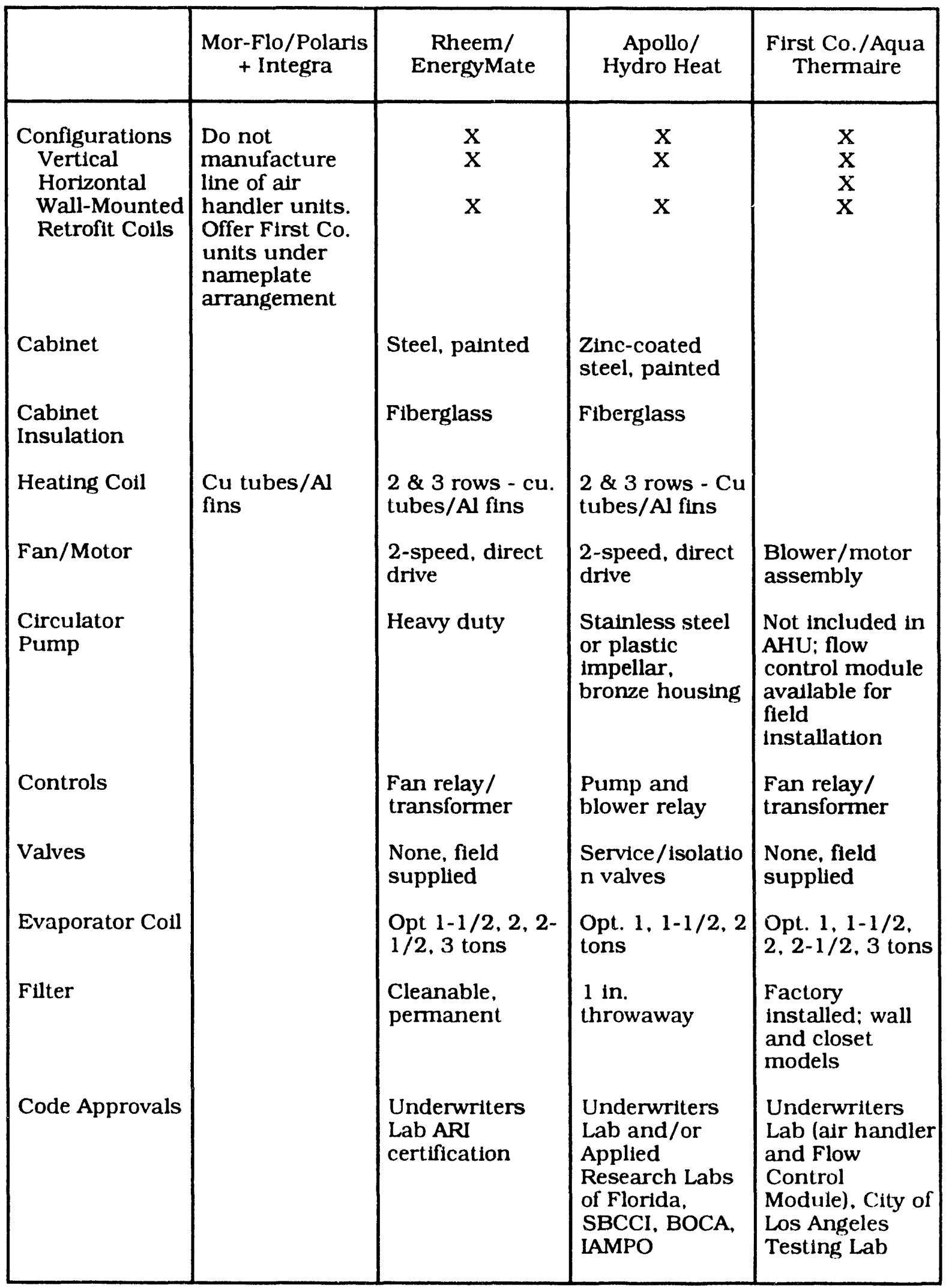


Both Rheem and Apollo offer a range of natural gas in 1 its from approximately 40,000 to $75,000 \mathrm{Btu} / \mathrm{hr}$ and recovery efficiencies of 75 to 85 percent. Warranties on the water heater tanks range from 5 years for four of the systems to 10 years for the Polaris water heater tank. All water heaters are AGA design certifled.

Air handlers are typically designed for three configurations: vertical, horizontal, and wall-mounted. Another important feature of air handlers is to provide for retrofitting of heating and/or cooling colls. The Rheem and Apollo atr handler lines do not Include a wall mounted unit. Otherwise, all other configurations are provided by the three manufacturers (Mor-Flo does not offer a line of air handlers). All of the air handler manufacturers offer an optional evaporator coll from 1- to 3-ton capacity for cooling applications. The Apollo unit also includes service and isolation valves. All of the other units require valves to be field installed. As a minimum, all of the air handlers are certified by Underwriters Laboratory.

A comparison of application types is presented in Table 4-13. The Polaris system has the highest space heating capacity, up to $80,000 \mathrm{Btu} / \mathrm{hr}$. It can also accommodate a hot water and a warm air distribution system. Finally, it offers unlimited water heating capacity. However, for most multifamily applications where the heating and cooling loads are much smaller than single-family homes, the other systems are probably more suitable.

Cost is always a major factor that the bullder or home owner must constder when choosing a water and/or space heating system. As presented in Table 4-14, the estimated installed cost for the five dual integrated systems range from a low of $\$ 905$ for the First Co.'s Aqua Therm system to $\$ 2,400$ for Mor-Flo's Polaris system. However, excluding the Polaris system, the range of installed costs is $\$ 905$ to $\$ 1,425$, a differential of $\$ 520$. Before a decision is reached on which system to choose, a lifecycle cost to operate and maintain each system should be factored into the total cost analysis.

\section{BENEFITS OF DUAL INTEGRATED 8T8TEMS}

Dual integrated systems offer several benefits to builders, home owners, and gas utilities over conventional separate water and space heating systems: 
Table 4-13. Types of Applications for Dual Integrated Systems

\begin{tabular}{|c|c|c|c|c|c|}
\hline & \multicolumn{2}{|c|}{ Mor-Flo } & \multirow[b]{2}{*}{ Rheem } & \multirow[b]{2}{*}{ Apollo } & \multirow[b]{2}{*}{ First Co. } \\
\hline & Polaris & Integra & & & \\
\hline $\begin{array}{l}\text { Space } \\
\text { Heating } \\
\text { Capacity } \\
\text { (Heat Loss) }\end{array}$ & $\begin{array}{l}\text { To } 80 \\
\text { MBtu/hr }\end{array}$ & $\begin{array}{l}25-29 \\
\text { MBtu/hr }\end{array}$ & $\begin{array}{l}38-75 \\
\text { MBtu/hr }\end{array}$ & $\begin{array}{l}30-75 \\
\text { MBtu/hr }\end{array}$ & $\begin{array}{l}30-75 \\
\text { MBtu/hr }\end{array}$ \\
\hline $\begin{array}{l}\text { Water } \\
\text { Heat.ing } \\
\text { Capacity }\end{array}$ & Unlimited & $\begin{array}{l}\text { Typical } \\
\text { demand of } \\
\text { large family }\end{array}$ & $\begin{array}{l}\text { Typical } \\
\text { demand of } \\
\text { large family }\end{array}$ & $\begin{array}{l}\text { Typical } \\
\text { demand of } \\
\text { large family }\end{array}$ & $\begin{array}{l}\text { Typical } \\
\text { demand of } \\
\text { large family }\end{array}$ \\
\hline $\begin{array}{l}\text { Cooling } \\
\text { Capacity }\end{array}$ & To 3 tons & To 2 tons & To 3 tons & To 2 tons & To 3 tons \\
\hline Vent Type & & & & & \\
\hline $\begin{array}{l}\text { Direct: air } \\
\text { in; flue } \\
\text { products out }\end{array}$ & $\mathrm{X}$ & $\mathbf{x}$ & $\mathbf{X}$ & $\mathbf{X}$ & \\
\hline $\begin{array}{l}\text { Thru-the- } \\
\text { wall flue } \\
\text { product } \\
\text { exhaust }\end{array}$ & & & & $\mathrm{X}$ & $\mathrm{X}$ \\
\hline Conventional & & & $\mathrm{X}$ & $\mathrm{x}$ & $\mathrm{X}$ \\
\hline $\begin{array}{l}\text { Space Heat } \\
\text { Distribution } \\
\text { Options }\end{array}$ & $\begin{array}{l}\text { Warm air } \\
\text { Hot water }\end{array}$ & Warm air & Warm air & Warm air & Warm air \\
\hline \multicolumn{6}{|c|}{$\begin{array}{l}\text { Note: Any one of the systems can be specified for a particular application; however, } \\
\text { direct vent systems are more easily applied to multifamily settings. Installation space } \\
\text { requirements for these systems usually depend upon the way in which the fan-coil } \\
\text { unit is installed (ceiling-, wall- or floor-mounted); however, floor mounting requires an } \\
\text { area of about } 36 \mathrm{ft}^{2} \text {. }\end{array}$} \\
\hline
\end{tabular}

- Additional heating alternatives to conventional gas furnace/hot water heater combination

- Conversion opportunities on heat pump, electric heat, or oll fired systems

- Opportunity to secure summer hot water load in addition to heating only

- Lower first cost of heating/hot water/cooling system compared to electric heat pump/electric water heater combination 
Table 4-14. Installed Costs for Dual Integrated Systems

\begin{tabular}{|c|c|c|c|c|c|}
\hline & \multicolumn{2}{|c|}{ Mor-Flo } & \multirow[b]{2}{*}{ Rheem } & \multirow[b]{2}{*}{ Apollo } & \multirow[b]{2}{*}{ First Co. } \\
\hline & Polaris & Integra & & & \\
\hline Equipment & $\$ 1,800$ & $\$ 950$ & $\begin{array}{l}\$ 490(\mathrm{AHU}) \\
\$ 310(\mathrm{WH})\end{array}$ & $\$ 750$ & $\begin{array}{l}\$ 378(\mathrm{AHU}) \\
\$ 225(\mathrm{WH})\end{array}$ \\
\hline Labor at $50 \%$ & $\$ 600$ & $\$ 475$ & $\$ 400$ & $\$ 375$ & $\$ 302$ \\
\hline Total & $\$ 2,400$ & $\$ 1,425$ & $\$ 1.200$ & $\$ 1,125$ & $\$ 905$ \\
\hline \multicolumn{6}{|l|}{ Notes: } \\
\hline \multicolumn{6}{|c|}{$\begin{array}{l}\text { Typical installed cost. for floor-mounted systems in } 30 \text { to } 40 \mathrm{MBt} \text { / hr heating capacity } \\
\text { range except for the Mor-Flo/Polaris which is } 100.000 \mathrm{MBtu} / \mathrm{hr} \text { as of March } 1992 \text {. }\end{array}$} \\
\hline \multicolumn{6}{|c|}{$\begin{array}{l}\text { Approximate cost based on 2-1/2-ton sir handler. } 40 \text {-gal water heater. Does not } \\
\text { include } \mathrm{A} / \mathrm{C} \text {. }\end{array}$} \\
\hline \multicolumn{6}{|c|}{$\begin{array}{l}\text { Installation costs vary for each installation. Costs shown are expected to be accurate } \\
\text { within plus or minus } 10 \text { percent. }\end{array}$} \\
\hline
\end{tabular}

- Improved overall efficiency of the water heater; lower standby, flue , and other miscellaneous losses

- An efficient heating system that can be purchased for less than gas furnace/ water heater combination of comparable efficiency.

\section{APPLIANCE VENTING}

Venting systems have not changed significantly since the 1950s. What has changed, which has had a dramatic affect on venting methods, is appliance design. The products of combustion for the new classes of appliances, mid-efiliciency with AFUE = 78 to 83 percent and high-efficiency with AFUE greater than 90 percent have required that a new set of standards be developed for safe venting. To complicate matters further, many of these new appliances have fan-assisted combustion systems. The following is an overview of recent changes affecting vent sizing requirements, materials selection, and combined vent systems. Appendix $\mathrm{G}$ contains additional detalled information concerning the establishment of appliance categories, development of new vent sizing tables. cornmon venting, and multistory vents. 
Conventional venting systems include a dralt hood or diverter and an atmospheric burner. The buoyant force of the hot gas is enough to drive it from the combustion chamber, up the vent pipe and oul to the almosphere. The draft hood. anong other things, allows additional indoor air to mix with the combustion products. This is called dilution. Diluled air lowers the dew point of the mixture by reducing the humidity, which also helps reduce condensation. There is a price to pay for adding indoor heated air to the combustion products. The overall efficiency of the appliance is lowered because some of the indoor air healed by the appliance goes out the vent.

During the energy crisis of the 1970s. consumers demanded more eflicient appliances. To reduce off-cycle appliance losses, fan-assisted combustion systems were developed. Fan-assisted systems reduce dilution air in the vent. Unlortunately, this causes the humidity and gas dew point to rise. Also, there is less flow in the vent. With a higher dew point temperature and less gas to warm the sidewalls of the vent. the potential for condensation increases. This is true for mid-efficiency and high-efficiency appliances. which are also referred to as near-condensing and full-condensing units, respectively.

Therefore, the development of a variety of more efficient appliances increased the need for different venting requirements. Four venting categories have been established by an ANSI standards committee are shown in Figure 4-32. Basically, the categories account for differences between:

- Positive and negative pressure vent systems

- Actual and dew point temperatures of the flue gas

Each appliance category with acceptable vent material can be characterized as follows:

- Category I: Non-condensing

- Negative pressure

- AFUE: 65 to 83 percent

- Typical materials Type B vent Single-wall metal Lined masonry chimney 


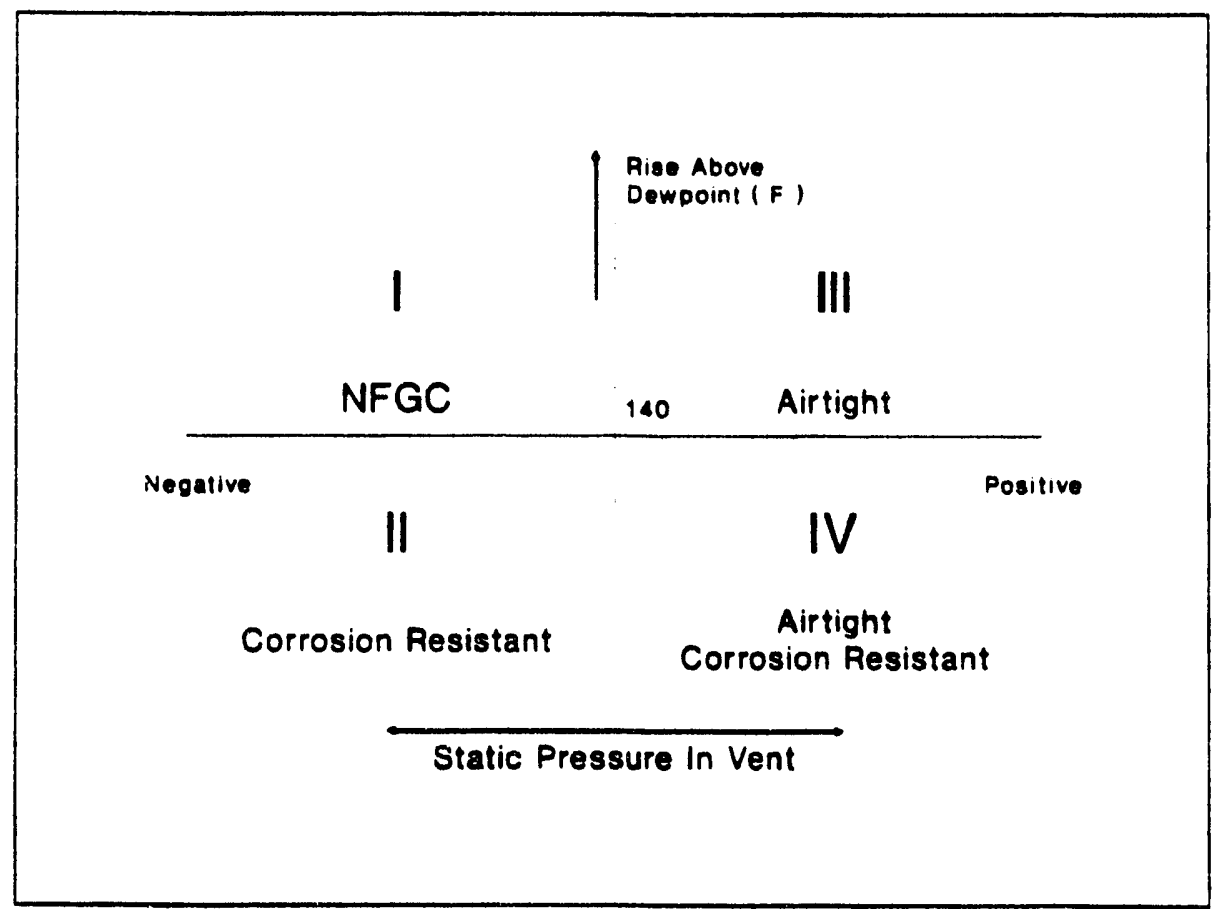

Figure 4-32. ANSI Categorization Criteria per ANSI 2223.1-1988

- Category II: Condensing

- Negative pressure

- Category III: Non-condensing

- Positive pressure

- AFUE: 78 to 83 percent

- Typical materials

Airtight high temperature plastic

Airtight single-wall metal

- Category IV: Condensing

- Positive pressure

- AFUE: 90 percent and higher

- Typical materials

Airtight high temperature plastic

Airtight PVC

Aurtight CPVC.

The NFGC provides guidelines for vent sizing of Category I appliances. However, these tables are in the process of being revised based on a worst-case design assumption. 
which is a steady-state appliance efficiency of 83 percent (AFUE). This category includes conventional draft-hood and most mid-efficiency, ? चn-assisted appliances. The new tables have been incorporated in the 1992 edition of the NFGC. Presently, appliances in Categories II, III, and IV are only vented according to the manufacturers installation instructions. Category II and IV appliances require vents with corrosion resistance and a method of condensate disposal. There are not very many, if any, Category II appliances.

The new tables can be used to size combined vent systems. These are very common systems that usually include a separate water heater and boller/furnace. Each individual vent connector has to be sized separately for each appliance. The common vent portion of the system is sized using a separate table. On a combination space and water heating system there is only one vent pipe to size and install, which is an economic advantage over the separate appliance system.

Multistory vents are necessary for multifamily buildings where appliances on each floor are connected via a common vertical pipe system. For rehabilitated multifamily buildings, the question is whether fan-assisted appliances can be retrofitted to replace draft-hood equipped appliances originally installed with larger vent systems. For example, the original vent system may have been sized for a $60,000 \mathrm{Btu} / \mathrm{hr}$ furnace. The replacement unit is apt to be a 40,000 to $45,000 \mathrm{Btu} / \mathrm{hr}$ mid-efficiency furnace. The smaller unit has less products of combustion. Thus, the vent system will experience a lower flow rate than with the original larger furnace.

The American Gas Association Laboratories is conducting a full-scale experiment to assess this issue. Some preliminary conclusions from that study are:

- The large amount of dilution air entrained by this vent system provides a good buffer against excessive condensation

- The worst-case failure modes applied equally to the draft hood-equipped appliances and were not caused by the retrofit operation.

Overall preliminary conclusions from that study have indicated that retrofitting fanassisted appliances into a multistory vent does not add to the risk for vent system failure. 
Combination space and water heating systems require a Category I vent because only the water heater portion of the system produces combustion products. The water heaters have efficiencies ranging from 76 to 83 percent, operate in the non-condensing range and vent under negative pressure. Therefore, no special materials or installation practices are required for the vent systems of combination space and water heating systems.

\section{CONSTRUCTION PRACTICES}

This section illustrates schematic details for routing flexible gas tubing in new and renovated installations. These details were developed by SWA using their in-house expertise in design and construction of multifamily projects. Research material from Foster-Miller and trade literature from the manufacturers of flexible gas tubing products were used as reference material.

These detalls suggest recommended practices for generic applications of various types of construction assemblies. The following pages illustrate schematic concepts for routing flexible gas tubing through the exterior walls, interior partitions, floors, and roofs. While these details take into account the safety of tubing material during construction, buildings codes related to the use, and installation of flexible tubing are not addressed. These detalls suggest the most appropriate way to run flexible tubing without going into the specific design of how and where valves, connections, clips, and other accessories will be required.

\section{INSTALLATION ASSUMPTIONS AND LIMITATIONS}

Several concerns and limitations described by the manufacturers of flexible gas tubing served as guidelines in the development of these concepts. Some of these are listed below:

- The flexible tubing shall be installed within the bullding structure and downstream of the gas metering unit.

- All connections between incoming rigid steel pipe and flexible tubing shall be made within the building structure.

- The vertical riser is assumed to be rigid steel pipe for all multifamily structures. This riser is run vertically through a chase inside the structure.

- All flexible tubing joints shall be installed in accessible locations. 
- The tubing shall never be directly embedded inside concrete walls, floors, or roofs or buried underground. When it is necessary to run through concrete, it shall be routed through rigid conduits.

- The piping material can receive significant damage as a result of impact, crushing or other abuse, and should be handled and installed according to the manufacturer's instructions. Sharp bends, stretching, kinking, or twisting of material should be avoided.

- Manufacturers' recommendations for maximum pressure requirement, bending, drilling, and notching of holes through structural members for tubing and support system shall be observed.

- The location of protection devices, branching, regulators, manifolds, and appliance connections shall be as required by the design and layout of gas lines.

- The flexible gas lines shall not be allowed to hang freely inside the structure. They should be appropriately attached to the building components.

- If the flexible tubing line creates a conflict of safety (electrical conducts) or limitations of space (close to ducts in cellings), the piping layout shall be rerouted.

- Damaged tubing sections shall be replaced with new tubing.

\section{Limitations}

The building codes for this technology are still not developed. Hence, these illustrations are developed without considering building codes restrictions. Within the scope of this project, it was impossible to anticipate and document every possible variation in construction assemblies and installation restrictions. However, an attempt has been made to recommend standard practice for all generic types of construction assemblies and installation. 


\section{LIST OF DRAWINGS}

Figure 4-33. Gas Pipe Penetration through Exterior Wall of Wood Studs and Siding

Figure 4-34. Flexible Tubing Run through Wood Frame Construction

Figure 4-35. Flexible Tubing Run through Wood Trusses at Attic Floor

Figure 4-36. Flexible Tubing Run through Wood Truss Floors

Figure 4-37. Gas Pipe Penetration through Exterior Wall of Brick Veneer on Metal Studs

Figure 4-38. Flextble Tubing Run through Stud Partition Wall

Figure 4-39. Flexible Tubing Run through Steel Stud Partition

Figure 4-40. Gas Pipe Penetration through Brick and Block Cavity Wall

Figure 4-41. Multiple Gas Lines Penetrating through Fire Wall

Figure 4-42. Gas Riser and Tubing Runs through Concrete Slab

Figure 4-43. Gas Line Penetration through Poured Concrete Slab at Roof

Figure 4-44. Gas Pipe Penetration through Hollow Core Concrete Slab at Roof

Figure 4-45. Gas Pipe Penetration Detail through Hollow Core Concrete Roof Slab

Figure 4-46. Flexdble Tubing Run through Concrete Roof Slab and Steel Joist Framing

Figure 4-47. Gas Pipe Penetration through Roof with Hung Ceiling

\section{SUMMARY}

A technology survey was conducted by Foster-Miller to identify emerging gas technologies that are considered innovative relative to conventional approaches in use today. Areas of investigation included metering, gas piping, space and water heating systems, and appliance venting. A second survey was conducted by SWA to identify installation methods for gas piping located in chaseways, fire protected areas, and other affected areas of rehabilitated and newly constructed multifamily buildings. The results of the SWA survey were documented by the development of 15 construction drawings showing detalls of flexible tubing and rigid piping installation techniques needed to implement this recently developed technology. 


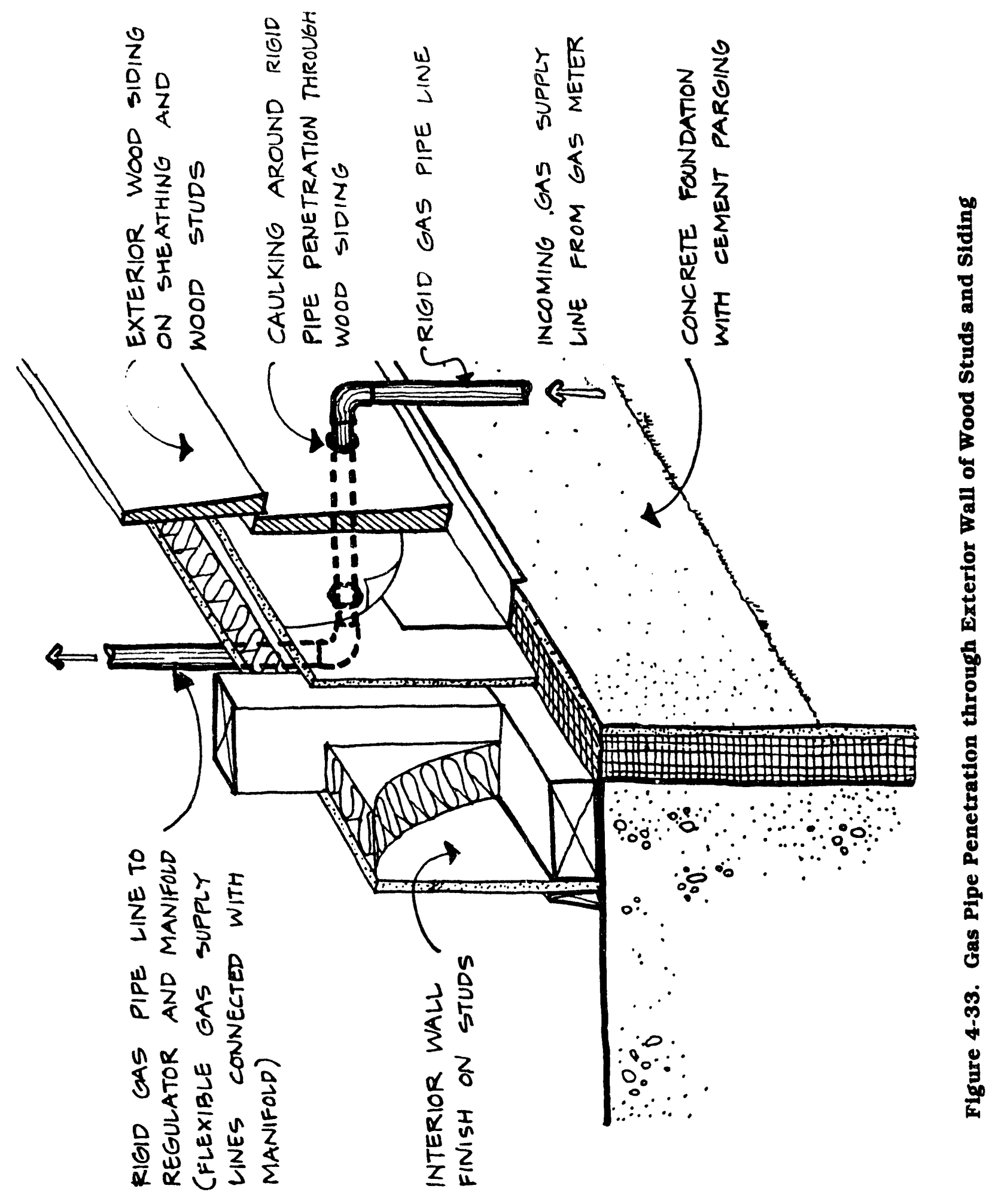




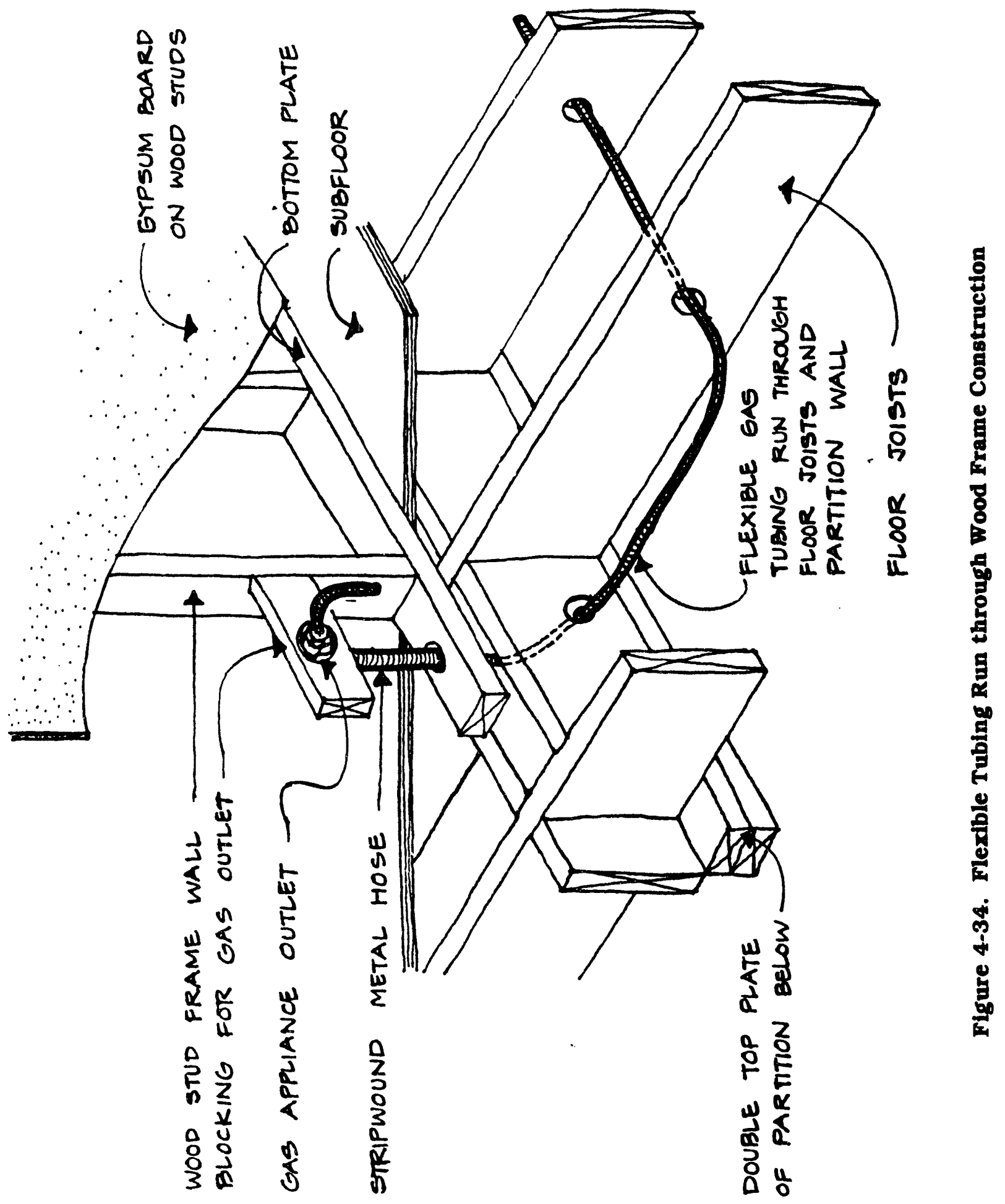




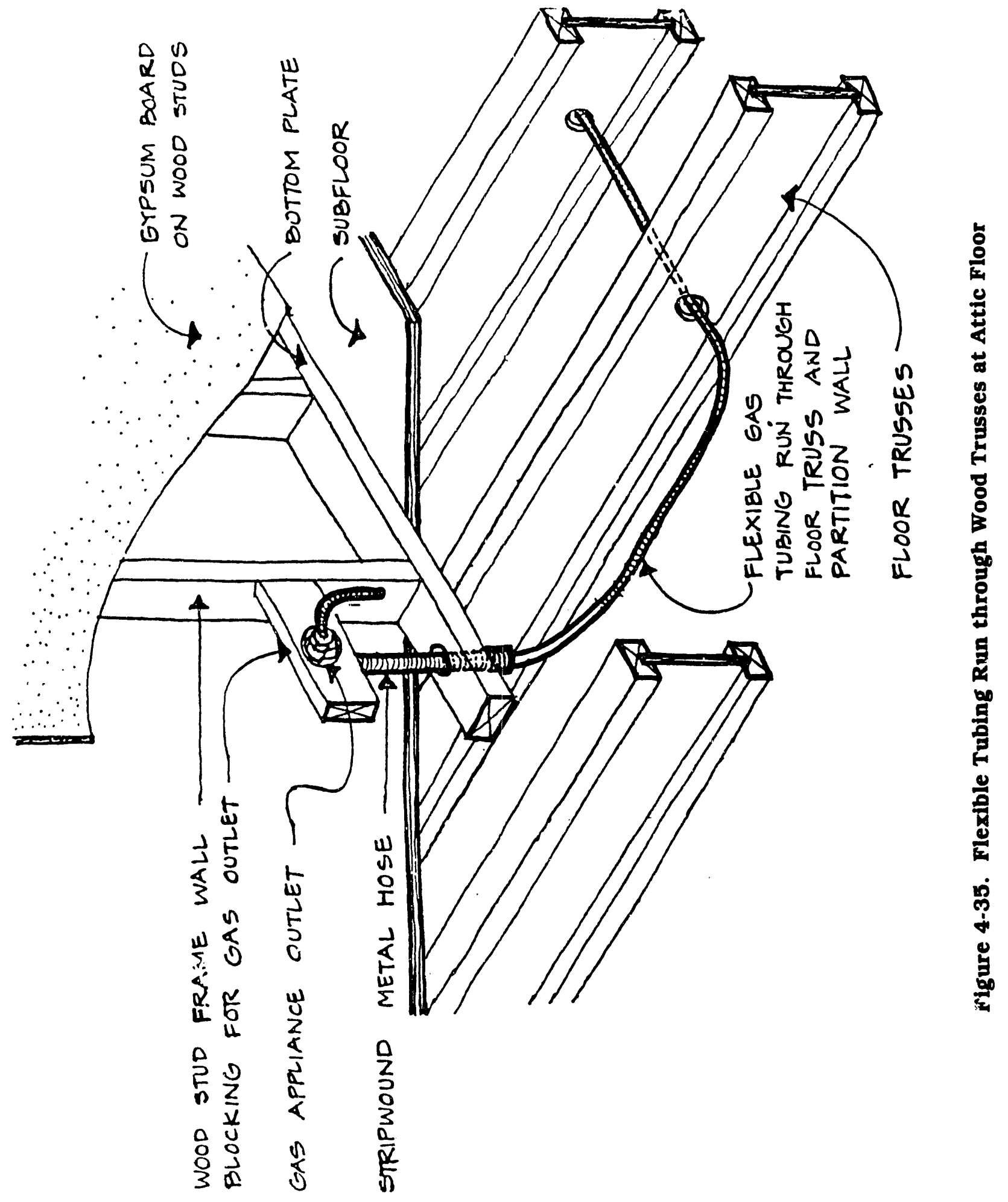




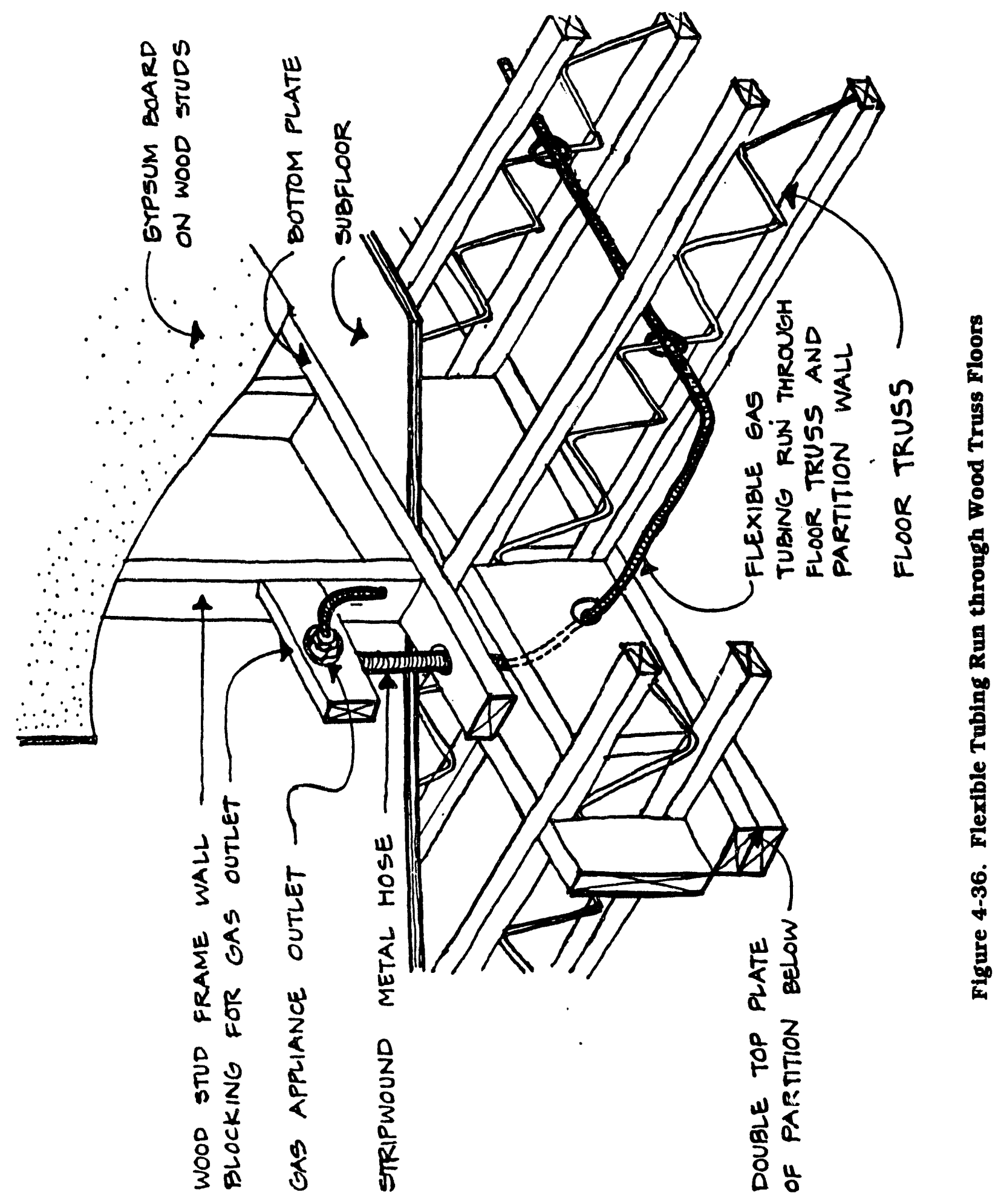




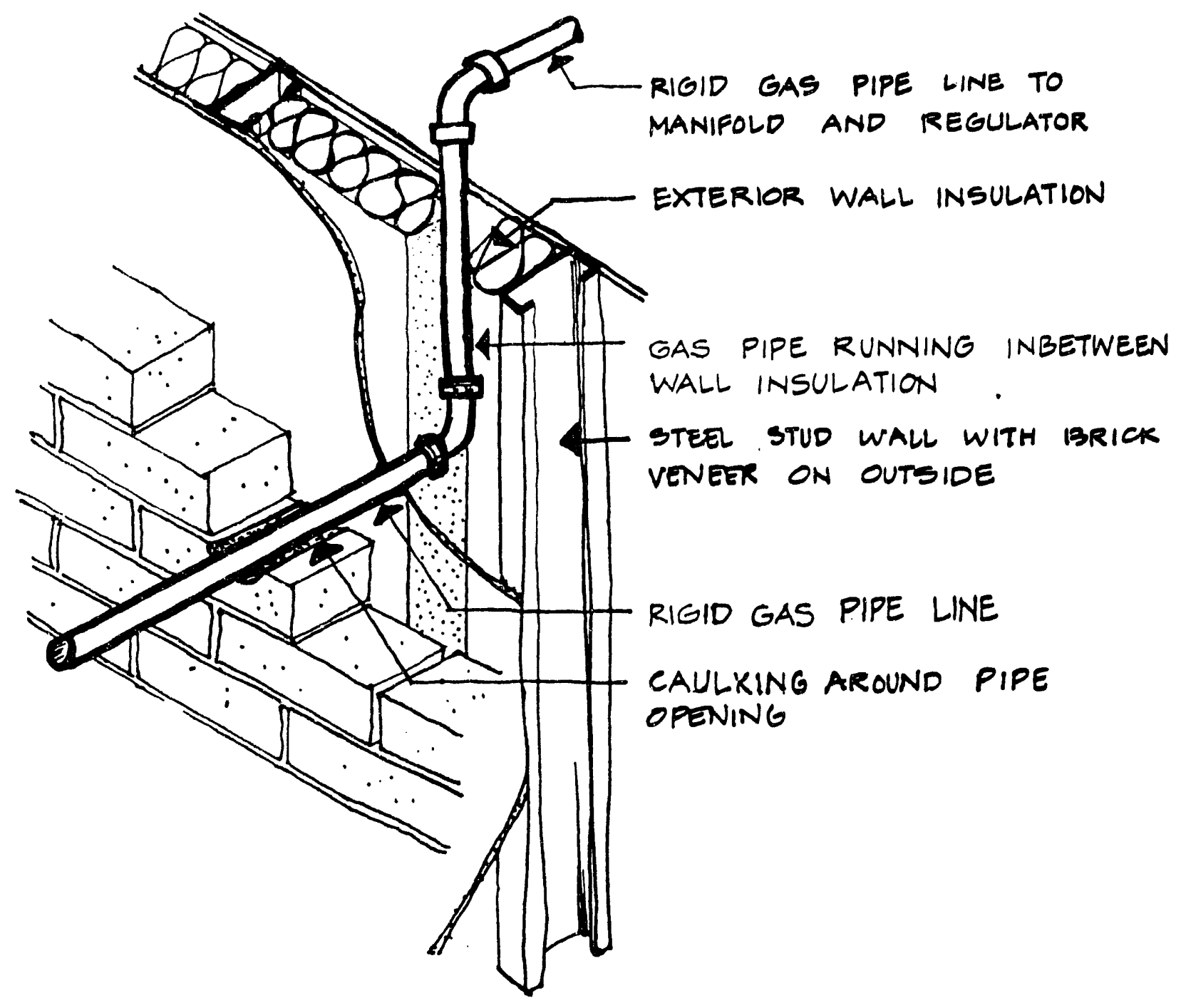

Figure 4-37. Gas Pipe Penetration through Exterior Wall of Brick Veneer on Metal Studs

\section{CONCLUSIONS}

A number of specific conclusions have been drawn from conducting the two surveys:

- There are commercially available, small residential meters that could be used effectively for multifamily new and rehabilitated construction projects in the State of New York. These downsized meters, which are $\mathbf{4 0}$ percent smaller than existing meters of the same flow capacity, can save valuable space in submetering closets. Several compact gas meters are under development, but are not commercially avallable and still a few years away.

- Automatic meter reading (AMR) systems can be adapted to conventional, small and compact meters. AMR systems promise to solve several utility problems, which include: inaccessible meters. estimated billings, injuries to utility field 


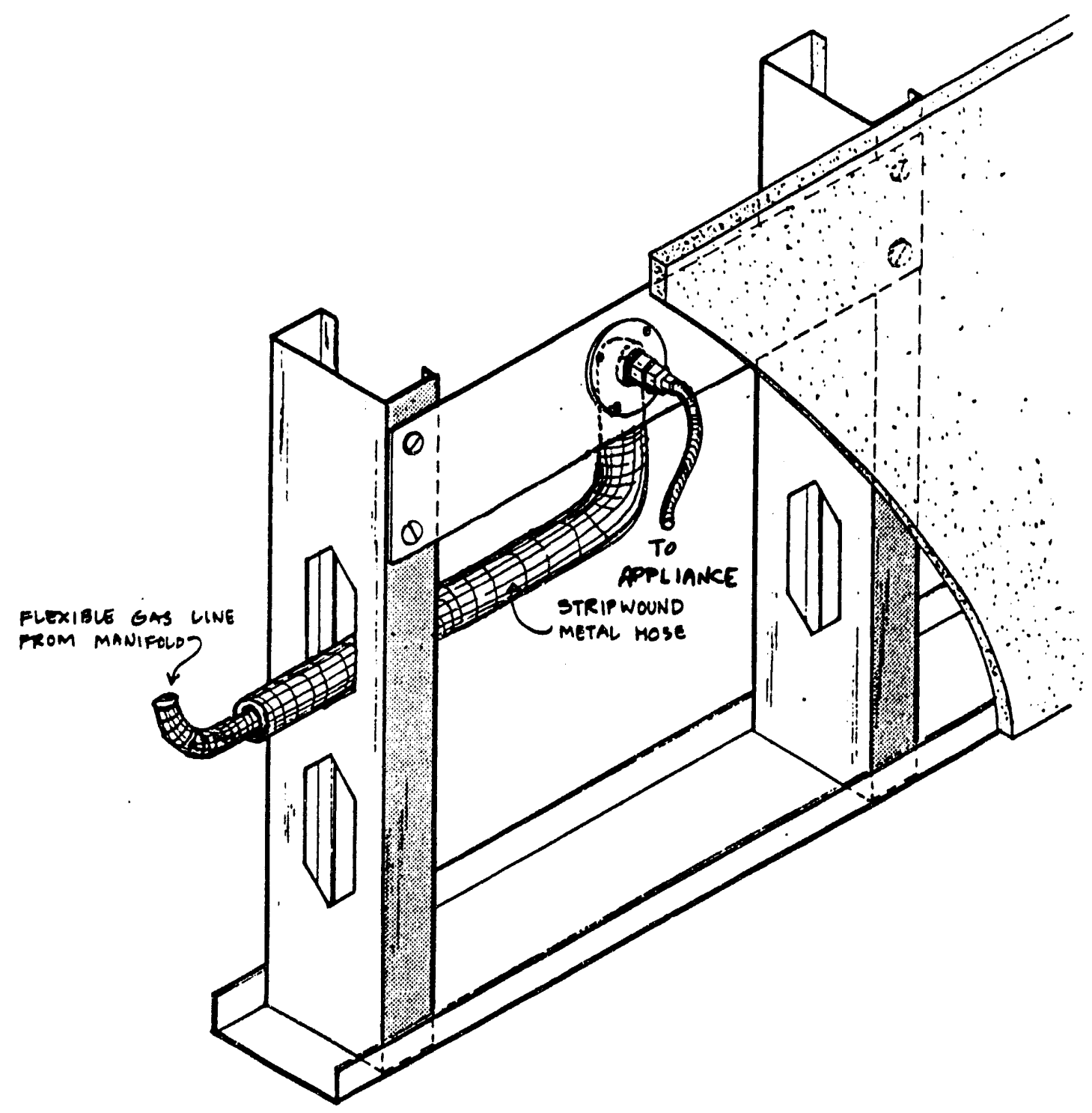

Figure 4-38. Flexible Tubing Run through stud Partition Wall

personnel, customer property damage, customer complaints, and security concerns. Although these systems are very popular on the gas utilities distribution systems, they have been slow to find their way to the multifamily market.

- A combination of rigid steel pipe (vertical riser) and/or semirigid tubing (CSST or copper tubing) operated at elevated pressure (up to $5 \mathrm{psi}$ ) offer the most advanced technologies that will result in the lowest total installed costs for multifamily new and rehabllitated bulldings.

- Although not code-approved for use in New York State, composite tubing comprised of polymer and metallic layers potentially offers lower total installation costs compared to CSST and steel pipe systems. Unlike copper tubing, which is also a low installation cost alternative to CSST and steel pipe, composite tubing has excellent resistance to long-term corrosion effects. 

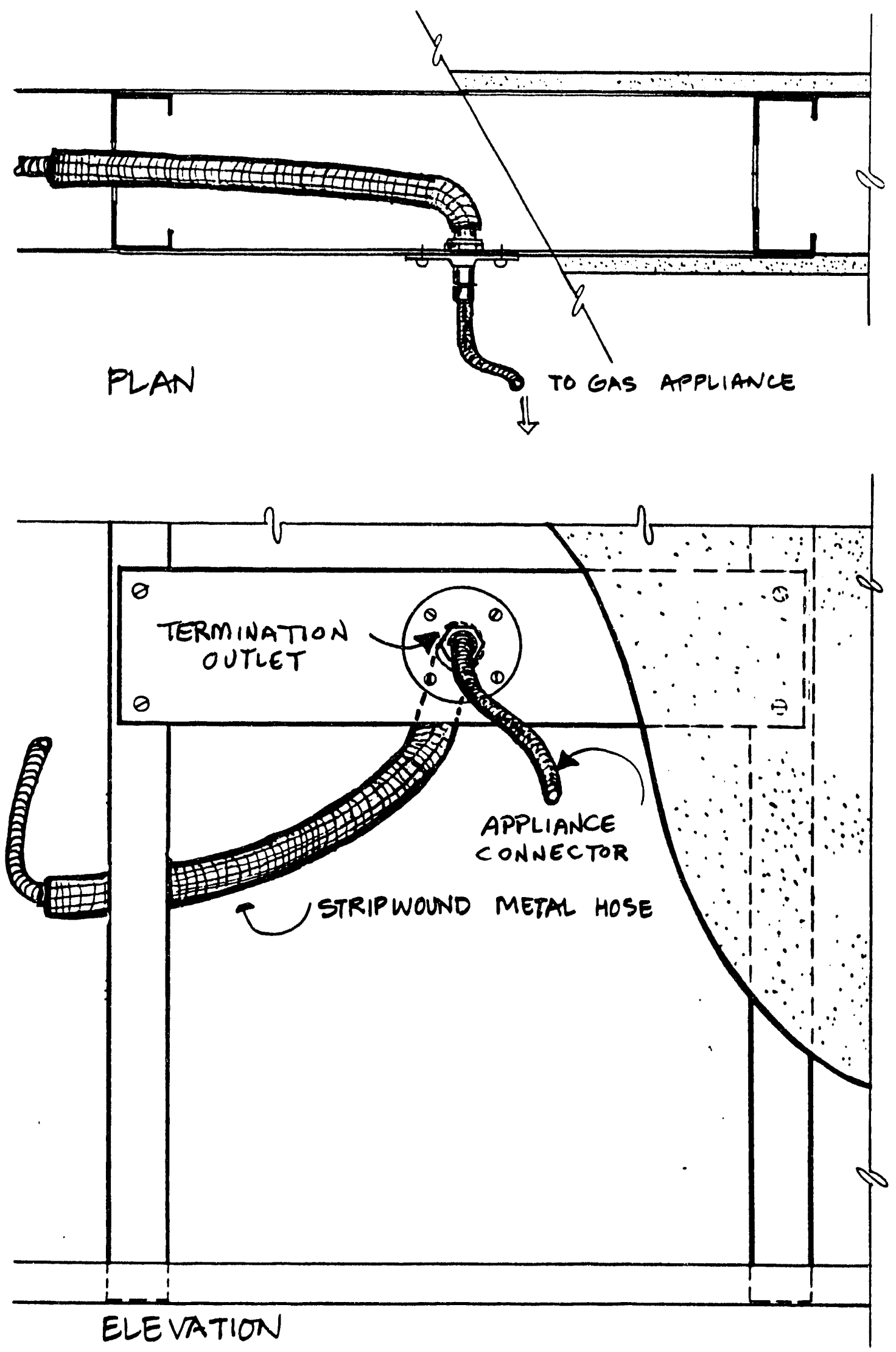

Figure 4-39. Flexible Tubing Run through Steel Stud Partition 


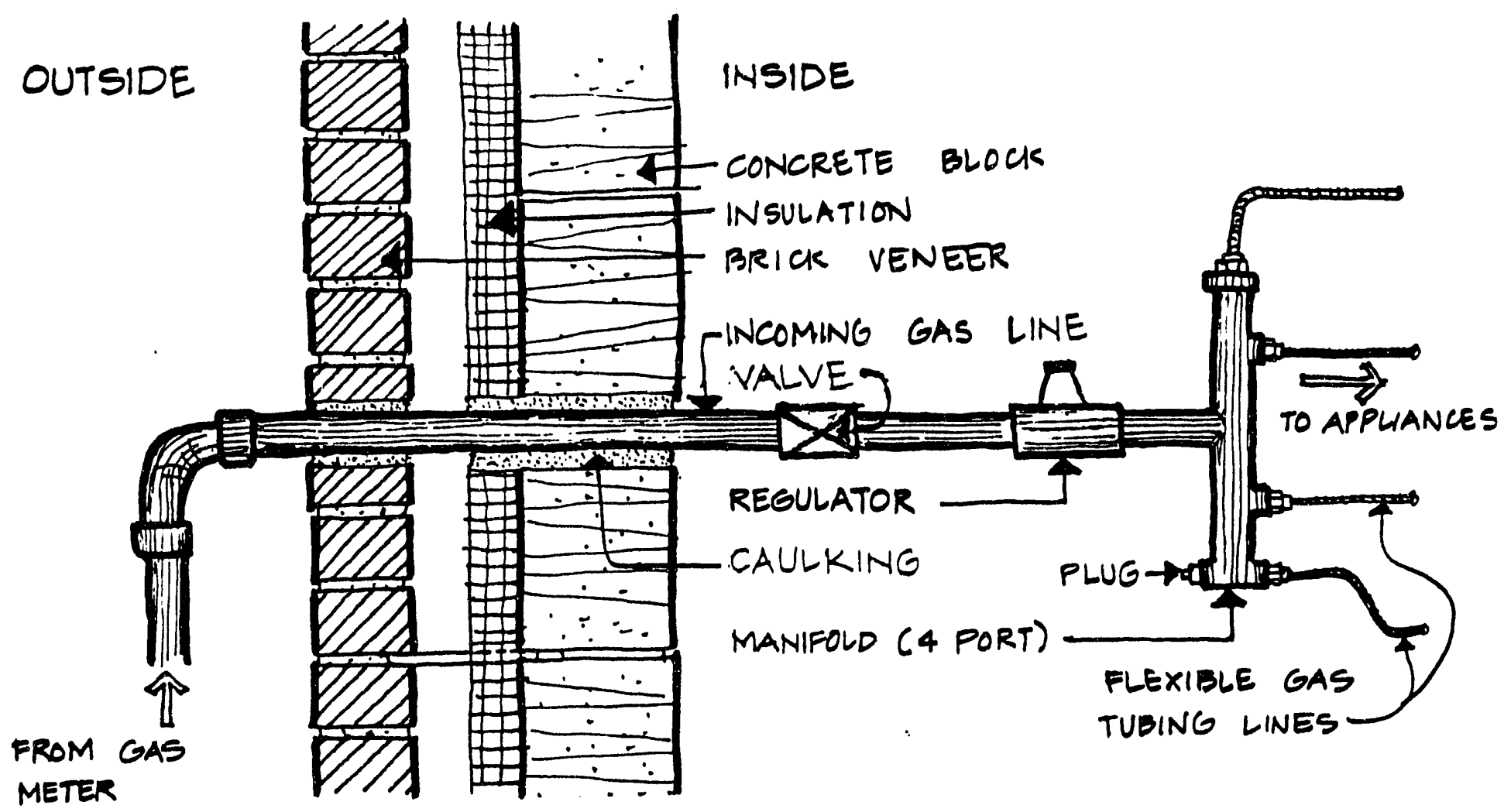

Figure 4-40. Gas Pipe Penetration through Brick and Block Cavity Wall

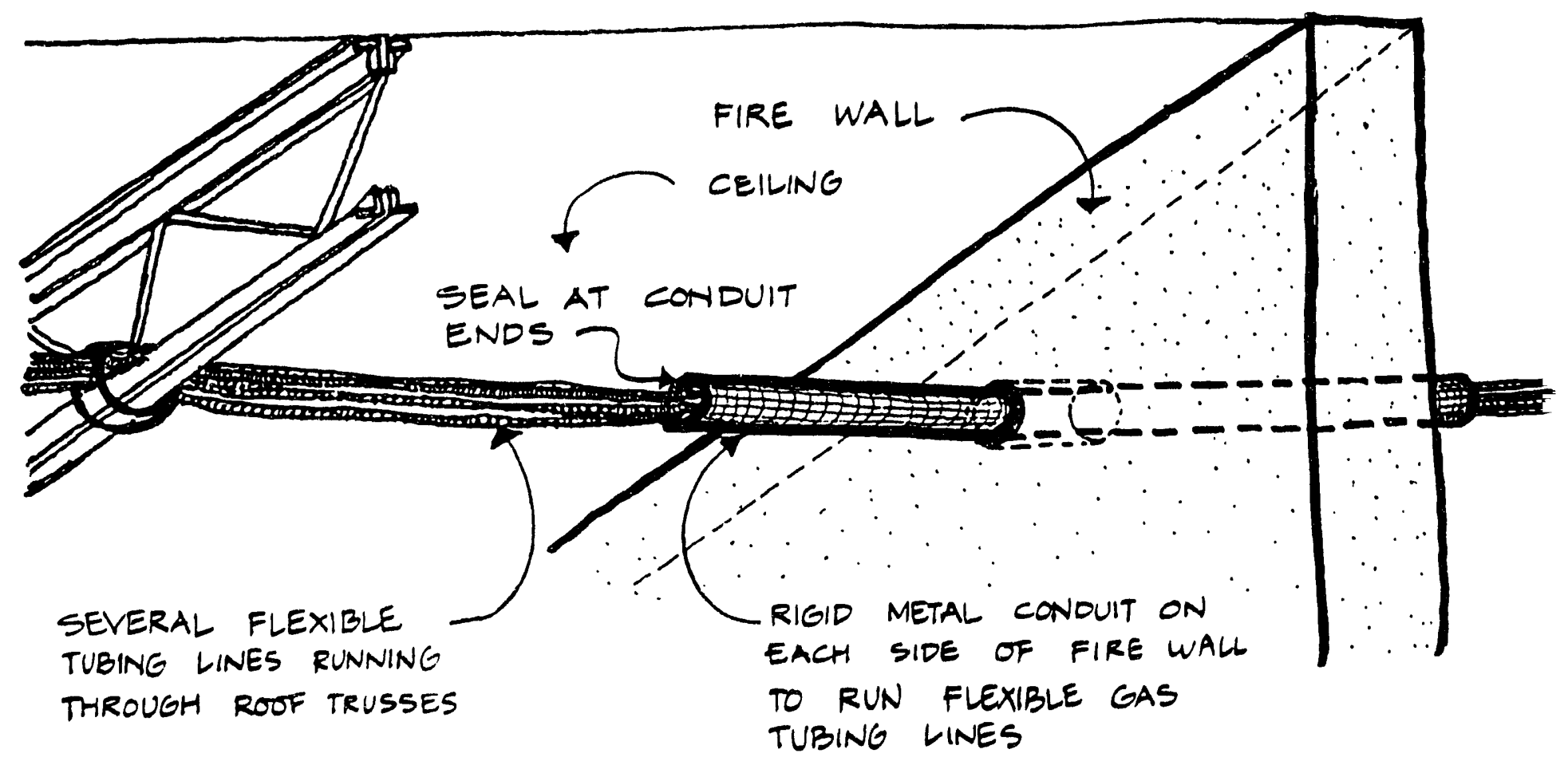

Figure 4-41. Multiple Gas Lines Penetrating through Fire Wall 


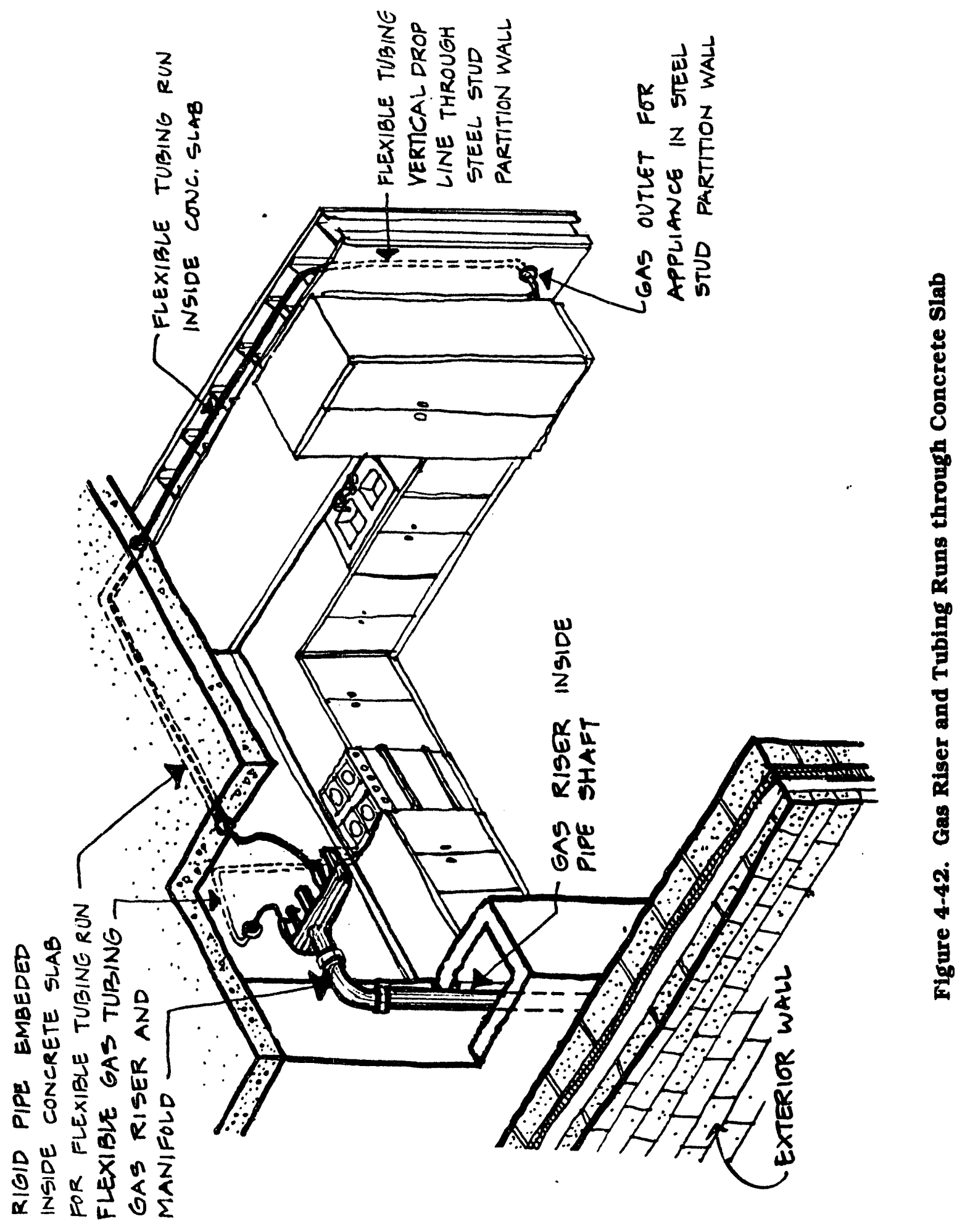




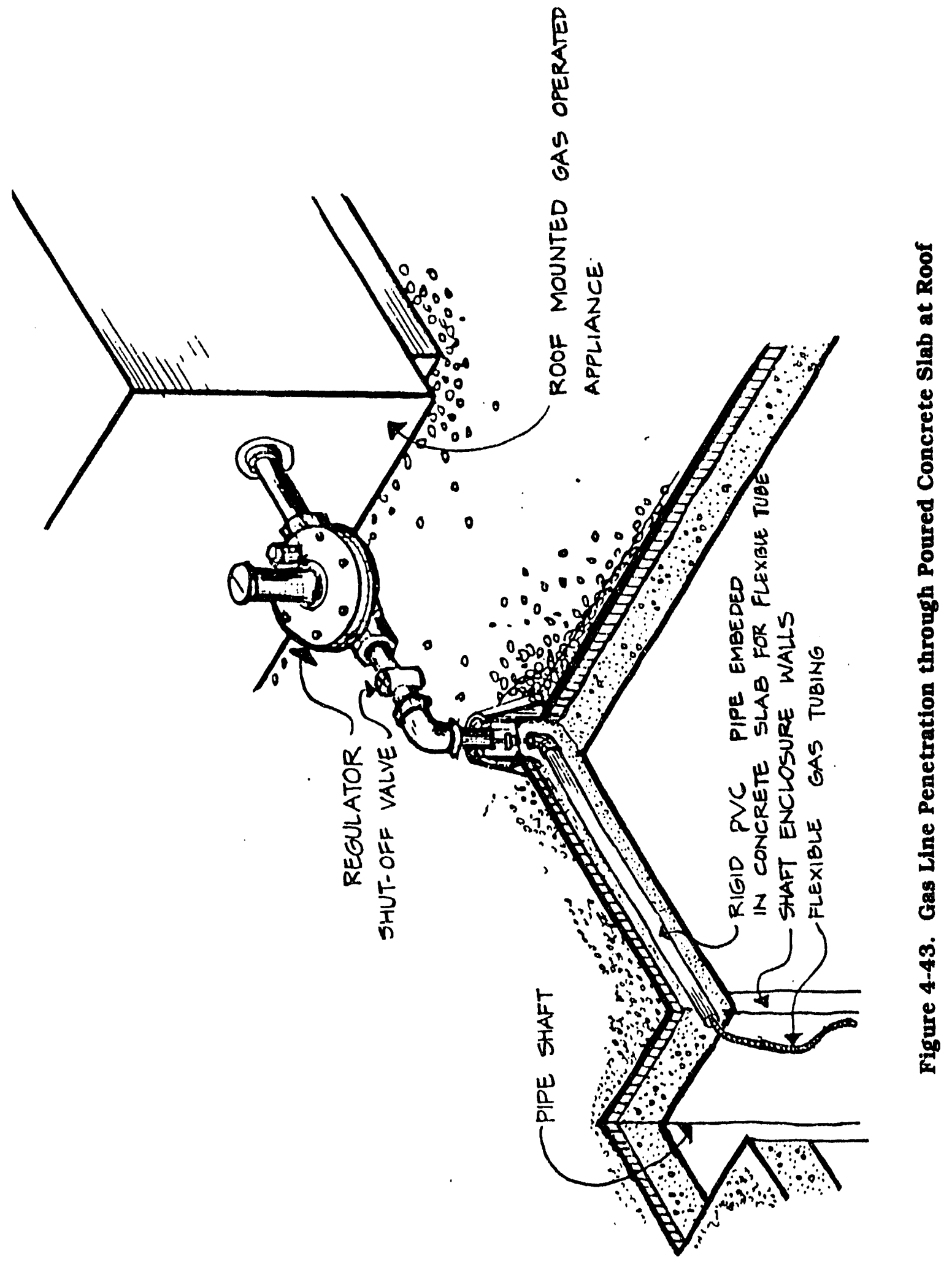




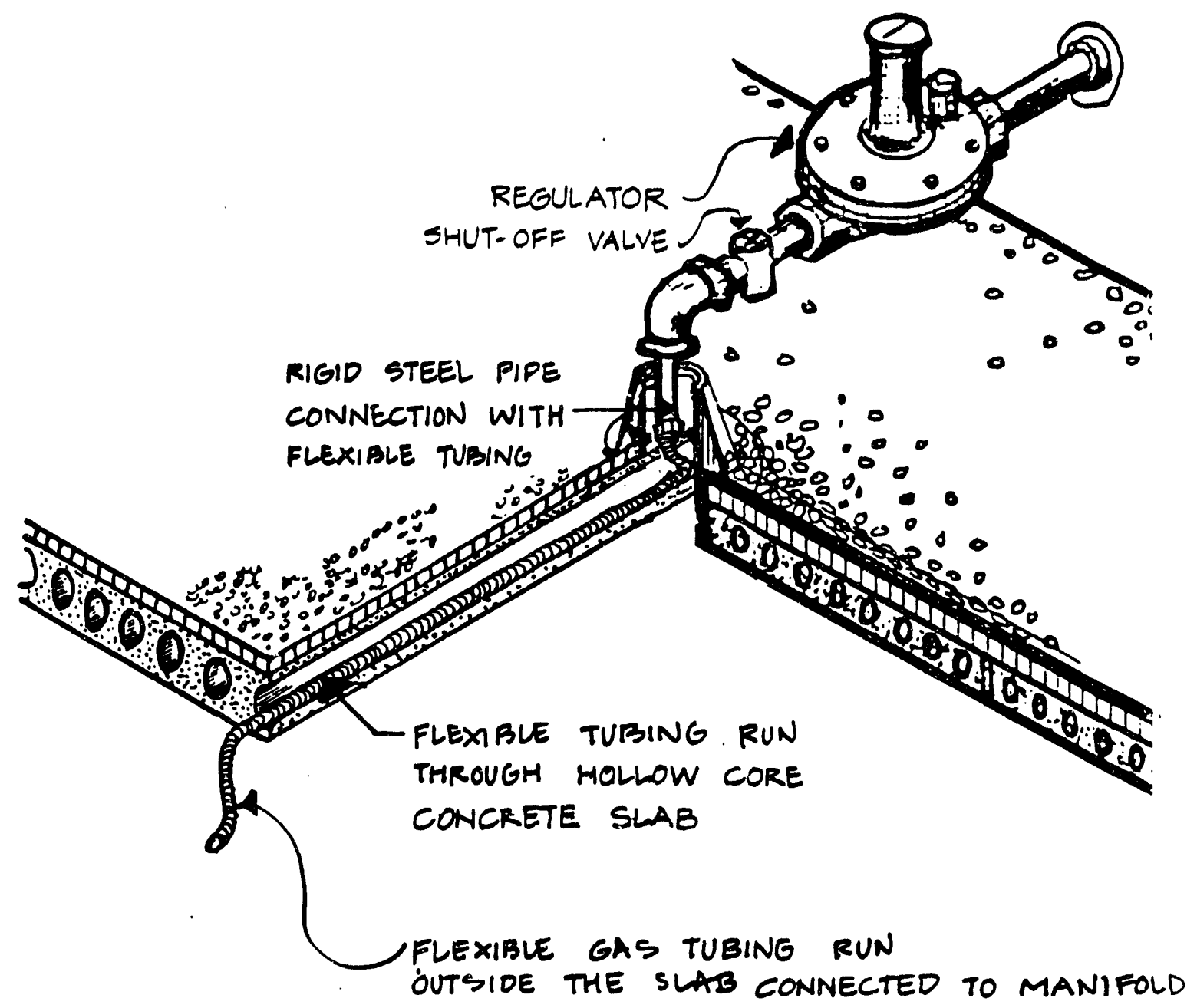

Figure 4-44. Gas Pipe Penetration through Hollow Core Concrete Slab at Roof

- The key to the development of an advanced gas piping system lies in the evolution of the distribution network from strictly a low-pressure system to a multipressure network that includes step down pressures of 5,2 , and $1 / 4$ psi. This approach, which maintains minimum pipe and tubing sizes, has been shown to result in lower total installed costs in multifamily buildings.

- Innovative, commercially available accessory hardware already exists to enhance the gas distribution network. These include modular meter and manifold enclosures, protection devices, baseboard channels, intermediate line regulators, and combined vents for regulators.

- Within 1 to 2 years, gas convenience outlets will be commercially available to promote the decentralization of gas distribution by making gas avallable, with significantly less cost and difficulty, at many locations throughout the multifamily building. 


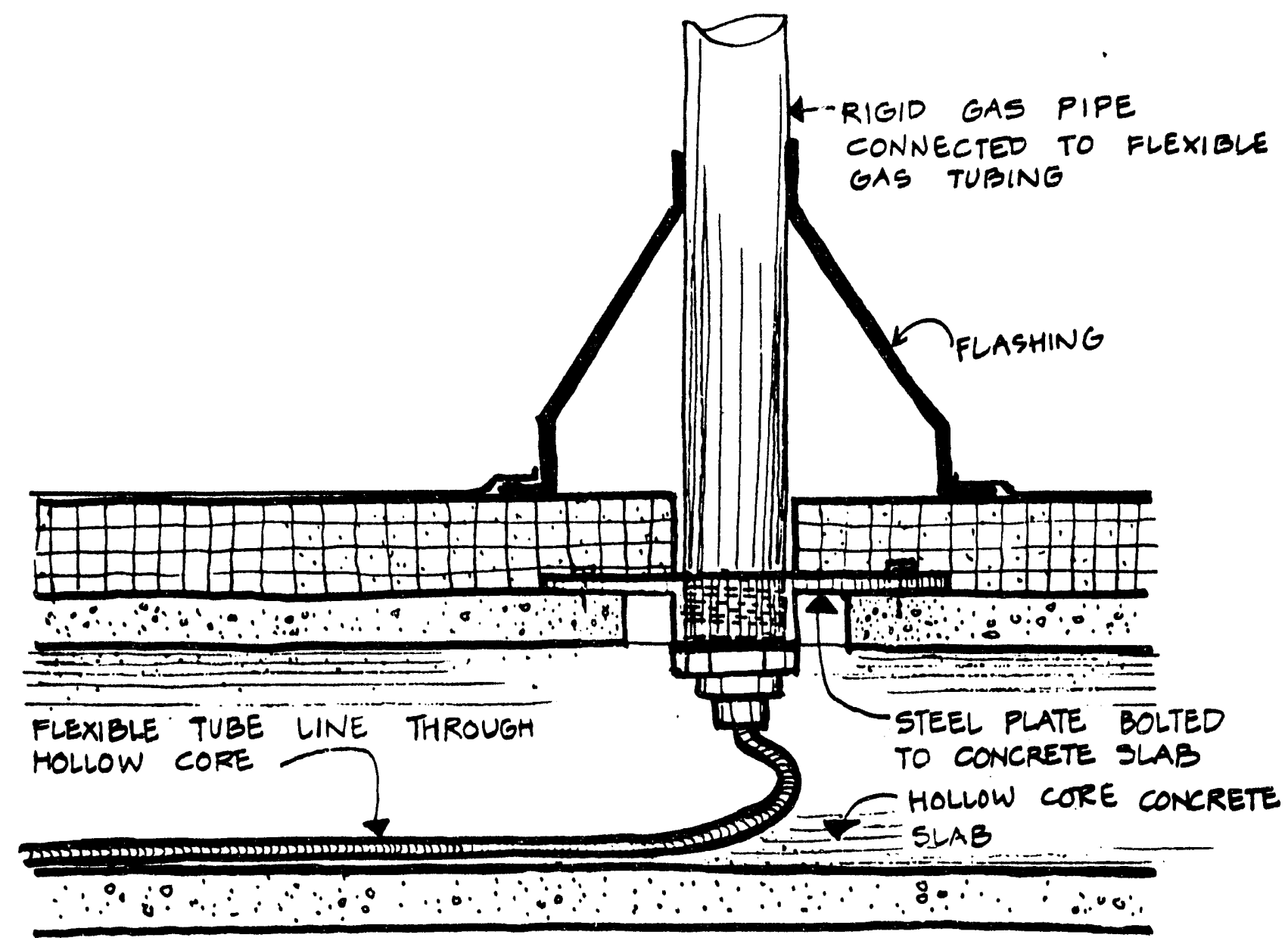

Figure 4-45. Gas Pipe Penetration Detail through Hollow Core Concrete Roof Slab

- Changes in appliance efficiency standards have prompted manufacturers to develop combination space and water heating systems. These combination or dual integrated systems are efficient, competitively priced, space saving, easy to install and maintain, and ideally suited for the multifamily market.

- The advent of two new classes of appliances, mid-efficiency, and highefficlency, has required that a new set of standards be developed for safe venting. Four venting categories (I, II, III, and IV) have been established by an ANSI standards committee that account for differences between: positive and negattve pressure vent systems, and actual and dew point temperatures of the flue gas.

- Combination space and water heating systems require a Category I vent because the water heater portion of the system produces combustion products. However, no special materials or installation practices are required for the vent systems of combination space and water heating systems. 


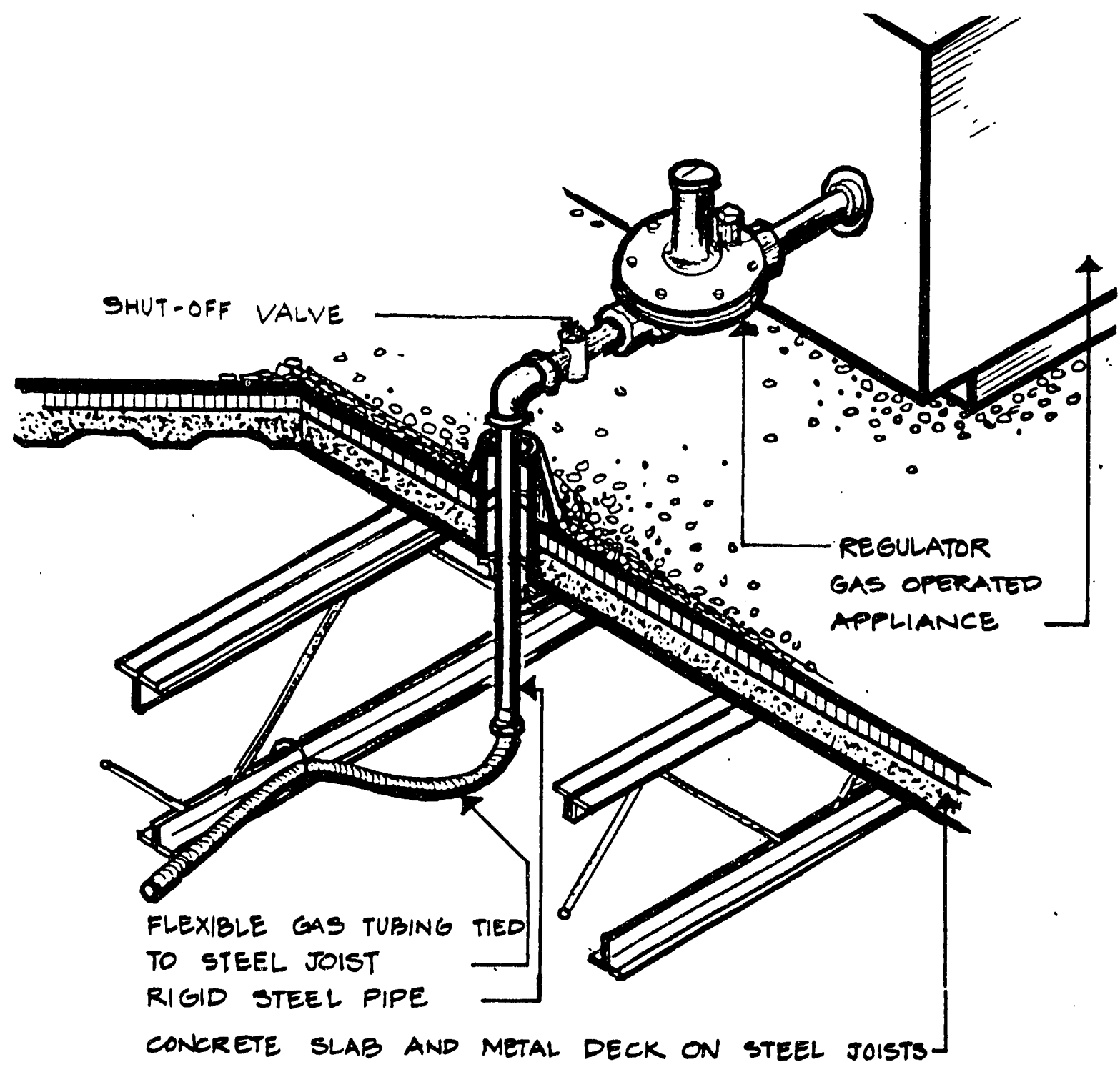

Figure 4-46. Flexible Tubing Run through Concrete Roof Slab and Steel Joist Framing

- Current installation practices to install gas piping (steel pipe and flexible tubing) are adequate as shown in the construction detalls prepared by SWA. They should be revised in the future to include the impact of New York State gas piping and building codes, and new installation techniques and/or hardware innovations as they become avallable. 


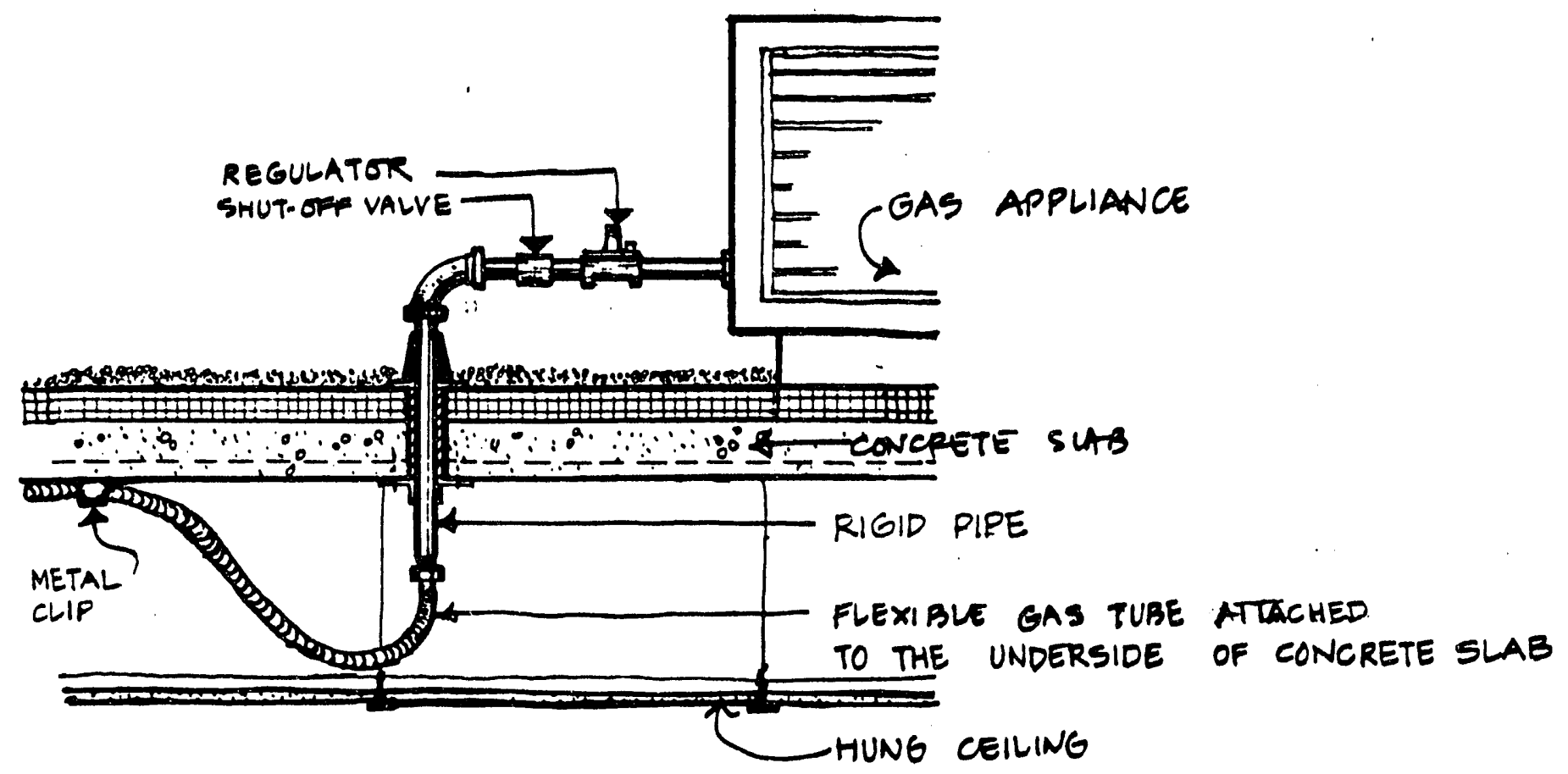

Figure 4-47. Gas Pipe Penetration through Roof with Hung Celling 
Section 5

SUMMARY AND CONCLUSIONS

This research project has determined the cost-benefit advantages of decentralized space and water heating versus centralized systems for multifamily applications based on innovative gas piping and appliance technologies. A complete review was performed to assess the energy requirements and potential for savirigs as a result of technical innovations applicable to decentralized gas-fired space and water heating systems for multifamily dwellings in the State of New York. The review included the characterization of the multifamily building stock in the State of New York to determine which types of multifamily buildings are most likely to benefit from innovations in decentralized space and water heating systems.

Conclusions based on the analysis of opportunities for decentralized space and domestic hot water heating are:

\section{RETROFIT OF PRE-1970 MULTIFAMILY BUILDINGS}

- Buildings with 10-49 apartments and bulldings with 50 or more apartments represent the largest share of the multifamily market in the State of New York (over 70 percent).

- The next tier is formed by bulldings with $3-9$ apartments.

- While the issue of the number of floors versus the number of apartments could not be resolved at the New York State level, an estimate based on a Cornell study suggests the breakdown shown in Table 5-1.

- Gas availability cannot be applied to the entire State of New York, given the unique characteristics of New York City.

- Gas availability is essential for the feasibility of a heating/domestic hot water system retrofit.

- A building that undergoes total rehabilitation or major HVAC work is more likely than others to be a candidate for decentralized heating/domestic hot water systems.

- In any renovation, except total rehabilitation, buildings with hydronic heating systems are by far the most attractive for conversion.

- Buildings already using gas for heating are much more likely to be converted to a decentralized system. 
Table 5-1. Estimate of Number of Floors versus Number of Units

\begin{tabular}{|l|cc|}
\hline \multirow{2}{*}{$\begin{array}{l}\text { Number of } \\
\text { Units }\end{array}$} & \multicolumn{2}{|c|}{$\begin{array}{c}\text { Percentage of Total Number } \\
\text { of Units }\end{array}$} \\
\cline { 2 - 3 } & $1-3$ Stories & 4 and Above \\
\hline $3-4$ & 18 & 1 \\
$5-9$ & 2 & 9 \\
$10-49$ & 1 & 18 \\
$50>$ & 2 & 49 \\
Total Units & 23 & 77 \\
\hline
\end{tabular}

- Codes and customary practice need to be reviewed.

- Energy use and cost need to be evaluated.

In summary, for retrofit multifamily butldings, the segment with a clear, high potential to benefit from conversion can be defined by low-rise (1-3 floors) buildings with 3-9 apartments that have gas-fired hydronic heating. Bulldings with over 10 units can be even more appropriate for decentralized heating/domestic hot water systems, provided the bulldings are less than 4 storles high, and either have gas heating or are attractive because of the economies of fuel switching. Seventy-flve to 80 percent of these buildings use fuel oll.

\section{NEW MULTIFAMALY BUILDNGS}

- The largest market for new multifamily buildings, when defined solely by the number of units in New York State, currently appears to be bulldings with $\mathbf{5 0}$ or more apartments.

- As with existing bulldings, the 1-3 story segment is a clear favorite.

- Gas avallability is a determining factor.

- The same bullding code and customary practice considerations apply as for retrofit situations.

- The same considerations for energy use and cost apply as for the retrofit situation. 


\section{ENERGY ASSESSMENT}

- The energy savings achievable solely as a result of the decentralized configurations are substantial. They range from 11 to 15 percent for the pre1940 buildings types, and from 7 to 17 percent for the post-1980 building types.

- Higher percent savings are achievable for the 10-story and more buildings.

- The heating energy nost increases for DIA systems. In the Consolidated Edison and Brooklyn Union Gas service territories, the increase ranges from 42 to 53 percent for pre-1940 buildings types, and 59 to 83 percent for post- 1980 bu'ding types. The cost increases are a result of the high gas rate for the first few therms, and the service charges assessed on each avartment. This rate structure constitutes a significant institutional impediment.

\section{INSTITUTIONAI CONSTRAINTS}

Institutional constraints that may affect the implementation of new gas piping systems and appliance technologies were investigated, identified, and strategies to overcome them were developed. The potential code barriers to the acceptance of CSST gas piping systems and DLAs in multifamily buildings focused on the use of elevated gas pressures, the use of circulating potable water for heating or cooling, and the actual approval or installation of the tubing material.

From the iniormal survey of professionals with an interest in these applications, NCSBCS found that areas of concern mentioned in Section 3 are fairly pervasive throughout the State of New York. These include:

- Fire marshals indicated a concern about gas pressures over 0.5 psig inside a residential structure.

- Cod 2 officials generally accepted the concept of DIAs. However, the use of po able water for space heating restriction appears to be the greatest reģulatory drawback for DLs.

- New York City code officials felt that CSST was not a proven safe product, despite lisuings, etc.

- The plumbing trade union official voiced strong negative opinions on CSST.

- The concerns over CSST applications by gas utility representatives ranged from possibilities of punctures during construction to meter and regulator app':cations.

- The Office of Uniform Fire Prevention and Builaing Code had no comment on DIAs, but discussion on CSST and elevated gas pressures was apprehensive. 
Code changes necessary to allow CSST and higher residential gas pressures were not anticipated.

In conclusion, a great deal of effort will be required to inform and educate the affected parties before acceptance and use of the technologies are achieved. To help accomplish this, strategies for overcoming the restriction to use potable water for space heating and elevated gas pressures in multifamily bulldings were developed and presented in Section 3.

\section{TECHNICAL INNOVATIONS}

A technology survey was conducted by Foster-Miller to identify emerging gas technologies that are considered innovative relative to conventional approaches that are in use today. Areas of investigation included metering, gas piping, space and water heating systems, and appliance venting. A second survey was conducted by SWA to identify installation methods for gas piping located in chaseways, fire protected areas, and other affected areas of rehabilitated and newly constructed multifamily buildings. The results of the SWA survey were documented by the development of 15 construction drawings showing detalls of flexible tubing and rigid piping installation techniques needed for the implementation of this recently developed technology.

A number of specific conclusions have been drawn from conducting the two surveys:

- There are commercially avallable, small residential meters that could be used for multifamily new and rehabilitated construction projects in the State of New York. These downsized meters, which are 40 percent smaller than existing meters of the same flow capacity, can save valuable space in submetering closets. Several compact gas meters are under development, but are not commercially avadlable and still a few years away.

- AMR systems can be adapted to conventional, small, and compact meters. AMR systems promise to solve several utility problems, which include: inaccessible meters, estimated billings, injuries to utility field personnel, customer property damage, customer complaints, and security concerns. Although these systems are very popular on the gas utilities distribution systems, they have been slow to find their way to the multifamily market.

- A combination of rigid steel pipe (vertical riser) and/or semirigid tubing (CSST or copper tubing) operated at elevated pressure (up to $5 \mathrm{psi}$ ) offer the most advanced technologies that will result in the lowest total installed costs for multifamily new and rehabilitated buildings. 
- Although not code-approved for use in New York State, composite tubing comprised of polymer and metallic layers potentially offers lower total installation costs compared to CSST and steel pipe systems. Unlike copper tubing, which is also a low installation cost alternative to CSST and steel pipe, composite tubing has excellent resistance to long-term corrosion effects.

- The key to the development of an advanced gas piping system lies in the evolution of the distribution network from strictly a low-pressure system to a multipressure network that includes step down pressures of 5,2 , and $1 / 4 \mathrm{psi}$. This approach, which maintains minimum pipe and tubing sizes, has been shown to result in lower total installed costs in multifamily buildings.

- Innovative commercially avallable accessory hardware already exists to enhance the gas distribution network. These include modular meter and manifold enclosures, protection devices, baseboard channels, intermediate line regulators, and combined vents for regulators.

- Within 1 to 2 years, gas convenience outlets will be commercially available to promote the decentralization of gas distribution by making gas available, with significantly less cost and difficulty. at many locations throughout the multifamily building.

- Changes in appliance efficiency standards has prompted manufacturers to develop combination space and water heating systems. These combination or dual integrated systems are efficient, competitively priced, space saving, easy to install and maintain, and ideally suited for the multifamily market.

- The advent of two new classes of appliances, mid-efficiency, and highefficiency, have required that 3 new set of standards be developed for safe venting. Four venting categories (I, II, III, and IV) have been established by an ANSI standards committee, which account for differences between: positive and negative pressure vent systems, and actual and dew point temperatures of the flue gas.

- Combination space and water heating systems require a Category I vent because the water heater portion of the system produces combustion products. However, no special materials or installation practices are required for the vent systems of combination space and water heating systems.

- Current installation practices to install gas piping (steel pipe and flexible tubing) are adequate as shown in the construction details prepared by SWA. These practices should be revised in the future to include the impact of New York State gas piping and building codes, and new installation techniques and/or hardware innovations as they become available. 
Appendix A

CRITERIA FOR ASSIGNING WEIGHTING FACTORS

AND OPPORTUNITY RATINGS

A-1 
Table 1: Units Per Structure

Weighting Factor:

Number of units in a structure is not very important since low-rise multifamily bulldings, which can more easily receive distributed heating, are built in a whole range of configurations from 3-4 apartments to over 50 apartments.

Opportunity Rating: The additional first cost of decentralized heating versus central heating increases in large developments because many small bollers must be provided to replace a single central boiler.

Table 2: Housing Stock (1970)

Weighting Factor:

The units built prior to 1970 have a high market potential because they are likely to need a change in heating equipment, opening the possibility to specify decentralized heating/DHW.

Opportunity Rating: Proportional to the number of units built

\section{Table 3: Replacement Potential for Existing Heating Fuel (1980)}

Weighting Factor: Oll: Connection to gas required

Gas: Everything is in place Electricity: Distribution problem

LPG: Pressure may not be adequate

Opportunity Rating: $\quad$ Number of units

\section{Table 4: Replacement Potential for Existing Heating System (1980)}

Weighting Factor:

Steam or hot water with piping: No additional or small additional distribution cost (piping, radiators) involved. The weighting factor is high.

Central warm air ducted system: A moderate increase in distribution cost (piping, radiators) expected. Alternately, the bollers could be provided with heat exchangers so that an air system continues to be used. The wetghting factor is medium.

Built-in electric units: High cost of additional distribution system involving piping, radiators, chases. The weighting factor is low.

Floor, wall or pipeless furnace: Distributed heating 
already exists.

Other means: High cost of additional distribution system involving piping, radiators, chases. The weighting factor is low.

Opportunity Rating: $\quad$ Proportional to the number of units.

Table 5: Number of Floors (New York State Bullding Stock)

Weighting Factor: Number of floors in a structure is a strong indicator of first cost for distribution system and code compliance problems.

Opportunity Rating: Distribution cost, codes, and customs do not favor structures above 4 floors.

Table 6: Number of Units Grouped According to Number of Floors Per Building

Weighting Factor: Same as Table 5. The data are only for new construction in the Northeast.

Opportunity Rating: $\quad$ Same as Table 5.

Table 7: Gas Avallabllity, Existing Housing Stock

Weighting Factor: Gas avallability is a very important factor because without inexpensive access to gas service, decentralized heating cannot be cost-effective.

Opportunity Rating: The cost of connecting decentralized heating system depends on the location of existing gas supply line.

Table 8: Housing Growth (1960 - 1990)

Weighting Factor: Relatively low weighting factor because the older housing stock is more important. Newer buildings are unlikely to need replacement of heating equipment. Therefore, the rate at which new buildings are erected is not as important as the existing housing stock built before 1970.

Opportunity Rating: $\quad$ Rate of growth from 1960 onwards.

Table 9: Newer Housing Stock (1970 - 1990)

Weighting Factor:

New housing units do not offer a strong potential for replacement of existing heating systems. As a result. the weighting factor is less than that for Table 3. 
Opportunity Rating: Number of units.

Table 10: Gas Avallability, New Construction

Weighting Factor:

Opportunity Rating:
Same as Table 7

Same as Table 7 


\section{APPENDIX B \\ MULTIPLE ATTRIBUTE ANALYSIS FOR DECENTRALIZED HEATING IN EXISTING MULTIFAMILY BUILDING STOCK IN \\ NEW YORK STATE \\ (RENTER OCCUPIED UNITS, 1980)}

B-1 


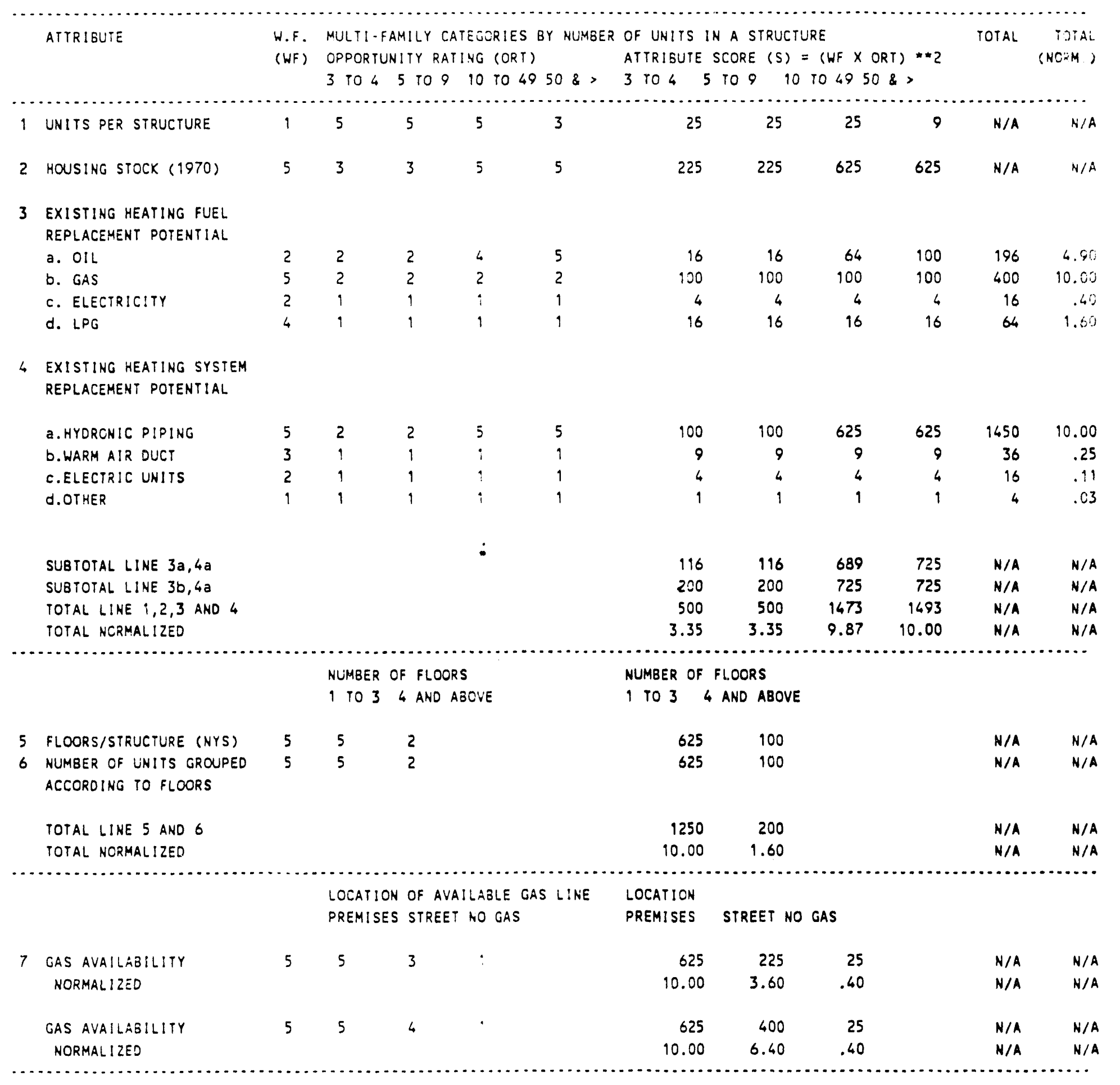


ATTRIBUTE

W.F. MULTI-FAMILY CATEGORIES BY NUMBER OF UNITS IN A STRUCTURE

ATTRIBUTE SCORE (S) $=(W F \times$ ORT) $* * 2$

(WF) OPPORTUNITY RATING (ORT)

3 TO 4 TO 9 TO TO $4950 \&$
3 TO 45 TO 9 TO TO $4950 \&>$
TOTAL TOTAL

(NORM.)

\begin{tabular}{|c|c|c|c|c|c|c|c|c|c|c|c|c|}
\hline & UNITS PER STRUCTURE & 1 & 5 & 5 & 5 & 3 & 25 & 25 & 25 & 9 & $N / A$ & $N / A$ \\
\hline & HOUSING STOCK (1970) & 5 & 3 & 3 & 5 & 5 & 225 & 225 & 025 & 625 & $N / A$ & $H / A$ \\
\hline & $\begin{array}{l}\text { EXISTING HEATING FUEL } \\
\text { REPLACEMENT POTENTIAL. }\end{array}$ & & & & & & & & & & & \\
\hline & a. OIL & 3 & 2 & 2 & 4 & 5 & 36 & 36 & 144 & 225 & 441 & 10.00 \\
\hline & b. GAS & 5 & 2 & 2 & 2 & 2 & 100 & 100 & 100 & 100 & 400 & 9.07 \\
\hline & C. ELECTRICITY & 2 & 1 & 1 & 1 & 1 & 4 & 4 & 4 & 4 & 16 & .36 \\
\hline & d. LPG & 4 & 1 & 1 & 1 & 1 & 16 & 16 & 16 & 16 & 64 & 1.45 \\
\hline
\end{tabular}

4 EXISTING HEATING SYSTEM

REPLACEMENT POTENTIAL.

a. HYDRONIC PIPING

b. WARM AIR OUCT

c.ELECTRIC UNITS

d.OTHER

$\begin{array}{lllll}5 & 2 & 2 & 5 & 5 \\ 3 & 1 & 1 & 1 & 1 \\ 2 & 1 & 1 & 1 & 1 \\ 1 & 1 & 1 & 1 & 1\end{array}$

$\begin{array}{rrrrrr}100 & 100 & 625 & 625 & 1450 & 10 \\ 9 & 9 & 9 & 9 & 36 & .25 \\ 4 & 4 & 4 & 4 & 16 & .11 \\ 1 & 1 & 1 & 1 & 4 & .03\end{array}$

SUBTOTAL LINE 3a,4a

SUBTOTAL LINE 3b,4a

TOTAL LINE 1,2,3 AND 4

136

200

520

136

200

520

$769 \quad 850$

850
725

N/A N/A

TOTAL NORMALIZED

3.21

3.21

$1553 \quad 1618$

N/A N/A

$N / A \quad N / A$

TOTAL nORMALIZED

NUMBER OF FLOORS

1 TO 34 ANO ABOVE

5 FLOORS/STRUCTURE (NYS)

6 NUMBER OF UNITS GROUPED

6 ACCOROING TO FLOORS

ACCORDING TO FLOORS

TOTAL LINE 5 AND 6

TOTAL NORMALIZED

$\begin{array}{lll}5 & 5 & 2 \\ 5 & 5 & 2 \\ 5 & 5 & 2\end{array}$

2

(n)

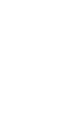

NUMBER OF FLOORS

1 TO 34 AND ABDVE

$\begin{array}{llll}625 & 100 & \text { N/A } & \text { N/A } \\ 625 & 100 & \text { N/A } & \text { N/A } \\ 625 & 100 & \text { N/A } & \text { N/A }\end{array}$

TOTAL NORMALIzED

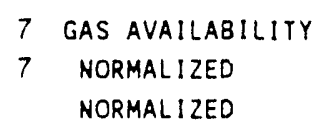

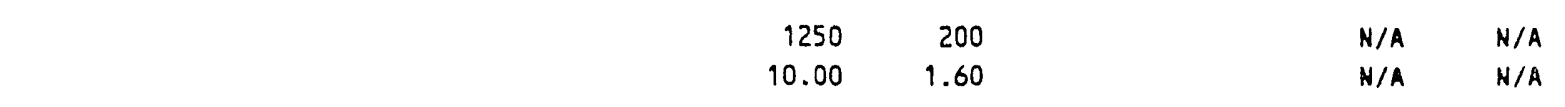

\begin{tabular}{|c|c|c|c|c|c|c|c|c|c|}
\hline NORMALIZED & 5 & 5 & 3 & 1 & 10.00 & 3.60 & .40 & $N / A$ & $N / A$ \\
\hline NORMALIZED & & & & & 10.00 & 3.60 & .40 & $N / A$ & $N / A$ \\
\hline GAS AVAILABILITY & 5 & 5 & 4 & 1 & 625 & 400 & 25 & $N / A$ & $N / A$ \\
\hline NORMALIZED & & & & & 10.00 & 6.40 & .40 & $N / A$ & $N / A$ \\
\hline
\end{tabular}


W.F. MULTI-FAMILY CATEGORIES BY NUMBER UF UNITS IN A STRUCTURE ATTRIBUTE SCORE (S) $=$ (WF X ORT) $\star \star 2$ (WF) OPPORTUNITY RATING (ORT) 3 TO 45 TO 9 TO TO $4950 \&>3$ TO 45 TO 9 10 TO 4950 \& >
TOTAL TOTAL (NORM.)

$\begin{array}{ll}1 \text { UNITS PER STRUCTURE } & 1 \\ 2 \text { HOUSING STOCK (1970) } & 5 \\ 3 \text { EXISTING HEATING FUEL } \\ \text { REPLACEMENT POTENTIAL } \\ \text { a. OIL } \\ \text { b. GAS } \\ \text { c. ELECTRICITY } & 2 \\ \text { d. LPG } & 5 \\ \end{array}$

5

4 EXISTING HEATING SYSTEM

REPLACEMENT POTENTIAL

\begin{abstract}
a. HYDRONIC PIPING
b. WARM AIR DUCT

c.ELECTRIC UNITS

d. OTHER
\end{abstract}

SUBTOTAL LINE 3a,4a

SUBTOTAL LINE 3b,4a

TOTAL LINE $1,2,3$ AND 4

TOTAL NORMAL IZED

$\begin{array}{lllll}5 & 2 & 2 & 5 & 5 \\ 4 & 1 & 1 & 1 & 1 \\ 2 & 1 & 1 & 1 & 1 \\ 1 & 1 & 1 & 1 & 1\end{array}$

$\begin{array}{rr}100 & 100 \\ 16 & 16 \\ 4 & 4 \\ 1 & 1\end{array}$

$\begin{array}{rr}625 & 625 \\ 16 & 16 \\ 4 & \\ 1 & \end{array}$

$\begin{array}{rr}1450 & 10.00 \\ 64 & .44 \\ 16 & .11 \\ 4 & .03\end{array}$

$\begin{array}{rrrr}116 & 116 & 689 & 725 \\ 200 & 200 & 725 & 725 \\ 507 & 507 & 1480 & 1500 \\ 3.38 & 3.38 & 9.87 & 10.00\end{array}$

N/A N/A

N/A N/A

N/A N/A

$N / A \quad N / A$

\begin{tabular}{|c|c|c|c|c|c|c|c|c|c|}
\hline & & & \multicolumn{2}{|c|}{ NUMBER OF FLOORS } & \multicolumn{5}{|c|}{ NUMBER OF FLOORS } \\
\hline & & & 11034 & 4 ANO ABOVE & 1 To 34 & AND ABOVE & & & \\
\hline 5 & FLOORS/STRUCIURE (NYS) & 5 & 5 & 2 & 625 & 100 & & $N / A$ & $N / A$ \\
\hline 5 & FLOORS/STRUCTURE (NYS) & 5 & 5 & 2 & 625 & 100 & & $N / A$ & $N / A$ \\
\hline \multirow[t]{5}{*}{6} & $\begin{array}{l}\text { NUMBER OF UNITS GROUPED } \\
\text { ACCORDING TO FLOORS }\end{array}$ & 5 & 5 & 2 & 625 & 100 & & $N / A$ & $N / A$ \\
\hline & TOTAL LINE 5 AND 6 & & & & 1250 & 200 & & $N / A$ & $N / A$ \\
\hline & TOTAL NORMALIZED & & & & 10.00 & 1.60 & & $N / A$ & $N / A$ \\
\hline & & & LOCATION & OF AVAILABLE GAS LINE & LOCATION & & & & \\
\hline & & & PREMISES & STREET NO GAS & PREMISES & STREET NO & GAS & & \\
\hline 7 & GAS AVAILABILITY & 5 & 5 & 31 & 625 & 225 & 25 & $N / A$ & H/A \\
\hline \multirow[t]{4}{*}{7} & GAS AVAILABILITY & 5 & 5 & 3 & 625 & 225 & 25 & $N / A$ & $N / A$ \\
\hline & NORMALIZED & & & & 10.00 & 3.60 & .40 & $N / A$ & $N / A$ \\
\hline & GAS AVAILABILITY & 5 & 5 & 1 & 625 & 400 & 25 & $N / A$ & $N / A$ \\
\hline & NORMALIZED & & & & 10.00 & 6.40 & .40 & $N / A$ & $N / A$ \\
\hline
\end{tabular}


ATTRIBUTE

W.F. MULTI-FAMILY CATEGORIES BY NUMBER OF UNITS IN A STRUCTURE

ATTRIBUTE SCORE (S) $=(W F \times$ ORT) $\star \star 2$

(WF) OPPORTUNITY RATING (ORT)

3 TO 45 TO 9 10 TO $4950 \&>$
3 TO 45 TO 9 TO TO $4950 \&>$

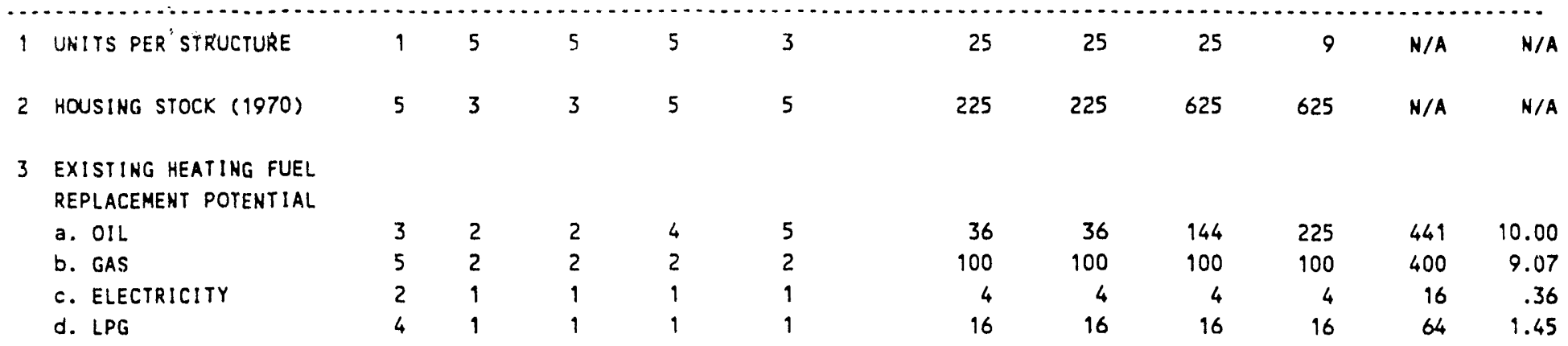

4 EXISTING HEATING SYSTEM REPLACEMENT POTENTIAL

a. HYORONIC PIPING

b. WARM AIR DUCT

c.ELECTRIC UNITS

d.OTHER

$\begin{array}{lllll}5 & 2 & 2 & 5 & 5 \\ 4 & 1 & 1 & 1 & 1 \\ 2 & 1 & 1 & 1 & 1 \\ 1 & 1 & 1 & 1 & 1\end{array}$

$\begin{array}{rr}100 & 100 \\ 16 & 16 \\ 4 & 4 \\ 1 & 1\end{array}$

$\begin{array}{rrrr}625 & 625 & 1450 & 10.00 \\ 16 & 16 & 64 & .44 \\ 4 & 4 & 16 & .11 \\ 1 & 1 & 4 & .03\end{array}$

SUBTOTAL LINE 3a,4a SUBTOTAL LINE 3b,4a TOTAL LINE 1,2,3 AND 4 TOTAL NORMALIZED

$\begin{array}{rrrrrrr}136 & 136 & 769 & 850 & \text { N/A } & \text { N/A } \\ \text { N/A } \\ \text { N/A } \\ 200 & 200 & 725 & 725 & \text { N/A } & \text { N/A } \\ \text { N/A }\end{array}$

NUMBER OF FLOORS

$\begin{array}{lllll}5 & \text { FLOORS/STRUCTURE (NYS) } & 5 & 5 & 2 \\ 5 & \text { FLOORS/STRUCTURE (NYS) } & 5 & 5 & 2 \\ 6 & \text { NUMBER OF UNITS GROUPED } & 5 & 5 & 2\end{array}$

ACCORDING TO FLOORS

TOTAL LINE 5 AND 6

TOTAL NORMALIZED

\section{NUMBER OF FLOORS}

1 TO $3 \quad 4$ ANO ABOVE

$\begin{array}{ll}625 & 100 \\ 625 & 100 \\ 625 & 100\end{array}$

$\begin{array}{ll}\text { N/A } & \text { N/A } \\ \text { N/A } & \text { N/A } \\ \text { N/A } & \text { N/A }\end{array}$

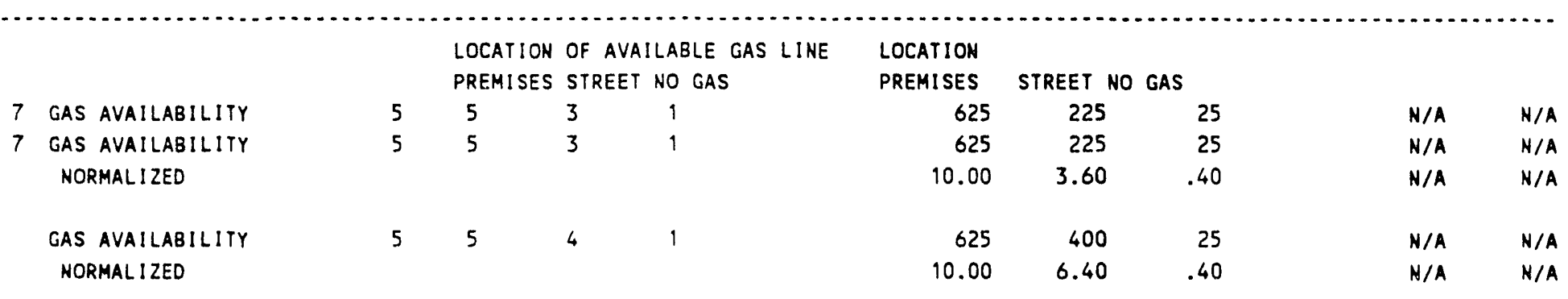


W.F. MULTI-FAMILY CATEGORIES BY NUMBER OF UNITS IN A STRUCTURE

(WF) OPPORTUNITY RATING (ORT) 3 TO 45 TO 9 TO TO 49
ATTRIBUTE SCORE (S) $=$ (WF $X$ ORT) $* 2$

3 TO 45 TO 9 TO TO $4950 \&>$
TOTAL TOTAL (NORM.)

\begin{tabular}{|c|c|c|c|c|c|c|c|c|c|c|c|}
\hline UNITS PER STRUCTURE & 2 & 5 & 5 & 5 & 3 & 100 & 100 & 100 & 36 & $N / A$ & $N / A$ \\
\hline HOUSING STOCK (1970) & 5 & 3 & 3 & 5 & 5 & 225 & 225 & 625 & 525 & $N / A$ & $N / A$ \\
\hline $\begin{array}{l}\text { EXISTING HEATING FUEL } \\
\text { REPLACEMENT POTENTIAL }\end{array}$ & & & & & & & & & & & \\
\hline a. OIL & 2 & 2 & 2 & 4 & 5 & 16 & 16 & 64 & 100 & 196 & 4.90 \\
\hline b. GAS & 5 & 2 & 2 & 2 & 2 & 100 & 100 & 100 & 100 & 400 & 10.00 \\
\hline c. ELECTRICITY & 2 & 1 & 1 & 1 & 1 & 4 & 4 & 4 & 4 & 16 & .40 \\
\hline d. LPG & 4 & 1 & 1 & 1 & 1 & 16 & 16 & 16 & 16 & 64 & 1.60 \\
\hline
\end{tabular}

4 EXISTING HEATING SYSTEM REPLACEMENT POTENTIAL

\begin{tabular}{|c|c|c|c|c|c|c|c|c|c|c|c|}
\hline a. HYDRONIC PIPING & 5 & 2 & 2 & 5 & 5 & 100 & 100 & 625 & 625 & 1450 & 10.00 \\
\hline b. WARM AIR DUCT & 3 & 1 & 1 & 1 & 1 & 9 & 9 & 9 & 9 & 36 & .25 \\
\hline C.ELECTRIC UNITS & 2 & 1 & 1 & 1 & 1 & 4 & 4 & 4 & 4 & 16 & .11 \\
\hline d.OTHER & 1 & 1 & 1 & 1 & 1 & 1 & 1 & 1 & 1 & 4 & .03 \\
\hline
\end{tabular}

SUBTOTAL LINE 3a,4a

SUBTOTAL LINE 3b,4a

TOTAL LINE $1,2,3$ ANO 4

200

$\begin{array}{lll}116 & 689 & 725\end{array}$

$200 \quad 725 \quad 725$

575

575

1548

1520

$\begin{array}{llll}3.71 & 3.71 & 10.00 & 9.82\end{array}$

H/A N/A

N/A N/A

TOTAL NORMALIZEO

NUMBER OF FLOORS

NUMBER OF FLOORS

1 TO 34 ANO ABOVE

$\begin{array}{lllll}5 & \text { FLOORS/STRUCTURE (NYS) } & 5 & 5 & 2 \\ 5 & \text { FLOORS/STRUCTURE (NYS) } & 5 & 5 & 2 \\ 6 & \text { NUMBER OF UNITS GROUPED } & 5 & 5 & 2\end{array}$

1 TO 34 AND ABOVE

$\begin{array}{ll}625 & 100 \\ 625 & 100 \\ 625 & 100\end{array}$

$N / A \quad N / A$

$N / A \quad N / A$

NUMBER OF UNITS GROUPED
ACCORDING TO FLOORS

$625 \quad 100$

$N / A \quad N / A$

TOTAL LINE 5 AND 6

TOTAL NORMALIZED

1250

10.00

200

1.60

N/A N/A

$N / A \quad N / A$

LOCATION OF AVAILABLE GAS LINE LOCATION

PREMISES STREET NO GAS

PREMISES STREET NO GAS

7 GAS AVAILABILITY

7 GAS AVAILABILITY

$\begin{array}{llll}5 & 5 & 3 & 1 \\ 5 & 5 & 3 & 1\end{array}$

NORMAL ¿ED

$\begin{array}{lll}625 & 225 & 25 \\ 625 & 225 & 25\end{array}$

$10.00 \quad 3.60 \quad .40$

N/A N/A

N/A N/A

N/A N/A

$\begin{array}{lrrrrrrrr}\text { GAS AVAILABILITY } & 5 & 5 & 4 & 1 & 625 & 400 & 25 & \text { N/A } \\ \text { NORMALIZED } & & & & & 10.00 & 6.40 & .40 & \text { N/A }\end{array}$


ATTRIBUTE

W.F. MULTI-FAMILY CATECORIES BY NUMBER OF UNITS IN A STRUCTURE

(WF) OPPORTUNITY RATING (ORT) 3 TO 4 S TO 9 TO TO 4950 \&
ATTRIBUTE SCORE (S) $=($ HF $X$ ORT) $* \approx 2$

TOTAL TOTAL

3 TO 45 TO 9 TO TO $4950 \&$ >

\begin{tabular}{|c|c|c|c|c|c|c|c|c|c|c|c|}
\hline UNITS PER STRUCTURE & 2 & 5 & 5 & 5 & 3 & 100 & 100 & 100 & 36 & N/A & $N / A$ \\
\hline HOUSING STOCK (1970) & 5 & 3 & 3 & 5 & 5 & 225 & 225 & 625 & 625 & N/A & $N / A$ \\
\hline \multicolumn{12}{|l|}{ EXISTING HEATING FUEL } \\
\hline REPLACEMENT POTENTIAL & & & & & & & & & & & \\
\hline a. $01 \mathrm{~L}$ & 3 & 2 & 2 & 4 & 5 & 36 & 36 & 144 & 225 & 441 & 10.00 \\
\hline b. GAS & 5 & 2 & 2 & 2 & 2 & 100 & 100 & 100 & 100 & 400 & 9.07 \\
\hline c. ELECTRICITY & 2 & 1 & 1 & 1 & 1 & 4 & 4 & 4 & 4 & 16 & .36 \\
\hline d. LPG & 4 & 1 & 1 & 1 & 1 & 16 & 16 & 16 & 16 & 64 & 1.45 \\
\hline
\end{tabular}

4 EXISTING HEATING SYSTEM

REPLACEMENT POTENTIAL

\begin{abstract}
a.HYDRONIC PIPING
b. WARM AIR OUCT

c.ELECTRIC UNITS

d.OTHER
\end{abstract}

SUBTOTAL LINE $3 a, 4 a$

SUBTOTAL LINE 3b,4a

TOTAL LINE 1,2,3 AND 4

TOTAL NORMAL!ZED

$\begin{array}{lllll}5 & 2 & 2 & 5 & 5 \\ 3 & 1 & 1 & 1 & 1 \\ 2 & 1 & 1 & 1 & 1 \\ 1 & 1 & 1 & 1 & 1\end{array}$

$\begin{array}{rrrr}625 & 625 & 1450 & 10.00 \\ 9 & 9 & 36 & .25 \\ 4 & 4 & 16 & .11 \\ 1 & 1 & 4 & .03\end{array}$

\section{NUMBER OF FLOORS}

1 TO 3 A AND ABOVE

5 FLOORS/STRUCTURE (NYS) 5452

5 FLOORS/STRUCTURE (NYS) 5425

6 NUMBER OF UNITS GROUPED 545 ACCORDING TO FLOORS

TOTAL LINE 5 AND 6

TOTAL NORMALIZED

$\begin{array}{rrrrrrr}136 & 136 & 769 & 850 & \text { N/A } & \text { N/A } \\ 200 & 200 & 725 & 725 & \text { N/A } & \text { N/A } \\ 595 & 595 & 1628 & 1645 & \text { N/A } & \text { N/A } \\ 3.62 & 3.62 & 9.90 & 10.00 & \text { N/A } & \text { N/A }\end{array}$

NUMBER OF FLOORS

1 TO 3 A AND ABOVE

$\begin{array}{llll}625 & 100 & \text { N/A } & \text { N/A } \\ 625 & 100 & \text { N/A } & \text { N/A } \\ 625 & 100 & \text { N/A } & \text { N/A }\end{array}$

$1250 \quad 200$

N/A N/A

10.00

1.60

N/A N/A

LOCATION OF AVAILAGLE GAS LINE LOCATION PREMISES STREET NO GAS

PREMISES STREET NO GAS

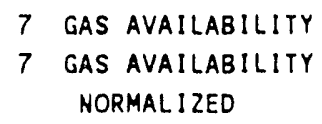

7 GAS AVAILABILITY NORMALIZED

$\begin{array}{llll}5 & 5 & 3 & 1 \\ 5 & 5 & 3 & 1\end{array}$

$5 \quad 5 \quad 4$

GAS AVAILABILITY NORMALIZED

625
625

10.00

$400 \quad 25$

6.40

.40

$\begin{array}{ll}\text { N/A } & \text { N/A } \\ \text { N/A } & \text { N/A } \\ \text { N/A } & \text { N/A } \\ & \\ \text { N/A } & \text { N/A } \\ \text { N/A } & \text { N/A }\end{array}$


ATTRIBUTE

H.F. MULTI-FAMILY CATEGORIES BY NUMBER OF UNITS IN A STRUCTURE

(WF) OPPORTUNITY RATING (ORT) 3 TO 45 TO 910 TO $4950 \&>$
ATTRIBUTE SCORE (S) $=(W F \times$ ORT) $* 22$ (NORM.)

3 TO 45 TO 9 TO TO $4950 \&$ >

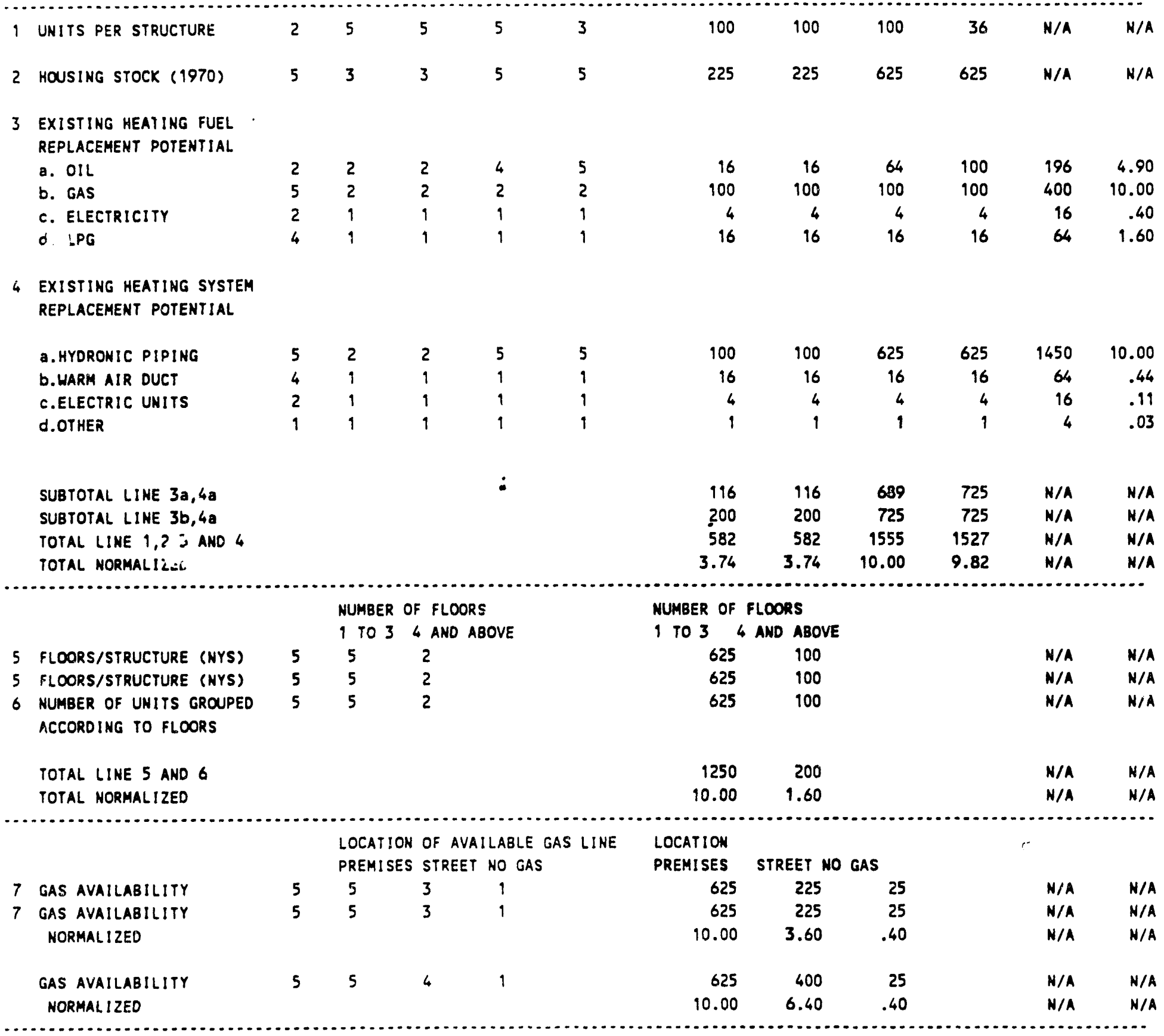




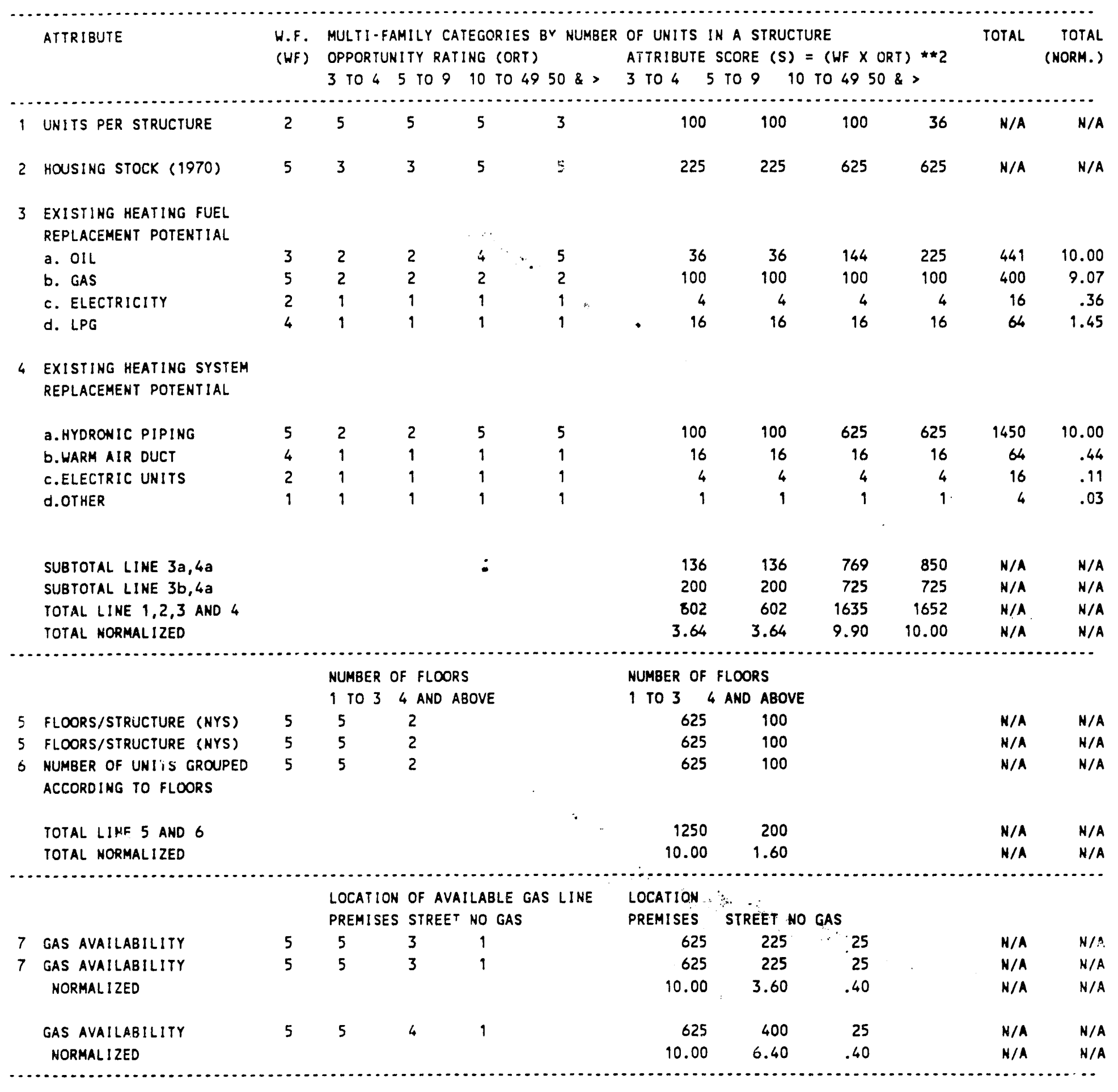


ATTRIBUTE

W.F. MULTI-FAMILY CATEGORIES BY NUMBER OF UNITS IN A STRUCTURE

(WF) OPPORTUNITY RATING (ORT)

3 TO 45 TO 9 10 TO $4950 \&>3$ TO 45 TO 910 TO 4950 \&
TOTAL TOTAL (NORM.)

\begin{tabular}{|c|c|c|c|c|c|c|c|c|c|c|c|c|}
\hline 8 & HOUSING GROWTH $(1960-90)$ & 1 & 5 & 5 & 4 & 1 & 25 & 25 & 16 & 1 & $N / A$ & $N / A$ \\
\hline 9 & NEW HOUSING (1970-90) & 2 & 4 & 2 & 1 & 5 & 64 & 16 & 4 & 100 & N/A & $N / A$ \\
\hline
\end{tabular}

TOTAL LINE 8 AND 9

TOTAL NORMALIZED

$\begin{array}{rrrrrr}89 & 41 & 20 & 101 & \text { N/A } & \text { N/A } \\ 8.81 & 4.06 & 1.98 & 10.00 & \text { M/A } & \text { M/A }\end{array}$

NUMBER OF FLOORS

1 TO 34 AND ABOVE

8.81

4.06

1.98

NUMBER OF FLOORS

1 TO $3 \quad 4$ AND ABOVE

$\begin{array}{lllll}\text { SR } & \text { FLOORS/STRUCTURE (NYS) } & 5 & 5 & 2 \\ \text { GR } & \text { NUMBER OF UNITS GROUPED } & 5 & 5 & 2\end{array}$

ACCORDING TO FLOORS

TOTAL LINE 5 AND 6

TOTAL NORMALIZED

2

$625 \quad 100$

N/A N/A

625100

N/A N/A

TOTAL NORHALIZED

10 GAS AVAILABILITY

NORMAL I ZED

$5 \quad N / A \quad 3 \quad 1$

LOCATION OF AVAILABLE GAS LINE

Location of avaILable gas line

PREMISES STREET NO GAS

PREMISES STREET NO GAS

$\begin{array}{ll}1250 & 200 \\ 10.00 & 1.60 \\ \text { MTION OF AVAILABLE GAS LINE } \\ \text { STREET HO GAS }\end{array}$

$\begin{array}{rrr}.0 & 225 & 25 \\ & 10.00 & 1.11 \\ 0 & 400 & 25 \\ & 10.00 & .63\end{array}$

N/A N/A

N/A N/A

GAS AVAILABILITY

$5 N / A \quad 4 \quad 1$

NORMALIZED

$5 \quad N / A \quad 4$

.63

N/A N/A

N/A N/A 
ATIRIBUTE

W.F. MULTI-FAMILY CATEGORIES BY NUMBER OF UNITS IN A STRUCTURE

(WF) OPPORTUNITY RATING (ORT)

3 TO 4 TO 9 TO TO $4950 \&$
ATTRIBUTE SCORE $(S)=$

3 TO 45 TO 9 TO $4950 \&>$

\begin{tabular}{|c|c|c|c|c|c|c|c|c|c|c|c|c|}
\hline 8 & HOUSING GROWTH (1960-90) & 1 & 5 & 5 & 4 & 1 & 25 & 25 & 16 & 1 & $N / A$ & $H / A$ \\
\hline 9 & NEW HOUSING (1970-90) & 3 & 4 & 2 & 1 & 5 & 144 & 36 & 9 & 225 & $N / A$ & $N / A$ \\
\hline & TOTAL LIHE 8 AND 9 & & & & & & 169 & 61 & 25 & 226 & $N / A$ & $N / A$ \\
\hline & TOTAL NORMALIZED & & & & & & 7.48 & 2.70 & 1.11 & 10.00 & $N / A$ & $N / A$ \\
\hline
\end{tabular}

NUMBER OF FLOORS

1 TO 3 4 AND ABOVE
NUMBER OF FLOORS

1 TO $3 \quad 4$ AND ABOVE

$\begin{array}{llllllll}\text { 5R FLOORS/STRUCTURE (NYS) } & 5 & 5 & 2 & 625 & 100 & \text { N/A } \\ \text { 6R NUMBER OF UNITS GROUPED } & 5 & 5 & 2 & 625 & 100 & \text { N/A } \\ \text { 6R ACCORDING TO FLOORS } & 5 & 5 & 2 & 625 & 100 & \text { N/A } \\ \text { ACCORDING TO FLOORS } & & & & 1250 & 200 & \text { N/A } \\ \text { TOTAL LINE 5 AND 6 } & & & & 1250 & 200 & \text { N/A } \\ \text { TOTAL LINE 5 AND 6 } & & & & 10.00 & 1.60 & \text { N/A } \\ \text { TOTAL NORMALIZED } & & & & \text { N/A }\end{array}$

LOCATION OF AVAILABLE GAS LINE LOCATION STREET MO GAS
LOCATION OF AVAILABLE GAS LINE LOCATION STREET NO GAS

$\begin{aligned} & 10 \text { GAS AVAILABILITY } \\ & \text { NORMALIZED }\end{aligned}$
$\begin{aligned} & \text { GAS AVAILABILITY } \\ & \text { NORMALIZED }\end{aligned}$
$\begin{aligned} & \text { N/A } \\ & \text { N }\end{aligned}$

$\begin{array}{rrrrr}0 & 225 & 25 & \text { N/A } & \text { N/A } \\ & 10.00 & 1.11 & \text { N/A } & \text { N/A } \\ & & & & \\ 0 & 400 & 25 & \text { N/A } & \text { N/A } \\ & 10.00 & .63 & \text { N/A } & \text { N/A }\end{array}$

TOTAL

(NORM.) 
ATTRIBUTE

W.F. MULTI-FAMILY CATEGORIES BY NUMBER OF UNITS IN A STRUCTURE

(WF) OPPORTUNITY RATING (ORT)

3 TO 45 TO 9 10 TO 4950

TOTAL TOTAL

3 TO 45 TO 9 TO $4950 \&>$

\begin{tabular}{|c|c|c|c|c|c|c|c|c|c|c|c|c|}
\hline 8 & HOUSING GRONTH (1960-90) & 2 & 5 & 5 & 4 & 1 & 100 & 100 & 64 & 4 & $N / A$ & N/A \\
\hline 9 & NEH HOUSING (1970.90) & 2 & 4 & 2 & 1 & 5 & 64 & 16 & 4 & 100 & $N / A$ & N/A \\
\hline
\end{tabular}

TOTAL LINE 8 AHD 9

TOTAL NORMALIZED

$\begin{array}{llllll}164 & 116 & 68 & 104 & \text { N/A } & \text { N/A }\end{array}$

$\begin{array}{llllll}15.77 & 11.15 & 6.54 & 10.00 & \mathrm{~N} / \mathrm{A} & \mathrm{N} / \mathrm{A}\end{array}$

NUMBER OF FLOORS

1 TO 34 AND ABOVE
NUMBER OF FLOORS

1 TO 3 AND ABOVE

$\begin{array}{llllllll}\text { 5R FLOORS/STRUCTURE (NYS) } & 5 & 5 & 2 & 625 & 100 & \text { N/A } \\ \text { 6R NUMBER OF UNITS GROUPED } & 5 & 5 & 2 & 625 & 100 & \text { N/A } \\ \text { GR ACCORDING TO FLOORS } & 5 & 5 & 2 & 625 & 100 & \text { N/A } \\ \text { ACCORDING TO FLOORS } & & & & & & \text { N/A } \\ \text { TOTAL LINE 5 AND 6 } & & & & 1250 & 200 & \text { N/A } \\ \text { TOTAL NORMALIZED } & & & & 10.00 & 1.60 & \text { N/A } \\ \text { TOTAL NORMALIZED } & & & & 10.00 & 1.60 & \text { N/A }\end{array}$

LOCATION OF AVAILABLE GAS LINE

PREMISES STREET NQ GAS

10 GAS AVAILABILITY

NORMALIZEO

GAS AVAILABILITY

NORMALIZED
$5 \quad$ N/A $3 \quad 1$

$5 \quad N / A \quad 4 \quad 1$
Location of aVAILABLE Gas lime

PREMISES STREET NO GAS

$\begin{array}{rrrrr}0 & 225 & 25 & N / A & N / A \\ & 10.00 & 1.11 & N / A & N / A \\ 0 & 400 & 25 & N / A & N / A \\ & 10.00 & .63 & N / A & N / A\end{array}$


ATTRIBUTE

H.F. MULTI-FAMILY CATEGORIES BY NUMBER OF UNITS IN A STRUCTURE

(WF) OPPORTUNITY RATING (ORT)

3 TO 45 TO 9 TO TO $4950 \&$

$$
\text { ATTRIBUTE SCORE (S) = (WF } \times \text { ORT) } \star \star 2
$$

TOTAL TOTAL

3 TO 45 TO 9 10 TO $4950 \&>$

\begin{tabular}{|c|c|c|c|c|c|c|c|c|c|c|c|c|}
\hline 8 & HOUSING GRONTH $(1960-90)$ & 1 & 5 & 5 & 4 & 1 & 25 & 25 & 16 & 1 & $N / A$ & $H / A$ \\
\hline 9 & HEW HOUSING (1970-90) & 3 & 4 & 2 & 1 & 5 & 144 & 36 & 9 & 225 & N/A & N/A \\
\hline & TOTAL LINE 8 AND 9 & & & & & & 169 & 61 & 25 & 226 & $N / A$ & $N / A$ \\
\hline & TOTAL NORMAL IZED & & & & & & 7.48 & 2.70 & 1.11 & 10.00 & $N / A$ & $N / A$ \\
\hline
\end{tabular}

\section{NUMBER OF FLOORS}

1 TO 3 A AND ABOVE
NUMBER OF FLOORS

1 TO 3 4 AND ABOVE

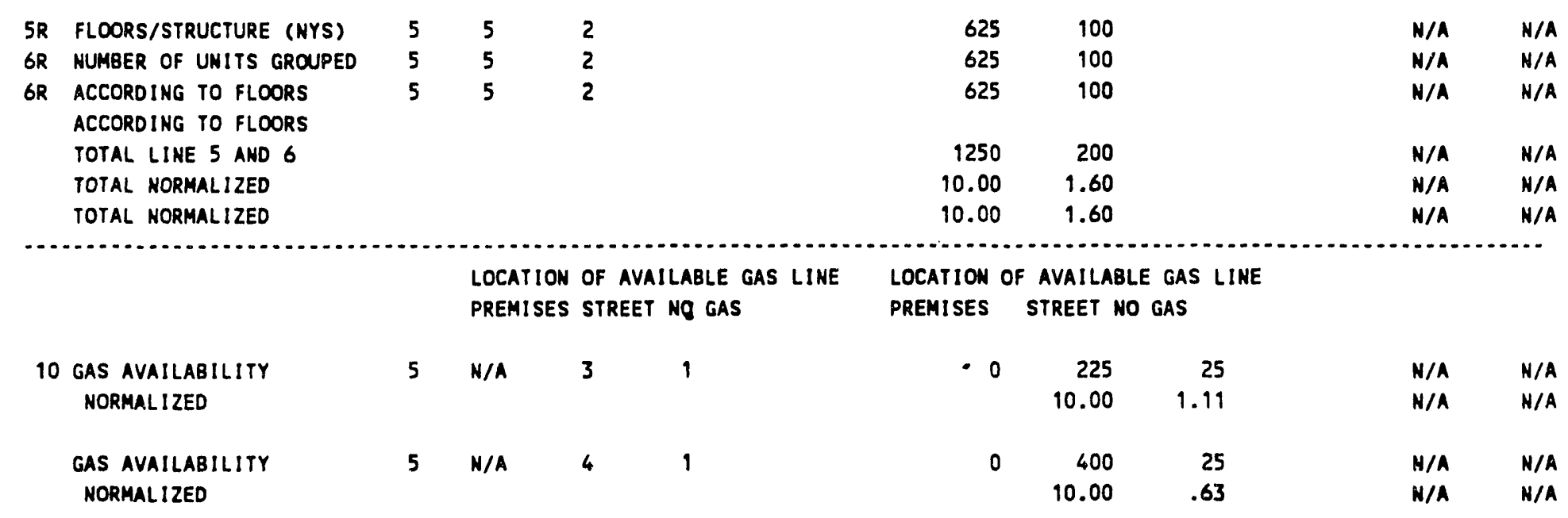


APPENDIX C

B IBLIOGRAPHY

C-1 
1. Palermini D. and Hewitt D., 1991. "Economic and Social Impact of Converting to Tenant Metering in Multi-Family Housing," ASHRAE Transactions, 1991, Volume 97, Part 1.

2. Scott W.L., 1991, "Energy Conservation from Individual Heat Use Monitoring in Multi-Family Properties," ASHRAE Transactions, 1991, Volume 97, Part 1.

3. Maher R.H., 1991, "Metering and Allocation of Gas Costs for Apartments - A Case Study," ASHRAE Transactions, 1991, Volume 97, Part 1.

4. Byrene S.J. and Fay J.M., 1989. "A Comparison of Central and Individual Systems for Space Conditioning and Domestic Hot Water in New Multi-Family Buildings," ASHRAE Transactions, 1989, Volume 95, Part 2.

5. Booz, Allen and Hamilton, Inc., 1979. Alternative Metering Practices: Implications for Conservation in Multi-Family Residences, U.S. Department of Energy: NTIS No. HCP/M 1963-03.

6. McClelland L., 1980. Encouraging Energy Conservation in Multi-Family Housing: RUBS and Other Methods of Allocating Energy Costs to Residents, Institute of Behavioral Science, University of Colorado, U.S. Department of Energy: NTIS No. DOE/CS 20050-T2.

7. McClelland L., 1983. Tenanti-Paid Energy Costs in Multi-Family Rental Housing: Effects on Energy Use. Owner Investment, and the Market Value of Energy Institute of Behavioral Science, University of Colorado, U.S. Department of Energy: NTIS No. DOE/CS-20050-1.

8. Bohac D.L., Hewett M.J., Staller T. and Dunsworth T.S., 1990. Retrofit Savings for Dual Integrated Appliances in Small Commercial and Multi-Family Buildings. Interim Report, Center for Energy and the Urban Environment.

9. Talbert S., Murray J., Borgeson R., Kam V. and Pietsch J., 1992. "Operating Characteristics and Annual Efficiencies of Combination Space/Water-Heating Systems, ASHRAE Transactions, 1992, Volume 98, Part 1. 
10. Fels M., 1986. "The Princeton Scorekeeping Method: An Introduction," Energy and Buildings, February/May 1986, Volume 9, Number 1-22, p. 5-18. 
APPENDIX E

GAS PIPING TECHNOLOGIES

E-1 


\section{CORRUGATED STAINLESS STEEL TUBING}

The corrugated stainless steel tubing (CSST), which is A.G.A. Labs design certified for use in fuel gas piping systems, is manufactured in both the United States and in Japan. In January 1991, the American National Standards Institute, Inc. adopted ANSI/A.G.A. LC-1 as the ANSI Standard for CSST systems. The system uses semirigid corrugated tubing made of 304 stainless steel. It is currently supplied in coils from 100 to $250 \mathrm{ft}$ in length. The tubing is manufactured in up to four different sizes, $3 / 8,1 / 2,3 / 4$, and 1 in. internal diameters.

The corrugated tubing is covered with a polyethylene (PE) or a polyvinyl chloride (PVC) coating, approximately $0.63 \mathrm{~mm}(0.025$ in.) thick. The purpose of the coating is threefold: to protect it against household chemicals, abrasion, and to reduce friction while snaking it through stud walls and floor joists. Special mechanical fittings are provided to interconnect the tubing with other components within the overall gas piping system.

There are currently two suppliers of this product, each with slight variations in the tubing size, shape and fitting design. Dimensional specifications for each of the current manufacturers product are shown in Figure E-1. Larger sizes up to 1-1/2 in. diam may be available in the future. Because of these variations, each manufacturer's system requires individual instruction on the proper sizing and installation procedures. A brief description including installation requirements for each manufacturer's system follows.

\section{WARD MANUFACTURING}

Ward Manufacturing manufactures an annular shaped tubing with mechanical fittings that can be installed with simple hand tools. The tubing is cut with a conventional tubing cutter supplied by Rigid or other such manufacturer.

The assemble process for the Ward Manufacturing fitting requires that the plastic covering over the tubing be removed near the joint, and the split retainer piece placed around the tubing at a prescribed location (see Figure E-2). The fitting is assembled by hand and tightened with conventional wrenches. The fiber washer must be replaced if the fitting is reused. 
4-GRI-9204-14

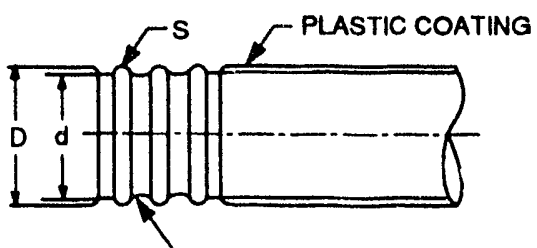

\begin{tabular}{|c|c|c|c|c|c|c|c|}
\hline & \multicolumn{4}{|c|}{ Ward Manufacturing } & \multicolumn{3}{|c|}{ Titeflex } \\
\hline Tubing Size (in.) & $\begin{array}{l}3 / 8 \\
(10 A)\end{array}$ & $\begin{array}{l}1 / 2 \\
(15 A)\end{array}$ & $\begin{array}{l}3 / 4 \\
(20 A)\end{array}$ & $\begin{array}{l}1 \\
(25 A)\end{array}$ & $\begin{array}{l}3 / 8 \\
(6 \mathrm{~A})\end{array}$ & $\begin{array}{l}1 / 2 \\
(8 A)\end{array}$ & $\begin{array}{l}3 / 4 \\
(11 B)\end{array}$ \\
\hline $\begin{array}{l}\text { Outside diameter } \\
\text { OD (in.) }\end{array}$ & 0.56 & 0.72 & 0.98 & 1.21 & 0.51 & 0.71 & 0.92 \\
\hline $\begin{array}{l}\text { Inside diameter } \\
\text { ID (in.) }\end{array}$ & 0.45 & 0.59 & 0.79 & 0.98 & 0.40 & 0.57 & 0.75 \\
\hline Wall thickness (in.) & 0.008 & 0.008 & 0.010 & 0.010 & 0.011 & 0.011 & 0.011 \\
\hline Coil length (tt) & 250 & 250 & & 180 & 100 & 100 & 100 \\
\hline $\begin{array}{l}\text { Corrugated Tubing } \\
\text { Shade (s) }\end{array}$ & \multicolumn{3}{|c|}{ Annular } & \multicolumn{4}{|c|}{ Annular } \\
\hline Covering & \multicolumn{3}{|c|}{ Polyvinyl chloride } & \multicolumn{4}{|c|}{ Polyethylene } \\
\hline
\end{tabular}

Figure E-1. Corrugated Tubing Dimensional Specifications

\section{TITEFLEX}

Titeflex also manufactures an annular shaped tubing with mechanical fittings that can be installed with simple hand tools. The tubing is cut with a modified Rigid tubing cutter fitted with self adjusting rollers to accommodate different tubing size $s$ which have different corrugated profiles. 


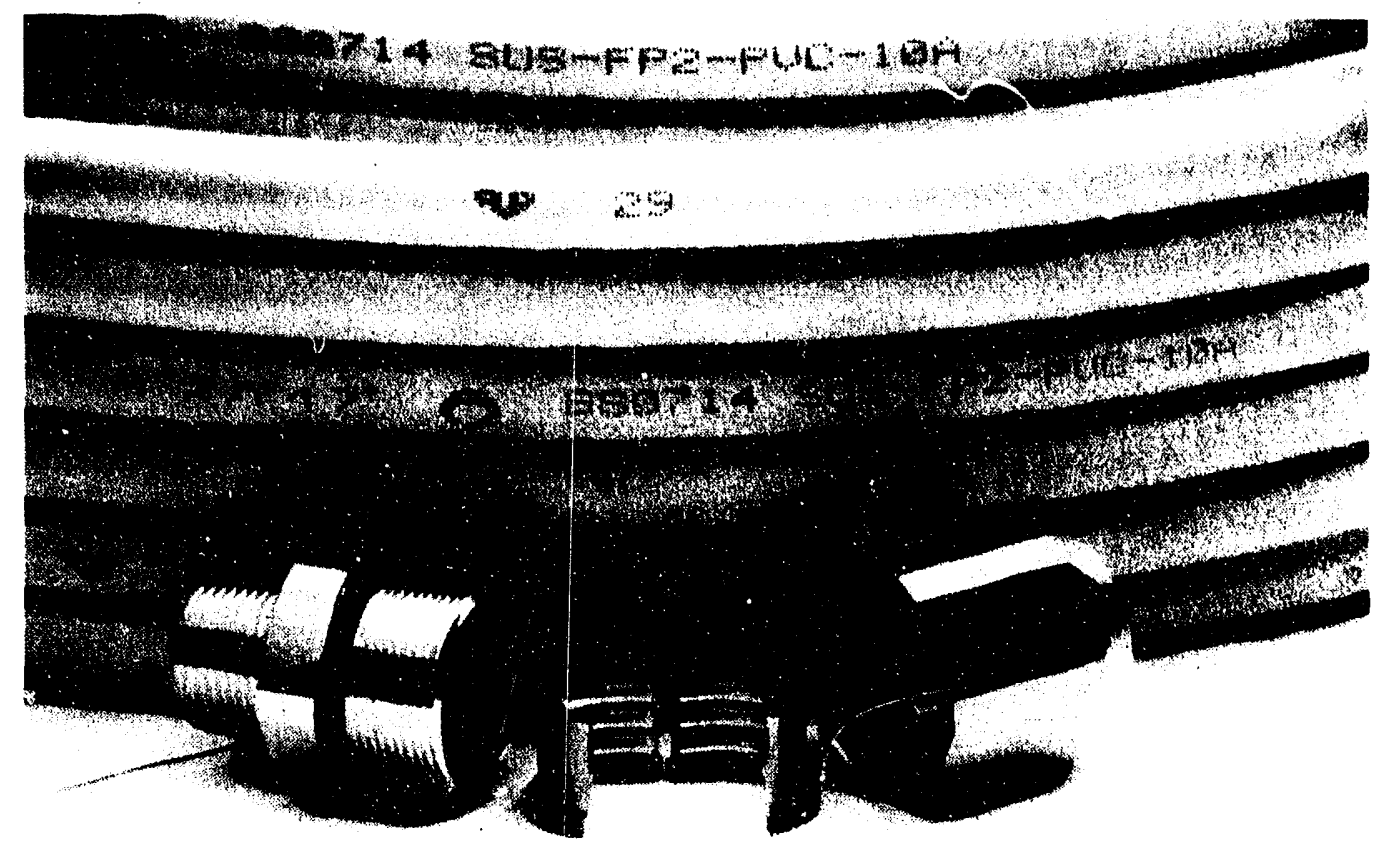

Figure E-2. Fitting Assembly (Ward Manufacturing)

The assemble process for the Titeflex fitting requires that the plastic covering over the tubing be removed near the joint, and the split retainer ring placed around the tubing at a prescribed location (see Figure E-3). The fitting is assembled by hand at ( $1 \mathrm{t}$ ghtened with conventional wrenches. If reused, no replacement parts are required.

Most semirigid tubing systems utilize a multiport gas distribution manifold. A system manifold would supply multiple gas appliances in a parallel arrangement from a single distribution point. Figure E-4 depicts several available configurations. The manifolds can be cast malleable iron or assembled from a series of standard tee fittings and pipe nipples.

There are several other unique hardware requirements associated witn the use of hybrid pressure and semirigid tubing. These include special metallic striker plates, Maxitrol line regulators, tubing clips, appliance stub-outs and other shielding devices. 


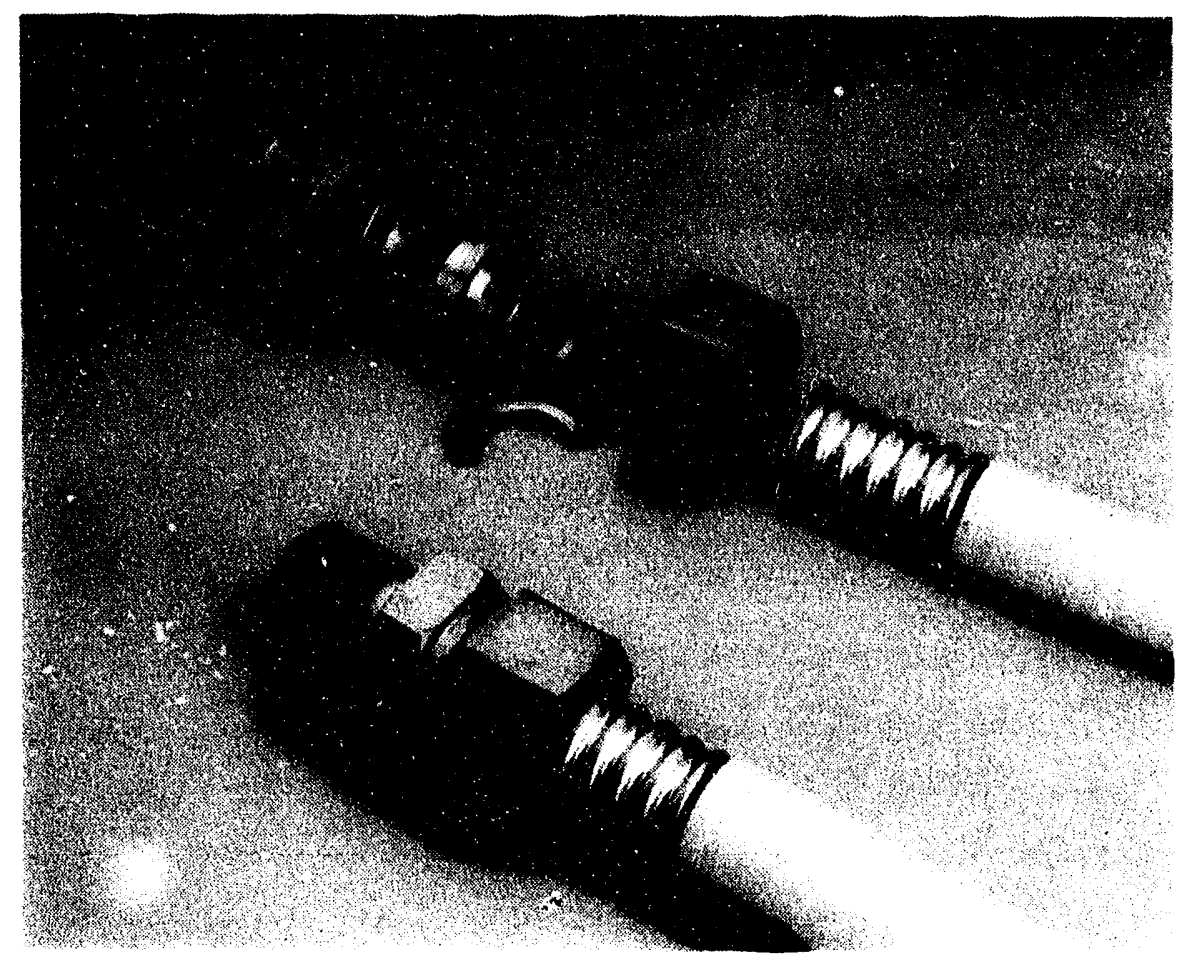

Figure E-3. Fitting Assembly (Titeflex)

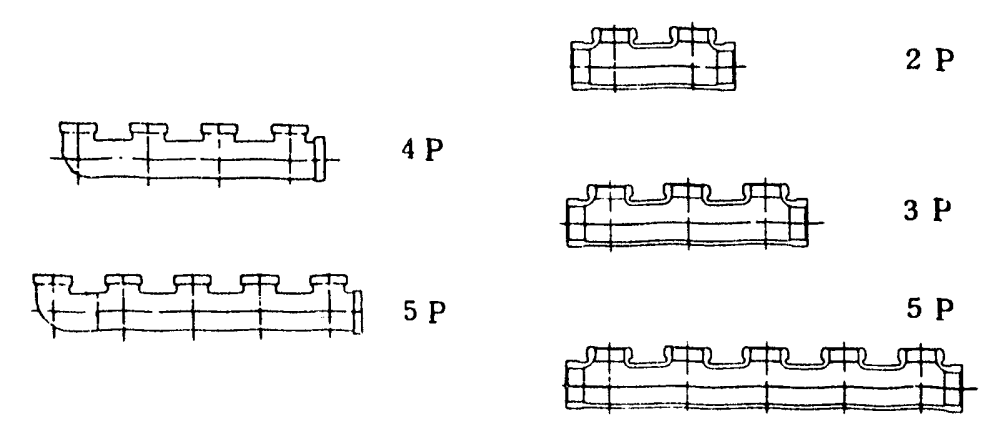

Figure E-4. Typical Multiport Manifolds (Tokyo and Osaka Gas Companies) 


\section{MEPLA AND KITEC TUBING SYSTEM DESCRIPTION}

\section{MEPLA TUBING}

Technical specifications are shown in Tables E-1 and E-2 for the MEPLA tubing product. Figures E-5 through E-11 show photographs of the tuting, fittings, accessory components, and special installation tools required to install the piping system. Initially, all performance tests and installation assessments were conducted on MEPLA tubing designated for underfloor heating applications (first category). The underfloor heating tubing was initially selected because of its greater flexibility compared to the natural gas tubing. However, it did not perform well when subjected to elevated temperature conditions.

Therefore, additional tests were conducted on MEPLA tubing designated for natural gas applications (fourth category). The metal tubing used in the MEPLA tubing for natural gas applications has a thicker wall and is an aluminum alloy material. The metal tubing used in the MEPLA tubing for underfloor heating applications is of a thinner wall, and pure aluminum material.

\section{KITEC TUBING}

Tables E-3 and E-4 give technical specifications for the Kitec tubing product. The photographs in Figures E-12 through E-16 show the tubing, fittings, accessory components, and special installation tools required to install the piping system. Two tubing t. pes, one designated for hot water/central heating applications and one designated for natural gas applications, were selected for evaluation. 
Table E-1. MEPLA Pipe Technical Specifications

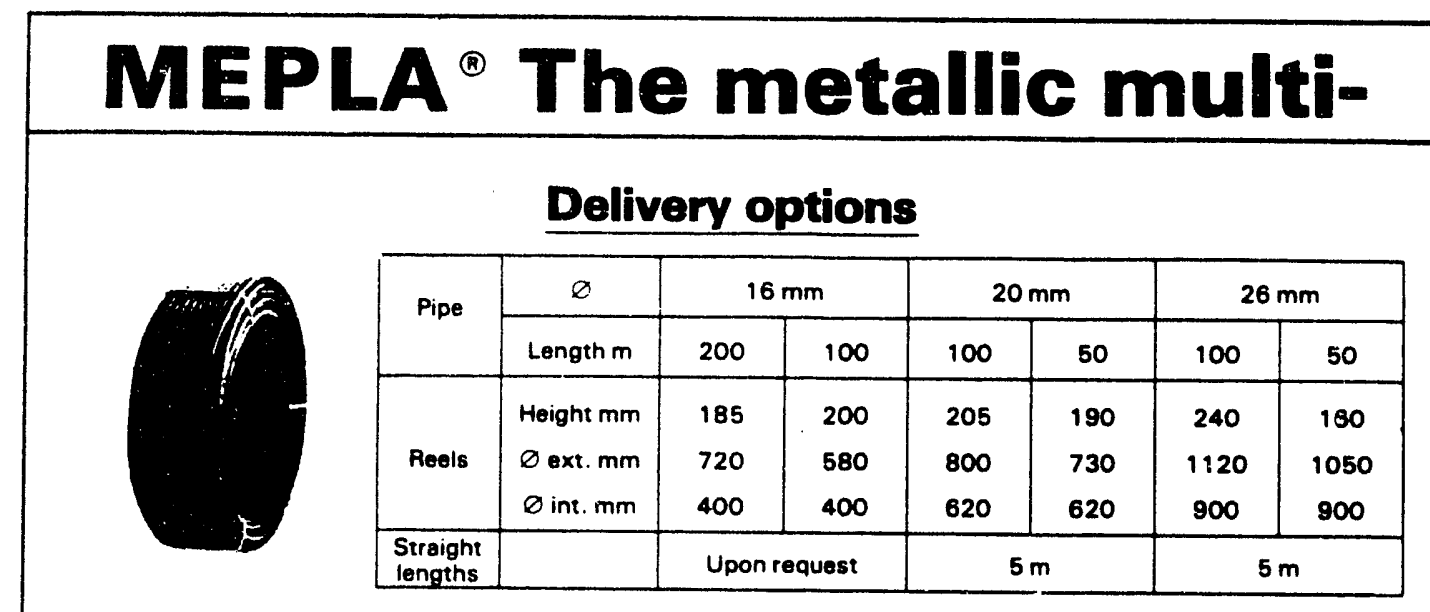

The 50 and $100 \mathrm{~m}$ reels are made to fit inside each other, thereby reducing shipment volume.

\section{Technical data}

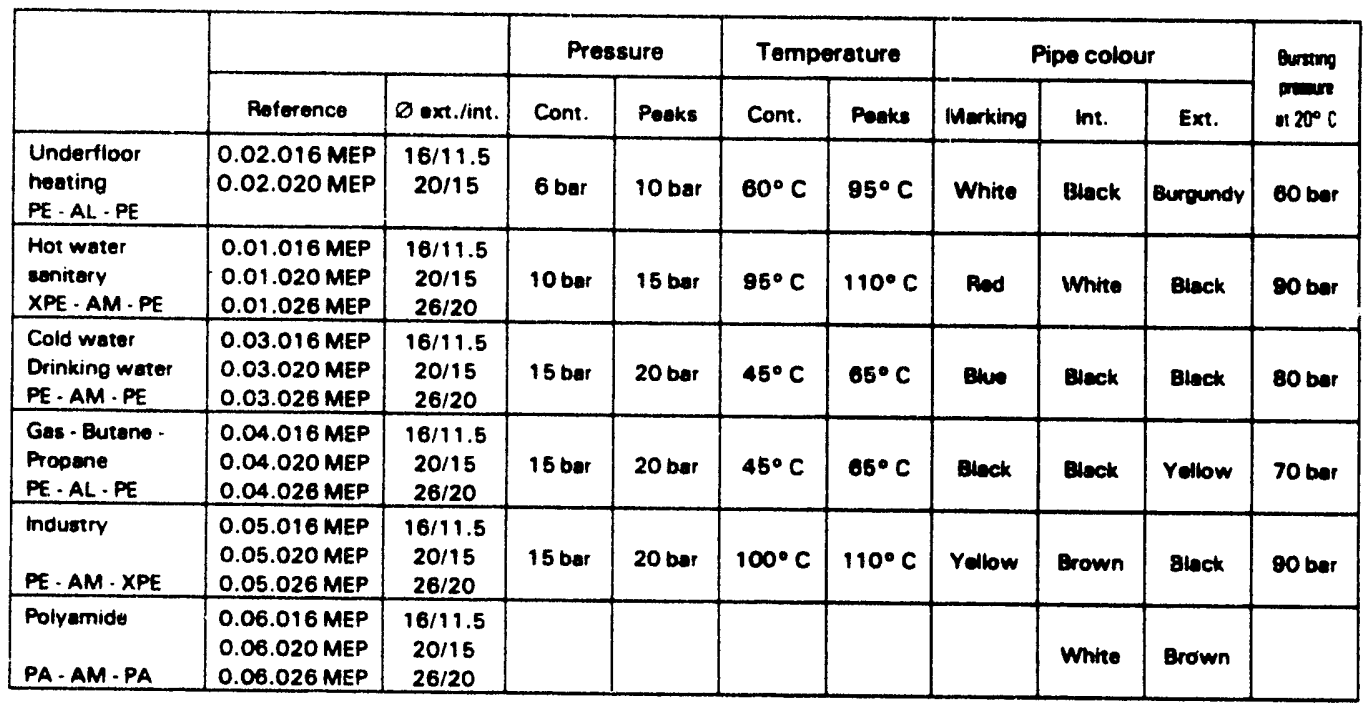

\section{Physical data}

\begin{tabular}{|c|c|c|c|}
\hline Pipe & $16 \mathrm{~mm}$ & $20 \mathrm{~mm}$ & $26 \mathrm{~mm}$ \\
\hline Linear mass & $125 \mathrm{~g} / \mathrm{m}$ & $185 \mathrm{~g} / \mathrm{m}$ & $300 \mathrm{~g} / \mathrm{m}$ \\
\hline Carrving capacity & $0,10381 / \mathrm{m}$ & $0,1767 \mathrm{l} / \mathrm{m}$ & $0,3146 \mathrm{l} / \mathrm{m}$ \\
\hline Thermal conductivity & \multicolumn{3}{|c|}{0,43 W/m.K } \\
\hline Linear thermal expension coefficient & \multicolumn{3}{|c|}{$26 \times 10^{-6} \times K^{-1}$} \\
\hline Gas diffusion & \multicolumn{3}{|c|}{ none } \\
\hline Absolute roughness of internal pipe & \multicolumn{3}{|c|}{$3 \mu \mathrm{m}$} \\
\hline Minimum bending radius $(5 \times$ pipe $\varnothing)$ & $80 \mathrm{~mm}$ & $100 \mathrm{~mm}$ & $130 \mathrm{~mm}$ \\
\hline
\end{tabular}


Table E-2. MEPLA Pipe Technical Specifications

\begin{tabular}{|c|c|c|c|c|c|}
\hline Peference & Designation & $5 \mathrm{~m}$ & $50 \mathrm{~m}$ & $100 \mathrm{~m}$ & $200 \mathrm{~m}$ \\
\hline $\begin{array}{l}\text { O.02.016 MEP } \\
\text { O.02.020 MEP }\end{array}$ & $\begin{array}{l}\text { Underfloor heating } \\
\qquad 16 \times 2.25 \\
\varnothing 20 \times 2.5\end{array}$ & & & & \\
\hline $\begin{array}{l}0.01 .016 \text { MEP } \\
0.01 .020 \text { MEP } \\
0.01 .028 \text { MEP }\end{array}$ & $\begin{array}{l}\text { Hot water - Sanitary - Hoating } \\
\qquad 16 \times 2.25 \\
\varnothing 20 \times 2.5 \\
\varnothing 26 \times 3\end{array}$ & & & & \\
\hline $\begin{array}{l}\text { O.03.016 MEP } \\
\text { O.03.020 MEP } \\
\text { O.03.026 MEP }\end{array}$ & $\begin{array}{l}\text { Cold- and drinking wator - } \\
\text { Food-stuffs } \\
\begin{array}{l}\varnothing 16 \times 2.25 \\
\varnothing 20 \times 2.5 \\
\varnothing 26 \times 3\end{array}\end{array}$ & & & & \\
\hline $\begin{array}{l}\text { O.04.016 MEP } \\
\text { O.04.020 MEP } \\
\text { O.04.026 MEP }\end{array}$ & $\begin{array}{l}\text { Gas - Butane - Propane - etc. } \\
\varnothing 16 \times 2.25 \\
\varnothing 20 \times 2.5 \\
\varnothing 26 \times 3\end{array}$ & & & & \\
\hline $\begin{array}{l}\text { O.05.016 MEP } \\
\text { O.05.020 MEP } \\
0.05 .026 \text { MEP }\end{array}$ & $\begin{array}{l}\text { Industry } \\
\qquad \begin{array}{l}\varnothing 16 \times 2.25 \\
\varnothing 20 \times 2.5 \\
\varnothing 26 \times 3\end{array}\end{array}$ & & & & \\
\hline $\begin{array}{l}\text { O.06.016 MEP } \\
0.06 .020 \text { MEP } \\
0.06 .028 \text { MEP }\end{array}$ & $\begin{array}{l}\text { Polyamide } \\
\qquad \begin{array}{l}\varnothing 16 \times 2.25 \\
\varnothing 20 \times 2.5 \\
\varnothing 26 \times 3\end{array}\end{array}$ & & & & \\
\hline & & & & & \\
\hline
\end{tabular}




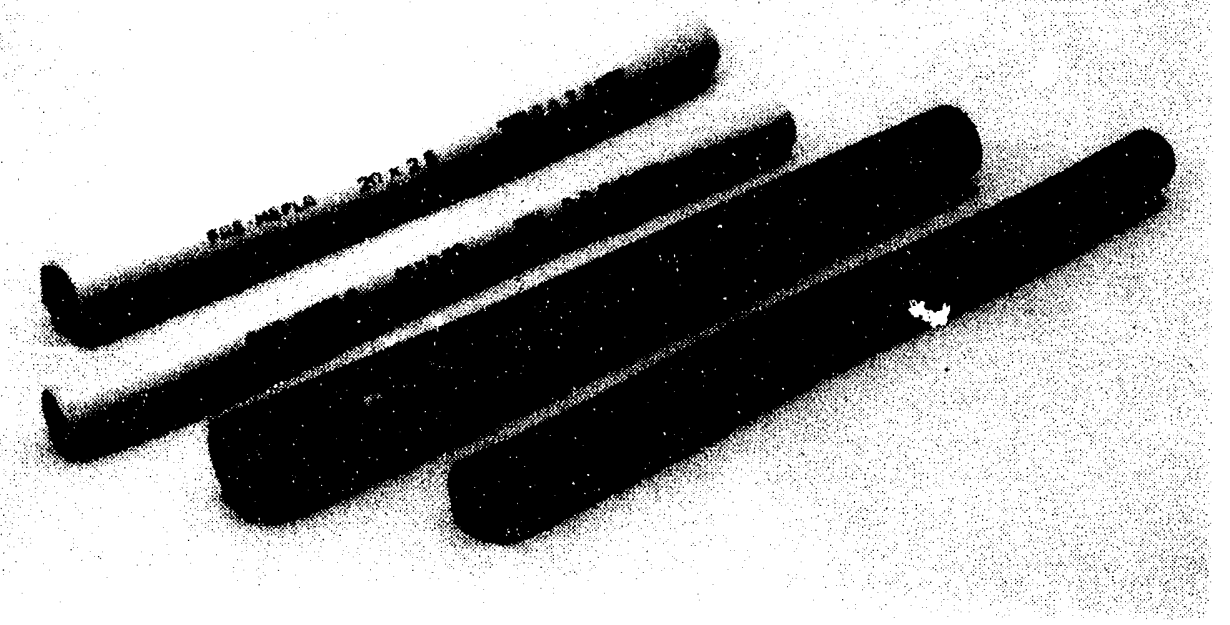

Figure E-5. MEPLA Pipe Samples

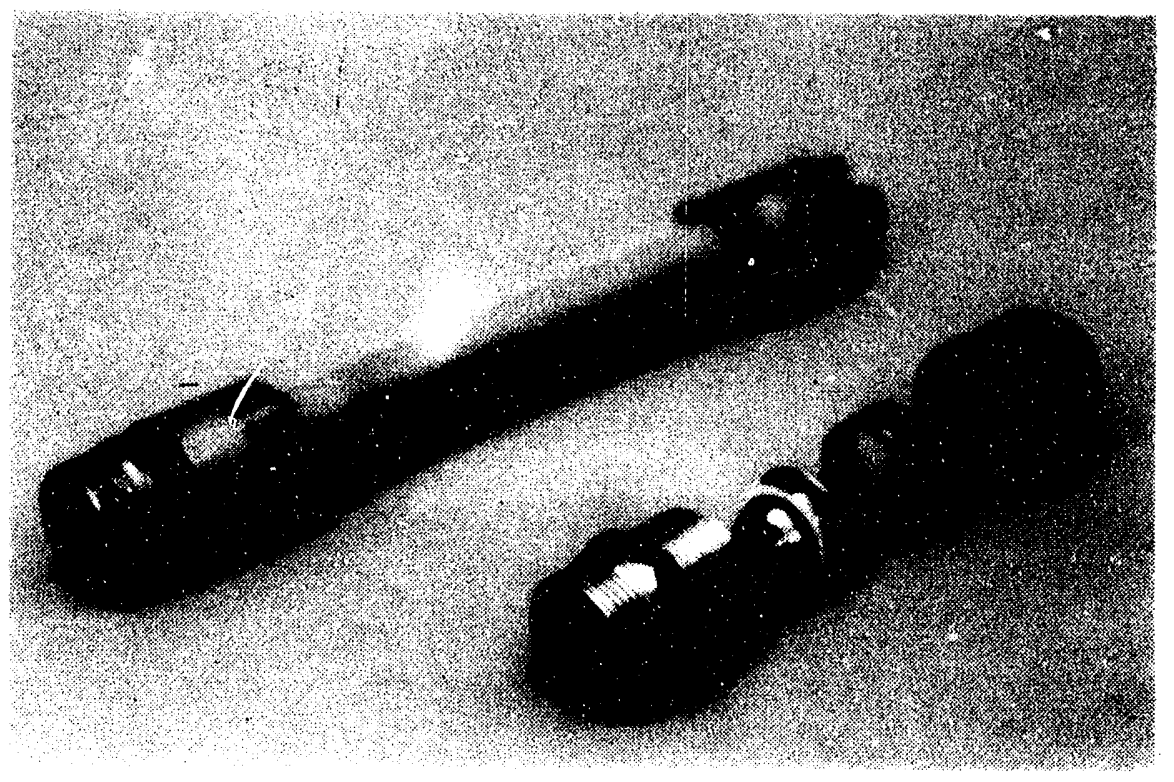

Figure E-6. MEPLA Pipe Mechanical Fittings 


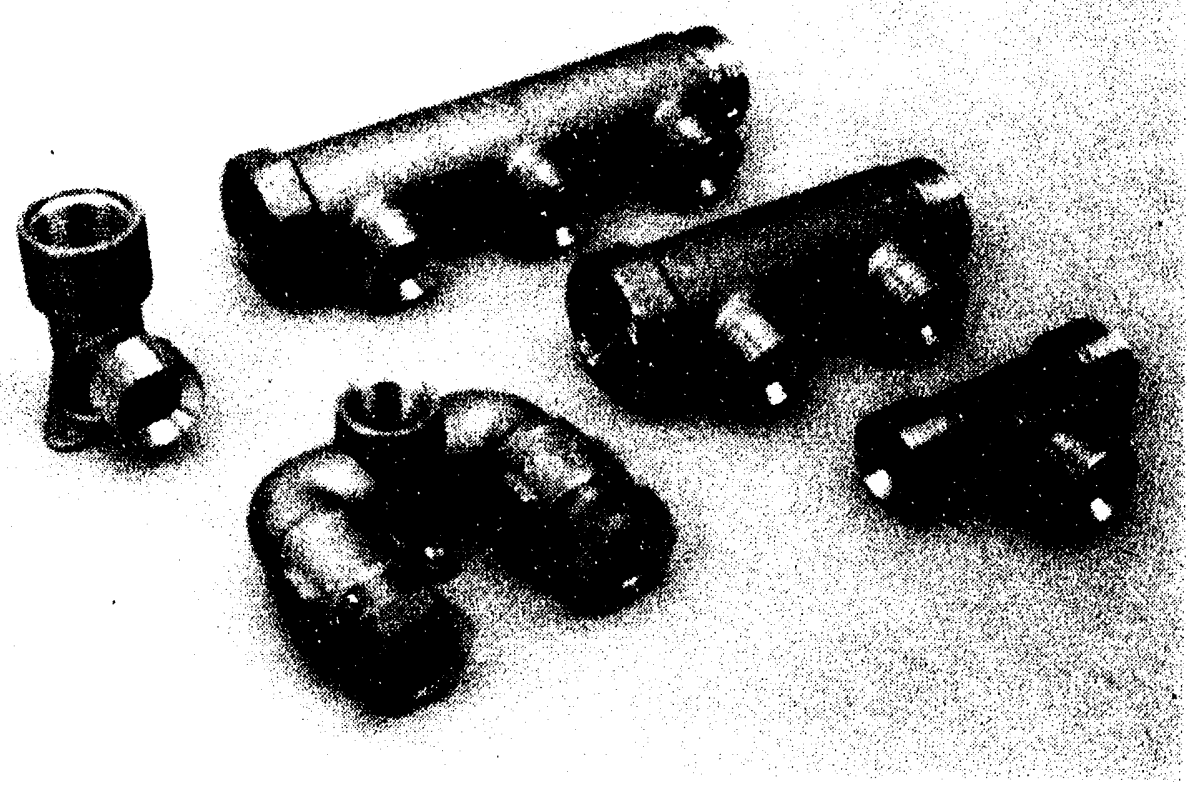

Figure E-7. MEPLA Pipe Multiport Manifolds

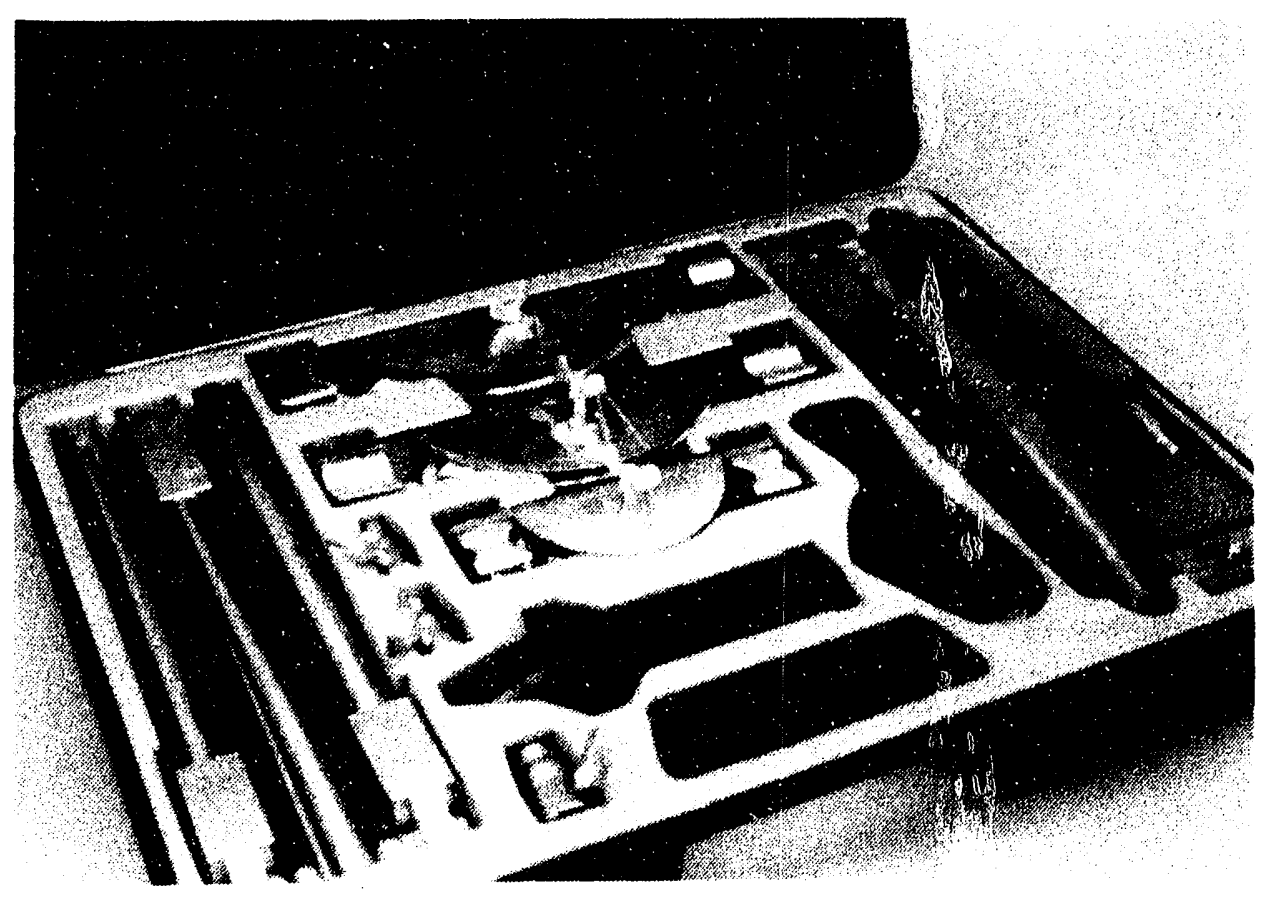

Figure E-8. MEPLA Pipe Installation Tool Kit 


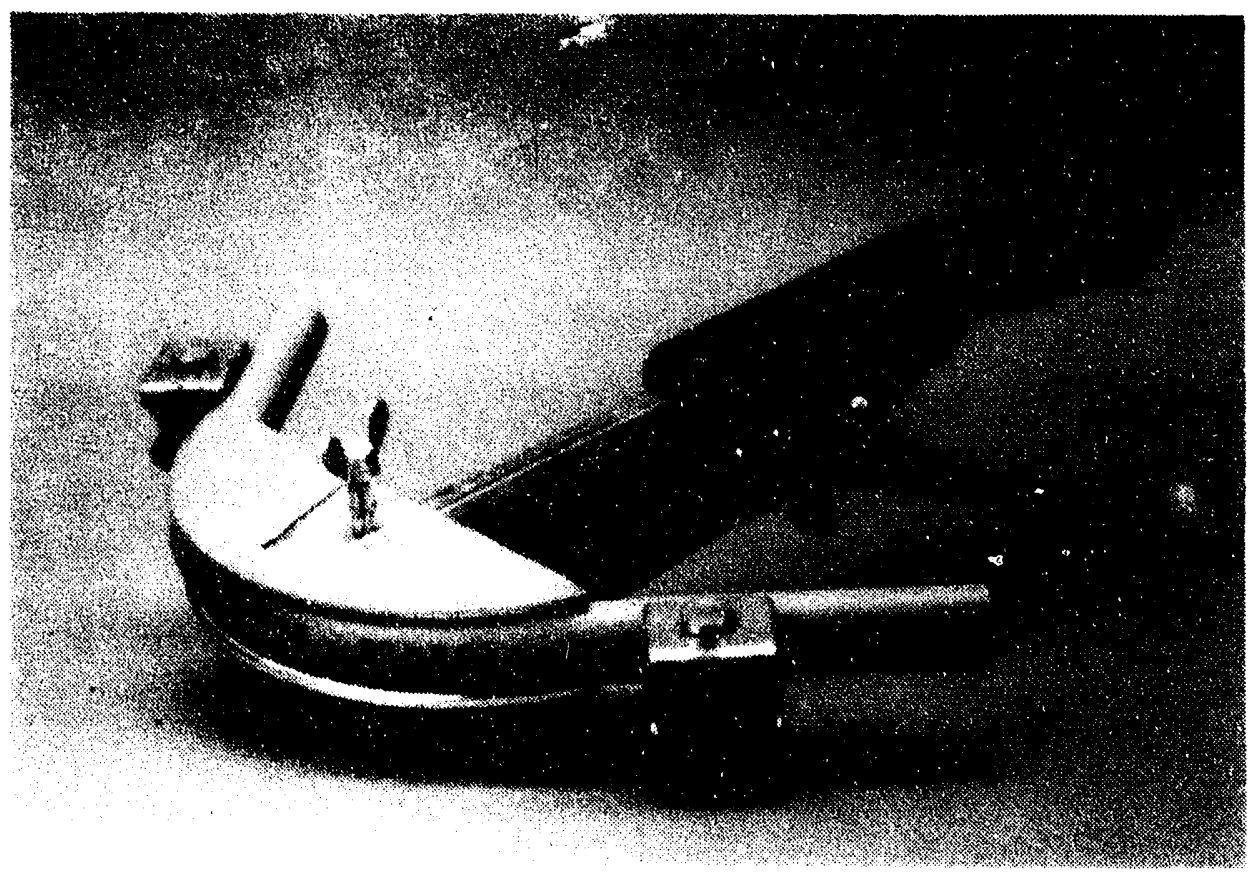

Figure E-9. MEPLA Pipe Installation Tools

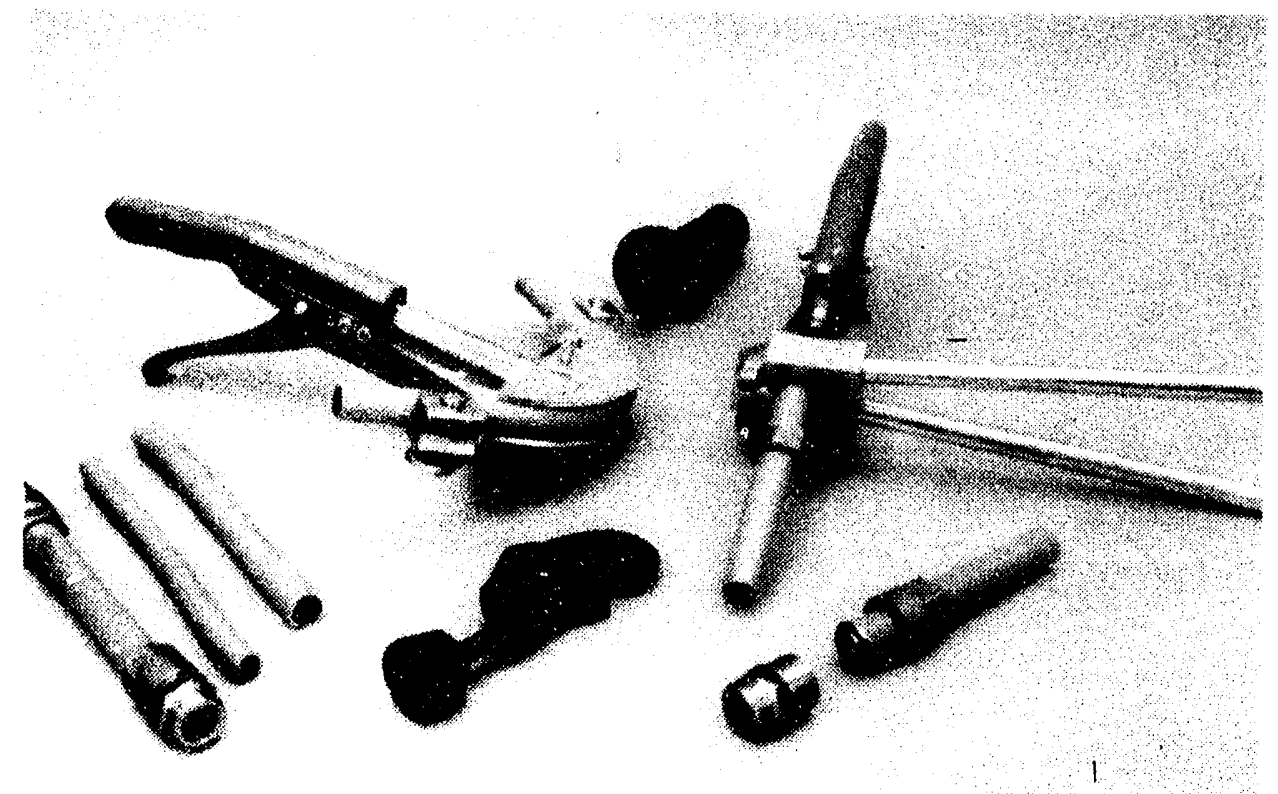

Figure E-10. MEPLA Pipe Bending Tool 


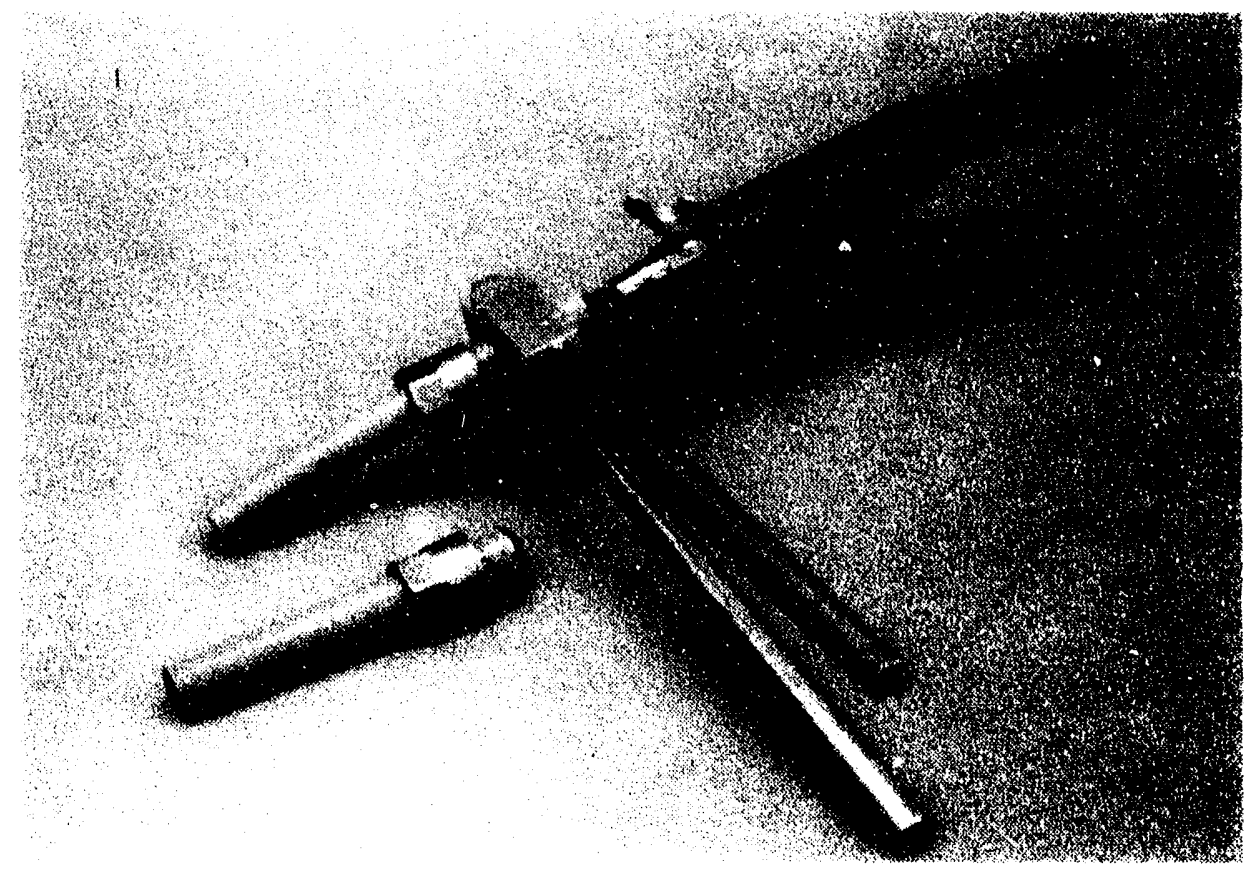

Figure E-11. MEPLA Pipe End Preparation Tool 
Table E-3. Kitec Tubing Technical Specifications

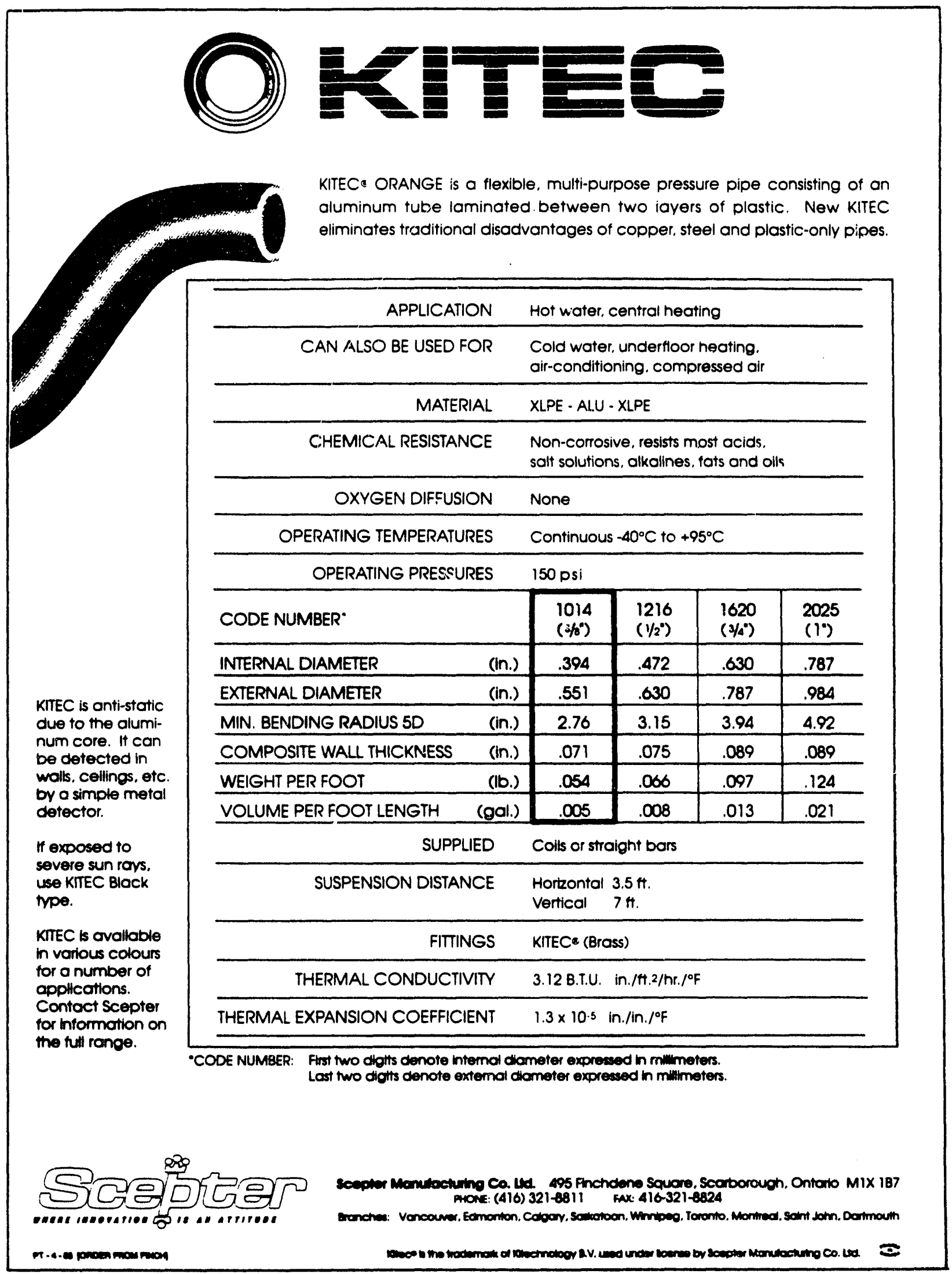


Table E-4. Kitec Tubing Technical Specifications

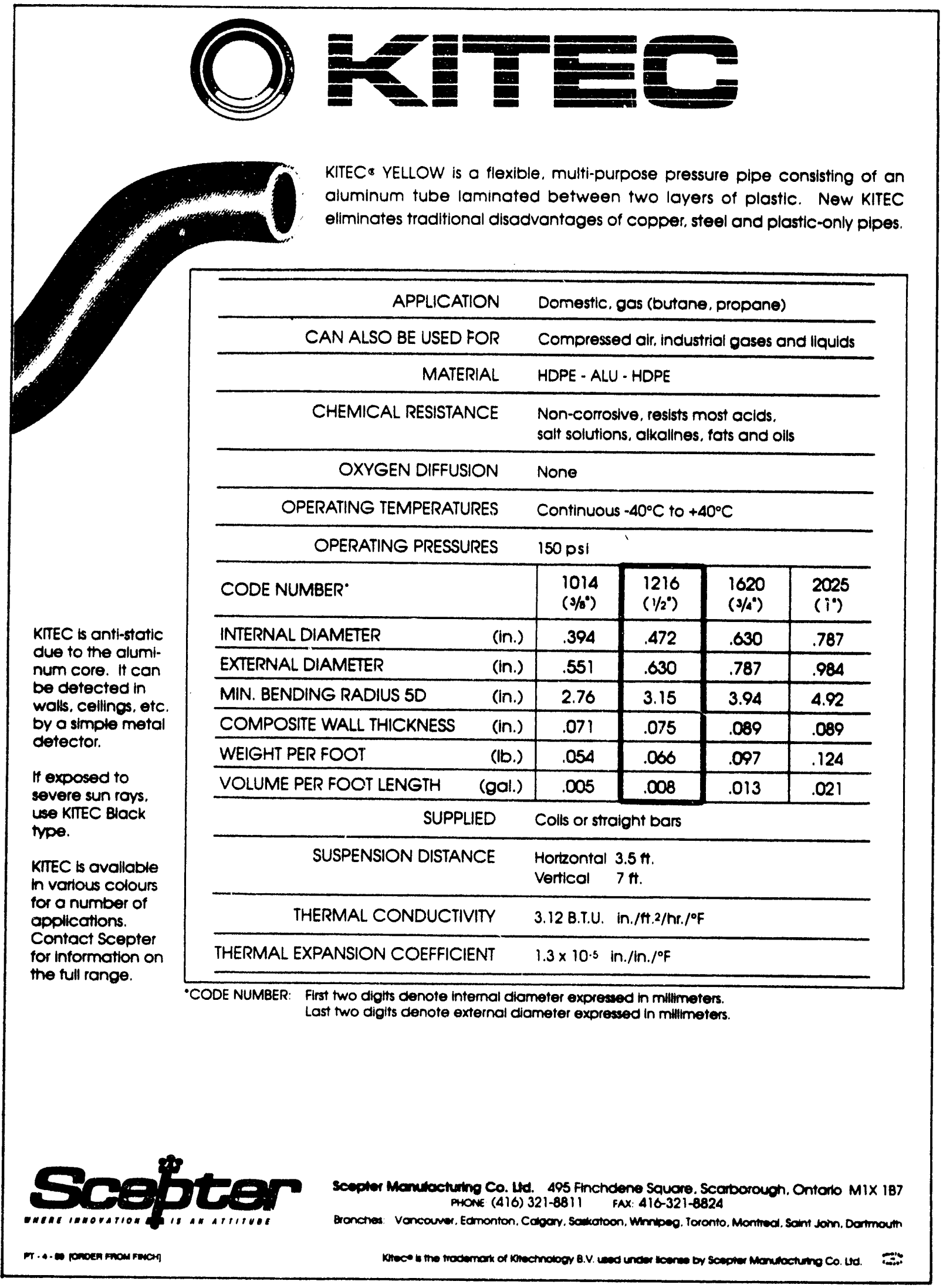




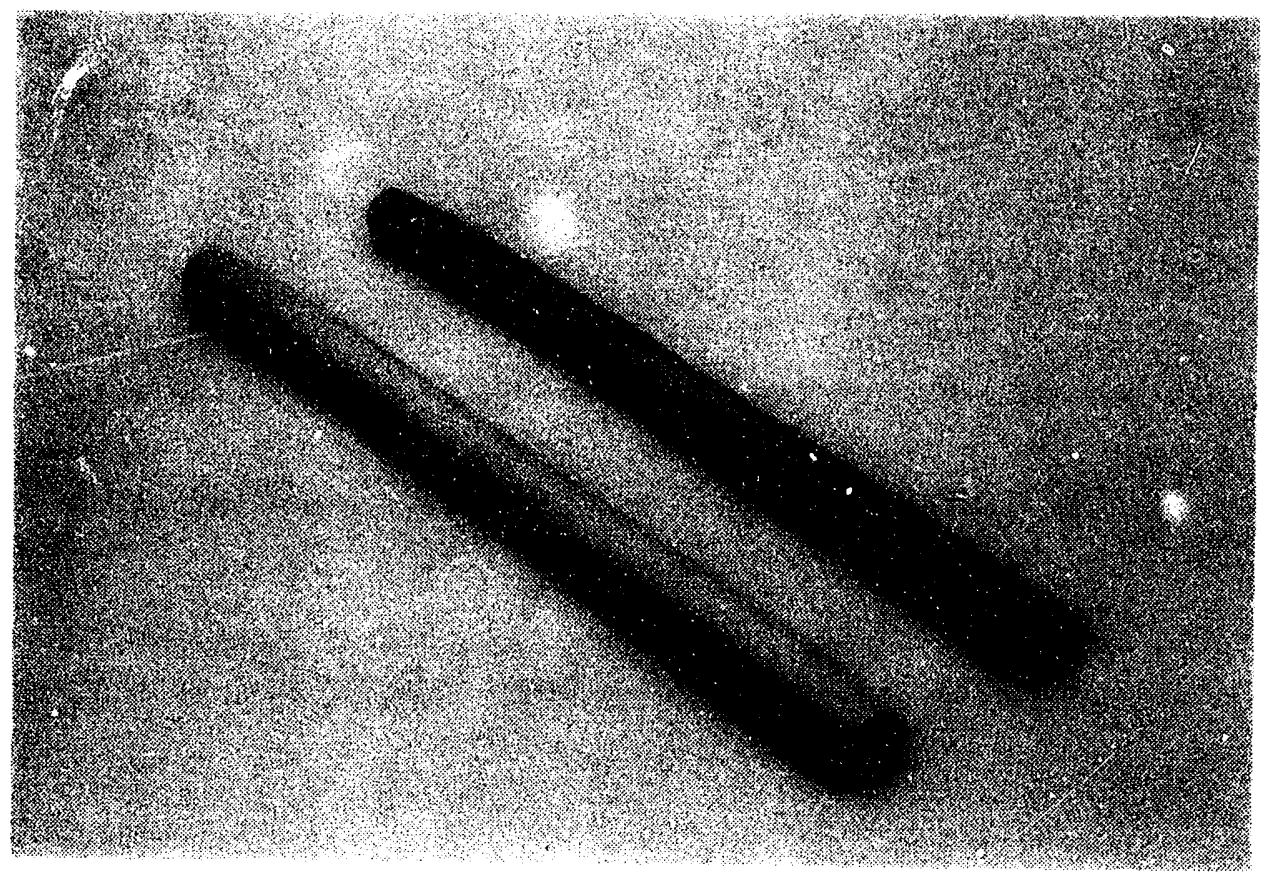

Figure E-12. Kitec Tubing Samples

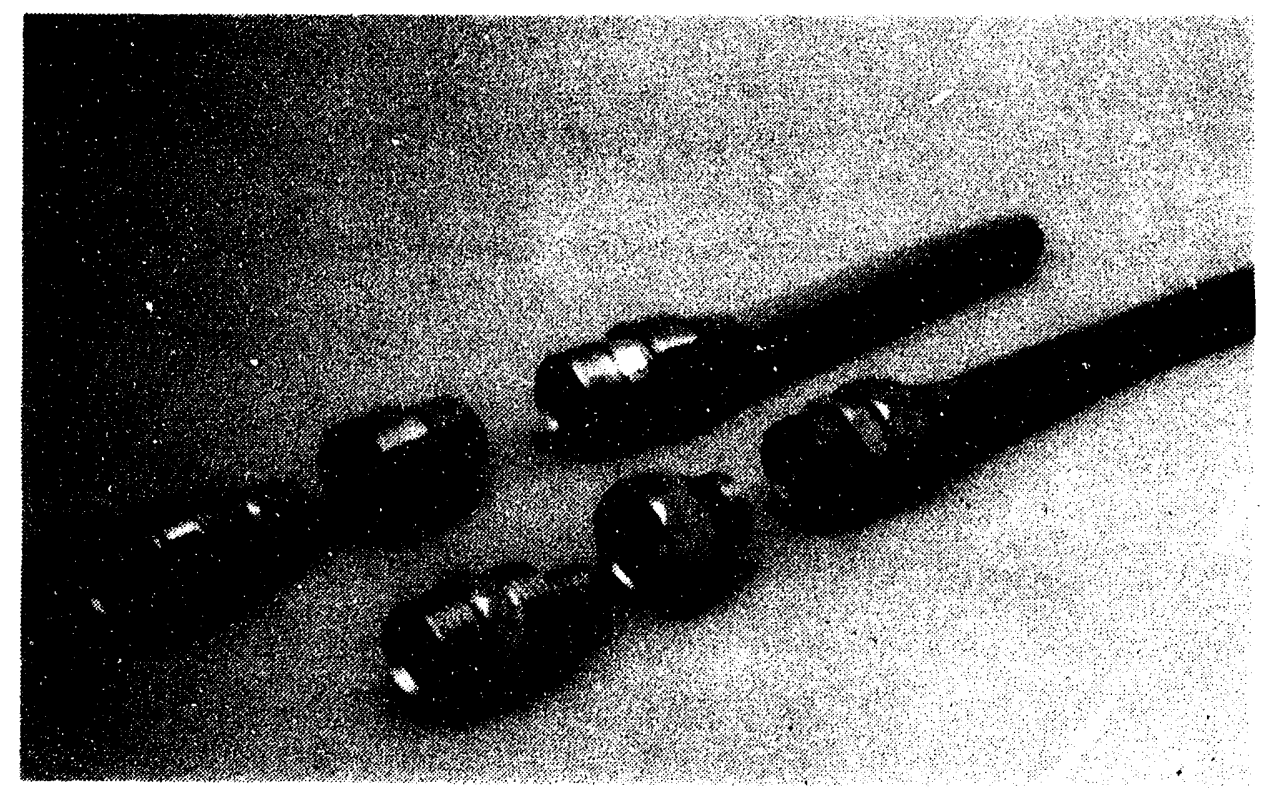

Figure E-13. Kitec Tubing Mechanical Fittings

E-15 


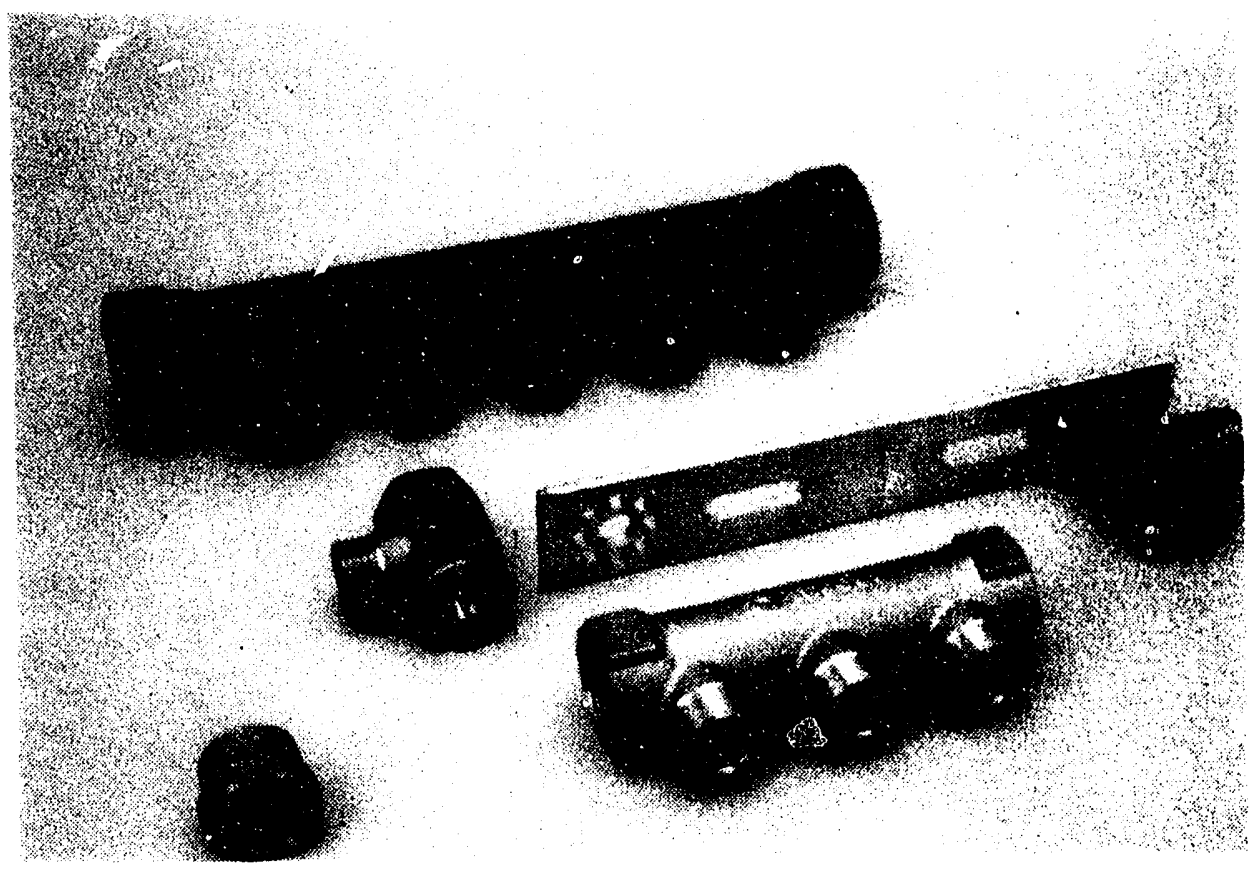

Figure E-14. Kitec Tubing Multiport Manifolds

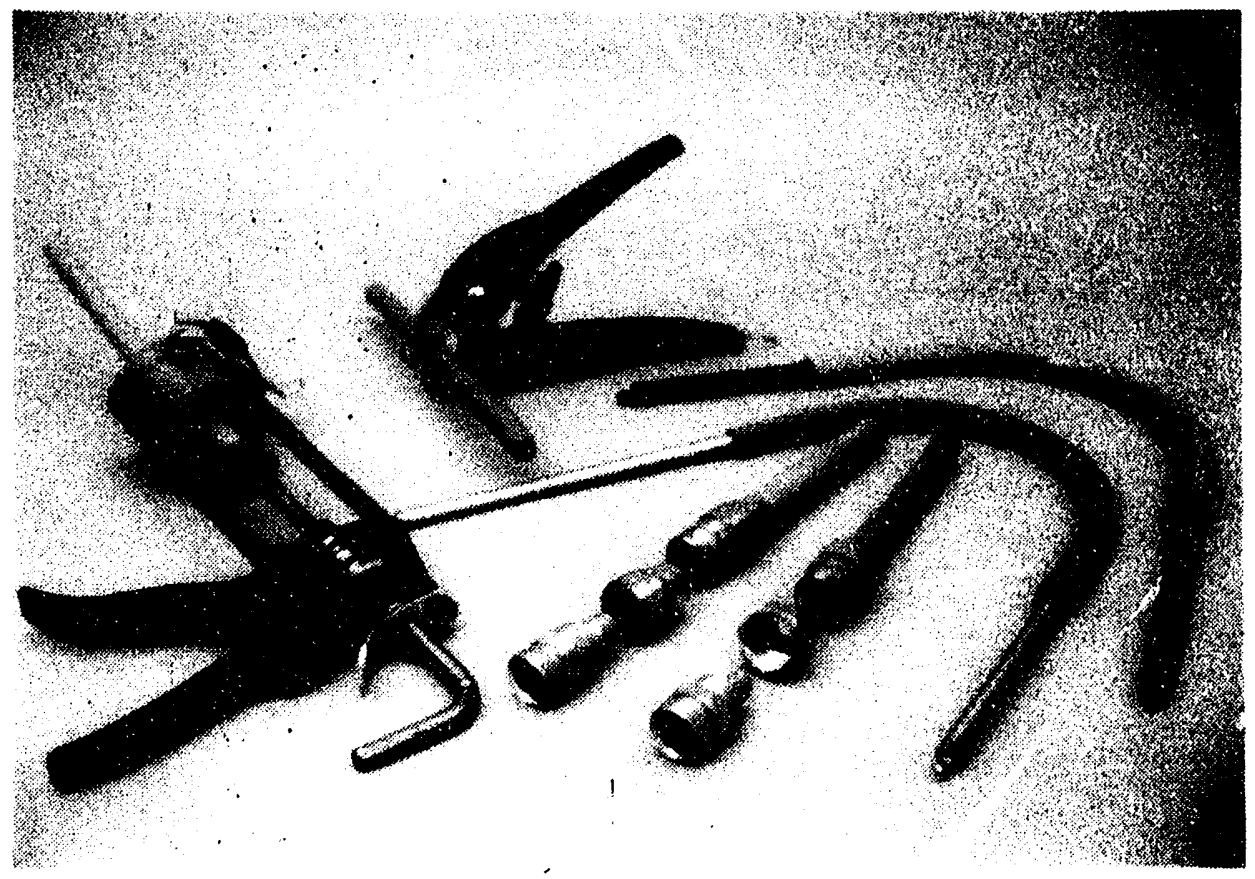

Figure E-15. Kitec Tubing Installation Tools 


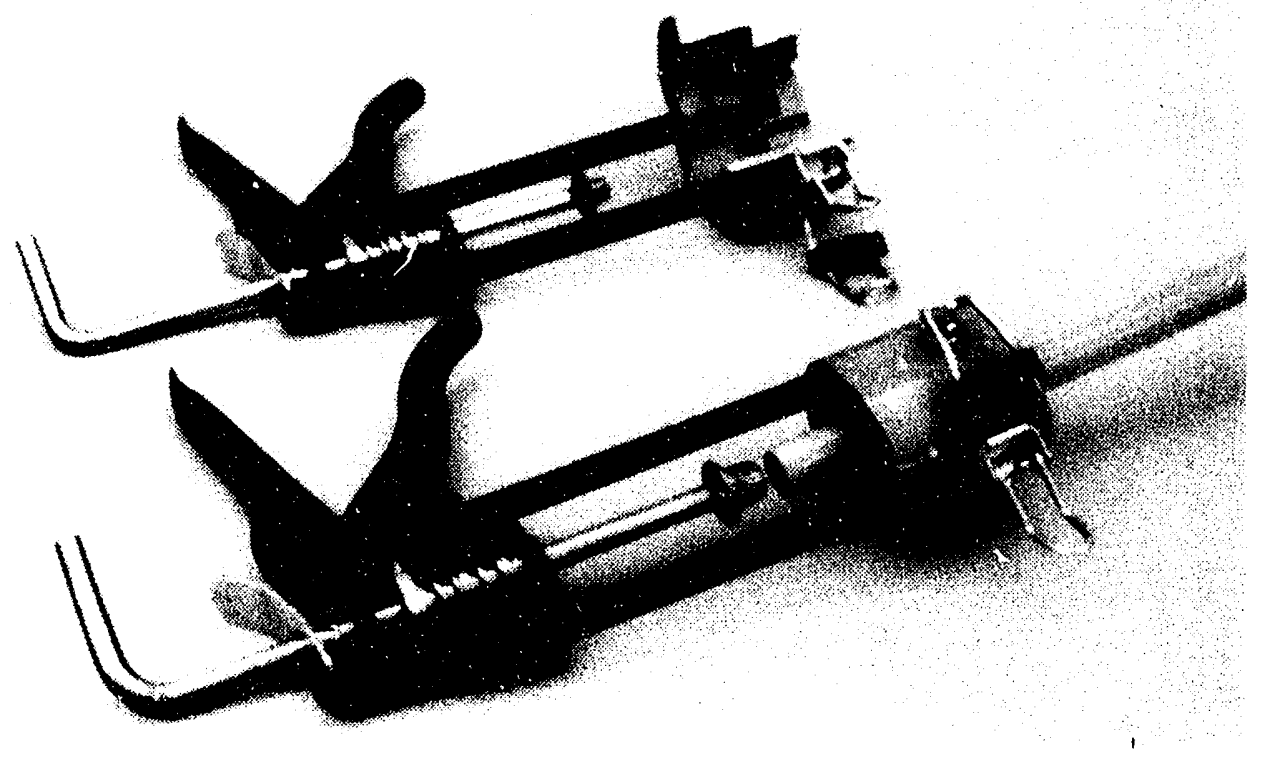

Figure E-16. Kitec Tubing End Preparation Tool 


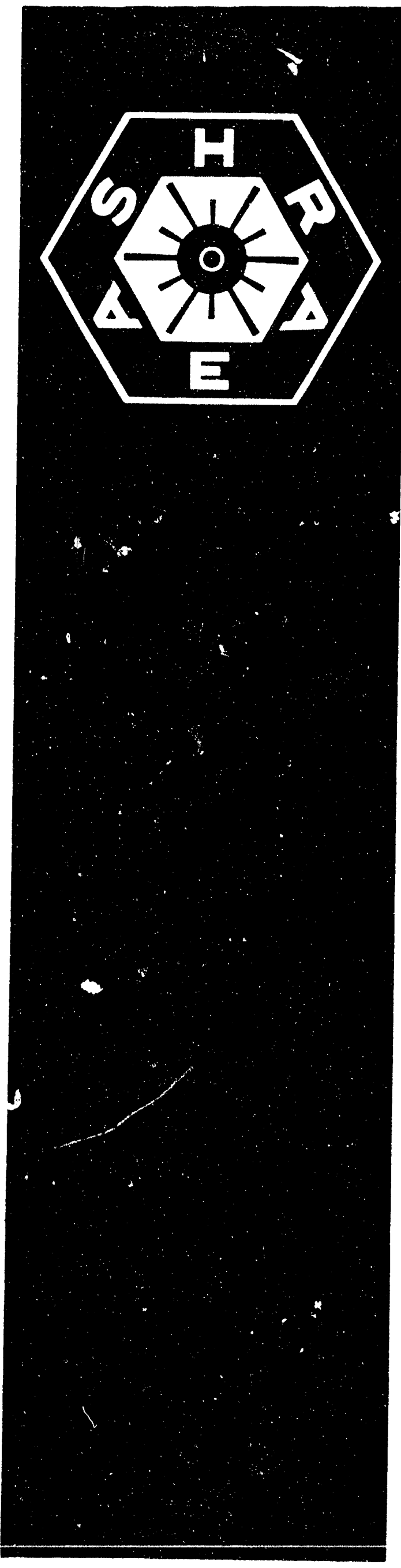

\section{ANSI/ASHRAE 124P}
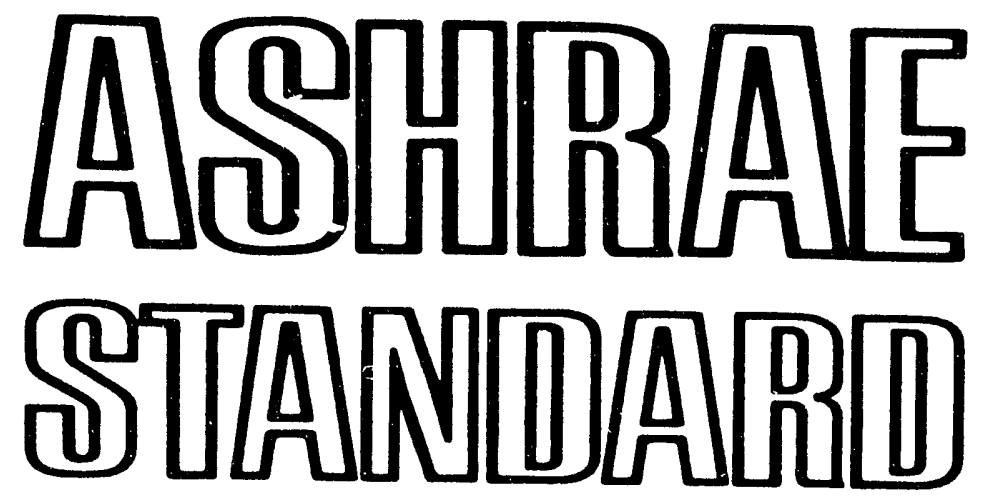

\section{PROPOSED AMERICAN NATIONAL STANDARD}

METHOD OF TESTING

FOR RATING

COMBINATION SPACE

HEATING/WATER

HEATING APPLIANCES

\section{PUBLIC REVIEW DRAFT}

March 13, 1987

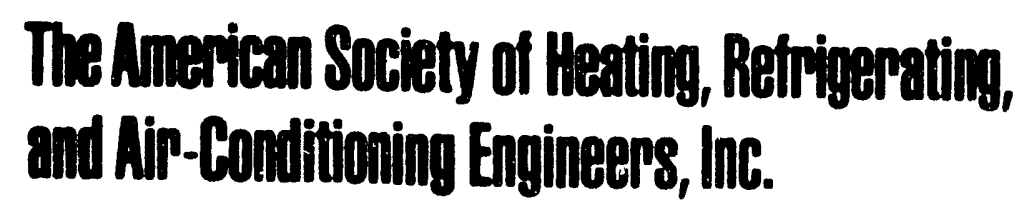

1791 Tullie Circle, NE, Allanta, en 30329 


\section{NOTICE : COMMENTS ON \\ DRAFT STANDARD}

\section{Instructions for Filing Comments}

A. If you wish to make comments on the attached draft standard, they must be submitted by: June 15, 1987

These should be sent to:

$$
\begin{aligned}
& \text { Manager of Standards } \\
& \text { ASHRAE } \\
& 1791 \text { Tullie Circle, NE } \\
& \text { Atlanta, GA } 30329
\end{aligned}
$$

B. In making comments the enclosed form must be used. Background documents to substantiate your comments should be included. Do not return marked up copies of the draft.

2. Information on Review and Disposition of Comments

All comments received by ASHRAE are acknowledged and forwarded to the Standards Project Committee (SPC) for its consideration. The SPC will inform commentors of the disposition of their comments. 
FORM FOR COMMENTING ON

PROPOSED ASHRAE STANDARDS

1. Name Date

Organization

Address

Telephone Number

Number and Title

of Standard

124P, "Method of Testing for Rating Combination

Space Heating/Water Heating Appliances"

2. Section or paragraph

3. Recommended changes

4. Substantiating statements

Use separate form for each comment, completing IInes 2 - 4 only

Mail To: Manager of Standards

ASHRAE

1791 Tullie Circle, NE

Atlanta, GA 30329 
Page

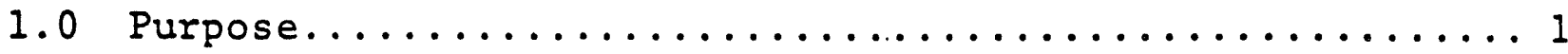

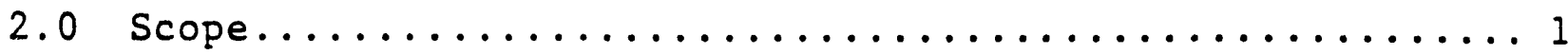

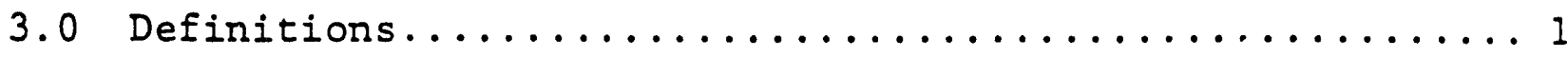

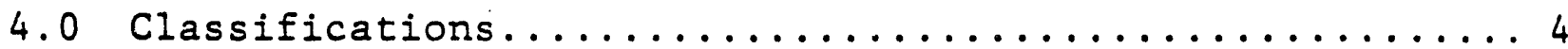

5.0 Requirements.........................

5.1 Space Heating Performance................ 4

5.2 Water Heating Performance................. 5

6.0 Instruments........................... 5

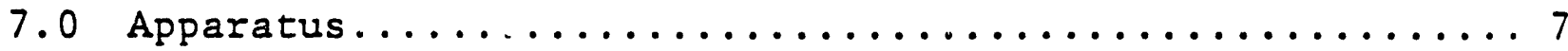

7.2 Type I Appliances..................... 7

7.2 .1 Space Heating Function................ 7

7.2 .2 Water Heating Function................ 7

7.3 Type II Appliances.....................

7.3 .1 Water Heating Function................ 9

7.3 .2 Space Heating Function....................

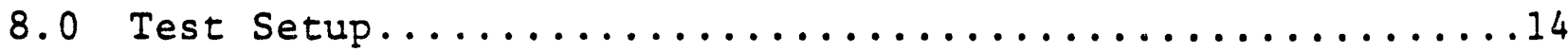

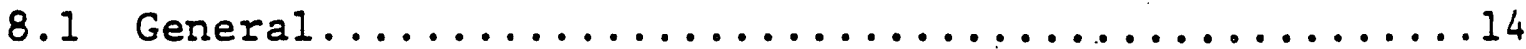

8.2 Air Water and Electrical....................

8.3 Power Input Determination....................

8.4 Setting the Tank Thermostat(Type II Appliances)....16

8.5 Setting Control of Type I Integrated

Water Heater.............................

8.6 Setting Control of Tankless Water Heater...........17

8.7 Flow Rate for Simulated Use Test................. 18

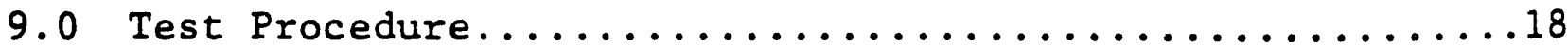

9.1 Type I Appliances........................

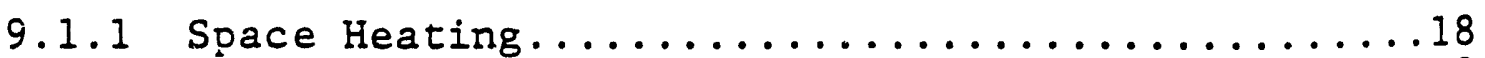

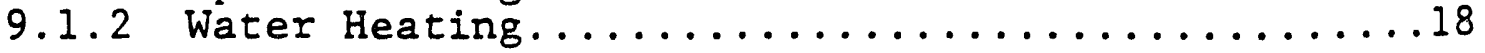


9.2 Type II Appliances................... 20

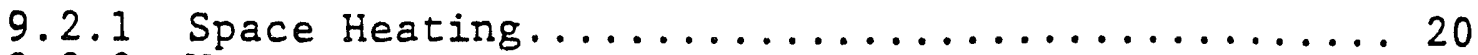

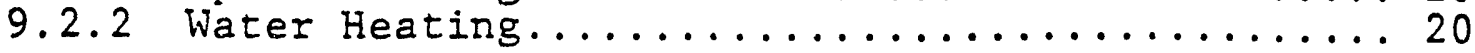

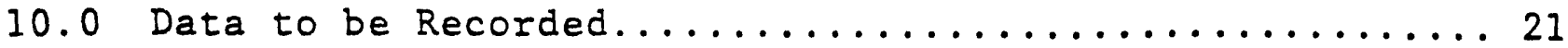

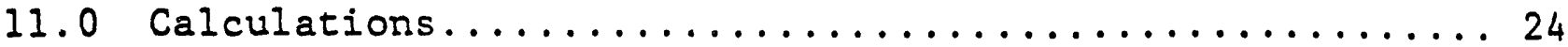

11.1 Type I Appliances...................... 24

11.1 .1 Space Heating Function.............. 24

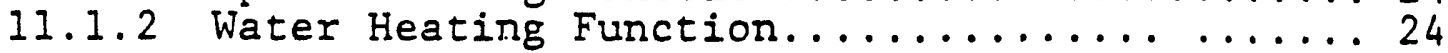

11.2 Type II Appliances................... 26

11.2.1 Space Heating Function............... 26

11.2.2 Water Heating Function................. 26

11.3 Combined Space and Water Heating Annual

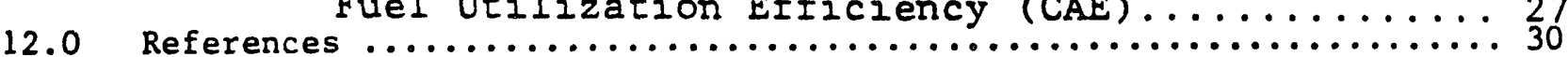

Figure 1 - Piping, Type I, Tankless Heater.............. 31

Figure 2 - Piping, Type I, Integrated Heater........... 31

Figure 3 - Piping, Type I, Tankless in Tank............ 32

Figure 4 - Test Flue, $\mathrm{Oil}$ and Power Gas Fired............ 32

Figure 5 - Test Flue, Atmospheric Gas Fired............. 33

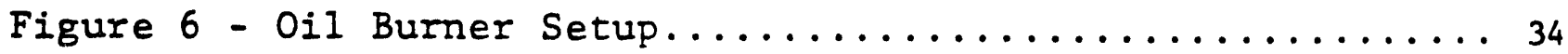

Figure 7 - Atmospheric Gas Burner Setup................ 34

Figure 8 - Setup Storage Water Heater................ 35

Figure 8A - Alternate Arrangement, Storage Water Heater...... 36

Figure 9 - Test Flue, Storage Water Heater............ 37

Figure 10 - Electrical Arrangement.................. 38

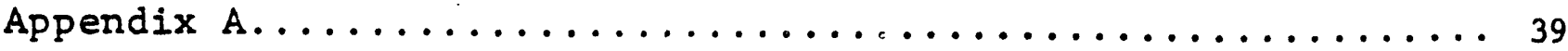

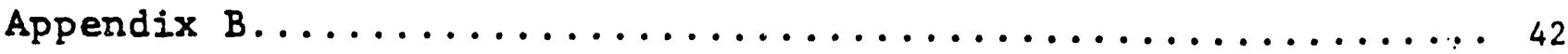

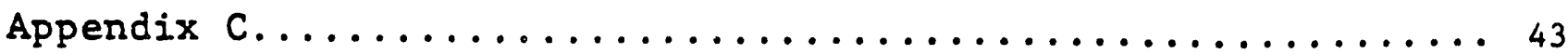


1.0 PURPOSE: The purpose is to establish a method of test to rate the performance of a combination space heating/water heating appliance.

\subsection{SCOPE :}

2.1 This test method is intended to cover electric, gas-fired or oilfired combination space heating/water heating appliances.

2.2 This standard covers appliances up $=0300,000$ Btuh rated input $(8 \% .9 \mathrm{~kW})$.

\subsection{DEFINITIONS}

boiler, low pressure steam or hot water. An electric, gas or oilburning boiler designed to supply low pressure steam or hot water for space heating application. A low pressure steam boiler operates at or below 15 psig steam pressure; a hot water boiler operates at or below $160 \mathrm{psig}$ water pressure and $250^{\circ} \mathrm{F}$ water temperature.

combination space heating/water heating eppliance. A unit which is designed to produce the total requiremenss of space heating and water heating from a single primary enercy source.

draft 00 d. A device that is not an intecral part of an appliance, and which is connected to the unit by a short length of flue pipe. It is designed to (1) provide for the exhaust of the products of combustion in the event of no draft, back draft, or stoppage beyond the draft hood, (2) prevent a back draft from entering the unit, and (3) neutralize the effact of stack action of the chimney or gas vent upon the operation of the unit. For the purpose of this Standard, this does not include integral draft diverters.

direct exhaust system. A mechanical appliance venting system supplied or recommended by the manufacturer througi which the products of combustion pass directly from the applianse to the outside and which does not employ a means of draft relief. This includes units which have small air passages in the flue which do not allow for air flow through it in excess of 108 of the maximin flue flow.

direct vent system. A system supplied by a ranufacturer which provides outdoor air directly to a unit for combustion and for draft relief, if the unit is equipped with a draft control device, and which provides for discharge of all flue gases to the outside atmosphere.

flue. A conduit between the flue outlet of the appliance and the integral draft diverter, draft hood, barometric draft regulator, vent terminal, or any other point of draft relief.

flue collar. A projection or recess provided to accomodate the vent connector or draft hood. 


\subsection{DEFINITIONS (continued)}

flue gases. All gases in the flue during the duration of combustion in the combustion chamber, including reaction products, inerts, and any excess air.

flue outlet (vent). The opening provided in an appliance for the escape of flue gases.

heat trap. A device which can be integrally cor nected or independently attached to the hot or cold water pipe connections of a water heater such that the device will develop a thermal or mechanical seal to minimize the recirculation of water due to natural thermal convection between the water heater tank and its water supply pipes and thereby reduce the heat loss to the environment from the hot water stored in the water heater.

higher heating value (H). The heat produced per unit of fuel when complete combustion takes place at constant pressure and the products of combustion are cooled to the initial temperature of the fuel and air and when the vapor formed during combustion is condensed. The higher heating value is expressed in Btu/lb or Btu/ft 3 for gaseous fuel, or Btu/lb or Btu/gal for liquid fue. .

hot water storage tank. A tank used to store water that is heated indirectly by a circulating water heater or by steam or hot waler circulating through coils or other heat exchange methods internal or external to the tank.

instantaneous water heater. A water heater which has an input rate of at least 4,000 Btu per hour per gallon of self-stored water. Automatic control is obtained by (a) water-actuated controls, (b) thermostatic control (c) combination of water actuated control and thermostatic control.

integral draft diverter. A device that is an integral part of an appliance and which is designed to (1) provide for the exhaust of the products of combustion in the event of no draft, back draft, or stoppage beyond the draft diverter, (2) prevent a back draft from entering the unit, and (3) neutralize the effect of stack action of the chimney or gas vent upon the operation of the unit. For the purpose of this standard, this does not include draft hoods.

integrated heater. A boiler and an external storage tank in which domestic water, heated by the boiler, is stored.

isolated combustion system. An installation in which a unit is installed indoors and all combustion and ventilation air is admitted through grills or ducts from outdoors and (all such air) does not communicate with air in the conditioned space.

outdoor appliance. A unit intended for installation out-of-doors, equipped with a weatherized jacket and integral venting means, and labeled for outdoor installation. 


\subsection{DEFINITIONS (continued)}

stack. The portion of the exhaust system downstream of the draft diverter, draft hood, or barometric draft regulator.

storage water heater. A closed vessel, in which water is heated by the combustion of fuels, electricity or any other source and is withdrawn for use external to the system at pressures not exceeding 160 psig, including the apparatus by which heat is generated and all controls and devices necessary to prevent water temperatures from exceeding $210 \mathrm{~F}$.

tankless heater. A heat exchanger for indirect heating of domestic water which is designed to be used without a storage tank. It may be attached directly to the boiler or installed external to the boiler and connected by piping.

thermostat, tank. A device which senses changes in stored water temperature and controls electrically, by means of separate components, the flow of fuel to the burner(s) to maintain selected temperacures.

vent connector. That portion of the venting system which connects the gas appliance to the gas vent, chimney or single-wall metal pipe.

vent pipe. Passages and conduits in a direct vent system through which gases pass from the combustion chamber to the outdoor air.

water temperature control. A device which senses boiler water temperature and controls the burner. 


\subsection{CLASSIFICATIONS}

Combination space heating/water heating appliances are classified as follows:

4.1 TYPE I APPLIANCE - An appliance whose primary function is space heating and which has a secondary function of domestic water heating. The space heating function of this type can be tested for performance and efficiency in accordance to ANSI/ASHRAE Standard 103-1982." Methods of Testing for Heating Seasonal Efficiency of Central Furnaces and Bollers as supplemented by the Federal Register of March 28, 1984 (49 FR 12148). (2) Subcategories include:

4.1.1 Tankless heater directly in appliance. See Fig. 1.

4.1.2 Tankless heater in external tank. See Fig. 3. This includes a tank within a tank where the volume of boller water is greater than the volume of domestic water.

4.1.3 Integrated heater with domestic water in external tank. See Fig. 2. This includes a tank within a tank where the volume of domestic water is greater than the volume of boiler water.

4.2 TYPE II APPLIANCE - An appliance hose primary function is domestic water heating and which has a secondary function of space heating. The domestic water heating function of this type can be tested for performance and efficiency in accordance with 10 CFR $430^{\text {(3) }}$ - subpart $B$, appendix $E$ of the Federal Regulations, or where appropriate, ANSI 221.10.3 - 1984. (4)

Subcategories include:

\subsubsection{Storage water heater}

\subsubsection{Instantaneous water heater}

4.3 TYPE III APPLIANCE - An appliance whose primary function is to both heat space and heat water. For the purpose of this standard it can be tested as a Type I or Type II appliance.

\subsection{REQUIREMENTS}

\subsection{SPACE HEATING PERFORMANCE}

5.1.1 Type I Appliance - The space heating performance shall be determined from tests conducted in accordance to ANSI/ASHRAE Standard 103-1982." Methods of Testing for Heating Seasonal Efficiency of Central Furnaces and Boilers as supplemented by the Federal Register of March 28, 1984 (49 FR 12148). (2) 
5.1.2 Type II Appliance - Space heating performance parameters shall be determined from tests conducted in accordance to ANSI/ASHRAE Standard 103-1982." Methods of Testing for Heating Seasonal Efficiency of Central Furnaces and Boilers as supplemented by the Federal Register of March 28, 1984 (49 FR 12148) (2) and the additional provistons of Sect. 6 through 10 of this standard.

5.1.2.1 Waiver of Space Heating Tests - If the optional procedure for calculating the combined efficiency as defined in section 11.3 .6 is employed for a Type II appliance intended to be installed as an isolated combustion system, the space heating tests prescribed in 5.1.2 do not have to be conducted for that appliance.

\subsection{WATER HEATING PERFORMANCE}

\subsubsection{Tyne I Appliance - hater heating performance parameters shail be determined from tests conducted in accordance with this standard. \\ 5.2.2 Type II Appliance - The water heating performance shall be determined from tests conducted in accordance with this standard,

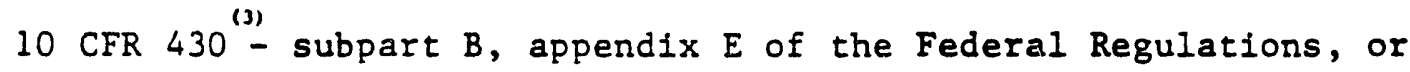 ANSI Z21.10.3-1984, ds appropriate.}

5.3 COMBINED SPACE HEATING/WATER HEATING PERFORMANCE - Combined space heating/ water heating performance of the combination appliance shall be determined from calculations as prescribed in Section 11.

\subsection{INSTRUNENTS}

\subsection{GENERAL}

All instruments shall be in working order and be calibrated periodically. Records of periodic calibration shall be kept and they shall contain at a minimum the date of calibration, method of calibration, and reference standard used.

\subsection{TEMPERATURE}

6.2.1 Thermometers. Thermometers shall have an error no greater than $\pm 1 F$.

6.2.2 Thermocouples. Thermocouples and their read out instrumentation shall have an error no greater than $\pm 2 F$. Thermocouples shall be the bead type having a wire size no greater than No. 24 American Wire Gauge (AWG). Where there is a possibility that the thermocouple(s) could receive direct radiation from the flame, use of a radiation shield is required. 
6.2.3 Thermocouple Grid. Thermocouple grid shall be constructed of thermocouples of the type described in 6.2.2. The grid shall be wired in parallel in a test plane perpendicular to the axis of the test flue, stack, or vent pipe (direct vent system) and the thermocouple leads shall be equalized in length before paralleling.

\section{3 PRESSURE}

Gas, oil, air, water, and steam pressure measuring instruments shall be calibrated so that the error is no greater than the following:

6.3 .1 Gas - \pm 0.2 inch water column.

6.3 .2 ㅇil - \pm 0.5 pounds per square inch.

6.3 .3 Air \pm 0.01 inch water column.

6.3 .4 Steam - \pm 0.2 inch mercury column.

6.3 .5 water - \pm 0.5 pounds per square inch.

6.4 DRAFT

Draft gauges shall have an accuracy of \pm 0.005 inch water column. Minimum divisions on the draft gauge shall be 0.005 inches of water column.

6.5 COMBUSTION PRODUCTS

Stack and flue $\mathrm{CO}_{2}$ (carbon dioxide) shall be determined with an instrument providing a ruading with an error no greater than \pm 0.1 percentage points. 6.6 WEIGHT OR VOLUNE

The error associated with the measuring instruments shall not exceed \pm 0.5 percent of the hourly rate.

6.7 TIME

The error associated with timing instruments shall not exceed \pm 0.5 second.

6.8 SMOKE

Smoke-measuring instruments shall comply with requirements for smoke meters as outlined in Method of Test for Smoke Density in the Flue Gases from Burnir Distillate Fuels, ANSI 211.182-1965 (R-1971) ASTM-D-2156-65 (1980).

\subsection{ENERGY FLOW RATE}

6.9 .1 Electricity. The error shall be no greater than one percent.

6.9 .2 Gas. The error shall be no greater than one percent.

6.9 .3 Oil The error shall be no greater than one percent.

6.10 ENERGY CONSUMPTION

6.10.1 Electricity. The error shall be no greater than two percent. 6.10 .2 Gas. The error shall be no greater than two percent. 6.10 .3 Oil. The error shall be no greater than two percent. 


\subsection{Higher Heating Value}

6.11 .1 Gas. The error shall be no greater than one percent.

6.11 .2 Oil. The error shall be no greater than one percent.

\subsection{APPARATUS}

\subsection{GENERAL}

The apparatus described below is used in conjunction with Type I or Type

II combination space heating water heating appliances during the testing.

\subsection{TYPE I APPLIANCES}

7.2.1 Space Heating Function - refer to Section 7 of ASHRAE 103-1982

\subsubsection{Water Heating Function Requirements}

\subsubsection{Flue requirements for gas fired Type I Appliances. For a gas} unit having a vertically discharging draft hood outlet, a 5 foot vertical flue pipe extension having a diameter equal to the largest flue collar size of the draft hood shall be connected to the draft hood outlet. For a gas unit having a horizontally discharging draft r.yod outlet, a 90 degree elbow having a diameter equal to the largest flue collar size of the draft hood shall be connected to the draft hood outlet. A 5 foot length of flue pipe shall be connected to the elbow and oriented to discharge vertically upward. Perform all tests with the natural draft established by this length of flue pipe. Direct vent and direct exhaust gas units shall be installed with venting equipment as specified in the manufacturer's instructions; however, the vertical length of the flue pipe shall be no greater than 5 feet. (See Figure 5.)

\subsubsection{Flue requirements for oil-fired and power gas fired Type I} appliances - The unit shall be provided with a flue pipe and elbows as shown in Figure 4. A length of flue pipe sufficient to establish the manufacturer's recommended draft shall be connected to the elbow fitting and oriented to discharge vertically upward. When ceiling height limits the use of a sufficient length of vertical flue pipe for an oil unit, a mechanical draft inducer may be used during periods of burner firing to establish the specified draft in the flue. Direct vent 
and direct exhaust units shall be installed with venting equipment as specified in the manufacturer's instructions.

\subsubsection{Piping}

See Figures 1, 2, and 3 for typical piping arrangements. Provision shall be made to assure constant water temperature and pressure being supplied to the unit.

\subsubsection{Water Flow Measurement}

Provide appropriate weigh tanks and scales, or calibrated meters to measure water flow rate.

\subsubsection{Fuel or Energy Consumption Measurement}

Install one or more instruments which measure, as appropriate, the quantity or rate of energy consumed by the appliance when heating water. Electrical energy consumption is to be expressed in units of Kilowatt-hours. Natural gas and propane consumption shall be expressed in units of Btu. Fuel oil consumption shall be expressed in units of Btu.

\subsubsection{Room Temperature}

Install a thermocouple to measure the amblent temperature with junction shielded against direct radiation from any heat source and positioned at the vertical midpoint of the unit at a perpendicular distance of approximately 24 inches from the surface of the boiler (tankless heater), or 24 inches from both the boiler and tank jacket. Provide an associated temperature measurement and indicator system to assure that the temperature indicated for the thermocouple location is within $\pm 1 F$ of the actual temperature at that location.

\subsubsection{Thermocouple Installation}

7.2.2.7.1 Thermocouple installation for domestic water storage tanks of integrated water heaters - Install six thermocouples inside the tank. Position each thermocouple measuring junction along a vertical line at the level of the center horizontal plane of each of six non-overlapping sections of approximately equal volume from the top to the bottom of the tank such that each 
thermocouple is surrounded by water and as far as possible from any heat input device, anodic protective device or a tank wall. The anodic protective device may be removed in order to install the thermocouples and all testing may be carried out with the device removed. Install thermocouples in both the cold-water inlet pipe and the hot-water outlet pipe not more than 18" from the connections to the water heater, or where those connections are inaccessible, at the closest accessible point to those connections. Locate the thermocouples downstream of two elbows, or a turbulator, to assure good mixing.

7.2.2.7.1.1 Mean tank temperature measurement - Mean tank temperature of the water in an integrated heater tank, wherever specified shall be the mean of the temperatures determined by using the six heater tank thermocouples.

7.2.2.7.2 Thermocouple installation for gas-and oil-fired tankless water heaters - Install thermocouples in both the cold water inlet pipe and the hot water outlet pipe not more than 18" from the connections to the heat exchange unit. Locate the thermocouples downstream of two elbows, or a turbulator, to assure good mixing. Install a themocouple to measure the boiler water temperature in the location where the control well is normally installed. The thermocouple shall extend into the boiler water a distance equal to $2 / 3$ the length of the control well supplied with the boiler. The thermocouple may be inside the well, or outside at the same level and within $1 "$ of the well, but not touching the coil.

\subsection{TYPE II APPLIANCES}

7.3.1 Water Heating Function Requirements - For water heating function of (נ) storage type appliances refer to 10 CFR 430 - subpart B, appendix E of the Federal regulations. For water heating performance of instantaneous type appliances refer to ANSI 21 .10.3-1984. 


\subsubsection{Space hea'ting function requirements.}

7.3.2.1 Installation - Install the water heater according to the manufacturer's installation instructions on a 3/4-inch thick plywood platform elevated approximately 4 " off the floor by three 2" $\times$ 4" runners. For water heaters without integral heat traps and with vertical inlet and outlet pipe connections, install the inlet and outlet piping with heat traps at the inlet and outlet ports. Such heat traps may be made using pipe fittings such as elbows connected in such a fashion that the inlet and the outlet piping make vertically upward runs just before turning downward to connect to the inlet and outlet ports. For water heaters with integral heat traps or with horizontal inlet and outlet pipe connections, install the inlet and outlet piping in any convenient fashion. Sufficient clearance shall be allowed between the water heater surface and the piping (including heat traps, if any) so that when the piping is insulated as specified below, the insulation does not contact any wister heater surface except at the location where the pipe connections penetrate the water heater jacket. Insulate the relief valve and the water heater inlet and outlet piping (including heat traps, if any) ror a length of four feet from the connection at the water heater with a material having a thermal resistance ( $R$ ) value of not less than $4 \frac{h r F}{B t u}$

\subsubsection{Flue Requirements}

7.3.2.2.1 sas-Fired Water Heaters - For a gas water heater having a vertically discharging draft hood outlet, a 5 foot vertical flue pipe extension having a diameter equal to the largest flue collar size of the draft hood shall be connected to the diaft hood outlet. For a gas water heater having a horizontally discharging draft hood outlet, a 90 degree elbow having a diameter equal to the largest flue collar size of the draft hood shall be connected to the draft hood outlet. A 5 foot length of flue pipe shall be 
connected to the elbow and oriented to discharge vertically upward. Perform all tests with the natural draft established by this length of flue pipe. (See figure 8) Direct vent gas water heaters shall be installed with venting equipment as specified by the manufacturer's instructions. If the manufacturer specifies optional or adjustable venting equipment, the arrangement that will result in the highest flue loss shall be used during testing of the direct vent water heater.

7.3.2.2.2 0il-Fired and Power Gas-Fired Water Heaters - For an oil fueled or power gas-fired water heater, establish a draft at the flue collar equivalent to at least 0.02 inch of water column during periods of burner firing. For a water heater having a vertically discharging flue outlet, establish the draft by using a sufficlent length of flue pipe connected to the water heater flue outlet and oriented to discharge vertically upward. For a water heater having a horizontally discharging flue outlet, a 90 degree elbow having a diameter equal to the largest flue collar size of the draft hood shall be connected to the flue outlet. A length of flue pipe sufficient to establish the draft shall be connected to the elbow fitting and oriented to discharge vertically upward. Direct vent water heaters should be installed with venting equipment as specified in the manufacturer's instructions. 


\subsubsection{Energy Supply}

7.3.2.3.1 Electrical Supply - For an electric water heater and for the auxiliary electrical system, if any, of an oil or gas water heater, maintain the electrical supply voltage to within \pm 5 percent of the center of the voltage range specified by the water heater manufacturer on the water heater nameplate throughout the entire operating portion of each test.

7.3.2.3.2 Natural Gas - For a gas water heater utilizing natural gas maintain the gas supply at a normal inlet test pressure imediately ahead of all controls of 7 to 10 inches of water column. Use natural gas with a higher heating value of approximately 1,025 Btu per standard cubic foot. Determine the actual higher heating value, $H$, in Btu per standard cubic foot, for the natural gas to be used in the test, with an error no greater than \pm 1 percent, and use that value for all calculations included herein. Alternatively, the test can be conducted using "bottled" natural gas of a higher heating value of approximately 1,025 Btu per standard cubic foot as long as the actual higher heating value of the bottled natural gas has been determined with an error no greater than \pm 1 percent as certified by the supplier.

7.3.2.3.3 Propane Gas - For a gas water heater utilizing propane gas, maintain the gas supply at a normal test pressure immediately ahead of all controls of 11 to 13 inches of water column. Use propane with a higher heating value of approximately 2,500 Btu per standard cubic foot. Determine the actual higher heating value, $\mathrm{H}$, in Btu per standard cubic foot, for the propane to be used in the test, with an error no greater than \pm 1 percent, and use that value for all calculations 
included herein. Alternatively, the test can be conducted using "bottled" propane of a higher heating value of approximately 2,500 Btu per standard cubic foot as long as the actual higher heating value of the bottled propane has been determined with an error no greater than \pm 1 percent as certified by the supplier.

7.3.2.3.4 Oil Supply - For an oil water heater, use fuel oil with a heating value of approximately $138,500 \mathrm{Btu}$ per gallon at $70^{\circ} \mathrm{F}$. Determine the actual higher heating value, $H$, in $B$ tu per gallon for the fuel oil to be used in the test, with an error no greater than \pm 1 percent, and use that value for all calculations included herein. Alternatively, the tests can be conducted using a tested fuel oil with a certified higher heating value other than $138,500 \mathrm{Btu}$ per gallon as long as the actual higher heating value of the test fuel oil has been determined with an error of no greater than \pm 1 percent as certified by the supplier.

\subsubsection{Thermocouple Installation}

7.3.2.4.1 Tank - Install six thermocouples inside the water heater tank. Position each thermocouple along a vertical line which is centrally located on the approximate center of a section of the tank away from any heat source or other irregularity. The level of each thermocouple measuring junction shall be the center of each of six horizontal sections of approximately equal volume. The anodic protective device may be removed in order to install the thermocouples and all testing may be carried out with the device removed. 
7.3.2.4.2 Piping - Install thermocouples in both the coldwater inlet pipe and the hot-water outlet pipe not more than 18 inches from the connections to the water heater, or where those connections are inaccessible, at the closest accessible point to those connections. Locate the thermocouples downstream of two elbows, or a turbulator, to assure good mixing.

7.3.2.4.3 Ambient - Install a thermocouple with junction shielded against direct radiation from the water heater and positioned at the vertical mid-point of the heater at a perpendicular distance of approximately 24 inches from the surface of the water heater jacket.

7.3.2.5 Fuel or Energy Consumption Measurement - Install one or more instruments which measure, as appropriate, the quantity and rate of electrical energy, natural gas, propane and fuel oil consumed by water heater and auxiliary devices.

7.3.2.6 Thermocouple installation in Flue Pipe - For determining flue temperatures install a 5 thermocouple grid 12" above the jacket top. Arrange the thermocouples in a grid with one thermocouple in the center of the test stack, and the remaining as shown in Fig. 9. If there is a possibility that the thermocouples could receive direct radiation from the flame, install radiation shields on the flame side of the thermocouple only and position the shields so that they do not touch the thermocouple junctions.

\subsection{TEST SETUP}

8.1 GENERAI - Type 1 and Type II combination space heating/water heating appliances shall be equipped with the apparatus described in 7 , and the instrumentation described in 6 shall be set up for recording data. Refer to Figures 1 through 10 when equipping the Type I and Type II appliances with the apparatus and instrumentation. The equipment shall be adjusted to the test requirements or conditions described in 8.4 . 
8.1.1 Test Unit - Type I and Type II combination space heating/water heating appliance.

8.1.1.1 Integrated Units - Install the unit according to the manufacturer's directions. Install the connecting piping between the boiler and the storage tank as recommended by the manufacturer.

8.1.1.2 Tankless Units - Tankless water heaters shall be installed in the boiler or in the external tank containing boiler water. The boiler shall be equipped with a pressure relief valve. Expansion of the water during the test shall be provided for.

8.1.1.3 Storage Tank Units - Install the appliance according to the manufacturer's installation instructions. Appliance shall be equipped with a pressure and temperature relief valve.

8.1.1.4 Instantaneous Units - Install the appliance according to the manufacturer's installation instructions.

8.2 AIR, WATER, AND ELECTRICAL

8.2.1 Water Supply - During the entire test maintain the water supply to the appliance inlet at a temperature of between $56 \mathrm{~F}$ and $60 \mathrm{~F}$, and at a gauge pressure of between 40 pounds per square inch and the maximum pressure specified by the manufacturer for the appliance under test. If the water supply pressure varies outside of these limits during testing, the heater shall be isolated by use of a shut-off valve in the supply line with an expansion tank installed in the supply line downstream of the shut-off valve. There shall be no shut-off means between the expansion tank and the water heater inlet.

8.2.2 Room Ambient Temperature - Maintain the ambient air temperature of the test room between $65 \mathrm{~F}$ and $70 \mathrm{~F}$ at all times during the test, as measured according to section 7.2 .2 .6 or 7.3.2.4.3.

8.3 POWER INPUT DETERMINATION - Initiate normal operation of the appliance and determine the power input, Qin, to the main burners (Including pilot light power, if any) or heating elements of the appliance under test, in Btu per hour or kilowatts, as appropriate. (Also see 8.3.3) 
8.3.1 For gas fired appliances, adjust the fuel rate to achieve an hourly Btu input that is within \pm 2 percent of the hourly Btu rating specified by the manufacturer as measured 15 minutes after initiation of appliance operation. If the water heater is equipped with a gas appliance pressure regulator, the regulator outlet pressure at normal test pressure shall be within $\pm 10 \%$ of the manufacturer's specifled manifold pressure.

8.3.2 For oil fired appliances, adjust the burner to obtain an hourly $\mathrm{Btu}$ rating with the $\mathrm{CO}_{2}$ reading in accordance with the manufacturer's instructions as measured 15 minutes after initiation of appliance operation. The fuel pump pressure shall be within $\pm 10 \%$ of the manufacturer's specified pump pressure.

8.3.3 For electric appliances with immersed heating elements, the power input, Qin to the heating element shall be taken to be the design power rating of the heating element as indicated on the appliance rating plate. For an electric water heater with dual immersed heating elements, the power input, Qin to the heating elements shall be taken to be the arithmetic mean of the design power ratings of the heating elements, if, in characterist: : operation of the appliance, only one heating element will be energized at any time; otherwise, Qin shall be taken to be the sum design power ratings of the heating elements.

\subsection{SETTING THE TANK THERMOSTAT, TYPE II APPLIANCES (where applicable)}

8.4.1 Single Thermostat - Starting with a tank of supply water, initiate normal operation of the appliance. After cutout, determine whether the maximum value of the mean tank temperature is within the range of $135 \pm 5 F$. If not, turn off the appliance, adjust the thermostat, refill with supply water, then initiate normal operation of the appliance, and once again determine the maximum mean temperature after cutout. Repeat this sequence until the maximum mean tank temperature after cutout is within the range of $135 \mathrm{~F} \pm 5 \mathrm{~F}$, at which time the thermostat is properly set. 
8.4.2 Two Thermostats - If an appliance has two thermostats, the upper thermostat shall be set first to yield a maximum water temperature of $135 \mathrm{~F} \pm 5 \mathrm{~F}$ as measured by the topmost tank thermocouple af ter cutout as described in 8.4.1. The lower thermostat shall then be set to yield a maximum mean tank temperature of $135 \mathrm{~F} \pm 5 \mathrm{~F}$ after cutout as described in 8.4.1.

8.4.3 Non-adjustable Thermostat - Remove the non-adjustable thermostat and replace it with an adjustable thermostat installed at the same location, and follow 8.4.1.

\subsection{SETTING CONTROL OE TYPE I INTEGRATED WATER HEATER - Starting with a} tank of unheated water, initiate normal operation of the unit. After thermostat cutout, determine whether the maximum mean tank water temperature is within the range of $135 \mathrm{~F} \pm 5 \mathrm{~F}$. If not, turn off the unit, adjust the thermostat, empty the tank and refill with unheated water, then initiate normal operation of the unit, and once agais determine the maxi - mean tank water temperature after cutout. Repeat this sequer. until the maximum mean tank water temperature after thermostat cutout is within the range of $135 \mathrm{~F} \pm 5 \mathrm{~F}$, at which time the thermostat is properly set. The boiler limit control shall be set not higher than $210 \mathrm{~F}$.

8.6 SETTING CONTROL OF TANKLESS WATER HEATER - Starting with a boiler full of unheated water, initiate normal operation of the boiler. After cutout, determine whether the maximum temperature measured by the thermocouple installed at the control well is within the range of $180 \mathrm{~F} \pm 5 \mathrm{~F}$, or the nominal setting recommended by the manufacturer's installation instructions, if higher. If not, turn off the boiler, adjust the water temperature control, empty the boller and refill with unheated water, then infiate normal operation of the boiler and once again determine the maximum temperature at the well after cutout. Repeat this sequence until the maximum temperature at the control well after cutout is within the range of $180 F \pm 5 F$, or the nominal setting recommended by the manufacturer's installation instructions, if higher, at which time the control is properly set. The differential setting of the control shall be set to $10 \mathrm{~F}$, or the setting nearest $10 \mathrm{~F}$, when a $10 \mathrm{~F}$ setting is not provided. The boiler limit control shall not be set higher than $210 \mathrm{~F}$. 
8.7 FLON RATE FOR SI:ILATED - USE TEST - The simulated-use test specifies six equal draws of U/6 gallons each during a 24 hour period. $(U=60$ gal.)

8.7.1 Systems with Storage of Domestic Water - The flow rate shall be $3 \pm 0.25 \mathrm{gpm}$ and the outlet water temperature ( $T_{0}$ ) shall not fall below

$115 \mathrm{~F}$ at any time during a draw. If necessary, the flow rate may be adjusted to a lower value in order that the outlet water temperature does not fall below $115 \mathrm{~F}$.

\subsubsection{Systems Without Storage of Domestic Vater - The flow rate shall}

be set to achieve a difference between the average outlet water temperature and inlet water temperature $(\Delta T)$ of $77 F \pm 3 F$.

\subsection{TEST PROCEDURE}

\subsection{TYPE I APPLIANCES}

9.1.1 Space heating - Space heating tests shall be conducted according to ASHRAE $103-1982^{\text {(1) }}$ and the Federal Register of

March 28, 1984 (49 FP. 12148).'

9.1.1.1 There are no test requirements for electric appliances installed in the heated space.

9.1.2 Water heating - Water heating tests shall be conducted according to the following sections.

9.1.2.1 Tank Storage Capacity Determination - Determine the storage capacity, $V$, of the integrated unit tank, in gallons, according to the method specified in section 2.28 of the American National Standard for Gas water Heaters, Volume I, designated ANSI 221.10.1-1984." No storage capacity measurement is necessar, for tankless water heaters.

\subsubsection{Simulated Use Test}

9.1.2.2.1 Initial Conditions - Initiate normal operation of the boller and heater with the controls set as specified in sections 8.5 or 8.6 . After initial cutout, or a subsequent cutout, draw $\mathrm{U} / 6$ gallons at the rate determined in 8.7 .1 or 8.7 .2 . Thirty minutes later again draw $\mathrm{t} / 6$ gallons at the same rate.

9.1.2.2.2 Simulated Test Conditions - When the burner and circulator (if used) shut off, start the 24 hour test clock following the second preliminary draw. After approximately 18 hours have elapsed,conduct six equal draws of $\mathrm{U} / 6$ gallons initiated one hour apart at the draw rate determined in 8.7 .1 or 8.7 .2 . 
At the beginning of the test, and at each 15 minute interval, record supply water temperature $\left(T_{i}\right)$, water temperature at the outlet $\left(T_{0}\right)$, air temperature $\left(T_{a}\right)$, and boiler water temperature $\left(T_{b}\right)$. Determine energy input for the 24 hour period ( $Q_{I s}$ ) and the 18 hour period $\left(Q_{s b}\right)$. Collect or meter the water drawn $\left(U_{s}\right)$. The total shall be $U \pm 2 \%$. Record the electrical usage for the 24 hour period ( $C_{\text {aux. }}$ ) and for the 18 hour period ( $C_{a u x . s b)}$ ), including a circulator if used. Stop the test after 24 hours have elapsed. For appliances with storage tanks, the mean stored water temperature shall also be recorded at 15 minute intervals throughout the 18 hour standby period.

\subsection{Measurements During Draw Periods - Record supply water} temperature $\left(T_{i}\right)$ and ovilet water temperature $\left(T_{0}\right)$ at the start and at continuing 15 second intervals during all draw periods. Determine the average temperature difference, $\Delta \mathrm{T}$, for all the water drawn.

\subsubsection{First Hour Draw Test}

Initiate normal operation of the boiler and heater with the controls set as specified in Section 8.5 or 8.6 .

At initial cutout start the test by drawing water at a rate of $3 \pm 0.25 \mathrm{gpm}$. Start readings of outlet water temperature at 15 seconds after start of draw and repeat every 15 seconds until the outlet water temperature drops 20F, or to a minimum of $115 \mathrm{~F}$. Stop the draw and read inlet water temperature and boiler water temperature.

Repeat this procedure at each cutout until one hour is completed. Collect and weigh the water drawn, or use a calibrated meter to determine the total water drawn (G).

If the hour terminates during a draw, turn off the burner at the end of the hour but continue the water draw until the outlet water temperature has dropped 20F. If the hour terminates outside a draw, turn off the burner at the end of the hour, and initiate a final draw which is continued until the outlet water temperature has dropped to the lowest level of the previous draw. 


\subsection{TYPE II APPLIANCES}

9.2.1 Space heating - Space heating tests shall be conducted according to the requirements for boilers in ASHRAE 103-1982 and the Federal Register of March 28, 1984 (49 FR 12138), (2) except as noted below:

9.2.1.1 During the steady state test determine the $\mathrm{CO}_{2} \mathrm{~F}$ (In the flue) and $\mathrm{CO}_{2 S}$ (in the stack) with the draft control device supplied by the manufacturer in its normal position.

9.2.1.2 For determining flue temperatures, consider the units as having an integral draft diverter. Use a 5 thermocouple grid.

9.2.1.3 The normal thermostat setting shall be bypassed and the burner operated manually in order to avoid shutdown of the burner during the test.

9.2.1.4 Begin cool-down test by setting the control of the unit to pilot position or turning the burner to the off position if there is no pilot position, and closing off the supply and water valves.

9.2.2 Water heating - Water heating tests shall be conducted in accordance with section 9.1.2, or, if appropriate, in accordance with 10 CFR $430^{(3)}$ - subpart $B$, appendix E, or, if appropriate, in accordance with ANSI 221.10 .3 (1984). (4) 


\subsection{DATA TO BE RECORDED}

10.1 NOMENCLATURE

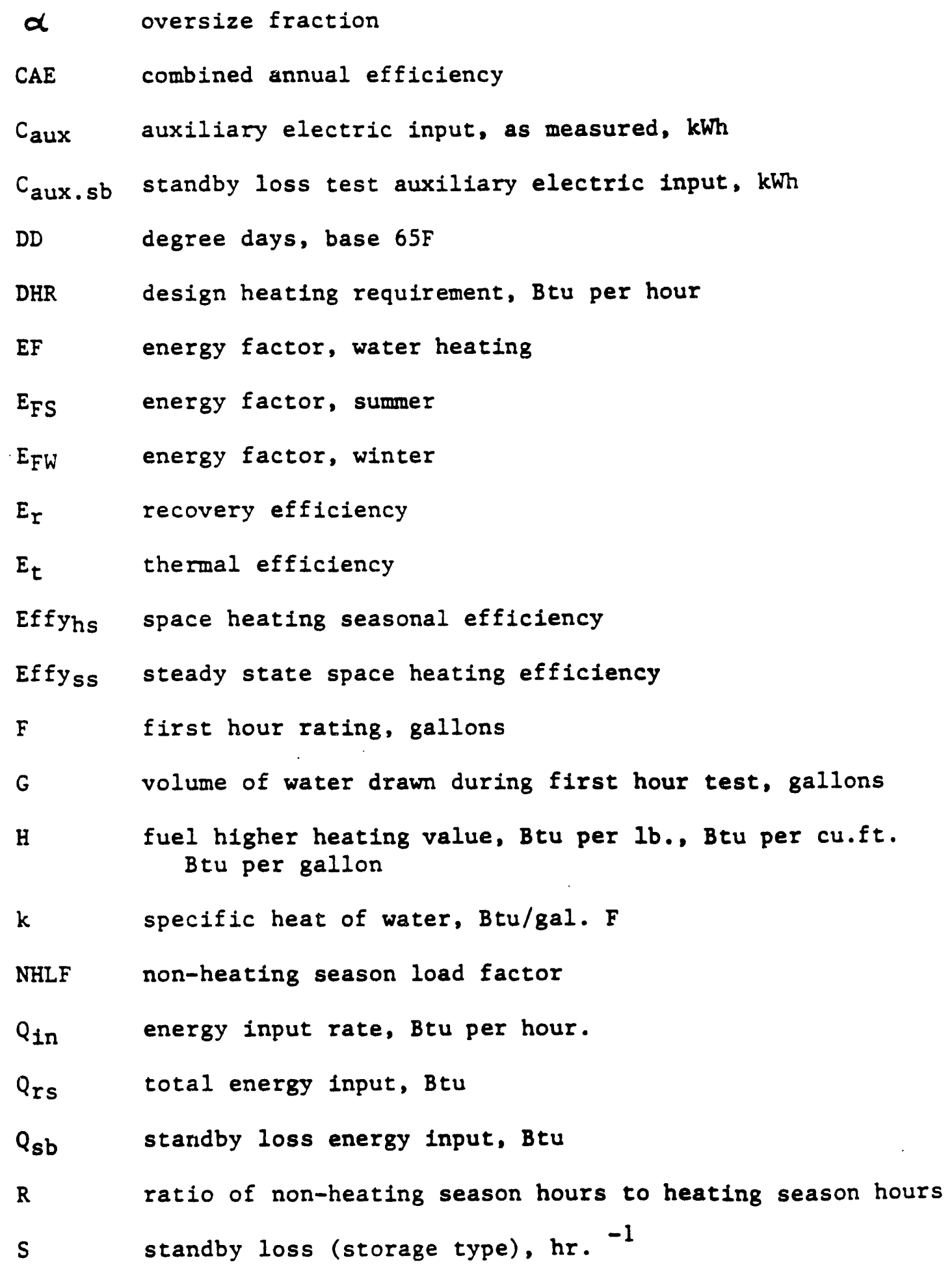




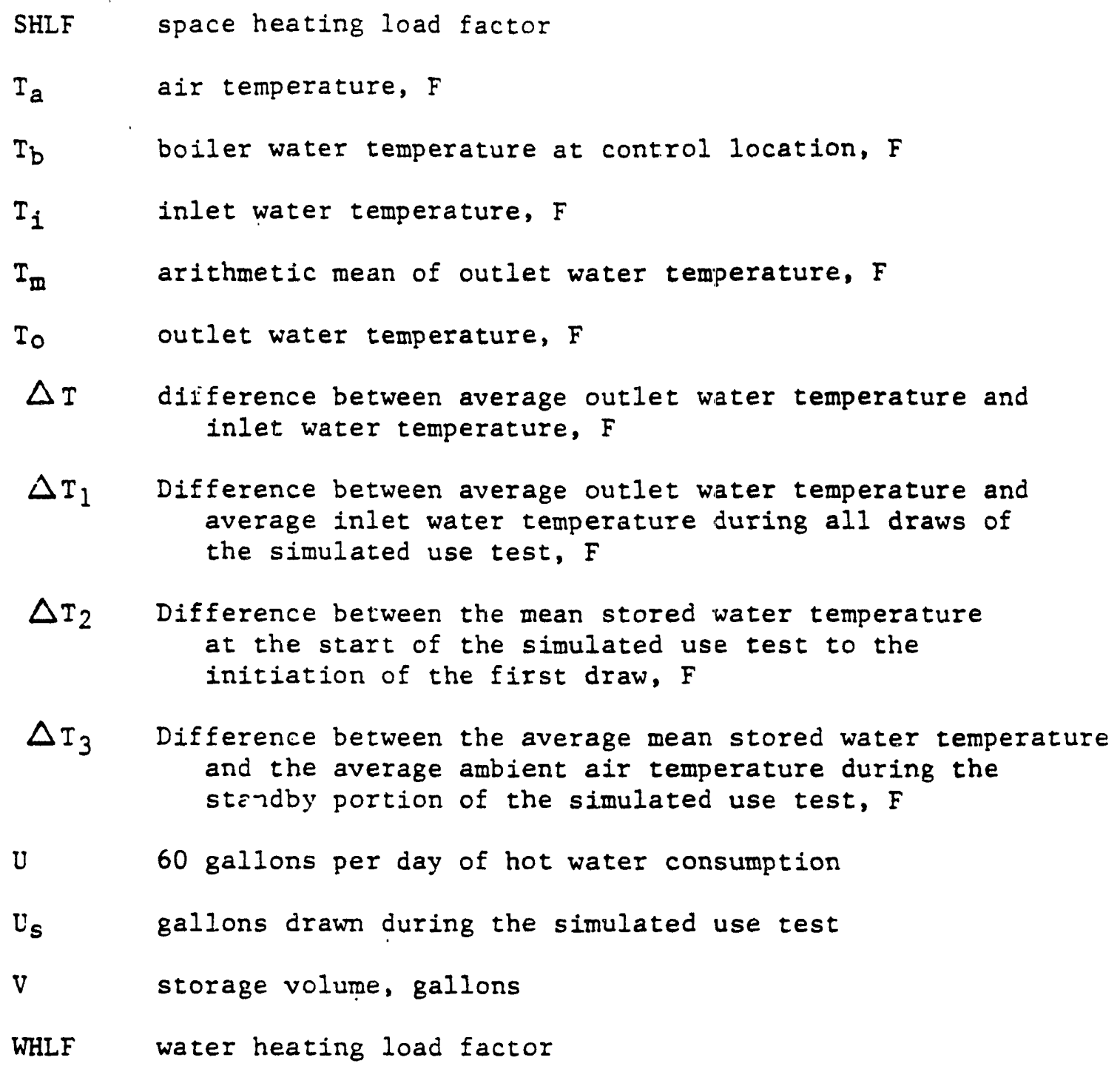




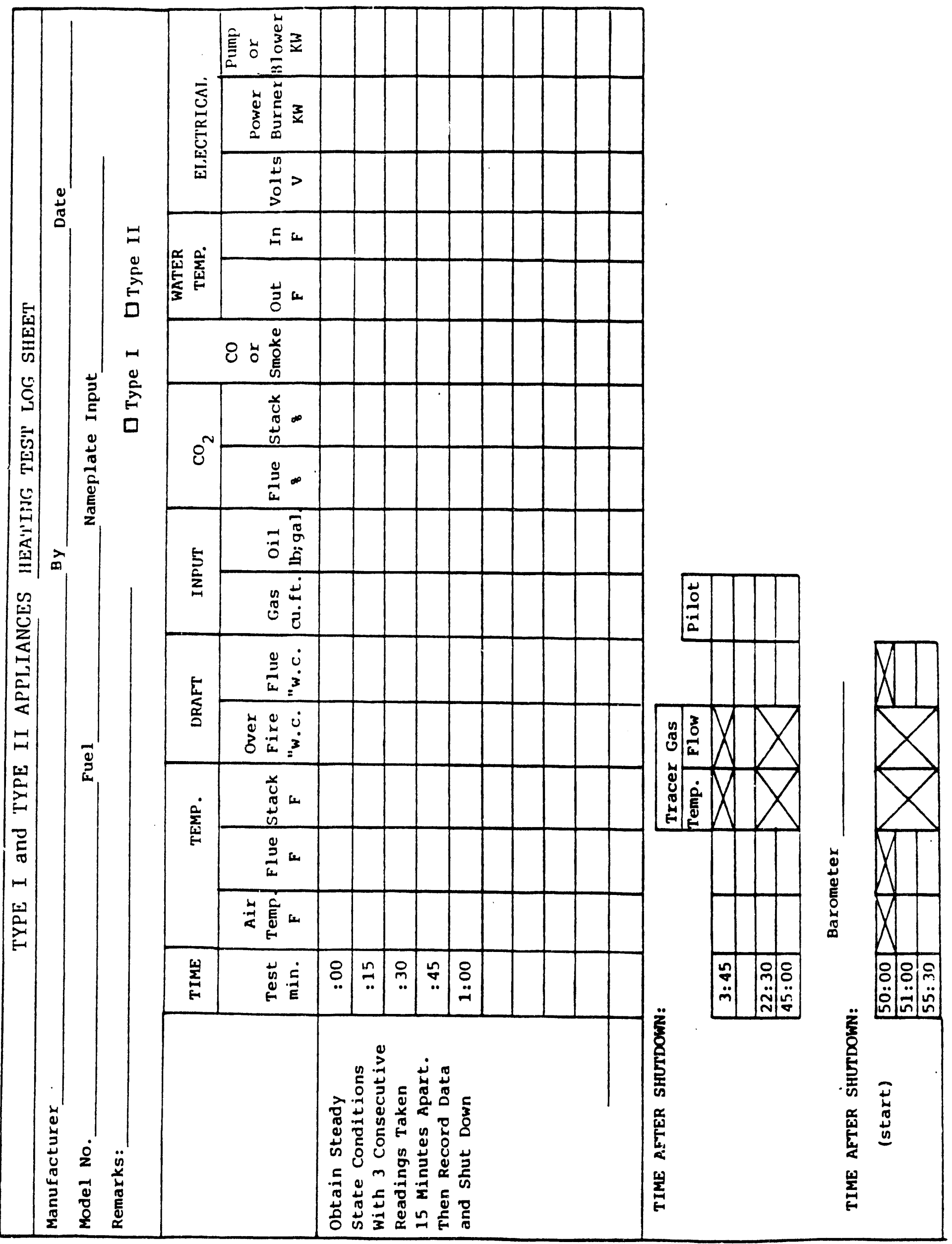




\subsection{CALCULATIO:IS}

1.1.1 TYPE I APPIIANCES

11.1.1 Space Heating Function - Space heating parameters shall be calculated for indoor installation, isolated combustion system installation, or outdoor installation, as applicable, in acco.dance with the procedures of as specified in Section 11 of ANSI/ASHRAE Standard 103-1982," Methods of Testing for Heating Seasonal Efficiency of Central Furnaces and Boilers as supplemented by Section 4.0 of the Federal Register of March 28, 1984 (49 FR 12148) with the inclusion of the following additionel requirements.

11.1.1.1 For electric appliali-es Effyss = Effyhs

11.1.2 Wo+2 heating function - i.se following calculations shall be performed:

11.1.2.1 First hour rating - Calculated the first hour rating, F, expressed in gallons and defined as:

$F=G \times \frac{T_{m}-T_{i}}{77}$

where:

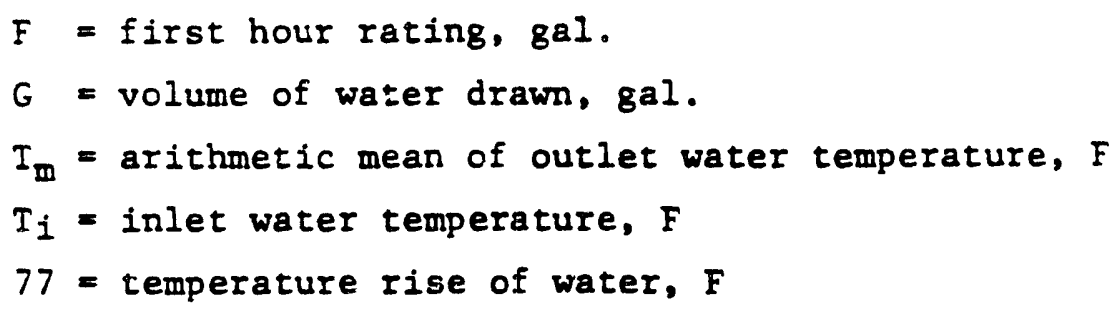

11.1.2.2 Energy Factor - The energy factor is calculated by dividing the energy delivered in the hot water draws during the 6 hour draw reriod by the energy consumption in the total 24 hour test period. This equation is as follows:

$$
E F=\frac{\left(8.25 * U_{s} * \Delta T_{1}\right)}{\left(Q_{\text {IS }}+3413 * C_{\text {aux }}\right)}
$$


where:

$$
\begin{aligned}
& 8.25 \text { = density of water, 1b./gal. } \\
& U_{s} \quad=\text { amount of water drawn during the simulated } \\
& \text { use test, gal. } \\
& \Delta T_{1}=\text { difference between average outlet water } \\
& \text { temperature and average inlet water } \\
& \text { temperature during all draws of the } \\
& \text { simulated use test, F } \\
& Q_{\text {rs }}=\text { total energy input, Btu } \\
& C_{\text {aux }}=\text { auxiliary electrical input, } \mathrm{kWh}
\end{aligned}
$$

\subsubsection{Recovery Efficiency - Calculate the recovery efficiency} as follows:

For appliances with storage tanks:

$$
E_{I}=\frac{8.25 * U_{s} * \Delta I_{1}+[(h+6) / h] * 8.25 * V * \Delta T_{2}}{\left(Q_{\text {Is }}+3413 * C_{\text {aux }}\right)-[(h+6) / h] *\left(Q_{s b}+3413 * C_{\text {aux }-s b}\right)}
$$

where:

$$
\begin{aligned}
& \text { Qrs = total energy input, Btu } \\
& \mathrm{C}_{\mathrm{aux}} \quad=\text { auxiliary electrical Input, } \mathrm{kWh} \\
& Q_{s b} \quad=\text { energy input during the standby period, Btu } \\
& \mathrm{C}_{\text {aux-sb }}=\text { auxiliary electric input during the } \\
& \text { standby period, kWh } \\
& h \text { = the number of hours from the start of the } \\
& \mathrm{V} \quad \text { = storage volume in gallons as determined } \\
& \text { in } 9.1 .2 .1 \\
& \Delta T_{2}=\text { the difference between the mean stored water }
\end{aligned}
$$


11.1.2.4 Standby Loss - For appliances with storage tanks, the standby loss in hour ${ }^{-1}$ shall be determined as follows:

$$
S=\frac{U_{S} * \Delta T_{1} *\left(1 / E F-1 / E_{r}\right)}{24 * V * \Delta T_{3}}
$$

where:
$\Delta \mathrm{T}_{3}=$ the difference between the average value of the mean stored water temperature and the average value of the ambient air temperature during the standby portion of the simulated use test, $F$.

\subsection{TYPE II APPIIANCES}

11.2.1 Space heating function - Space heating parameters shall be calculated for indoor installation, isolated combustion system installation, or outdoor installation, as applicable in accordance with the requirements for boilers as specified in Section 11 of ANSI/ASHRAE Standard 103-1982." Methods of Testing for Heating Seasonal Efficiency of Central Furnaces and Boilers as supplemented by Section 4.0 of the Federal Register of March 28, 1984 (49 FR 12148) with the inclusion of the following additional requirements.

11.2.1.1 For electric appliances, Effyss $=$ Effyhs

11.2.2 Water heating function - One of the following calculations shall be performed, depending on the method of test.

11.2.2.1 DOE Procedure - For those heaters covered by DOE rules, 10 CFR 430 (') subpart B, appendix E of the Federal Regulations shall be followed to obtain EF.

11.2.2.2 ANSI 221.10.31984 (1) For instantaneous heaters the value of $E_{t}$ and $S$ shall be obtained in accordance with paragraph 2.8 THERMAL EFFICIENCY, and 2.9 STANDBY LOSS, ANSI 221.10.3 $1984 .^{(4)}$

$$
\begin{aligned}
& \quad E F=\frac{E_{t}}{1+\frac{C_{\text {aux }} \times 3413}{Q_{i n}}} \\
& \text { where: } \\
& E_{t}=\text { thermal efficiency, \%. } \\
& C_{\text {aux }}=\text { auxiliary electrical usage, } \mathrm{kWh} \\
& \text { Qin }=\text { fuel input rate, Btu/hr. }
\end{aligned}
$$


11.3 COMBINED SPACE AND WATER HEATING ANNUAL FUEL UTILIZATION EFFICIENCY (CAE)

11.3.1 Heating Season - Space Heating Load Factor (SHLF) shall be obtained from:

SHLF $=\frac{\text { Effyss }}{\text { Effyhs }} \times \frac{65-42}{65-5} \times \frac{D D}{5200} \times \frac{1}{1+a}$

where:

$D D=$ the local number of heating degree days with a $65 \mathrm{~F}$ base

$a=$ the oversize fraction of the space heating cutput as determined from:

$\frac{\left(Q_{i n}\right)\left(E f f y_{s s}\right)}{(D H R)}-1$

where:

$Q_{\text {in }}=$ the input rate at maximum rated input $B t u / h$.

Effyss = the steady state efficiency expressed as a decimal.

DHR = the design heating requirement (Btu/h) from ASHRAE 103-1982,"'rable C-1

\subsubsection{Heating Season - Water Heating Load Factor (WHLF)}

Calculate the water heating load factor applicable during

the space heating season as:

WHLF $=\frac{U(77)(8.25)(1.0)}{\left(Q_{\text {in }}\right)(\text { Effyss })(24)}$

where:

$$
\begin{aligned}
& \mathrm{U} \quad=\text { the gallons per day of hot water consumption } \\
& 77=\text { temperature rise of water } F \text {. } \\
& 8.25=\text { density of water at the average stored } \\
& \text { water temperature (Lb/Gal) } \\
& 1.0=\text { specific heat of water (Btu/Lb F) } \\
& \text { Qin = the input rate in } B t u / h \\
& \text { Effyss }=\text { as determined in } 11.1 .1 \text { or } 11.2 .1 \\
& 24 \text { = hours per day }
\end{aligned}
$$


11.3.3 Non-Heating Season Load Factor (NHLF) - Calculate the non-heating season load factor (for water heating only) as:

NHLF $=\frac{(U)(77)(8.25)(1.0)}{\left(Q_{\text {in }}\right)(E F)(24)}$

where:

U, 77, 8.25, 1.0, Q $\mathrm{in}$, and 24 are defined in 11.3.2.

$E F$ is the water heating energy factor as determined in 11.1 .2 .2 or 11.2 .2 .

11.3.4 Calculation of CAE - Calculate CAE, Combined Annual Efficiency, from:

$\mathrm{CAE}=\frac{(\mathrm{SHLF})\left(\mathrm{Eff}_{\mathrm{h}_{\mathrm{S}}}\right)+\left(\text { WHLF }_{(\mathrm{Eff}} \mathrm{y}_{\mathbf{s}}\right)+(\mathrm{R})(\mathrm{NHLF})(\mathrm{EF})}{(\mathrm{SHLF})+(\text { WHLF })+(\mathrm{R})(\mathrm{NHLF})}$

where:

SHLF as defined in 11.3 .1

Effyhs as determined in 11.1 .1 or 11.2 .1

WHLF as defined in 11.3.2

Effyss as determined in 11.1 .1 or 11.2 .1

NHLF as defined in 11.3.3

$E F$ as determined in 11.1 .2 or 11.2 .2

$R=$ Ratio of non-heating season hours to heating season hours. 


\subsubsection{Season Efficiencies}

11.3.5.1 The heating season efficiency can be obtained from Heating Season Eff. $\frac{\text { (SHLF) (Effyhs) }+ \text { (WHLF) (Effyss) }}{(\text { SHLF })+(\text { WHLF) }}$

11.3.5.2 The non-heating season efficiency is obtained by Non-heating Season Eff. $=\frac{(R)(N H L F)(E F)}{(R)(N H L F)}=E F$

11.3.6 Optional Method of Calculating CAE - for combined space heating/ water heating Type II appliances intended to be installed as isolated combustion systems, the CAE term may be optionally calculated as follows:

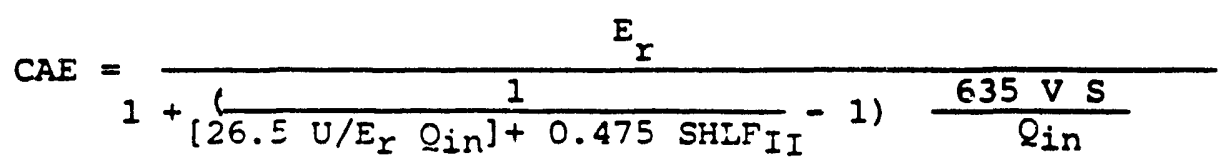

where:

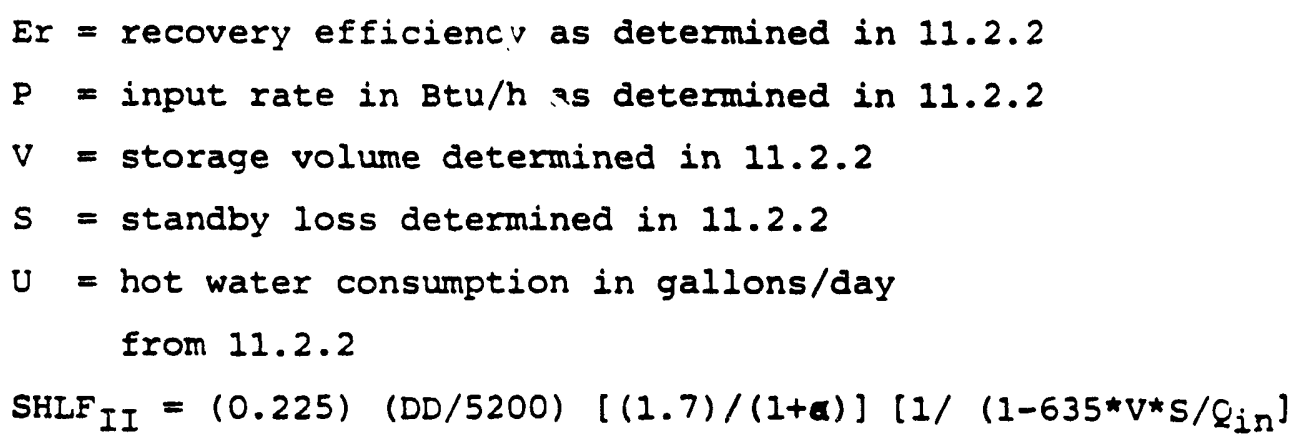

$$
\begin{aligned}
26.5 & =\left(\frac{77 \times 8.25}{24}\right) \\
635 & =77 \times 8.25 \\
0.475 & =\left(\frac{8760-4600}{8760}\right) \\
1.7 \times 0.225 & =\left(\frac{65-42}{65-5}\right)
\end{aligned}
$$

11.3.7 Comparison of Combined Appliance Efficiency with Efficiencies of Single Function Appliances.

For a methodology enabling comparison of a combined appliance with single function appliances see Appendix A. 


\subsection{REFERENCES}

1. "Methods of Testing for Heating Seasonal Efficiency of Central Furnaces and Boilers," ANSI/ASHRAE Standard 103-1982, American Society of Heating Refrigerating and Air-Conditioning Engineers, Inc., 1791 Tullie Circle, NE, Atlanta, GA 30329, 1982.

2. Federal Register, March 28, 1984, 49 FR 12148, U.S. Government Printing Office, Washington, DC 20402, 1984.

3. Federal Regulations, 10 CFR 430, U.S. Government Printing office, Washington, DC 20402.

4. "Gas Water Heaters Volume III: Circulating Tank, Instantaneous and Large Automatic Storage Water Heaters," ANSI/AGA Standard 221.10.3-84, American Gas Association, 8501 East Pleasant Valley Road, Cleveland, OH 44131,1984 .

5. "Test Method for Smoke Density in Flue Gases from Burning Distillate Fuels," ANSI/ASTM Standard D2156-80, American Society for Testing and Materials, 1916 Race Street, Philadelphia, PA 19103, 1980.

6. "Gas Water Heaters Volume I: Automat1c Storage Water Heaters with Inputs of 75,000 BTU per Hour or Less," ANSI/AGA Standard 221.10.1-84, American Gas Association, 8501 East Pleasant Valley Road, Cleveland, OH $44131,1984$. 


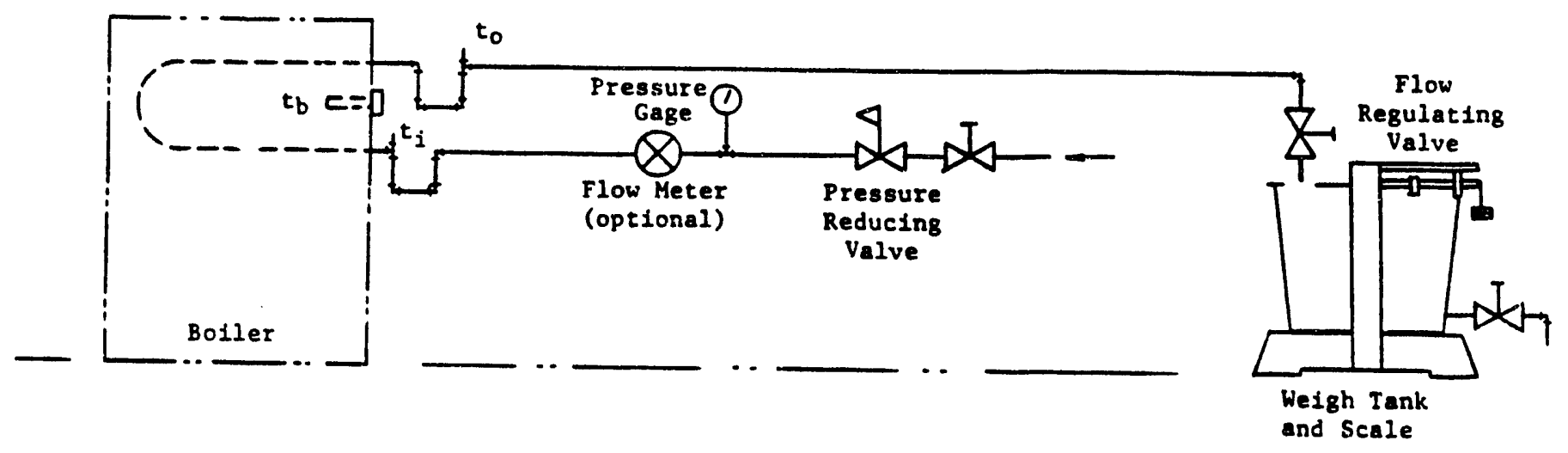

TYPE I APPLIANCES

TYPICAL PIPING ARRANGEMENT

TANKLESS HEATER IN BOILER

FIGURE 1

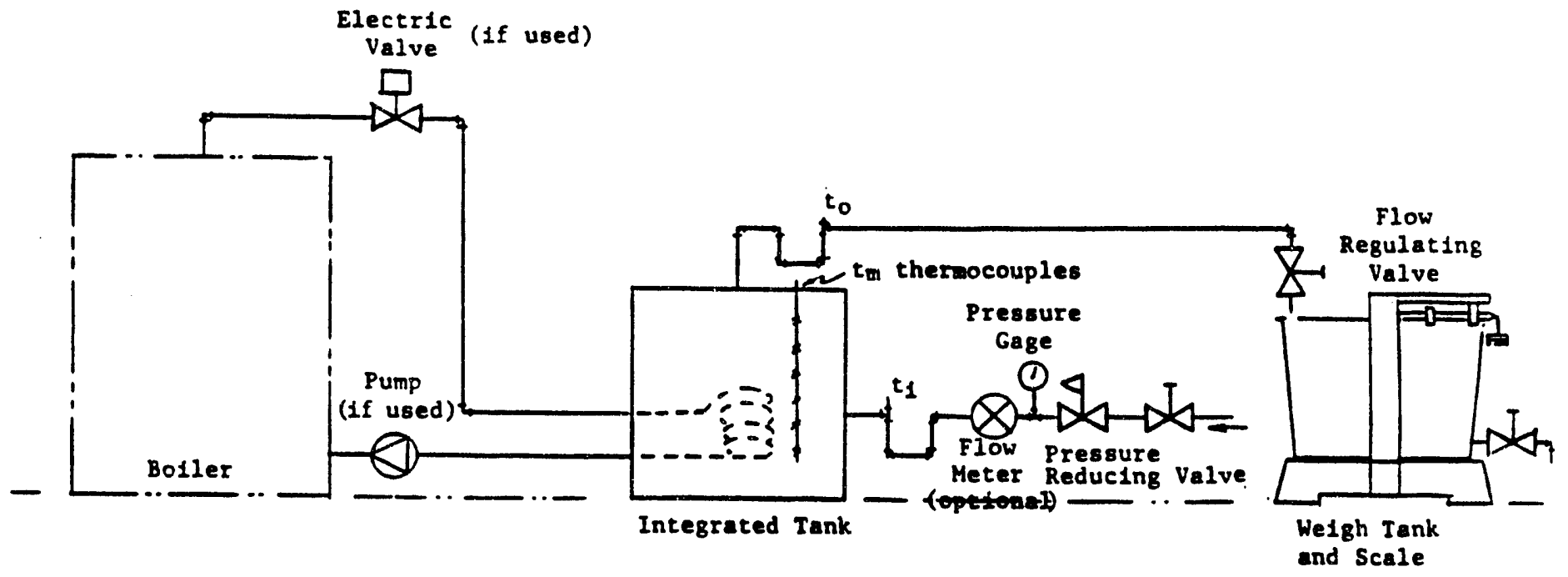

TYPE I APPLIANCES

TYPICAL PIPING ARRANGEMENT

INTEGRATED WATER HEATER - DOMESTIC WATER IN TANK

FIGURE 2 


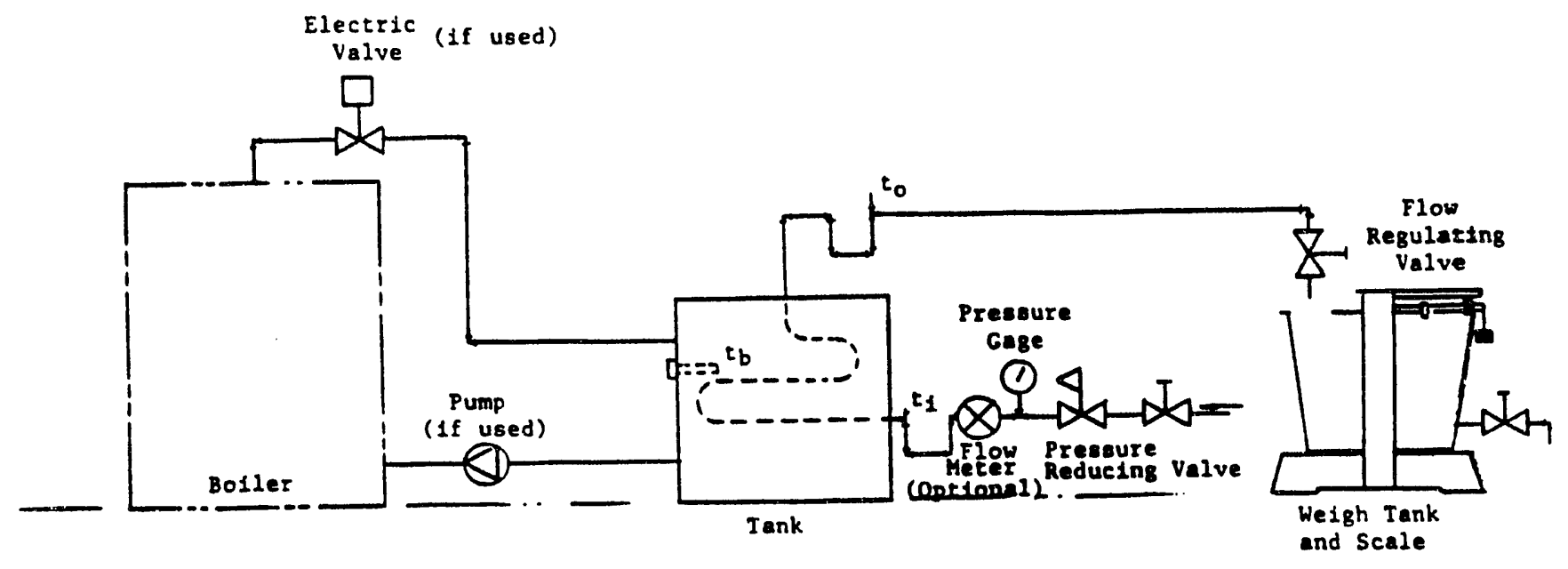

TYPE I APPLIANCES

TYPICAL PIPING ARRANGENENT

TANKLESS WATER HEATER - BOILER WATER IN TANR

FIGURE 3

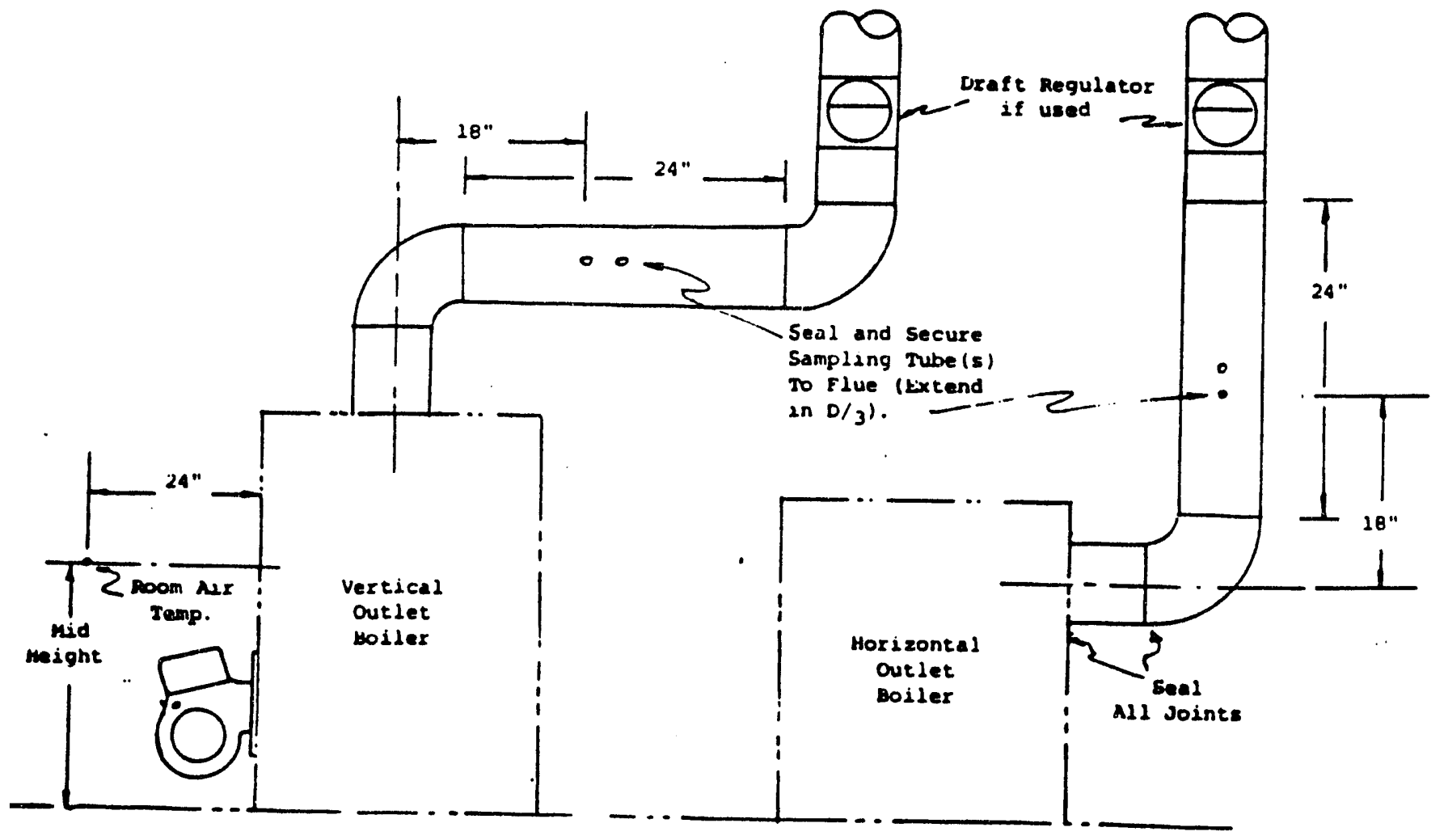



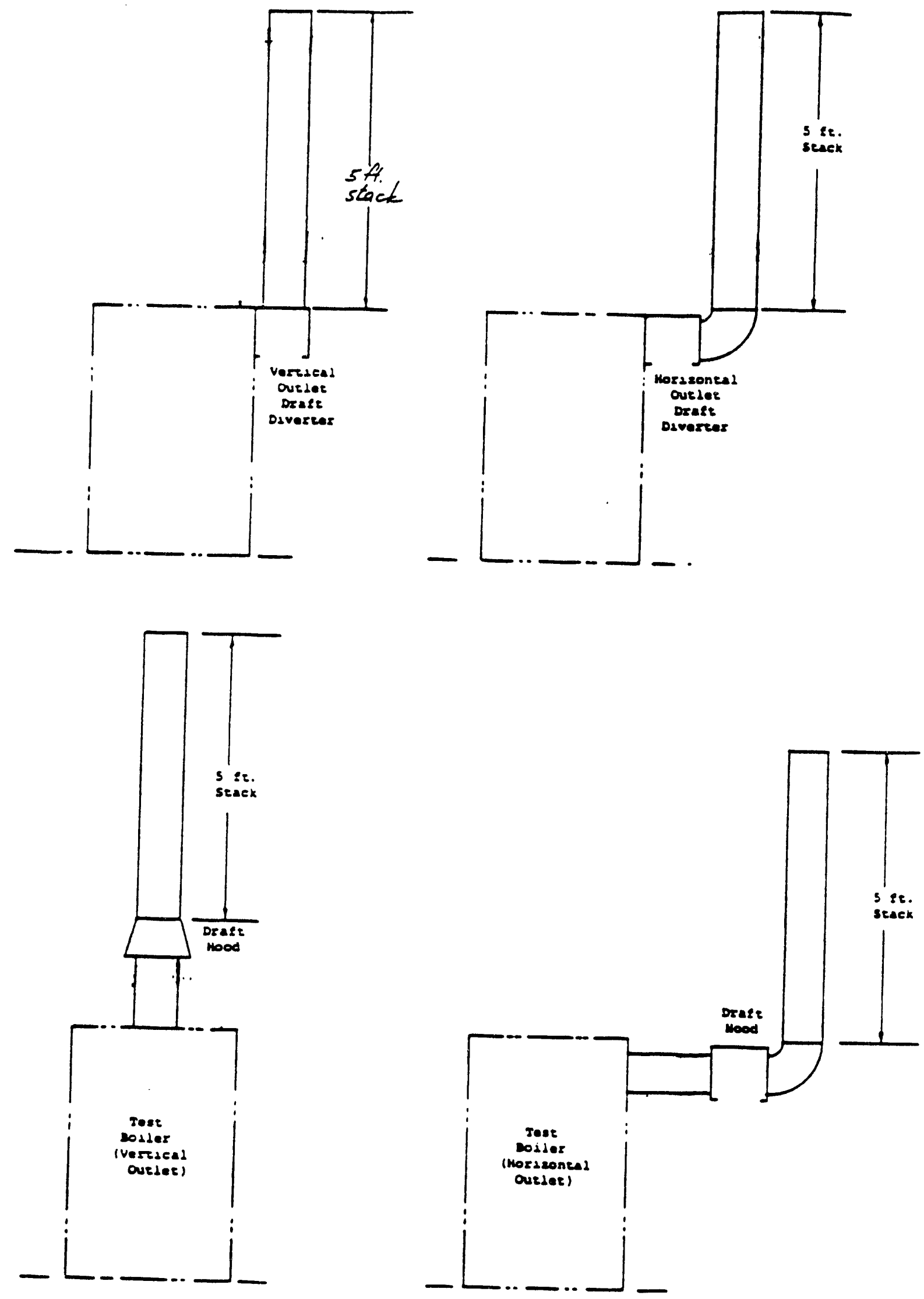

TEST FLUES AND STACKS FOR ATMOSPHERIC GAS FIRING

FIGURE 5

Page 33 


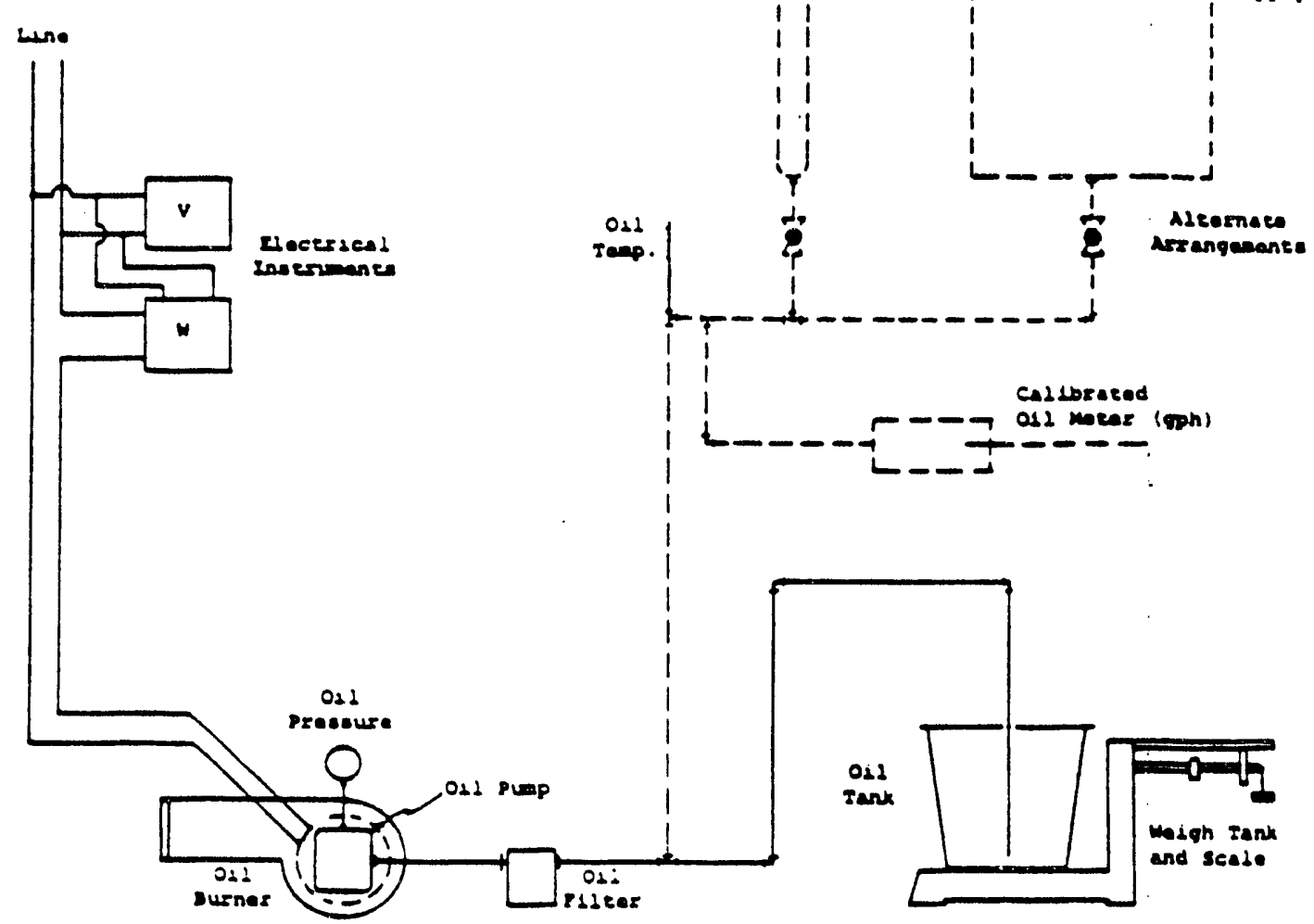

SUGGESTED OIL BURNER TEST SETUP

FIGURE 6

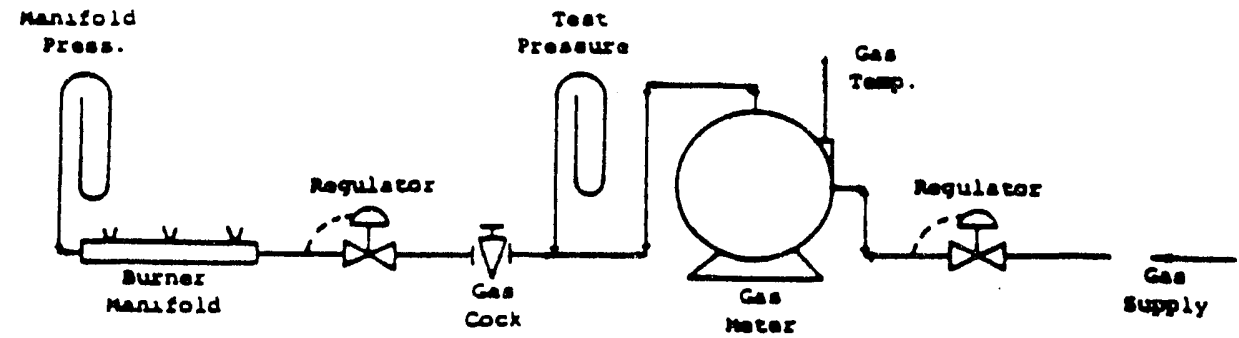

SUGGESTED ATMOSPHERIC GAS BURNER TEST SETUP

FIGURE 7 


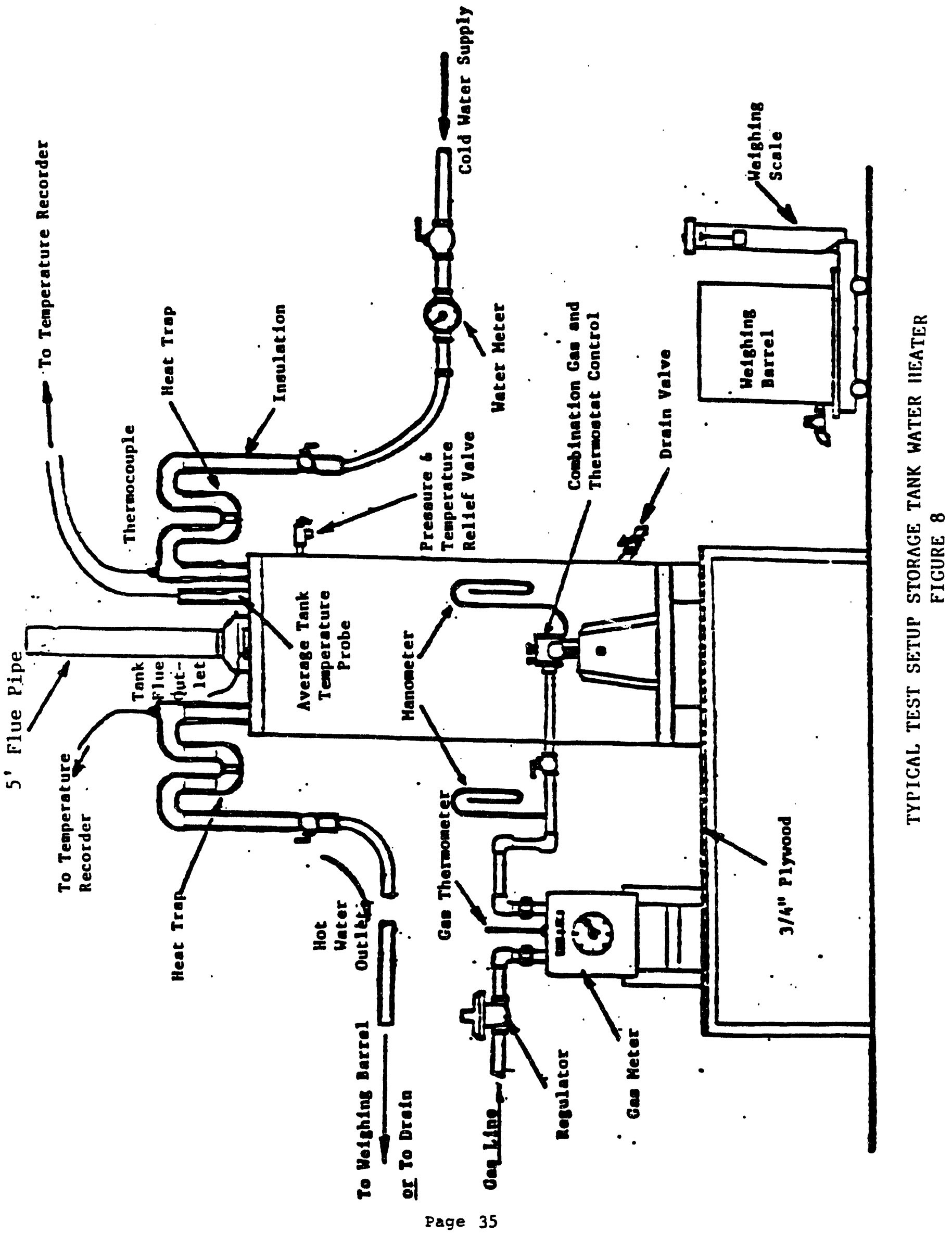



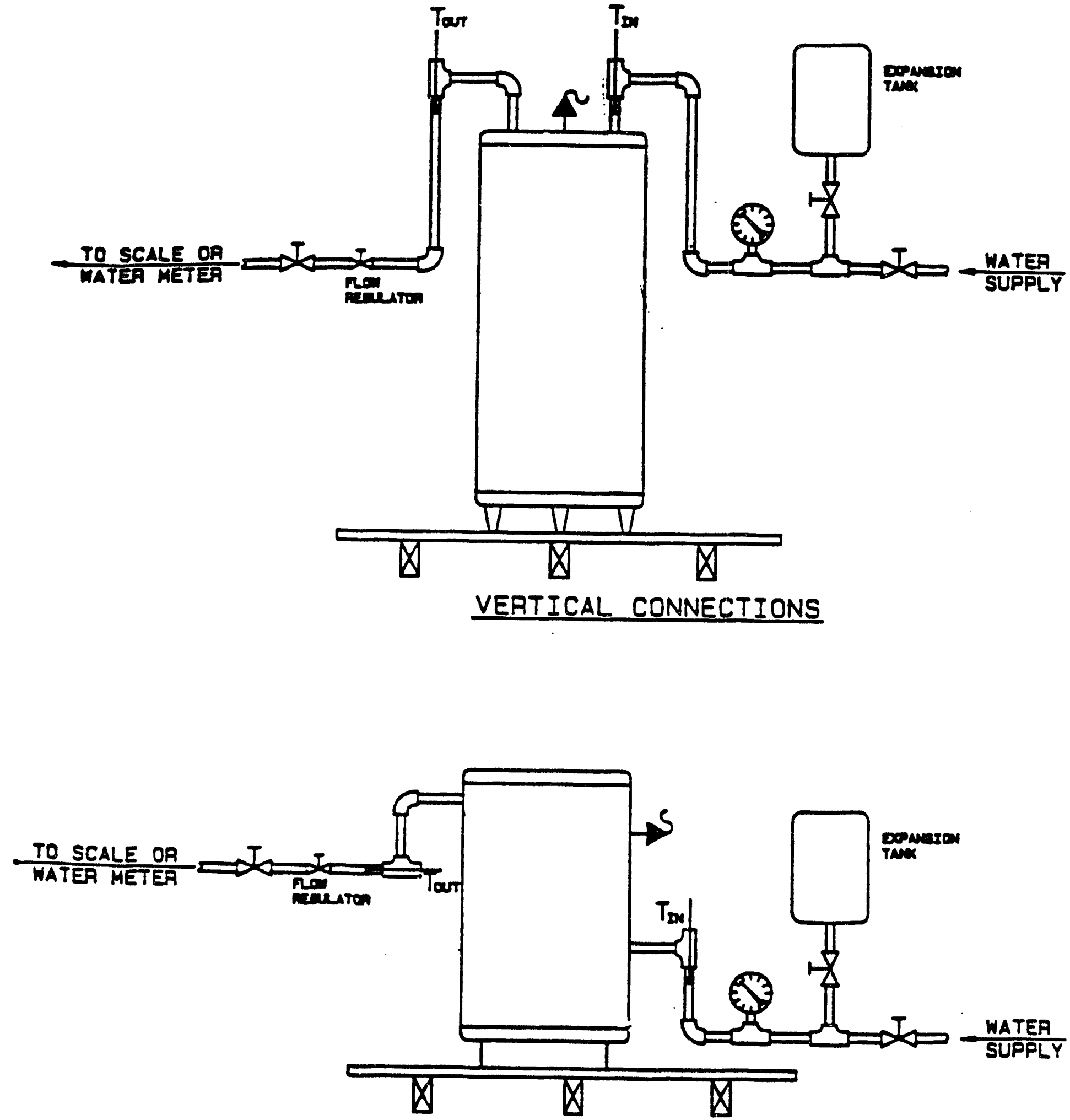

HORIZONTAL CONNECTIONS

FIGURE 8 A

ALTERNATIVE PIPING ARRANGEMENT

Page 36 


\section{TYPE II COMBINATION SPACE HEATING/ \\ WATER HEATING APPLIANCE}

$\mathrm{CO}_{2 \mathrm{~s}}$ before blocking draft hood

$\mathrm{CO}_{2 \mathrm{~F}}$ after blocking draft hood and restricting flue

5 Thermocouple Grid

$\mathrm{CO}_{2 \mathrm{f}}$

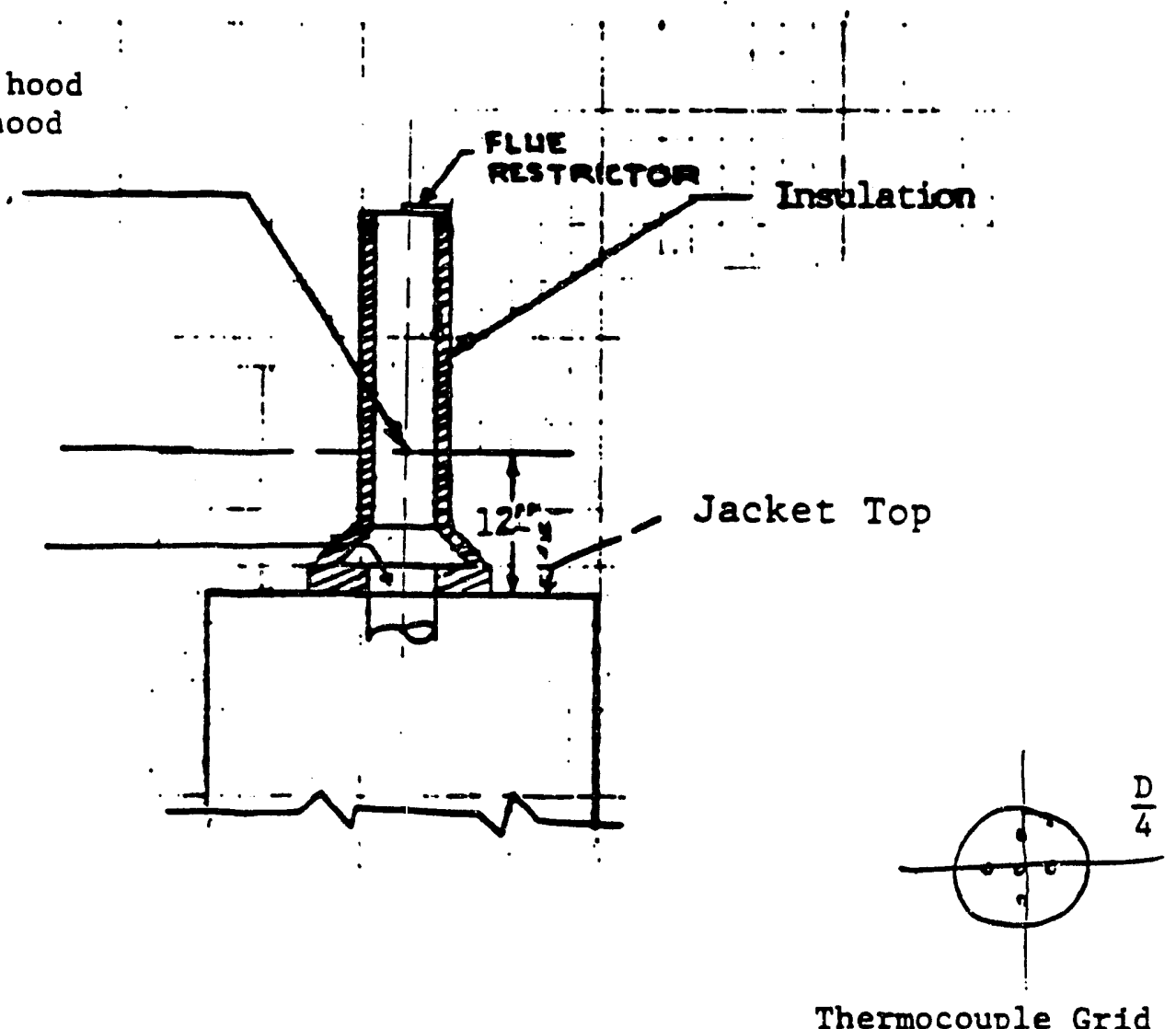

Space heating test setup

FIGURE 9 


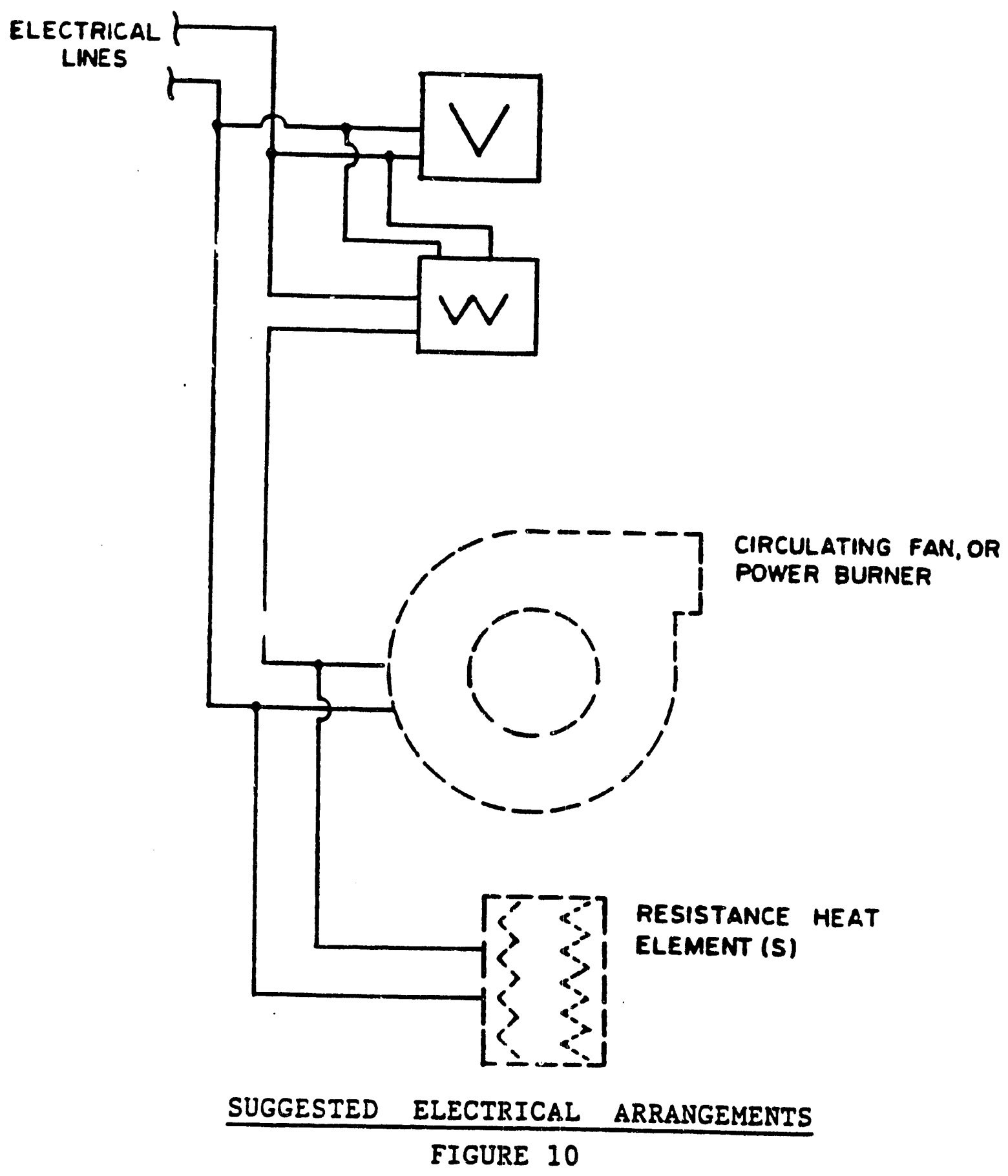


兰: $: \equiv=:=2.0$ Fuel Consumption to Space Heating and Water Heating

- $\therefore$ : caminned annual efficiency of the combined appliance is expressed $\because \because:=. \quad: \therefore$ ennual efficiency for each function of the appliance was not $\dot{\vdots}:==-: \equiv \equiv$ ex:licitly, but an arbitrary allocation of the total annual fuel

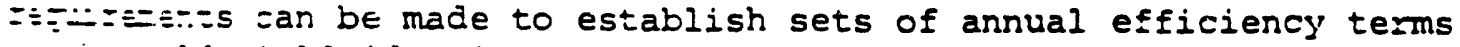
$\because-: \therefore:-:-i$ Yield identical annual fuel consumption. The resulting $:=:=:=-$ a ennul efficiency terms can then be used to indicate compliance

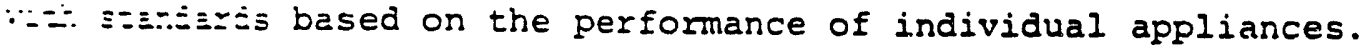

:. $\Xi: \vdots l$ innual Efficiencies for Space Heating and Domestic $\because \vdots \equiv \equiv=$ : Heating (Type I or Type II Appliances)

Z: $\vdots$ is desired to designate equal annual efficiencies iz: saze heating and domestic water heating the following İ三Eionships apply:

$$
\begin{aligned}
& \text { inrual Space Heating Efficiency (ASHE) }=\text { CAE } \\
& \text { inr:ual Water Heating Efficiency (AWHE) }=\text { CAE }
\end{aligned}
$$

:-. :-:ual Space Heating Efficiency Established at ANSI/ $\therefore::_{i}=$ Standard 103-1982 (1) AFUE Level (Type I Appliances s:: : $:)$

$\because \therefore s$ Eembined Annual Efficiency (CAE) of the combination $\equiv \equiv \equiv$ inizce can be defined as:

$$
C: E=\frac{\text { Annual Output }}{\text { Annual Input }}=\frac{\text { ASHL }+ \text { AWHL }}{\frac{A S H L}{A S H E}+\frac{A W H L}{A W H E}}
$$

$\ddot{n}: \leq \Sigma=e$

isii = Annual Space Heating Load in Btu

inf: = Annual water Heating Load in Btu

isiz = Annual Space Heating Efficiency

sir: = Annual Water Heating Efficiency

Eoving this expression for the Annual Water Heating Efficiency (Sit:) gives:

$$
A W H E=\frac{C A E}{1+\frac{A S H L}{A W H L}\left(1-\frac{C A E}{A S H E}\right)}
$$

इoz a Type I appliance,

$$
\text { ASHE = AFUE }
$$

$\therefore シ ニ ミ:$

$\therefore=$ is cetermined from ANSI/ASHRAE 103-1982" 
The annual space heating load is determined from

$$
\text { ASHL }=(4160)\left(Q_{i n}\right)(\text { SHLF })\left(E f y_{h s}\right)
$$

where:

$$
\begin{aligned}
4160= & \text { National average heating season hours } \\
Q_{\text {in }}= & \text { Appliance input in Btu/h } \\
\text { SHLF }= & \text { Space Heating Load Factor as determined in } 11.3 .1 \\
\text { Effy hs }= & \text { Heating Seasonal Efficiency as determined from } \\
& \text { ANSI/ASHRAE } 103-1982 \text { (I) }
\end{aligned}
$$

The annual water heating load is

AWH' $=(U)(365)(8.25)(77)$

where:

$$
\begin{aligned}
& U \text { = Daily hot water usage in gallons } \\
& 365=\text { Days in year } \\
& 8.25 \text { = Heat content of water in Btu/gal-F } \\
& 77 \text { = Temperature rise of water in } F \\
& \frac{A S H L}{A W H L}=\frac{\left.\left(Q_{i n}\right) \text { SHLF }\right)\left(E f Z_{i E}\right)}{(55.74)(i)} \\
& \text { AWHE }=\frac{C A E}{1+\frac{\left(Q_{\text {in }}\right)(\text { SHLE })\left(E_{\text {ffy }}\right)}{55.74(U)}\left(1-\frac{C A E}{A F U E}\right)}
\end{aligned}
$$

If the type I appliance does not have a standing pilot, ther. AFUE $=E E f_{\text {hs }}$ and (5) simplifies to:

$$
\text { AWHE }=\frac{8760}{4160 / \text { EffYSS }+4600 / E F}
$$

where:

$$
\begin{array}{r}
\text { Effy }_{\mathrm{SS}} \text { as determined in } 11.1 .1 \\
E F \text { as determined in } 11.1 .2
\end{array}
$$

If the Type 1 appliance were used for space heating only and domestic water heating is provided by a separate water heater, it would require a water heater with an Energy Factor (EF) equal to AWHE to provide the same total annual energy consumption as the combination appliance providing both functions. Therefore, the combination appliance can be considered to have an effective domestic water heating EF equal to AWHE. 
III. Annual Water Heating Efficiency Established at CFR 10 Energy

Factor Level (Type II Appliances Only)

Solving (1) for Annual Space Heating Efficiency (ASHE) gives:

$$
\text { ASHE }=\frac{C A E}{1-\left(\frac{A W H L}{A S H L}\right)\left(\frac{C A E}{A W H E}-1\right)}
$$

For a Type II appliance,

$$
A W H E=E F
$$

where:

EF is determined from CFR 10

Substituting (4) and (7) into (6) yields:

$$
\text { ASHE }=\frac{C A E}{1-\frac{(55.74)(U)}{\left(Q_{\text {in }}\right)(S H L F)\left(E f_{Y h s}\right)}\left(\frac{C A E}{E F}-1\right)}
$$

If the oftional method of determining CAE as provided for in 11.3 .6 is employed, the space heating efficiency is given by a comparaisle
expression.

$$
\text { ASHE }=\frac{C A E}{1-\frac{(55.7 \hat{S})(U)}{\left(Q_{I_{n}}\right)\left(S H L F_{I I}\right)\left(E_{Y}\right)}\left(\frac{C A E}{E F}-1\right)}
$$

where:

$$
\begin{aligned}
& \text { SHLF }_{I I}=\text { as determined in } 11.3 .6 \\
& E_{Y}=\text { Recovery Efficiency as determined from CFR } 10 .
\end{aligned}
$$

If the water heating Energy Factor (EF) of the type II appliance is based on not having heat traps on the outlet water connection and the inlet water connection as integral parts of the appliance and also is based on not consuming any auxiliary electric energy, then ( 9 ) simplifies to:

$$
\text { ASHE }=\frac{E_{r}}{1-(77)(8.25)(S)(V) /\left(Q_{\text {in }}\right)}
$$

where:

$$
\begin{aligned}
E_{x} & =\text { Recovery Efficiency as determined in } 11.2 .2 \\
S & =\text { Standby Loss as determined in } 11.2 .2 \\
V & =\text { Storage Volume as determined in } 11.2 .2 \\
Q_{\text {in }} & =\text { Btu/h Input as determined in } 11.2 .2
\end{aligned}
$$

If the Type II appliance were used for domestic water heating only and space heating is provided by a separate furnace/boiler, it would require a furnace/boiler with an Annual Fuel Utilization Efficiency (AFUE) equal to ASHE to provide the same total annual energy consumption as the combination appliance providing both functions. Therefore the combination appliance can be considered to have an effective space heating AFUE equal to ASHE. 
TIIIS APPEISDIX IS NOT PART OF THIS STANDARD BUT IS INCLUDED

FOR INFORMATION PURPOSES ONLY.

\section{APPEINDIX B}

Determination of Combined Annual Efficiency (CAE) for Installations with

Single Function Appliances

The Combined Annual Efficiency ( $C A E$ ) of an installation consisting of a single function appliance providing the space heating plus a single function appliance providing water heating can be determined from the following expression:

$\frac{\text { ANNUAL OUTPUT }}{\text { ANNUAL INPUT }}=\frac{\text { ASHL }+ \text { AIHL }}{\frac{\text { ASHL }}{\text { AFUE }}+\frac{A W H L}{E F}}$

where:

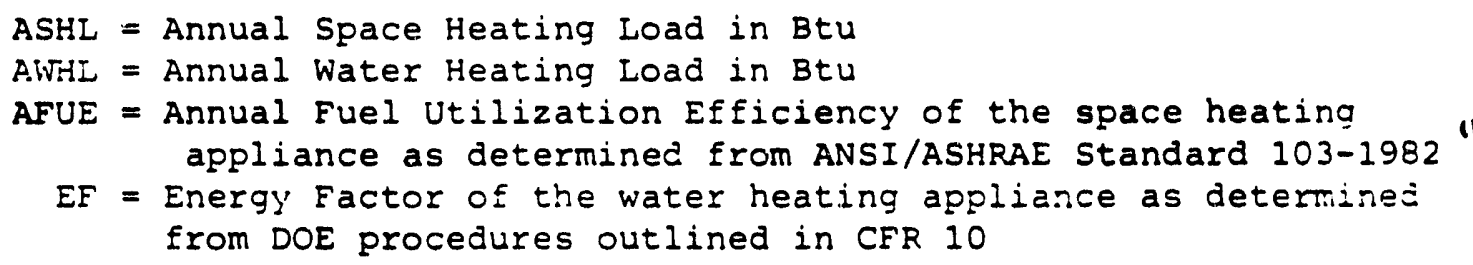

The annual space heating load is

$$
\text { ASHL }=[(65-42) /(65-5)](4160)(\text { DHR })=(1595) \text { (DHR) }
$$

where:

$$
\begin{aligned}
& 4160=\text { Hours in heating season } \\
& \text { DHR = Space Heating Design Heating Requirement in Btu/h }
\end{aligned}
$$

The annual space heating load can also be expressed as

$$
\text { ASHL }=\frac{(1595)(\text { Qout })}{(1+\alpha)}
$$

where:

$$
\begin{aligned}
\text { Lout } & =\text { Heating capacity of space heating appliance in Btu/h } \\
& =\text { Oversize fraction }=(\text { Qout } / \text { DHR })-1
\end{aligned}
$$

The annual water heating load consistent with the DOE Energy Factor of the water heating appliance is

$$
\text { AWHL }=(60) \quad(365)(77)(8.25)=13,911,975
$$


1. National Average SHLF:

$$
\begin{aligned}
& \text { SHLF }=\frac{\text { Effyss }}{\text { Effyhs }} \times \frac{65-42}{65-5} \times \frac{5200}{5200} \times \frac{1}{1.7} \\
& \operatorname{SiLF}=\frac{\text { EEEYSS }}{\text { EEFyins }} .3833 \times 1 \times .5882 \\
& \text { SHLF }=0.225 \times \frac{\text { EE EVSS }}{\text { EELYiSS }}
\end{aligned}
$$

2. National Average $R$ :

$$
R=\frac{4600}{8760-4000}
$$

$R=1.1$

3. Exazple:

$$
\begin{aligned}
& \text { Assume an appliance with the following: } \\
& \text { Qin }=50,000 \text { Btuh } \\
& \text { Heating Capacity }=40,000 \text { Btuh } \\
& \text { Effyss }=80 \% \\
& \text { Effyhs }=73 \% \\
& \text { EF } \quad=.55
\end{aligned}
$$

From Table C-3, ASHRAE 103-1982 "' DHR $=25$

SHIF $=.225 \times \frac{.80}{.73}=.247$

WHLF $=\frac{60 \times 77 \times 8.25 \times 1.0}{50.000 \times .80 \times 24}=.04$

NHLF $=\frac{60 \times 77 \times 8.25 \times 1.0}{50.000 \times .55 \times 24}=.058$

$\operatorname{CAE}=\frac{(.247 \times .73)+(.04 \times .80)+1.1(.058 \times .55)}{.247+.04+1.1(.058)}=.7052$ 


\title{
RETROFIT SAVINGS FOR DUAL INTEGRATED APPLIANCES IN SMALL COMMERCIAL AND MULTIFAMILY BUILDINGS
}

\author{
INTERIM REPORT
}

Center for Energy and the Urban Environment

\author{
David L. Bohac \\ Martha J. Hewett \\ Ted Staller \\ Timothy S. Dunsworth
}

December, 1990

Prepared under contract to

Minnegasco, Inc. 


\section{INTRODUCTION}

A dual integrated appliance is defined as a unit that provides both domestic hot water and space heat to a building. There are generally three types of dual integrated appliances (DIA). The first consists of a boiler which has a primary function of producing space heat, but has either an integral heat exchanger or a separate storage tank, heat exchanger, and pump for producing domestic hot water (DHW). The second type of appliance is a water heater that has the primary function of supplying DHW but includes a separate heating coil and pump for producing space heat. The third type has a primary function of supplying both DHW and space heat. This study examines only a type II DIA, or otherwise called combination heater. For the remainder of the report the term DIA is considered to indicate a type II DIA.

A typical DIA system configuration is displayed in Figure 1. The heater water hot outlet supplies not only DHW but also water to a heating coil. When space heat is required, a pump circulates hot water through the heating coil and returns it to either to the cold water inlet or separate inlet. A check valve is included on the heating coil supply pipe so that cold water is not drawn through the heating coil when there is a DHW draw in the building. The heating coil can be located near the heater or remote and is available in vertical, horizontal, and wall-recessed units. If the proper materials are used, fin tube baseboards can be used in place of a fan coil; however that is not the preferred configuration. The building thermostat typically activates both the blower and circulation pump. Installations can incorporate a time delay relay on the blower which reduces the small period of time that cool air is supplied to the heating registers. The heater is controlled as it would be for a typical heater, by an aquastat inserted in the tank.

A DIA has many advantages compared to a separate furnace and water heater:

1) There is only one combustion appliance to maintain or replace.

2) Side or vertical venting will typically be easier for a DIA.

3) Using a horizontally mounted air handler provides a reduction in the required floor area for the mechanical system.

4) The heating supply system is easier to zone and zones are easier to add after the initial installation.

5) For comparable heating appliances, the DIA off-cycle losses are lower.

However, a DIA system also has the following disadvantages:

1) When the system is recovering from a temperature setback and has a large DHW draw, there will be an increased recovery time for both the DHW and building air temperatures.

2) The range of input and efficiency for approved DIA heaters is limited.

3) The DIA system is relatively new to the Twin Cities Metropolitan area. There are fewer contractors experienced with installing DIA systems and some cities may be hesitant in allowing them to be installed. 
In many cases, the advantages of a DIA system will outweigh the disadvantages.

DIA systems have had a greater market penetration in the warmer climates of the southern states, but there are appropriate selected markets in colder climates. DIA systems are generally best suited to locations which have relatively high DHW loads. In this situation, it may not be necessary to increase the heater size from the level that would have been used with a separate system. Higher loads on the heater will also usually make it cost effective to use a more efficient heater. This study targets two markets as being appropriate for DIA systems: small comercial businesses and multifamily buildings that have space heat and DHW provided on an individual unit basis.

This study is designed to assess the applicability of dual integrated appliances in small commercial and multi-family buildings. Ten systems are installed at five small commercial and five multi-family locations. The savings of the DIA systems are determined by systematically comparing the measured gas use of the DIA systems to that of the existing systems. Two of the systems are more intensively monitored in order to measure their seasonal efficiency. Various methods of computing the combined DIA seasonal efficiency are examined. The field measurements are applied to these methods in order to compare the energy use of the DIA systems to separate systems with different efficiencies. Finally, the field experiences of installing and operating the DIA systems are reported. This section discusses equipment sizing, code issues and city approval, equipment availability, and equipment malfunctions. This interim report presents information on the installed equipment and the preliminary results of the gas use analysis. The final report will be submitted after the $1990 / 91$ heating season.

\section{SITE SELECTION AND DESCRIPTION}

This study targeted two markets: multi-family buildings with unit-level heating and DHW equipment and small commercial buildings. 10 sites were selected for the study based primarily on the potential to achieve energy savings using a DIA system and also the capability of demonstrating savings. One of the important factors for achieving savings is the size of the domestic hot water load. The increased usage of the integrated system, compared to a DHW only separate system, usually will make it cost effective to use a heater with a higher recovery efficiency. With a higher recovery efficiency, the absolute savings will be greater for buildings with higher DHW loads. A second source of savings is the reduced off-cycle losses of a single appliance compared to a heater and furnace. However, the reduction in total off-cycle losses may only be realized if the increase in the heater size does not significantly increase the loss rate. Thus, a second factor considered for building selection was the increase in the heater size required to meet both the building $\mathrm{OHW}$ and space heat loads.

Another important consideration is the availability of acceptable water heaters. In order to achieve savings for the space heating load, the heater recovery efficiency must be at least as high as the AFUE of the furnace under consideration. The National Appliance Energy Conservation Act (NAECA 1987) 
has established a minimum AFUE standard of $78 \%$ for furnaces with inputs less than 225,000 Btu/hr manufactured after January 1992. Table i lists a total of 34 natural gas heaters from four manufacturers that are specified for use as integrated appliances. 14 of the heaters have recovery efficiencies of $78 \%$ or above, but only four of these have inputs greater than $40,000 \mathrm{Btu} / \mathrm{hr}$ (at the time of the installations, the authors were not aware of the two units with inputs of 57,500 and $75,500 \mathrm{Btu} / \mathrm{hr}$ ). The lack of available efficient equipment limited the DIA systems to either sites with low to moderate heating loads or ones with higher loads that could justify the cost of using the expensive (1ist price of $\$ 3,200)$, condensing heater with an input of 100,000 Btu/hr.

Small multi-family units meet many of the stated criteria for successful DIA system application. Typically, small multi-family units have heaters with inputs that range from 30,000 to $40,000 \mathrm{Btu} / \mathrm{hr}$. Similar sized heaters, with recovery efficiencies of $78 \%$, can handle heating loads from 19,000 to 26,000 Btu/hr (see later section on equipment sizing). A slightly increased heater size of $55,000 \mathrm{Btu} / \mathrm{hr}$, with a recovery efficiency of $80 \%$, can handle a heating load of $35,000 \mathrm{Btu} / \mathrm{hr}$. This should be sufficient for units with floor areas of $1000 \mathrm{ft}^{2}$ or less that are built to the more recent higher energy efficiency standards. Thus, small multi-family units meet the criteria of having heater sizes that are either sufficient or would be only increased slightly to meet the heating load. Also, there are numerous manufacture approved DIA heaters of the required size that meet the efficiency requirements. Since it is not expected that the level of DHW load would normally be known or considered when selecting a DIA system, DHW use was not used as a selection criteria for the multi-family sites. Consequeptly, relatively new multi-family units with floor areas less than $1000 \mathrm{ft}^{2}$ were considered for the study.

Certain small commercial businesses are expected to be good candidates for DIA systems. Those with high, but not excessive, DHW loads (e.g. hair salons but not laundromats) or which have heaters that do not require significant increases in heater input are most promising. The following businesses were among those identified as potentially having high DHW loads:- sandwich shops, bakeries, dog grooming salons, hair styling salons, and doctors offices. The second selection criteria was the heater input required to meet the heating load. Due to limitations of available equipment, sites were considered which had relatively low heating loads that could be satisfied with only slightly larger heaters and sites with heating loads high enough to require the high input, condensing heater. Sites were also considered if they could demonstrate an innovative use of a DIA system.

The capability of accurately determining the savings from the DIA retrofit was also a consideration. The sites needed to have few or no changes during the previous and upcoming year which would significantly effect the DHW and space heat loads. This required that the building occupants and their activities would not change, the existing equipment was expected to last for another year, and no significant modifications would be made to the building thermal envelope. It was also necessary to select sites which had monthly gas use which was adequately modelled by outdoor temperature. The energy analysis for some of the sites was to be performed by comparing the normalized annual energy use of the existing system to the use of the retrofit DIA system. For these sites, a more stringent selection criteria was applied to the results of the gas use model. 
The candidate buildings were found from previous contacts with CEUE and Minnegasco or from listings in the phone directory. A total of 25 multifamily and 26 small commercial sites agreed to be considered for acceptance into the study and had their fuel bills analyzed. Sites were removed from consideration due to poorly modelled gas use, possibilities for future load changes, or incompatible heating load levels. For their participation in the study, the owners received the retrofit equipment for the equivalent cost of three years of savings.

The five multi-family units are all located in a single, two story, eight-plex built in the early 1980. A description of each of the units is contained in Table 2. All of the units have ground entrances and two stories. They are built in a single row with four two-bedroom and four three-bedroom units. The four three-bedroom units occupy the two end and center positions. The three two-bedroom units used in the study have floor areas of $675 \mathrm{ft}^{2}$ and engineering estimated (e.g. heating contractor computed) design heat loss of $20,000 \mathrm{Btu} / \mathrm{hr}$. The design heat loss estimated from the gas use analysis $(17,400$ to $21,100 \mathrm{Btu} / \mathrm{hr})$ showed good agreement with the contractor computation. The two three-bedroom end units used in the study have floor areas of $930 \mathrm{ft}^{2}$ and engineer heat losses of $27,000 \mathrm{Btu} / \mathrm{hr}$. This loss rate also agreed well with the gas use analysis estimates of 26,600 and 25,500 $\mathrm{Btu} / \mathrm{hr}$. The loss rates of 20,000 and $27,000 \mathrm{Btu} / \mathrm{hr}$ fell with in the range for available equipment. The annual base (OHW and stove) use estimated from the gas use analysis ranged from 30 to $37 \%$ (211 to 371 ccf) of the total for all the units, except $\$ 72$ which had a relatively higher base use of $52 \%$ (436 ccf). Each unit had one or two adult occupants and two children - except $\$ 4$, which had no children.

All of the units had the same furnace and water heaters. The furnaces had inputs and outputs of 55,000 and 42,000 Btu/hr respectively and AFUEs of $60.3 \%$ (see bottom of Table 3 ). They appear to be greatly oversized for the building design heat loss, but were probably the smallest furnaces readily available in the Minneapolis metro area at the time they were installed. The water heaters have an input of $36,000 \mathrm{Btu} / \mathrm{hr}$ and storage capacities of 40 gallons.

The five small commercial sites are located in the Minneapolis Metropolitan area. Due to the unanticipated difficulty of finding "ideal" sites, the selection criteria were relaxed in some cases in order to complete the installations during the winter of 1990. The two medical offices ( $\$ 3920$ and \#3925) have low annual base loads of 9 and $12 \%$ (120 and 164 ccf) consisting almost entirely of DHW use (see Table 4). The design heat losses from gas use analysis for sites 3920 and 3925 are 42,700 and $44,200 \mathrm{Btu} / \mathrm{hr}$ respectively and the annual heating usages are 1208 and 1201 ccf. The design and construction of the buildings are similar to single family homes and have floor areas of 2,900 and $3,600 \mathrm{ft}^{2}$ - including basement area. A description of the existing equipment at the small commercial sites is displayed in Table 5 . The two medical offices have similar type furnaces with AFUEs of $65.8 \%$. The input for the furnace at $\$ 3920$ is lower, $110,000 \mathrm{Btu} / \mathrm{hr}$ compared to $165,000 \mathrm{Btu} / \mathrm{hr}$ for the one at $\$ 3925$. The heater at $\$ 3920$ has an input of $33,000 \mathrm{Btu} / \mathrm{hr}$, storage capacity of 30 gallons, and recovery efficiency of approximately $70 \%$. The heater at $\# 3925$ is more than double the size. It has an input of 75,000 , storage capacity of 63 gallons, and recovery efficiency of approximately $76 \%$. 
In contrast to the medical offices, the sandwich shop (\#4409) and dog grooming salon (\$4207) have relatively large annual base uses of 36 and $40 \%$ ( 496 and 382 ccf) respectively (see Table 4). These base uses are more than a factor of two greater than that usually found for small commercial businesses (German et al. 1988) and provided a better match to the selection criteria than the medical offices. Site 4409 has a floor area of $3,350 \mathrm{ft}^{2}$ and a design heat loss of $54,200 \mathrm{Btu} / \mathrm{hr}$. However, the furnace that is being used for comparison in this study is only used to heat the rear of the shop. A roof-top unit is used to heat the front sandwich preparation and customer service section. Site 4207 has a floor area of $1,400 \mathrm{ft}^{2}$ and a design heat loss of 26,000 Btu/hr. The existing equipment at $\$ 4409$ consisted of a furnace with an input of 50,000 Btu/hr and AFUE of $71.4 \%$. The water heater had an input of 38,000 Btu/hr, storage capacity of 40 gallons, and recovery efficiency of $73 \%$ (see Table 5). The existing equipment at \$4207 was comparatively larger. It consisted of a furnace with an input of $80,000 \mathrm{Btu} / \mathrm{hr}$ and AFUE of approximately $66 \%$. The heater had an input of $40,000 \mathrm{Btu} / \mathrm{hr}$, storage capacity of 30 gallons, and recovery efficiency of $70 \%$.

The final small commercial site is a combination bagel shop and bakery. The reported annual gas use and design heat loss are somewhat misleading. The furnace and water heater were connected to the same meter that supplies gas to the bagel cooker. Thus, a significant portion of the reported base use is due to the cooker. In addition, it appears that the heat from the cooker and ovens is sufficient to heat the building on most days. Although this site is not a good candidate for obtaining accurate and substantial energy savings, it is useful for demonstrating an innovative DIA application.

\section{INSTALLED SYSTEMS}

Dual integrated appliances are a relatively new type of system that do not have an extensive history to guide equipment sizing and system design. Firm guidelines are in the process of being developed. The sizing considerations for DIA systems include the heating coil output, heater output, and heater storage capacity. The standard practices that are used for other systems to determine the heat output based on the design heat loss, safety factor, and pick up load can also be used for sizing the heating coil output. A report has recently been published which uses a simplified model of system operation to recommend guidelines for sizing DIA systems for multi-family and single family applications (Pietsch and Talbert 1989). The authors assumed that an adequately sized integrated system should be able to "recover from a large hot water draw in one hour or less, while also supplying the space heat load". The recommended "rule of thumb", was that the heater output should typically be 1.2 times the rated coil output. In addition, the storage capacity should be between 3 to 5 times the peak hot water draw. For units without laundries this would require a storage of 40 to 50 gallons but 50 to 75 gallons may be required for units with laundries.

The heater output requirement was somewhat more conservative than that specified by a gas utility (EOGC 1987): 
$Q_{0}=\left(Q_{d}+12,700\right) / E_{r}$

where:

$Q_{0}=$ heater output [Btu/hr]

$Q_{d}=$ design loss [Btu/hr]

$E_{r}$ - recovery efficiency, fraction

However, the recommended heater output was higher than that of one manufacturer which specifies that the heater output should be equal to or greater than the heating coil output (AHHC 1987). The manufacturer also does not recommend increasing the storage capacity above that normally recommended for the building use (but states that the capacity should not be less than 40 gallons). In general, the DIA systems for this study followed the guidel ine of having heater outputs at least a factor of 1.2 times the heating coil output.

The State of Minnesota has recently adopted several DIA system design guidelines into the plumbing code (SM 1990). The entire code is included in this report as appendix A. In summary, the code requires the following design features:

1) A user controlled mixing valve for $\mathrm{DHW}$.

2) A drainage port and isolation valves or purge control to prevent stagnation of heater coil water.

3) The unit must be specifically approved by the manufacturer as a integrated heater.

4) All components in the system must be approved for potable water.

All systems installed for this study met the code specifications outlined in (1), (3), and (4). However, since the installations were performed before the code went into effect, not all the systems included a drain port or intermittent purging of the heating coil. The systems all have similar controls. The existing thermostat was used to activate the pump and blower and the heater burner is controlled by its aquastat, as it would be under normal operation.

One of the difficulties of the study design was specifying the heating coil outputs of the DIA systems. Minnesota State Energy code, at the time of the installations, specified that the rated capacity of a heating system could not exceed 115\% of the design load (SM 1985). However, all of the existing systems, except multi-family units 60 and 74 , had capacities over $200 \%$ of the estimated design load. The system capacities of $\$ 60$ and $\$ 74$ were $155 \%$ of the design load. It was expected that matching the existing capacities would allow a better comparison to the existing systems, but would not provide a fair test of the DIA systems. A compromise was selected in which some systems were designed to either match the existing furnace output or use the maximum output available which would come as close as possible to the furnace capacity. Other systems used the design heat loss as a guide. One multifamily system was selected to match the output of two of the other multifamily DIA systems. 
The five DIA systems installed in the multi-family units are described in Table 3. Each of the heaters has the same storage capacity of the old system, except the heater for \#74 which is 10 gallons larger. The systems for the two larger units have coil outputs of $41,500 \mathrm{Btu} / \mathrm{hr}$, which closely match the output of the furnace $(42,000 \mathrm{Btu} / \mathrm{hr})$. The recovery efficiencies are both $76 \%$. The heater for $\$ 74$ has an input of $65,000 \mathrm{Btu} / \mathrm{hr}$ and output of 49,400 $B t u / h r$. The output is nearly a factor of 1.2 times the heating coil output. The heater for \#60 was slightly undersized, even by the manufactures guidelines. The heater output of $39,900 \mathrm{Btu} / \mathrm{hr}$ is only $96 \%$ of the rated coil output. It was decided to test two, recently available, systems which have integral heaters and air handlers. These are installed in two of the smaller units, $\$ 70$ and $\$ 72$, and have inputs of $40,000 \mathrm{Btu} / \mathrm{hr}$, outputs of 33,200 Btu/hr, and coil outputs of $29,000 \mathrm{Btu} / \mathrm{hr}$. The heating coil output is the highest available and is a compromise between the furnace output and the design load (145\% of the design). The heater outputs are a factor of 1.14 times the coil output rated for the high fan flow. A similar sized unit, with separate heater and air handler, is installed in $\$ 64$. The heater input and storage capacity is the same as for the integral unit, but the recovery efficiency, heater output, and coil output are all slightly larger. This site is expected to allow a comparison between the two types of DIA systems.

The five systems installed at the small commercial sites are described in Table 6. Sites 3920 and 3925 use the high input $(100,000 \mathrm{Btu} / \mathrm{hr})$ condensing heater with the largest available heating coil $(67,000 \mathrm{Btu} / \mathrm{hr})$. For $\$ 3920$ the coil output is still 20\% below the furnace capacity and for \#3925 it is $47 \%$ below. With the high input and recovery efficiency of the heater, the heater output is a factor of 1.4 times the coil output. The heater storage capacity is four gallons more than the existing heater in $\$ 3920$, but 29 gallons less than that in \$3925. However, the gas use analysis indicates a low DHW load that could be satisfied by the smaller storage capacity.

The same system as that installed in multi-family unit \#74 is installed in \$4409. The coil output is closely matched with the furnace capacity (only $6 \%$ above) and the heater output is a factor of 1.19 times the coil output. The storage capacity is 10 gallons larger than the existing heater but both have similar energy factors. Since the recovery efficiency of the OIA heater is only $4.3 \%$ above the furnace AFUE, this is expected to serve as a good comparison of DIA and separate systems with similar efficiencies. Site 4207 is used as another test of the recently released integral heater and air handler. The coil output is only $112 \%$ of the design load and the heater output is a factor of 1.14 times the heater output. The storage capacity is 10 gallons larger than the existing heater and the energy factor is $31 \%$ higher.

The fifth small commercial site (\$4412) was selected to demonstrate an innovative application of a DIA system. A single, high efficiency, condensing heater with an output of $94,000 \mathrm{Btu} / \mathrm{hr}$ is installed with two separate air handlers, heating, and cooling coils. A two-stage heating/single stage cooling thermostat sequentially activates the two heating coil pumps and air handlers. The system also incorporates a manually controlled outdoor air economizer. The rated coil output of the two coils combined is 134,000 $\mathrm{Btu} / \mathrm{hr}$. The over-capacity allows the heating coils to produce as much heat as the heater can generate. This is useful for occasions when maximum heat output is desired, such as recovery from setback. However, the coil over- 
capacity will cause the heater temperature to drop when both air handlers and coil pumps are operated. The heater output is $23 \%$ less than the furnace but is a factor of 7 times the, somewhat uncertain, design load estimated from the gas use analysis. As previously discussed, the low design loss is probably due to the heat generated from the bakery and the uncertainty in the analysis due to the multiple appliances connected to the one gas meter.

\section{EXPERIMENTAL DESIGN}

The primary purpose of this study is to compare the energy use of a dual integrated appiiance to that of an existing furnace and water heater. This is performed b. analyzing the weekly or biweekly gas use of the two different systems. Tra of the sites are also intensively monitored to measure the ansial efficiency of the DIA systems. In addition, the final report will examine various methods of computing the combined annual efficiency of the separate and integra ed systems and apply the field results to these methods.

\section{Gas Use Analysis}

The DIA systems were insialled either in parallel with the existing systems or as a complete change out. When possible, the DIA systems were installed in parallel. This allowed alternating mode, or flip/fiop tests to be performed on the two systems. This type of test has been successfully used by CEUE to perform various studies of energy retrofits (Hewett et al 1988; Hewett and Peterson 1984). The test is carried out by switching between the two systems every one or two weeks and recording the gas use by the active system. The inactive system is isolated so that it does not contribute to off-cycle losses. Isolation consists of switching water valves so that there is no flow through the heater, turning off pilot lights, and shutting off electrical power.

Due to space limitations, the five multi-fami?y and two of the small commercial installations (\$4207 and \$4412) had to be complete change outs. At these sites, the existing equipment was completely removed and DIA systems installed in their place. The analysis at these sites is performed by comparing the gas use of the existing system from the previous year to that of the entire year following the installation (i.e. pre/post test). The monthly gas use records for the previous year were obtained from the local gas utility, Mirunegasco.

Gas use is normalized for weathe: (i.e. outdoor temperature) using PRISM, the PRInceton Scorekeeping Method (Fels 1986). PRISM uses meter reading data and a historic weather file to fit a three parameter model of summer non-heating use, a heating slope, and the outdoor reference temperature below which heating is required. These three paraneters are used with a table of longterm weather norms to yield an estimate of gas use in an average weather year. This state-of-the-art computer program is considered highly accurate in estimating normalized annual consumption.

Intensive W,nitoring

Two of the sites are intensively monitored to measure the seasonal efficiency of the DIA systems. The useful energy output, DHW and heating coil, and 
heater input are monitored in order to establish the relationship between the heater energy input and output. Heating and non-heating efficiencies will be computed and combined to estimate an annual system efficiency.

The data logging equipment and sensors have been installed at small commercial site 3920 and will also be implemented at site 4207 . Hour averages or totals of each measured variable are recorded using a Hewlett Packard 3421A data acquisition and control unit and MetraByte CTM-05 counter/timer interface board operated by a IBM compatible computer. A complete list of the measured variables is displayed in Table 7 and a schematic of the sensors located on the DIA system is displayed in Figure 2. The data acquisition system monitors the heating coil flow rate, heating coil supply temperature, and return temperature in order to compute the heating coil energy output. The heater inlet water flow rate, inlet water temperature, and DHW supply temperature (after the mixing valve) are monitored in order to compute the DHW energy demand (or DHW output). The water temperatures are monitored using thermocouples placed on the surface of the pipes. In order to more accurately measure the temperature difference across the heating coil, the heating coil supply temperature is used as the reference temperature (i.e. the second thermocouple junction) for the heating coil return temperature. A similar arrangement is used for the DHW inlet and supply temperatures. The percentage of time that the existing heater, DIA heater, and furnace operate are multiplied by the respective energy input rates to compute the average energy input rates of the appliances. If an appliance has a standing pilot, the pilot use rate has been measured and is added to the average energy use of that appliance.

Additional air temperatures are al so recorded in order to document the variation in the seasonal space heating load and examine any differences in building temperatures between the two systems. The temperature measurements are made with thermocouples and include the following locations: outdoor air, heating system supply and return air, upstairs and basement air, and data logger case. The number of times the existing heater, DIA heater, and furnace turn on are also recorded to document the cycling behavior of the appliances.

The monitoring system requires approximately one second to monitor a single channel. The complete set of variables is read in no longer than 30 seconds. Every one hour the time and average or total value of each variable are stored to a file on a floppy disk. The computer is connected to a modem and can be remotely accessed for data file transfer and the display of current data values.

\section{RESULTS AND DISCUSSION}

\section{Gas Use Analysis}

The present results of the gas use analysis are preliminary. Due to possible hysteresis and other seasonal effects, the analysis is most accurate using an entire year of data (Rachlin et al. 1985, Dunsworth and Hewett 1985). All of the systems were installed in the mid to later portion of the 1989/90 heating season and require further heating season data to obtain a full year of data. Gas use data has been collected at the multi-family sites over 2 to 3 week periods during the heating season and one month periods over the summer. The 
data at the small commercial sites has been collected on a weekly basis during the heating season and biweekly thereafter. Biweekly gas use will continue to be recorded at all the sites until late March to early May, depending on the actual installation date of the particular system.

A pre/post test procedure is used to estimate the savings of the DIA systems in the five multi-family units. The seven or eight data values for the "pre" year of existing system use span from approximately November 1988 through October 1989. The result of the gas use analysis is displayed in Table 8 and show a good fit to the PRISM model. The standard errors for the normalized annual consumption (NAC) range from 1.1 to $3.7 \%$ (8 to $30 \mathrm{ccf} /$ year) - well below the 5 or $10 \%$ limit commonly used for screening PRISM results (Dunsworth and Hewett 1985, Reynolds 1990). The NACs of the pre-period range from 705 to $1003 \mathrm{ccf} /$ year with the three smaller units being lower than the two threebedroom units.

The DIA systems were installed in early February, 1990. PRISM results from the 16 post-period measurements are also displayed in Table 8. Thus far, the savings for all the units except $\$ 74$ are quite promising. The NACs of units $60,64,70$, and 72 for the post-period range from 592 to $870 \mathrm{ccf} /$ year and represent savings from 113 to $157 \mathrm{ccf} /$ year or from 13.2 to $19.4 \%$. There is not presently a clear, significant pattern of savings between the different types of DIA systems. It appears that the savings for these four units will be significant. The standard errors of the savings range from a factor of 0.20 to 0.32 of the computed savings. However, it is important to note that the DIA systems are being compared to furnaces with AFUEs of $60.2 \%$. Further analysis, to be presented in the final report, is necessary to compare the energy use of the DIA systems to units that would be installed afier the new NAECA standard takes effect in 1992 (NAECA 1987).

There has been a $17.2 \%$ increase in the energy use of unit 74 . Unfortunately, there was a change of occupants about one month after the system was installed. Studies have shown that indentical single family homes with different occupants can have more than a two to one variation in building energy use (Dutt et al. 1986) and that occupants effects are responsible for a significant portion of this variation (Sonderegger 1978). In fact, the two data values obtained with the DIA system while the original occupant was still present (designated "Postl" in Figure 3) show a decrease in the energy use of 13 to $16 \%$ from that predicted from the pre-PRISM model. While the two points obviously do not constitute conclusive evidence, they are consistent with savings estimates similar to those obtained in the other multi-family cases. However, each of the values for the second occupant (designated "Post2" in Figure 3) has been above that predicted by the pre-model. The PRISM results using data generated from the DIA system with only the second occupants (designated "Post2 PRISM" in Figure 3), show a base use increase of 14.1\%, reference temperature increase of $3.0 \mathrm{~F}$, and increase in the slope of $6.0 \%$. However, the change in any the three individual parameters is not very statistically significant. Changes in the DHW use, indoor temperature, or window opening behavior could all contribute to changes in the energy use. is likely that the DHW use has increased, since the new occupants have one more child and both children are older than the child of the original occupants. 
The two medical offices had DIA systems installed in parallel with the existing systems and are analyzed using the alternating mode data. The DIA system installation was completed in January, 1990. The PRISM results for the existing and DIA system operation during the post-period are displayed in Table 9. The NAC of the existing system at $\$ 3920$ is $1282 \mathrm{ccf} /$ year and has a low standard error of $51 \mathrm{ccf} /$ year. In comparison, the DIA system shows a savings of $241 \mathrm{ccf} /$ year $(18.8 \%)$. The relatively low standard error of 63 ccf/year for the savings indicates that they are statistically significant. The base use and heating slope of the DIA system are both comparatively lower than for the existing system. However, the reduction in the base use is not significant compared to the standard errors of the existing and DIA system base uses. The results for site 3925 are very similar. The NAC of the existing system is $1217 \mathrm{ccf} /$ year with a low standard error of $27 \mathrm{ccf} /$ year. The DIA savings are $252 \mathrm{ccf} /$ year $(20.7 \%)$ and are statistically significant, with a standard error of $45 \mathrm{ccf} /$ year. The DIA system al so shows reduced base use and heating slope. Since the existing and DIA systems at these two sites are similar, the similarity of their savings was expected.

The pre and post-period NACS of the existing system at $\$ 3920$ differ by only 46 $\mathrm{ccf} /$ year. However, there is a decrease of $148 \mathrm{ccf} /$ year of the NAC at $\$ 3925$. This is probably due to the numerous window openings while the building was being partially renovated during the pre-period. There is sufficient heating season data and consistency between the pre and post-periods to indicate that the savings estimates will not change considerably with the addition of more heating season data.

The DIA system at site 4409 was installed in parallel with the existing furnace and water heater in early March, 1990. Since there is little 1989/90 heating season data, the post-period results are very preliminary. The PRISM results, shown in Table 9, indicate a savings of $841 \mathrm{ccf} /$ year $(50.5 \%)$. However, the post-period NAC for the existing system have increased by an unexpected $20.8 \%$. In addition, the post-period results for the DIA system show a remarkable decrease in the heating slope (88\%) and increase in the reference temperature $\left(20.4^{\circ} \mathrm{F}\right)$. As indicated by the post-period results displayed in Figure 4, the data for the two systems collected to this date does not appear to be significantly different. Further heating season data is required for accurate results.

The DIA system at site 4207 was a complete change out and was completed in mid April, 1990. The pre-period data, pre-period PRISM model, and post-period data is displayed in Figure 5. There have been 15 measurements made during the post-period; however, this data contains only 184 degree days and only three measurements have average outdoor temperatures below $50^{\circ} \mathrm{F}$. The PRISM results for the post-period are inconclusive. The DIA NAC is $4.7 \%$ greater than that for the existing system, but the standard error of the difference in use is greater than the actual difference in use. In fact, there does not appear to be any significant difference between any of the pre/post PRISM parameters. Further data is required to draw significant conclusions.

The DIA system at site 4412 was a complete change nut and was installed in mid February, 1990. As previously discussed, this system was installed primarily to demonstrate an innovative application of a DIA system. Due to the gas use of the large cooking appliances and the small dependence on outdoor temperature, this site was not expected to show significant energy savings. 
The data for the pre and post-periods is displayed in Figure 6 and shows that there is generally an increase of $22.7 \%$ in average energy use for the postperiod. This increase is entirely due to a statistically significant increase in the base use. However, neither period shows much dependence on outdoor temperature. In fact, the PRISM results for both periods (see Table 9) meet the "flatness index" criteria, with coefficients of about $4 \%$. Data with a coefficient lower than $11 \%$ is considered to unmodelable by PRISM (Reynolds 1990). The inability of PRISM to determine a proper reference temperature for either period confirms that the data is unmodelable.

It is unlikely that the increase in the base use $(5.4 \mathrm{ccf} /$ day or 22,500 $\mathrm{Btu} / \mathrm{hr}$ ) could be due to a difference in efficiency of the existing and DIA heaters. It is possible that other factors could be influencing the building energy use. The street in front of the store was under construction during the pre-period and was completed about the time the DIA system was installed. Information on the relative sales volume will be examined as a possible explanation for the increase in building energy use.

\section{CONCLUSIONS}

The gas use results for all 10 sites are preliminary and require further heating season data. Gas use measurements will continue to be collected until the mid or end of the 1990/91 heating season. The present results from the rulti-family units indicate a 13.2 to $19.4 \%$ savings for the DIA systems in the four units that did not have a change in occupant. The energy use in the fifth unit has increased by $17.2 \%$, but this is most likely due to the change in occupants that occurred shortly after the system was installed. It is important to note that the existing equipment included furnaces with AFUEs of 60.3\%. The savings demonstrated in this study would be lower if the DIA systems were compared to the more efficient furnaces and heaters that will be required after January, 1992.

The results from two of the small commercial sites (\#3920 and \#3925) which installed high efficiency, condensing heaters, show savings of 18.8 and $20.7 \%$. Further data are not expected to significantly changes these results. The remaining three small commercial sites have more limited heating season data. The results from sites 4409 and 4207 show a savings of over $50 \%$ and an increase of $4.7 \%$ respectively. Numerous inconsistencies in the modelled data indicate that these results are not yet significant and may change with further heating season data. The final small commercial site (4412) was primarily used to demonstrate an innovative installation of a DIA system. The average energy use at this location has increased by $22.7 \%$. This is most likely due to changes in other uses in the building and does not necessarily reflect the differences in efficiencies of the existing and DIA systems.

The final report will include an examination of possible methods for computing the combined efficiency of the DIA and separate equipment. This should allow a comparison of the DIA system efficiency to more efficient equipment. In addition, the results from the intensive monitoring and a qualitative summary of the field experiences will be reported. 


\section{DEFINITIONS}

Annual Fuel Utilization Efficiency (AFUE) - A rating of the annual efficiency of an appliance that is based on average input, losses, and on and off cycling using procedures specified by the US Department of Energy.

Dual Integrated Appliance (DIA) - A system that uses a water heater to supply both domestic hot water and space heat to the building. ASHRAE defines a type I appliance as "An appliance whose primary design function is space heating and which has a secondary function of domestic water heating" (ASHRAE 1990). A type II appliance is defined to be "An appliance whose primary design function is domestic water heating and which has a secondary function of space heating".

Energy Factor (EF) - A measure of the overall efficiency of a water heater based on the model's recovery efficiency, standby loss, and energy input.

Recovery Efficiency - The percentage of energy put into the water compared to the total energy used by the water heater.

\section{ACKNOWLEDGEMENTS}

This research was funded by Minnegasco under their Conservation Improvement Program. The authors gratefully acknowledge their financial support and the help of Sue Makredes and Paul Walton in planning this study and finding field sites. We also wish to thank the owners and tenants of the test sites for their cooperation in the study.

A number of CEUE personnel have also contributed to this project. The authors wish to thank Mark Hancock for his work on the figures and schematics, Scott Rohr for assisting in the implementation of the data acquisition units and field visits, Mary Sue Lobenstein for helping with the PRISM analysis of the numerous candidate sites, and Pat Heim for locating possible test sites.

\section{REFERENCES}

ASHRAE, 1990. ASHRAE Standard 124P, "Method of Testing For Rating Combination Space-Heating and Water-Heating Appliances," Third Public Review Draft. ASHRAE, At Tanta, GA.

Apollo Hydro Heat: The Inside Story, 1987. Form A125-1187, Apollo HydroHeat and Cooling, Ashland City, TN.

Dunsworth, T. and Hewett, M., 1985. "Data Quality Considerations in Using the "PRISM" Program," Proceedings of the Second National Conference on Energy Conservation Program Evaluation, Vol 1: p. 170-179, Chicago, IL.

Dutt, G., Lavine, M., Levi, B., and Socolow, R., 1986. "The Modular Retrofit Experiment: Design, Scorekeeping, and Evaluation," Energy and Buildings, February/May 1986, Vol 9, Numbers 1 \& 2, p. 21-33. 
Fels, M., 1986. "The Princeton Scorekeeping Method: An Introduction," Eneray and Buildings, February/May 1986, Vol 9, Numbers $1 \& 2$, p. 5-18.

German, M., Itteilag, R., Hopkins, M., Aniba, K., Tucker, R., 1988.

"Commercial Gas Market Survey: 1987." American Gas Association, Arlington, Virginia.

Hewett, M. and Peterson, G., 1984. "Measured Energy Savings from Outdoor Resets in Modern Hydronicaliy Heated Apartment Buildings, "Proceedings of the Amertcan Council for an Eneray Efficient Economy 1984 Summer Study, vol C, $p$. 135-152.

Hewett, M., Dunsworth, T., Emslander H., Koehler M., 1988. "Measured Energy Savings from Vent Dampers in Low Rise Apartment Buildings," MEO/TR88-2-MF, CEUE, 510 First Ave. N., Suite 400, Minneapolis, MN 55403.

National Appliance Energy Conservation Act of 1987, Public Law 100-12, March $17,1987$.

Pietsch, J. and Talbert, S., 1989. "Equipment Sizing Procedures for Combination Space-Heating/Water-Heating Systems". ASHRAE Transactions, Vol. 95, part 2, Atlanta, GA.

Rachlin, F., Fels, M., and Socolow, R., 1985. "The Stability of PRISM estimates," Eneray and Buildings, February/May 1986, Vol 9, Numbers 1 \& 2, p 149-157.

Reynolds, C., Komar, P., and Fels, M., 1990. "Using Monthly Billing Data to Find Energy Efficiency Opportunities in Small Comercial Buildings," Proceedings of the American Council for an Energy Efficient Economy 1990 Summer Study, vol 10, p. 10.221-10.235.

Sonderegger, R., 1978. "Movers and Stayers: The Resident's Contribution to Variation Across Houses in Energy Consumption for Space Heating, "Saving Engrax in the Home, edited by Robert Socolow, published by Ballinger Publishing Company, Cambridge, MA.

State of Minnesota Plumbing Code, 1990. Section 4715.2190.

State of Minnesota, Department of Energy and Economic Development, 1985. Model Energy Code Amendments, section 4215.2500 amendment to 503.2. 
APPENDIX A: Minnesota Plumbing Code: Chapter 4715 As in effect July 16, 1990

Section 4715.2190 Combination Water and Space Heating Equipment.

Equipment used for heating domestic or service hot water and for space heating must be installed with a mixing valve to permit the user to control the temperature of the domestic or service hot water regardless of the space heating demand.

The installation must include a drainage port and isolation valve to permit the user to purge the heating colls to waste after the non-heating season, or the system must be designed to automatically prevent stagnation.

The water heater must be specifically designated by the manufacturer for use as a combination hot water and space heater.

Al1 pipes, joints, and appurtenances in the system must be of a type approved for potable water distribution. This provision is not intended to address the wall thickness of heating coils, which must be the responsibility of the manufacturer. 
Figure 1

\section{Typical DIA System Configuration}

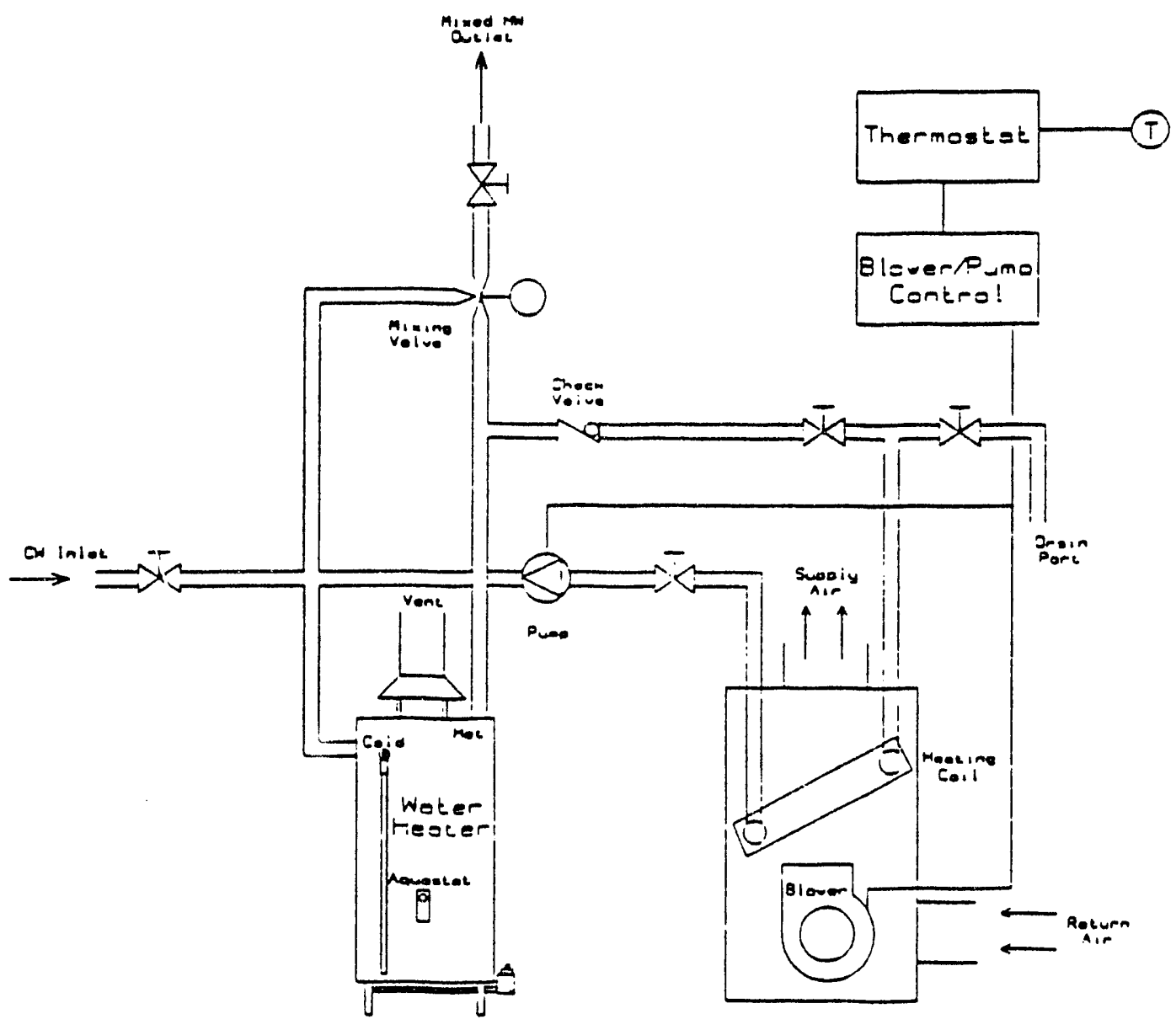


Figure 2

\section{DIA System with DAS Sensors}

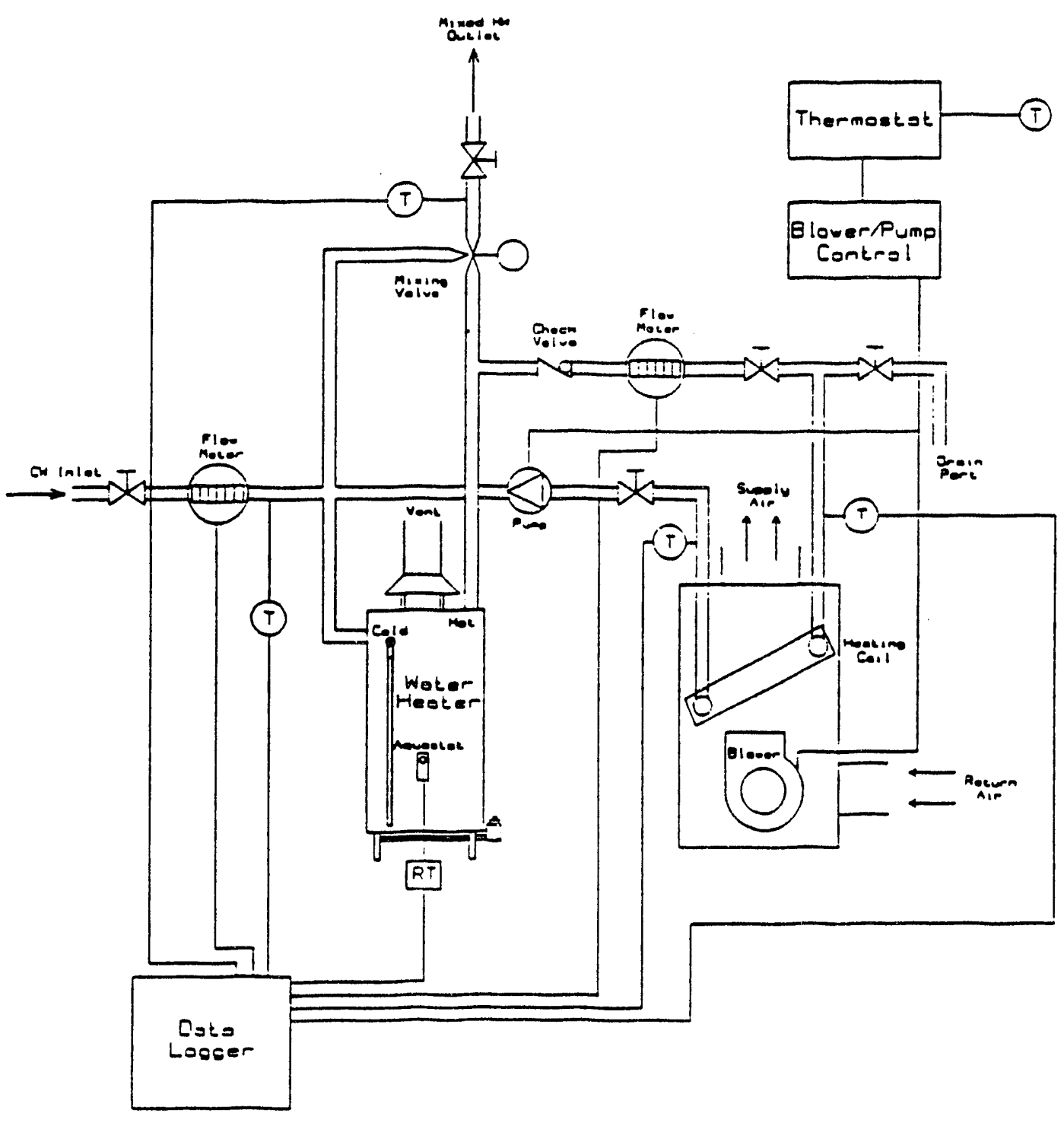


Figure 3

Residential DIA Gas Use Results

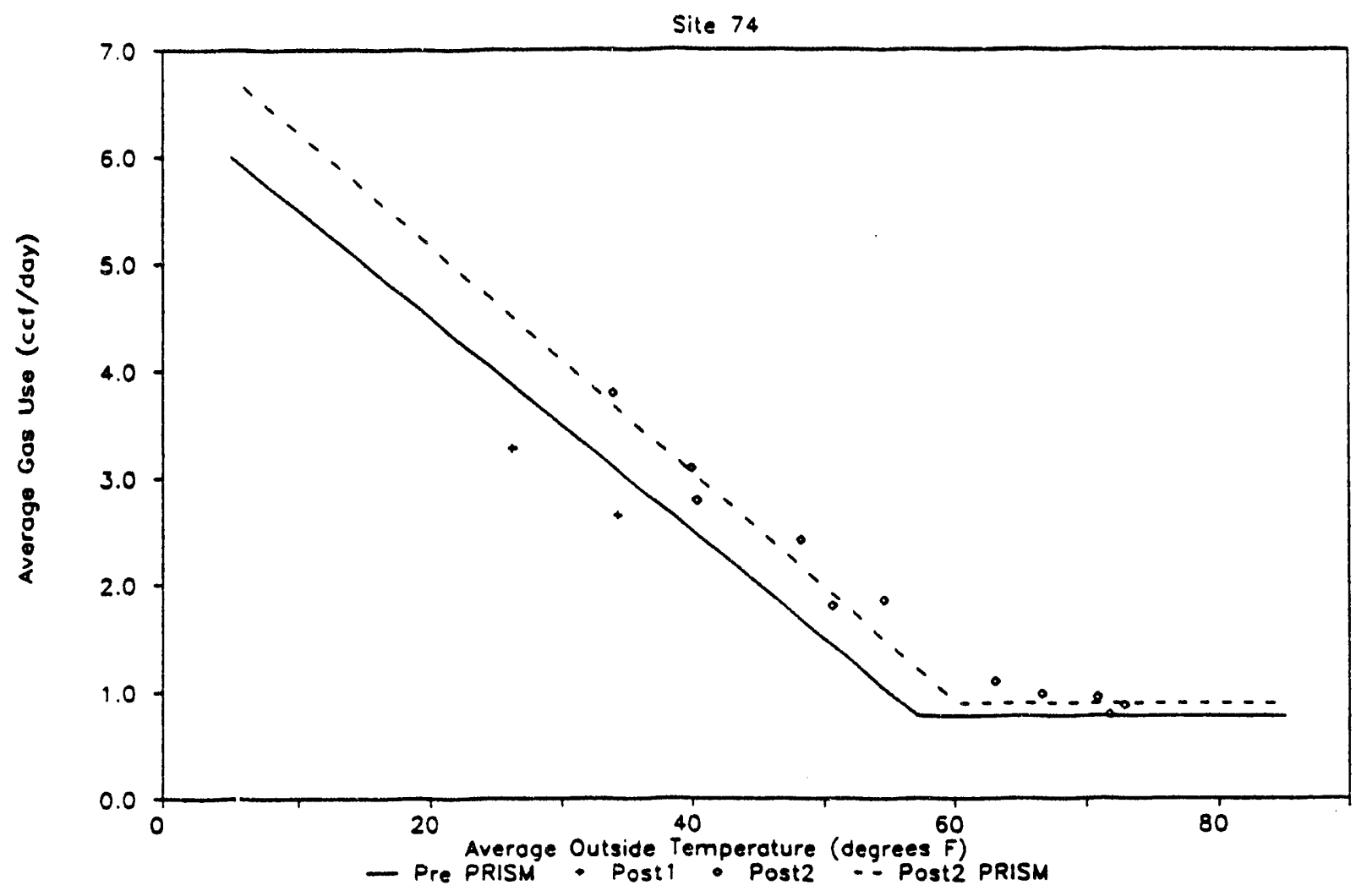

Figure 4

Small Commercial DIA Gas Use Results

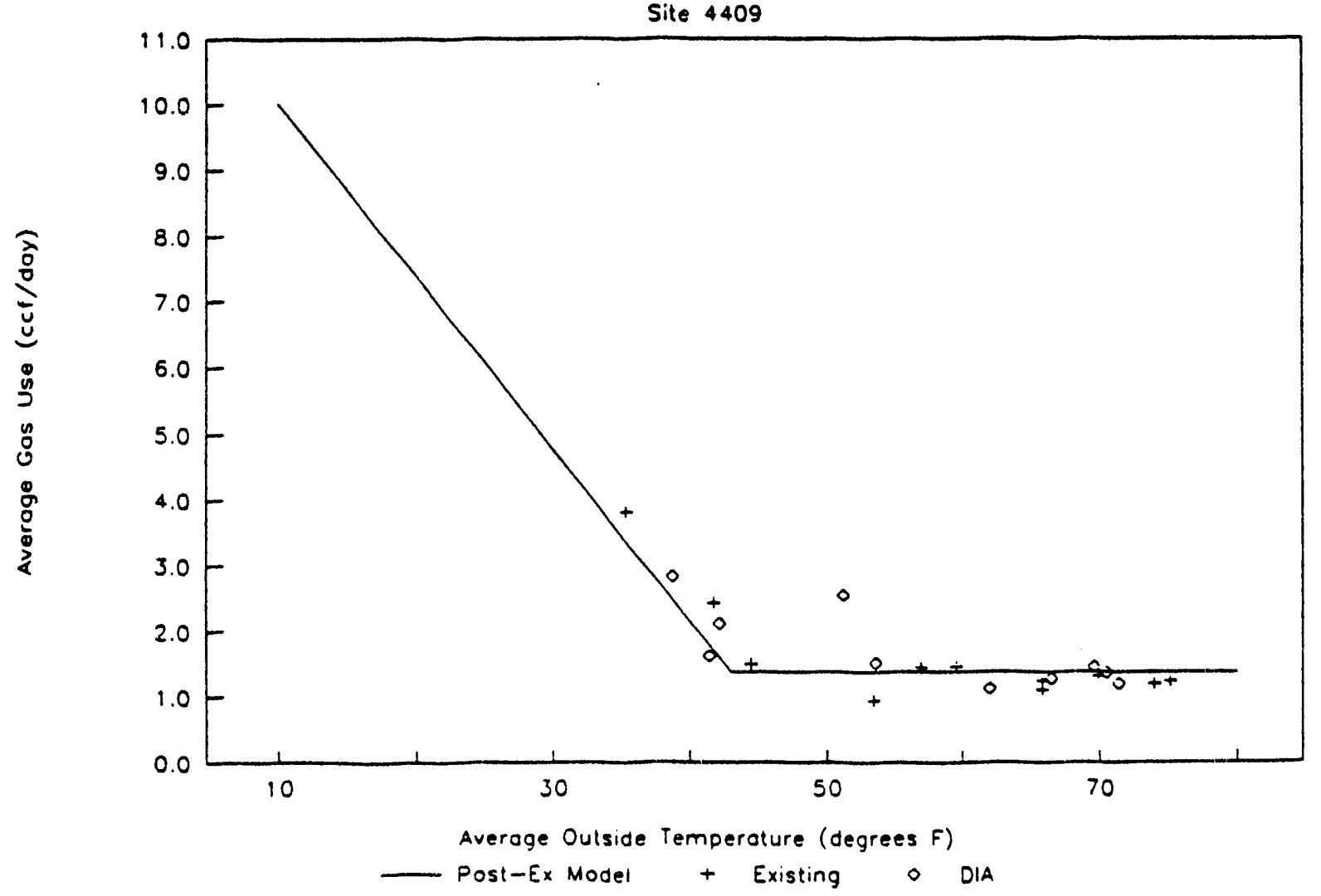


Figure 5

Small Commercial DIA Gas Use Results

Site 4207

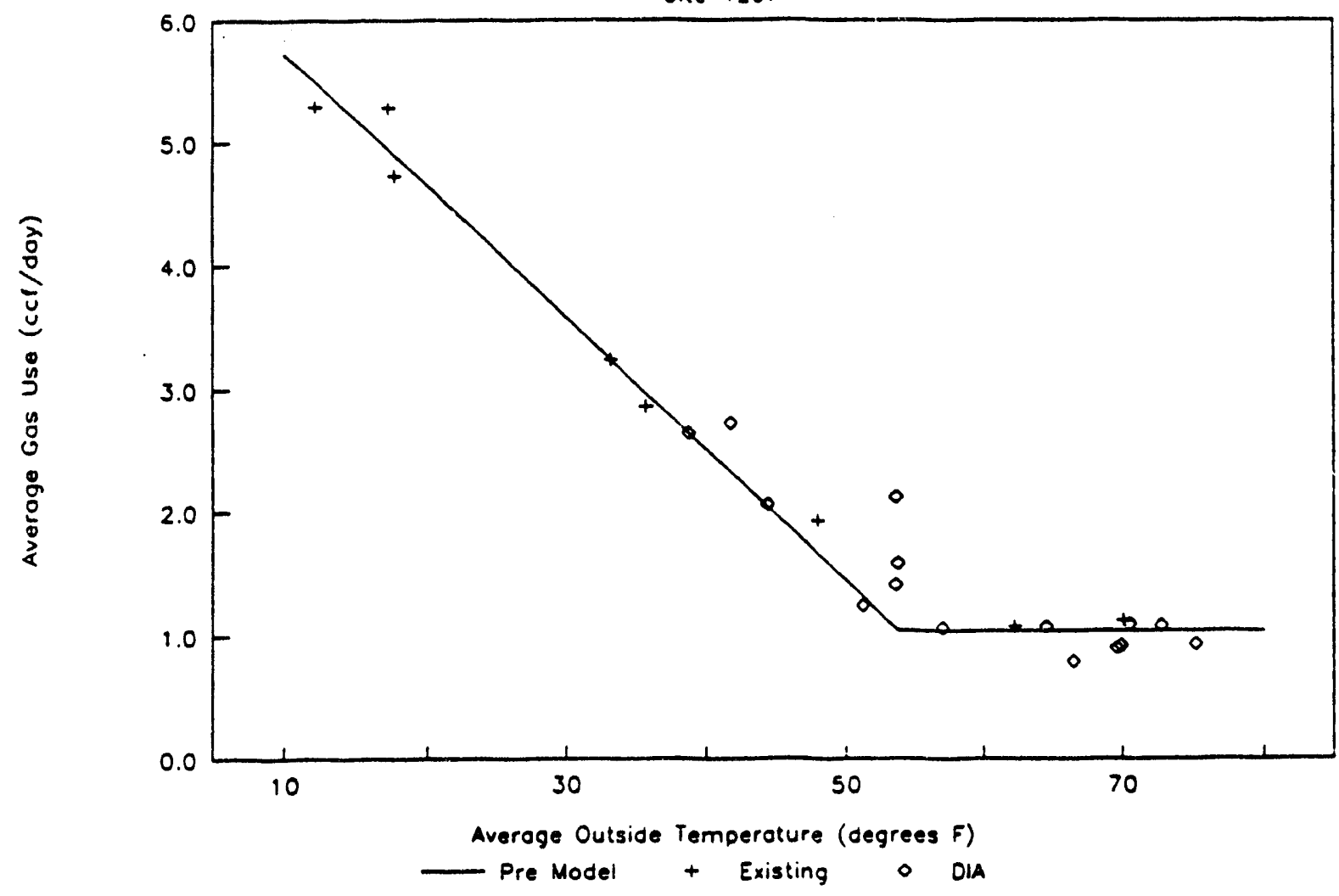

Figure 6

Small Commercial DIA Gas Use Results

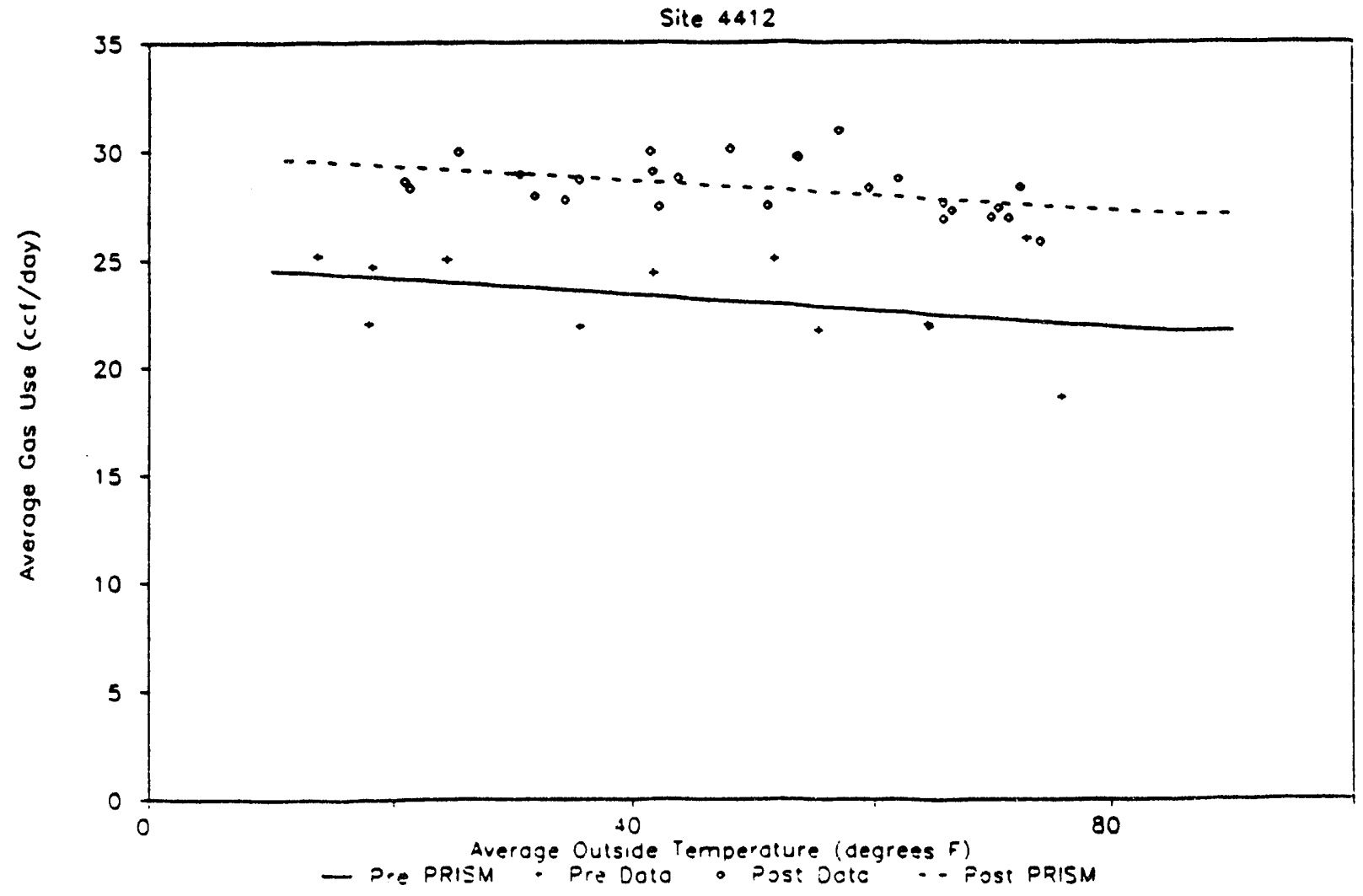


Table 1

\section{Available DIA Heaters}

Manufactor specified for DIA use

\begin{tabular}{|c|c|c|c|c|c|c|c|}
\hline $\begin{array}{c}\text { Input } \\
\text { (BTU//4r) }\end{array}$ & $\begin{array}{c}\text { Stange } \\
\text { Capacity } \\
\text { (Gal) }\end{array}$ & $\begin{array}{l}\text { Recov. } \\
\text { Eff } \\
\text { (\%) }\end{array}$ & $\begin{array}{l}\text { Energy } \\
\text { Factor }\end{array}$ & $\begin{array}{l}\text { Burner } \\
\text { Type }\end{array}$ & $\begin{array}{l}\text { Veat } \\
\text { Type }\end{array}$ & $\begin{array}{l}\text { List } \\
\text { Price } \\
(\$) \\
\end{array}$ & Availability \\
\hline 38,000 & 40 & 85 & 0.60 & Atrospheric & Vertical & $\$ 250$ & immodinte \\
\hline 38,000 & 40 & 76 & 0.58 & Atmospheric & Side & $\$ 308$ & immodiate \\
\hline 38,000 & 40 & NA & 0.56 & Sealed & Direct & $\$ 387$ & 2 weeks \\
\hline 40,000 & 40 & 83 & 0.64 & Power,Senlod & Sido & $\$ 445$ & immodinte \\
\hline 40,000 & 40 & 80 & 0.62 & Atmospheric & Vertical & 534 & 2 weeks \\
\hline 40,000 & 40 & 85 & 0.61 & A.mospheric & Vertical & $\$ 625$ & 4 week \\
\hline 40,000 & 50 & 85 & 0.60 & Atmospheric & Vertical & $\$ 461$ & 2 weels \\
\hline 40,000 & 50 & 85 & 0.59 & Atmospheric & Vertical & $\$ 298$ & immediate \\
\hline 40,000 & 40 & 78 & 0.59 & Atmospheric & Direct & 5738 & 2-3 weeks \\
\hline 40,000 & 50 & 85 & 0.58 & Atmospheric & Vertical & 5730 & 4 woeks \\
\hline 40,000 & 40 & 76 & 0.57 & Atmospheric & Vertical & $\$ 450$ & 4 weeks \\
\hline 40,000 & 40 & 76 & 0.57 & Atmospheric & Vertical & $\$ 550$ & 4 weeks \\
\hline 40,000 & 50 & 78 & 0.57 & Atmospheric & Direct & $\$ 793$ & $2-3$ weeks \\
\hline 40,000 & 40 & 85 & 0.55 & Atmospheric & Vertical & $\$ 248$ & 2 weeks \\
\hline 40,000 & 50 & 76 & 0.54 & Sealed & Direct & $\$ 431$ & 2 weeks \\
\hline 40,000 & 40 & 75 & NA & Sealed & Vertical & 5713 & 4 weeks \\
\hline 40,000 & 40 & 76 & $\overline{N A}$ & Atmospheric & Direct & $\$ 787$ & 4 weeks \\
\hline 42,000 & 50 & 76 & 0.57 & Atmospheric & Side & 5344 & immediate \\
\hline 48,000 & 50 & 76 & NA & Sealed & Vertical & $\$ 792$ & 4 weeks \\
\hline 48,000 & 50 & 76 & NA & Atmospheric & Direct & $\$ 892$ & 4 weeks \\
\hline 52,500 & 40 & 76 & 0.54 & Atmospheric & Vertical & $\$ 575$ & 4 weeks \\
\hline 52,500 & 40 & 76 & 0.54 & Atmospheric & Vertical & $\$ 485$ & 4 weeks \\
\hline 52,500 & 50 & 76 & 0.52 & Atmospheric & Vertical & $\$ 605$ & 4 weeks \\
\hline 52,500 & 50 & 76 & 0.52 & Atmospheric & Vertical & 5705 & 4 weeks \\
\hline 55,000 & 75 & 80 & NA & Atmospheric & Vertical & $\$ 1,075$ & 4 weeks \\
\hline 57,500 & 40 & 80 & 0.59 & Atmospheric & Vertical & 5310 & 2 woeks \\
\hline 0,000 & 50 & 76 & 0.52 & Atmospheris & Vertical & $\$ 426$ & 2 weeks \\
\hline 65,000 & 50 & 76 & 0.52 & Atmospheric & Vertical & $\$ 655$ & 4 weeks \\
\hline 65,000 & 50 & 76 & 0.52 & Atmospheric & Vertical & $\$ 755$ & 4 weeks \\
\hline 75,100 & 75 & 76 & 0.48 & Atmospheric & Vertical & $\$ 903$ & 4 weeks \\
\hline 75,100 & 75 & 76 & 0.48 & Atmospheric & Vertical & $\$ 953$ & 4 weeks \\
\hline 75,500 & 62 & 80 & NA & Atmospheric & Vertical & $\$ 533$ & 2 weeks \\
\hline 83,000 & 100 & 76 & NA & Atmospheric & Vertical & $\$ 1,453$ & 4 weeks \\
\hline 100,000 & 34 & 94 & 0.90 & Power,Sealed & Side & $\$ 3,278$ & immediate \\
\hline
\end{tabular}

NA - Not Available 
Table 2

\section{Building Description}

Multifamily Units

\begin{tabular}{|c|c|c|c|c|c|c|c|c|c|c|}
\hline \multirow{3}{*}{$\begin{array}{l}\text { Buiding } \\
\text { ID }\end{array}$} & \multicolumn{2}{|c|}{ * of Occupants } & \multirow{3}{*}{$\begin{array}{l}\text { Floor } \\
\text { Area } \\
\left(\mathrm{f}^{\wedge} 2\right) \\
\end{array}$} & \multirow{3}{*}{$\begin{array}{l}\text { Unit } \\
\text { Location }\end{array}$} & \multicolumn{2}{|c|}{ Design Heat Locs } & \multicolumn{4}{|c|}{ Amuual Gas Use } \\
\hline & \multirow{2}{*}{\multicolumn{2}{|c|}{ Adults Childreo }} & & & \multirow{2}{*}{$\begin{array}{c}\text { Engineering } \\
\text { (Buthr) }\end{array}$} & \multirow{2}{*}{$\begin{array}{l}\text { Gas Use* } \\
\text { (Bar/hr) }\end{array}$} & \multicolumn{2}{|c|}{ Heating } & \multicolumn{2}{|c|}{ Base } \\
\hline & & & & & & & $(\%)$ & $(\mathrm{ccf})$ & $(\%)$ & $(\mathrm{ccl})$ \\
\hline 60 & 1 & 2 & 930 & End & 27,000 & 26,600 & 63 & 632 & 37 & 371 \\
\hline 64 & 1 & 0 & 675 & Interior & 20,000 & 21,100 & 70 & 494 & 30 & 211 \\
\hline 70 & 1 & 2 & 675 & Interior & 20,000 & 22,000 & 70 & 566 & 30 & 242 \\
\hline 72 & 2 & 2 & 675 & Interior & 20,000 & 17,400 & 48 & 403 & 52 & 436 \\
\hline 74 & 2 & 2 & 930 & End & 27,000 & 25,500 & 68 & 609 & 32 & 286 \\
\hline
\end{tabular}

- - estimated from PRISM gas use analysis at -19F design temperature

MTTABI

Table 3

\section{Description of DIA Equipment}

\section{Multifamily Units}

\begin{tabular}{|c|c|c|c|c|c|c|c|c|c|c|}
\hline $\begin{array}{l}\text { Build. } \\
\text { ID }\end{array}$ & $\begin{array}{l}\text { Heater } \\
\text { Imput } \\
(\mathrm{Bta} / \mathrm{hr})\end{array}$ & $\begin{array}{l}\text { Heater } \\
\text { Orutput } \\
\text { (Btur/hr) }\end{array}$ & $\begin{array}{c}\text { Col } \\
\text { Ontput } \\
(\mathrm{Bur} / \mathrm{hr})\end{array}$ & $\begin{array}{c}\text { Storage } \\
\text { Capacity } \\
\text { (gal) } \\
\end{array}$ & $\begin{array}{c}\text { Recov. } \\
\text { Esf. } \\
(\%) \\
\end{array}$ & $\begin{array}{l}\text { Energy } \\
\text { Factor }\end{array}$ & $\begin{array}{c}\text { Comb. } \\
\text { Eff. } \\
(\%) \\
\end{array}$ & $\begin{array}{c}\text { Flue } \\
\text { Temp. } \\
\text { (F) } \\
\end{array}$ & $\begin{array}{l}\text { Vent } \\
\text { Type }\end{array}$ & $\begin{array}{c}\text { Installed } \\
\text { Cost } \\
(\$)\end{array}$ \\
\hline 60 & 52,500 & 39,900 & 41,500 & 40 & 76 & 0.54 & 77.6 & 471 & vert. wat & 2,212 \\
\hline 64 & 40,000 & 34,000 & 30,000 & 40 & 85 & 0.61 & 81.2 & 310 & vert, nat & 2.067 \\
\hline 70 & 40,000 & 33,200 & 25,000 & 40 & 83 & 0.64 & 84.5 & 275 & power, side & 2.809 \\
\hline 72 & 40,000 & 33,200 & 25,000 & 40 & 83 & 0.64 & 85.6 & 257 & power. side & 2,809 \\
\hline 74 & 65,000 & 49,400 & 41,500 & 50 & 76 & 0.52 & 78.3 & 423 & vert, nat & 2.212 \\
\hline equi & 36,000 & $\mathbf{N A}$ & NA & 40 & NA & 0.49 & 77.2 & 494 & vert, nat & \\
\hline
\end{tabular}

- computed from (heater input) (recovery eff.)

- - rated at inlex temperature $=140 \mathrm{~F}$

Old furnace: Input $=55,000 \mathrm{Btu} / \mathrm{hr}$, Output $=42,000 \mathrm{Btu} / \mathrm{hr}$

AFUE $=60.3 \%$

New Furnace

\begin{tabular}{cc} 
AFUE (\%) & replacemene cost \\
\hline 70 & $\$ 1,200$ \\
80 & $\$ 1,350$
\end{tabular}

MFTAli2

Water heater replacement $\cos :=\$ 400(E F=0.5)$ 
Table 4

Building Description

Small Commercial Buildings

\begin{tabular}{|c|c|c|c|c|c|c|c|}
\hline \multirow{3}{*}{$\begin{array}{l}\text { Building } \\
\text { I }\end{array}$} & \multirow{3}{*}{$\begin{array}{l}\text { Type of } \\
\text { Buimess }\end{array}$} & \multirow{3}{*}{$\begin{array}{l}\text { Floor } \\
\text { Areato } \\
\text { (at2) }\end{array}$} & \multirow{3}{*}{$\begin{array}{c}\text { Deaign } \\
\text { Heat Loss" } \\
(\mathrm{Bta} / \mathrm{hr})\end{array}$} & \multicolumn{4}{|c|}{ Annual Gas Use } \\
\hline & & & & \multicolumn{2}{|c|}{ Heating } & \multicolumn{2}{|c|}{ Base } \\
\hline & & & & $(\%)$ & $(\mathrm{ces})$ & (\$) & $(\cot t)$ \\
\hline 3920 & Doctors Office & 2,900 & 42,700 & 91 & 1208 & 9 & 120 \\
\hline 3925 & Dentist Office & 3,600 & 44,200 & 88 & 1201 & 12 & 164 \\
\hline 4409 & Sandwich Shop & 3,350 & $54,200+$ & 64 & 881 & 36 & 496 \\
\hline 4207 & \begin{tabular}{|l|} 
Dog Grooring \\
\end{tabular} & 1,400 & 26,000 & 60 & 572 & 40 & 382 \\
\hline 4412 & Bagel Shop/Bakery & 4,000 & 13,200 & 7 & 592 & 93 & 7869 \\
\hline
\end{tabular}

- estimated from PRISM gas use analysis at -19F design temperature

* - includes first floor and basement area

+ - a portion of heating load satisfied by roof top unit in the front section of the shop

xTA21

Table 5

\section{Description of Existing Equipment Small Commercial Buildings}

\begin{tabular}{|c|c|c|c|c|c|c|c|c|}
\hline $\begin{array}{l}\text { Build. } \\
\text { ID }\end{array}$ & $\begin{array}{l}\text { Furonace } \\
\text { Impute } \\
\text { (Btu/hr) } \\
\end{array}$ & $\begin{array}{l}\text { Furnace } \\
\text { Outpot } \\
\text { (Btw/hr) } \\
\end{array}$ & $\begin{array}{c}\text { AFUE } \\
(\%) \\
\end{array}$ & $\begin{array}{c}\text { Water Htr. } \\
\text { Input } \\
(\mathrm{Bta} / \mathrm{hr})\end{array}$ & $\begin{array}{c}\text { Water Htr. } \\
\text { Output } \\
\text { (Bti/hr) }\end{array}$ & $\begin{array}{c}\text { Storage } \\
\text { Capacity } \\
\text { (gal) } \\
\end{array}$ & $\begin{array}{c}\text { Recov. } \\
\text { Eff. } \\
(\%) \\
\end{array}$ & $\begin{array}{l}\text { Energy } \\
\text { Factor }\end{array}$ \\
\hline 3920 & 110,000 & 84,000 & 65.8 & 33,000 & 23,100 & 30 & 70 & NA \\
\hline 3925 & 165,000 & 126,000 & 65.8 & 75,000 & 57,000 & 63 & $76 *$ & $0.5 .1 *$ \\
\hline 4409 & 50,000 & 39,000 & 71.4 & 38,000 & 27,740 & 40 & 73 & 0.51 \\
\hline 4207 & 80,000 & 62,000 & $66^{*}$ & 40,000 & 28,000 & 30 & 70 & 0.49 \\
\hline 4412 & 160,000 & 121,600 & $66^{*}$ & $\mathbf{N A}$ & NA & NA & $N A$ & NA \\
\hline
\end{tabular}

NA - information not available 
Table 6

\section{Description of DIA Equipment}

Small Commercial Buildings

\begin{tabular}{|c|c|c|c|c|c|c|c|c|c|}
\hline $\begin{array}{c}\text { Build. } \\
\text { ID }\end{array}$ & $\begin{array}{l}\text { Henter } \\
\text { Input } \\
\text { (Bti/hr) } \\
\end{array}$ & $\begin{array}{l}\text { Henter } \\
\text { Outpat: } \\
\text { (Bta/hr) }\end{array}$ & $\begin{array}{c}\text { Heating Coil } \\
\text { Output } \\
\text { (Bur/hr) }\end{array}$ & $\begin{array}{l}\text { Storage } \\
\text { Capacity } \\
\text { (gal) } \\
\end{array}$ & $\begin{array}{l}\text { Rocov. } \\
\text { Eff.: } \\
\text { (\%) } \\
\end{array}$ & $\begin{array}{l}\text { Eocrgy } \\
\text { Fector }\end{array}$ & $\begin{array}{l}\text { Burner } \\
\text { Type }\end{array}$ & $\begin{array}{l}\text { Teat } \\
\text { Type }\end{array}$ & $\begin{array}{c}\text { Installed } \\
\text { Cost } \\
(\$) \\
\end{array}$ \\
\hline 3920 & 100,000 & 94,000 & 67,000 & 34 & 94 & 0.90 & power, sealed & side & 2,850 \\
\hline 3925 & 100,000 & 94,000 & 67,000 & 34 & 94 & 0.90 & power, sealed & side & 2.875 \\
\hline 4409 & 65,000 & 49,400 & 41,500 & 50 & 76 & 0.52 & atmospheric & ver. & 2,809 \\
\hline 4207 & 40,000 & 33,200 & 29,000 & 40 & 83 & 0.64 & power, sealed & side & 2,848 \\
\hline 4412 & 100,000 & 94,000 & 134,000 & 34 & 94 & 0.90 & power, sealed & side & 5,680 \\
\hline
\end{tabular}

- computed from (heater input) (recovery eff.)

* - rated at inlet temperature $=140 \mathrm{~F}$ 


\section{Data Acquisition System Channel Description}

\begin{tabular}{|c|c|c|}
\hline $\begin{array}{l}\text { Secossor } \\
\text { Name }\end{array}$ & 8 & Type of Seosor \\
\hline RTpump & Percent runtime of heating coil pump & $\begin{array}{l}\text { Electrical relay } \\
\text { Resistance }\end{array}$ \\
\hline EVpump & Number of times pump turns on & $\begin{array}{l}\text { Electrical relay } \\
\text { Resintunce }\end{array}$ \\
\hline RTfurn & Percent rumtime of furmace & $\begin{array}{l}\text { Electrieal relay } \\
\text { Resistunce }\end{array}$ \\
\hline EVfurs & Number of times furnsce turns on & $\begin{array}{l}\text { Eloctrical relay } \\
\text { Reointunce }\end{array}$ \\
\hline Retair & Heatiog system return air temperature & T-type Thermocouple \\
\hline supair & Heating system supply air temperature & T-type Thermocouple \\
\hline RTpols & Percent runtime of DIA Heater & $\begin{array}{l}\text { Electrical relay } \\
\text { Resistance }\end{array}$ \\
\hline EVpols & Number of times the heater turns on & $\begin{array}{l}\text { Electrical relay } \\
\text { Resistance }\end{array}$ \\
\hline Fcoil & Heating coil flow rate & Paddle wheel type flow meter \\
\hline Tclsup & Heating coil supply temperature & $T$-type Thermocouple \\
\hline Tclret & Heating coil return temperature & $\begin{array}{l}\text { T-type Thermocouple } \\
\text { Differential }\end{array}$ \\
\hline Ecoil & Heating coil energy output & $\begin{array}{l}\text { Calculated from flow and } \\
\text { temperature difference }\end{array}$ \\
\hline Gasuse & Building gas use & Gas meter switch \\
\hline RTheat & Percent runtime of existing heater & Pressure differential switch \\
\hline EVheat & Number of times existing heater turns on & Pressure differential switch \\
\hline Fdhw & Domestic hot water flow & $\begin{array}{l}\text { Nutating disk positive } \\
\text { displacement flow meter }\end{array}$ \\
\hline Tdhsup & DHW supply temperature & T-type Thermocouple \\
\hline Tdhind & DHW cold water inlet temperanure & $\begin{array}{l}\text { T-type Thermocouple } \\
\text { Differential }\end{array}$ \\
\hline Edhw & DHW energy demand (output) & $\begin{array}{l}\text { Calculated from flow and } \\
\text { temperature difference }\end{array}$ \\
\hline Tout & Outdoor temperature & T-type Thermocouple \\
\hline Tbasel & Basement air temperature & T-type Thermocouple \\
\hline Tupst & Upstairs air temperature & T-type Thermocouple \\
\hline Thp & DAS temperature & Intermal \\
\hline
\end{tabular}


Table 8

\section{Results of PRISM Gas Use Analysis}

Multifamily Units

\begin{tabular}{|c|c|c|c|c|c|c|c|c|c|c|}
\hline \multirow{3}{*}{$\begin{array}{c}\text { Build. } \\
\text { ID }\end{array}$} & \multicolumn{4}{|c|}{ Pre } & \multicolumn{4}{|c|}{ Post } & \multirow{2}{*}{\multicolumn{2}{|c|}{$\begin{array}{c}\text { NAC } \\
\text { Savings }\end{array}$}} \\
\hline & \multirow{2}{*}{$\begin{array}{l}\text { NAC } \\
(c e f) \\
\end{array}$} & \multirow{2}{*}{$\begin{array}{c}\text { Base } \\
\text { (cct/day) }\end{array}$} & \multirow{2}{*}{$\begin{array}{c}\text { Slope } \\
\text { (ccf/F day) } \\
\end{array}$} & \multirow{2}{*}{$\begin{array}{l}\text { Tref } \\
\text { (F) } \\
\end{array}$} & \multirow{2}{*}{$\begin{array}{l}\text { NAC } \\
\text { (cef) }\end{array}$} & \multirow{2}{*}{$\begin{array}{r}\text { Base } \\
\text { (cof/day) }\end{array}$} & \multirow{2}{*}{$\begin{array}{c}\text { Slope } \\
\text { (cctJf day) }\end{array}$} & \multirow{2}{*}{$\begin{array}{l}\text { Tref } \\
(F)\end{array}$} & & \\
\hline & & & & & & & & & $(\%)$ & $(\mathrm{ccf})$ \\
\hline 60 & $\begin{array}{l}1003 \\
(23) \\
\end{array}$ & $\begin{array}{r}1.01 \\
(0.11) \\
\end{array}$ & $\begin{array}{c}0.105 \\
(0.008) \\
\end{array}$ & $\begin{array}{l}56.7 \\
(3.2) \\
\end{array}$ & $\begin{array}{l}870 \\
(12) \\
\end{array}$ & $\begin{array}{r}0.97 \\
(0.04) \\
\end{array}$ & $\begin{array}{r}0.082 \\
(0.005) \\
\end{array}$ & $\begin{array}{l}58.0 \\
(1.2) \\
\end{array}$ & 13.2 & $\begin{array}{r}133 \\
(26) \\
\end{array}$ \\
\hline 64 & $\begin{array}{l}705 \\
(8) \\
\end{array}$ & $\begin{array}{r}0.58 \\
(0.05) \\
\end{array}$ & $\begin{array}{r}0.084 \\
(0.003) \\
\end{array}$ & $\begin{array}{l}56.0 \\
(1.6) \\
\end{array}$ & $\begin{array}{l}592 \\
(35) \\
\end{array}$ & $\begin{array}{c}0.60 \\
(0.08) \\
\end{array}$ & $\begin{array}{c}0.084 \\
(0.016) \\
\end{array}$ & $\begin{array}{l}49.3 \\
(3.5) \\
\end{array}$ & 16.0 & $\begin{array}{r}113 \\
(36) \\
\end{array}$ \\
\hline 70 & $\begin{array}{r}808 \\
(30) \\
\end{array}$ & $\begin{array}{c}0.67 \\
(0.17) \\
\end{array}$ & $\begin{array}{c}0.083 \\
(0.008) \\
\end{array}$ & $\begin{array}{r}60.0 \\
(4.5) \\
\end{array}$ & $\begin{array}{r}651 \\
(23) \\
\end{array}$ & $\begin{array}{c}0.67 \\
(0.07) \\
\end{array}$ & $\begin{array}{c}0.061 \\
(0.008) \\
\end{array}$ & $\begin{array}{l}59.7 \\
(3.1) \\
\end{array}$ & 19.4 & $\begin{array}{r}157 \\
(38) \\
\end{array}$ \\
\hline 72 & $\begin{array}{r}839 \\
(10) \\
\end{array}$ & $\begin{array}{c}1.19 \\
(0.06) \\
\end{array}$ & $\begin{array}{c}0.070 \\
(0.004) \\
\end{array}$ & $\begin{array}{l}55.9 \\
(2.4)\end{array}$ & $\begin{array}{l}703 \\
(32) \\
\end{array}$ & $\begin{array}{c}0.77 \\
(0.07) \\
\end{array}$ & $\begin{array}{c}0.092 \\
(0.015) \\
\end{array}$ & $\begin{array}{r}49.8 \\
(2.9) \\
\end{array}$ & 16.2 & $\begin{array}{r}136 \\
(34) \\
\end{array}$ \\
\hline $74+$ & $\begin{array}{l}895 \\
(12)\end{array}$ & $\begin{array}{r}0.78 \\
(0.06) \\
\end{array}$ & $\begin{array}{c}0.100 \\
(0.004)\end{array}$ & $\begin{array}{l}57.2 \\
(1.9) \\
\end{array}$ & $\begin{array}{l}1049 \\
(31)\end{array}$ & $\begin{array}{c}0.89 \\
(0.07) \\
\end{array}$ & $\begin{array}{c}0.106 \\
(0.010) \\
\end{array}$ & $\begin{array}{l}60.2 \\
(2.1) \\
\end{array}$ & $-17.2+$ & $\begin{array}{c}-154+ \\
(33) \\
\end{array}$ \\
\hline
\end{tabular}

* - period spans November 1988 to October 1989

* - period spans February. 1990 to November 1990

+ - change of occupant, March 1990, post results for second occupant

Values in 0 are standard errors 
Table 9

\section{Results of PRISM Gas Use Analysis}

Small Commercial Buildings

\begin{tabular}{|c|c|c|c|c|c|c|c|c|c|c|}
\hline \multirow{3}{*}{$\begin{array}{l}\text { Build. } \\
\text { ID }\end{array}$} & \multicolumn{4}{|c|}{ Exieting System } & \multicolumn{4}{|c|}{ DLA System } & \multirow{2}{*}{\multicolumn{2}{|c|}{$\begin{array}{c}\text { NAC } \\
\text { Savings }\end{array}$}} \\
\hline & \multirow{2}{*}{$\begin{array}{l}\text { NAC } \\
(\infty) \text {. }\end{array}$} & \multirow{2}{*}{$\begin{array}{c}\text { Base } \\
\text { (cef/day) }\end{array}$} & \multirow{2}{*}{ Slope } & \multirow{2}{*}{$\begin{array}{l}\text { Tref } \\
\text { (F) }\end{array}$} & \multirow{2}{*}{$\begin{array}{l}\text { NAC } \\
\text { (cch) }\end{array}$} & \multirow{2}{*}{$\begin{array}{c}\text { Base } \\
(\cos / d x y)\end{array}$} & \multirow{2}{*}{$\begin{array}{c}\text { Slopo } \\
\text { (cceff day) }\end{array}$} & \multirow{2}{*}{$\begin{array}{l}\text { Tref } \\
\text { (F) }\end{array}$} & & \\
\hline & & & & & & & & & (\%) & (ccf) \\
\hline $\begin{array}{c}3920 \\
\text { Pre }\end{array}$ & $\begin{array}{l}1328 \\
(36)\end{array}$ & $\begin{array}{c}0.35 \\
(0.19)\end{array}$ & $\begin{array}{c}0.154 \\
(0.009)\end{array}$ & $\begin{array}{l}64.0 \\
(2.4)\end{array}$ & & & & & & \\
\hline Post & $\begin{array}{l}1282 \\
(51)\end{array}$ & $\begin{array}{c}0.31 \\
(0.21) \\
\end{array}$ & $\begin{array}{c}0.198 \\
(0.016)\end{array}$ & $\begin{array}{l}56.3 \\
(2.2) \\
\end{array}$ & $\begin{array}{l}1041 \\
(36)\end{array}$ & $\begin{array}{c}0.21 \\
(0.17)\end{array}$ & $\begin{array}{c}0.153 \\
(0.012)\end{array}$ & $\begin{array}{l}58.1 \\
(2.5)\end{array}$ & 18.8 & $\begin{array}{l}241 \\
(63)\end{array}$ \\
\hline $\begin{array}{c}3925 \\
\text { Pre }\end{array}$ & $\begin{array}{l}1365 \\
(36)\end{array}$ & $\begin{array}{c}0.47 \\
(0.20)\end{array}$ & $\begin{array}{c}0.163 \\
(0.009)\end{array}$ & $\begin{array}{l}62.3 \\
(2.7)\end{array}$ & & & & & & \\
\hline Post & $\begin{array}{l}1217 \\
(27) \\
\end{array}$ & $\begin{array}{r}0.44 \\
(0.09) \\
\end{array}$ & $\begin{array}{c}0.194 \\
(0.012)\end{array}$ & $\begin{array}{l}54.2 \\
(1.6) \\
\end{array}$ & $\begin{array}{l}965 \\
(53)\end{array}$ & $\begin{array}{c}0.11 \\
(0.15)\end{array}$ & $\begin{array}{c}0.147 \\
(0.017)\end{array}$ & $\begin{array}{l}58.0 \\
(2.7)\end{array}$ & 20.7 & $\begin{array}{l}252 \\
(45)\end{array}$ \\
\hline $\begin{array}{l}4409 \\
\text { Pre }\end{array}$ & $\begin{array}{l}1377 \\
(88) \\
\end{array}$ & $\begin{array}{c}1.73 \\
(0.35)\end{array}$ & $\begin{array}{c}0.262 \\
(0.052)\end{array}$ & $\begin{array}{l}43.0 \\
(5.1)\end{array}$ & & & & & & \\
\hline Post & $\begin{array}{l}1664 \\
(153) \\
\end{array}$ & $\begin{array}{c}1.23 \\
(0.06)\end{array}$ & $\begin{array}{c}0.410 \\
(0.081)\end{array}$ & $\begin{array}{l}40.6 \\
(1.6)\end{array}$ & $\begin{array}{c}823 \\
(105)\end{array}$ & $\begin{array}{c}1.30 \\
(0.23)\end{array}$ & $\begin{array}{c}0.050 \\
(0.027)\end{array}$ & $\begin{array}{c}61.0 \\
(10.9)\end{array}$ & 50.5 & $\begin{array}{l}841 \\
(186)\end{array}$ \\
\hline 4207 & $\begin{array}{l}954 \\
(29) \\
\end{array}$ & $\begin{array}{r}1.04 \\
(0.17)\end{array}$ & $\begin{array}{c}0.107 \\
(0.009)\end{array}$ & $\begin{array}{l}53.7 \\
(3.5)\end{array}$ & $\begin{array}{l}999 \\
(79)\end{array}$ & $\begin{array}{c}0.98 \\
(0.07)\end{array}$ & $\begin{array}{c}0.116 \\
(0.025)\end{array}$ & $\begin{array}{l}54.6 \\
(3.1)\end{array}$ & -4.7 & $\begin{array}{l}-45 \\
(84)\end{array}$ \\
\hline $4412+$ & $\begin{array}{l}8461 \\
(219)\end{array}$ & $\begin{array}{l}21.64 \\
(1.27)\end{array}$ & $\begin{array}{c}0.038 \\
(0.028)\end{array}$ & $85.0^{*}$ & $\begin{array}{c}10386 \\
(81)\end{array}$ & $\begin{array}{l}27.05 \\
(0.48)\end{array}$ & $\begin{array}{c}0.034 \\
(0.012)\end{array}$ & $86.0^{*}$ & -22.7 & $\begin{array}{r}-1925 \\
(234)\end{array}$ \\
\hline
\end{tabular}

- PRISM could not determine a proper reference temperature

+ - gas use includes cooking appliances

Values in 0 are standard errors 


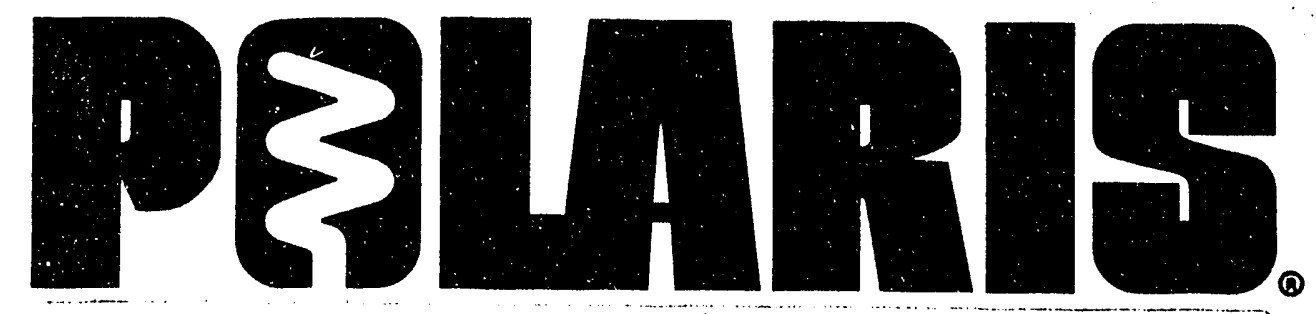

\section{MOR-FLO $\mathbb{Q}^{\circ}$ AMERICAN ${ }^{\otimes}$}

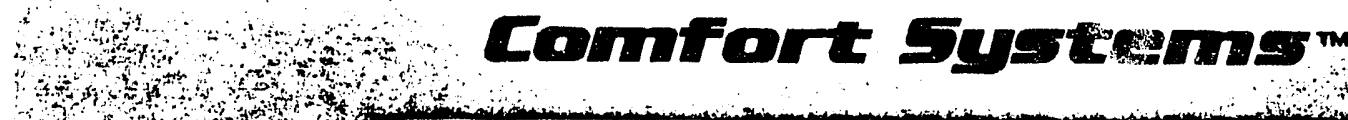

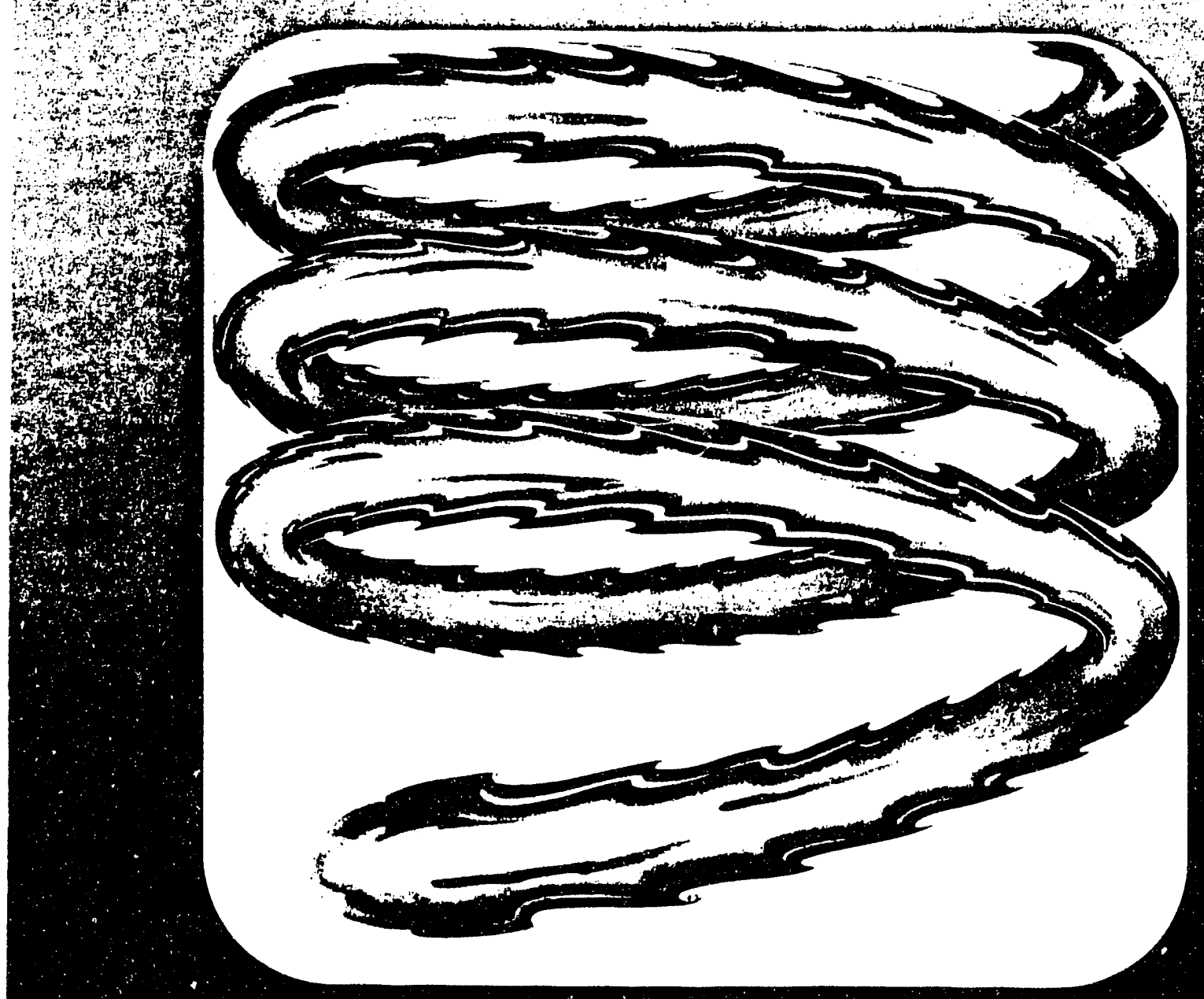




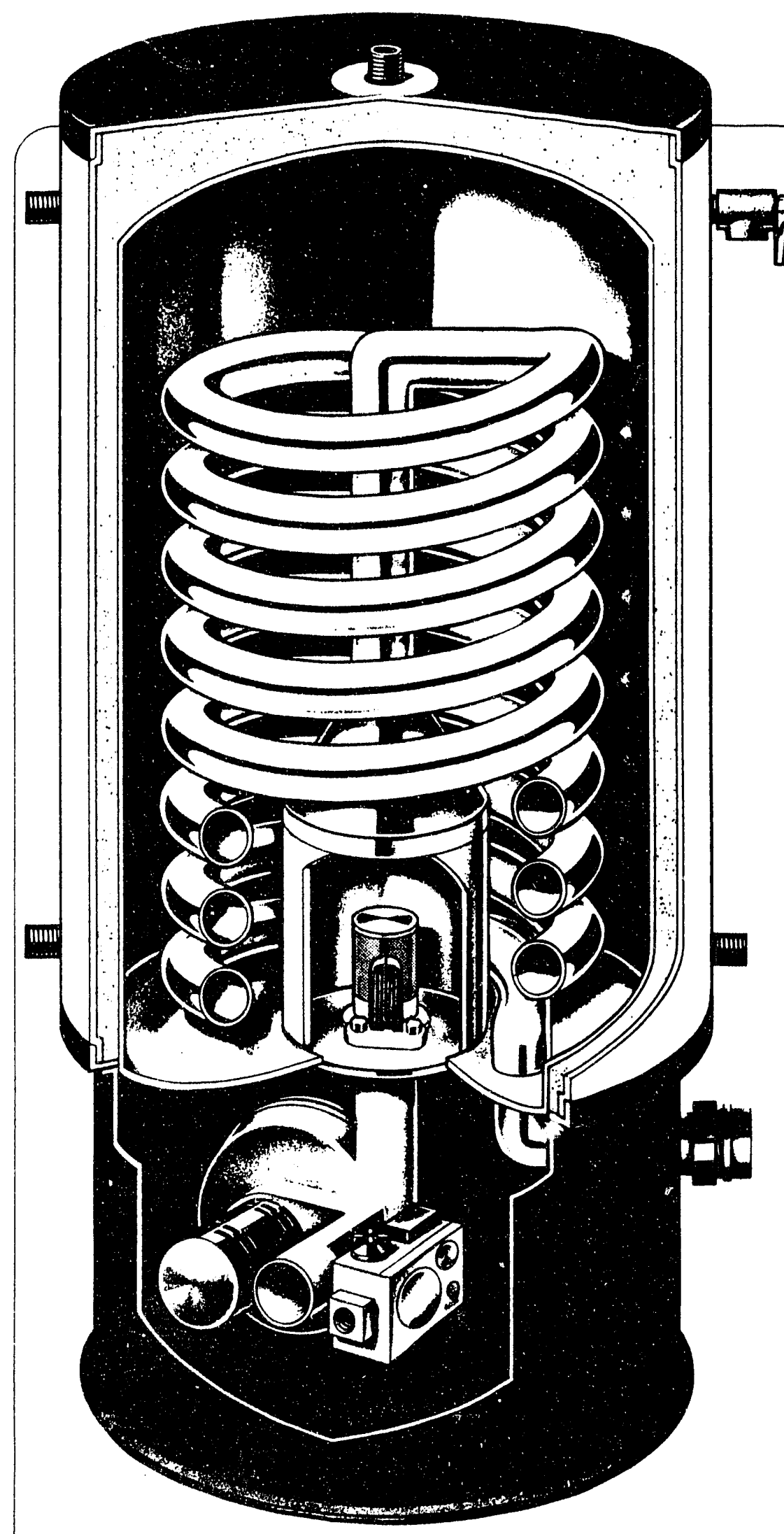

\section{Recovery Efficiency: +94 percent.}

Stainless steel tank assures long life. No glass lining necessary.

Foam insulati in with R-16 factor minimizes heat joss; meets

California Title 24 requirements.

Stainless steel coiled flue transfers heat from flue gases to the water resulting in $94 \%$ recovery efficiency.

Bullet-shaped submerged stainless steel combustion chamber reduces conventional water heater heat loss, lime build-up and noise.

Burner generates intense heat that is forced through the combustion chamber and coiled flue by a powered combustion air blower.

Plastic vent pipes, which can be installed through the wall or roof at distances up to $40 \mathrm{ft}$., serve as combustion air inlet and flue gas outlet.

Negative pressure gas valve maintains uniform gas/air mixture for even, efficient combustion for a variety of inlet pipe applications.

Other features/benefits:

- Solid state electronic thermostat assures precise temperature control.

- LED indicator for Power, Igniter, Burner displays heater operation, simplifies troubleshooting.

- All flue connections are at the bottom of the water heater eliminating standby flue heat loss.

- Submerged combustion chamber allows for water heater to be installed with zero clearance to combustible building materials.

- Silicon carbide hot surface igniter heats to $2600^{\circ} \mathrm{F}$ to light burner flame. Solid state electronic control eliminates pilot flame and automatically shuts off gas should flame go out.

- All water connections, including additional side taps, are 1 -in. nipples.

- Supplied condensate trap, wall-termination kit and tempering $v$ alve. 
4.MORFILO/AMERJ CAN POLARIS

\section{Gas Combo Comfort For Every Home}
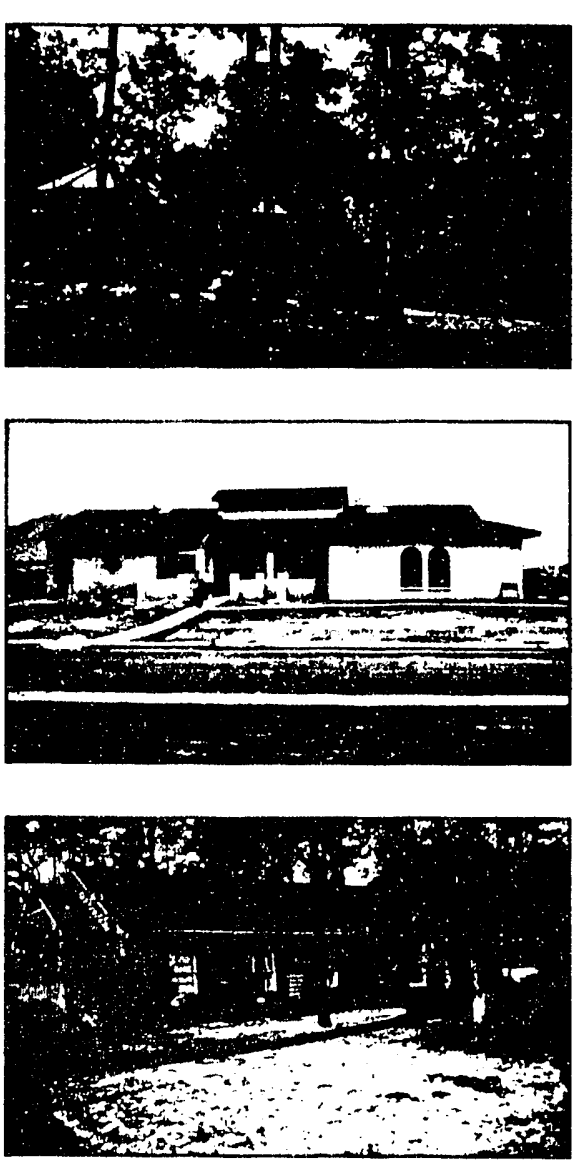

- TOTAL COMFORT FOR CIISTOM HOMES

- PENNY-PINCHING POWERHOUSE

- THE GAS ANSWER FOR ALL-ELECTRIC HOMES

- VERSATILITY

- GREAT FOR COMMERCIAL APPLICATIONS
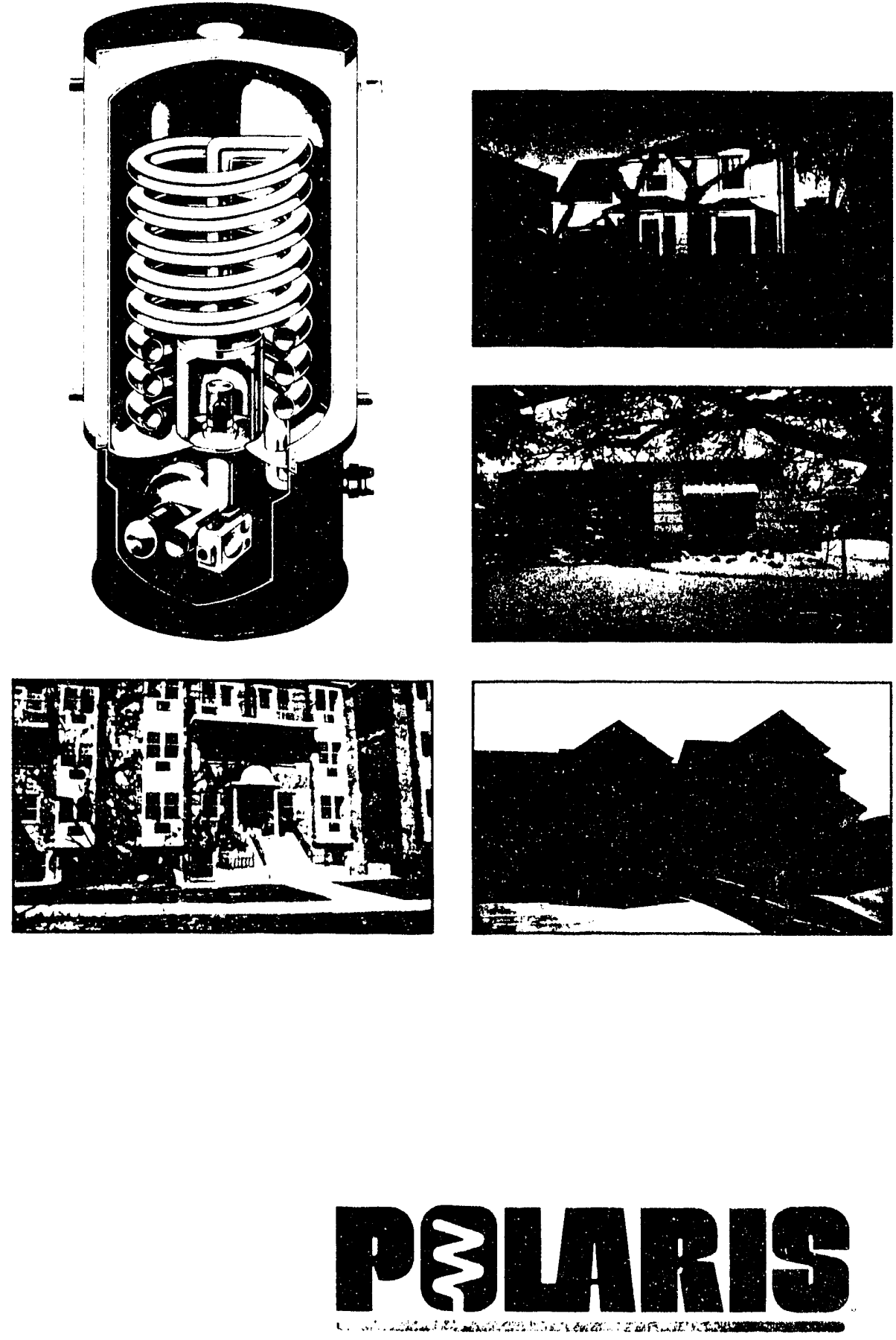


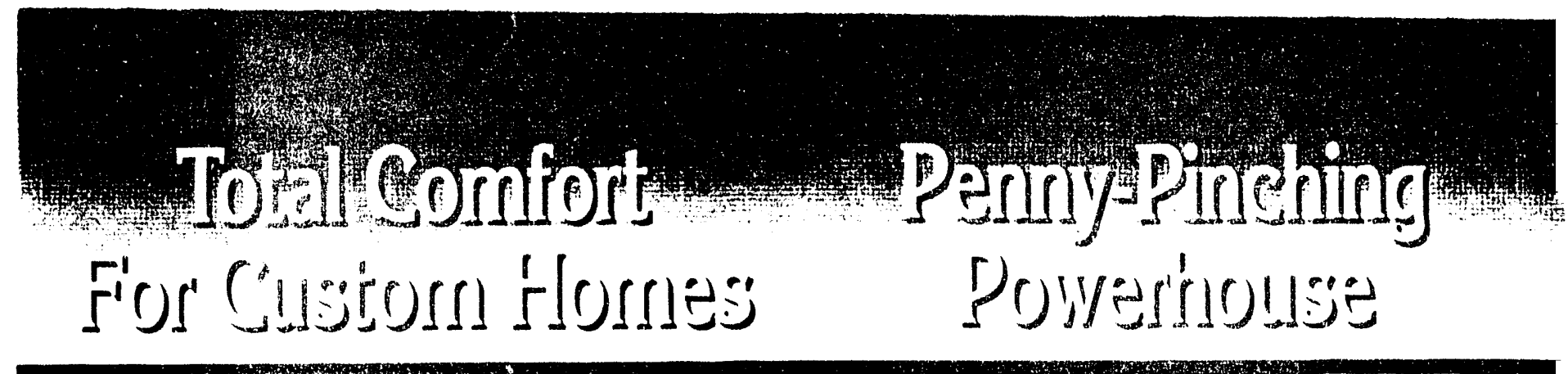

The Mor-Flo/American

POL.A.RIS is the only energy source you need for total home heating comfort - both space and water. With its power, versatility and quick recovery, the POLARIS is ideal for meeting the heating needs of any family in large, custombuilt homes - in any climate. A single POLARIS with multiple Air Heaters ${ }^{\mathrm{TM}}$ brings consistent comfort to those hard-to-heat homes.

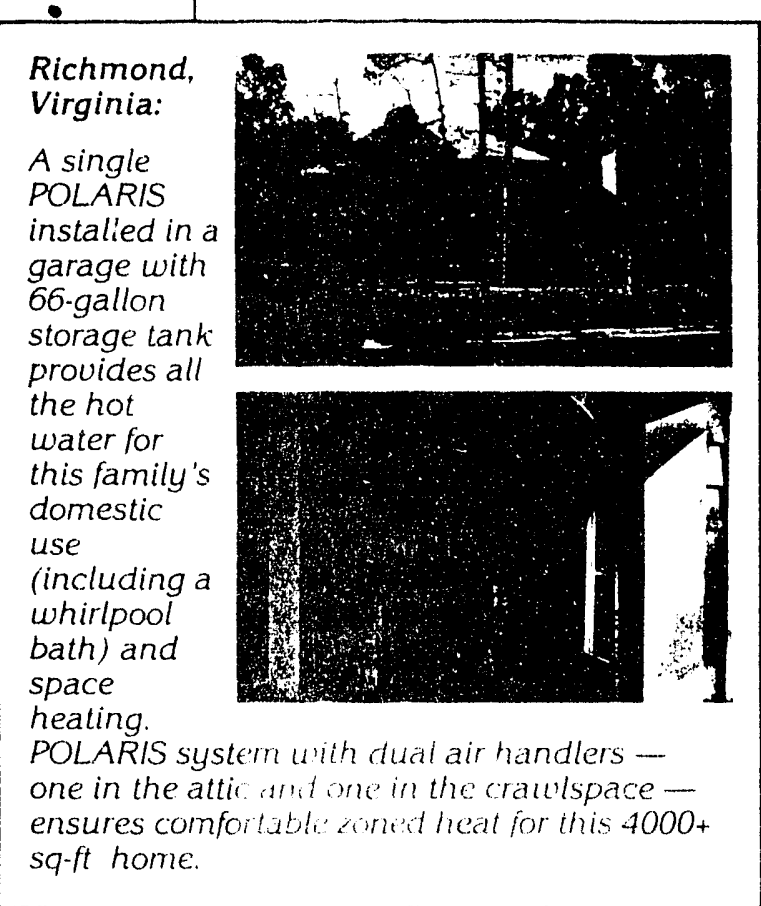

POLARIS has the power and efficiency to economically satisfy all the space and water heating requirements of any home. With a condensing efficiency of $+94 \%$, the simple fact is there is no more efficient gas-fired system than POLARIS. This means plenty of hot water - more than 2 gallons per minute - with only $1 / 3$ the standby heat loss of the best energy-efficient gas water heaters.

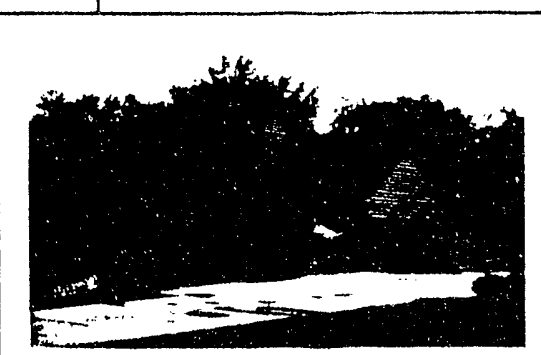

Pewaukee, Wisconsin:

These three homes, featured in the 1989

Parade of Homes in suburban

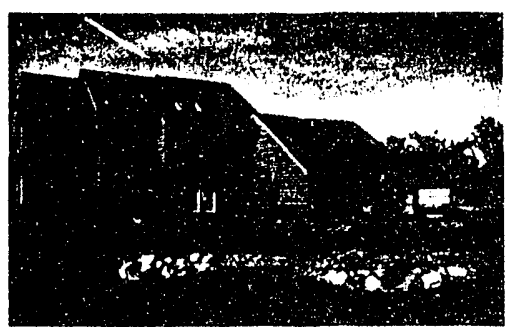
Milwaukee, range from 2,873 to 3,400 sq ft. In each a single POLARIS water heater provides for all space and

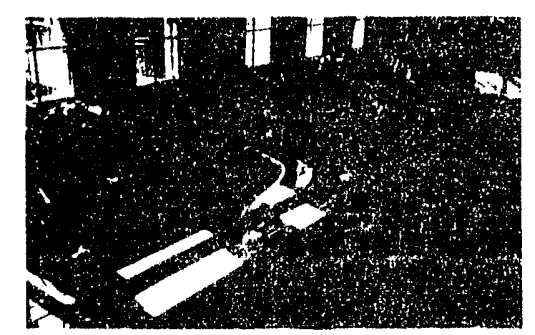
water heating requirements. Dual Air Heaters ${ }^{I M}$ provide zoned heat. Since the POLARIS provides unmatched efficiency for both space and water healing, it is the perfect system for energy-roncious homes. 
POLARIS brings economical gas homes. comfort tonsing, low-temp

Its conduses can be ventell or roo

through an outside When you

with plastic PIP PIS, you

choos patically conver heating to gas. automace and water he gas appliance

Since it is a job of a convention the

doing the joct water heater.

furnace and can be the easion
POLARIS can

most economical this means one flue

choice. Thas line instead oven

and one PARIS you can andler.

$=\quad \begin{aligned} & \text { With POLAR existing air hantally } \\ & \text { utilize an en is environmental } \\ & \text { POLAR is autside } \\ & \text { friendly because it diaws a low }\end{aligned}$

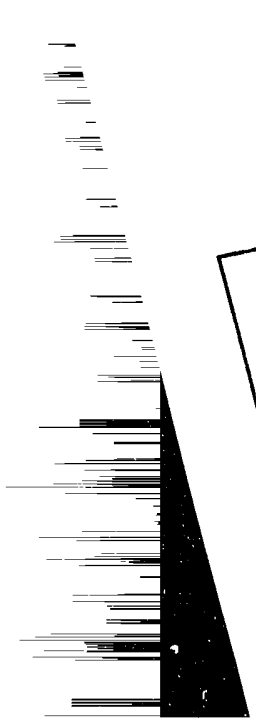

air for combustion, uses clean-

NOx burner as.

burning gas.

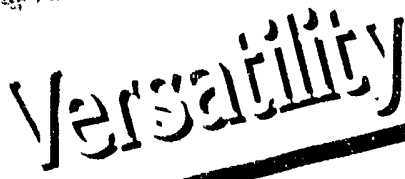

pOLARIS gives you Flexible construction optiong a wall or

roof - with no chimney

needed; use it with ner radiant floor

baseboard or radians; install the

heating sy POLARIS just about

compact use multiple Air for

anywhere; fan convectors areas. In

Heaters or heat, remote areas

hard-to-hOLARIS give your

short, ways to make youral,

homes more econirable. 


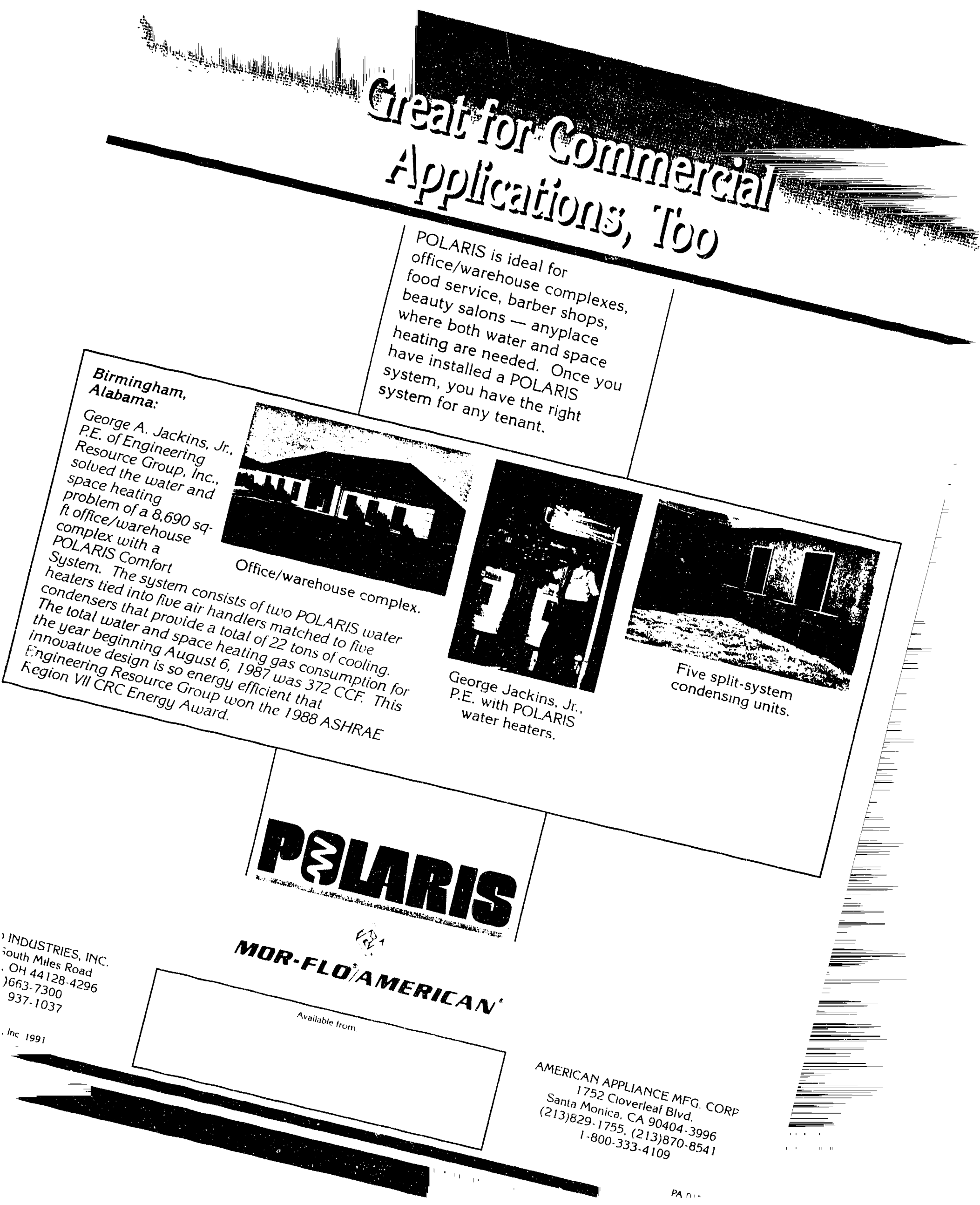




\section{D3 1 . Heats both homes and water in any climate.}

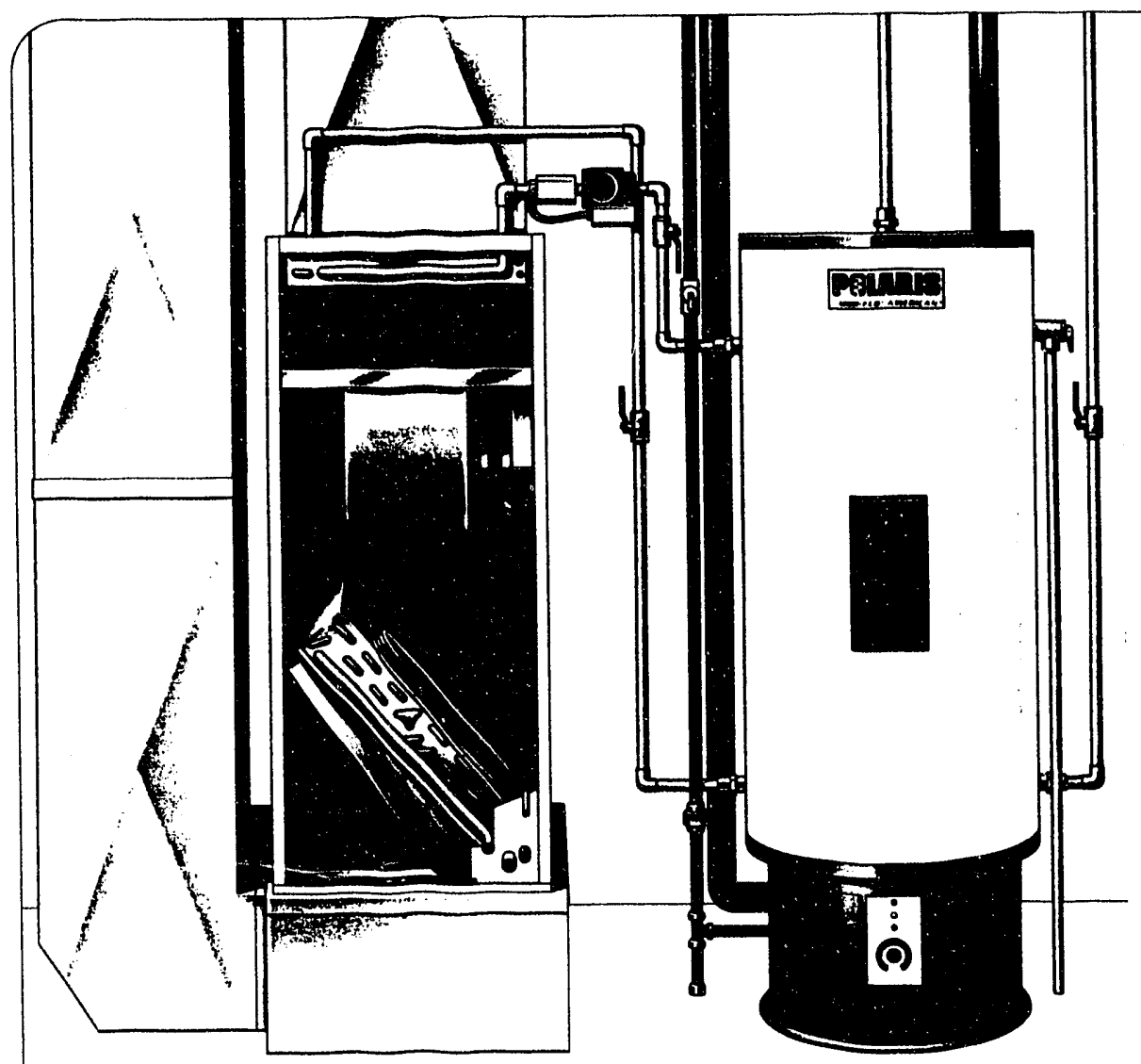

Mor-Flo/American Comfort Systems ${ }^{\mathrm{TM}}$, utilizing a Polaris water heater as a single energy source, will heat homes, the hot water used in those homes and in any climate.

These reliable and energy-efficient systems, designed primarily for use with forced-air heating, combine the Polaris with Mor-Flo/American Air Heaters ${ }^{\text {rs. }}$.

Compact ceiling, wall and closet Air Heaters come in space heating capacities of $14,000 \mathrm{Btu} / \mathrm{hr}$, and higher. In addition, Air Heaters are supplied with a DX cooling coil for air conditioning during warmer months.

After having proven themselves in extensive laboratory and inthe-field tests, Polaris water heaters are now providing $+94 \%$ recovery efficiency in installations nationwide.

With its compact size -22 inches in diameter, $471 / 2$ inches tall (34 gal.) and $611 / 2$ inches tall (50 gal.) - the Polaris :s engineered with inputs of $100,000 \mathrm{Btu} / \mathrm{hr}$ and will provide more than enough hot water to heat homes and the water used in those homes. The Polaris also can be used in many largeusage, residential water-heating only applications.

There are a number of reasons why these reliable, highefficiency water heaters provide optimum energy efficiency. The submerged stainless steel combustion chamber is completely surrounded by water. This eliminates bottom heat loss and reduces energy consumption. The design provides almost noiseless operation.

When the thermostat calls for heat, the igniter is activated. The power blower and negative pressure gas valve force air and gas into the combustion chamber and the burner ignites. The combustion heat is forced into the flue coil. However, the flue, rather than exiting at the top of the tank, coils down and around the combustion chamber and exits and the bottom of the tank.
The water in the tank continually draws heat from the hot gases in the flue coil. Normal flue losses are eliminated during standby because the heat cannot descend without being forced by the power blower.

Another significant advantage is that these condensing, low temperature flue gases can be vented through an outside wall or roof, at distances up to $40 \mathrm{ft}$., using 2 -inch $A B S$ or CPVC pipe. Additionally, outside combustion air can be provided with 2-inch ABS or CPVC pipe. In short, the Polaris can be installed in homes or light commercial buildings without chimneys. 


\begin{tabular}{|c|c|c|c|c|c|c|c|c|}
\hline \multicolumn{10}{|c|}{$\begin{array}{c}\text { MODEL } \\
\text { NUMBER }\end{array}$} & $\begin{array}{c}\text { DATA } \\
\text { PROCES } \\
\text { NUMBER }\end{array}$ & $\begin{array}{c}\text { TANK } \\
\text { CAP } \\
(\mathrm{gal})\end{array}$ & $\begin{array}{c}\text { NPPUT } \\
(\mathrm{Btu} / \mathrm{hr})\end{array}$ & $\begin{array}{c}\text { RECOVERY } \\
90^{\circ} \text { rise (gph) }\end{array}$ & $\begin{array}{c}\text { INPUT } \\
(\mathrm{Btu} / \mathrm{hr})\end{array}$ & $\begin{array}{c}\text { RECOVERY } \\
90^{\circ} \text { rise (gph) }\end{array}$ & $\begin{array}{c}\text { RECOVERY } \\
\text { EFF } \\
(\%)\end{array}$ & $\begin{array}{c}\text { SHIPPING } \\
\text { WGT } \\
(\mathrm{lb})\end{array}$ \\
\hline *PR 34 & $\begin{array}{c}\text { Nat: } 0310002 \\
\text { LP: } 0310003\end{array}$ & 34 & 100,000 & 125.4 & 100,000 & 125.4 & 94 & 136 \\
\hline PR 50 & $\begin{array}{c}\text { Nat: } 0310004 \\
\text { LP: } 0310005\end{array}$ & 50 & 100,000 & 125.4 & 100,000 & 125.4 & 94 & 190 \\
\hline
\end{tabular}

\begin{tabular}{|c|cc|cc|c|c|c|}
\hline \multicolumn{7}{|c|}{ DIMENSIONS (in.) } \\
\hline $\begin{array}{c}\text { MODEL } \\
\text { NUMBER }\end{array}$ & EXTERIOR & \multicolumn{2}{c|}{$\begin{array}{c}\text { 1" WATER } \\
\text { CONNECTIONS }\end{array}$} & $\begin{array}{c}\text { TEP } \\
\text { HGT. }\end{array}$ & $\begin{array}{c}1 / 2 " \text { GAS } \\
\text { SUPPLY }\end{array}$ & $\begin{array}{c}\text { 2" EXHAUST, } \\
\text { 2" INLET }\end{array}$ \\
\hline & A & B & C & D & E & F & G \\
\hline PR 34 & $471 / 2$ & 22 & $163 / 4$ & $393 / 4$ & $403 / 4$ & $53 / 4$ & 8 \\
\hline PR 50 & $611 / 2$ & 22 & $163 / 4$ & $533 / 4$ & $543 / 4$ & $53 / 4$ & 8 \\
\hline
\end{tabular}

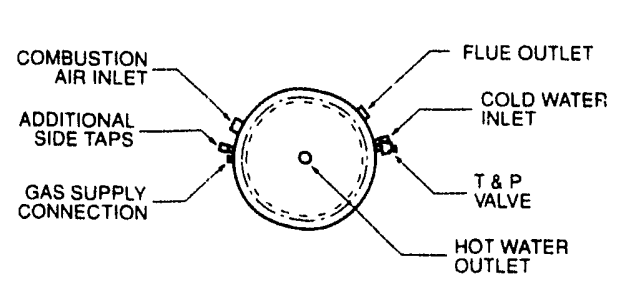

*Call for availability

\section{0-year Limited Tank Warranty}

Specifications are subject to change without notice.

Input, output and recovery may vary depending upon air inlet and vent outlet installations. Length and number of bends in inlet and outlet pipes may reduce input, output and recovery efficiency.

Mor-Flo Industries is recognized as the leader in the development of new, energy efficient water heating products. As a result of this on-going commitment, new and innovative water heating technologies have been established and incorporated into a series of proven products that include energy saving residential commercial water heaters; the first water heater with a submerged combustion chamber; solar water heating systems; heat pump water heaters; and now Polaris the first in a series of space/water heating Comfort Systems.
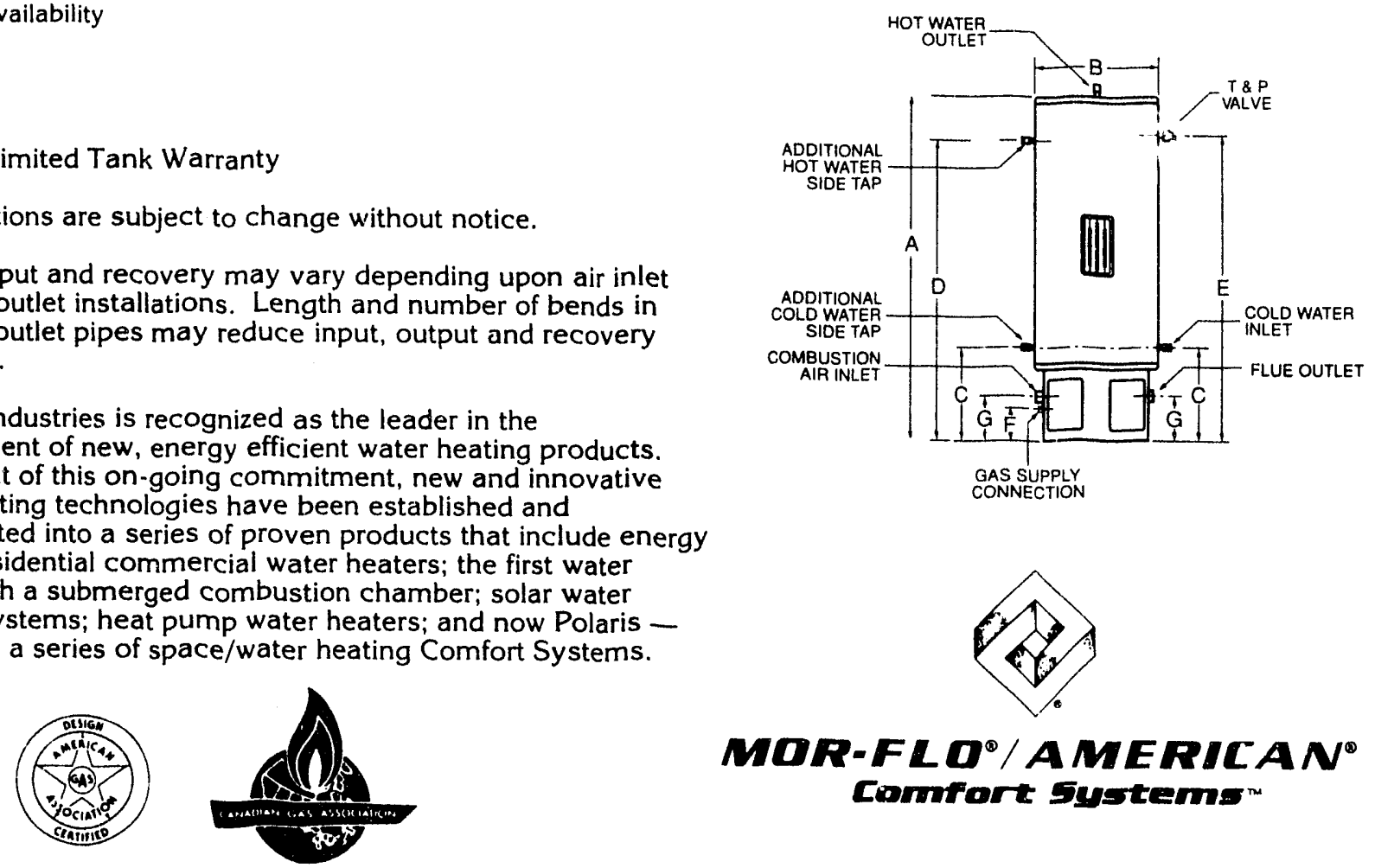

MOR-FLO INDUSTRIES, INC. 18450 South Miles Road Cleveland, $\mathrm{OH} 44128-4296$ (216)663-7300

$1-800-937-1037$

OMor.Flo Industries, Inc. 1991

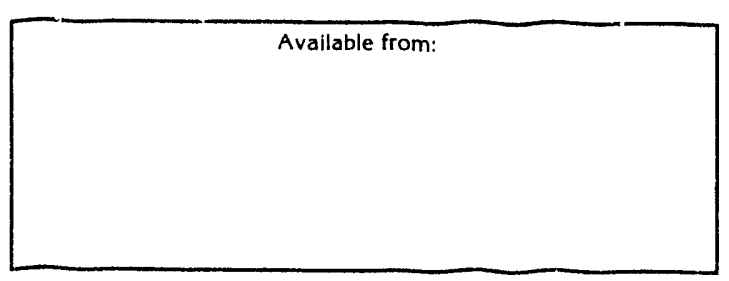

AMERICAN APPLIANICE MFG. CORP. 1725 Cloverfield Blvd.

Santa Monica, CA 90404-3996

(213)829-1755, (213)870-8541

$1.800-333-4109$

POLARIS Residential Brochure, 8/91 

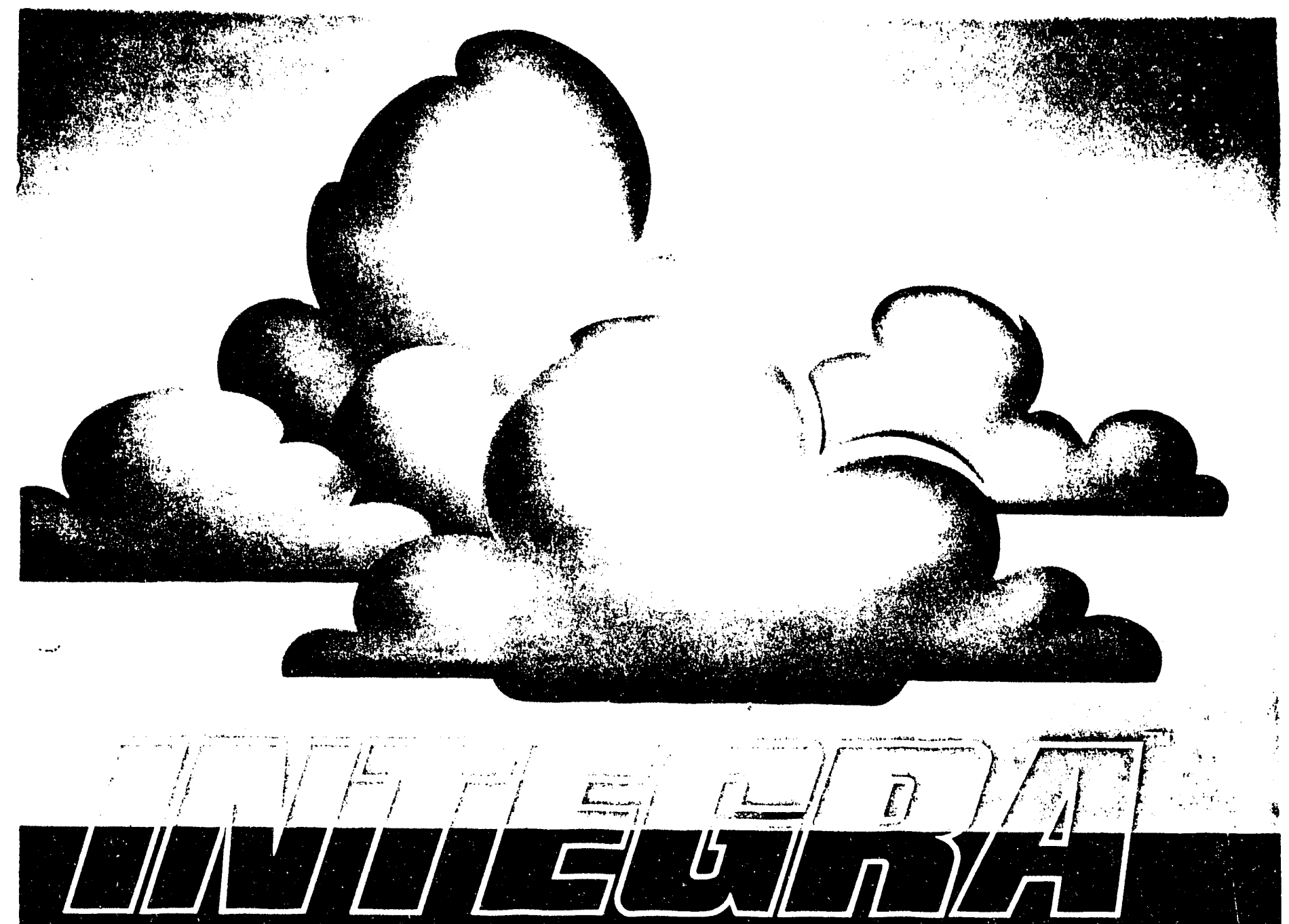

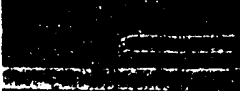

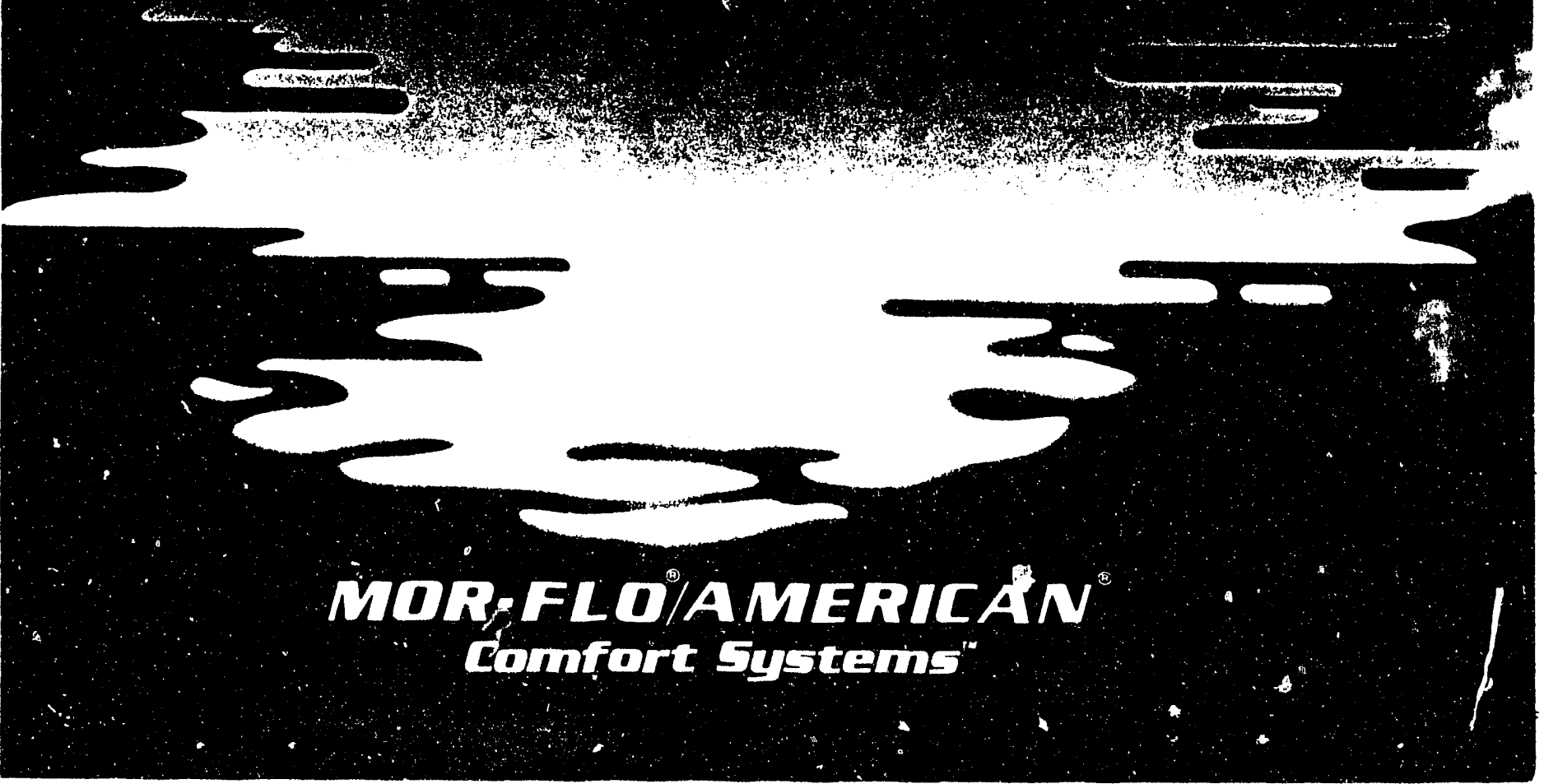




\section{Q: WHAT HEATS BOTH SPACE AND WATER WITH GAS, MEEDS MO CHIMNEY, INCREASES LIVING SPACE AMD DOESN'T COST MUCH?}

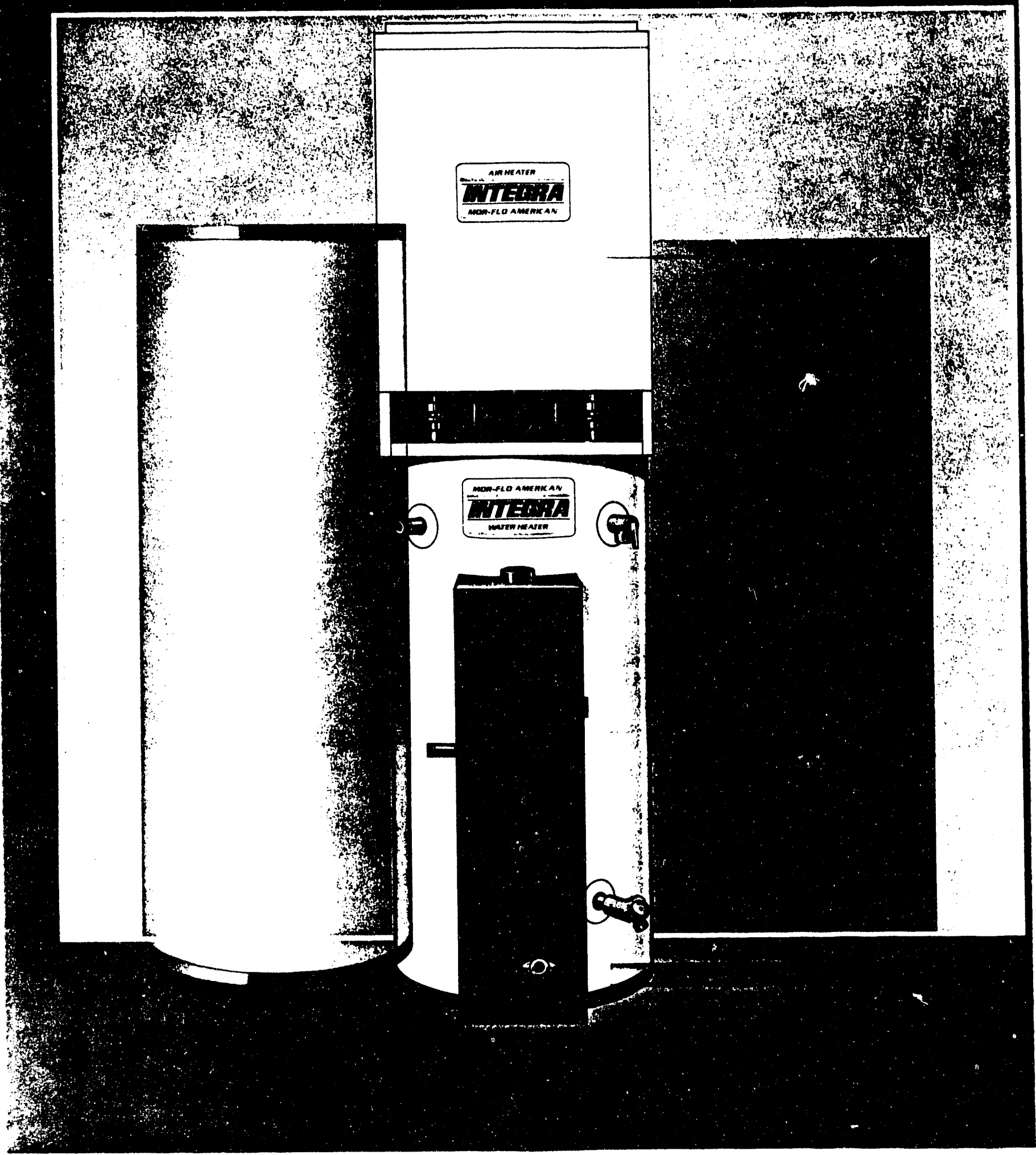




\section{A: IMTEGRA' \\ Mor-Flo/American's Mew, Integrated Gas-Combo Heater For Apartments, Condos And Small Homes}

Low Cost - To buy, to install and to operate

Compact - Increases living space

Vents through-a-wall as far as $\mathbf{2 5}$ feet away with up to four elbows

- Brings gas heating to apartments, condos and small homes

- Sealed combustion

- High efficiency

\section{Inexpensive to Buy, Install and Operate}

The INTEGRA is a low-cost gas combo heater. Since one appliance does the work of two, there is one gas line, one burner and one plastic flue. And because the INTEGRA Air Heater" and INTEGRA Water Heater quick-connect together, installation costs are kept to a minimum. INTEGRA heated residences are in high demand because of low operating costs.

\section{More Space for Living}

With INTEGRA, you can offer a more livable home. One appliance does the work of two in a single compact footprint reducing equipment space by $50 \%$ or more. With zero clearance to wails and floors and unique, plastic venting, the INTEGRA may be installed as far as 25 feet from an outside wall with up to four elbows, no chimney needed. And with its quiet operation, the INTEGRA may be installed almost anywhere. Because the INTEGRA has sealed direct venting, no inside air is used for combustion. With a slide-in cooling coil that matches your air conditioner or heat pump for cooling, the INTEGRA provides for heating, cooling and water heating in a single self-contained comfort package.

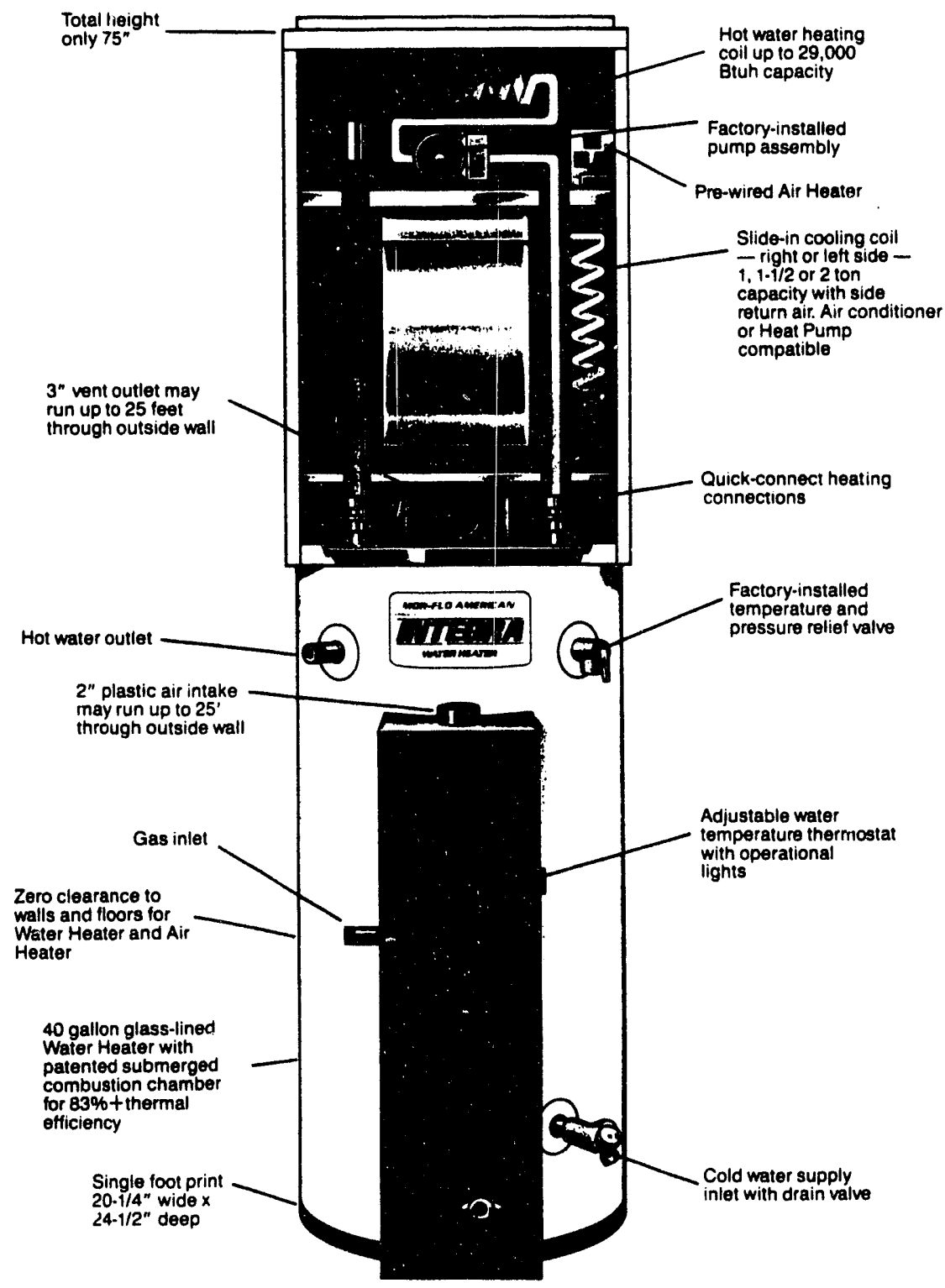

Brings High-Efficiency Gas Water and Space Heating to Apartments, Condos and Small Heat-Loss Homes.
Designed in conjunction with the gas industry, the INTEGRA makes gas water and space heating affordable for smaller heat-loss living units. Warmth, comfort, reliability, economy, quiet all reasons why INTEGRA heated residences are preferred by consumers everywhere. 


\section{Mor-Flo/American COMFORT SYSTEMS" A Growing Family of Total Home-Heating Appliances}

INTEGRA is the latest addition to the Mor-Flo/American line of Comfort System home and water-heating products. By using any one of a number of efficient Mor-Flo/American gas energy sources, a Comfort System can be sized to meet the heating needs of almost any home.

\section{INTEGRA WATER HEATER}

Product Number

Input

Output

Recovery@90'F Rise

Recovery Efficiency

Tank Size

Weight

Electrical

INTEGRA AIR HEATER

Product Number

Heating Capacity*

Weight

Electrical - blower motor

INTEGRA COOLING COIL

Product Number

Cooling Capacity

Weight

\section{SPECIFICATIOMS}

$$
\begin{gathered}
0101184 \text { PVVN463S-V, nat. gas } \\
0101185 \text { PVVN463S-V, LPG } \\
40,000 \text { Btuh, nat. gas } \\
37,000 \text { Btuh, L.PG } \\
33,200+\text { Btuh, nat. gas } \\
30,710+\text { Btuh, LPG } \\
44.4+\text { US gal/hr, nat gas } \\
41.1+\text { US gal/hr, LPG } \\
83 \%+ \\
40 \text { US gal } \\
160 \text { lb } \\
120 V \text { less than } 7 A
\end{gathered}
$$

0900414 MF870PM Q 600 cfm: 25,000 Btuh @ 700 cfm: 27,200 Btuh (1) 800 cfm: 29,000 Btuh $85 \mathrm{lb}$

120V 1/5hp 1075 rpm 2.7A

0900415 DX870

$1,1-1 / 2$ or 2 tons $15 \mathrm{lb}$
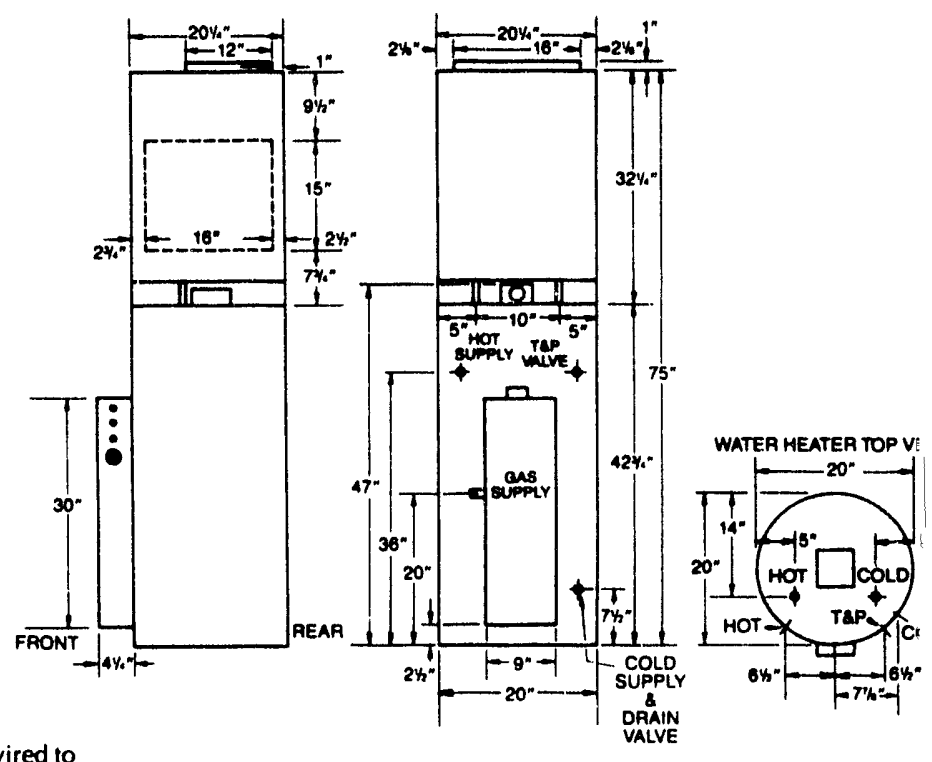

- INTEGRA Air Heater two-speed blower pre-wired at low speed. May be field wired to high speed. CFM varies with static pressure and with presence of heating coil only, or both heating and cooling coils.

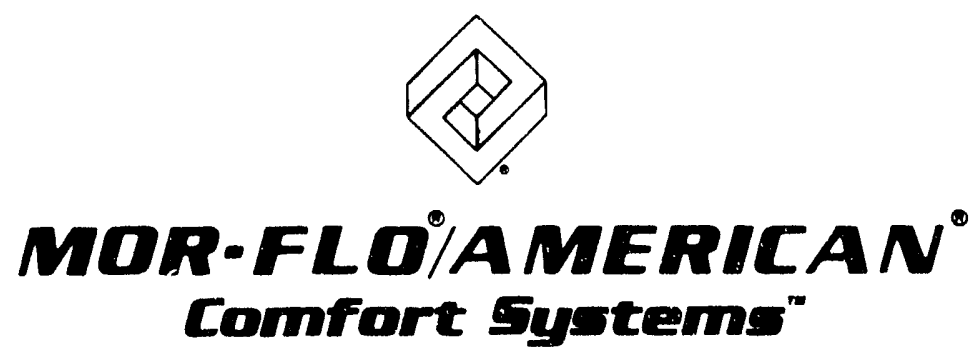

MOR-FLO INDUSTRIES, INC.

18450 South Miles Road

Cleveland, $\mathrm{OH} 44128-4296$

(216) $663-7300$
AMERICAN APPLIANCE MFG. CORP. 2341 Michigan Avenue Santa Monica, CA 90404-3996 (213) $829-1755 \cdot(213) 870-8541$ 


\section{MCRFLOMMESTINECRA}

\section{The Cas Corite in mind closet

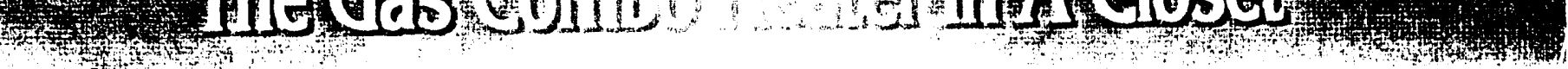

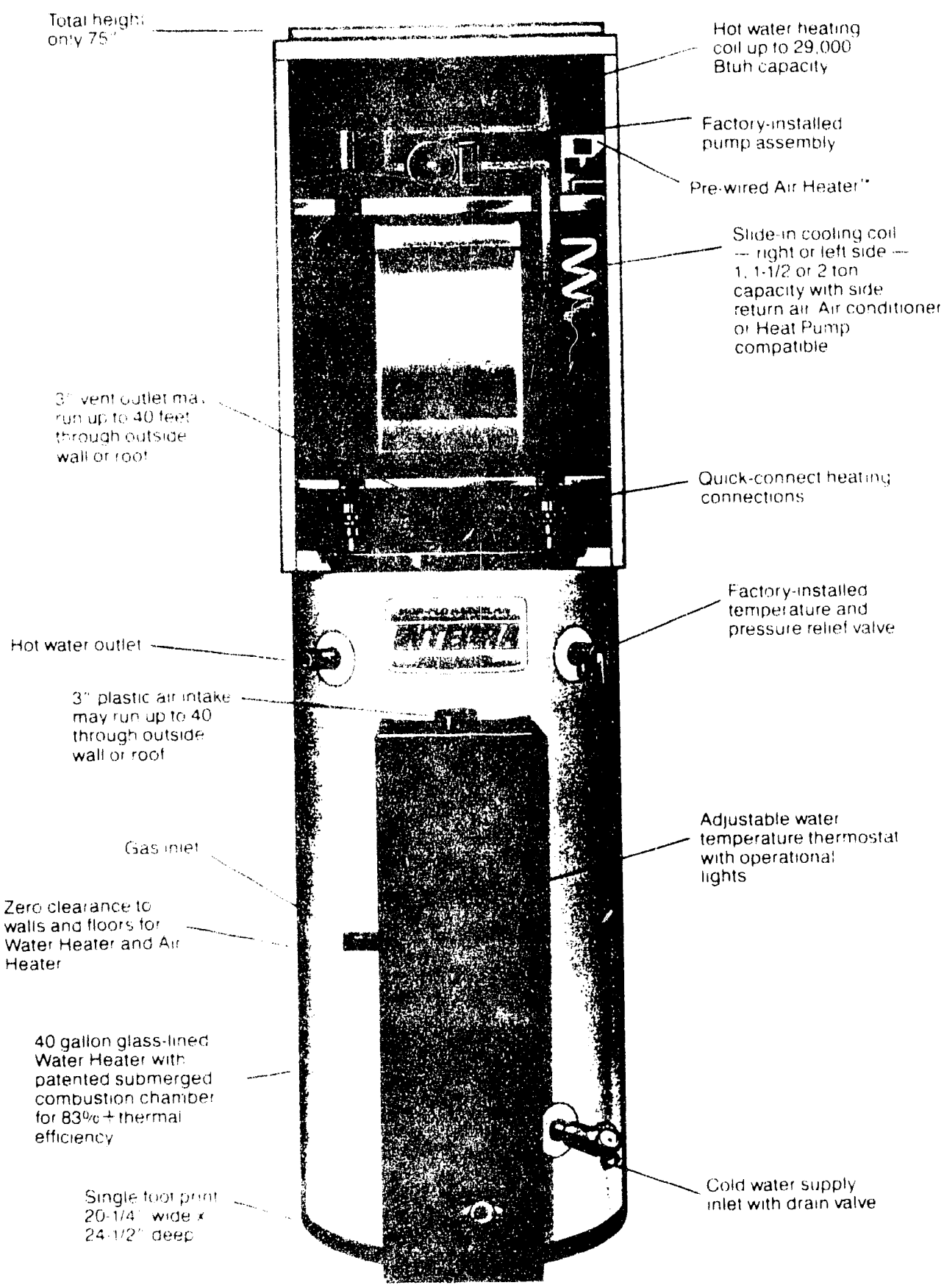




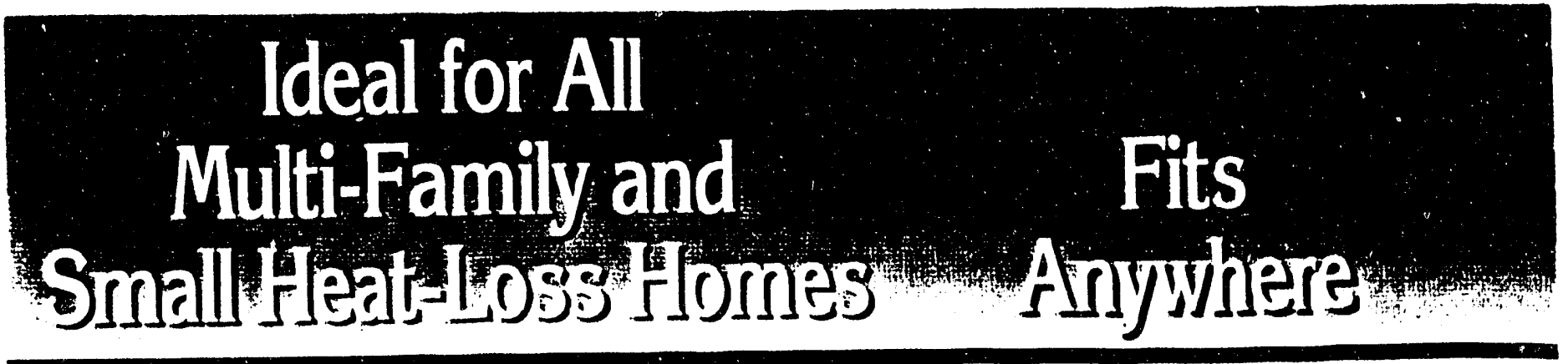

Mor-Flo/American's INTEGRA is the perfect heating source for domestic space and water where space is at a premium. With its single, small footprint, INTEGRA only requires the space of a small closet.

Homeowners and tenants will not be aware of the INTEGRA -even if it is in the same room - as it silently and consistently delivers comfortable warm-air heating and plenty of hot water. And it's also a snap to install with flexible venting that allows the INTEGRA to fit neatly into almost any floorplan.

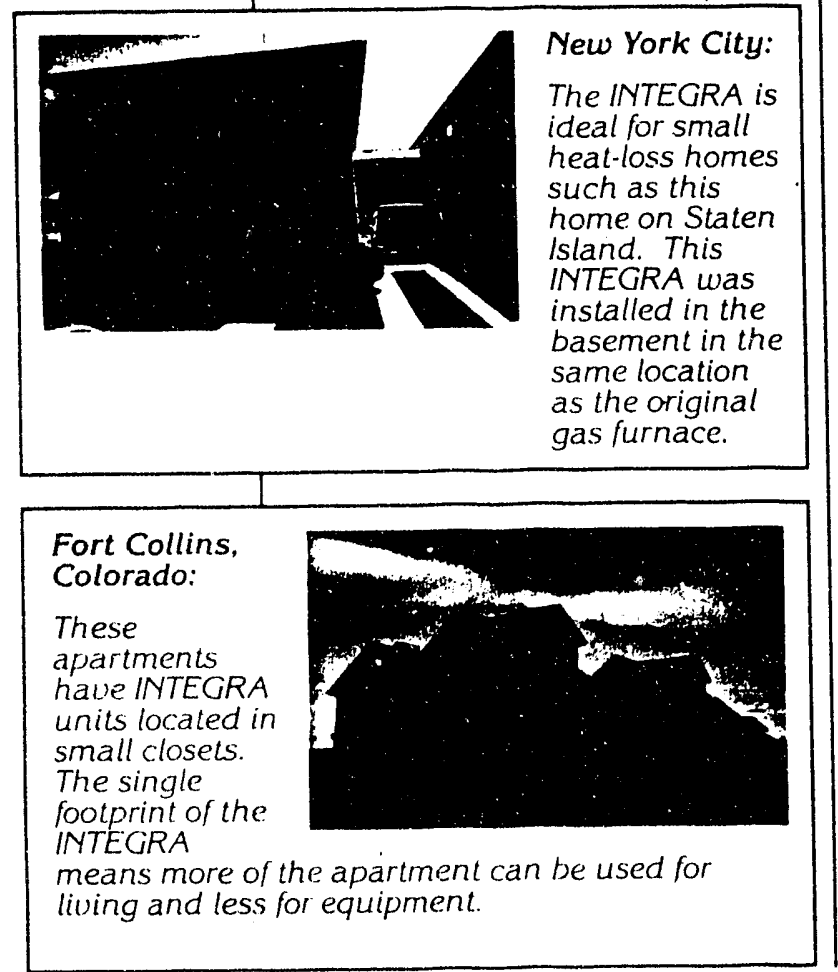

Wherever there are a few square feet of floorspace, even with zero clearance to construction materials, an INTEGRA can be installed. Venting, with plastic pipe, can be through a roof or outside wall as far away as 40 feet. Return air can either be ducted or through a central-return air grill - whichever best fits your needs. Because its Air Heater ${ }^{\mathrm{TM}}$ sits right on top of the water heater, heating with an INTEGRA gives you a bonus more living space to make your homes more desirable.

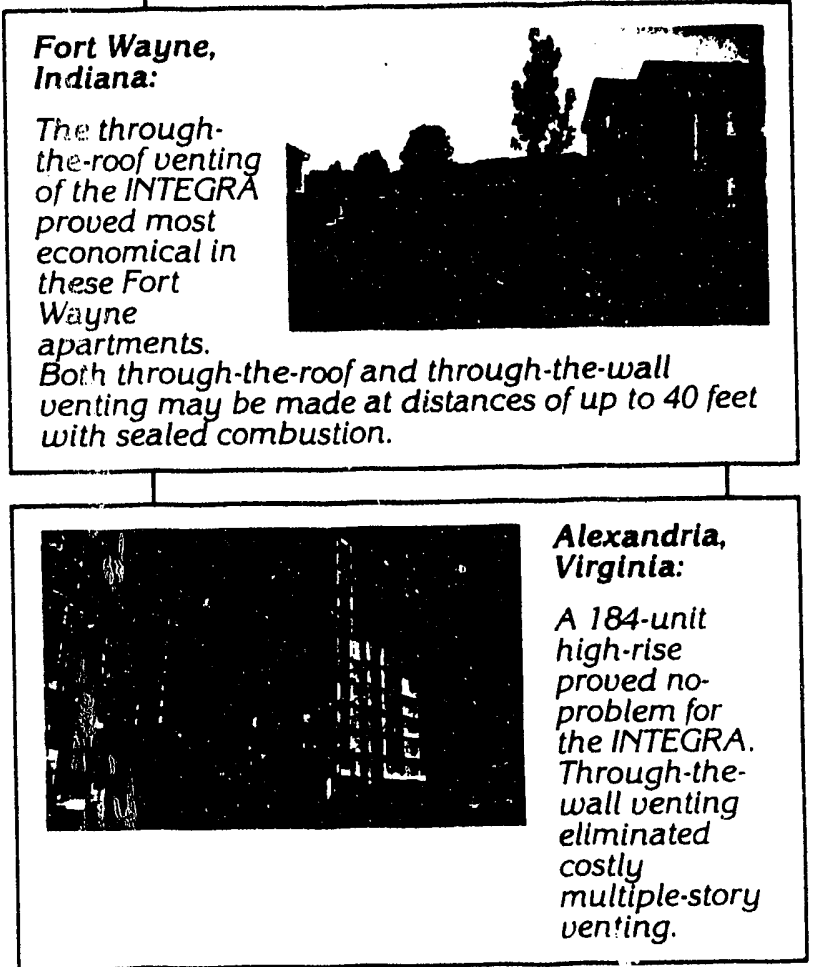




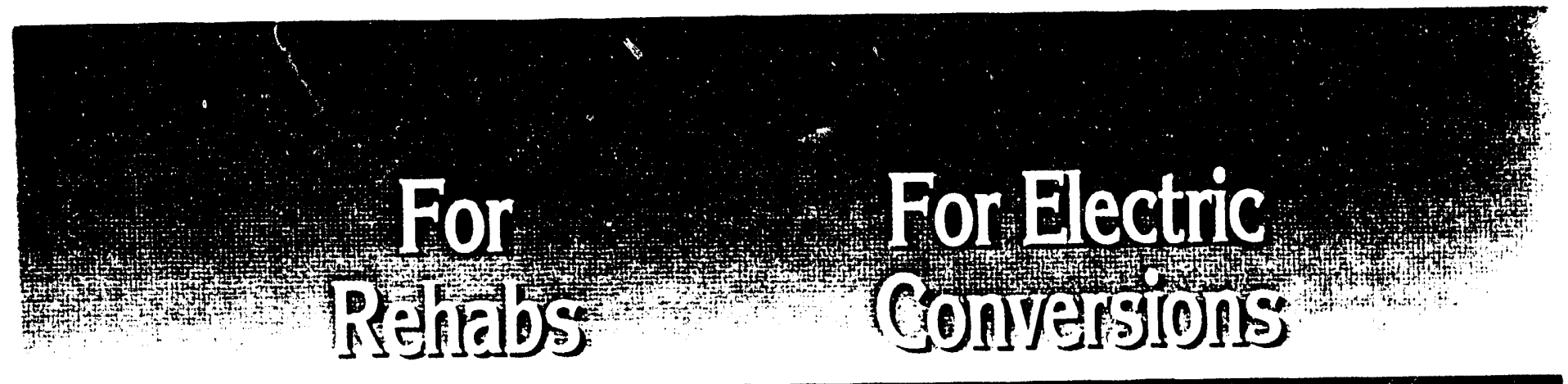

Because of its space-saving flexibility, INTEGRA is ideal for those hard-to-heat rehabs. Use it with or without air conditioning (cooling can be easily added later) or use it without an Air Heater for water heating only. INTEGRA is also the best answer for converting from an old. centrally-metered system to upto-date, individually metered systems. With INTEGRA you save up-front because of its low installed cost and you save down the road because of its low maintenance requirements. thanks to a proven. uncomplicated, rugged design.

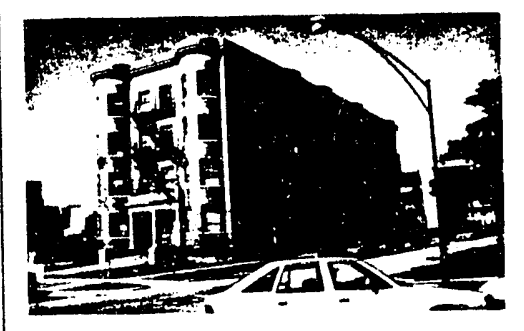

Chicago, Illinois:

When a centrally metered building in Chicago ulas converted to a 2C-unit. individually metered apartment house for homeless families. the INTEGRA provided affordable high-efficiency water and space heating.

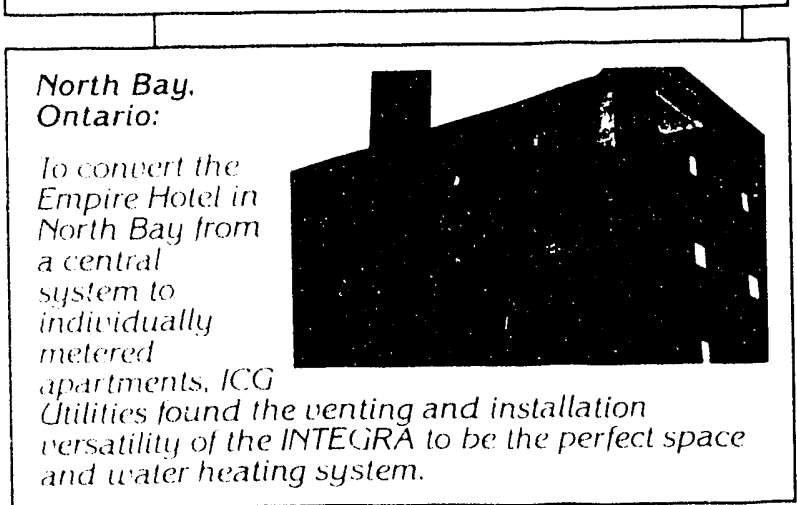

Now, with INTEGRA, you can bring the comfort and economy of gas heating to allelectric homes. INTEGRA draws outside air for combustion, has a low $\mathrm{NO}_{x}$ burner, requires zero clearance to construction materials and often fits in the same space as the original electric equipment. For comfort and economy nothing beats INTEGRA - it is the easiest way to convert both electric water and space heating.

\section{Ottawä, \\ Ontario:}

The INTEGRA is a quiet, economical gas alternative to electric PTAC units and electric water heaters.

INTEGRA units are so safe and quiet they are installed in kitchen pantries in these apartments.

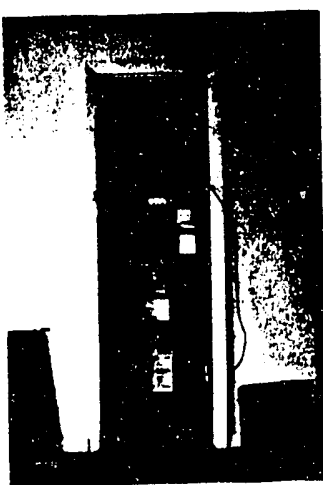

Tampa, Florida:

The INTEGRA often can fit in the same area as the original electric water heater and furnace as was the case in this electric conversion in Tampa. Zero clearance and chimneyless sealed combustion venting are only two of the many reasons that the INTEGRA is the ideal gas combo heater for electric conversions. 


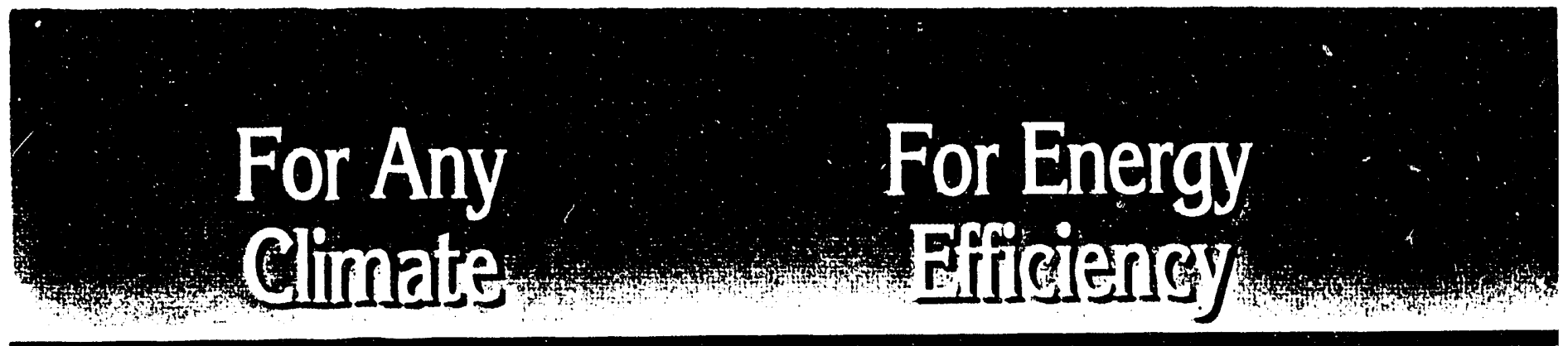

From Canada to California, INTEGRA is right whatever the climate. In the coldest weather, INTEGRA is ideal for apartments, condos and even for small, single-family homes with a net heating loss of $29,000 \mathrm{Btu} /$ hour, or less. For cooling flexibility, with just a simple orifice change, INTEGRA can utilize either a $1,1-1 / 2$ or 2 -ton condenser.

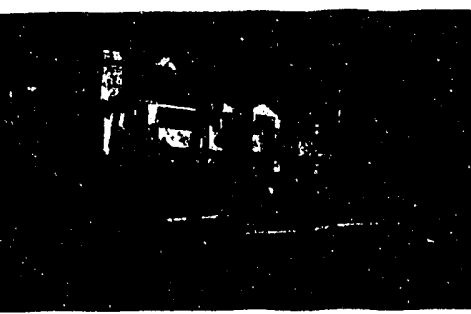

Las Vegas, Nevada:

The heavy cooling load of these Las Vegas apartments proved to be no problem for the INTEGRA Air

Heater ${ }^{\mathrm{T}}$. With a simple orifice change the INTEGRA cooling coil matches 1, 1-1/2 or 2-ton condensing units and is heat-pump compatible.

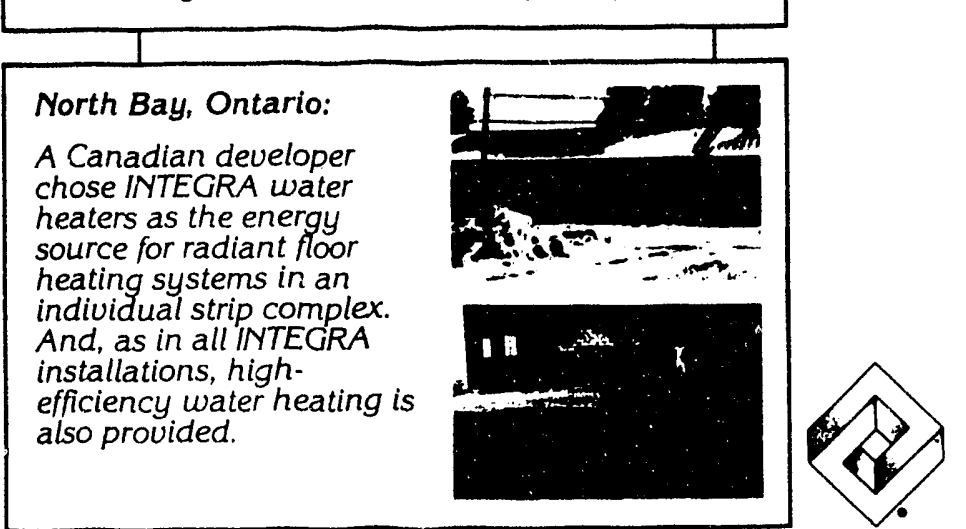

Thanks to its unique, submerged combustion chamber, INTEGRA is extremely energy efficient. With an $+80 \%$ space heating efficiency, and very high water-heating efficiency, INTEGRA exceeds the 1992 Federal energy standards. Total gas comfort and economy in a compact, easy-to-install and maintain integrated appliance. This is the competitive advantage you'll enjoy when you heat with the Mor-Flo/American INTEGRA.

\section{Vermillion, South Dakota:}

This student housing project at the University of South Dakota posed a difficult energy problem

- high water consumption (2, 3 and 4 .

bedroom apartments), space and venting restrictions and the need for energy-efficient equipment in a severe climate. The INTEGRA solved all these problems and proved to be the right answer to this space and water-heating challenge.

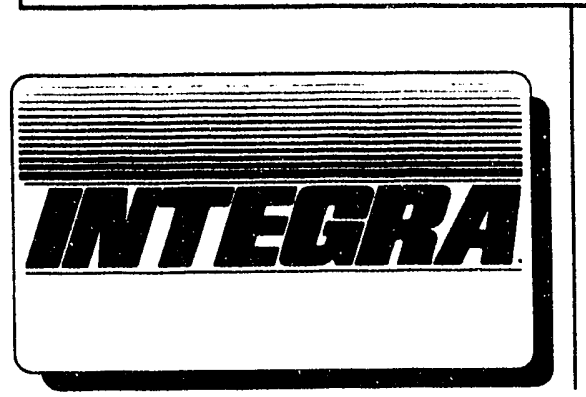

MOR-FLO'AMERICAN"

MOR-FLO INDUSTRIES, INC. 18450 South Miles Road Cleveland, $\mathrm{OH} 44128.4296$

(216) 663.7300

$1.800-937.1037$
Available from:

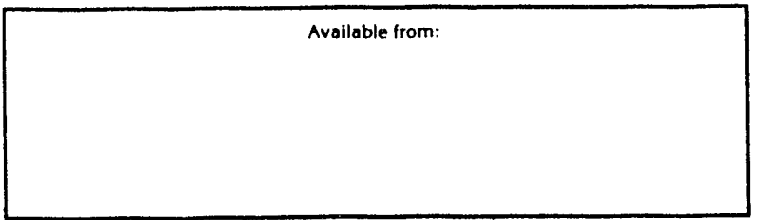

AMERICANI APPLIANCE MFG. CORP.

1752 Cloverleaf Blvd.

Santa Monica, CA 90404-3996

(213)829-1755, (213)870-8541 $1-800 \cdot 333-4109$ 


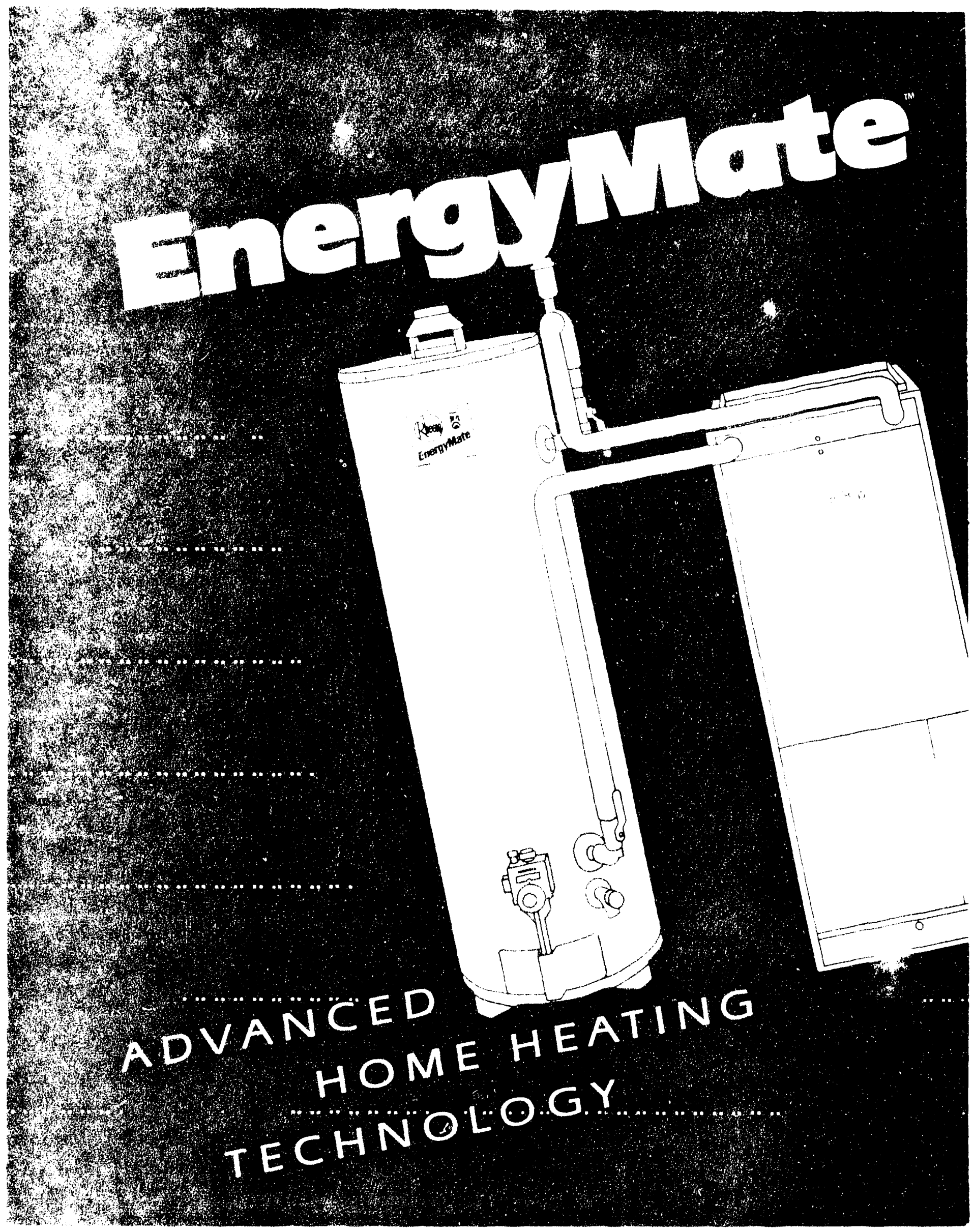




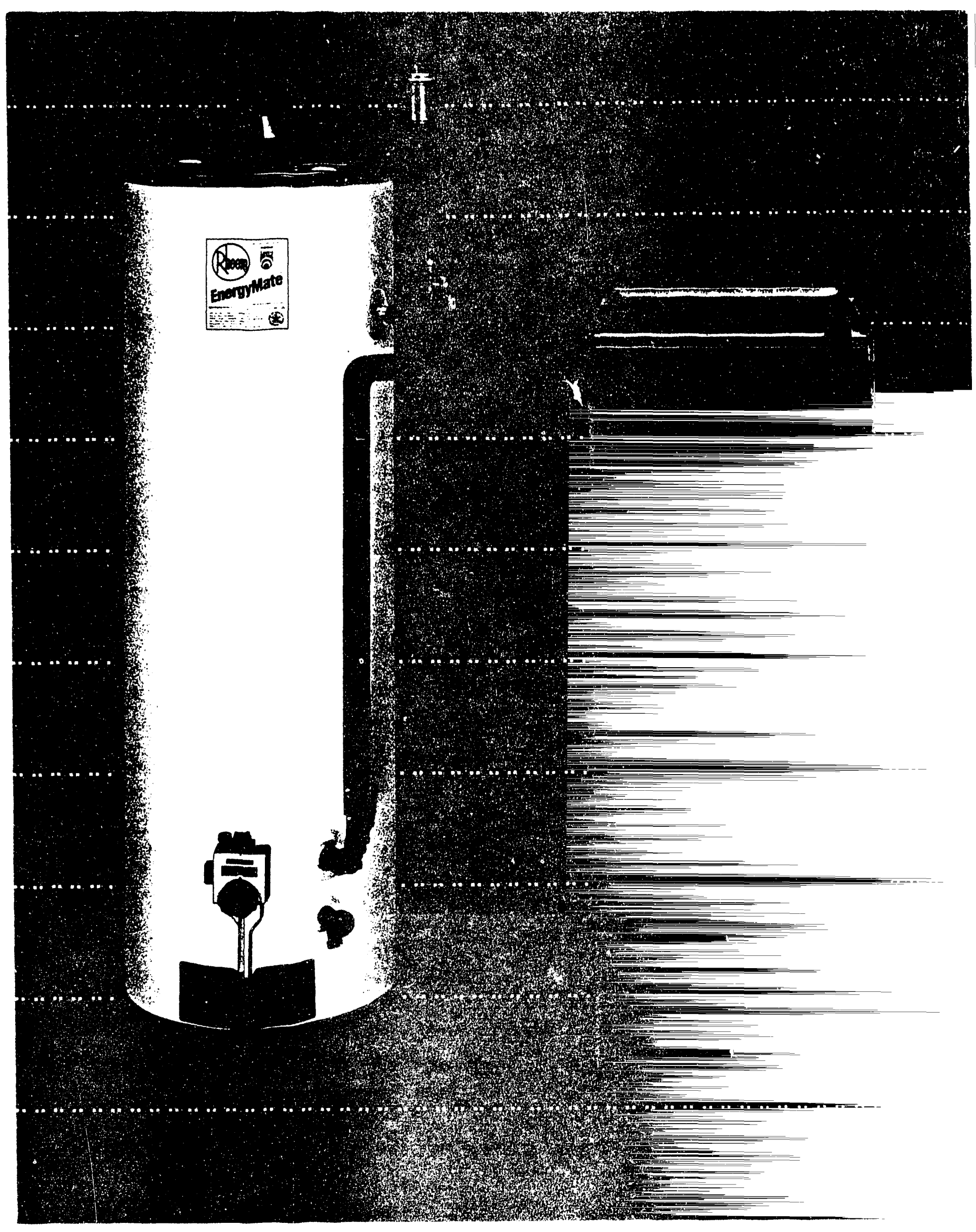




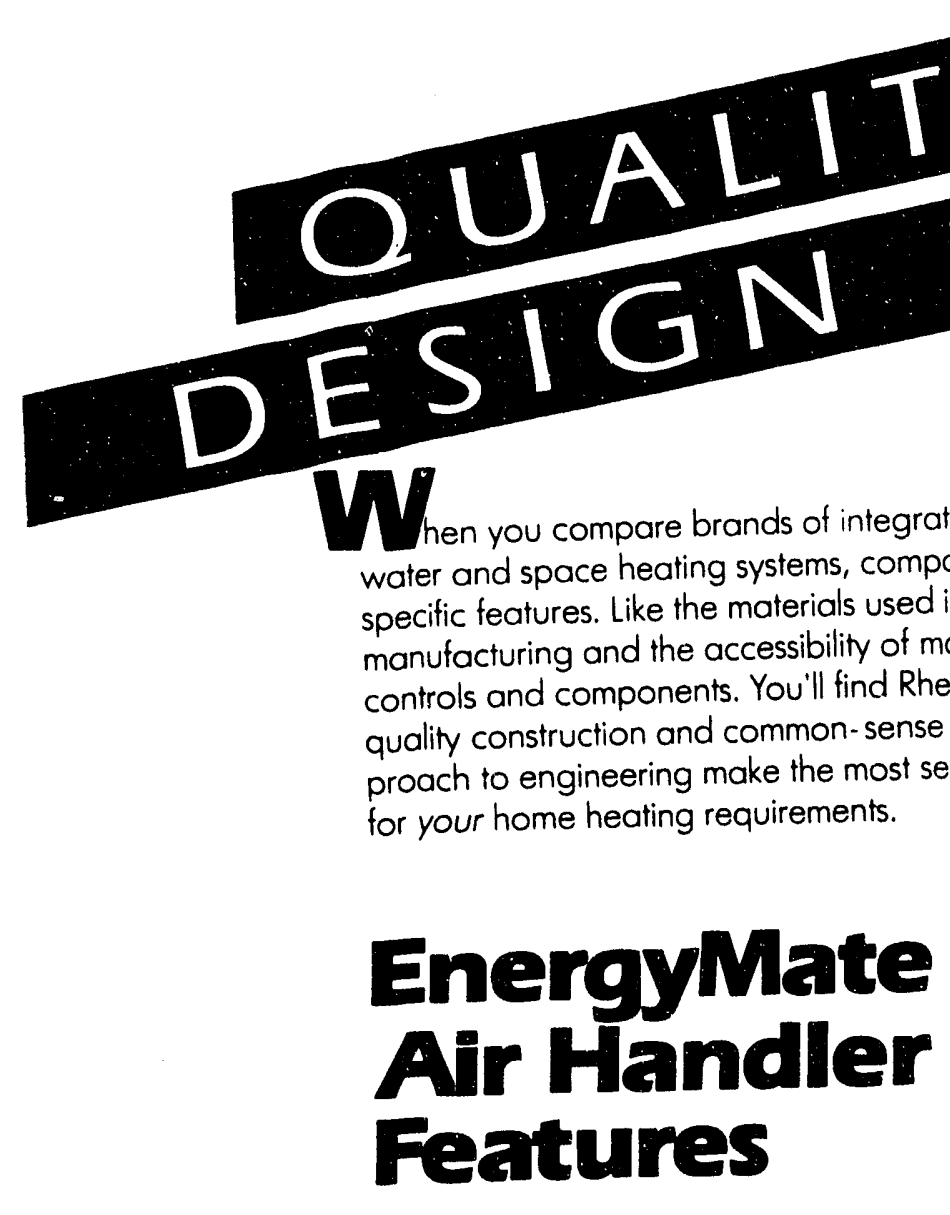

The Rheem EnergyMate Air Handler was designed especially for use with the EnergyMate Water Heater. Available for upflow, downflow or horizontal airflow applications, these versatile air handlers allow contractors to meet virtually any installation requirement from basement to attic. The design features of the air handler unit include:
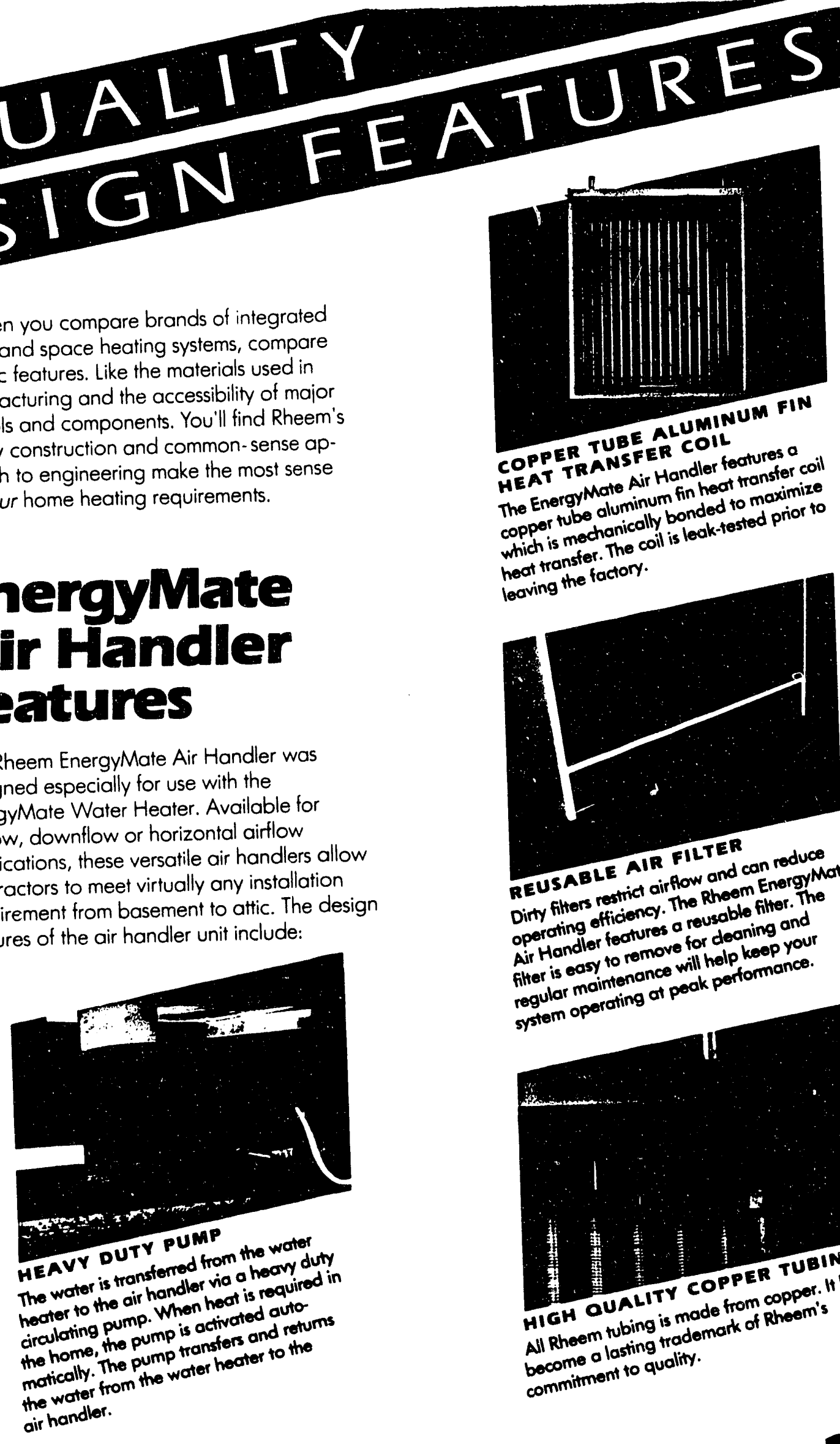
COPPER TUBE AR COIL
HEAT TRANSFER Air Handler features a
The The Energy Mate Ainum fin hed to maximize copper tube alumically bonded to med prior to which is mechanically The coil is leakheat transter. Tactory.

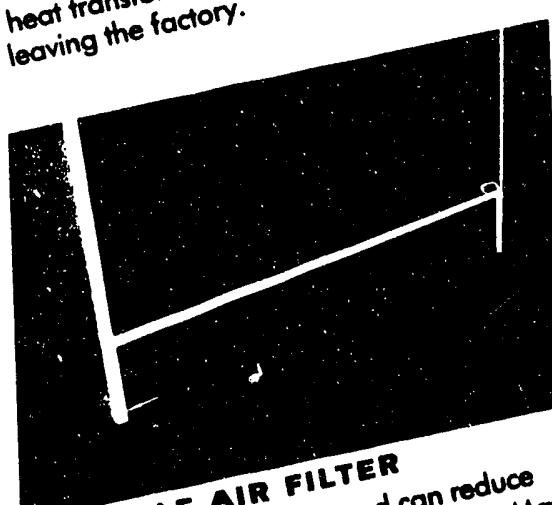
REUSABLE AIR FILT and can reduce Dirty fitters restrict air the Rheem Enter. The operating efficioncy a reusable filter. operatingler foctures a for deaning and Air Handler to remove for de kelp keep your filter is easy to renance will holp formance. regular maintenance weak pert

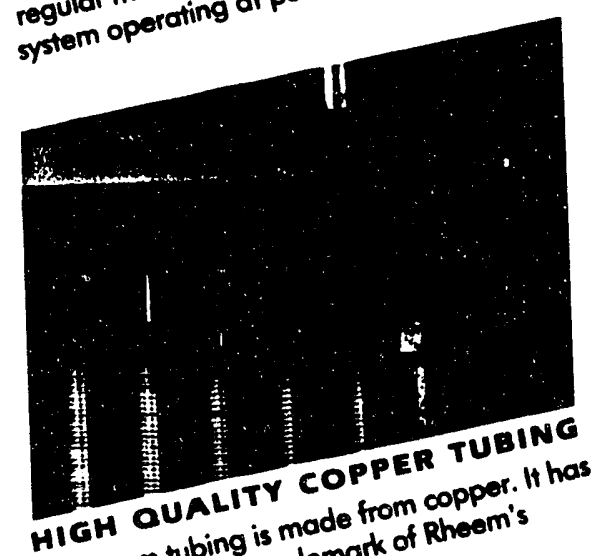
HIGH OUALIT
All Rheem tubing is made from a lasting trademark of Rheem'
become O lity. commitment to quality. the water for handler. 


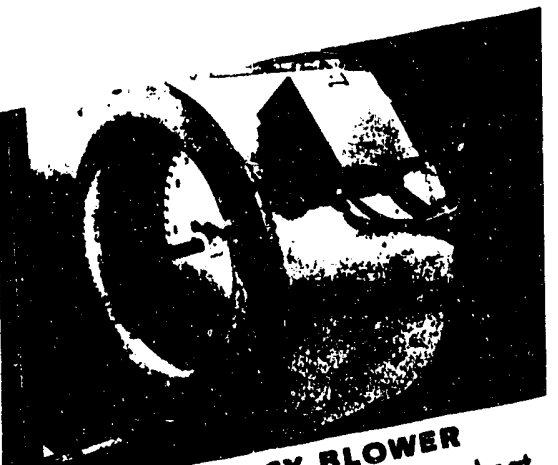

AICH-EFNCY BLOW the heat AI GH-E mer unit forees the air ove ducts to each The blower und through the alr unit indudes transter coll cheme. The blower un and a multiroom in the home ascermbly and a dimia direct-drive blowe direct-drive sysem to weor speed motor. The dilleys which tend to went. nates belts and puire frequent adjuticienty out and can require motor responds ering The multi-speed moliflew under verying The mulide proper airf. Trie blower is slides to provide propditions. The blewier to inspent operating which makes it eosier compartment mounted which And the blower com and service. And minimize noise. is insulated to

\section{EnergyMate Water Heater Features}

The Rheem EnergyMate Water Heater line is designed to be matched with the EnergyMate Air Handler to provide optimum performance and efficiency. The line offers a full range of Energy Efficient or High Performance models with tank capacities from 40 to 62 gallons. The High Performance models feature Thermal Efficiency ratings of $80 \%$ and above. Vertical vent and direct vent models are available to meet virtually any installation requirement. Natural and LP gas models are available. The line features a five-year tank and parts warranty. Your Rheem contractor can provide a full and complete description of warranty terms.

The EnergyMate Water Heater features the following quality components:

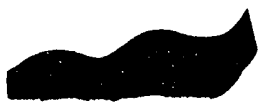




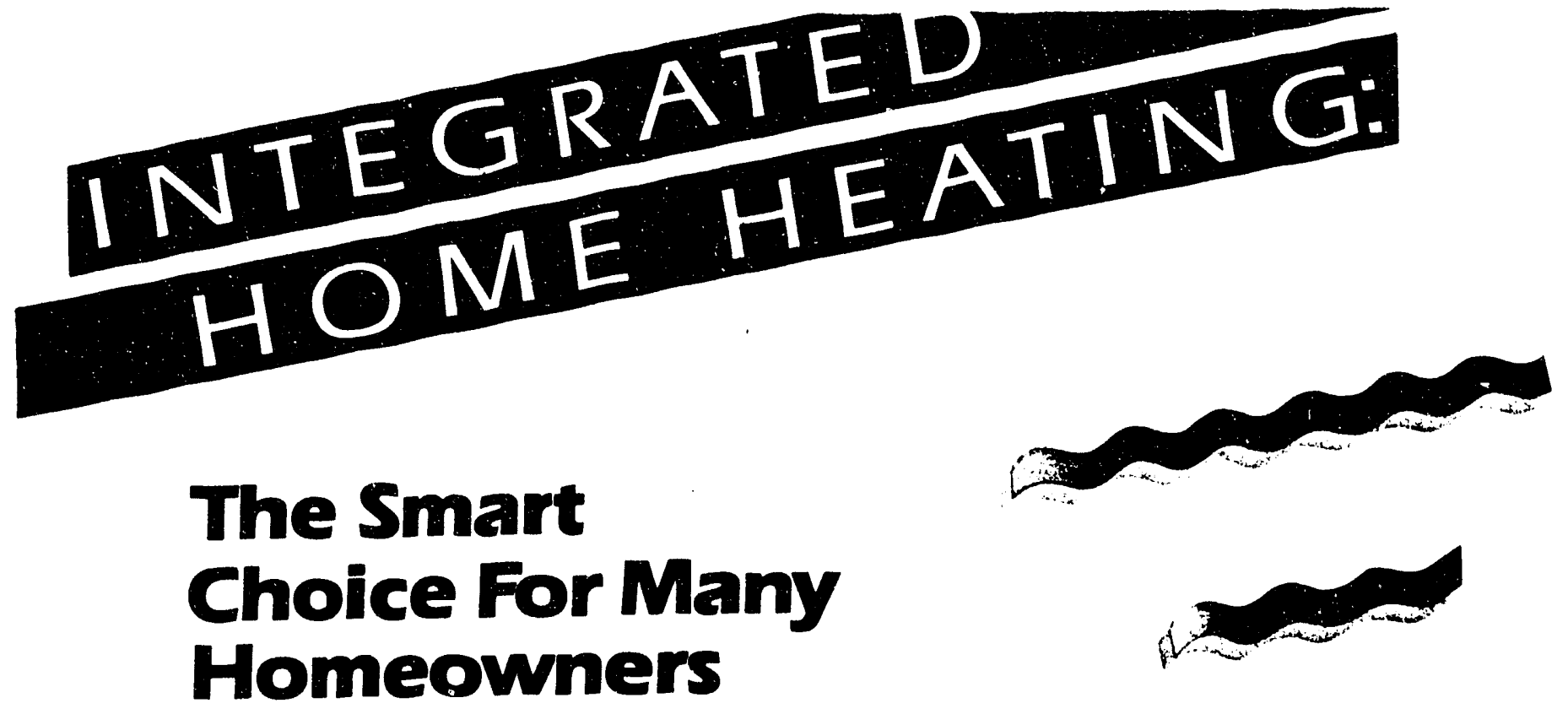

If you're in the market for a new central heating system for your home, you should consider the Rheem EnergyMate, an integrated space and water heating system. The EnergyMate Water Heater works with the EnergyMate Air Handler to provide both the hot water and space heating your home requires.

In the traditional home, a water heater supplies hot water throughout the home and a separate electric air t. r.r.dler or gas furnace heats the home. Most of the time, the water heater stands idle. By utilizing the excess capacity of the water heater to heat your home you could realize an overall increase in the efficiency of your home heating system.

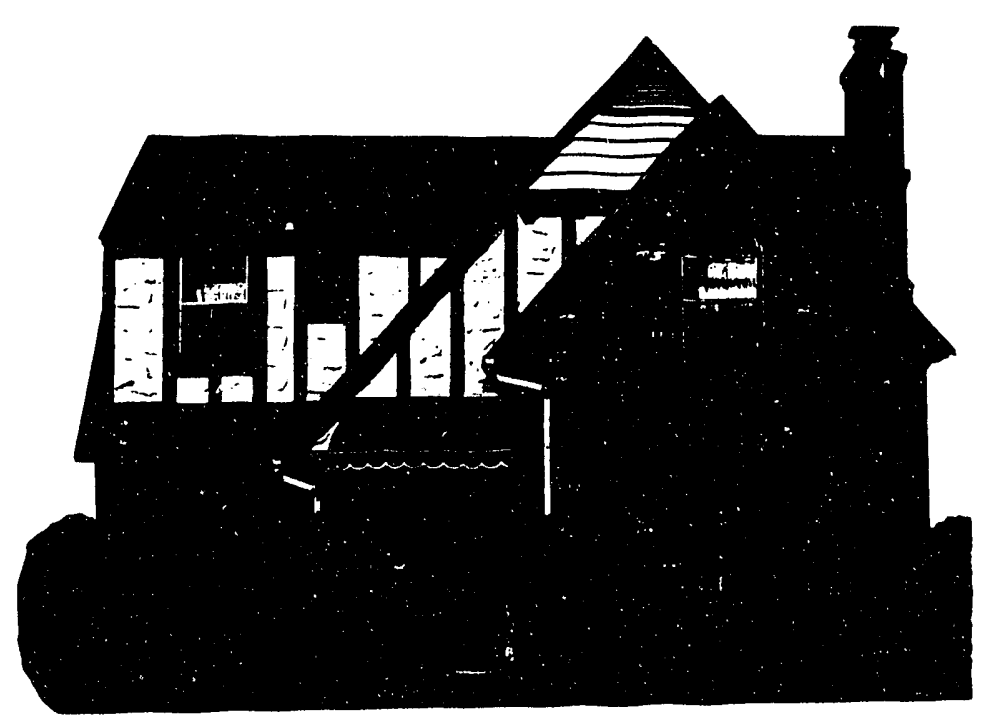

\section{How The EnergyMate System Works}

The water heater and the air handler units are connected by two copper pipes, which transter water between the units. When space heating is required, the wall thermostat in the home activates a small pump in the air handler unit which transfers the water from the water heater to the air handler. There, the hot water is circulated through a copper tube aluminum fin coil located in the air handler. The air handler's high efficiency blower pulls return air trom the home and blows it over the heated coil. This warm air is then transterred throughout the home via the conventional duct system. The water in the air handler coil is pumped back into the water heater for reheating. The water will usually only lose 15 to 25 degrees in temperature while being circulated through the air handler.

The Rheem EnergyMate system can also be used to cool your home with the addition of a coolirig coil and air conditioning or heat pump system.

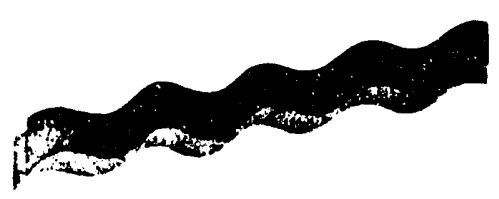




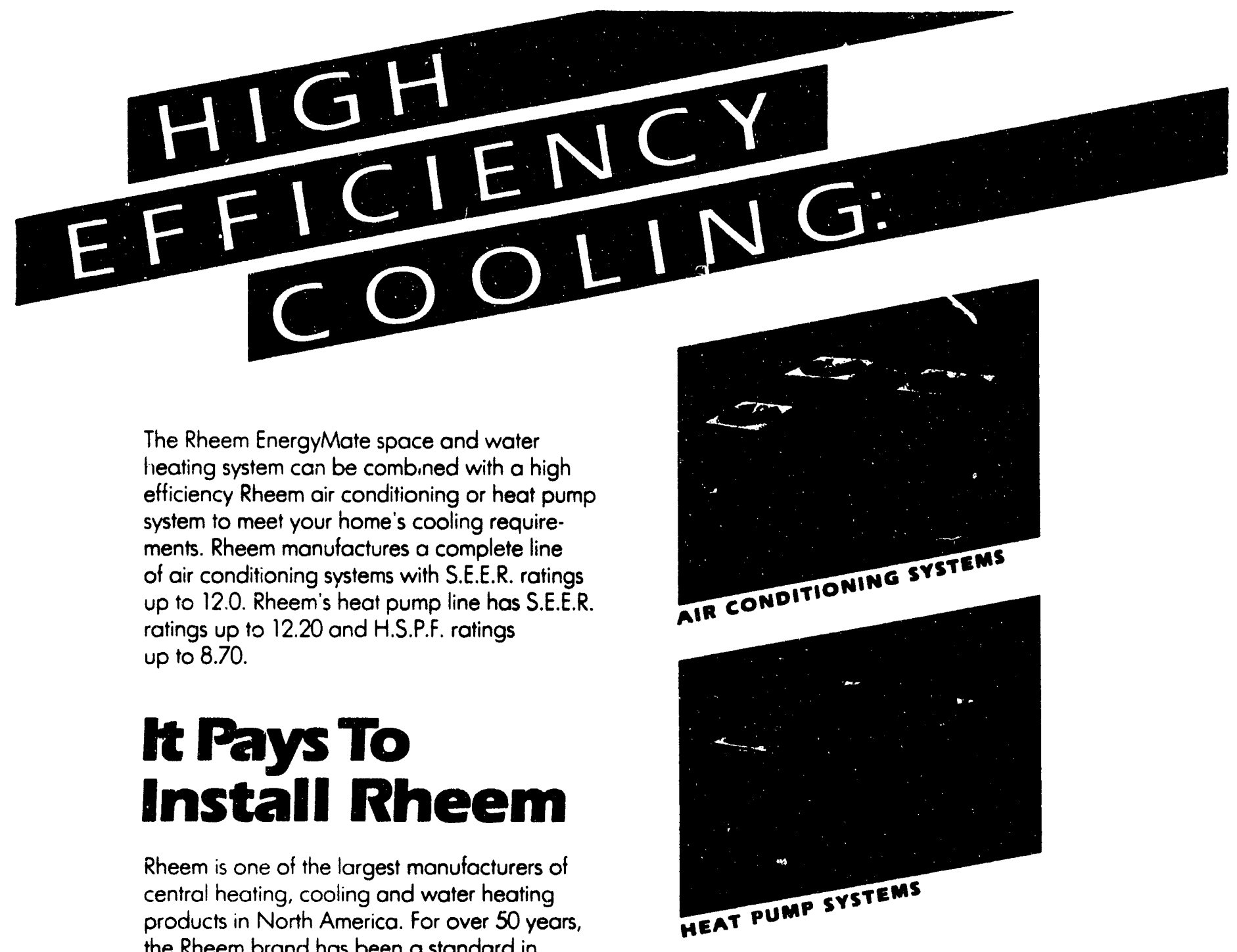

the Rheem brand has been a the industry. The company has earned its reputation by building affordable, dependable, efficient products that provide homeowners with lasting value.

Your neighborhood Rheem contractor is knowledgeable about what heating and cooling systems are best for homes in your area, and he'll happily answer any questions you may have about properly heating and cooling your home.

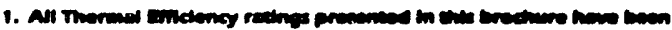

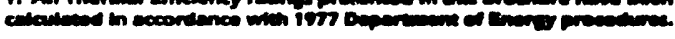

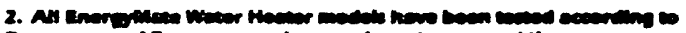

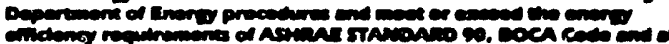

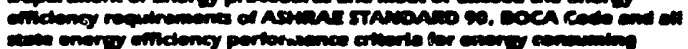

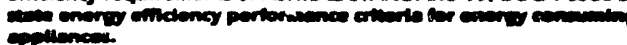

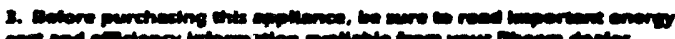

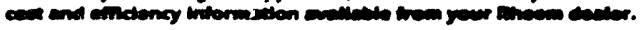

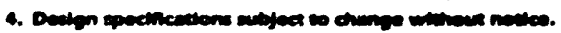
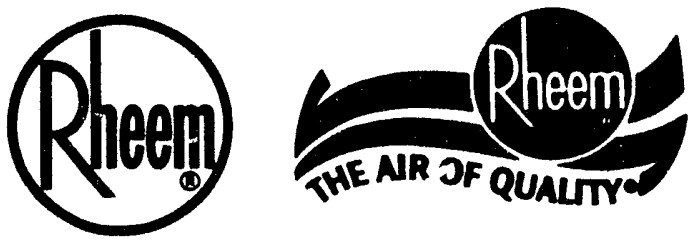

RHEEM WATER HEATER DIVISION

5780 Peachtree Dunwoody Road, N.E. Atianta, GA 30342

404-256-20.37

\section{RHEEM NA CONDINONING DIVISION}

5600 Old Greenwood Road

P.O. Box 6444

Fort Smith, AR 72903

$501-646-4311$ 


\section{HOT WATER SPACE HEAT FURNACES}

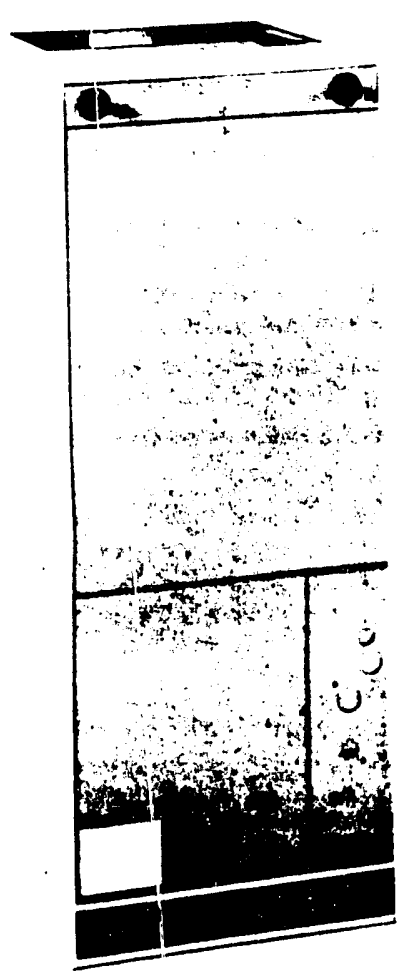

Indoor unit shown for upflow application. Unit may also be field modified for either downflow or horizontal application.

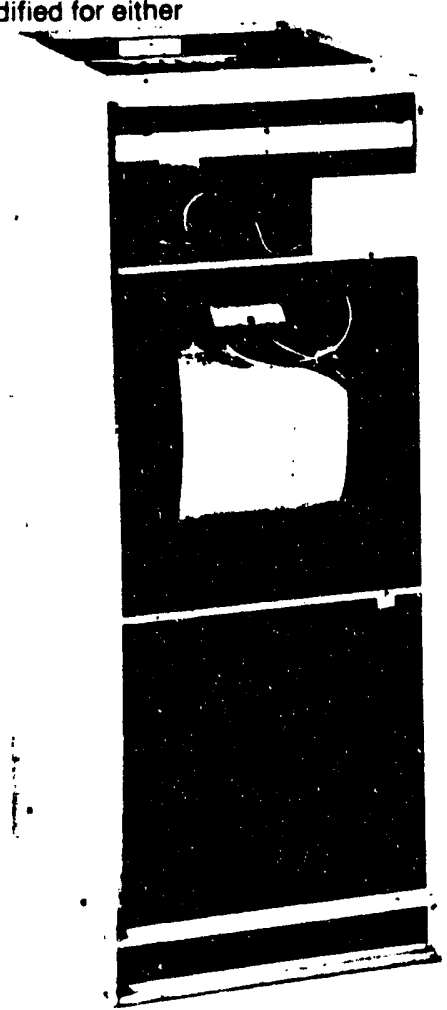

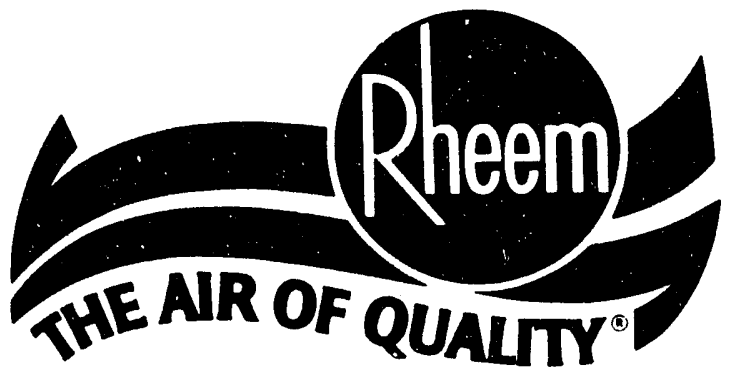

\section{HOT WATER SPACE HEAT FURNACES}

\section{RHWA- SERIES}

\section{Two Basic Models}

Cooling Capacities

from $1-1 / 2$ thru 3 Tons.

Heating Capacities

from 30,000 to 45,000 BTUH.

The Rheem RHWA- Hot Water Space Heat Furnace is designed for use in residential and multifamily heating and cooling applications. The unit is also available for heating only applications.

The units can be installed for either vertical (upflow or downflow) or horizontal airflow applications.

The unit is designed to be connected to a water heater incorporating recirculation loop connections. If the water heater does not have these connections, a kit (RXHW-A01) is required.

The RHWA Hot Water Space Heat Furnace can be com. bined with Rheem Condensing units and coils to achieve cooling efficiencies of up to 12.00 S.E.E.R. (Seasonal Energy Efficiency Ratio). The RHWA can also be fieldinstalled with Rheern Heat Pumps.
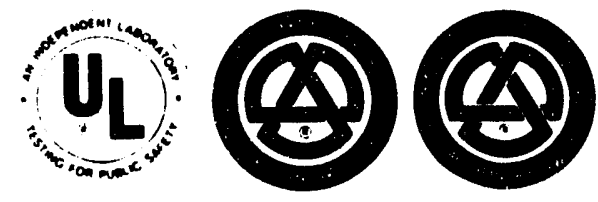

"CERTIFIED UNDER THE A.R.I. CERTIFICATION PROGRAM - A.R.I. STANDARDS 210/240.84" 


\section{Features}

RHWA-Series Hot Water Space Heat Furnaces

The following features, plus its installation flexibility, make it an excellent choice for new construction or replacement/Add-on.

- Avallable upflow, downflow, or horizontal airflow applications.

- Cooling coils mount inside the cabinet.

- Cleanable air filter furnished standard.

- Direct drive blower both statically and dynamically balanced.

- All models are U.L. listed for either attic or closut installation.

- Insulated blower compartment furnished staridard.

- Heavy Duty Pump with replaceable cartridge furnished standard.

- All models feature copper sweat connections for heating and cooling coils.

- All models are U.L. listed at 115 volt, $60 \mathrm{~Hz}$, single phase.

\section{Engineering Features}

1. Insulated cabinet for cooling section standard on all units (units may have cooling coil added later in space provided).

2. Wide selection of cooling coils fit inside the cabinet for either upflow, downflow, or horizontal applications.

3. Direct drive blower assemblies are mounted on a slide-out rail for ease of service.

4. Blower compartment is factory insulated for thermal and sound benefits.

5. Cleanable air filter furnished standard, for bottom return only.

6. Direct drive blower assembly with motor factory lubricated does not require periodic maintenance.

7. Ease of access through front panel for electrical controls and components and blower-air filter access.

8. Sweat fittings standard on all models (cooling and heating).

9. All units feature copper tube/aluminum fin heat transfer coils.

10. All units are 115 volt, $60 \mathrm{~Hz}$, single phase.

11. Heavy duty pump is mounted for easy service access.

\section{Optional Equipment}

- De-pneumatic Kit (RXHW-A01)

\section{Rheem Hot Water Space Heat System How the Hot Water Space Heat Furnace Works}

The water heater and the furnace units are connected by two copper pipes, which transfer water between the units. When space heating is required, the wall thermostat in the home activates a small pump in the furnace which transfers the water from the water heater to the furnace. There, the hot water is circulated through a copper tube aluminum fin coil located in the furnace. The furnace's high efficiency blower pulls return air from the home and blows it over the heated coil. This warm air is then transferred throughout the home via the comventional duct system. The water in the furnace coil is pumped back into the water heater for reheating. The water will usually only lose 15 to 25 degrees in temperature while being circulated through the furnace.

The Rheem RHWA can also be used to cool your home with the addition of an air conditioning or heat pump system.

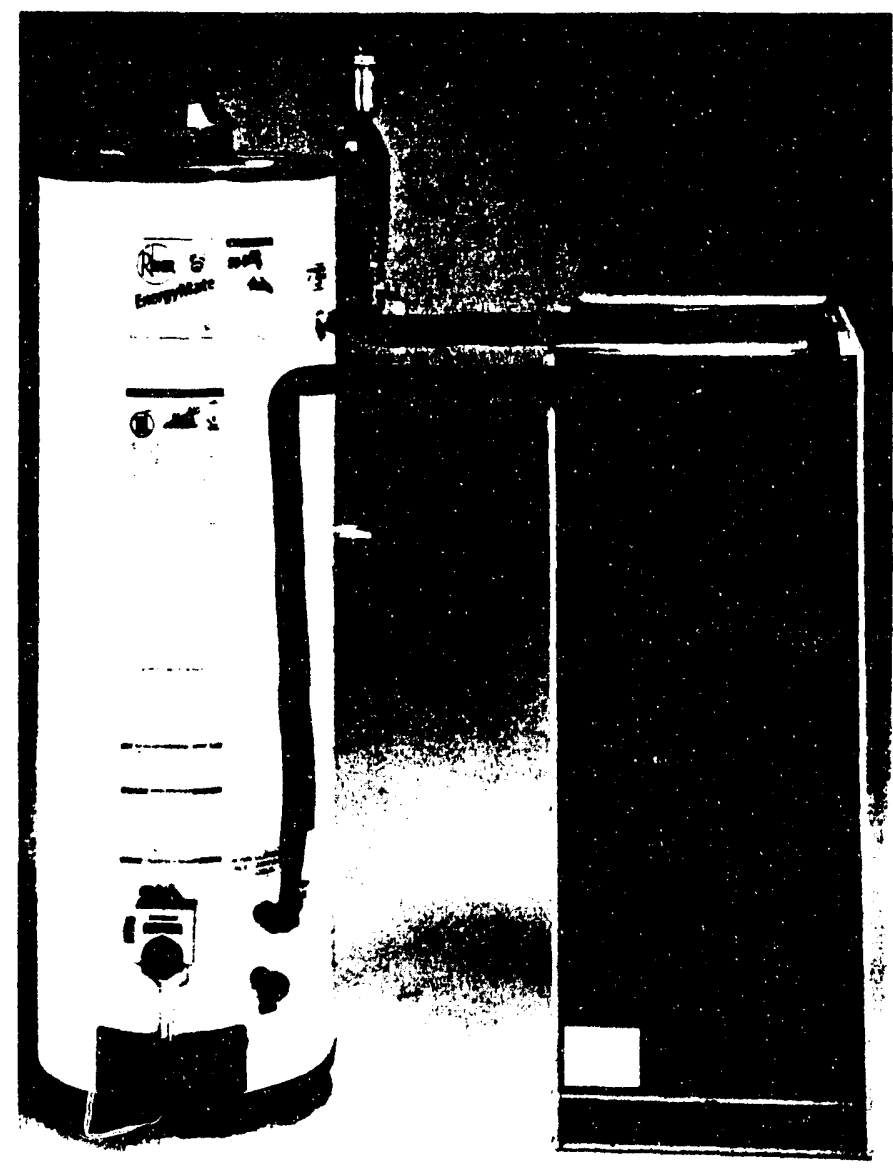


Table 6-Unit Airflow Data

\begin{tabular}{|c|c|c|c|c|c|c|c|}
\hline \multirow{2}{*}{$\begin{array}{l}\text { modat } \\
\text { Numbar }\end{array}$} & \multirow{2}{*}{$\begin{array}{c}\text { Coll } \\
\text { Application }\end{array}$} & \multirow{2}{*}{$\begin{array}{l}\text { Blower } \\
\text { Speed }\end{array}$} & \multicolumn{5}{|c|}{$\begin{array}{l}\text { CFM/Extermal Ducl Static } \\
\text { Inches of Water }\end{array}$} \\
\hline & & & .10 & .20 & .30 & .40 & .50 \\
\hline \multirow{2}{*}{ RHWA.08 } & \multirow{2}{*}{ RCAB-A021 } & $\mathrm{HI}$ & 815 & 785 & 740 & 690 & 630 \\
\hline & & LO & 625 & 615 & 595 & 565 & 505 \\
\hline \multirow{2}{*}{ RHWA-08 } & \multirow{2}{*}{ No Coil } & $\mathrm{HI}$ & 825 & 805 & 780 & 750 & 700 \\
\hline & & LO & 625 & 615 & 610 & 590 & 550 \\
\hline \multirow{2}{*}{ RKWWA-12 } & \multirow{2}{*}{ RCAB-A037 } & $\mathrm{HI}$ & 1110 & 1040 & 950 & 870 & 780 \\
\hline & & LO & 1050 & 980 & 915 & 810 & 710 \\
\hline \multirow{2}{*}{ RHWA.1' } & \multirow{2}{*}{ No Coil } & $\mathrm{HI}$ & 1280 & 1200 & 1120 & 1020 & 910 \\
\hline & & LO & 1100 & 1060 & 990 & 900 & 840 \\
\hline
\end{tabular}

Table 7-Unit Dimensions

\begin{tabular}{|c|c|c|c|c|c|}
\hline \multirow[b]{3}{*}{ Dim. } & \multicolumn{2}{|c|}{ RHWA } & \multirow[b]{3}{*}{ Dim. } & \multicolumn{2}{|c|}{ RHWA } \\
\hline & 0 & 12 & & 98 & 12 \\
\hline & Ineh & Ineh & & Inch & Inch \\
\hline $\bar{A}$ & $42^{1 / 2}$ & $471 / 4$ & $\bar{P}$ & $343 / 4$ & $391 / 2$ \\
\hline$B$ & $181 / \mathrm{s}$ & $181 / 8$ & 0 & $351 / 4$ & 41 \\
\hline C & $197 / 8$ & 22 & $R$ & $61 / 4$ & $83 / 8$ \\
\hline D & $165 / 6$ & $16^{5 / 8}$ & $\mathrm{~S}$ & 8 & $101 / 4$ \\
\hline$E$ & 18 & $201 / 8$ & $T$ & $105 / 8$ & $12^{7 / 6}$ \\
\hline$F$ & $155 / 8$ & $155 / 8$ & $\bar{U}$ & $141 / 4$ & $141 / 4$ \\
\hline G & $173 / 8$ & $19^{1 / 2}$ & $\bar{v}$ & $251 / 2$ & 28 \\
\hline $\mathrm{H}$ & $12^{1 / 4}$ & $121 / 4$ & $\bar{w}$ & $317 / 6$ & $343 / 6$ \\
\hline $\mathrm{J}$ & $95 / 8$ & $95 / 6$ & $\bar{x}$ & $34^{1 / 2}$ & 37 \\
\hline$k$ & $41 / 8$ & $41 / 8$ & $\bar{Y}$ & $21 / 8$ & $21 / 0$ \\
\hline$L$ & $27 / 6$ & $27 / 6$ & 2 & $2^{5 / 16}$ & $25 / 16$ \\
\hline$M$ & $171 / 4$ & $193 / 6$ & $\overline{A A}$ & $40^{7} / 8$ & $45 \%$ \\
\hline$N$ & $141 / 4$ & $16^{3 / 8}$ & - & - & - \\
\hline
\end{tabular}

NOTES:

1. All drain fittings are $3 / 4 "$ male pipe thread

2. Hot water connections are $3 / 4^{\prime \prime}(0.0$.) sweat connections

3. Horizontal units with factory-installed cooling colls are shipped for right hand arf flow.
Table 8

\begin{tabular}{|c|c|c|}
\hline \multirow{2}{*}{ Unit Modal } & \multicolumn{2}{|c|}{ Whight, Lhs } \\
\cline { 2 - 3 } & Net & Ship \\
\hline RHWA-08 & 90 & 95 \\
\hline RHWA-12 & 100 & 105 \\
\hline
\end{tabular}
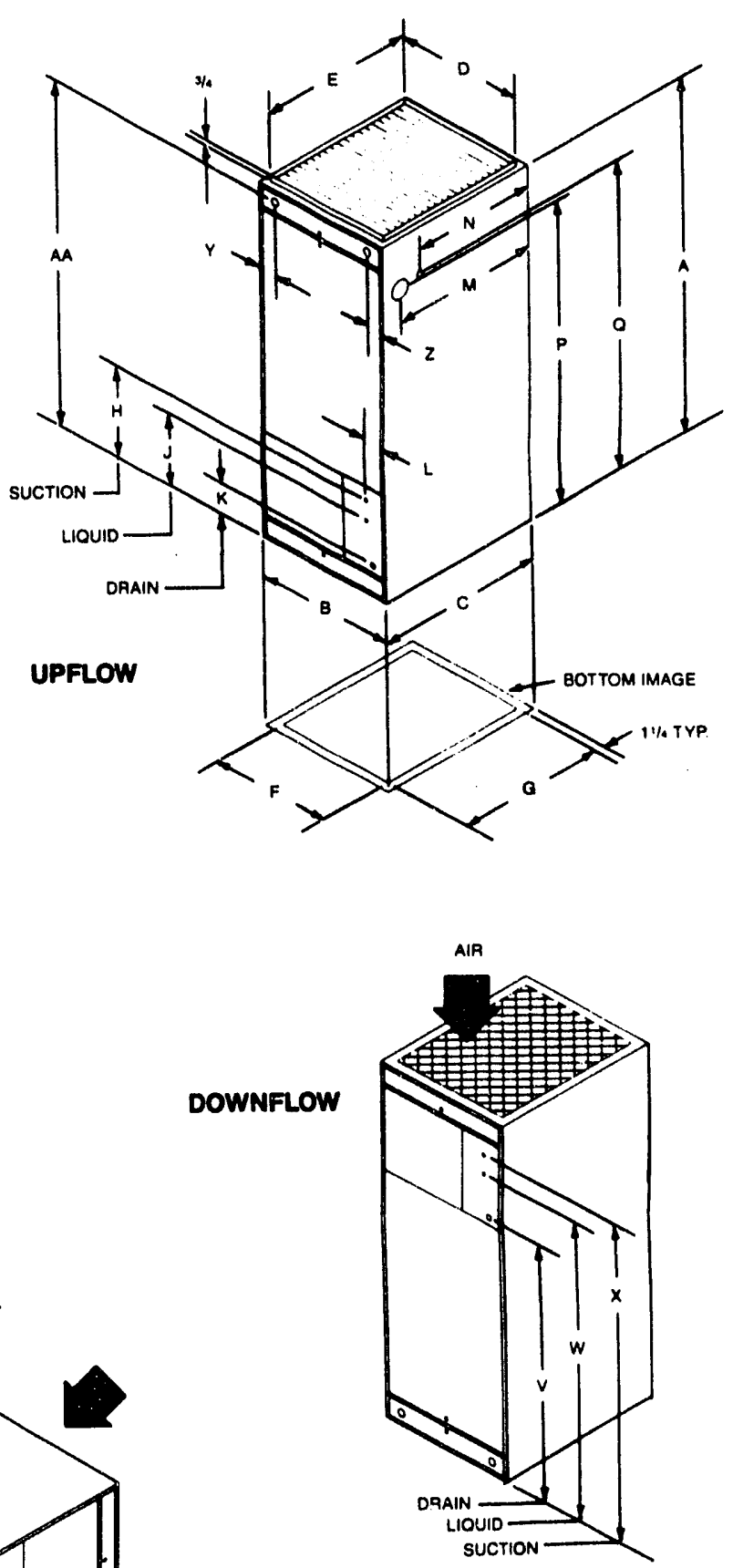

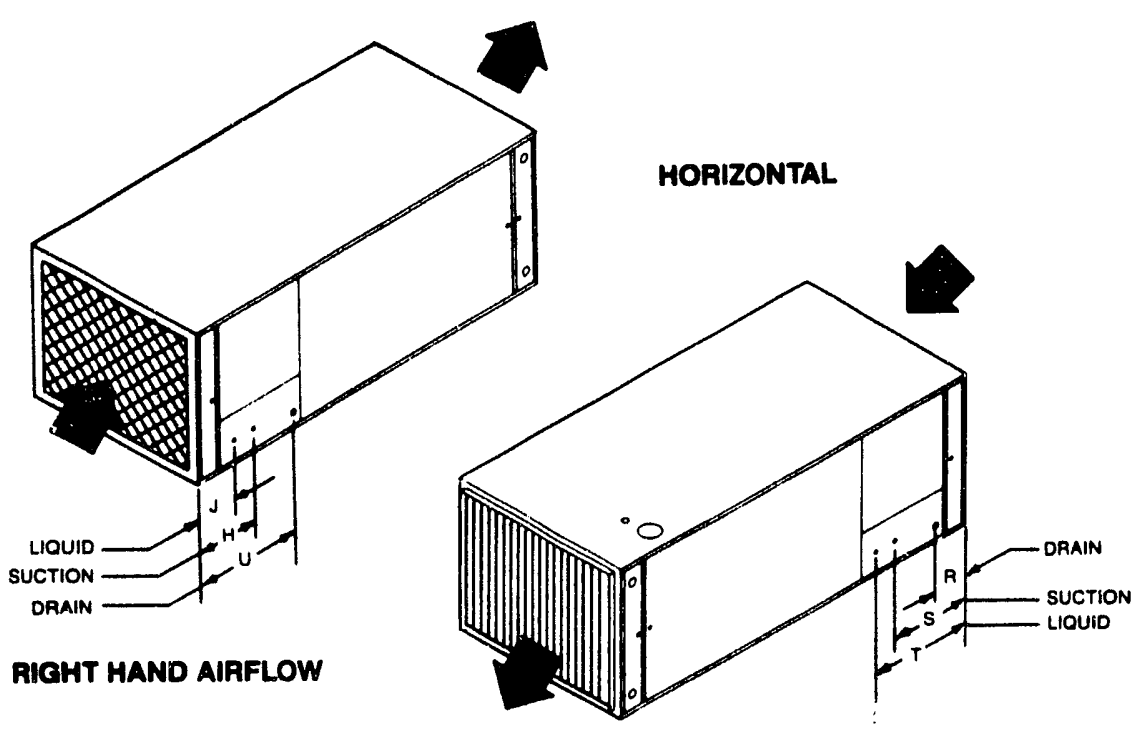

LEFT HAND AIRFLOW 


\begin{tabular}{ll|}
\hline Bofore proceeding with inatallation, & RHEFM \\
refor to Installation instructions & AIR CONDITIONINA \\
packaged with each model, as well as \\
complying with all Federal, State, and \\
Local codes, regulations, and practices.
\end{tabular}

"In keeping with its policy of continuous progress and product improvement, Rheem reserves the right to make changes without notice." PRINTEDINU.S.A. $\quad 11.90 \mathrm{BP}$ FORM NO. H11.507 REV. 1 


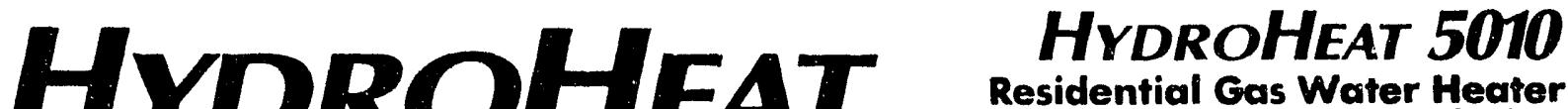 with Foam Insulation}

40,50 and 75 Gallon Storage Capacity Natural and Propane (L.P.) Gas Input BTU/Hr: 35,500 through 75,100 Natural and Propane (L.P.) Gas Five-year Limited Warranty on Tank and One-year on Parts

Compared to a standard fiberglass insulated water heater of the same capacity, the HydroHeat 5010 models furnish more hot water per hour and offer $76 \%$ recovery efficiency.

Apollo Comfort Products offers this HydroHeat 5010 gas water heater for any system requiring the addition of recirculating hot water loop.

\section{Check these Quality Features}

- Competitively Priced

- Foam Insulation retains heat $2 \frac{1}{2}$ times better than standard

fiberglass insulation.

- Aluminized Steel Multi-Port Burner for quiet, efficient

combustion.

- Energy-Saving Pilot.

- Nylon Drain Valve eliminates electrolytic corrosion.

- Glasslined Tank for years of rust-free operation.

- Automatic Temperature Control, with four settings for plenty of hot water at a desired temperature.

- A.G.A. Design Certified E.C.O. (Energy Cut-Off).

- Maximum hydrostatic working pressure is 150 psi.

- Five-year limited tank warranty. Complete details on these warranties available at your nearest Apollo sales office

- Temperature-Pressure Relief Valve.

- Side mounted tapping for recirculating system.

- Optional recirculating loop assembly - part \#9001262

- Optional Hot check valve - part \# 9001378

- Optional Cold check valve - part \#9000948
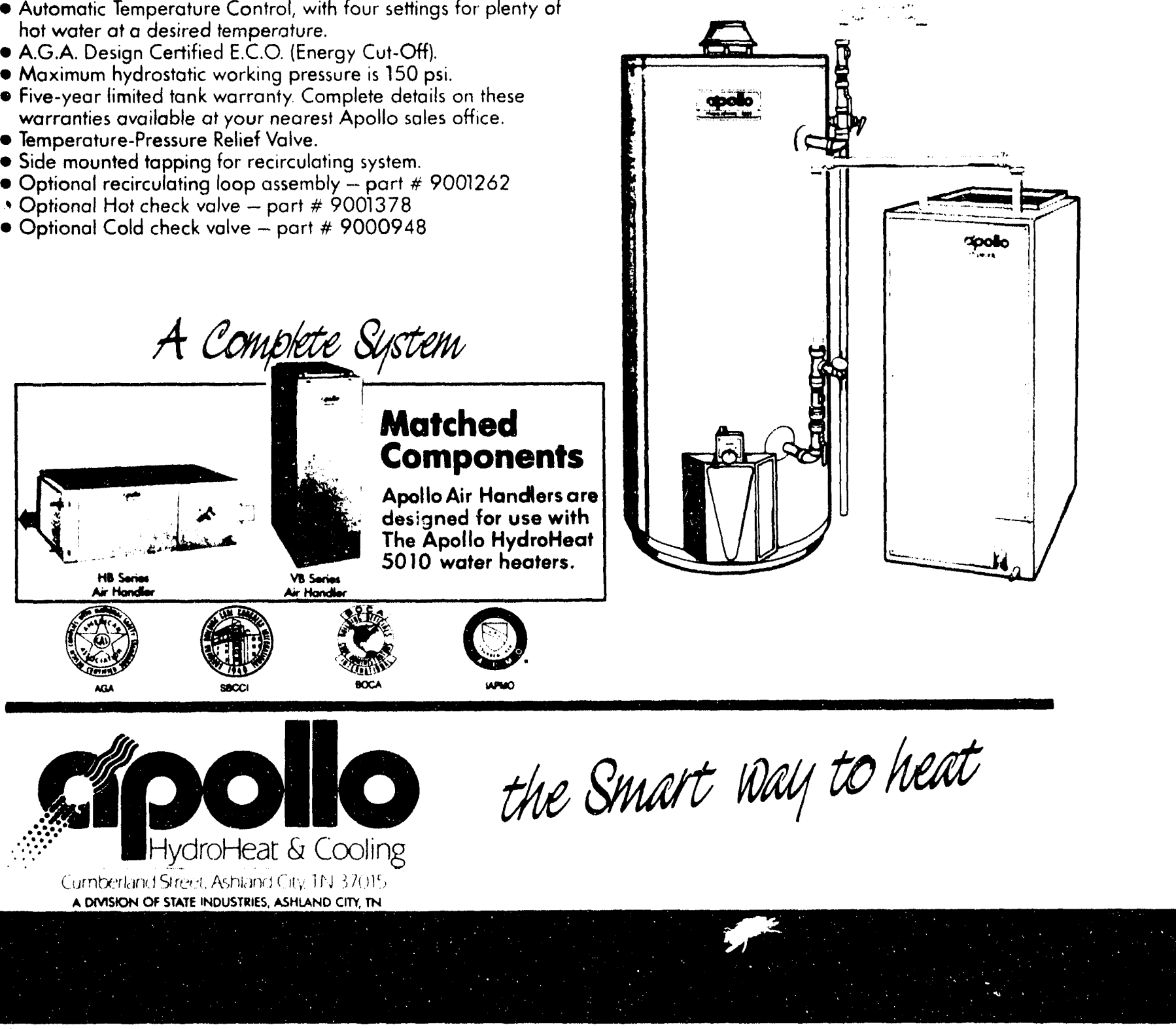


\section{Specifications}

Hydrofloen 5010 Residential Gas Wator Hoater with Foam Insulation

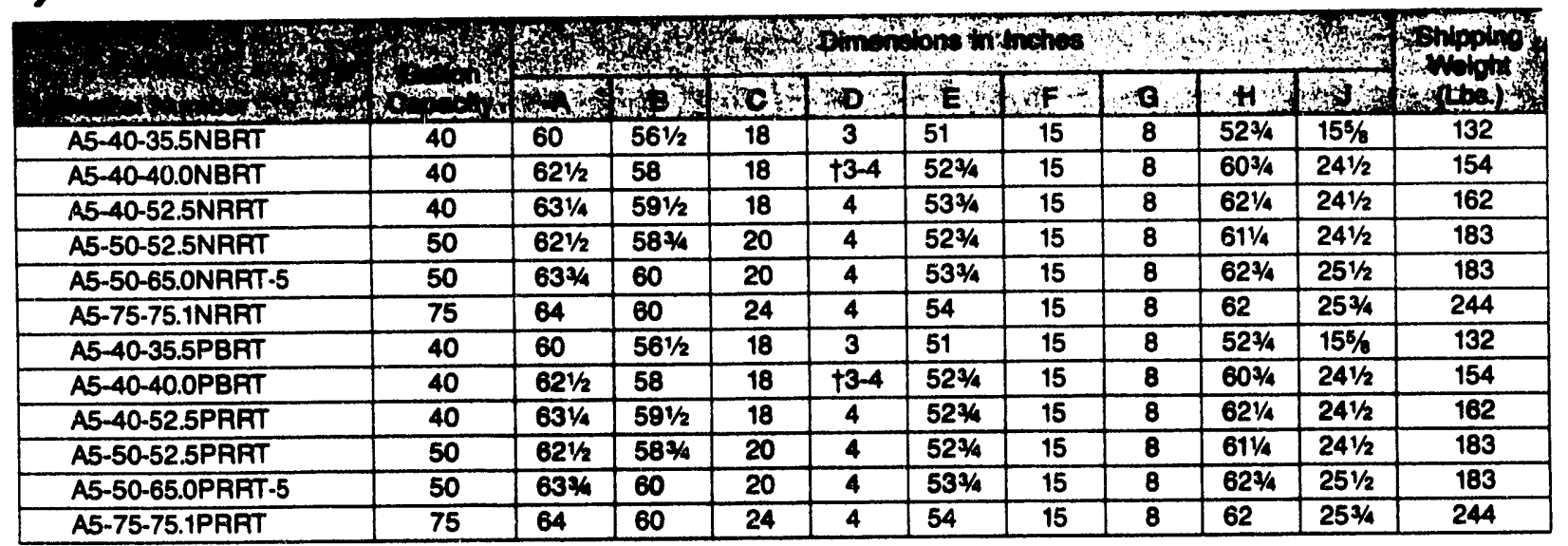

\begin{tabular}{|c|c|c|c|c|c|c|c|c|c|}
\hline 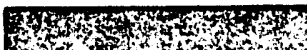 & 23 & 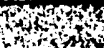 & noc & $y$ Dox & Aing & & & (y) & $\mathrm{An}$, \\
\hline 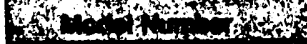 & & 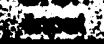 & $\infty$ & $\infty$ & $\infty$ & & & Xentent & Enowor \\
\hline A5-40-35.5NBFT & 40 & 35,500 & 33 & 36 & 55 & & $76 \%$ & 26,980 & .56 \\
\hline A5-40-40.0NBFT & 40 & 40,000 & 37 & 41 & 61 & 69 & $76 \%$ & 30,400 & .57 \\
\hline A5-40-52.5NART & 40 & 52,500 & 48 & 54 & 81 & 80 & $76 \%$ & 39,900 & .54 \\
\hline A5-50-52.5NART & 50 & $-52,500$ & 48 & 54 & 81 & 87 & $76 \%$ & 39,900 & .52 \\
\hline A5-50-65.0NRRT-5 & 50 & 65,000 & 60 & 67 & 100 & 98 & $76 \%$ & 49,400 & .52 \\
\hline A5-75-75.1NRRT & 75 & 75,100 & 69 & 77 & 115 & 122 & $76 \%$ & 57,076 & .48 \\
\hline A5-40-35.5PBRT & 40 & 35,500 & 33 & 36 & 55 & 65 & $78 \%$ & 26,280 & .56 \\
\hline A5-40-40.0PBRT & 50 & 40,000 & 37 & 41 & 61 & 69 & $76 \%$ & 30,400 & .57 \\
\hline A5-40-52.5PRAT & 40 & 52,500 & 48 & 54 & 81 & 80 & $76 \%$ & 39,900 & .54 \\
\hline A5-50-52.5PRAT & 50 & 52,500 & 48 & 54 & 81 & 87 & $76 \%$ & 39,900 & .52 \\
\hline A5-50-65.0PRRT-5 & 40 & 65,000 & 60 & 67 & 100 & 98 & $78 \%$ & 49,400 & .52 \\
\hline A5-75-75.1PRRT & 75 & 75,100 & 69 & 77 & 115 & 122 & $76 \%$ & 57,076 & .48 \\
\hline
\end{tabular}

Racoveries are rounded to nearest gallon. tProvision for 3" or 4" nue pipe.

\section{Woter Hooper/Air Haindler Sizing}

The water heater should be a minimum of $\mathbf{4 0}$ gallon capacity. The water heater's input (BTUH) must equal or exceed the capacity of the air handler's heating coil, when divided by the recovery efficiency of the water heater.

The air handler's heating capability must equal or exceed the (ACCA Method J) heat loss of the structure.

Assistance in sizing can be obtained from your Apollo Distributor. In oddition, the Apollo Systems Handbook which includes installation and operotion information, can be found under the "Installation Information" tab of the Apollo Catalog.

In keeping with our policy of continuous product improvement we reserve the right to make changes without prior notice.

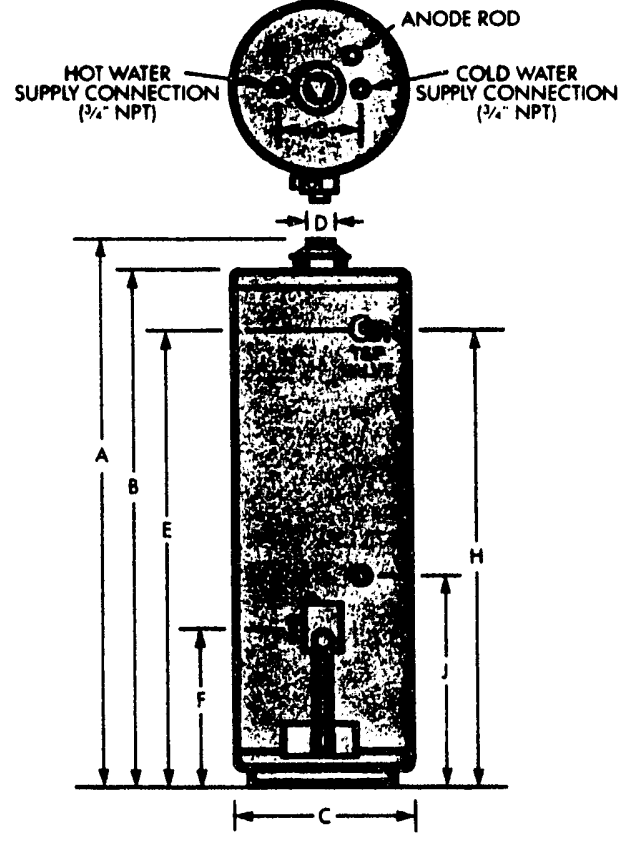

HH 13/691 


\section{HYDROSWIRL 5050 Residential Gas Water Heater with foam Insulation}

40,50 and 75 Gallon Storage Capacity Notural and Propane (LP.) Gas Input BUT/Hr: 40,000 through 75,100 Natural and Propane (L.P.) Gas Five-year Limited Warranty on Tank and Parts

Compared to a standard fiberglass insulated water heater of the same capacity, the HydroSwirl 5050 models fumish more hot water per hour and offer $76 \%$ recovery efficiency.

Apollo Comfort Products offers this HydroSwir 5050 gas water heater for any system requiring the addition of recirculating hot water loop. All models are equipped with side-mounted recirculating taps and valves.

Energy-efficient water heaters don't always stay energy-efficient. Deposits of lime and other sediments can accumulate on heat transfer areas of the tank, affect tank life, and gradually decrease the water heater's recovery efficiency. But the HydroSwirl $\mathbf{5 0 5 0}$ features a specially designed HydroSwirt Dip Tube that creates turbulence inside the tank to help prevent harmful sediment from collecting.

\section{Check these Quality Foatures}

- HydroSwir Dip Tube.

- Side-mounted tapping and valves for recirculating system.

- Foam Insulation retains heat $2 \frac{1}{2}$ times better than standard fiberglass insulation.

- Aluminized Steel Mutti-Port Bumer for quiet, efficient combustion.

- Energy-Saving Pilot.

- Nylon Drain Valve eliminates electrolytic corrosion.

- Glasslined Tank for years of rust-free operation.

- Automatic Temperature Control, with four settings for plenty of hot water at a desired temperature.

- A.G.A. Design Certified E.C.O. (Energy Cut-Off).

- Zinc-Coated Plasticent Nipples reduce electrolytic action.

- Maximum hydrostatic working pressure is 150 psi.

- Five-year limited tank and parts warranty. Complete details on these warranties available at your nearest Apollo sales office.

- Temperature-Pressure Relief Valve.
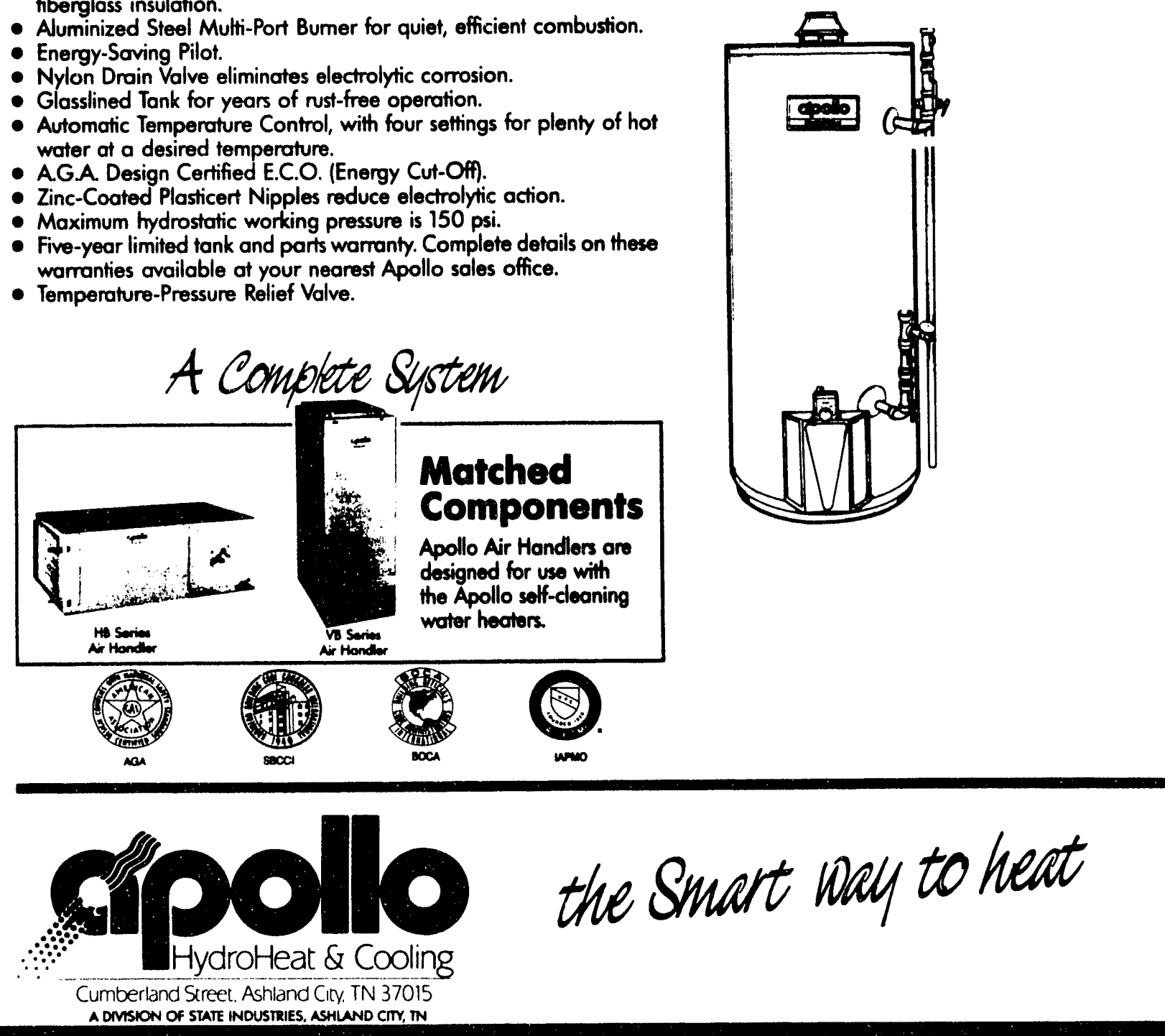


\section{Specifications}

\section{HydroSwirl 5050 Residential Gas Water Heater with Foam Insulation}

\begin{tabular}{|c|c|c|c|c|c|c|c|c|c|c|c|}
\hline \multirow[b]{2}{*}{ Model Number } & \multirow{2}{*}{$\begin{array}{l}\text { Gallon } \\
\text { Capacity }\end{array}$} & \multicolumn{9}{|c|}{ Dimensions in Inches } & \multirow{2}{*}{$\begin{array}{l}\text { Shipping } \\
\text { Weight } \\
\text { (Lbs.) }\end{array}$} \\
\hline & & A & B & $C^{*}$ & D & $\mathbf{E}$ & $\mathbf{F}$ & $\mathbf{G}$ & H & $\mathbf{J}$ & \\
\hline A5-40-40.0NART & 40 & $621 / 2$ & 58 & 18 & $+3-4$ & $52^{3 / 4}$ & 15 & 8 & $603 / 4$ & $241 / 2$ & 154 \\
\hline A5-40-52.5NQRT & 40 & $631 / 4$ & $591 / 2$ & 18 & 4 & $53 \frac{3}{4}$ & 15 & 8 & $621 / 4$ & $241 / 2$ & 162 \\
\hline A5-50-52.5NQRT & 50 & $62^{1 / 2}$ & $583 / 4$ & 20 & 4 & $523 / 4$ & 15 & 8 & $611 / 4$ & $241 / 2$ & 183 \\
\hline A5-50-65.0NQRT -5 & 50 & $633 / 4$ & 60 & 20 & 4 & $533 / 4$ & 15 & 8 & $623 / 4$ & $251 / 2$ & 183 \\
\hline A5-75-75.1NQRT & 75 & 64 & 60 & 24 & 4 & 54 & 15 & 8 & 62 & $253 / 4$ & 244 \\
\hline A5-40-40.OPART & 40 & $621 / 2$ & 58 & 18 & $+3-4$ & $523 / 4$ & 15 & 8 & $60^{3 / 4}$ & $241 / 2$ & 154 \\
\hline A5-40-52.5PQRT & 40 & $631 / 4$ & $591 / 2$ & 18 & 4 & $533 / 4$ & 15 & 8 & $621 / 4$ & $241 / 2$ & 162 \\
\hline A5-50-52.5PQRT & 50 & $621 / 2$ & $583 / 4$ & 20 & 4 & $52^{3 / 4}$ & 15 & 8 & $611 / 4$ & $241 / 2$ & 183 \\
\hline A5-50-65.0PQRT-5 & 50 & $633 / 4$ & 60 & 20 & 4 & $533 / 4$ & 15 & 8 & $623 / 4$ & $251 / 2$ & 183 \\
\hline A5-75-75.1PQRT & 75 & 64 & 60 & 24 & 4 & 54 & 15 & 8 & 62 & $253 / 4$ & 244 \\
\hline
\end{tabular}

\begin{tabular}{|c|c|c|c|c|c|c|c|c|c|}
\hline \multirow[b]{2}{*}{ Model Number } & \multirow{2}{*}{$\begin{array}{c}\text { Gallon } \\
\text { Capacity }\end{array}$} & \multirow{2}{*}{$\begin{array}{l}\text { BTUH } \\
\text { Input }\end{array}$} & \multicolumn{3}{|c|}{$\begin{array}{c}\text { Recovery } \\
\text { Degree Rise }\end{array}$} & \multirow{2}{*}{$\begin{array}{c}\text { First } \\
\text { Hour } \\
\text { Rating }\end{array}$} & \multirow{2}{*}{$\begin{array}{l}\text { Recovery } \\
\text { Efficiency }\end{array}$} & \multirow{2}{*}{$\begin{array}{l}\text { BTUH } \\
\text { Output }\end{array}$} & \multirow{2}{*}{$\begin{array}{l}\text { Energy } \\
\text { Factory }\end{array}$} \\
\hline & & & $100^{\circ}$ & $90^{\circ}$ & $60^{\circ}$ & & & & \\
\hline A5-40-40.0NART & 40 & 40,000 & 37 & 41 & 61 & 69 & $76 \%$ & 30,400 & .57 \\
\hline A5-40-52.5NQRT & 40 & 52,500 & 48 & 54 & 81 & 80 & $76 \%$ & 39,900 & .54 \\
\hline A5-50-52.5NQRT & 50 & 52,500 & 48 & 54 & 81 & 87 & $76 \%$ & 39,900 & .52 \\
\hline A5-50-65.0NQRT -5 & 50 & 65,000 & 60 & 67 & 100 & 98 & $76 \%$ & 49,400 & .52 \\
\hline A5-75-75.1NQRT & 75 & 75,100 & 69 & 77 & 115 & 122 & $76 \%$ & 57,076 & .48 \\
\hline A5-40-40.0PART & 40 & 40,000 & 37 & 41 & 61 & 69 & $76 \%$ & 30,400 & .57 \\
\hline A5-40-52.5PQRT & 40 & 52,500 & 48 & 54 & 81 & 80 & $76 \%$ & 39,900 & .54 \\
\hline A5-50-52.5PQRT & 50 & 52,500 & 48 & 54 & 81 & 87 & $76 \%$ & 39,900 & .52 \\
\hline A5-50-65.0PQRT-5 & 50 & 65,000 & 60 & 67 & 100 & 98 & $76 \%$ & 49,400 & .52 \\
\hline A5-75-75.1PQRT & 75 & 75,100 & 69.0 & 77 & 115 & 122 & $76 \%$ & 57,076 & .48 \\
\hline
\end{tabular}

Recoveries are rounded to nearest gallon.

†Provision for $3^{\prime \prime}$ or 4 " flue pipe.

"The " $\mathrm{C}$ " dimension will be 2 " larger on heaters monufactured to meet CEC requirements.

\section{HydroSwirl dip tube makes sure thet the money saving parformance lastst}

The HydroSwirl is equipped with the exclusive, patented Hydroswirl allp tube. It creates a "vortex" of turbulence inside the tank, which prevents sediment accumulation. In ordinary water heaters, lime and their sediments can accumulate on heat transfer areas, affect tank life, and decrease the water heater's efficiency. But HydroSwirl water heaters clean themselves, so they're energy efficient and stay that wayl No ofthor gas wetur heater saves homeowners this much on operating costsl The Energy Guide label found on all water heaters tells consumers how much it costs to heat water. And the HydroSwit label tells a powerful story. Homeowners can seve more money on operating cost with the HydroSwirl over the life of the water heater, compared to less efficient models. HydroSwirl has the lowest operating cost of any gas water heater madel

\section{Woter Hocter/Air Handler Sizing}

The water heater should be a minimum of $\mathbf{4 0}$ gallon capacity. The water heater's input (BTUH) must equal or exceed the capacity of the air handler's heating coil, when divided by the recovery efficiency of the water heater.

The air handler's heating capability must equal or exceed the (ACCA Method J) heat loss of the structure.

Assistance in sizing can be obtained from your Apollo Distributor. In addition, the Apollo Systems Handbook which includes installation and operation information, can be found under the "Installation Information" tab of the Apollo Catalog.

In keeping with our policy of continuous product improvement we reserve the right to make changes without prior notice.

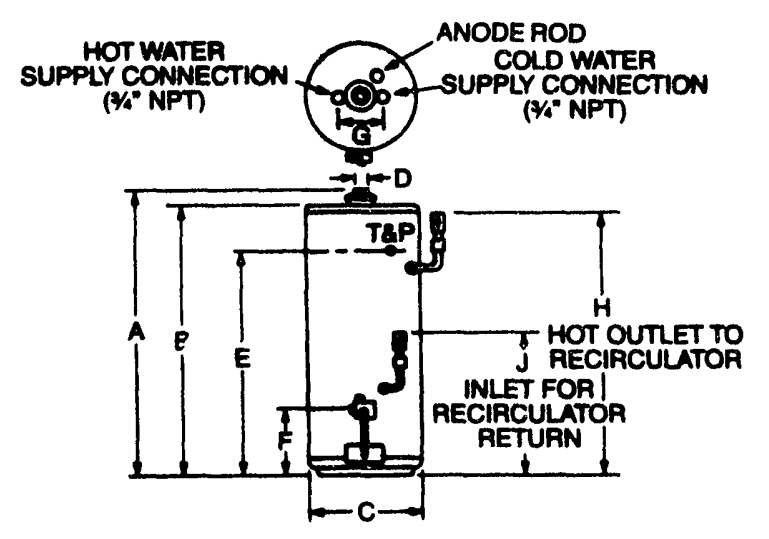

H-10-3-89 


\section{HYDROHEAT HrDROSWIR SUPER 5050}

80-85\% Recovery Efficiency for the industry's lowest operating cost 40,000-55,000 BTU natural gas input for high recovery 40 and 50 Gallon Storage Capacity

Five-year Limited Warranty on Tank and Parts Apollo offers a gas residential water heater with $\mathbf{8 0 - 8 5 \% ~ r e c o v e r y ~ e f f i c i e n c y ~ f o r ~ l o w ~ o p e r a t i n g ~ c o s t s ~ a n d ~ h i g h ~}$ recovery for plenty of hot water.

Apollo Hydro Heat offers this HydroSwirl Super 5050 gas water heater for any system requiring the addition of recirculating hot water loop. All models are equipped with side-mounted recirculating taps and valves.

Energy-efficient water heaters don't always stay energy-efficient. Deposits of lime and other sediments can accumulate on heat transfer areas of the tank, affect tank life, and gradually decrease the water heater's recovery efficiency. But the HydroSwirl Super $\mathbf{5 0 5 0}$ features a specially designed HydroSwirl Dip Tube that creates turbulence inside the tank to help prevent harmful sediment from collecting.

\section{Check these Quality Feafures}

- HydroSwirl Dip Tube.

- Side-mounted tapping and valves for recirculating system.

- Foam Insulation retains heat 21/2 times better than standard fiberglass insulation.

- Heat Traps prevent heat loss at inlet and outlet.

- Aluminized Steel Multi-Port Burner for quiet, efficient combustion.

- Energy-Saving Pilot.

- Nylon Drain Valve eliminates electrolytic corrosion.

- Glasslined Tank for years of rust-free operation.

- Automatic Temperature Control, with four settings for plenty of hot water at a desired temperature.

- A.G.A. Certified E.C.O. (Energy Cut-Off).

- Zinc-Coated Plasticert Nipples reduce electrolytic action.

- Maximum hydrostatic working pressure is 150 psi.

- Five-year limited tank and parts warranty. Complete details on these warranties available at your nearest Apollo sales off:ce.

- Temperature.Pressure (T\&P) Relief Valve.
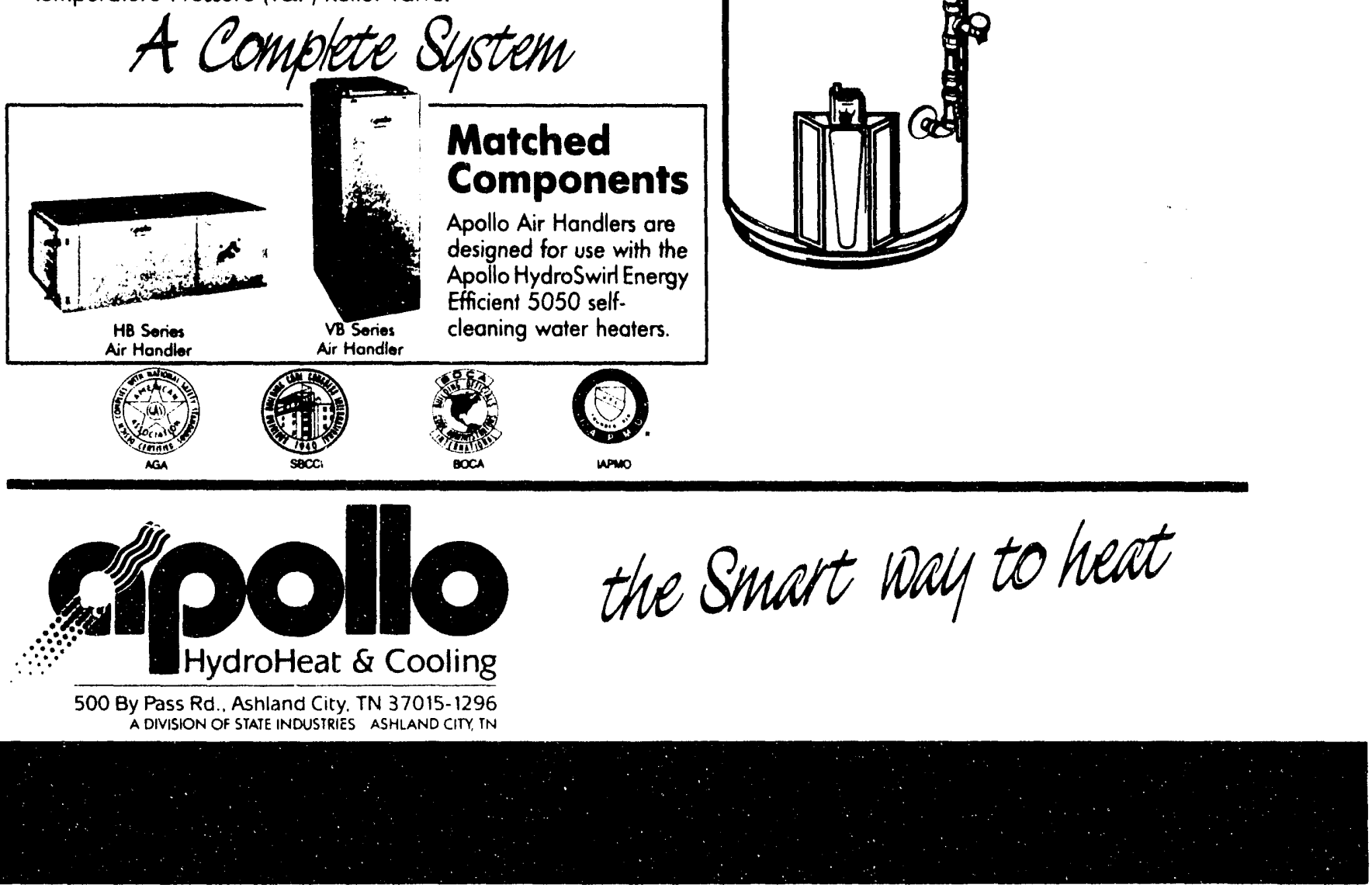


\section{Specifications}

\section{HydroSwirl Super 5050 Residential Gas Water Heater}

- Lowest Operating Cost - $\quad$ Pagh Recovery ted, sediment-fighting HydroSwirl dip tube

\begin{tabular}{|c|c|c|c|c|c|c|c|c|c|c|c|}
\hline \multirow[b]{2}{*}{ Model Number } & \multirow{2}{*}{$\begin{array}{c}\text { Gallon } \\
\text { Capacity }\end{array}$} & \multicolumn{9}{|c|}{ Dimensions in Inches } & \multirow{2}{*}{$\begin{array}{l}\text { Shipping } \\
\text { Weight } \\
\text { (Lbs.) }\end{array}$} \\
\hline & & A & B & C & D & $E$ & $\mathbf{F}$ & $\mathbf{G}$ & $H$ & $J$ & \\
\hline A5-40-40.0NXRT & 40 & $64 \frac{1}{2}$ & 60 & 18 & $+3-4$ & $541 / 4$ & $151 / 4$ & 8 & 63 & 29 & 166 \\
\hline A5-50-40.0NXRT & 50 & 64 & $591 / 2$ & 20 & $+3-4$ & $54 \frac{1}{4}$ & $151 / 4$ & 8 & $621 / 4$ & 31 & 188 \\
\hline A5-40-40.0PXRT & 40 & $64 \frac{112}{2}$ & 60 & 18 & +3.4 & $541 / 4$ & $151 / 4$ & 8 & 63 & 29 & 166 \\
\hline A5-50-39.0PXRT & 50 & 64 & $59^{1 / 2}$ & 20 & $+3-4$ & $541 / 4$ & $151 / 4$ & 8 & $62^{1 / 4}$ & 31 & 188 \\
\hline A5-40-55.0NXQT & 40 & $641 / 2$ & 60 & 18 & $+3-4$ & $541 / 4$ & $151 / 4$ & 8 & 63 & 29 & 166 \\
\hline A5-50-55.0NXQT & 50 & 64 & $591 / 2$ & 20 & +3.4 & $54 \frac{1}{4}$ & $151 / 4$ & 8 & $621 / 4$ & 31 & 188 \\
\hline A5-40-48.0PXQT & 40 & $641 / 2$ & 60 & 18 & $+3-4$ & $541 / 4$ & $151 / 4$ & 8 & 63 & 29 & 166 \\
\hline $\mathrm{A} 5-50-48.0 \mathrm{PXQT}$ & 50 & 64 & $59 \% / 2$ & 20 & $+3-4$ & $54 \frac{1}{4}$ & $15 \frac{1}{4}$ & 8 & $621 / 4$ & 31 & 188 \\
\hline
\end{tabular}

tProvision for 3" or 4" flue pipe.

\begin{tabular}{|c|c|c|c|c|c|c|c|c|c|}
\hline \multirow[b]{2}{*}{ Model Number } & \multirow{2}{*}{$\begin{array}{c}\text { Gallon } \\
\text { Capacity }\end{array}$} & \multirow{2}{*}{$\begin{array}{c}\text { BTUH } \\
\text { Input }\end{array}$} & \multicolumn{3}{|c|}{$\begin{array}{c}\text { Recovery } \\
\text { Degree Rise }\end{array}$} & \multirow{2}{*}{$\begin{array}{l}\text { First } \\
\text { Hour } \\
\text { Rating }\end{array}$} & \multirow[b]{2}{*}{$\begin{array}{l}\text { Recovery } \\
\text { Efficiency }\end{array}$} & \multirow{2}{*}{$\begin{array}{l}\text { BTUH } \\
\text { Output }\end{array}$} & \multirow{2}{*}{$\begin{array}{l}\text { Energy } \\
\text { Factory }\end{array}$} \\
\hline & & & $100^{\circ}$ & $90^{\circ}$ & $60^{\circ}$ & & & & \\
\hline A5-40-40.0NXRT & 40 & 40,000 & 41 & 46 & 69 & 73 & $85 \%$ & 34,000 & .61 \\
\hline A5-50-40.0NXRT & 50 & 40,000 & 41 & 46 & 69 & 80 & $85 \%$ & 34,000 & .58 \\
\hline A5-40-40.0PXRT & 40 & 40,000 & 41 & 46 & 69 & 73 & $85 \%$ & 34,000 & .61 \\
\hline A5-50-39.0PXRT & 50 & 39,000 & 40 & 45 & 67 & 79 & $85 \%$ & 33,150 & .58 \\
\hline A5-40-55.0NXQT & 40 & 55,000 & 53 & 59 & 89 & 109 & $80 \%$ & 44,000 & .52 \\
\hline A5-50-55.0NXQT & 50 & 55,000 & 53 & 59 & 89 & 109 & $80 \%$ & 44,000 & .52 \\
\hline A5-40-48.0PXQT & 40 & 48,000 & 44 & 48 & 73 & 83 & $80 \%$ & 38,400 & .52 \\
\hline A5-50-48.0PXQT & 50 & 48,000 & 44 & 48 & 73 & 83 & $80 \%$ & 38,400 & .52 \\
\hline
\end{tabular}

Recoveries are rounded to nearest gallon.

\section{Water Heater/Air Handler Sizing}

The water heater should be a minimum of 40 gallon capacity. The water heater's input (BTUH) must equal or exceed the capacity of the air handler's heating coil, when divided by the recovery efficiency of the water heater.

The air handler's heating capability must equal or exceed the (ACCA Method J) heat loss of the structure.

Assistance in sizing can be obtained from your Apollo Distributor. In addition, the Apollo Systems Handbook which includes installation and operation information, can be found under the "Installation Information" tab of the Apollo Catalog.

In keeping with our policy of ccntinuous product improvement we reserve the right to make changes without prior notice.

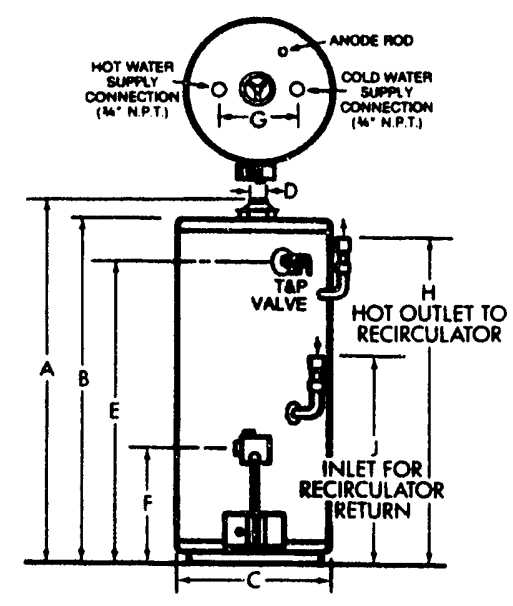

\section{HydroSwirl dip tube makes sure that the money-saving performance lasts!}

The HydroSwirl is equipped with the exclusive, patented HydroSwirl dip tube. It creates a "vortex" of turbulence inside the tank, which prevents sediment accumulation. In ordinary water heaters, lime and their sediments can accumulate on heat transfer areas, affect tank life, and decrease the water heater's efficiency. But Hydroswirl walar heaters clean themselves, so they're energy efficient and stay that way! No other gas water heater saves homeowners this much on operating costs! The Energy Guide label found on all water heaters tells consumers how much it costs to heat water. And the HydroSwirl label tells a powerful story. Homeowners can save more money on operating cost with the HydroSwirl over the life of the water heater, compared to less efficient models. HydroSwirl has the lowest operating cost of any gas water heater madel

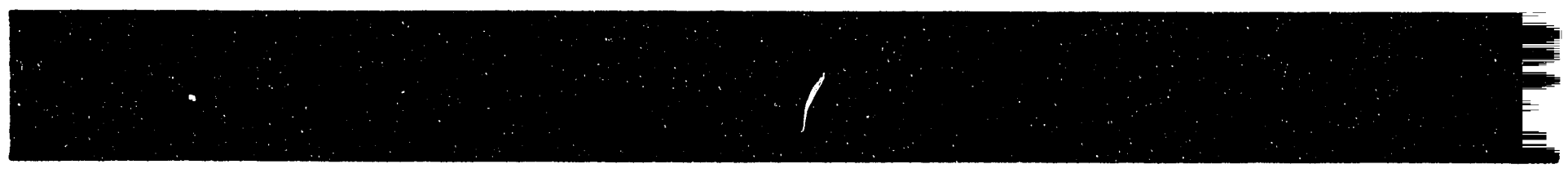




\section{HYDROHEAT DIRECT VENT 5050}

A new altemative to electric water heating in multi-unit buildings, basements, garages and other applications. A gas water heater that vents horizontally, directly through an exterior wall, without complicated, costly venting. Specially-designed vent kits adjusts for wall thickness up to $48^{\prime \prime}$. Also ovailable with four different vertical vent heights. 40-gallon and 50-gallon storage capacities.

\section{Apollo fills a need...}

Until now, architects and builders hove hesitated to include more economical gas water heaters in multi-unit, mulii-story apartment and condominium buildings, as well as in some kitchens, garages and other complex residential applications. To do so required complex, costly multiple venting systems to vent the products of combustion through the roof of the building. But Apollo's direct vent gas water heater can be easily installed in an apartment closet or utility space, and features a dual-channel contained combustion vent system that vents horizontally, directly through the building wall Because of this through-the-wall design, the availability and lower costs of gas water heating compared to electric make the building more attractive to prospective renters or buyers.

\section{Chock these Quality Features}

- HydroSwirl Dip Tube.

- Side-mounted tappings and valves for recirculating system.

- Foam Insulation retains heat $2 \frac{1}{2}$ fimes better than standard fiberglass insulation.

- Aluminized Steel Multi-Port Burner for quiet, efficient combustion.

- Energy-Soving Pilot.

- Nylon Drain Valve eliminates electrolytic corrosion.

- Glasslined Tank for years of nust-free operation.

- Automatic Temperature Control, with four settings for plenty of hot woter at a desired temperature.

- A.G.A. Design Certified E.C.O. (Energy Cut-Off).

- Zinc-Coated Plasticert Nipples reduce electrolytic acticn.

- Maximum tydrostatic working pressure is 150 psi.

- Five-year limited tank and parts warranty. Complete details on these warranties available at your nearest Apollo sales office.

- Temperature-Pressure Relief Valve.
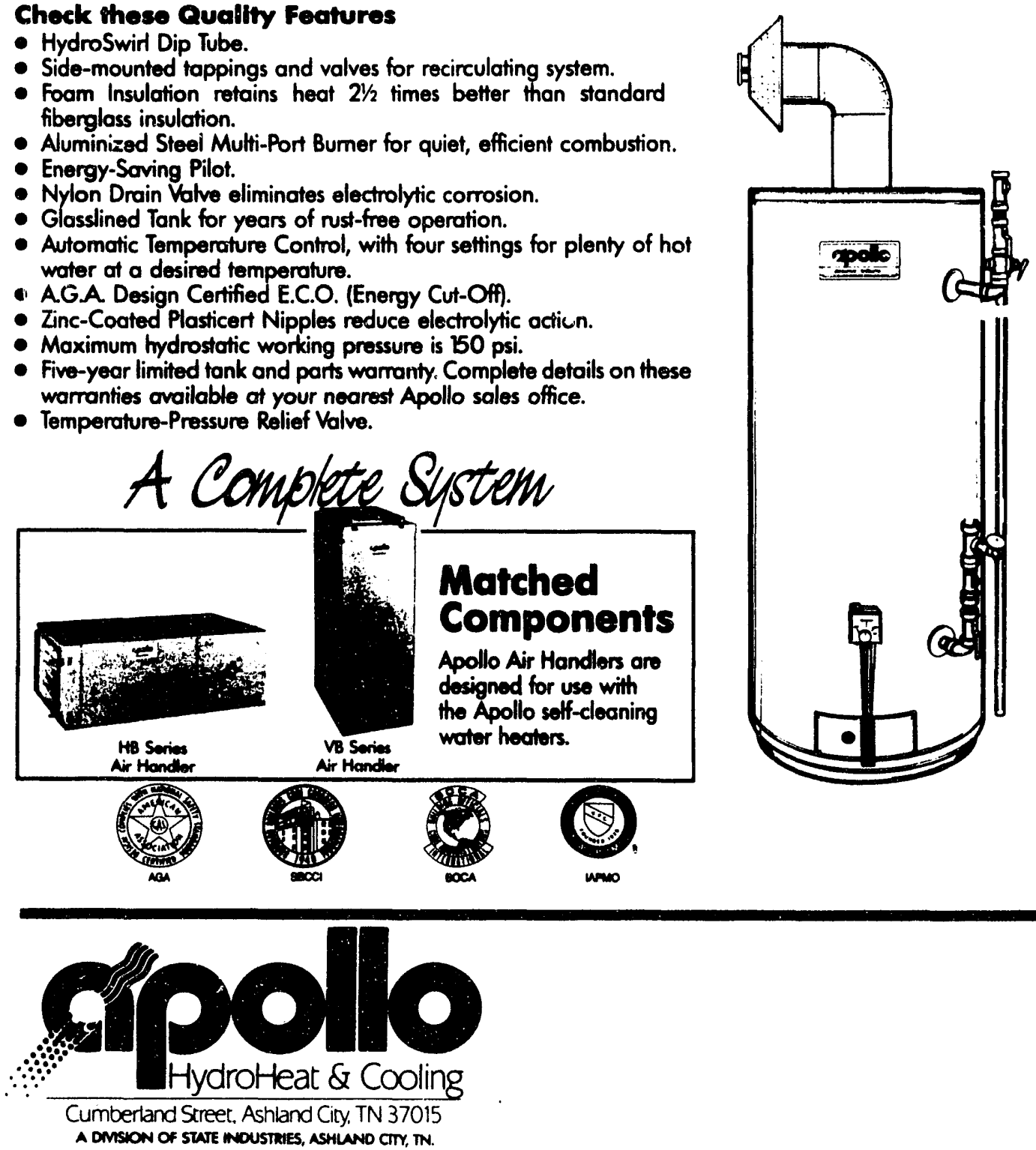


\section{Specifications}

\section{Direct Vent 5050 Residential Gas Water Heafer}

The Direct Vent 5050 Gas Fired Water Heater comes with a standard vent kit (\#9000687) unless otherwise specified when ordering.

In addition to the standard kit ( $\# 900687$ ) there are three optional kits which telescope to give adjustments up to $48^{\prime \prime}$ horizontally and $1221 / 4$ (50 Gallon) vertically.

Each kit is listed below and outlines the minimum and maximum dimensions it covers. There is no distinction between a kit being used horizontally or vertically. However, only one kit can be used horizontally or vertically. If optional kits are required, specify when ordering.

\section{Horizontal Length (Extension Kit)}

To determine the horizontal length and extension kit needed, simply plug the dimensions " $A$ " and " $B$ " into the equation below. The answer "C" should then be located in chart to the side. The size range in which " $\mathrm{C}$ " dimensions falls, indicates the kit that should be used horizontally to obtain the desired length.

"A" = The wall thickness

" $B$ " = The distance wanted between the edge of the water heater and the inside edge of the wall " $\mathrm{C}$ " = The distance the extension kit must be able to extend The Equation

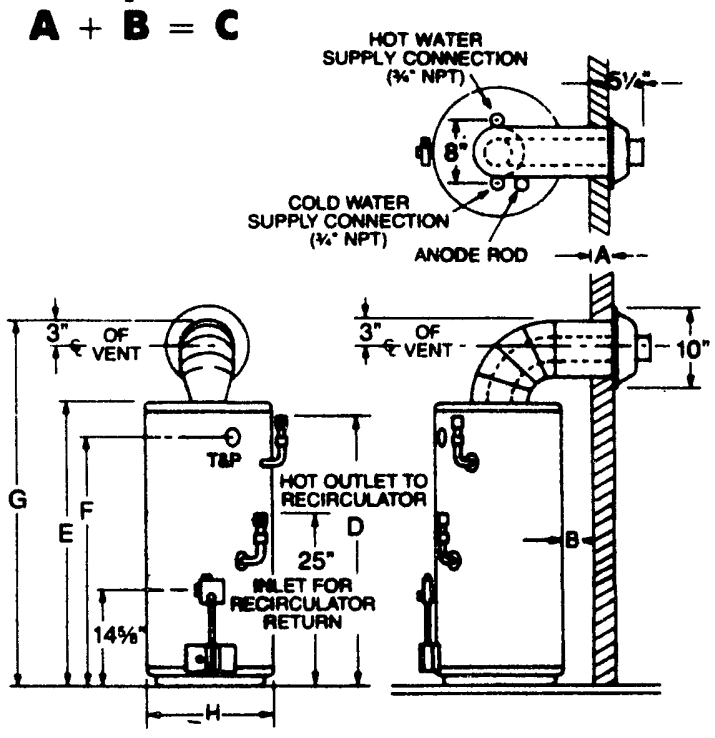

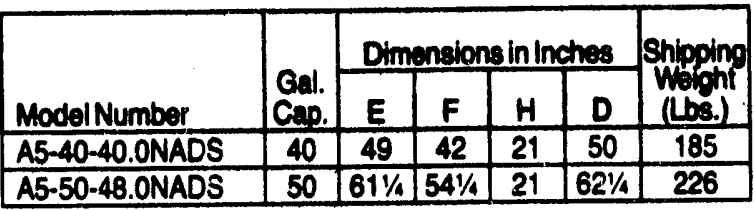

Dimensions shown obove apply to equivalent Propone (L.P.) models.

\begin{tabular}{|c|c|c|c|}
\hline \multirow{2}{*}{$\begin{array}{l}\text { Vertical Vent } \\
\text { Extension Kit } \\
\text { Number }\end{array}$} & \multirow{2}{*}{$\begin{array}{l}\text { ArDimension } \\
\text { Maximum } \\
\text { Wall Thickenoes }\end{array}$} & \multicolumn{2}{|c|}{$\mathrm{C}^{\prime}$ Dimenion } \\
\hline & & $\mathrm{min}$ & Max \\
\hline 9000687 (Std.) & $10^{\prime \prime}$ & $31 / 2$ & $10^{n}$ \\
\hline $9001246(0 \mathrm{pt})$ & $151 / 2^{\prime \prime}$ & $10^{n}$ & $15^{1 / 21}$ \\
\hline $9001247($ Opt.) & $261 / 2^{n}$ & $151 / 2^{\prime \prime}$ & $261 / 2^{11}$ \\
\hline $9001248(0 \mathrm{pt})$ & $48^{n}$ & $261 / 2^{n}$ & $43^{n}$ \\
\hline
\end{tabular}

\begin{tabular}{|c|c|c|c|c|c|c|c|c|c|c|}
\hline \multirow{3}{*}{ 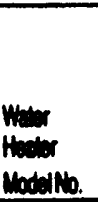 } & \multirow{3}{*}{ Co. } & \multirow{3}{*}{$i_{0 \rightarrow 0}$} & \multirow{3}{*}{ 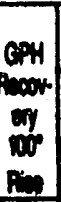 } & \multicolumn{7}{|c|}{ 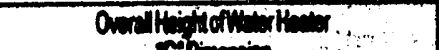 } \\
\hline & & & & $\underset{10}{n=1}$ & 10 & & & & & 20 \\
\hline & & & & (n) & En & $m_{x}$ & $N_{2}$ & $n$ & 2 & $m_{x}$ \\
\hline $\begin{array}{c}A 5-40-40.0 \\
\text { MAOS }\end{array}$ & 40 & 4040 & 36 & $63^{3 / 4}$ & $72^{n}$ & $77 / 2$ & $\pi / \%$ & $89 \%$ & $881 k^{\circ}$ & $110^{*}$ \\
\hline $\begin{array}{l}\text { A5.50-48.0 } \\
\text { NADS }\end{array}$ & 50 & 4844 & 44 & $76^{\circ}$ & BA\%" & $89 \% \%^{\circ}$ & $89 \% 4^{\circ}$ & $100 \% "$ & $100 \% "$ & $122 \%$ \\
\hline
\end{tabular}

Dimencions shown above atso opply to equivolent Propane (L.P.) models.

\section{Mether Hoctor/Air Mendfor Sizing}

The water heoter should be a minimum of $\mathbf{4 0}$ gallon capacity. The water heater's input (BTUH) must equal or excued the capacity of the air handler's heating coil, when divided by the recovery efficiency of the water heater.

The air handler's heoting capability must equal or exceed the (ACCA Method J) heat loss of the structure.

Assistance in sizing can be obtained fiom your Apollo Distributor. In addition, the Apollo Systems Handbook which includes installation and operation information, can be found under the "Installation Information" tab of the Apollo Cotalog.

In keeping with our policy of continuous product improvement we reserve the right to make changes without prior notice.

\section{HydroSwirl dip tube makes sure thet the monoy-soving parformance lasts!}

The direct vent is equipped with the exclusive, patented Hydroswirl dip tulbe. It creates a "vortex" of turbulence inside the tank, which prevents sediment accumulation. In ordinary water heaters, lime and their sediments can accumulate on heat transfer areas, affect tank life, and decrease the water heater's efficiency. But HydroSwirt equipped water heaters clean themselves, so they're energy efficient and stay that woyl. No other gas weter hedier saves homeowners this much on operating costs! The Energy Guide label found on all woter heaters tolls consumers how much it costs to heat water. And the HydroSwirl label tells a powerful story. Homeowners can save more money on operating cost with the HydroSwirl over the life of the water hecater, compared to less efficient models. Direct Vent has the lowest operating cost of any gas water heater madel

DV-11-989 


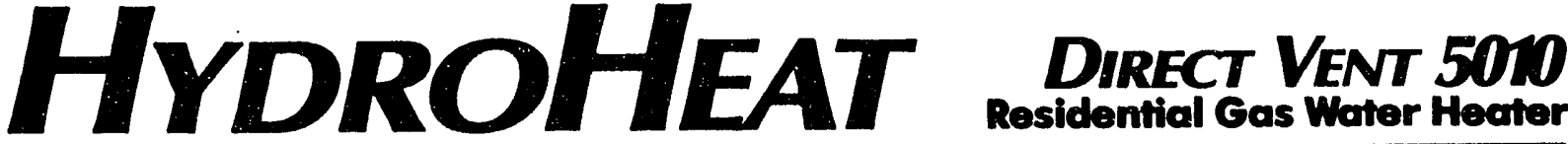

A new alternative to dectric woter heating in multi-unit buildings, basements, garages and other applications.

A gas water heater that vents horizontally, directly through an exterior wall, without complicated, costly venting. Specially-designed vent kits adjusts for wall thickness up to $48^{\prime \prime}$. Also available with four different vertical vent heights.

40-gallon and 50-gallon storage capacities.

\section{Apollo fills a nood...}

Until now, architects and builders have hesitated to include more economical gas water heaters in multi-unit, multi-story apartment and condominium buildings, as well as in some kitchens, garages and other complex residential applications. To do so required complex, costly multiple venting systems to vent the products of combustion through the roof of the building. But Apollo's direct vent gas water heater can be easily installed in an apartment closet or utility space, and features a dual-channel contained combustion vent system that vents horizontally, directly through the building wall! Because of this through-the-wall design, the availability and lower costs of gas water heating compared to electric make the building more attractive to prospective renters or buyers.

\section{Chodk these Quallity Foetures}

- Side mounted tapping for recirculating system.

- Optional recirculating loop assembly - part * 9001262

- Foam Insulation retains heat $21 / 2$ times better than standard fiberglass insulation.

- Aluminized Steel Multi-Port Bumer for quiet, efficient combustion.

- Energy-Soving Pilot.

- Nylon Drain Valve eliminates electrolytic corrosion.

- Glasslined Tank for years of rust-free operation.

- Automatic Tomperature Control, with four seltings for plenty of hot woter at a desired temperature.

- A.G.A. Design Certifiod E.C.O. (Enengy Cut-Off)

- Zinc-Cocolod Plasticert Nipples reduce electrolytic action.

- Maximum hydrostatic working pressure is 150 psi.

- Five-year limited tank warranty. Complete datails on these warranties ovailable at your nearest Apollo sales office.

- Temperature-Pressure Relief Vatre.
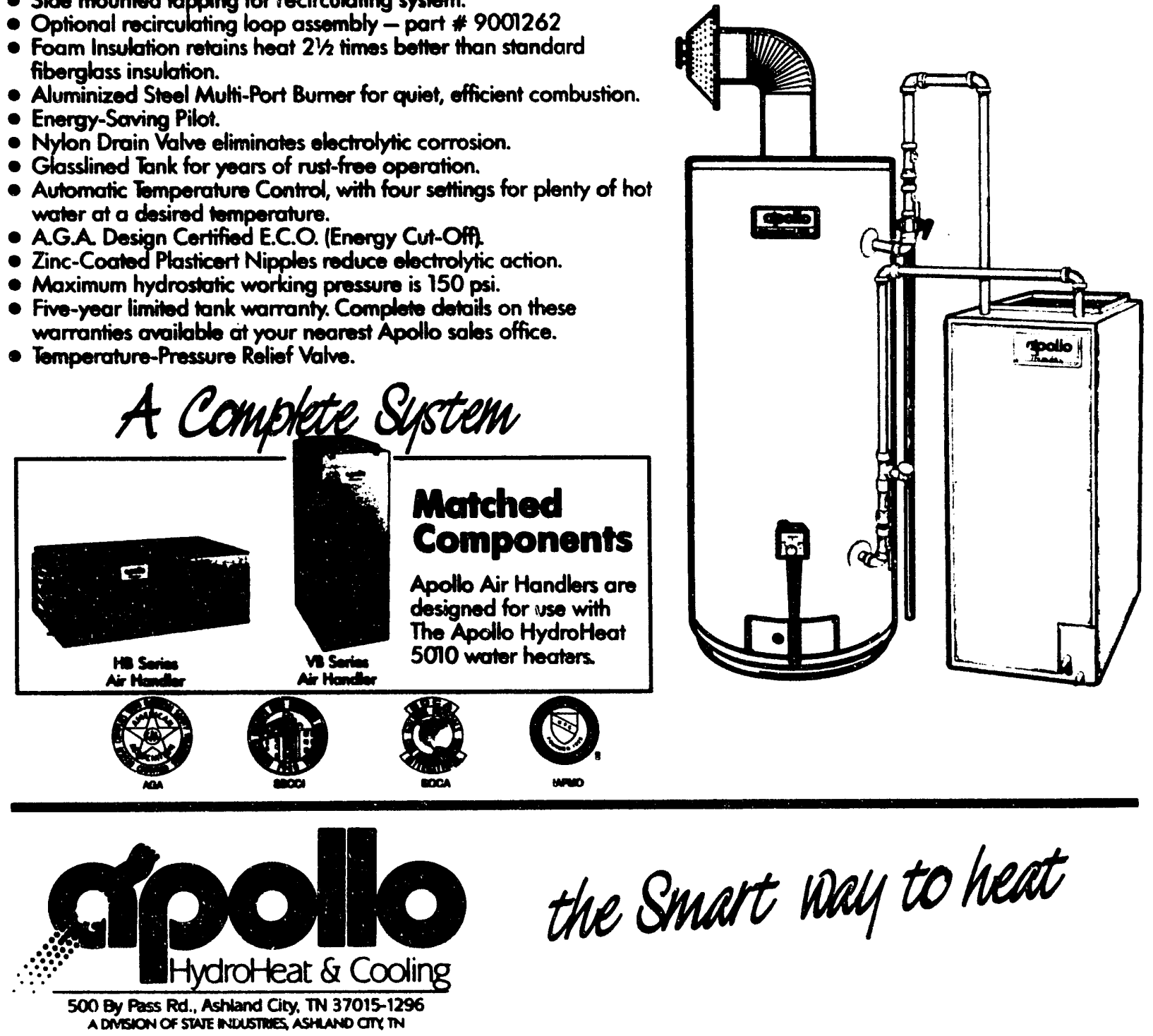

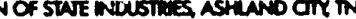




\section{Specifications}

\section{Direci Vent 5010 Residential Gas Water Heater}

The Direct Vent 5010 Gas Fired Water Heater comes with a standard vent kit (\#9000687) unless otherwise specified when ordering.

In addition to the standard kit (\$9000687) there are three optional kits which telescope to give adjustments up to $48^{\prime \prime}$ horizontally and $12214^{\prime \prime}$ (50 Gallon) vertically.

Each kit is listed below and outlines the minimum and maximum dimensions it covers. There is no distinction between a kit being used horizontally or vertically. However, only one kit can be used horizontally or ventically. If optional kits are required, specify when ordering.

\section{Horizontal Length (Extension Kii)}

io cietermine the horizontal length and extension kit needed, simply plug the dimensions " $A$ " and " $B$ " into

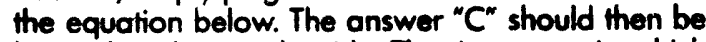
located in chart to the side. The size range in whicl " $C$ " dimensions falls, indicates the kit that should be used horizontally to obtain the desired length.

$A^{\prime \prime}=$ The wall thickness

$" B^{\prime \prime}=$ The distance wanted between the edge of the water heater and the inside edge of the wall

$\mathrm{C}^{\prime \prime}$ = The distance the extension kit must be able to extend

\section{The Equation}

$$
A+B=C
$$

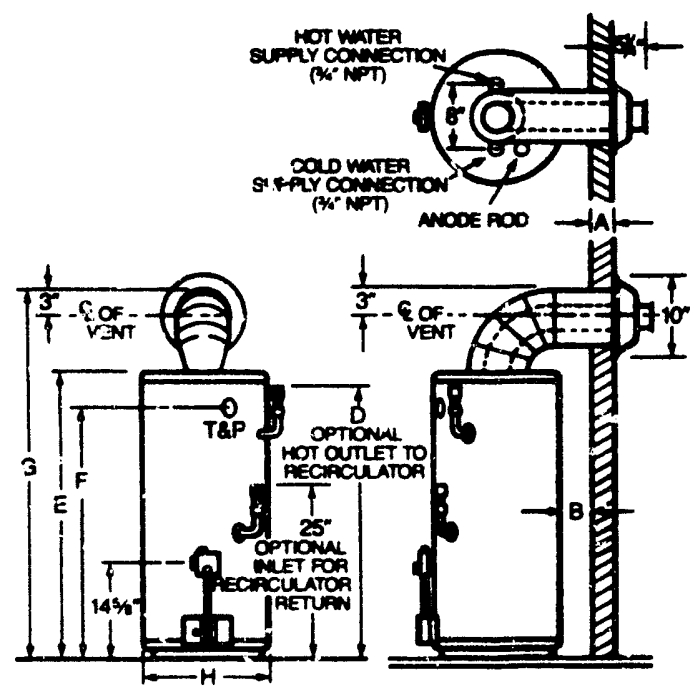

\begin{tabular}{|c|c|c|c|c|c|c|}
\hline \multirow[b]{2}{*}{ Model Number } & \multirow{2}{*}{$\begin{array}{l}\text { Cal. } \\
\text { Cap }\end{array}$} & \multicolumn{4}{|c|}{ Dimensions in Inches } & \multirow{2}{*}{$\begin{array}{l}\text { Shippling } \\
\text { Weight } \\
\text { (Lbe.) }\end{array}$} \\
\hline & & $E$ & $F$ & $H$ & D & \\
\hline A5-40-40.0NBDS & 40 & 49 & 42 & 21 & 50 & 185 \\
\hline A5-50-48.0NBDS & 50 & $61 \%$ & $541 / 4$ & 21 & $621 / 4$ & 226 \\
\hline
\end{tabular}

Dimensions shown above apply to equivalent Propane (L.P.) models.

\begin{tabular}{|c|c|c|c|}
\hline \multirow{2}{*}{$\begin{array}{l}\text { Vertical Vont } \\
\text { Extension Kit } \\
\text { Number }\end{array}$} & \multirow{2}{*}{$\begin{array}{c}\text { "A" Dimenaion } \\
\text { Maximum } \\
\text { Wall Thicknoes }\end{array}$} & \multicolumn{2}{|c|}{ "C" Dimension } \\
\hline & & Min & Max \\
\hline 9000687 (Std.) & $10^{\prime \prime}$ & $31 / 2$ & $10^{\prime \prime}$ \\
\hline 9001246 (Opt.) & $151 / 2^{\prime \prime}$ & $10^{n}$ & $151 / 2^{\prime \prime}$ \\
\hline 9001247 (Opt.) & $261 / 2^{\prime \prime}$ & $15^{1 / 2 "}$ & $261 / 2$ \\
\hline 9001248 (Opt.) & $48^{\prime \prime}$ & $261 / 2^{\prime \prime}$ & $48^{\prime \prime}$ \\
\hline
\end{tabular}

\begin{tabular}{|c|c|c|c|c|c|c|c|c|c|c|}
\hline \multirow{3}{*}{$\begin{array}{l}\text { What } \\
\text { Hoater } \\
\text { Model No. }\end{array}$} & \multirow{3}{*}{ Gal } & \multirow{3}{*}{$\mid \begin{array}{c}\text { BTUH } \\
\text { in } \\
1000 \\
\text { bet/LP }\end{array}$} & \multirow{3}{*}{$\begin{array}{c}\text { GPH } \\
\text { Recov- } \\
\text { ory } \\
100^{\circ} \\
\text { Rise }\end{array}$} & \multicolumn{7}{|c|}{$\begin{array}{l}\text { Overall Hoight of Water Heater } \\
\text { "G" Dimension }\end{array}$} \\
\hline & & & & \multirow{2}{*}{$\begin{array}{c}\mathrm{Kt} \\
5000687 \\
(\mathrm{StU} .)\end{array}$} & \multicolumn{2}{|c|}{$\begin{array}{c}\text { Kat } \\
9001246 \\
(0 p t .)\end{array}$} & \multicolumn{2}{|c|}{\begin{tabular}{c|} 
Kt \\
so01247 \\
$(0 p t)$. \\
\end{tabular}} & \multicolumn{2}{|c|}{$\begin{array}{c}\mathrm{Kt} \\
\mathbf{s 0 0 1 2 4 8} \\
\text { (Opt.) }\end{array}$} \\
\hline & & & & & Min. & $\max$. & Min. & Max. & Min. & Mox. \\
\hline $\begin{array}{l}\text { A5-40-40.0 } \\
\text { NBDS }\end{array}$ & 40 & $40 / 40$ & 36 & $633^{\prime \prime}$ & $72^{\prime \prime}$ & $77^{1 / 2 n}$ & $7^{1 / 2 \pi}$ & $881 / 2^{\prime \prime}$ & $88^{1} \mathrm{r}^{\prime \prime}$ & $110^{\prime \prime}$ \\
\hline $\begin{array}{l}\text { A5-50-48.0 } \\
\text { NBDS }\end{array}$ & 50 & $48 / 44$ & 44 & $76^{\prime \prime}$ & $841 / 4^{n}$ & $893 / 4^{\prime \prime}$ & $8934^{m}$ & $1003 / 4^{n}$ & $100 \% / 4^{n}$ & $\mid 1221 / 4$ \\
\hline
\end{tabular}

Dimensions shown above apply to equivalent Propane (L.P.) models.

\section{Wottor Hoater/Air Handlor Sizing}

The water heater should be a minimum of $\mathbf{4 0}$ gallon capacity. The water heater's input (BTUH) must equal or exceed the capacity of the air handler's heating coil, when divided by the recovery efficiency of the water heater.

The air handler's heating capability must equal or exceed the (ACCA Method J) heat loss of the structure.

Assistance in sizing can be obtained from your Apollo Distributor. In addition, the Apollo Systems Handbook which includes installation and operation information, can be found under the "Installation Information" tab of the Apollo Canalog.

In keeping with our policy of continuous product improvement we reserve the right to make changes without prior notice. 


\section{HYDROSWIRL ENERGY EFFICIENT 5050 Residential Gas Water Heater}

$80 \%$ Recovery Efficiency 55,000-BTU natural/propane (L.P.) gas input for high recovery 75 Gallon Storage Capacity

Five-year Limited Warranty on Tank and Parts

Apollo offers a gas residential water heater with $\mathbf{8 0 \%}$ recovery efficiency for low operating costs and high recovery for plenty of hot water.

Energy-efficient water heaters don't always stay energy-efficient. Deposits of lime and other sediments can accumulate on heat transfer areas of the tank, affect tank life, and gradually decrease the water heater's recovery efficiency. But the HydroSwirl Energy Efficient 5050 features a specially designed Hydro Swirl Dip Tube that creates turbulence inside the tank to help prevent harmful sediment from collecting.

\section{Check these Quality Features}

- HydroSwirt Dip Tube.

- Foamite Insulation retains heat $2 \frac{1}{2}$ times better than standard fiberglass insulation.

- Heat Traps prevent heat loss at inlet and outlet.

- Aluminized Steel Multi-Por Bumer for quiet, efficient combustion.

- Energy-Saving Pilot.

- Nylon Drain Valve eliminates electrolytic corrosion.

- Glasslined Tank for years of rust-free operation.

- Automatic Temperature Control, with four settings for plenty of hot water ot a desired temperature.

- A.G.A. Certified E.C.O. (Energy Cut-Off).

- Maximum hydrostatic working pressure is 150 psi.

- Five-year limited tank and parts warranty. Complete details on these warranties available at your nearest Apollo sales office.

- Temperature-Pressure Relief Valve.
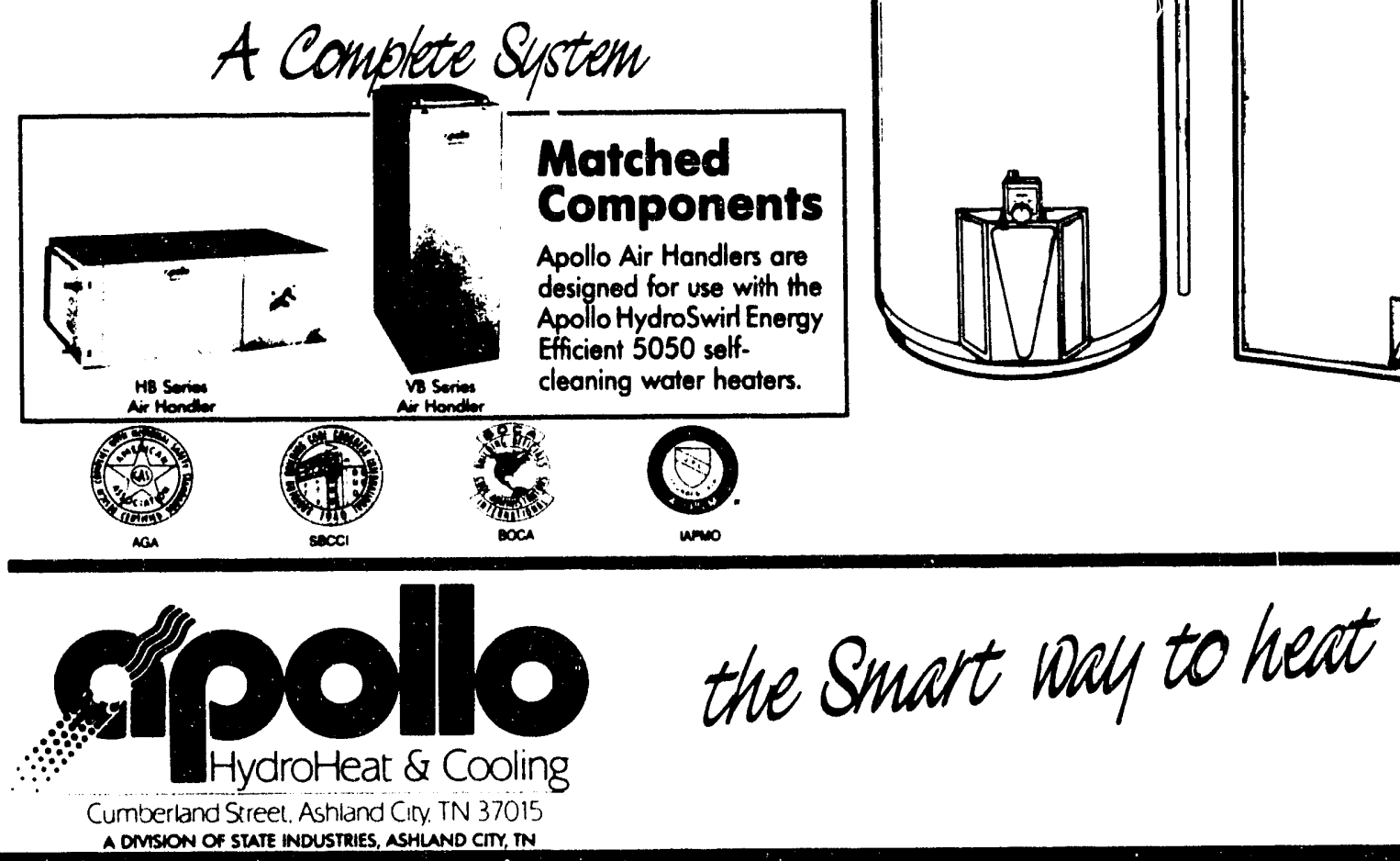

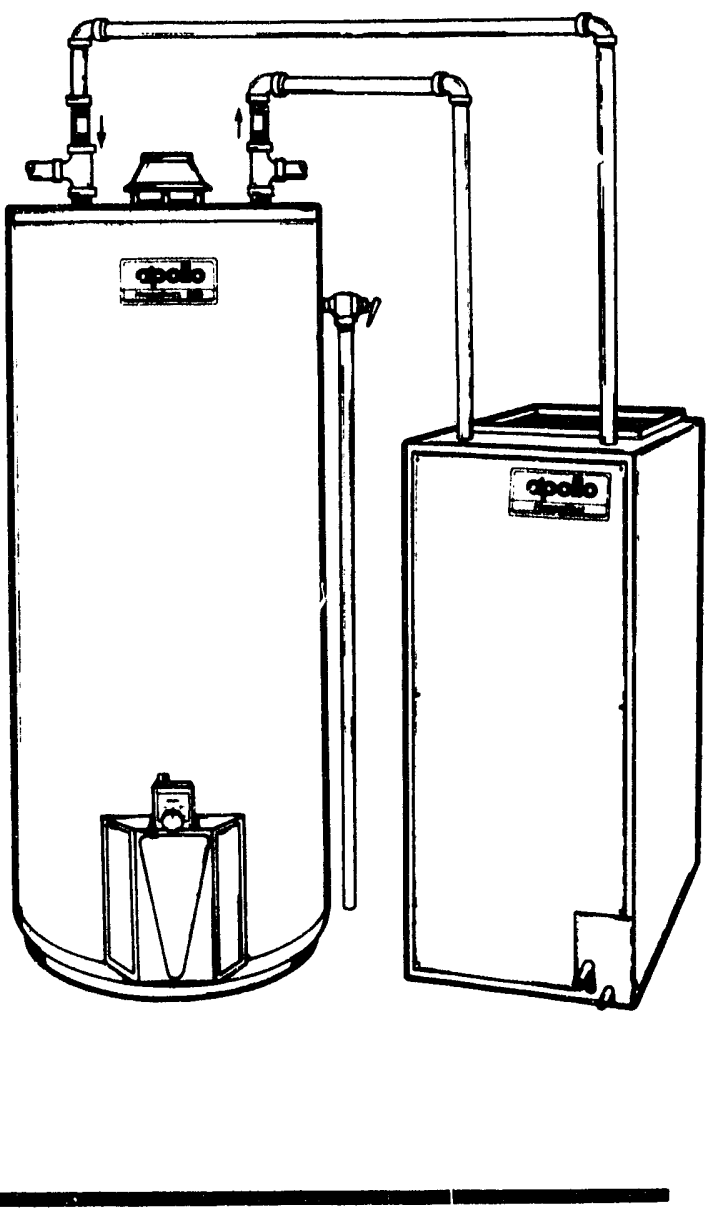




\section{Specifications}

\section{HydroSwirl Enerey Efficiont 5050 Resldential Cas Woter Hoafer}

- Lowest Operating Cost - High Rocovery

- Potented, sediment-fighting HydroSwir dip tube

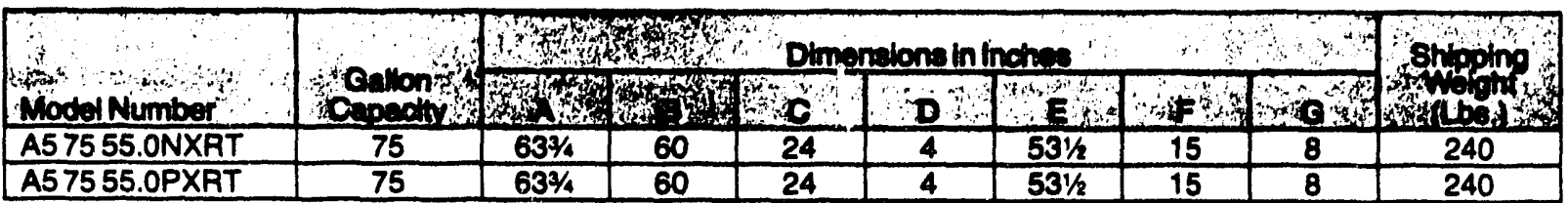

\begin{tabular}{|c|c|c|c|c|c|c|c|c|c|}
\hline $\begin{array}{l}\text { Model Number } \\
\text { Nor }\end{array}$ & $\begin{array}{l}\text { Callon } \\
\text { Cepactu }\end{array}$ & 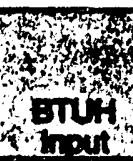 & 40 & $80^{\circ}$ & 600 & Fin: & Rocouns & 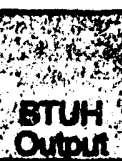 & 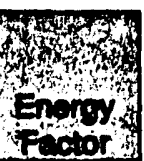 \\
\hline A57555.0NXAT & 75 & 55,000 & 53 & 59 & 89 & 109 & $80 \%$ & 44,000 & .49 \\
\hline A5 7555.0PXRT & 75 & 55,000 & 53 & 59 & 89 & 109 & $80 \%$ & 44,000 & .49 \\
\hline
\end{tabular}

Recoveries are rounded to nearest gallon.

\section{Wofer Hootor/Air Hondlor Sizing}

The water heater's input (BTUH) must equal or exceed the capacity of the air handler's heating coil, when divided by the recovery efficiency of the water heoter. The air handler's heating capability must equal or exceed the (ACCA Method J) heat loss of the structure.

Assistance in sizing can be obtained from your Apollo Distributor. In addition, the Apollo Systems Handbook which includes installation and operation information, can be found under the "Inatallation Information" tab of the Apollo Catalog.

In keeping with our policy of continuous product improvement we reserve the right to make changes without prior notice.

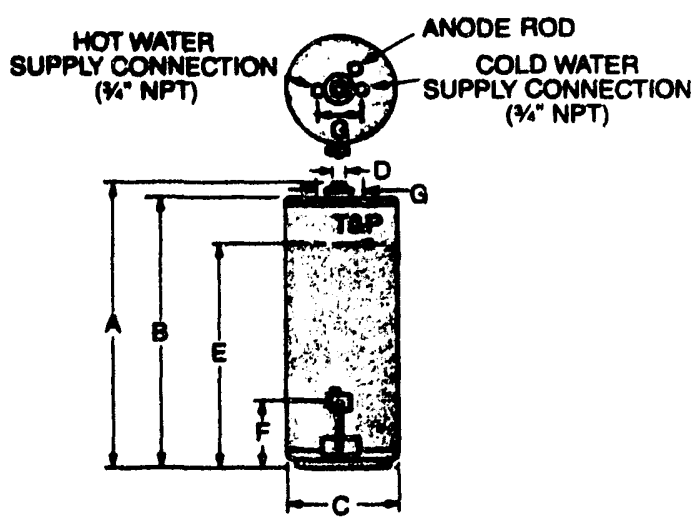

\section{Hydroswit dip tobe makes sure thet tho monoy-soving porformence lastal}

The HydroSwirt is equipped with the exclusive, potented Hydroswirl dip wbe. If creates a "vortex" of furbulence inside the tank, which prevents sadiment accumulation. In ordinary woter heaters, lime and their sediments can occumulate on heat transfer areas, offect tank life, and decrease the woter heoter's efficiency. But HydroSwirl water heaters clean themselves, so they're energy efficient and stery that woyl. No exther eas wetter heater saves homeow. ners this much on operofing costal The Energy Guide labol found on all woter heaters tells consumers how much it costs to heat water. And the HydroSwit label tells a powerful sory. Homeowners can seve more money on operating cost with the HydroSwirt over the life of the woter heoter, compared to less efficient models. HydroSwir has the lowest operating cost of any gas water heoter madel 
Compared to a standard fiberglass insulated water heater of the same capacity, the Oil-Fired 5010 models furnish more hot water per hour and offer $76 \%$ recovery efficiency.

Apollo Hydro Heat offers this Oil-Fired 5010 oil water heater for any system requiring the addition of recirculating hot water loop. All models are shipped with depneumatic assembly in carton.

Energy-efficient water heaters don't always stay energy-efficient. Deposits of lime and other sediments can accumuiate on heat transfer areas of the tonk, affect tank life, and gradually decrease the water heater's recovery efficiency. But the Oll-Fingd 5010 features a specially designed HydroSwirl Dip Tube that creates turbulence inside the tank to help prevent harmful sediment from collecting.

\section{Check these Quality Features}

- HydroSwirl Dip Tube.

- Foam Insulation rotains heat $2 \frac{1}{2}$ times better than standard fiberglass insulation.

- Glasslined Tank for years of rust-free operation.

- Automatic Temperature Control, with four settings for plenty of hot water at a desired temperature.

- Zinc-Coated Plasticert Nipples reduce electrolytic action.

- Maximum hydrostatic working pressure is 150 psi.

- Five-year limited warronty on tank and two-year limited warranty on parts. Complete details on these warranties available at your nearest Apollo sales office.

- Temperature-Pressure Relief Valve.

- Fuel unit single stage standard, two stage optional.

- Electrical requirement-115 volts/60 cycles/single phase, total load 12 amps or loss.

- Brass Drain Volve.

- Combustion chamber-one piece of light weight refractory.

- Hand hole cloanout.

- Primary safety controt-cadmium cell for flame detection.

- U.L. listed bumer designed to fire at 0.65 gallons of oil per hour.
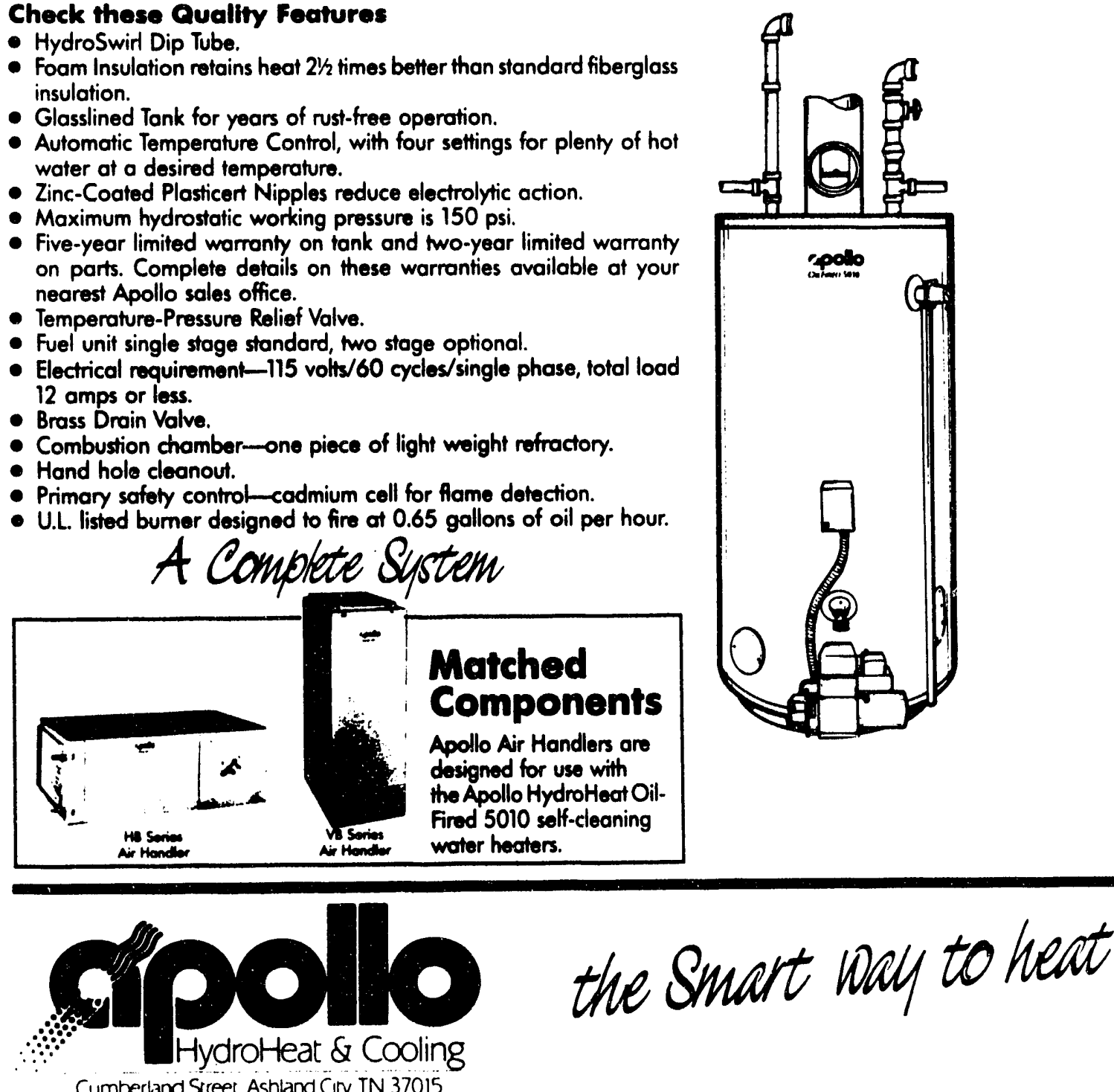

Cumberland Sreet. Ashiand Ciry. TN 37015 A DIMSION OF STATE WDUSTRES, ASH AND CIT, IN 


\section{Specifications}

\section{Oll-Fired 5010 Residential Oll-Fired Water Hoater with Foam Insulation}

\begin{tabular}{|c|c|c|c|c|c|c|c|c|c|c|c|c|c|}
\hline \multirow{2}{*}{$\begin{array}{l}9 \mathrm{P} \\
\text { Moded }\end{array}$} & \multirow{2}{*}{$\begin{array}{l}\text { Firing } \\
\text { Rate } \\
\text { to.p.h. }\end{array}$} & \multirow{2}{*}{$\begin{array}{l}\text { Tank: } \\
\text { Storege }\end{array}$} & \multirow{2}{*}{$\begin{array}{c}\text { Recovery } \\
\text { input } \\
\text { BTU/hr. }\end{array}$} & \multirow{2}{*}{$\begin{array}{l}\text { First } \\
\text { Hour } \\
\text { Pating }\end{array}$} & \multirow{2}{*}{$\begin{array}{c}\text { Rate } \\
100^{\circ} \text { Rise }\end{array}$} & \multirow{2}{*}{$\begin{array}{l}\text { Shipping } \\
\text { Woight }\end{array}$} & \multicolumn{5}{|c|}{ Dimensions in Incties } & & \\
\hline & & & & & & & A & B & C & D & $E$ & Paruired & \\
\hline A5-40. & 0.65 & 40 & 90,000 & 125 & 83 & 195 & $557 / 8$ & $507 / 10$ & 20 & $22 \%$ & 5 & $\begin{array}{l}115 \mathrm{~V} \\
60 \mathrm{CY} \\
1 \mathrm{PHJ}\end{array}$ & 4. \\
\hline
\end{tabular}

150 lbs. Hydrostatic working pressure.

UL listed burner shipped unattached.

\section{Hydroswirl dip tube makes sure thet the money-saving porformance lastsl}

The HydroSwit is equipped with the exclusive, patented Hydroswirl dip fube. It creates a "vortex" of turbulence inside the tank, which prevents sediment accumulation. In ordinary water heaters, lime and their sediments can accumulate on heat transfer areas, affect tank life, and decrease the water heater's efficiency. But HydroSwirl water heaters clean themselves, so they're energy efficient and stay that wayl. No other oll werter hearor soves homeowners this much on operating costs/ The Energy Guide label found on all water heaters tells consumers how much it costs to heat water. And the HydroSwirt label tells a powerful story. Homeowners can save more money on operating cost with the HydroSwit over the life of the water heater, compared to less efficient models. HydroSwirl has the lowest operating cost of any oil water heater madel

\section{Woter Hector/Air Hondler Sizing}

The water heater should be a minimum of 40 gallon capacity. The water heater's input (BTUH) must equal or exceed the capacity of the air handler's heating coil, when divided by the recovery efficiency of the water heater.

The air handler's heating capability must equal or exceed the (ACCA Method J) heat loss of the structure.

Assistance in sizing can be obtained from your Apollo Distributor. In addition, the Apollo Systems Handbook which includes installation and operation information, can be found under the "Installation Information" tab of the Apollo Catalog.

In keeping with our policy of continuous product improvement we reserve the right to make changes without prior notice.

\section{Barometric Droft Regulator}

Since chimneys natural draft can vary greatly, a barometric draft regulator must be installed whenever the chimney height is over 8 feet vertical. The function of the draft regulator is to maintain a stable or fixed draff to the water heater within the limits of available draft of the chimney. This allows the oil burner air shutters to be set for maximum combustion efficiency consistent with clean burning of the oil. The 5 inch draft regulator is for use on the 5 inch flue, 40 gallon short residential or SBT 40-90 OESF commercial oil-fired water heater only. Larger draft regulators, suitable for the other commercial oilfired water heaters, can be obtained.

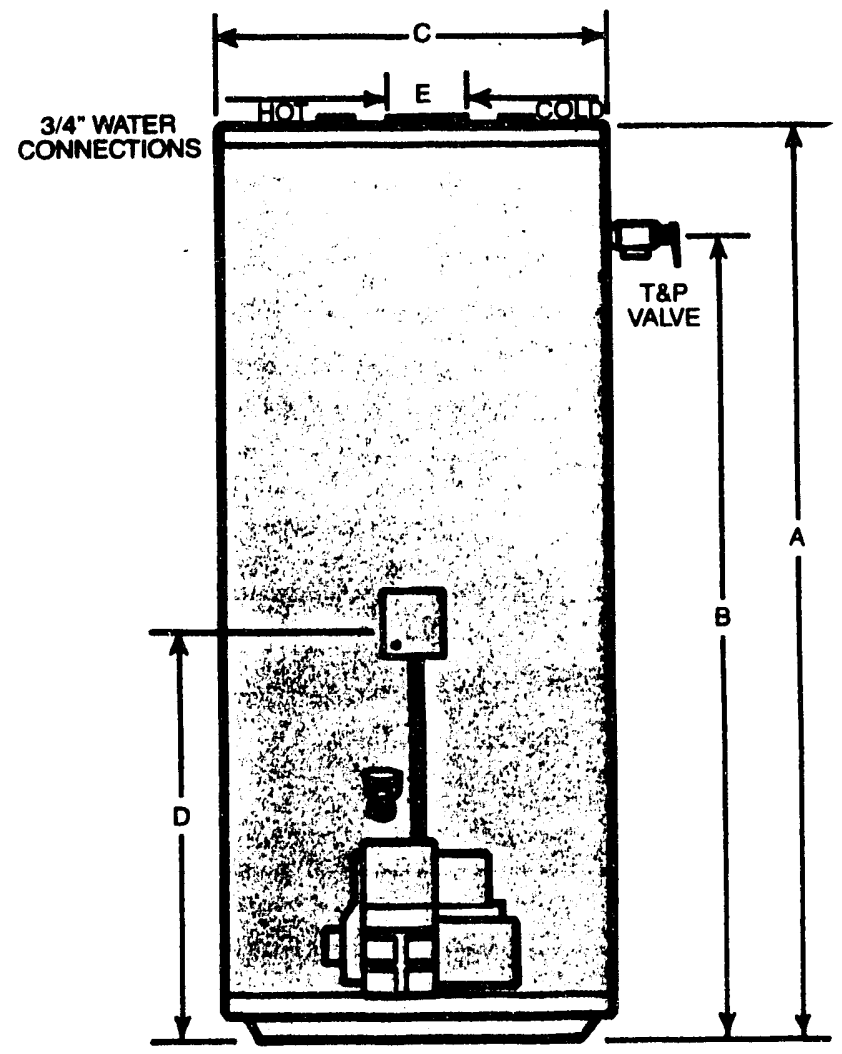

OF-12-4-90 

with Foam Insulation

100 Gallon Storage Capacity Natural and Propane (L.P.) Gas Input BTU/Hr: 83,000 BTU Natural, 77,000 BTU Propane (L.P.) Gas Five-year Limited Warranty on Tank and One-year on Parts Compared to a standard fiberglass insulated water heater of the same capacity, the HydroHeat 5010 models furnish more hot water per hour and offer $76 \%$ recovery efficiency.

\section{Check these Quality Features}

- Competitively Priced

- Foam Insulation retains heat $2 \frac{1}{2}$ times better than standard fiberglass insulation.

- Aluminized Steel Multi-Port Burner for quiet, efficient combustion.

- Energy-Soving Pilot.

- Nyton Drain Valve eliminates electrolytic corrosion.

- Glasslined Tank for years of rust-free operation.

- Automatic Temperature Control, with four settings for plenty of hot water at a desired temperature.

- A.G.A. Design Certified E.C.O. (Energy Cut-Off).

- Maximum hydrostatic working pressure is 150 psi.

- Five-year limited tank warranty. Complete details on these warranties available at your nearest Apollo sales office.

- Temperature-Pressure Relief Valve.
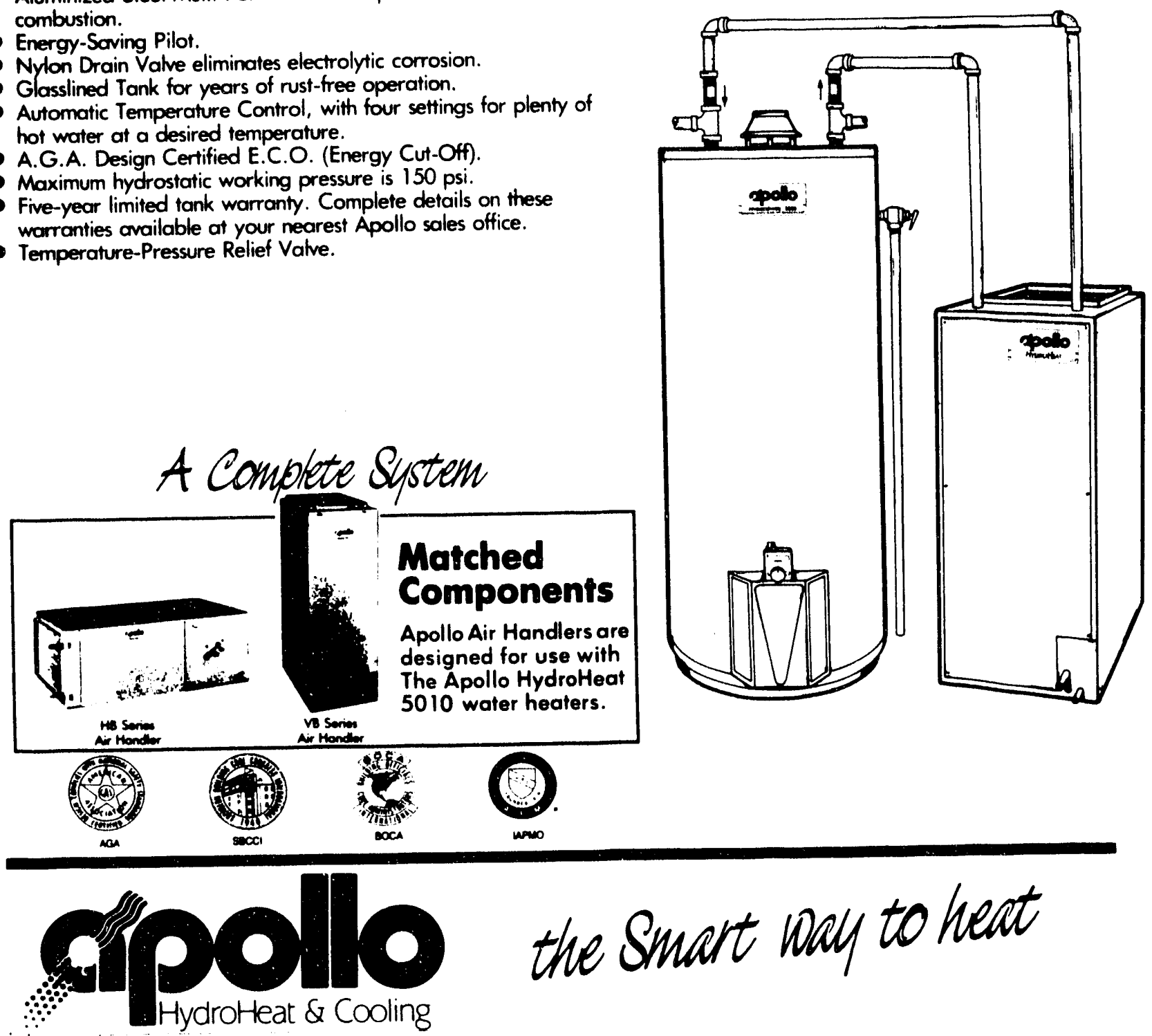

Cumberlana Srreec. Ashland Ciry IN 37015

A DMISION OF STATE INDUSTRIES, ASHLAND CITY. IN 


\section{Specifications}

\section{HydroHoat 5010 Residential Gas Water Heater with foam Insulation}

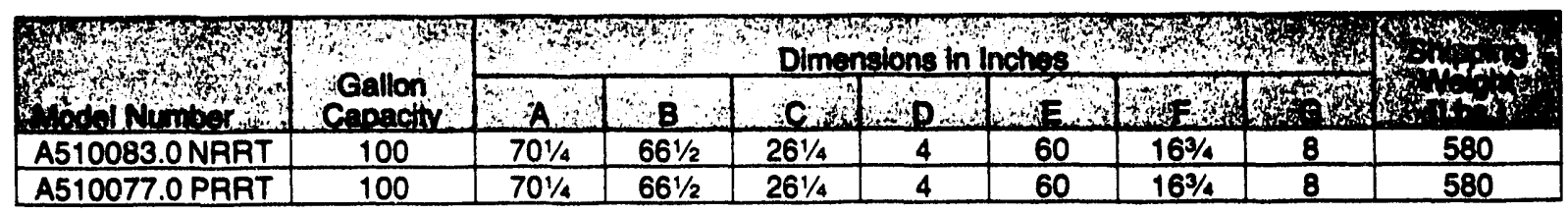

\begin{tabular}{|c|c|c|c|c|c|c|c|}
\hline $\begin{array}{l}3 \\
3 \\
3\end{array}$ & कीons & 4 & ond & & & & 4 \\
\hline 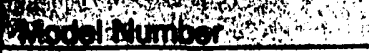 & Copacty & & $100^{\circ}$ & $-\pi 00^{\circ}$ & & & \\
\hline A510083.0 NRRT & 100 & 83,000 & 76 & 85 & 127 & $76 \%$ & 63,080 \\
\hline A510077.0 PRRT & 100 & 77,000 & 69 & 77 & 115 & $76 \%$ & 58,520 \\
\hline
\end{tabular}

\section{Wator Hoctorlair Handler Sizing}

The water heater should be a minimum of $\mathbf{4 0}$ gallon capacity. The water heoter's input (BTUH) must equal or exceed the capacity of the air handler's heating coil, when divided by the recovery efficiency of the water hooter.

The air handler's heating capability must equal or exceed the (ACCA Method J) heat loss of the structure.

Assistance in sizing can be obtained from your Apollo Distributor. In oddition, the Apollo Systems Handbook which includes installation and operation information, can be found under the "Installation Information" tab of the Apollo Catalog.

In keeping with our policy of continuous product improvement we reserve the right to make changes without prior notice.

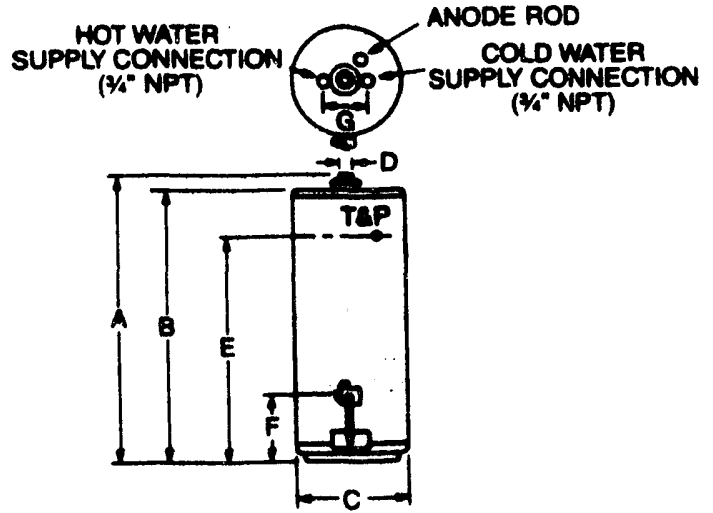




\section{HYDROHEAT Mutheries Heating gany}

The M Series is the most economical answer to the builder's needs for heating. Compact design and aifflow capabilities for $21 / 2$ and 3 ton cooling systems make the M Series ideal for the replacement market. This superior new heating system has fewer parts than any other heating system, making it virtually maintenance free.

\section{Check these Quality Features}

- Heating coils with copper tubes and aluminum fins.

- Circulator pump with stainless steel or plastic impeller and bronze housing. Front mounted for ease of access.

- Pump relay and blower relay.

- Two speed direct drive blower/motor assembly.

- 115/24 volt transformer

- Painted, insulated zinc coated steel cabinet (one piece wraparound).

- Copper sweat connections for heating coil.

- Service/isolation valves for pump.

- Reusable ${ }^{r}$. $r$

- Ten-yen .red Warranty on Heating Coil.

- One. Limited Warranty on Parts.

- All mociels are listed under one or more of the organizations shown below.

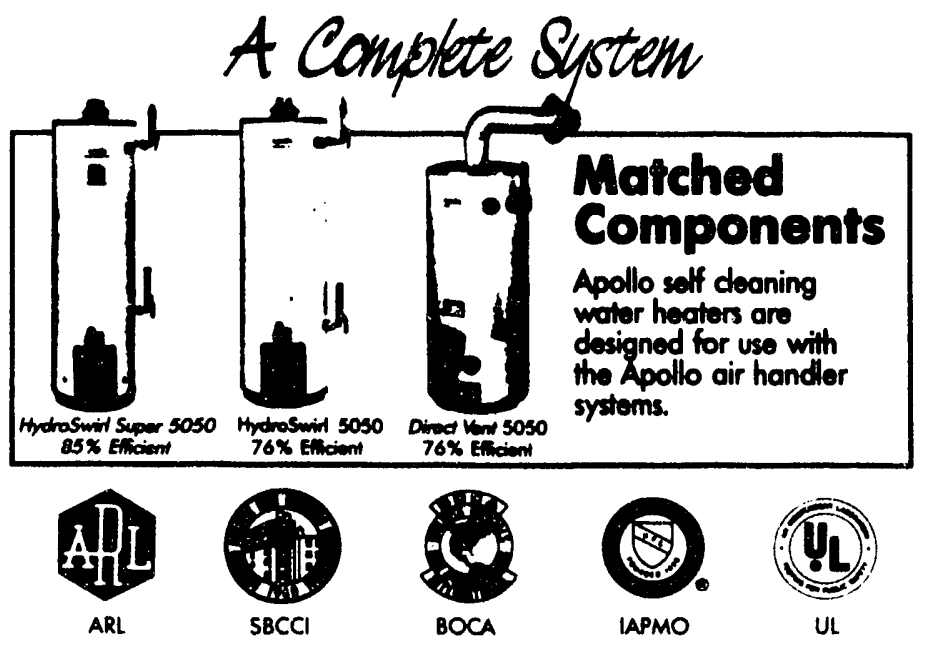

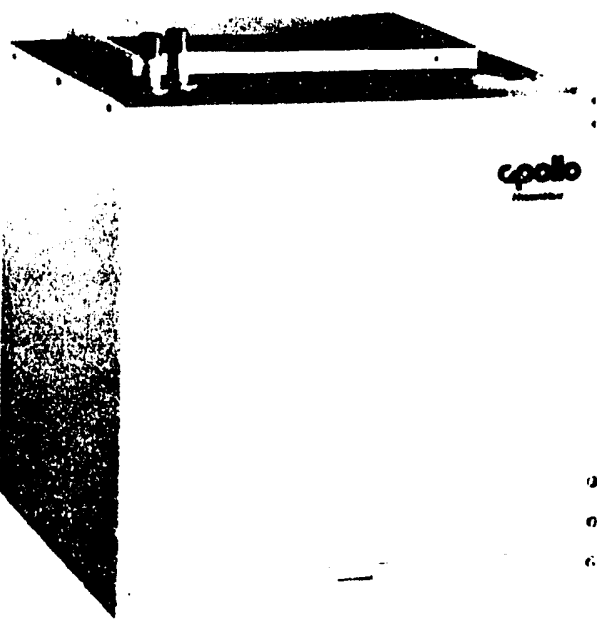

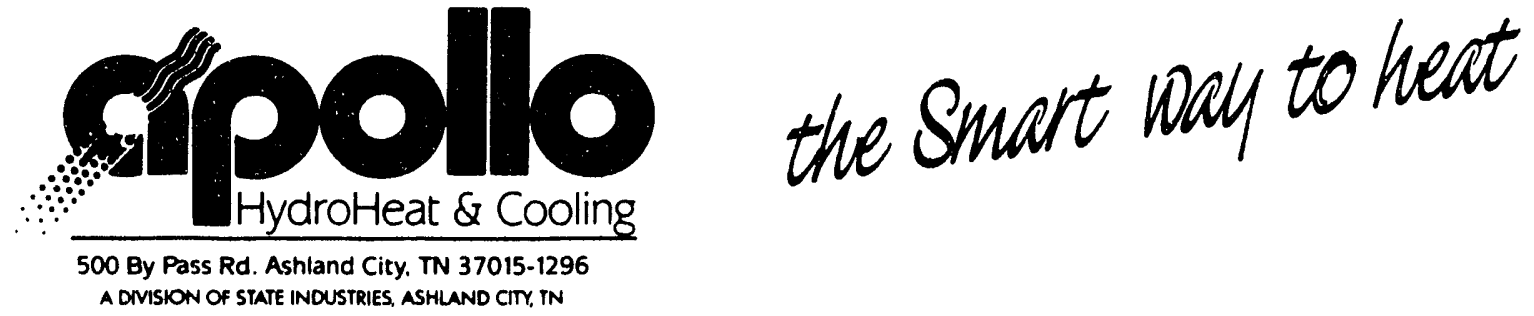




\section{Specifications}

\begin{tabular}{|c|c|c|c|c|c|c|c|c|c|c|c|}
\hline Model & $\begin{array}{l}\text { Nom. Ho. } \\
\text { Cop. } \\
\text { BTUH' }\end{array}$ & $\begin{array}{l}\text { Nom. } \\
\text { CFM }\end{array}$ & $\begin{array}{l}\text { Blower } \\
\text { Motor } \\
\text { HP }\end{array}$ & $\begin{array}{l}\text { Pump } \\
\text { Motor } \\
\text { HP }\end{array}$ & $\begin{array}{l}\text { Elec. } \\
\text { Chor. }\end{array}$ & $\begin{array}{l}\text { Rotud } \\
\text { Anps }\end{array}$ & $\begin{array}{c}\text { Min. } \\
\text { Circuit } \\
\text { Anpocity }\end{array}$ & $\begin{array}{l}\text { Wotor } \\
\text { Conn. } \\
\text { l.D. }\end{array}$ & $\begin{array}{l}\text { Supply } \\
\text { Conn. }\end{array}$ & $\begin{array}{c}\text { Rewim } \\
\text { Opening }\end{array}$ & Ship \\
\hline$M-45-H$ & 45,000 & 1200 & $1 / 3$ & $1 / 20$ & $1-60.115 \mathrm{~V}$ & 6.5 & 15 & $3 / 4$ & $12 \times 16$ & $18.5 \times 9$ & 75 \\
\hline
\end{tabular}

3 GPM NOM. CFM. $65^{\circ} \mathrm{F}$ Entering Air Temperature

CFM vs STATIC

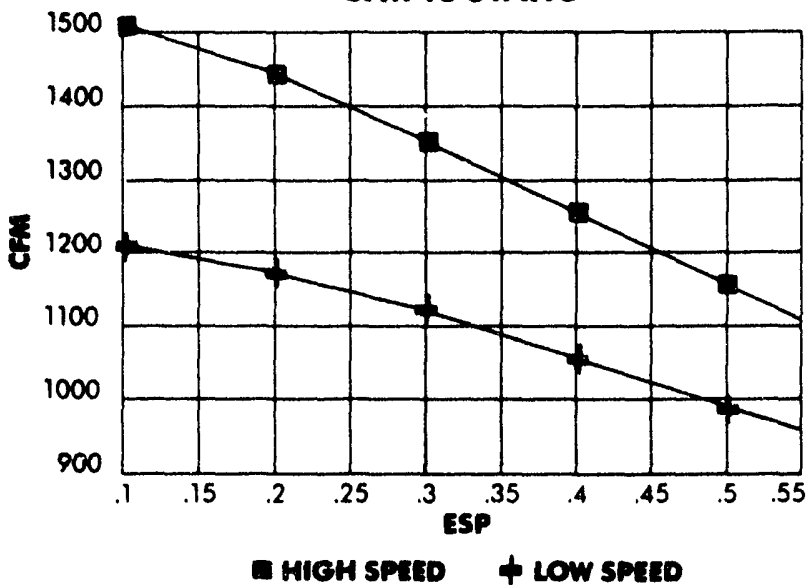

How Does The Apollo Air Handlor Work?

The HydroHeat Air Handler is connected to a conventional heating or heating/cooling thermostat. When the thermostat calls for heat, the circulating pump in the air handler begins circulating the warm water from the water heater through the finned tube heating coil of the air handler. The air handler's blower has also been activated and the air passing over the heating coil is heated and blown into the home through the duct system. When the thermostat is satisfied, the pump and blower both stop.

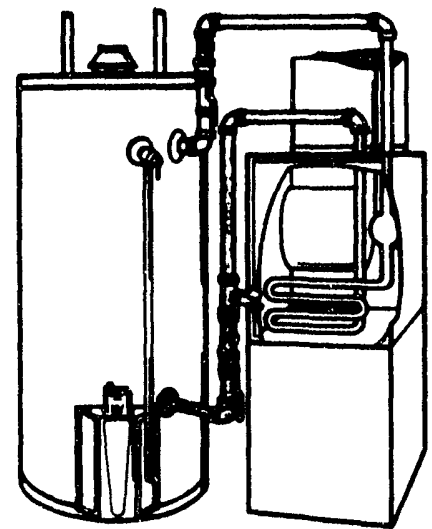

CAPACITY vs CFM vS EWT

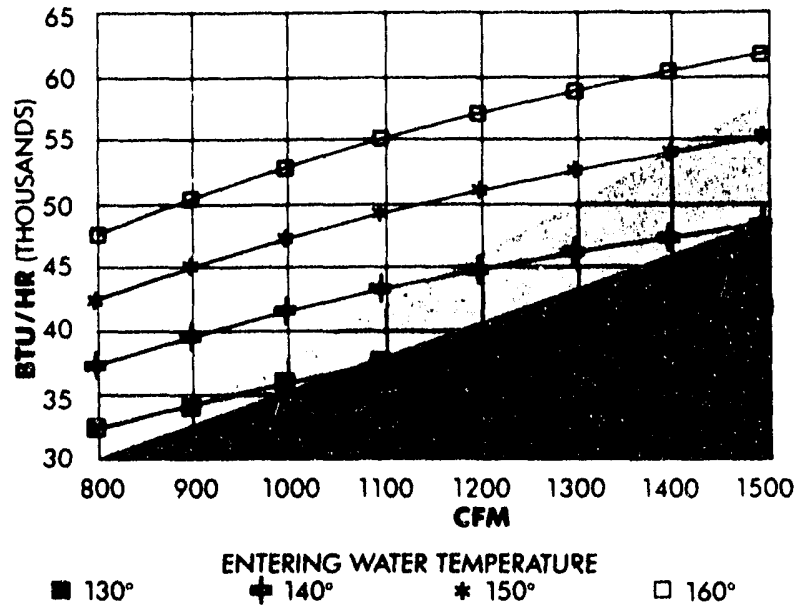

Systems that operate in the lighlly shadod area will have temperature nises of $30^{\circ}-35^{\circ} \mathrm{F}$

Operation in the dark gray area will result in a temperature rise of less than $30^{\circ} \mathrm{F}$.

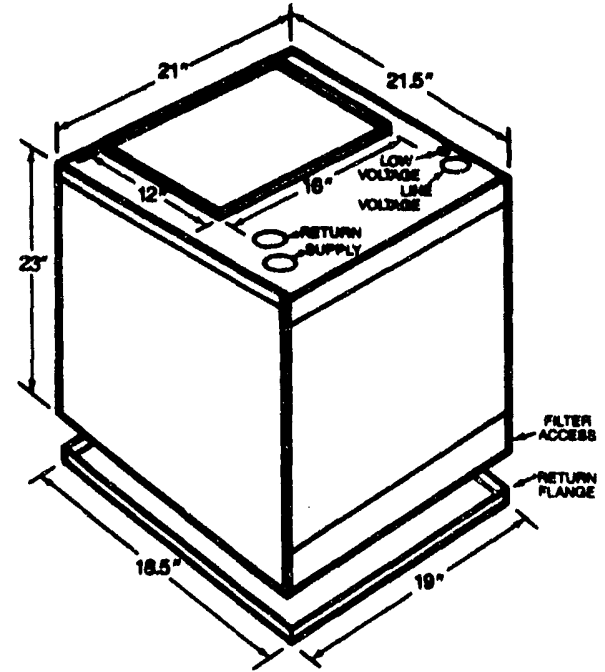

In keeping with our policy of continuous product improvement we reserve the right to make changes without prior notice.

\section{Air Handlor/Wator Hoator Sizing}

The air handler's heating capability must equal or exceed the (ACCA Method J) heat loss of the structure.

The water heater should be a minimum of $\mathbf{4 0}$ gallon capacity. The water heater's input (BTUH) must equal or exceed the capacity of the air handler's heating coil, when divided by the recovery efficiency of the water heater.

Assistance in sizing can be obtained from your Apollo Distributor. In addition, the Apollo Systems Handbook which includes installation and operation information, can be found under the "Installation Information" tab of the Apollo Catalog.

Form M46-18/1190

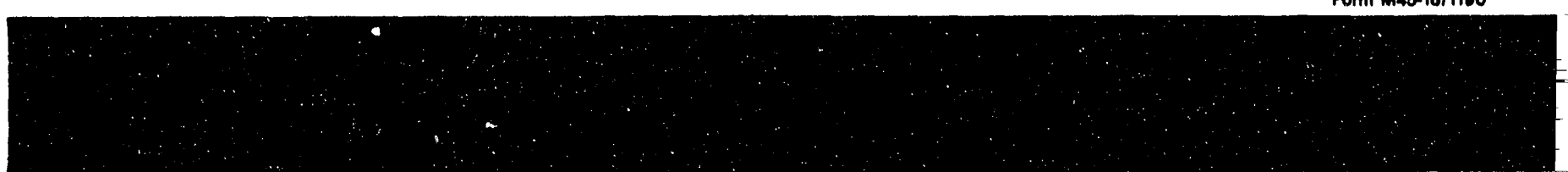




\section{HYDROHEAT a Series Multi-Position Heating Systems}

\section{Upflow, Horizontal \\ Heating Capacities 42,000-46,000 BTUH Cooling Capacities 30,000-48,000 BTUH}

The M Series is the most economical answer to the builder's needs for heating, with cooling coils available. This superior new heating system has one-third as many parts as a heat pump, making it virtually maintenance free. It is designed and tailored with heating and cooling capacities to fit from single family homes up to the multi-family market.

Check these Quality Foatures

- Heating coils with copper tubes and aluminum fins.

- Circulator pump with stainless steel or plastic impeller and bronze housing. Front mounted for ease of access.

- Pump relay and blower relay.

- Multi-speed direct drive blower/motor assembly.

- 115/24 volt transformer

- Painted, insulated zinc coated steel cabinet (one piece wraparound).

- Copper sweat connections for heating coil, cooling coil.

- Service/isolation valves for pump.

- Ten-year Limited Warranty on Heating Coil.

- Five-year Limitad Warranty on Evaporator Coil.

- One-year Limited Warranty on Parts.

- All models are listed under one or more of the organizations shown below.
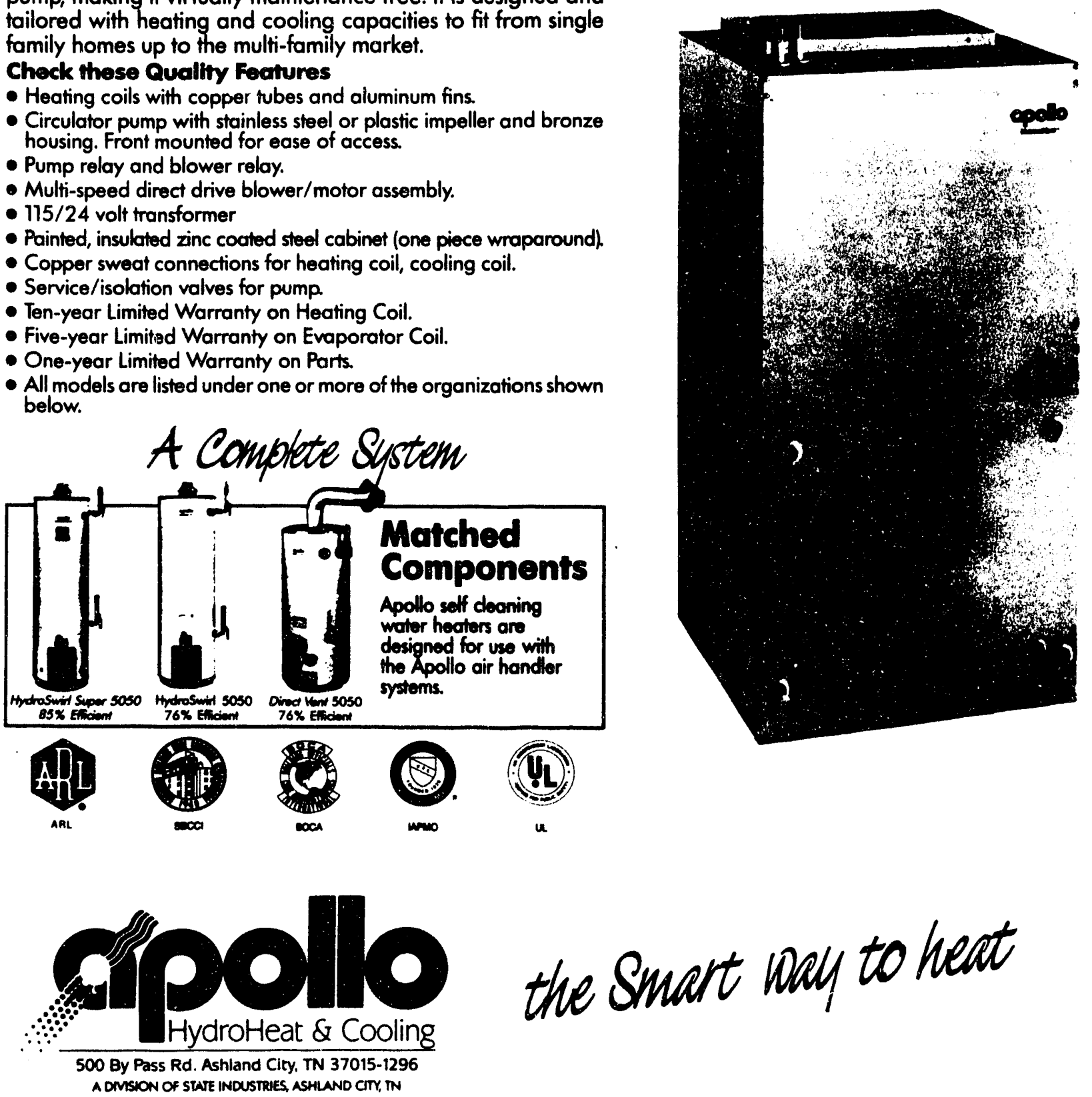


\section{Specifications}

\begin{tabular}{|c|c|c|c|c|c|c|c|c|c|c|c|c|c|c|}
\hline & & nool & & romer & Punpe & & & Choin & $\rightarrow$ & & & & & \\
\hline$M-42-2.5$ & 42,000 & 30,000 & 1000 & $1 / 3$ & $1 / 20$ & $1.60 .115 \mathrm{~V}$ & 6.5 & 15 & $3 / 4$ & $3 / 4$ & $\%$ & $12 \times 16$ & $18.5 \times 19$ & 115 \\
\hline$M-45-3.0$ & 45,000 & 36,000 & 1200 & $1 / 3$ & $1 / 20$ & $1.60-115 \mathrm{~V}$ & 6.5 & 15 & $3 / 4$ & 3 & $7 / 6$ & $12 \times 16$ & $18.5 \times 19$ & 120 \\
\hline$M-46-4.0$ & 46,000 & 48,000 & 1600 & $1 / 2$ & $1 / 20$ & $1.60-115 \mathrm{~V}$ & 7.9 & 15 & $3 / 4$ & 3 & $7 \%$ & $12 \times 16$ & $18.5 \times 19$ & 135 \\
\hline
\end{tabular}

\begin{tabular}{|c|c|c|c|c|}
\hline$=0$ & $480 \times$ & torant on & Acor. & $180 \%$ \\
\hline$=x_{2}$ & ath & $4 \times b^{2}=1$ & 14 & \\
\hline$M-42-2.5$ & 6000 & Ganoo & 47,330 & 53,090 \\
\hline$M-45-3.0$ & $(5,3,600 \div 1$ & toinseon is & 50,930 & 57.150 \\
\hline$M-46-4.0$ & $y=0,000$ & 240,000 A & 52,500 & 59,000 \\
\hline
\end{tabular}

- 3 GPM, Nom. CFM, 65 F entering shaded area indicates recommended wabi heater temperature range

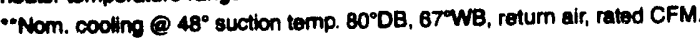

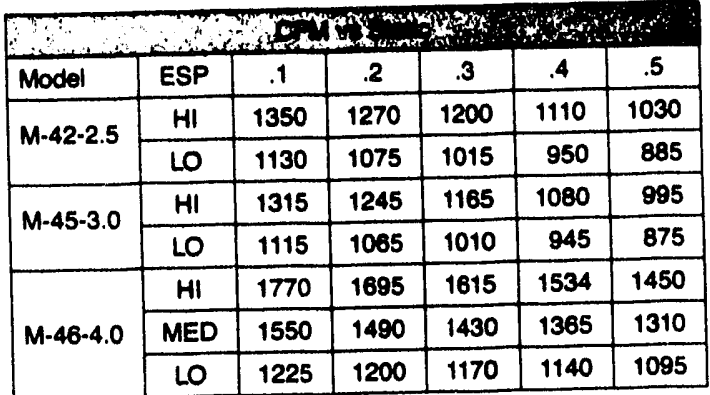

\section{How Does The Apollo Air Handler Work?}

The HydroHeat Air Handler is connected to a conventional heating or heating/cooling thermostat. When the thermostat calls for heat, the circulating pump in the air handler begins circulating the warm water from the water heater through the finned tube heating coil of the air handler. The air handler's blower has also been activated and the air passing over the heating coil is heated and blown into the home through the duct system. When the thermostat is satisfied, the pump and blower both stop.
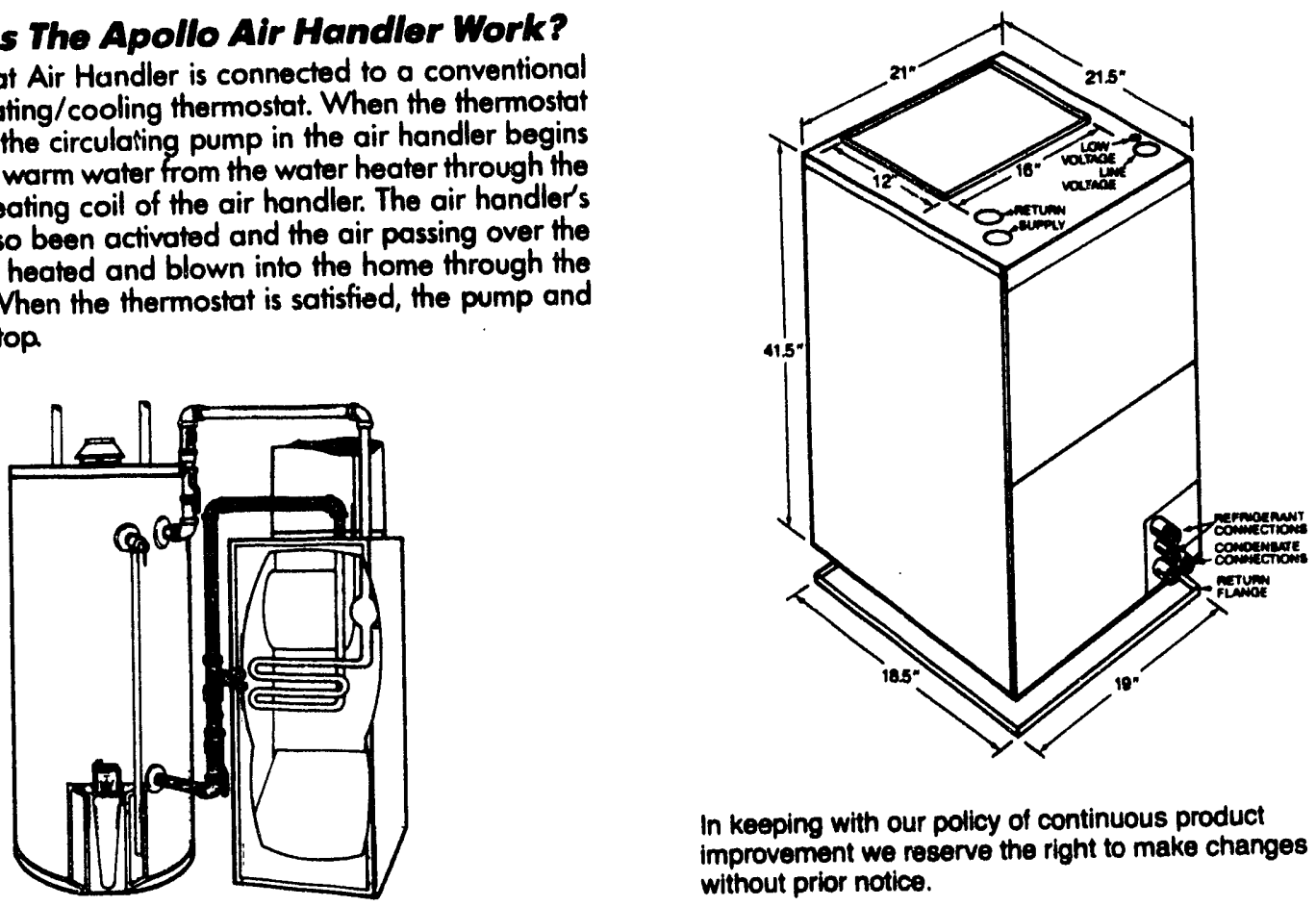

In keeping with our policy of continuous product improvement we reserve the right to make changes without prior notice.

\section{Air Handlor/Wafor hloator Sizing}

The air handler's heating capability must equal or exceed the (ACCA Method J) heat loss of the structure.

The water heater should be a minimum of $\mathbf{4 0}$ gallon capacity. The water heater's input (BTUH) must equal or exceed the capacity of the air handler's heating coil, when divided by the recovery efficiency of the water heater. Assistance in sizing can be obtained from your Apollo Distributor. In addition, the Apollo Systems Handbook which includes installation and operation information, can be found under the "Installation Information" tab of the which includes insto

Form M-17-1090

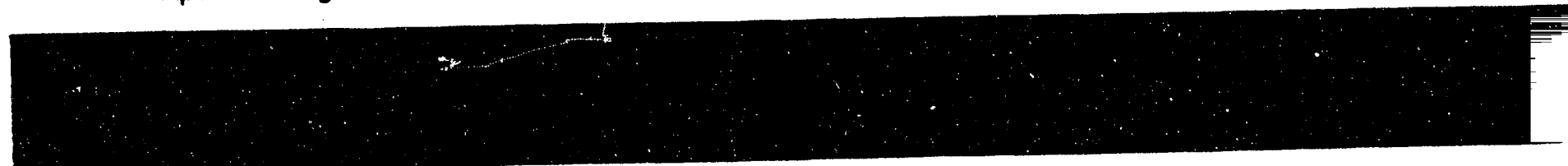




\section{HYDROHEAT VB Series Vertical-Posifion Heating Systems}

\section{Vertical-Upfiow unit Heating Capacities 20,000 through 30,000 BTUH Evaporator (Cooling Coil) Avallable in 1, 11/2 or 2 Ton Capacities}

The VB Series is the most economical answer to the builder's needs for heating, with cooling coils available. This superior new heating system has one-third as many parts as a heat pump, making it virtually maintenance free. It is designed and tailored with heating and cooling capacities to fit from single family homes up to the multi-family market.

\section{Check these Quality Features}

- Heating coils with copper tubes and aluminum fins.

- Circulator pump with stainless steel or plastic impelier and bronze housing. Front mounted for ease of access.

- Pump relay and blower relay.

- Two speed direct drive blower/motor assembly.

- 115/24 volt transformer

- Painted, insulated zinc coated steel cabinet (one piece wraparound).

- Copper sweat connections for heating coil, cooling coil.

- Service/isolation valves for pump.

- I" throwoway type air filter.

- Ten-year Limited Warranty on Heating Coil.

- Five-year Limited Warranty on Evaporator Coil.

- One-year Limited Warranty on Parts.

- All models are listed under one or more of the organizations shown below.
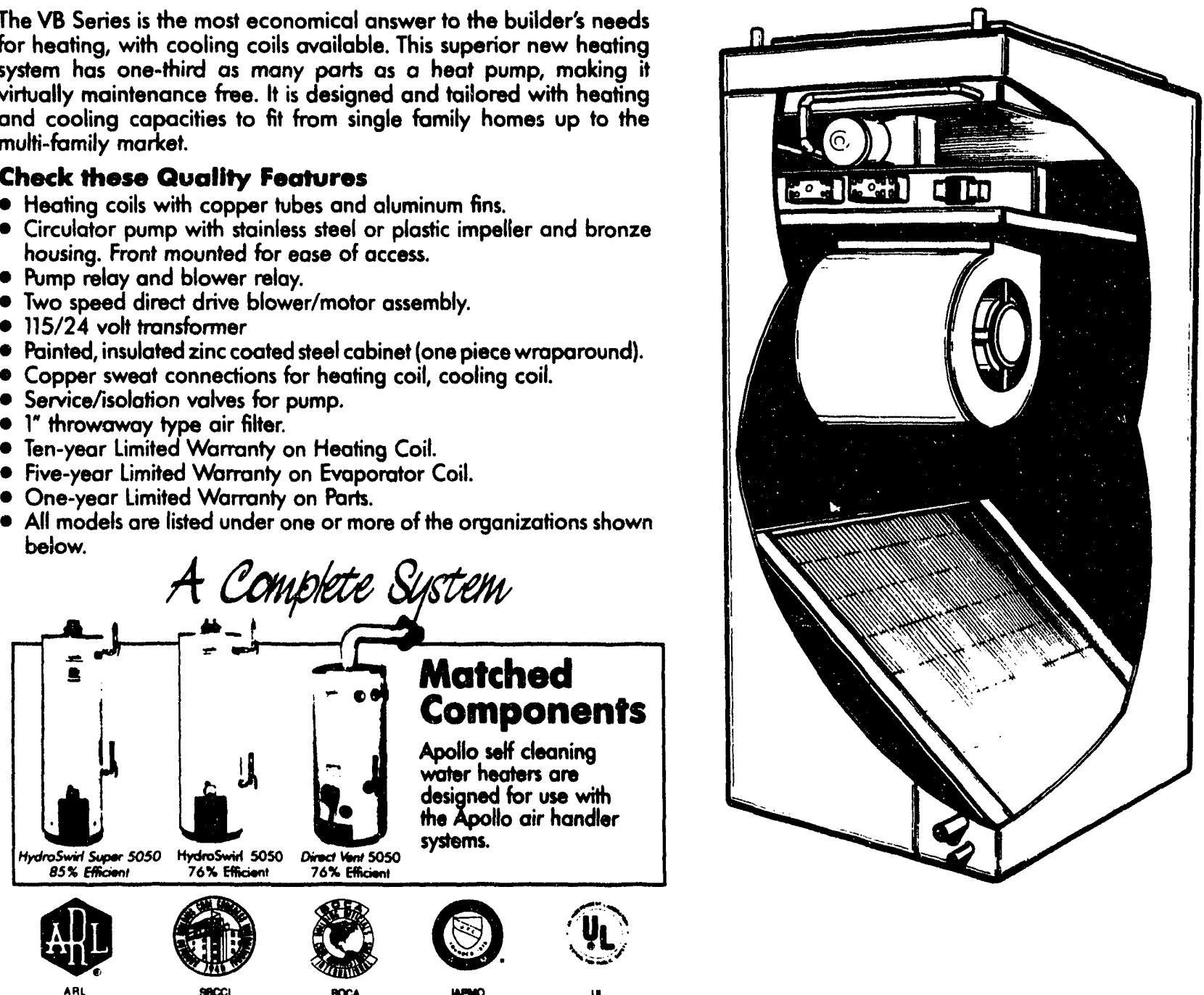

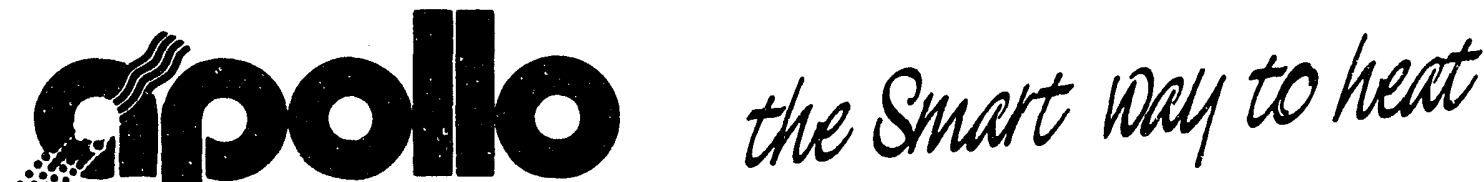

HydroHeat \& Cooling

Cumberland Sireet. Ashland City. TN 37015

A DNSLON OF STATE INDUSTRIES, ASHLAND CITY, IN 


\section{Specifications}

\begin{tabular}{|c|c|c|c|c|c|c|c|c|c|c|c|c|c|c|}
\hline imain & 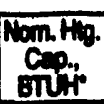 & $\begin{array}{c}\text { Tom. Cool } \\
\text { Cip.i. } \\
\text { Bit. }\end{array}$ & $\underset{\mathrm{Com}}{\mathrm{Nom}}$ & $\begin{array}{l}\text { Blawer } \\
\text { Motor } \\
\text { he }\end{array}$ & $\begin{array}{c}\text { Pump } \\
\text { molox } \\
\text { hip }\end{array}$ & $\begin{array}{l}\text { Exc. } \\
\text { Che. } \\
\end{array}$ & $\begin{array}{l}\text { Pind } \\
\text { Antes }\end{array}$ & 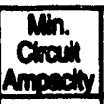 & $\begin{array}{l}\text { Wom } \\
\text { Com } \\
\text { L.D. } \\
\end{array}$ & $\begin{array}{l}.22 \\
0.0 . \\
u \Omega \\
\end{array}$ & $\begin{array}{c}\text { Supply } \\
\text { Com. }\end{array}$ & $\begin{array}{l}\text { Potum } \\
\text { Oponithe }\end{array}$ & $\begin{array}{l}F_{1}=x \\
\text { Ston } \\
\end{array}$ & $\begin{array}{l}\text { ship. } \\
\text { whine }\end{array}$ \\
\hline V82012-1 & 20,000 & 12,000 & 425 & $1 / 5$ & $1 / 20$ & $160-115 v$ & 2.5 & 15 & $1 / 2$ & $1 / / k^{\prime \prime}$ & $12 W \times 170$ & $91 / 2 \times 19^{\circ}$ & $14^{\prime \prime} \times 20^{\prime \prime} \times 1^{\prime \prime}$ & 87 \\
\hline VB2418-1 & 24,000 & 18,000 & 650 & $1 / 4$ & $1 / 20$ & $160-115 \mathrm{v}$ & 3.0 & 15 & $1 / 2$ & $1 / 4 s^{*}$ & $127 \times 170$ & $9 / 2 \times 19^{n}$ & $14 \times 20^{\circ} \times 1^{\prime \prime}$ & 89 \\
\hline V82618-1 & 26,000 & 18,000 & 650 & $1 / 4$ & $1 / 20$ & $160-115 v$ & 3.0 & 15 & $1 / 2$ & $1 / / \psi^{\circ}$ & $12 W \times 170$ & $91 / 2 \times 19^{4}$ & $14^{4} \times 20^{\circ} \times 1^{1}$ & 92 \\
\hline VBSO24-1 & 30,000 & 24,000 & 800 & $1 / 4$ & $1 / 20$ & $160-115 \mathrm{v}$ & 4.0 & 15 & $1 / k^{\circ}$ & W**" & $12 W \times 170$ & $91 / 2 \times 19^{\circ}$ & $14^{7} \times 20^{2} \times 1^{10}$ & 96 \\
\hline
\end{tabular}

\begin{tabular}{|c|c|c|c|c|c|}
\hline \multicolumn{6}{|c|}{ 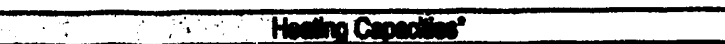 } \\
\hline ENT & thrF & MOF & $200 \mathrm{~F}$ & $\cos$ & $170 \mathrm{r}$ \\
\hline noded & \multicolumn{5}{|c|}{ BNCH } \\
\hline VB2012-1 & 86,700 & 20,000 & 21,700 & 23,300 & 24,500 \\
\hline VB2418-1 & 20,200 & 24000 & 26,500 & 29,100 & 31,200 \\
\hline VBE2618-1 & 22200 & 28,000 & 29,200 & 32,100 & 34,700 \\
\hline VBSOR41 & 25,100 & 30,000 & 34,200 & 38,200 & 43,200 \\
\hline
\end{tabular}

3 GPM, Nom. CFM, 65F entering shaded area indicetes recommended weter heater temperature range

"Nom. Cooling @45 suction temp. 8008, 677WB, notum at rated CFM.

How Doos the Apollo Ar Handlor Work?

The HydroHeat Air Handler is connected to a conventional heating or heating/cooling thermostat. When the thermostat calls for heat, the circulating pump in the air handler begins circulating the warm water from the water heater through the finned tube heating coil of the air handler. The air handler's blower has also been activated and the air passing over the heating coil is heated and blown into the home through the duct system. When the ihermostat is satisfied, the pump and blower both stop.

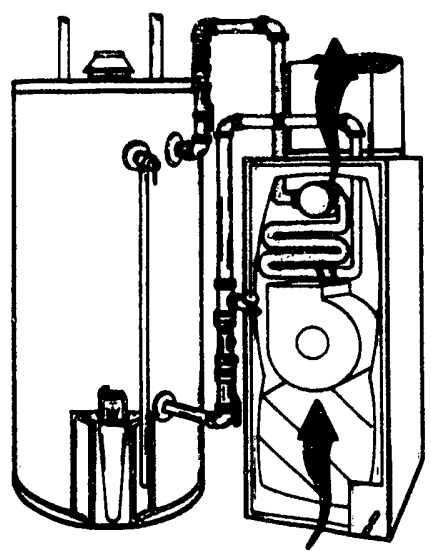

\begin{tabular}{|c|c|c|c|c|c|c|c|c|c|}
\hline \multicolumn{10}{|c|}{ CFIV VS Sthe } \\
\hline moded & ESP & .05 & .10 & .15 & 20 & 25 & .90 & 25 & $\infty$ \\
\hline VB2012-1 & $\begin{array}{l}0 \\
\text { SPD }\end{array}$ & 450 & 440 & 435 & 430 & 425 & 420 & 415 & 410 \\
\hline VB2418-1 & $\begin{array}{l}0 \\
\text { SPD }\end{array}$ & 750 & 730 & 705 & 680 & 655 & 635 & 630 & 600 \\
\hline VB2618-1 & $\begin{array}{l}10 \\
\text { SPD }\end{array}$ & 750 & 730 & 705 & 680 & 655 & 635 & 630 & 600 \\
\hline \multirow{2}{*}{ VESP24-1 } & $\begin{array}{l}10 \\
\text { SPD }\end{array}$ & 750 & 730 & 705 & 680 & 655 & 635 & 615 & 600 \\
\hline & $\begin{array}{l}\text { HI } \\
\text { SPD }\end{array}$ & 835 & 805 & 775 & 740 & 710 & 680 & 650 & 625 \\
\hline
\end{tabular}

With $14^{\prime \prime} \times 20^{\prime \prime} \times 1^{\prime \prime}$ Filler Installed
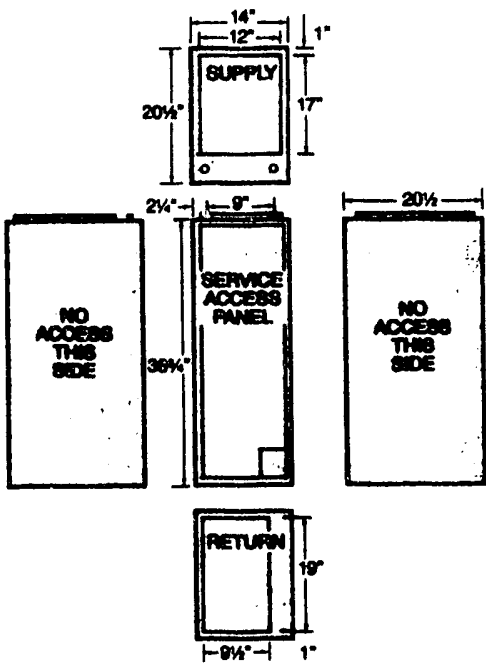

In keeping with our policy of continuous product improvement we reserve the right to make changes without prior notice.

\section{Ar Handlor/Woner Hoator Sizing}

The air handler's heating capability must equal or exceed the (ACCA Method J) heat loss of the structure.

The water heater should be a minimum of $\mathbf{4 0}$ gallon capacity. The water heater's input (BTUH) must equal or exceed the capacity of the air handler's heating coil, when divided by the recovery efficiency of the water heater.

Assistance in sizing can be obtained from your Apollo Distributor. In addition, the Apollo Systems Handbook which includes installation and operation information, can be found under the "Installation Information" tab of the Apollo Catalog.

VB-3-1-88 


\section{HYDROHEAT ${ }^{\text {HB Series }}$ Horizontal-Position Heating Systems}

Left" or Right-Hand Air Flow Heating Capacities 20,000 through 30,000 BTUH Evaporator (Cooling Coil) Available in 1, $1 \frac{12}{2}$ or 2 Ton Capacifies

The HB Series is the most economical answer to the builder's needs for heating, with cooling coils ovailable. This superior new heating system has one-third as many parts as a heat pump, making it virtually maintenance free. It is designed and tailored with heating and cooling capacities to fit from single family homes up to the multi-family market.

-Shipped standard for left hand air flow, field convertible to right hand air flow.
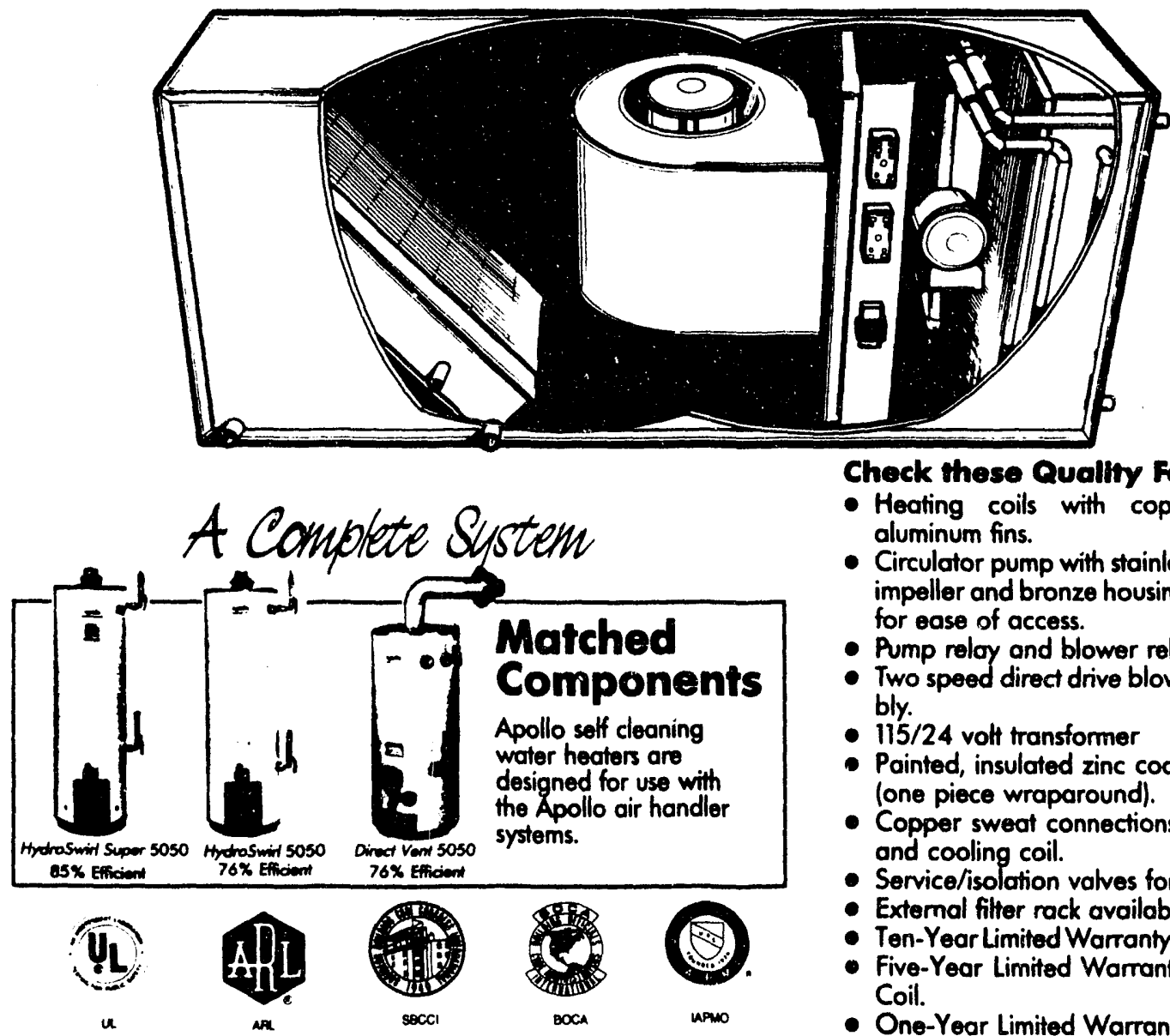

Check these Qualtiy Foatures

- Heating coils with copper tubes and aluminum fins.

- Circulator pump with stainless steel or plastic impeller and bronze housing. Front mounted for ease of access.

- Pump relay and blower relay.

- Two speed direct drive blower/motor assembly.

- $115 / 24$ volt transformer

- Painted, insulated zinc coated steel cabinet (one piece wraparound).

- Copper sweat connections for heating coil and cooling coil.

- Service/isolation valves for pump.

- External filter rack available.

- Ten-Year Limited Warranty on Heating Coil.

- Five-Year Limited Warranty on Evaporator Coil.

- One-Year Limited Warranty on Parts.

- All models are listed under one or more of the organizations shown.

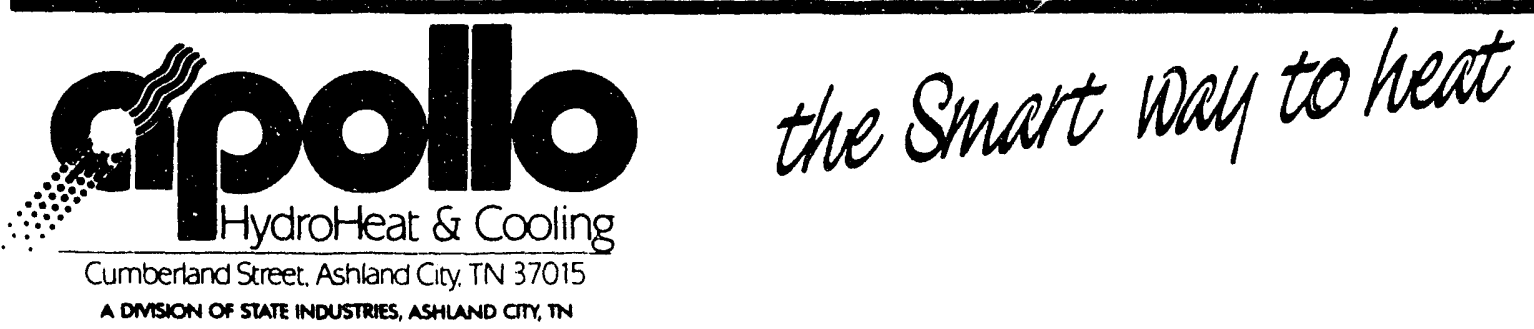




\section{Specifications}

\begin{tabular}{|c|c|c|c|c|c|c|c|c|c|c|c|c|c|c|}
\hline d & 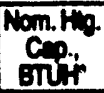 & $\begin{array}{l}\text { Nym.cool } \\
\text { Cintion }\end{array}$ & $\begin{array}{l}\text { Nom. } \\
\text { CFM }\end{array}$ & $\begin{array}{l}\text { Elower } \\
\text { Motor } \\
\text { hip }\end{array}$ & $\begin{array}{l}\text { Puxp } \\
\text { Motor } \\
\text { MP }\end{array}$ & $\begin{array}{l}\text { Eloc. } \\
\text { Che. }\end{array}$ & $\begin{array}{l}\text { Reted } \\
\text { Amps }\end{array}$ & $\begin{array}{c}\text { Min. } \\
\text { Clicaik } \\
\text { Anpeciny }\end{array}$ & $\begin{array}{l}\text { Wom } \\
\text { com } \\
1.0 \text {. }\end{array}$ & 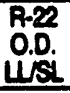 & $\begin{array}{l}\text { Supply } \\
\text { Comn. }\end{array}$ & $\begin{array}{l}\text { Retum } \\
\text { Cont. }\end{array}$ & $\begin{array}{l}\text { Finor. } \\
\text { Singo"... }\end{array}$ & $\begin{array}{l}\text { Ship. } \\
\text { mille. }\end{array}$ \\
\hline HB2012-1 & 20,000 & 12,000 & 425 & $1 / 5$ & $1 / 20$ & $160-115 \mathrm{v}$ & 2.5 & 15 & $1 / 2^{n}$ & $36 x^{\prime \prime}$ & $12 W \times 170$ & $12^{2} \times 18^{\prime \prime} \kappa^{\prime \prime}$ & $14^{\prime} \times 20^{\circ} \times 1^{\circ}$ & 87 \\
\hline HB2418-1 & 24,000 & 18,000 & 650 & $1 / 4$ & $1 / 20$ & $160-115 \mathrm{~V}$ & 3.0 & 15 & $1 / h^{n}$ & */4*" & $12 W \times 170$ & $12^{2} \times 18^{2} h^{2}$ & $14^{2} \times 20^{\circ} \times 1^{10}$ & 89 \\
\hline H82618-1 & 26,000 & 18,000 & 650 & $1 / 4$ & $1 / 20$ & $160-115 \mathrm{v}$ & 3.0 & 15 & $k^{\prime \prime}$ & HWt & $12 W \times 170$ & $12^{\prime \prime} \times 18 \mathrm{~h}^{\prime \prime}$ & $14^{\prime \prime} \times 20^{\circ} \times 1^{1}$ & 92 \\
\hline 1830241 & 30,000 & 24,000 & 800 & $1 / 4$ & $1 / 20$ & $160-115 \mathrm{~V}$ & 4.0 & 15 & $1 / 2$ & *⿻/丿6t" & $12 W \times 1700$ & $12^{2} \times 18 \% "$ & $14^{\prime} \times 20^{\circ} \times 1^{\prime \prime}$ & 96 \\
\hline
\end{tabular}

\begin{tabular}{|c|c|c|c|c|c|}
\hline \multicolumn{6}{|c|}{ 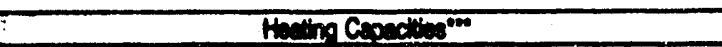 } \\
\hline EMT. & torf & not & 1 DOF & $100 \mathrm{~F}$ & $170 \%$ \\
\hline Moded & \multicolumn{3}{|c|}{ BTUH } & & \\
\hline H82012-1 & 16,700 & 20,000 & 21,700 & 23,300 & 24,500 \\
\hline HB2418-1 & 20,200 & 24,000 & 26,500 & $29,10 \mathrm{u}$ & 31,200 \\
\hline $1+32618-1$ & 22200 & 20,000 & 29,200 & 32,100 & 34,700 \\
\hline $1183024-1$ & 25.100 & 30000 & 34,200 & 38.200 & 3,200 \\
\hline
\end{tabular}

" 3 GPM, Nom. CFM, 65\% entering air temp. shaded area indicates recommended water heater temperature range

"Nom. cooling @45" suction temp., 800D8,67WB retum air, rated CFM.

". Shaded area incicates recommended water heater lemperature selting.
How Doos Tha Apollo Air Handlor Work?

The HydroHeat Air Handler is connected to a conventional heating or heating/cooling thermostat. When the thermostat calls for heat, the circulating pump in the air handler begins circulating the wa.mi water from the water heater through the finned tube heating coil of the air handler. The air handler's blower has also been activated and the air passing over the heating coil is heated and blown into the home through the duct system. When the thermostat is satisfied, the pump and blower both stop.

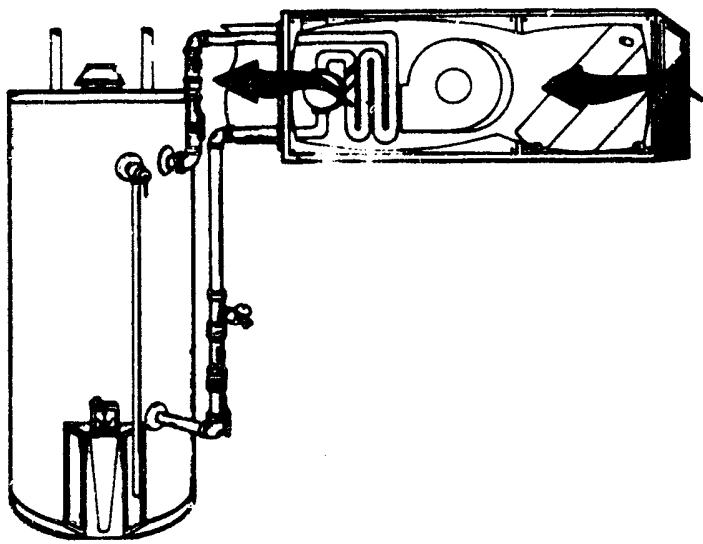

\begin{tabular}{|c|c|c|c|c|c|c|c|c|c|}
\hline \multicolumn{10}{|c|}{ CFM vo Suatic } \\
\hline Model & ESP & .05 & .10 & .15 & 20 & 25 & 30 & .35 & .40 \\
\hline H82012-1 & \begin{tabular}{|l}
0 \\
SPD
\end{tabular} & 450 & 40 & 435 & 430 & 425 & 420 & 415 & 410 \\
\hline H82418-1 & $\begin{array}{l}0 \\
\text { SPD }\end{array}$ & 750 & 730 & 705 & 680 & 655 & 635 & 630 & 600 \\
\hline HB2618-1 & \begin{tabular}{|l}
10 \\
SPD
\end{tabular} & 750 & 730 & 705 & 680 & 655 & 635 & 630 & 600 \\
\hline \multirow{2}{*}{ HB3024.1 } & $\begin{array}{l}\text { LO } \\
\text { SPD }\end{array}$ & 750 & 730 & 705 & 680 & 655 & 635 & 615 & 600 \\
\hline & $\begin{array}{c}A 1 \\
S P D\end{array}$ & 835 & 805 & 75 & 740 & 710 & 680 & 650 & 625 \\
\hline
\end{tabular}

In keeping with cur policy of continuous product improvement we reserve the right to make changes without prior notice.
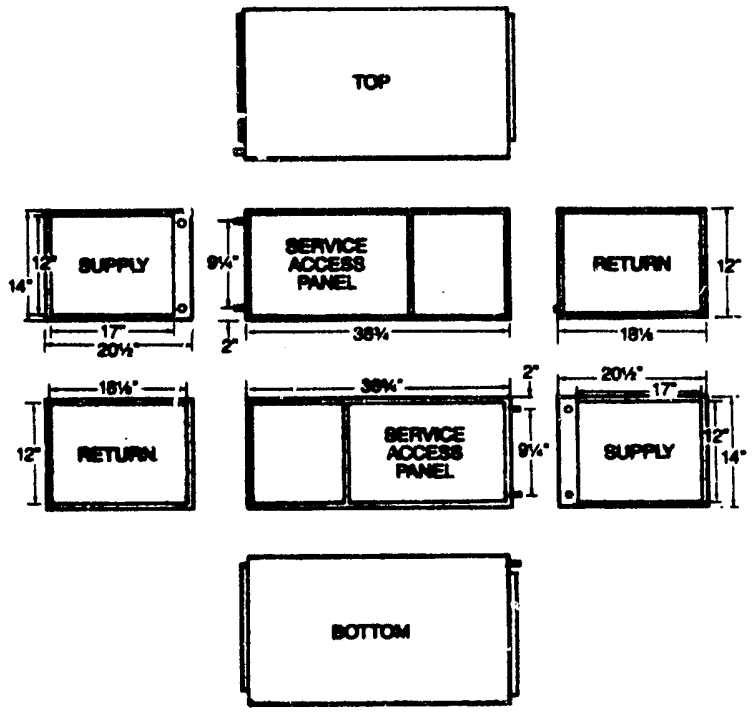

\section{Ar Handlor/Wotor Mooter Sizing}

The air haridler's heating copability must equal or exceed the (ACCA Method J! heot loss of the structure.

The water heater should be a minimum of $\mathbf{4 0}$ gallon copacity. The water heoter's input (BTUH) must equal or exceed the capacity of the air handler's heating coil, when divided by the recovery efficiency of the woter heater.

Assistance in sizing can be obtained from your Apollo Distributor. In addition, the Apollo Systems Handbook which includes installation and operation information, can be found under the "Installation Information" tab of the Apollo Catalog.

HB-1-1-8B 


\section{HYDROHEAT HB Series Heating Only Multi-Position Heating Systems}

Verfical (upflow or downflow), Horizontal (right or left) or Counter flow Heating Capacities 20,000 through 30,000 BTUH

The HB Series is the most economical answer to the builder's needs for heating. This superior new heating system has onethird as many parts as a heat pump, making it virtually maintenance free. It is designed and tailored with heating capacities to fit from single family homes up to the multi-family market.
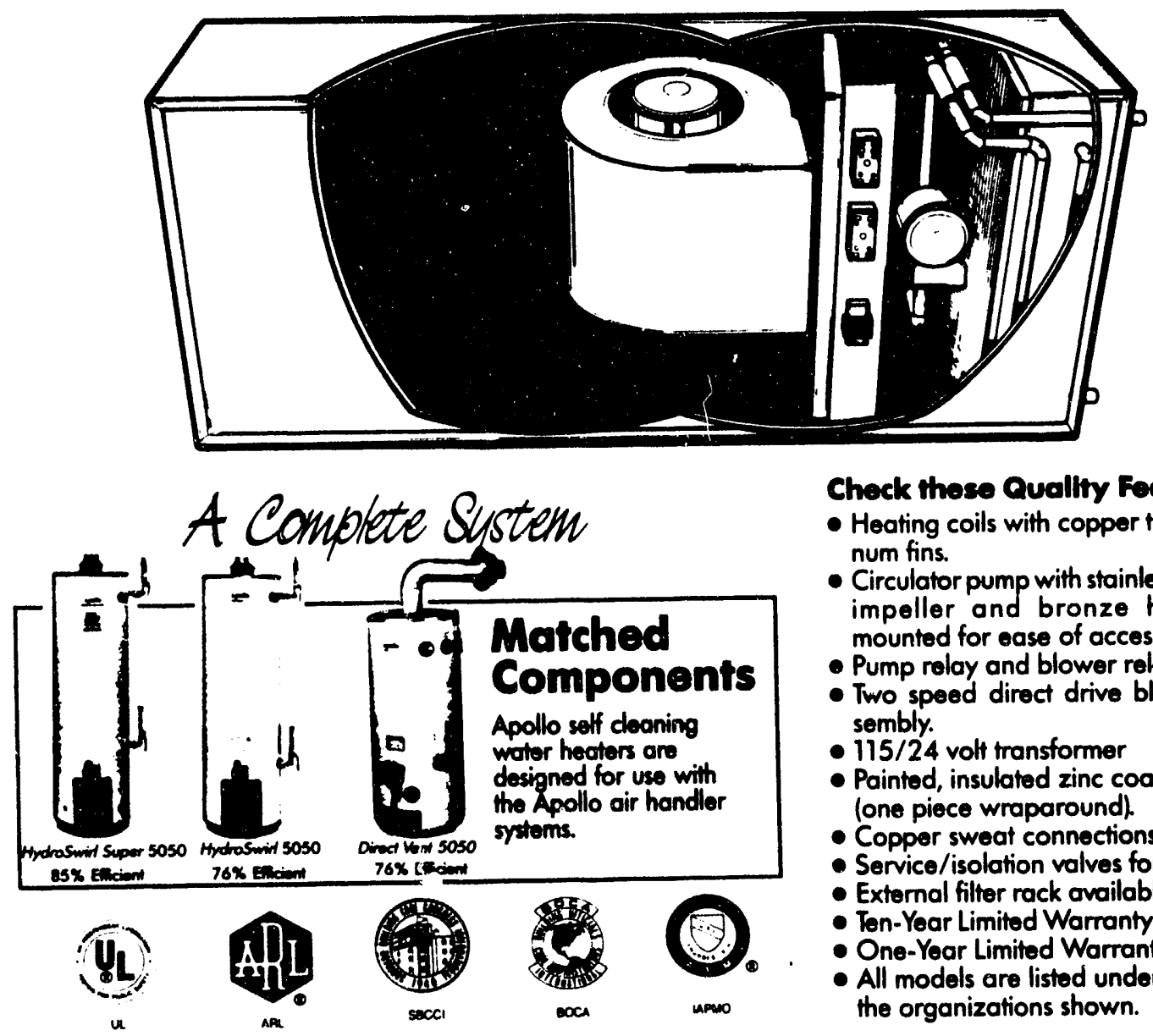

Check these Quality Foctures

- Heating coils with copper tubes and aluminum fins.

- Circulator pump with stainless steel or plastic impeller and bronze housing. Front mounted for ease of access.

- Pump relay and blower relay.

- Two speed direct drive blower/motor assembly.

- 115/24 volt transformer

- Painted, insulated zinc coated steel cabinet (one piece wraparound).

- Copper sweat connections for haating coil

- Service/isolation valves for pump.

- External filter rack available.

- Ton-Year Limited Warranty on Heating Coil.

- One-Year Limited Warranty on Parts.

- All models are listed under one or more of the organizations shown.

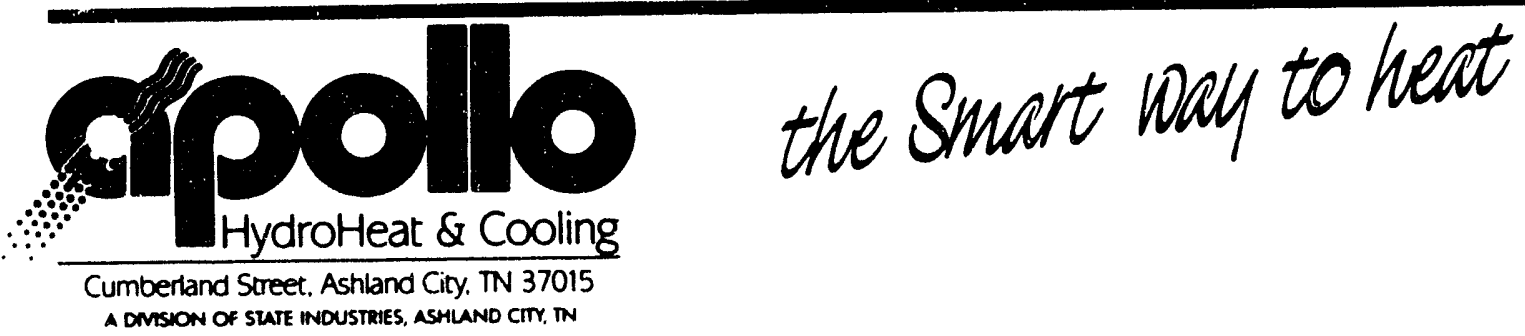




\section{Specifications}

\begin{tabular}{|c|c|c|c|c|c|c|c|c|c|c|c|}
\hline HB2400-1 & 24,000 & $1 / 4$ & $1 / 20$ & $1-60-115 \mathrm{v}$ & 3.0 & 15 & $1 / 2{ }^{\prime \prime}$ & $12^{2} W \times 17^{\prime \prime D}$ & $12^{\prime \prime} \times 18^{1} / 6^{\prime \prime}$ & $14^{\prime \prime} \times 20^{\prime \prime} \times 1^{\prime \prime}$ & 79 \\
\hline HB3000-1 & 30,000 & $1 / 4$ & $1 / 20$ & $1-60-115 v$ & 4.0 & 15 & $1 / 2^{n}$ & $12^{2} W \times 17^{n} D$ & $12^{n} \times 18^{1} / 8^{m}$ & $14^{\prime \prime} \times 20^{n} \times 1^{n}$ & 86 \\
\hline
\end{tabular}

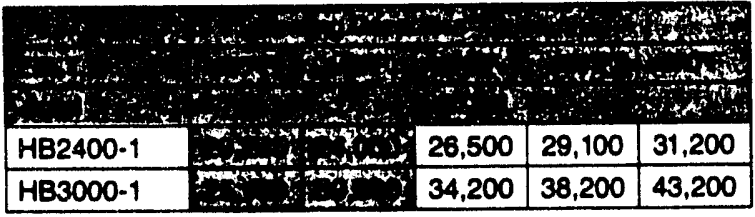

3 GPM, 65\% entering air temp. shaded area indicates recommended water heater temperature range.

-*Shaded area indicates recommended water heater temperature setting.

\section{How Does The Apollo Air Handlor Work?}

The HydroHeat Air Handler is connected to a conventional heating or heating/cooling thermostat. When the thermostat calls for heat, the circulating pump in the air handler begins circulating the warm water from the water heater through the finned tube heating coil of the air handler. The air handler's blower has also been activated and the air passing over the heating coil is heated and blown into the home through the duct system. When the thermostat is satisfied, the pump and blower both stop

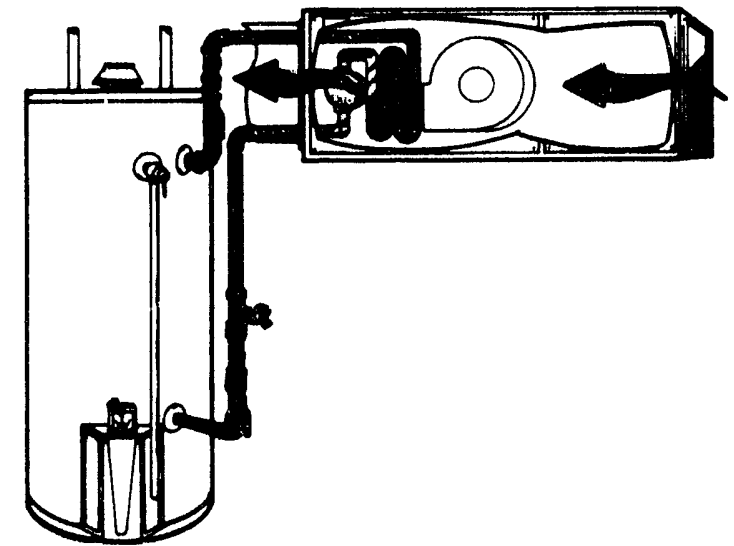

\begin{tabular}{|c|c|c|c|c|c|c|}
\hline HB 2400-1 & High Speed & 910 & 900 & 855 & 805 & 715 \\
\hline HB 3000-1 & Low Speed & 800 & 765 & 725 & 690 & 600 \\
\hline
\end{tabular}

In keeping with our policy of continuous product improvement we reserve the right to make changes without prior notice.

\section{Air Handlor/Wator Hoctor Sizing}

The air handler's heating capability must equal or exceed the (ACCA Method J) heat loss of the structure.

The water heater should be a minimum of $\mathbf{4 0}$ gallon capacity. The water heater's input (BTUH) must equal or exceed the capacity of the air handler's heating coil, when divided by the recovery efficiency of the water heater.

Assistance in sizing can be obtained from your Apollo Distributor. In addition, the Apollo Systems Handbook which includes installation and operation information, can be found under the "Installation Information" tab of the Apollo Catalog.

HB-2/10-88 


\section{HYDROHEAT HSeries Horizontal Heating Systems}

Heating Capacities 20,000-36,000 Evaporator (Cooling Coil) Available in 1, 11/2, 2, or 21/2 Ton Capacities

The H Series is designed for the builder who has a need for overhead installation, above dropped or firred-down ceilings. This unit is the most economical answer to applications such as apartments, townhouses, motels, etc.
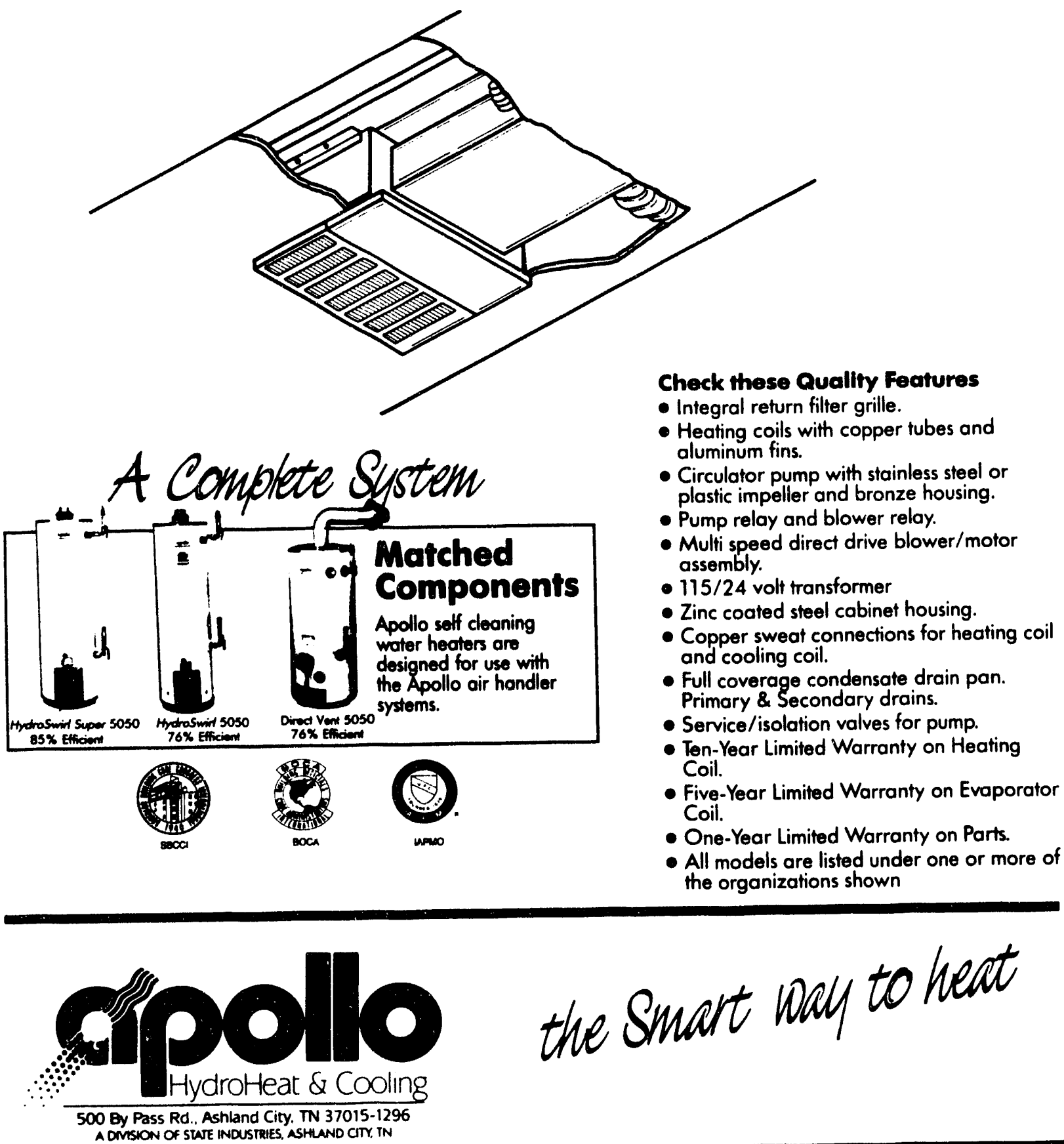


\section{Specifications}

\begin{tabular}{|c|c|c|c|c|c|c|c|c|c|c|c|c|c|}
\hline \multirow[b]{2}{*}{ Model } & \multirow{2}{*}{$\begin{array}{c}\text { Nom. Htg. } \\
\text { Cap. } \\
\text { BTUH. }\end{array}$} & \multirow{2}{*}{$\begin{array}{c}\text { Vom. Clg. } \\
\text { Cap. } \\
\text { BTuH. }\end{array}$} & \multirow{2}{*}{$\begin{array}{l}\text { Nom. } \\
\text { CFM }\end{array}$} & \multirow{2}{*}{$\begin{array}{l}\text { Blower } \\
\text { Motor } \\
\text { HP }\end{array}$} & \multirow{2}{*}{$\begin{array}{l}\text { Pump } \\
\text { Motor } \\
\text { HP }\end{array}$} & \multirow{2}{*}{$\begin{array}{l}\text { Elec. } \\
\text { Char. }\end{array}$} & \multirow{2}{*}{$\begin{array}{l}\text { Rated } \\
\text { Amps }\end{array}$} & \multirow{2}{*}{$\begin{array}{c}\text { Min. } \\
\text { Circuit } \\
\text { Ampacity }\end{array}$} & \multirow{2}{*}{$\begin{array}{l}\text { Wator } \\
\text { Conn. } \\
\text { I.D. }\end{array}$} & \multirow{2}{*}{$\begin{array}{l}\text { Supply } \\
\text { Duct } \\
\text { Conn. }\end{array}$} & \multirow{2}{*}{$\begin{array}{l}\text { Ship. } \\
\text { Wh. Lbs. }\end{array}$} & \multicolumn{2}{|c|}{$\begin{array}{c}R \cdot 22 \\
\text { Conn O.D. }\end{array}$} \\
\hline & & & & & & & & & & & & $\mathrm{UL}$ & SL \\
\hline $\mathrm{H}-20.1 .0$ & 20,000 & 12,000 & 400 & $1 / 5$ & $1 / 20$ & $1-60-115 \mathrm{~V}$ & 3.5 & 15 & $1 / 2^{\prime \prime}$ & $28 \times 63 / 4$ & 75 & $5 / 16$ & $5 / 8$ \\
\hline $\mathrm{H}-24-1.5$ & 24,000 & 18,000 & 600 & $1 / 5$ & $1 / 20$ & $1.60-115 \mathrm{~V}$ & 3.5 & 15 & $1 / 2^{\prime \prime}$ & $28 \times 63 / 4$ & 75 & $3 / 8$ & $5 / 8$ \\
\hline$H-33-2.0$ & 33,000 & 24,000 & 800 & $1 / 3$ & $1 / 20$ & $1.60-115 \mathrm{~V}$ & 5.5 & 15 & $1 / 2^{\prime \prime}$ & $28 \times 63 / 4$ & 85 & $3 / 8$ & $5 / 8$ \\
\hline$H \cdot 36-2.5$ & 36,000 & 30,000 & 1.000 & $1 / 3$ & $1 / 20$ & $1.60 .115 \mathrm{~V}$ & 5.5 & 15 & $1 / 2^{\prime \prime}$ & $28 \times 63 / 4$ & 85 & $3 / 8$ & $5 / 8$ \\
\hline
\end{tabular}

\begin{tabular}{|l|c|c|c|c|c|c|}
\hline \multicolumn{7}{|c|}{ Heating Capacities"* } \\
\hline E.W.T. & $130^{\circ} \mathrm{F}$ & $140^{\circ} \mathrm{F}$ & $150^{\circ} \mathrm{F}$ & $160^{\circ} \mathrm{F}$ & $170^{\circ} \mathrm{F}$ \\
\hline Model & \multicolumn{7}{|c|}{ BTUH } \\
\hline H-20-1.0 & 17,400 & 20,000 & 23,000 & 25,800 & 28,600 \\
\hline H-24-1.5 & 21.000 & 24,000 & 27,800 & 31,200 & 34,700 \\
\hline H-33-2.0 & 28.300 & 33.000 & 37,500 & 42.000 & 46,700 \\
\hline H-36-2.5 & 30.900 & 36,400 & 40,900 & 46.000 & 51,000 \\
\hline
\end{tabular}

. 3 GPM, Nom. CFM, $65^{\circ} \mathrm{F}$ entering air temp.

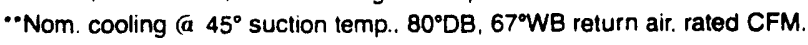

-.. Shaded area indicates recornmended water heater temperature setting.

How Does The Apollo Air Handler Work?

The HydroHeat Air Handler is connected to a conventional heating or heating/cooling thermostat. When the thermostat calls for heat, the circulating pump in the air handler begins circulating the warm water from the water heater through the finned tube heating coil of the air handler. The air handler's blower has also been activated and the air passing over the heating coil is heated and blown into the home through the duct system. When the thermostat is satisfied, the pump and blower both stop.

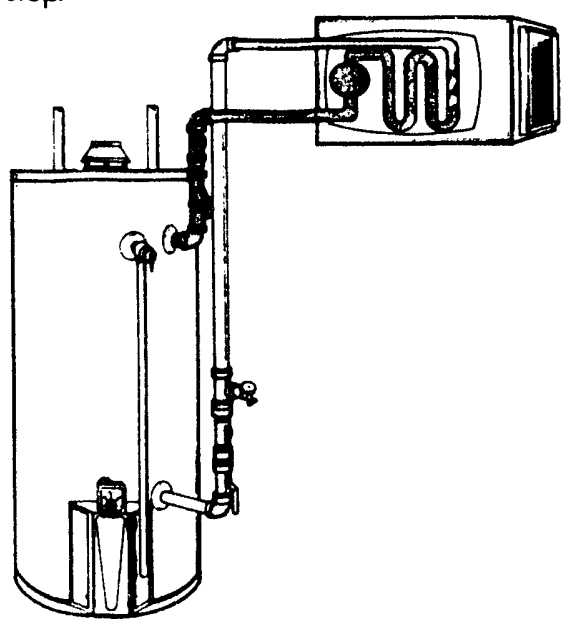

\begin{tabular}{|l|c|c|c|c|c|c|c|c|c|}
\hline \multicolumn{10}{|c|}{ CFM ve Static } \\
\hline Hodel & ESP & .05 & .10 & .15 & .20 & .25 & .30 & .35 & .40 \\
\hline H-20-1.0 & HI & 820 & 790 & 760 & 720 & 665 & 615 & 575 & 535 \\
\cline { 2 - 10 } & LO & 625 & 615 & 585 & 565 & 530 & 500 & 465 & 430 \\
\hline \multirow{3}{*}{ H-33-2.0 } & HI & 1130 & 1115 & 1060 & 1035 & 985 & 940 & 880 & 825 \\
\cline { 2 - 10 } & MED & 1055 & 1035 & 980 & 955 & 910 & 860 & 800 & 735 \\
\cline { 2 - 10 } & LO & 930 & 915 & 870 & 895 & 805 & 755 & 710 & 655 \\
\hline \multirow{4}{*}{ H-36-2.5 } & HI & 1075 & 1060 & 1020 & 975 & 930 & 885 & 825 & 760 \\
\cline { 2 - 10 } & MED & 1010 & 995 & 950 & 910 & 860 & 815 & 740 & 670 \\
\cline { 2 - 9 } & LO & 895 & 885 & 850 & 815 & 770 & 725 & 675 & 625 \\
\hline
\end{tabular}
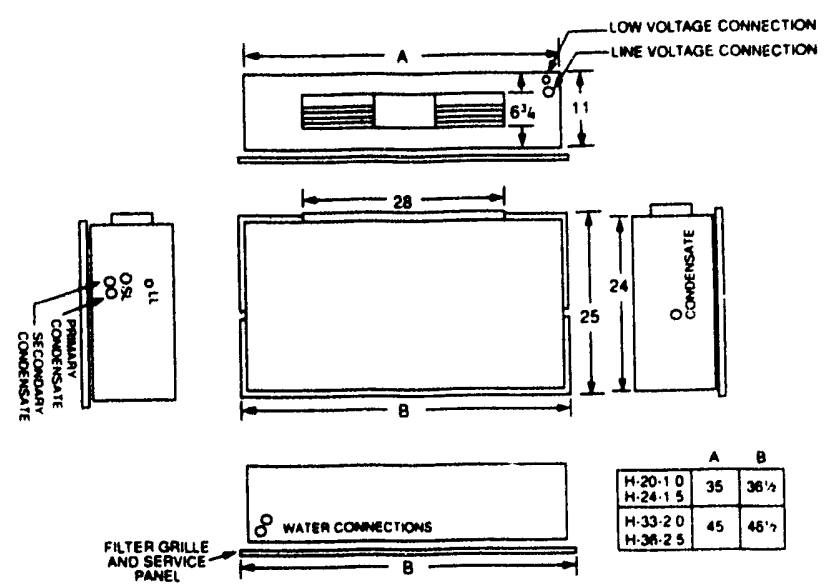

\section{Air Handler/Water Heater Sizing}

The air handler's heating capability must equal or exceed the (ACCA Method J) heat loss of the structure.

The water heater should be a minimum of $\mathbf{4 0}$ gallon capacity. The water heater's input (BTUH) must equal or exceed the capacity of the air handler's heating coil, when divided by the recovery efficiency of the water heater.

Assistance in sizing can be obtained from your Apollo Distributor. In addition, the Apollo Systems Handbook which includes installation and operation infermation, can be found under the "Installation Information" tab of the Apollo Catalog. 


\section{HYDROHEAT}

W Series

In-The-Wall Heating Systems

The W Series is the most economical answer to the builder's needs for heating, "In-the-Wall" with cooling coils available. This superior new heating system has one-third as many parts as a heat pump, making it virtually maintenance free. It is designed and tailored with heating and cooling capacities to fit from single family homes up to the multi-family market.

\section{Check these Quality Features}

- Heating coils with copper tubes and aluminum fins.

- Circulator pump with stainless steel or plastic impeller and bronze housing. Front mounted for ease of access.

- Pump relay and blower relay.

- Two-speed direct drive blower/motor assembly.

- 115/24 volt transformer

- Insulated zinc coated steel cabinet (one piece wraparound).

- White enamel service panel and louvered return grille.

- Optional decorative panels available white, textured finish. W-20, W-26, W-30-\#9001610 W-42, W-45-\#9001611

- Copper sweat connections for heating coil, cooling coil and condensate drains.

- Service/isolation valves for pump.

- 1" throwaway type air filter.

- Ten-year Limited Warranty on Heating Coil.

- Five-year Limited Warranty on Evaporator Coil.

- One-year Limited Warranty on Parts.

- All models are listed under one or more of the organizations shown below.

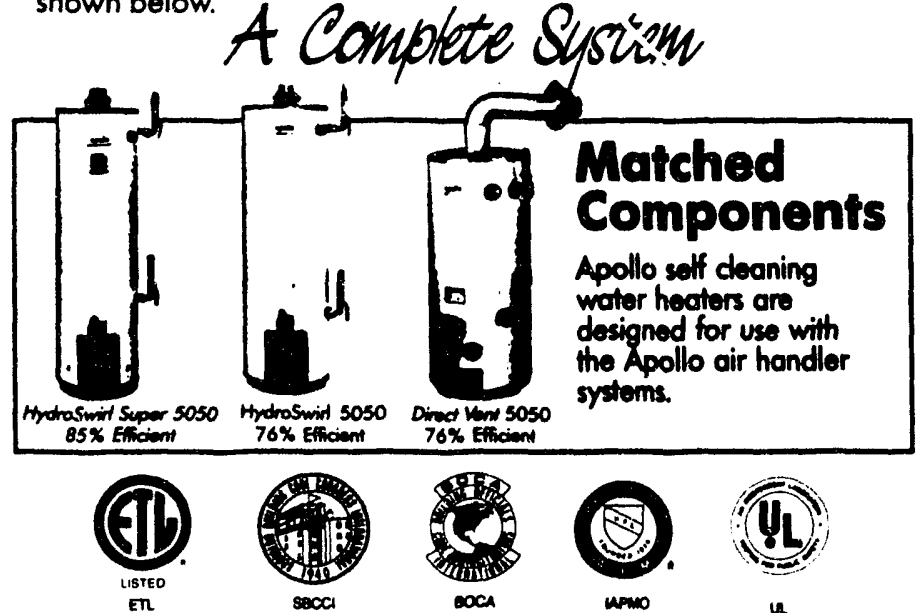

\section{Heating Capacities \\ BTUH/Hour 20,000-45,000 \\ Evaporator (Cooling Coil) Available \\ 1-3 Ton Capacities}

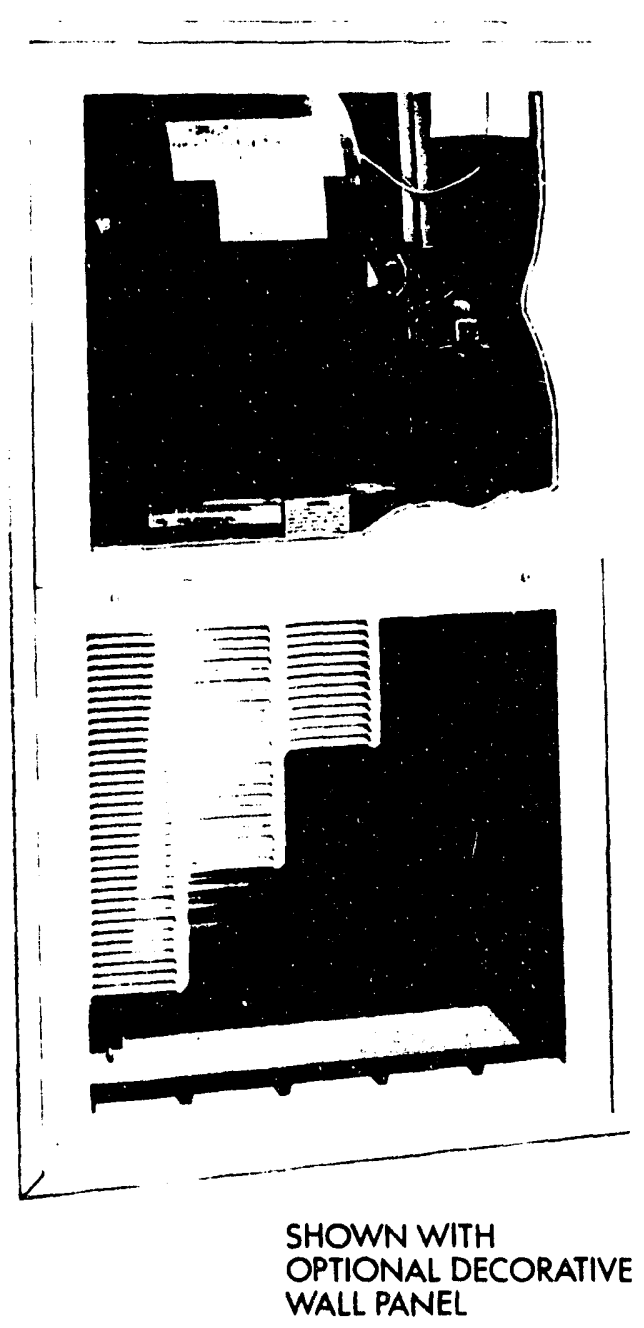

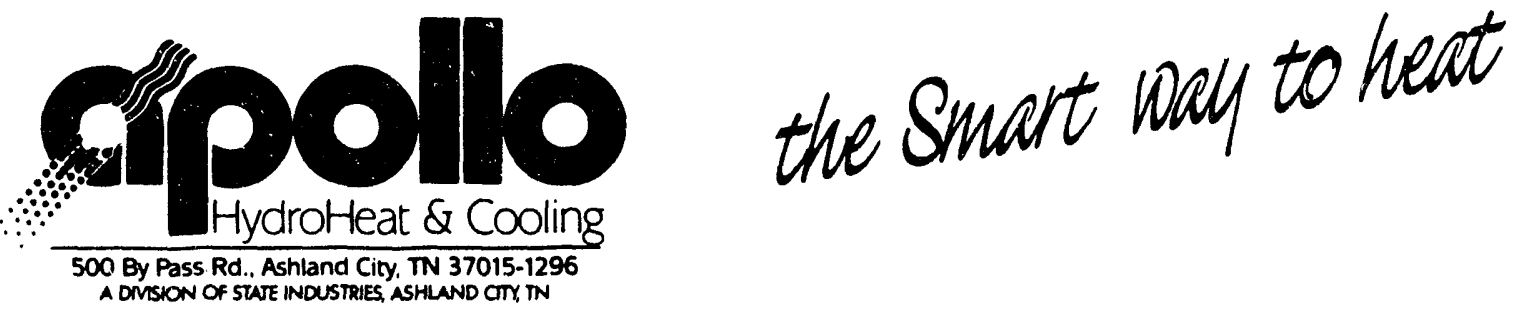




\section{Specifications}

\begin{tabular}{|c|c|c|c|c|c|c|c|c|c|c|c|c|c|}
\hline moded & $\begin{array}{l}\text { Tom. Wh: } \\
\text { Cofuty }\end{array}$ & 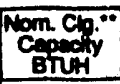 & Nom & $\begin{array}{l}\text { glower } \\
\text { Motor } \\
\text { itP }\end{array}$ & $\begin{array}{c}\text { Pump } \\
\text { Motor } \\
\text { HP }\end{array}$ & $\begin{array}{l}\text { Evec. } \\
\text { Cherecior- } \\
\text { Detice }\end{array}$ & $\begin{array}{l}\text { Aand } \\
\text { AMPS }\end{array}$ & $\begin{array}{c}\text { Nin. } \\
\text { Cirain } \\
\text { Ampectity }\end{array}$ & 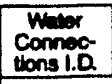 & $\begin{array}{c}\text { A.22 Conn. } \\
\text { O.D. } \\
\text { LisL } \\
\end{array}$ & $\begin{array}{c}\text { supply } \\
\text { connection }\end{array}$ & $\begin{array}{l}\text { Finor } \\
\text { Size } \\
\end{array}$ & WT \\
\hline$W-20.1 .0$ & 22,000 & 12,000 & 400 & $1 / 3$ & $1 / 20$ & $1-60-115 \mathrm{v}$ & 2.5 & 15 & $1 / 2^{\prime \prime}$ & $1 / 4 \%$ & $12 \mathrm{~W} \times 10^{1 / 40}$ & $16 \times 20 \times 1$ & 90 \\
\hline$W-26-1.5$ & 26,000 & 18,000 & 600 & $1 / 4$ & $1 / 20$ & $1.60-115 \mathrm{v}$ & 3.0 & 15 & $1 / 2^{\prime \prime}$ & $1 / 4 \quad 3 / 6$ & $12 W \times 10^{1 / 4 D}$ & $16 \times 20 \times 1$ & 92 \\
\hline$W-30-2.0$ & 30,000 & 24,000 & 800 & $1 / 4$ & $1 / 20$ & $1.60 .115 v$ & 4.0 & 15 & $1 / 2 n$ & $\begin{array}{|ll|}3 & 5 / 6 \\
\end{array}$ & $12 W \times 10 \% \mathrm{D}$ & $16 \times 20 \times 1$ & 96 \\
\hline W-42-2.5 & 42,500 & 30,000 & 1000 & $1 / 3$ & $1 / 20$ & $1-60.115 \mathrm{v}$ & 4.4 & 15 & $1 / 2^{\prime \prime}$ & $3 / 8 \quad 7 / 6$ & $16 \mathrm{~W} \times 12 \mathrm{D}$ & $25 \times 20 \times 1$ & 115 \\
\hline$W-45-3.0$ & 45,000 & 36,000 & 1200 & $1 / 3$ & $1 / 20$ & $1-60.115 v$ & 4.7 & 15 & $1 / 2^{n}$ & $3 / 6$ & $16 \mathrm{~W} \times 120$ & $25 \times 20 \times 1$ & 120 \\
\hline
\end{tabular}

\begin{tabular}{|c|c|c|c|c|c|}
\hline \multicolumn{5}{|c|}{ HEATING CAPACTES } \\
\hline E.W.T. & $1200^{\circ} \mathrm{F}$ & $1300^{\circ} \mathrm{F}$ & $140^{\circ} \mathrm{F}$ & $150^{\circ} \mathrm{F}$ & $160^{\circ} \mathrm{F}$ \\
\hline MOOEL & \multicolumn{5}{|c|}{ BTUH } \\
\hline W-20-1.0 & 15,500 & 19,000 & 22,000 & 24,500 & 28,000 \\
\hline W-26-1.5 & 19,300 & 23,000 & 28,000 & 30,500 & 35,000 \\
\hline W-30-2.0 & 22,200 & 27,500 & 30,000 & 34,700 & 40,000 \\
\hline W-42-2.5 & N/R & 36,900 & 42,500 & 48,100 & 53,700 \\
\hline W-45-3.0 & N/R & 40,000 & 45,000 & 52,187 & 58,250 \\
\hline
\end{tabular}

3 GPM, Nom. CFM, 65\% ontoring air temp. shaded area indicates

recommended water heater temperature range

-Nom. cooling @ 48 suction temp., 80 DB, 67\% WB retum air, rated CFM.

\begin{tabular}{|l|c|c|c|c|c|c|c|c|c|}
\hline \multicolumn{8}{|c|}{ CFM - VS - STATKC } \\
\hline Model & ESP & .05 & .10 & .15 & .20 & .25 & .30 & .35 & .40 \\
\hline \multirow{2}{*}{ W-20-1.0 } & HI & 525 & 490 & 465 & 445 & 425 & 400 & 375 & 350 \\
\cline { 2 - 9 } & LO & 300 & 295 & 290 & 280 & 278 & 275 & 260 & 250 \\
\hline \multirow{2}{*}{$W \cdot 26-1.5$} & HI & 905 & 880 & 855 & 820 & 770 & 740 & 720 & 710 \\
\cline { 2 - 9 } & LO & 725 & 700 & 685 & 675 & 665 & 650 & 630 & 610 \\
\hline \multirow{2}{*}{ W-30-2.0 } & HI & 920 & 900 & 880 & 855 & 795 & 750 & 735 & 725 \\
\cline { 2 - 9 } & LO & 765 & 735 & 715 & 700 & 685 & 675 & 655 & 620 \\
\hline \multirow{2}{*}{$\begin{array}{l}\text { W-42-2.5 } \\
\text { W-45-3.0 }\end{array}$} & HI & 1340 & 1310 & 1280 & 1250 & 1210 & 1180 & 1145 & 1110 \\
\cline { 2 - 9 } & LO & 1245 & 1205 & 1150 & 1150 & 1120 & 1090 & 1060 & 1025 \\
\hline
\end{tabular}

\section{How Doos The Apollo Air Hondlor Work?}

The HydroHeat Air Handler is connected to a conventional heating or heating/cooling thermostat. When the thermostot calls for heat, the circulating pump in the air handler begins circulating the warm water from the water hoater through the finned tube heating coil of the air handler. The air handler's blower has also been activated and the air passing through the heating coil is heated and blown into the home through the duct system. When the thermostat is sotisfied, the pump and blower both stop.

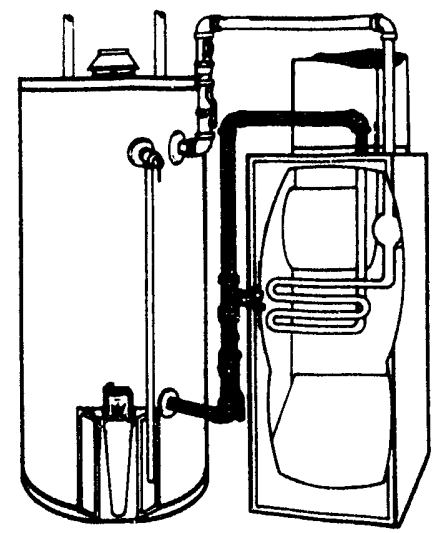

In keoping with our policy of continuous product improvement we reserve the right to make changes without prior notice.

\section{Air Hondlor/Woter Heoter Sizing}

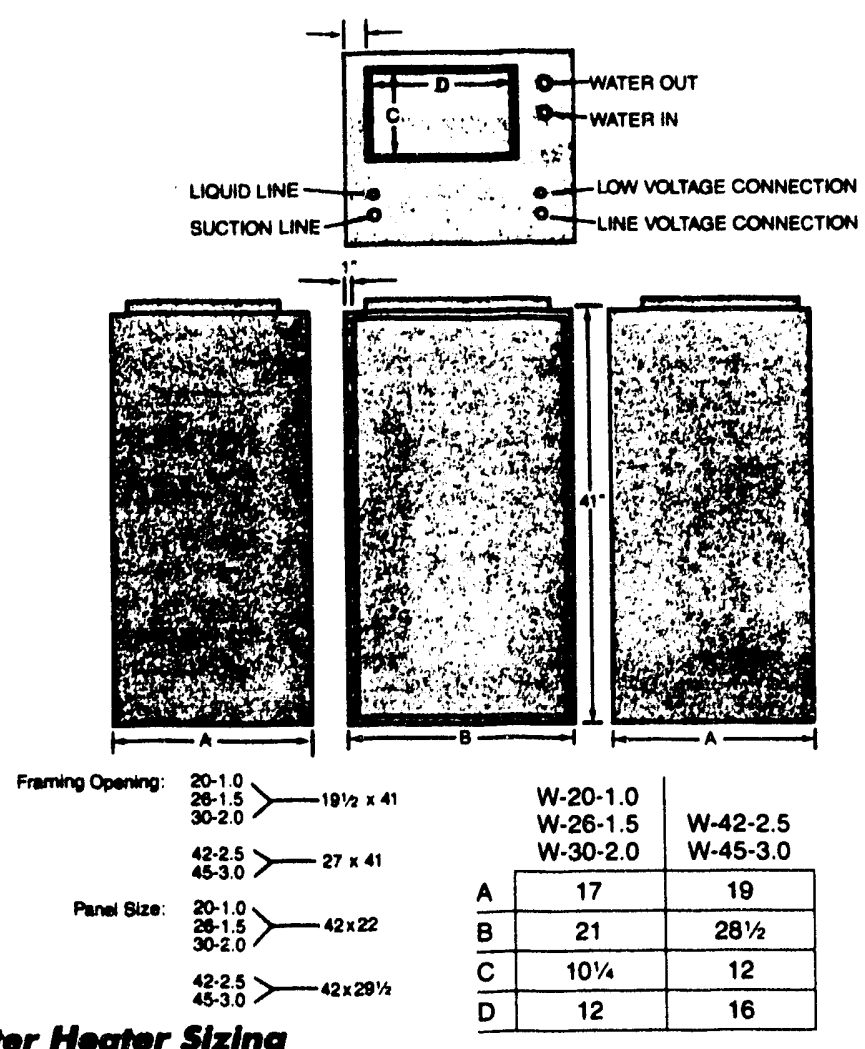

The air handler's heating capability must equal or exceed the (ACCA Method J) heat loss of the structure.

The water heater should be a minimum of $\mathbf{4 0}$ gallon capacity. The water heater's input (BTUH) must equal or exceed the capacity of the air handler's heating coil, when divided by the recovery efficiency of the water heater.

Assistance in sizing can be obtained from your Apollo Distributor. In addition, the Apollo Systems Handbook which includes installation and operation information, can be found under the "Installation Information" tab of the Apollo Catalog.

Form W.6/1190 


\section{HYDROHEAT CBC Senies Multi-Position Heating Systems \\ Left or Right Hand Airflow or Vertical-Upflow Heating Capacity 30,800 BTUH Evaporator (Cooling Coil) Available in $1 \frac{1}{2}$ or 2 Ton Capacities}

The CBC Series is the most economical answer to the builder's needs for heating, with cooling coils available. This superior new heating system has one-third as many parts as a heat pump, making it virtually maintenance free. It is $d t$ :aned and tailored with heating and cooling capacities to ' from single family homes up to the multifamily market.

\section{Check these Quality Foatures}

- Heating coils with copper tubes and aluminum fins.

- Circulator pump with stainless steel or plastic impeller and bronze housing.

- Rump relay and blower relay.

- Two speed direct drive blower/motor assembly.

- $115 / 24$ volt transformer

- Painfed, insulated zinc coated steel cabinet

- Copper sweat connections for heating coil and cooling coil.

- Service/isolation valves for pump.

- External filter rack available.

- Ten-Year Limited Warranty on Heating Coil.

- Five-Year Limited Warranty on Evaporator Coil.

- One-Year Limited Warranty on Parts.

- All models are listed under one or more of the organizations shown below.
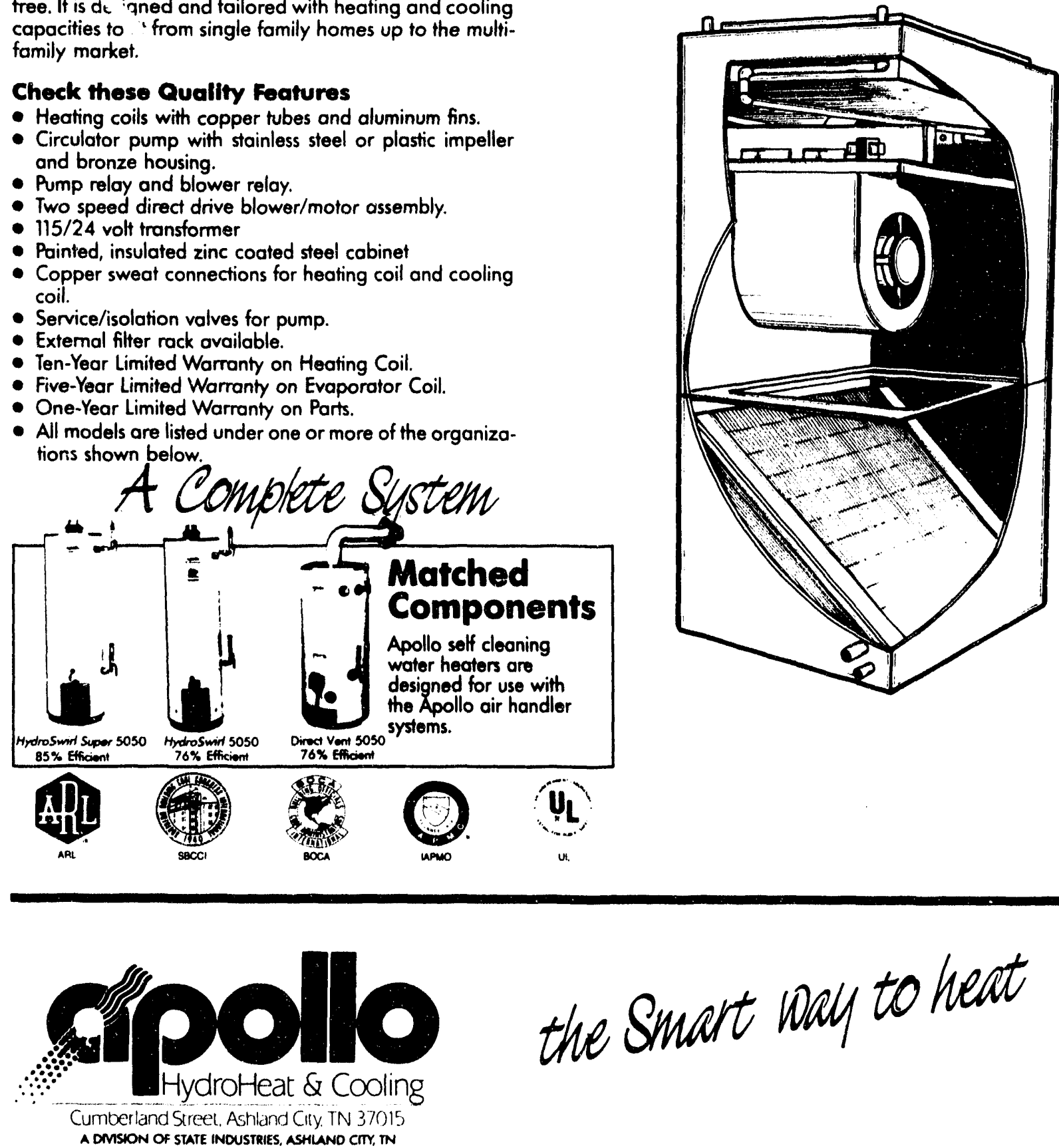

Cumberland Streel Ashland Cily TN 37015 


\section{Specifications}

\begin{tabular}{|c|c|c|c|c|c|c|c|c|c|c|c|c|c|c|c|c|c|c|c|}
\hline \multirow[b]{2}{*}{ Model } & \multirow[t]{2}{*}{$\begin{array}{l}\text { Nom. } \\
\text { Ho. } \\
\text { Clo., } \\
\text { BTUH }\end{array}$} & \multirow[t]{2}{*}{$\begin{array}{l}\text { Nom. } \\
\text { Cod } \\
\text { Ced. } \\
\text { BTUH }\end{array}$} & \multirow{2}{*}{$\begin{array}{l}\text { Nom. } \\
\text { CFM }\end{array}$} & \multicolumn{4}{|c|}{$\begin{array}{l}\text { Blowor } \\
\text { E.S.P. }\end{array}$} & \multirow{2}{*}{$\begin{array}{c}\text { Motor } \\
\text { MP }\end{array}$} & \multirow{2}{*}{$\begin{array}{l}\text { Pump } \\
\text { Motor } \\
\text { HP }\end{array}$} & \multirow{2}{*}{$\begin{array}{l}\text { Elec. } \\
\text { Cher. }\end{array}$} & \multirow{2}{*}{$\begin{array}{l}\text { Rated } \\
\text { Amps }\end{array}$} & \multirow{2}{*}{$\begin{array}{c}\text { Min. } \\
\text { Circult } \\
\text { Ampectiol }\end{array}$} & \multirow{2}{*}{$\begin{array}{l}\text { What } \\
\text { Conn } \\
1.0 \text {. }\end{array}$} & \multirow{2}{*}{\multicolumn{2}{|c|}{$\begin{array}{l}\begin{array}{l}\text { A.22 } \\
0 . D .\end{array} \\
\text { LISSL }\end{array}$}} & \multirow{2}{*}{$\begin{array}{l}\text { Ship } \\
\text { m. } \\
\text { Lbe. }\end{array}$} & \multirow{2}{*}{$\begin{array}{l}\text { Unit } \\
\text { Dim. }\end{array}$} & \multirow{2}{*}{$\begin{array}{l}\text { Supply } \\
\text { Conn. }\end{array}$} & \multirow{2}{*}{$\begin{array}{l}\text { Rotum } \\
\text { Conn. }\end{array}$} \\
\hline & & & & 0.1 & 0.2 & 0.3 & 0.4 & & & & & & & & & & & & \\
\hline$C B C-8 A$ & 30,800 & - & $\begin{array}{l}\text { LOW } \\
\text { SPD }\end{array}$ & 820 & 780 & 740 & 890 & \begin{tabular}{|l}
$/ 4 H P$ \\
$2 S P D$ \\
\end{tabular} & $1 / 20$ & $1.60-115 \mathrm{v}$ & 4.0 & 15 & $1 / 2 "$ & -1 & - & 78 & $\begin{array}{c}14^{\prime} W \mathrm{x} \\
202^{\prime \prime} \mathrm{D} \times 26^{\prime \prime} \mathrm{H} \\
\end{array}$ & $12^{n} \times 17^{n}$ & $121 / 2^{\prime \prime} \times 17^{\prime \prime}$ \\
\hline $\begin{array}{l}\text { E.24. } \\
\text { CBC. } 8 A\end{array}$ & 30,800 & $\begin{array}{l}18,000 / \\
24,000\end{array}$ & $\begin{array}{l}\text { HIGH } \\
\text { SPD }\end{array}$ & 830 & 770 & 700 & 630 & $\begin{array}{l}\text { 1/HPP } \\
\text { 2SPD }\end{array}$ & $1 / 20$ & $1-60.115 \mathrm{~V}$ & 4.0 & 15 & $1 / k^{n}$ & * & Hon $^{\prime \prime}$ & 106 & $\begin{array}{c}14^{n} W x \\
201 / 2 D \times 40^{n} H\end{array}$ & $12^{\prime \prime} \times 17^{\prime \prime}$ & $121 / 2 " \times 17^{\prime \prime}$ \\
\hline
\end{tabular}

\begin{tabular}{|l|c|c|c|c|c|}
\hline \multicolumn{7}{|c|}{ Heating Capsctiog" } \\
\hline E.W.T. & $130^{\circ} \mathrm{F}$ & $140^{\circ} \mathrm{F}$ & $150^{\circ} \mathrm{F}$ & $160^{\circ} \mathrm{F}$ & $170^{\circ} \mathrm{F}$ \\
\hline BTUH & 26,000 & 30,800 & 35,000 & 39,500 & 44,000 \\
\hline
\end{tabular}

`3 GPM, Nom. CFM, 65\% entering air temp. shaded area indicates recommended water heater temperature range

"Nom. cooling ( $a .45^{\circ}$ suction temp., 80 DB, 67WB return air, rated CFM

... Shaded area indicates recommended water heater temperature range.

\section{How Doos the Apollo Air Handler Work?}

The HydroHeat Air Handler is connected to a conventional heating or heating/cooling thermostat. When the thermostat calls for heat, the circulating pump in the air handler begins circulating the warm water from the water heater through the finned tube heating coil of the air handler. The air handler's blower has also been activated and the air passing over the heating coil is heated and blown into the home through the duct system. When the thermostat is satisfied, the pump and blower both stop.

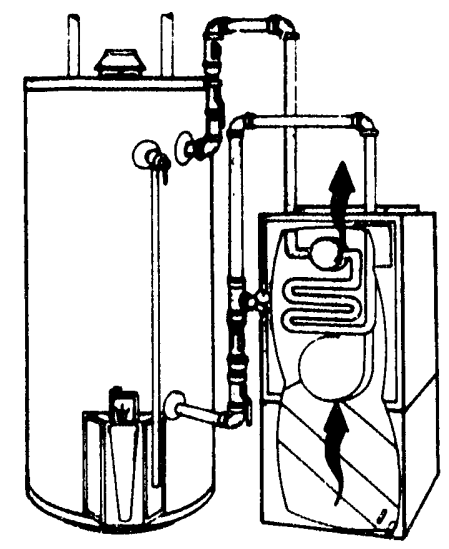

In keeping with our policy of continuous product improvement we reserve the right to make changes without prior notice.

\section{Air Handler/Wator Hoaror Sizing}

The air handler's heating capability must equal or exceed the (ACCA Method J) heat loss of the structure.

The water heater should be a minimum of $\mathbf{4 0}$ gallon capacity. The water heater's input (BTUH) must equal or exceed the capacity of the air handler's heating coil, when divided by the recovery efficiency of the water heater.

Assistance in sizing can be obtained from your Apollo Distributor. In addition, the Apollo Systems Handbook which includes installation and operation information, can be found under the "Installation Information" tab of the Apollo Catalog.

CBC-2-3-89 


\section{HYDROHEAT HH Senies Multi-Position Heating Systems}

\section{Multi-Position unit \\ Heating Capacities 14,700 through 19,300 BTUH Add-On Evaporator (Cooling Coil) Available in 1 Ton Capacity}

The HH Series is the most economical answer to the builder's needs for heating, with cooling coil available. This superior new heating system has one-third as many parts as a heat pump, making it virtually maintenance free. It is designed and tailored with heating and cooling capacities to fit from single family homes up to the multi-family market. Ideal for rehabilitation and replacement.

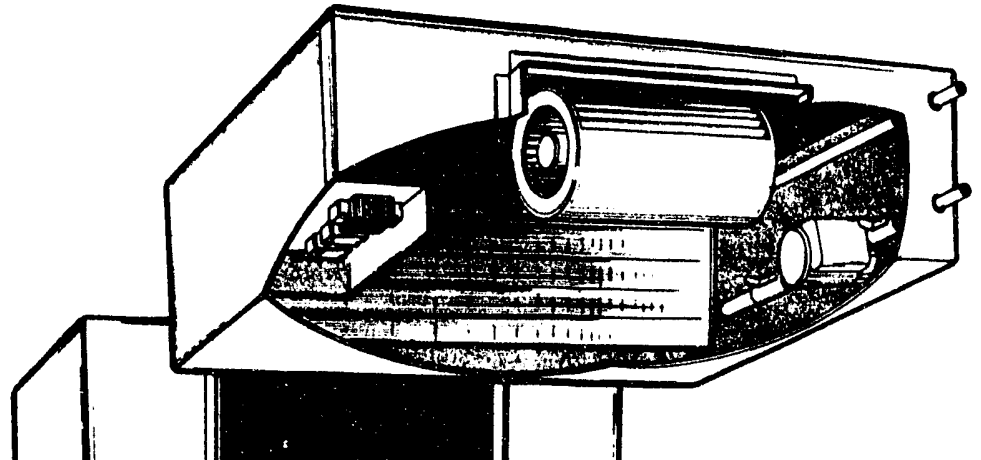

Check these Quality Features

- Heating coils with copper tubes and aluminum fins.

- Circulator pump with stainless steel or plastic impeller and bronze housing. Front mounted for ease of access.

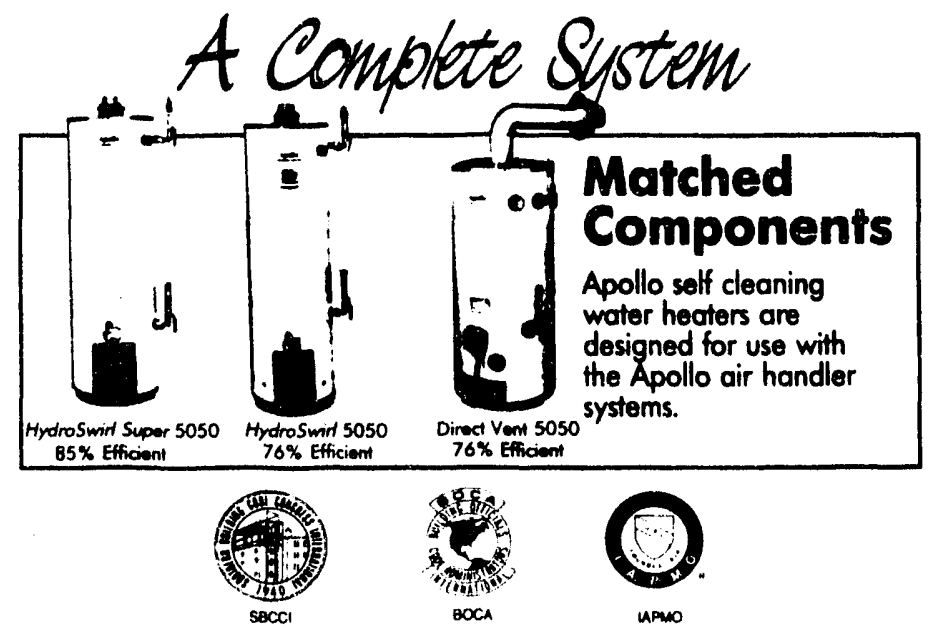

- Pump relay and blower relay.

- 115/24 volt transformer

- Painted, insulated zinc coated steel cabinet (one piece wraparound).

- Copper sweat connections for heating coil and cooling coil.

- Service/isolation valves for pump.

- Ten-Year Limited Warranty on Heating Coil.

- Five-Year Limited Warranty on Evaporator Coil.

- One-Year Limited Warranty on Parts.

- All models are listed under one or more of the organizations shown below.

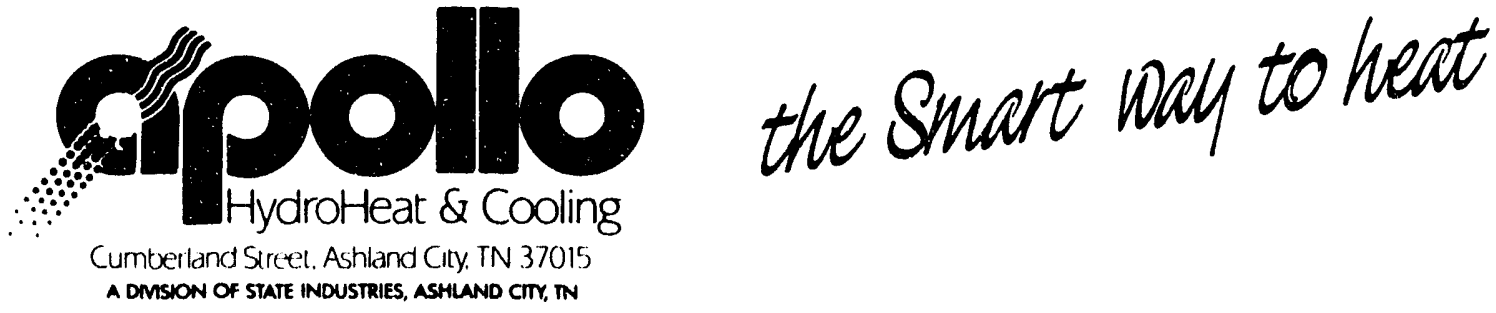




\section{Specifications}

\begin{tabular}{|c|c|c|c|c|c|c|c|c|c|c|c|c|c|}
\hline Model & $\begin{array}{l}\text { Nom. Hitg. } \\
\text { Cap. } \\
\text { BTUH. }\end{array}$ & $\begin{array}{l}\text { Nom. Clg. } \\
\text { Cap. } \\
\text { BTUH"- }\end{array}$ & $\begin{array}{l}\text { Nom. } \\
\text { CFM }\end{array}$ & $\begin{array}{l}\text { Blower } \\
\text { Motor } \\
\text { HP }\end{array}$ & $\begin{array}{l}\text { Pump } \\
\text { Molor } \\
\text { HP }\end{array}$ & $\begin{array}{l}\text { Eloc. } \\
\text { Char. }\end{array}$ & \begin{tabular}{c|} 
Min. \\
Circuit \\
Ampacity
\end{tabular} & $\begin{array}{l}\text { Water } \\
\text { Conn } \\
\text { I.D. }\end{array}$ & $\begin{array}{c}\text { Supply } \\
\text { Duct } \\
\text { Conn. }\end{array}$ & $\begin{array}{c}\text { Return } \\
\text { Duct } \\
\text { Conn. } \\
\end{array}$ & $\begin{array}{c}\text { Ship. } \\
\text { Wh. Lbs. }\end{array}$ & $\begin{array}{r}\text { R- } \\
\text { Conn } \\
\text { III } \\
\end{array}$ & $\frac{22}{S L}$ \\
\hline $\mathrm{HH} 2000-1$ & 19,000 & - & 480 & $1 / 5$ & $1 / 20$ & $1-60.115 v$ & 15 & $1 / 2^{\prime \prime}$ & $6^{n} \times 12^{n}$ & $7^{\prime \prime} \times 21^{1 / 2 n}$ & 45 & - & $=$ \\
\hline $\begin{array}{l}\mathrm{HH} 2000-1 \\
\text { with EH12 }\end{array}$ & 17,250 & 12,000 & 400 & $1 / 5$ & $1 / 20$ & $1.60 .115 v$ & 15 & $1 / 2^{n}$ & $6^{n} \times 12^{n}$ & $7^{\prime \prime} \times 211 \frac{1}{2^{n}}$ & 55 & $1 / 4$ & $3 / 6$ \\
\hline
\end{tabular}

Model HH2000-1/HH2000-1 w/EH12 Heating Capacities. (BTUH)

\begin{tabular}{|l|c|c|c|c|}
\hline E.W.T. & $130^{\circ} \mathrm{F}$ & $140^{\circ} \mathrm{F}$ & $150^{\circ} \mathrm{F}$ & $160^{\circ} \mathrm{F}$ \\
\hline 300 CFM & 12,716 & 14,723 & 16,739 & 18,764 \\
\hline 350 CFM & 13,863 & 16,058 & 18,263 & 20,480 \\
\hline 400 CFM & 14,885 & 17,247 & 19,622 & 22,010 \\
\hline 450 CFM & 15,804 & 18,318 & 20,846 & 23,389 \\
\hline 500 CFM & 16,639 & 19,292 & 21,960 & 24,645 \\
\hline
\end{tabular}

$3 \mathrm{GPM}$, Nom. CFM, $65^{\circ} \mathrm{F}$ entering air temp.

Shaded area indicates recommended water heater temperature range

"Nom. cooling @ $45^{\circ}$ suction temp., 80 DB, $67^{\circ}$ WB return air, rated CFM.

\section{How Doos The Apollo Air Handlor Work?}

The HydroHeat Air Handler is connected to a conventional heating or heating/cooling thermostat. When the thermostat calls for heot, the circulating pump in the air handler begins circulating the warm water from the water heater through the finned tube heating coil of the air handler. The air handler's blower has also been activated and the air passing over the heating coil is heated and blown into the home through the duct system. When the thermostat is satisfied, the pump and blower both stop.

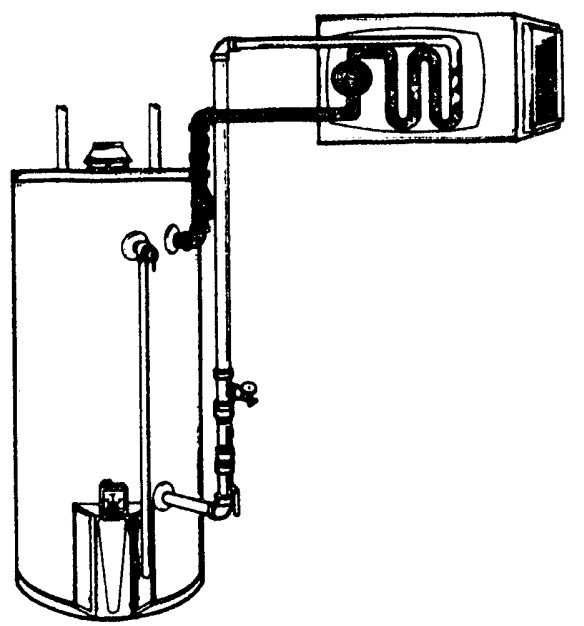

\begin{tabular}{|c|c|c|c|c|c|c|}
\hline \multicolumn{6}{|c|}{ Model HH2000-1/HH 2000-1 with EH12 CFM vs Static } \\
\hline ESP* (both) & .05 & .10 & .15 & .20 & .25 & .30 \\
\hline HH2000-1 & 515 & 500 & 490 & 480 & 465 & 435 \\
\hline $\begin{array}{c}\text { HH2000-1 } \\
\text { with EH12 }\end{array}$ & 440 & 430 & 410 & 400 & 390 & 370 \\
\hline
\end{tabular}

-ESP must include fitter and duct pressure drop.
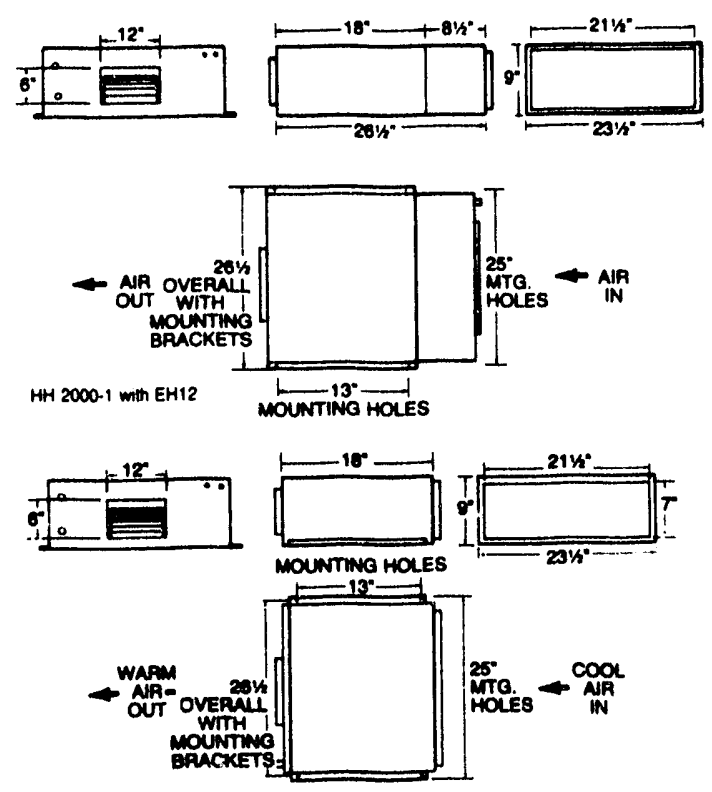

HH 2000-1

In keeping with our policy of continuous product improvement we reserve the right to make changes without prior notice.

\section{Air Handler/Water Hearor Sizing}

The air handler's heating capability must equal or exceed the (ACCA Method J) heat loss of the structure.

The water heater should be a minimum of $\mathbf{4 0}$ gallon capacity. The water heater's input (BTUH) must equal or excoed the capacity of the air handler's heating coil, when divided by the recovery efficiency of the water heater.

Assistance in sizing can be obtained from your Apollo Distributor. In addition, the Apollo Systems Handbook which includes installation and operation information, can be found under the "Installation Information" tab of the Apollo Catalog. 


\section{HYDROHEAT RFC Series Multi-Poshion Heating Syatoms \\ Vortical or Horizonfal Air Flow Heating Capacifies up to 57,500 BTUH}

The RFC Series is the most economical answer to today's needs for heating. This superior new heating system is virtually maintenance free. It is designed and tailored with heating capacities to fit from single family homes up to the multi-family market. Ideal for the retrofit market.
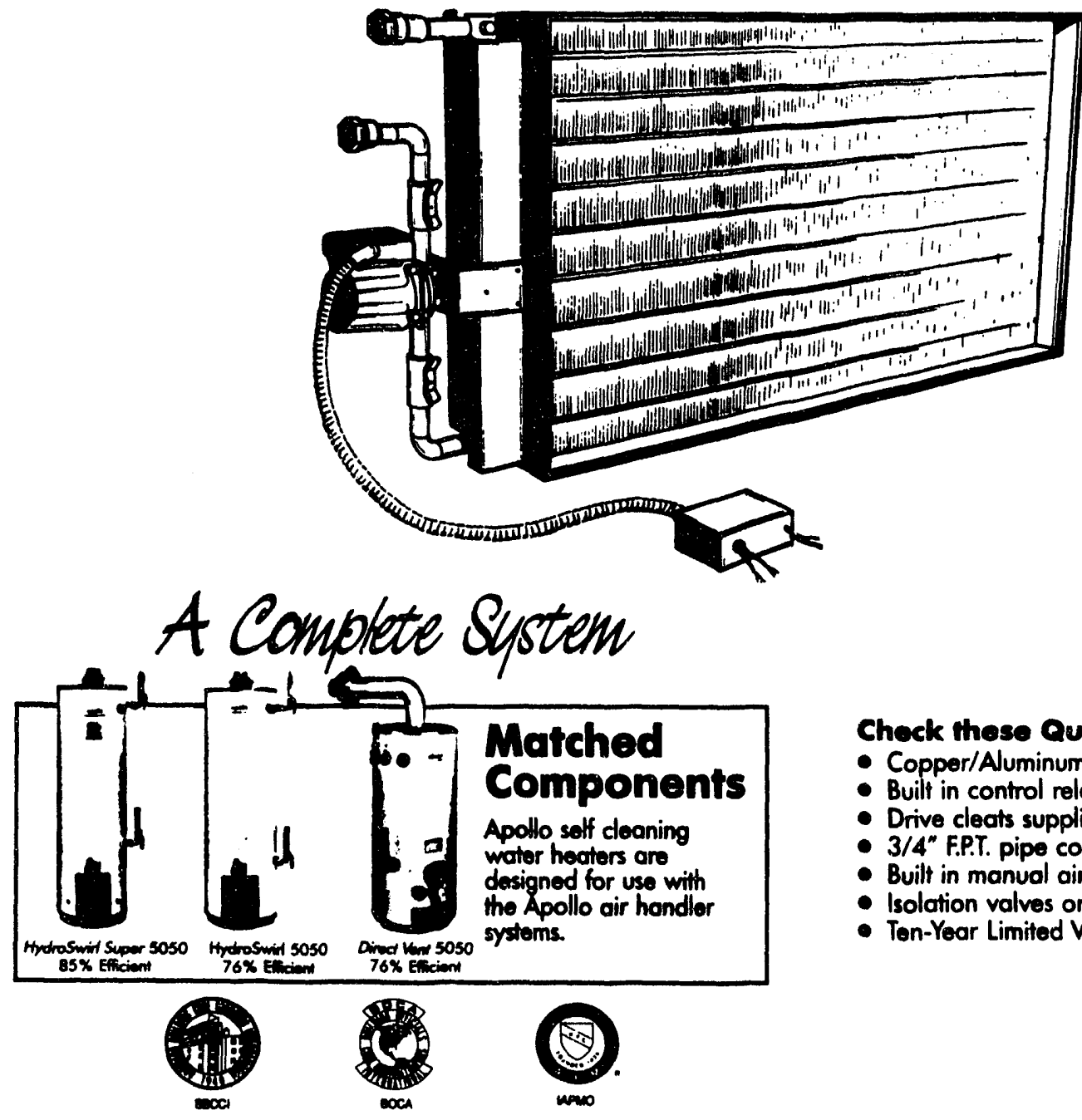

Chock these Qualtity Foatures

- Copper/Aluminum construction

- Built in control relay

- Drive cleats supplied on short side of coil

- 3/4" F.P.T. pipe connections

- Built in manuol air vent

- Isolation valves on pump

- Ton-Year Limited Warranty on Heating Coil

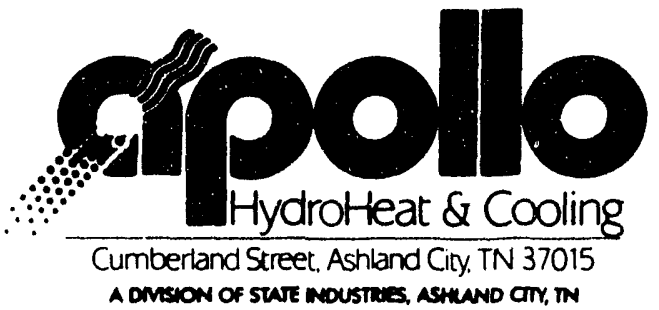

the smart way to heat

Cumberland Street. Ashland City. TN 37015 


\section{Specifications}

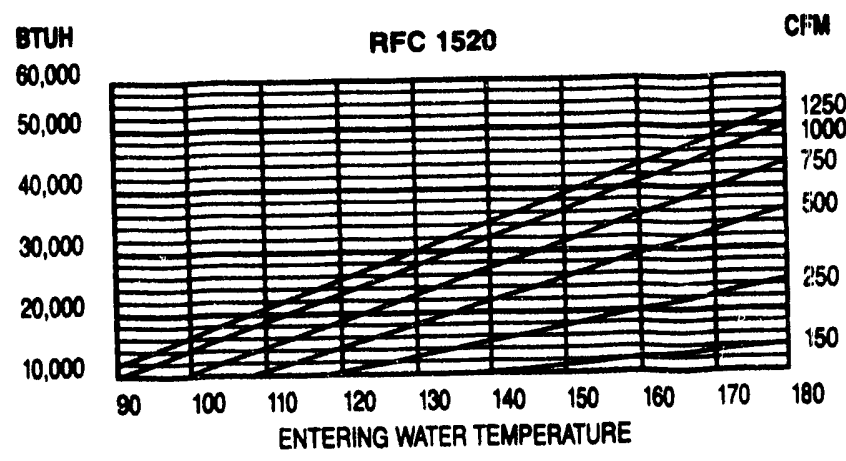

BTUH

60,000

50,000

40,000

30,000

20,000

10,000

BTUH

60,000

50,000

40,000

30,000

20,000

10,000

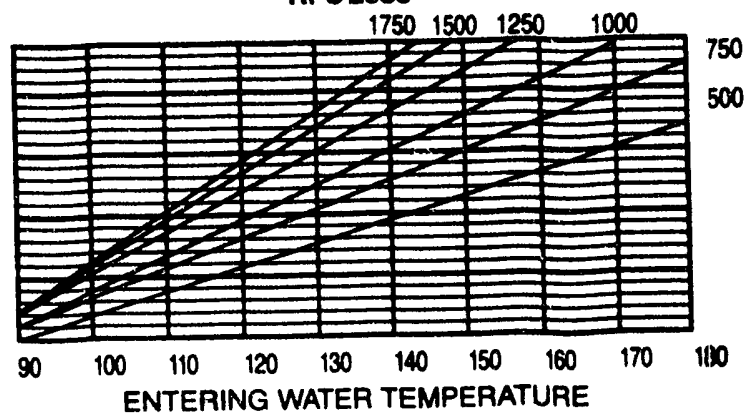

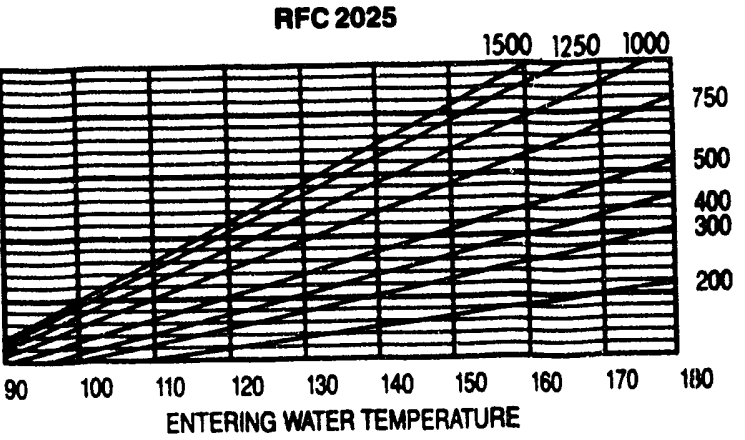

\section{How Does The Apollo Coll Work?}

The HydroHeat Coil is connected to a conventional heating or heating/cooling thermostat. When the thermostat calls for heat, the circulating pump on the coil begins circulating the warm water from the water heater through the finned tube heating coil. The blower has also been activated and the air passing through the heating coil is heated and blown into the home through the duct system. When the themostat is satisfied, the pump and blower both stop.
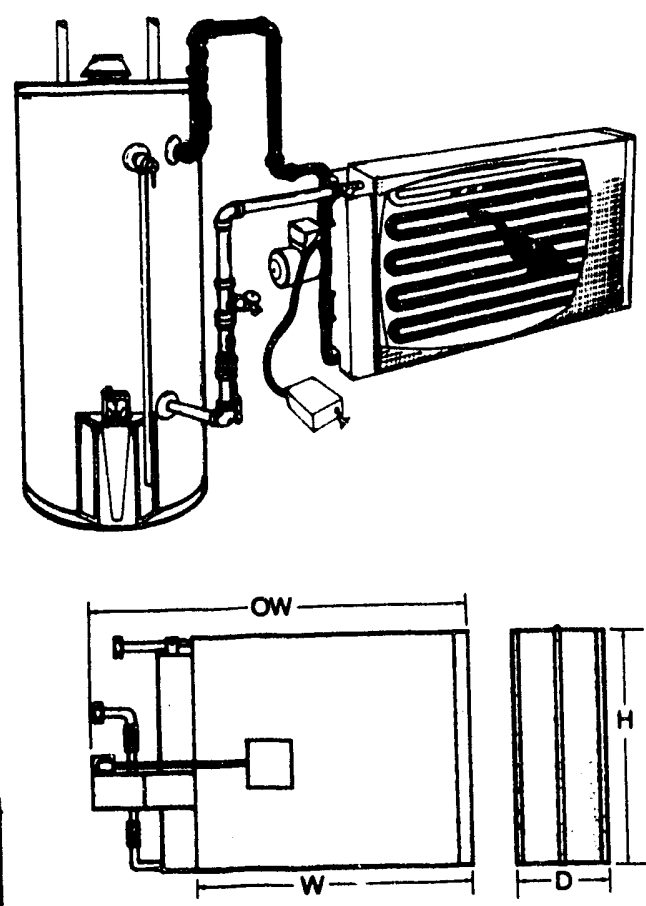

\begin{tabular}{|c|c|c|c|c|c|c|}
\hline \multicolumn{7}{|c|}{ RFC NA FLOWPAESSUAE DAOP (WCHES OF WAIUE) } \\
\hline coll & $\begin{array}{c}\mathrm{AT} \\
500 \mathrm{CF}\end{array}$ & $\begin{array}{c}\text { AT } \\
750 \mathrm{CFM}\end{array}$ & $1000 \mathrm{CP}$ & $A T$ & $1000 \mathrm{CF}$ & 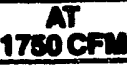 \\
\hline RFC 1520T & .039 & .081 & .135 & .201 & - & - \\
\hline RFC2025T & .016 & .033 & .054 & .082 & .112 & .148 \\
\hline RFC2030T & .011 & .024 & .039 & .060 & .084 & .115 \\
\hline
\end{tabular}

\section{CollWoter Heater Sizing}

The coil's heating capability must equal or exceed the (ACCA Method J) heat loss of the structure.

The water heater should be a minimum of $\mathbf{4 0}$ gallon capacity. The water heater's input (BTUH) must equal or exceed the capacity of the heating coil, when divided by the recovery efficiency of the water heater.

Assistance in sizing can be obtained from your Apollo Distributor. In addition, the Apollo Systems Handbook which includes installation and operation information, can be found under the "Installation Information" tab of the Apollo Catalog.

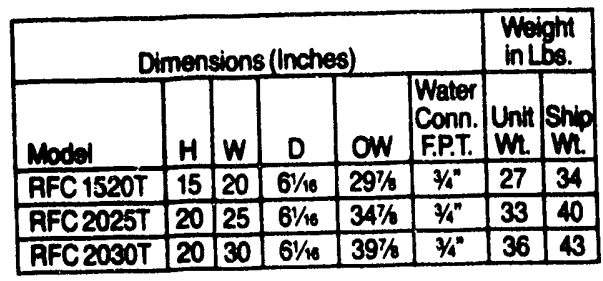

In keeping with our policy of continuous product improvement we reserve the right to make changes without prior notice.

RFC-8-1-88 


\section{New Models Added for 1992!}

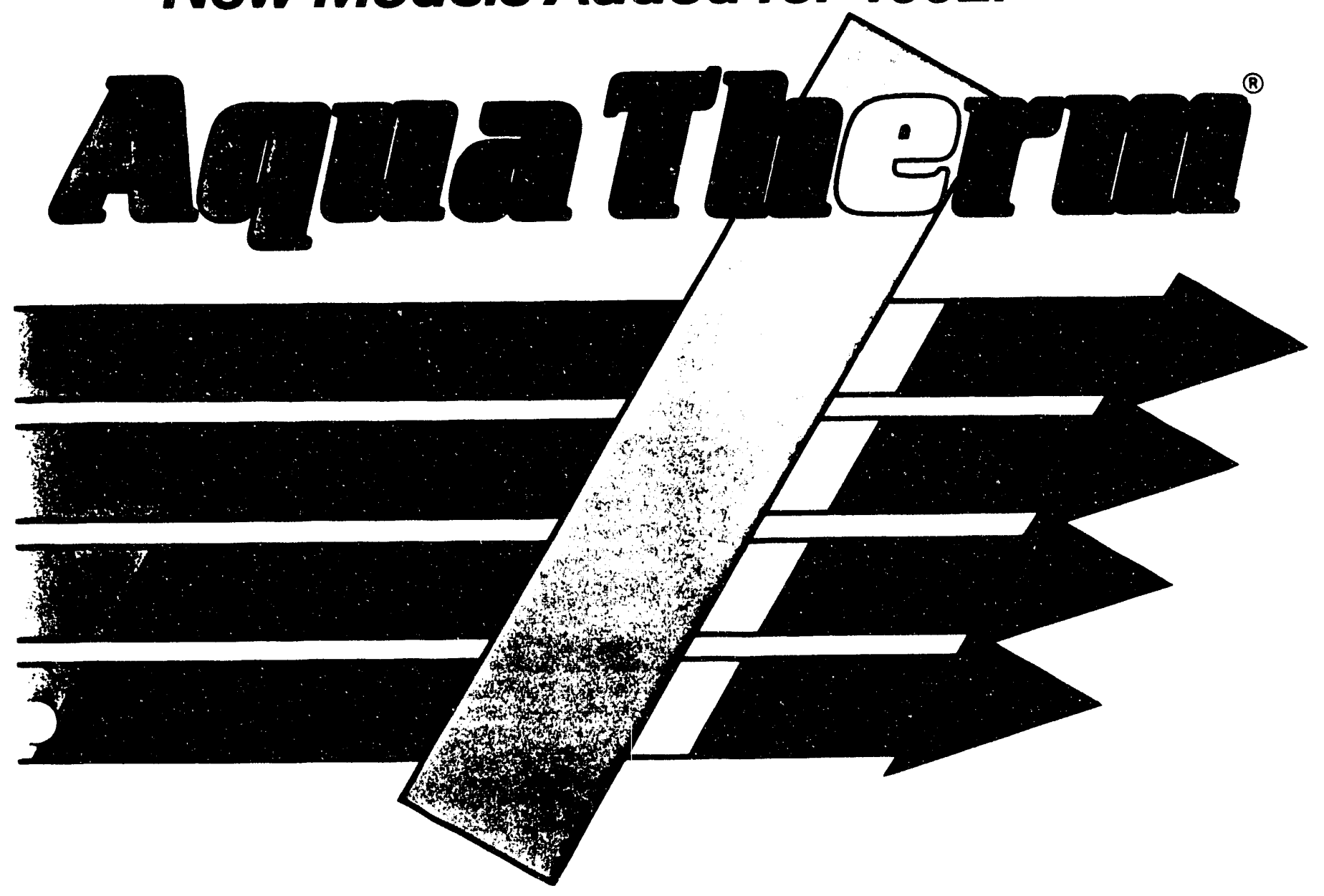

\section{By FIRST CO.}

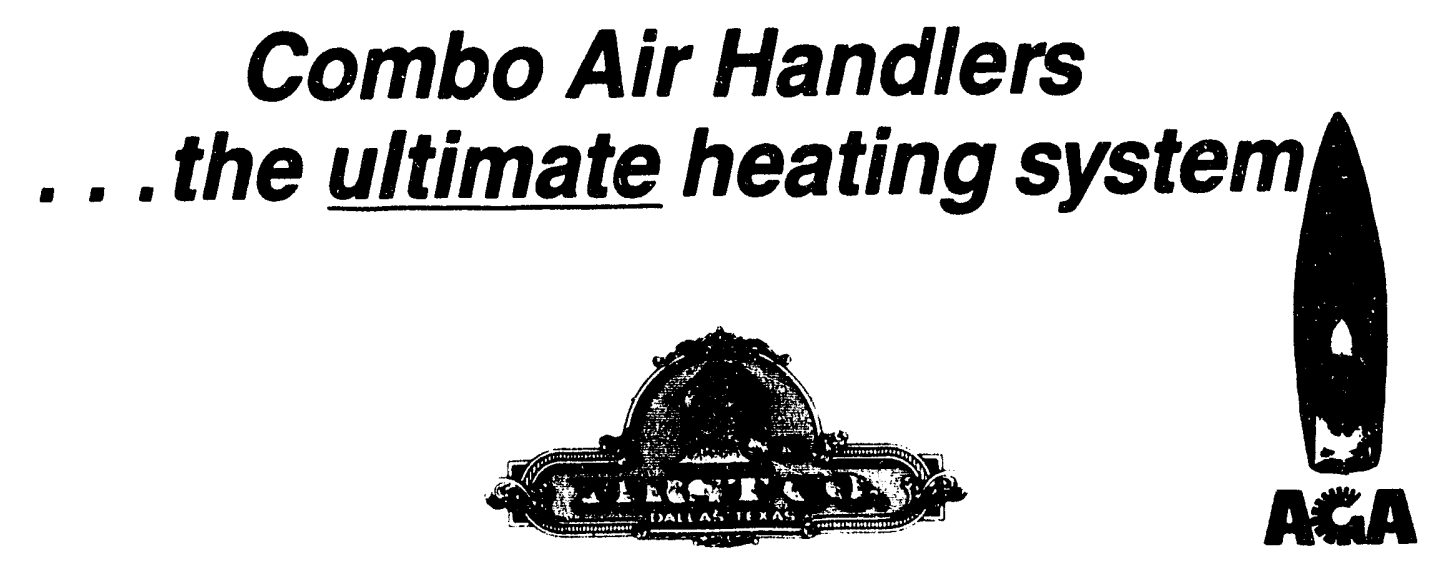




\section{High Efficiency The , (c) ranter T 0 Space (B)

\section{The "Integrated" Appliance} has Arrived!

Tested for over 16 years in the laboratory and in the field, the AQUA THERM System - a FIRST CO. air handler - converts any properly sized gas or oil-fired water heater into a highly efficient, dual-purpose appliance that can heat your home as well as provide hot water for domestic purposes. And it doesn't make any difference where you live!

Any properly sized water heater (for heating) and split system type condensing unit (for cooling) will work with FIRST CO. AQUA THERM air handlers. No special water heeter is required. NOTE: FIRST CO. onty supplies the AQUA THERM Air Handler.

AQUA THERM air handlers consist of a fan motor for air circulation, hot water circulating pump, hot water heating coil, air purge valve, check valve, components for low voltage control, and most include a cooling coil for air conartioning. All components in the water piping are aprrived for potable water use.

\section{Sequence of Operation (Heating mode)}

When space heating is needed, the wall thermostat energizes a small pump which circulates hot water (135 to 140 degrees) from the water heater to the hot water coil in the air handler. As the fan motor forces the cool retum air from the home over the hot water coil, the air absorbs heat from the hot water and this warm air (about 105 to 110 degrees) is then circulated throughout the duct system and into the home. MPOATANT... in most applications the water will lose only 15 to 25 degrees in temperature while circulating through the hot water coil and will RETURN to the water heater at about 120 to 130 degrees to be reheated!

\section{High Efficiency from your Water Heater}

Laboratory and field tests have proven thai the more a water heater is used the more effic ant it is. While the "recovery efficiency" (maximum operating efficiency) of most water heaters is from 76 to $85 \%$, their "annuzl efficiency" is only 50 to $60 \%$ because of standby and other miscellaneous losses. However, when used for SPACE HEATING as well as domestic water heating the "annual efficiency" is increased dramatically. The equivalent A.F.U.E. of this system will be 2 to 3 percentage points above the recovery efficiency of the water heater.

Compared to the standard heat pump system with an electric water heater, the AQUA THERM System from FIRST CO. can cut the utility bills IN HALF and can save even more when compared to straight electric heat! The AQUA THERM System can even save over $16 \%$ compared to a standarn gas furnace with a gas water heater.

Water heater efficiency intormation may be obtained from the water heater manufacturer or the latest Gas Appliance Manufacturers Association (GAMA) Directory.

\section{Additional Benefits}

Low maintenance costs: The AQUA THERM System is extremely simple and uncomplicated compared to other high efficiency heating systems. Normal maintenance and service on the heating system can be pertormed easily and quickly because of the lack of sophisticated controls.

Consistentty warm air: A property sized AQUA THERM System will provide warm, comfortable air temperatures no matter what the temperature is outside. Heat pumps, however, tend to blow cooler air as the temperature outside drops.

No venting or gas piping of the air handler to required: The AQUA THERM air handler can be installed virtually anywhere without worrying about costly venting or gas piping.

Cimpatible with most condensing units: All AQUA THERM air handlers with cooling coils are completely compatible with most major brands of condensing units manufactured by Carrier, Pheem, Lennox, etc. Contact the factory for capacity and efficiency information on specific combinations.

Compatible with All ges or oil-fired weter hoeters and boilers: This allows you to package the most efficient heating and cooling system together at the best possible price. NO SPECIAL WATER HEATER IS REQUIRED.

Longer water heater life: Water heaters used for space heating in conjunction with AQUA THERM air handlers have shown dramatically less internal scaling and corrosion due to the gentle increase in water circulation caused by the pump.

Reduced electrical service requirements: All AQUA THERM air handlers operate on 120 volts and only draw 2 to 13 amps. In addition to being inexpensive to operate, the AOUA THERM System will save even more money on overall electrical installation costs smaller distribution panels and less wiring for electric water heaters and electric heating elements.

\section{Air Handlers for Every Application}

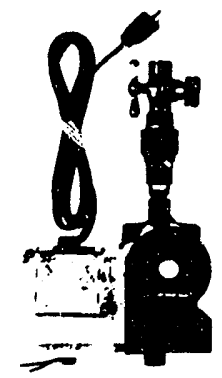

FIRST CO. has been building AQUA THERM air handlers since 1974 and now offers Ten different air handler models plus an add-on hot water coil.

MAQ, VAQ and RAQ Series air handlers have factory installed circulating pumps and controls while all other air handiers and addon hot water coils feature the FIRST $\mathrm{CO}$. exclusive extemal "flow control module" for flexible field installation anywhere between the water heater and air handier. 


\section{from a Wat
FIRST CO.}

The "flow control module" is a U.L. listed device that consists of the circulating pump. check valve, pump relay, and 6' plug-in line cord and is designed to circulate a precise amount of hot water between the water heater and air handler or coil.

All air handlers and/or "flow control modules" include large air purge valves for faster air purging during start-up.

\section{Equipment sizing}

(For complete installation and application manual, order catalog number "IAM").

\section{Air handler}

Select an air handler with a heating output that exceeds the space heat loss and that has a cooling coil matched to the outdoor condensing unit.

Please note that the heating output of the air handler (BTUH) will not be greater than the NET BTUH of the selected water heater (BTUH INPUT $\times$ RECOVERY EFFICIENCY.

\section{Water Heater}

Add 10 to $20 \%$ to the structure's heat loss to obtain the minimum OUTPUT of the required water heater

(Output = Input $\times$ Rocovery Efficioncy).

A minimum 40 gallon high recovery and/or high efficiency gas or oilfired water heater is recommended. In addition to the above formula, the following volume sizing guide is satisfactory in most parts of the country:

600-800 CFM air handlers - minimum 40 gallon water heater 1000-1200 CFM air hancters - minimum 50 gallon water heater

1400-1600 CFM air handiers - either two 40 gallon water

heaters piped together, one high input 50 gallon $(63,000$ to

75,000 BTU input), or one 72 to 75 gallon.

2000 CFM air handlers - any combination of water heaters having at least 98,000 BTU Output.

For additional assistance in water heater sizing contact the factory or a qualified professional engineer.

\section{Condenaing unit}

Selection of the condensing unit size should be determined by the "Manual J" method or other approved heat load/gain calculation procedure.

Approved cooling capacities and efficiency information are available upon request from FIRST $\mathrm{CO}$. once the manufacturer name and model number of the outdoor condensing unit are provided.

\section{- Thermosiat}

Any 24 volt thermostat having positive heat and cool fan cycle control should be used. This is usually called an "electric heat" thermostat. A gas furnace thermostat will only work with Saries $M A Q, V A Q$ and $P A Q$ air handlers.

\section{Water piping}

Water piping between the water heater and air handler should be $3 / 4^{\prime \prime}(1 "$ on $60 \mathrm{MAQ}$ ) nominal copper or other approved material and should be insulated to prevent freezing and to minimize heat loss if penetrating an unconditioned space.

To prevent air lock of the pump, the piping connections to and from the air handler must come from the horizontal connections of the " $T$ " fittings in the vertical hot and cold water supply lines at the water heater. (See diagram above.)

Maximum distance between the water heater and air handler should not exceed 100 feet (one way). 


\section{AlatLerto \\ VAQ Series Upflow/Horizontal Air Handler}

\section{Features:}

Installed circulating pump and check valve

- Large air purge valve

Copper tube/aluminum fin heating and cooling coils

- Piston type metering on cooling coil

Factory installed filter

- Primary and secondary drain connections

- Manual air vent on hot water coil

Blower door safety switch

Attractive beige baked-on finish

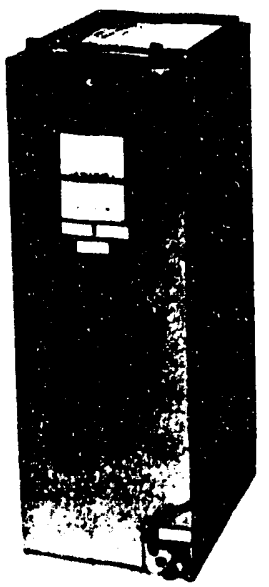

Notes:

1. BTUH capecities are based on $140^{\circ} \mathrm{EWT}, 70^{\circ}$ EAT.

2. Consult factory for boiler applications.

3. Accessories: (Field installed)

1. Horizontal Drain Pans (Air flow right to left) *935-1 fits 24 through 36 VAQ (not $18 \mathrm{VAQ}$ )

\#935-2 fits 42 and $48 \mathrm{VAO}$

2. Froeze Protector - \#941-1 brings on pump below $38^{\circ}$

\section{MAQ Series Upflow/Horizontal Air Handler}

\section{Features:}

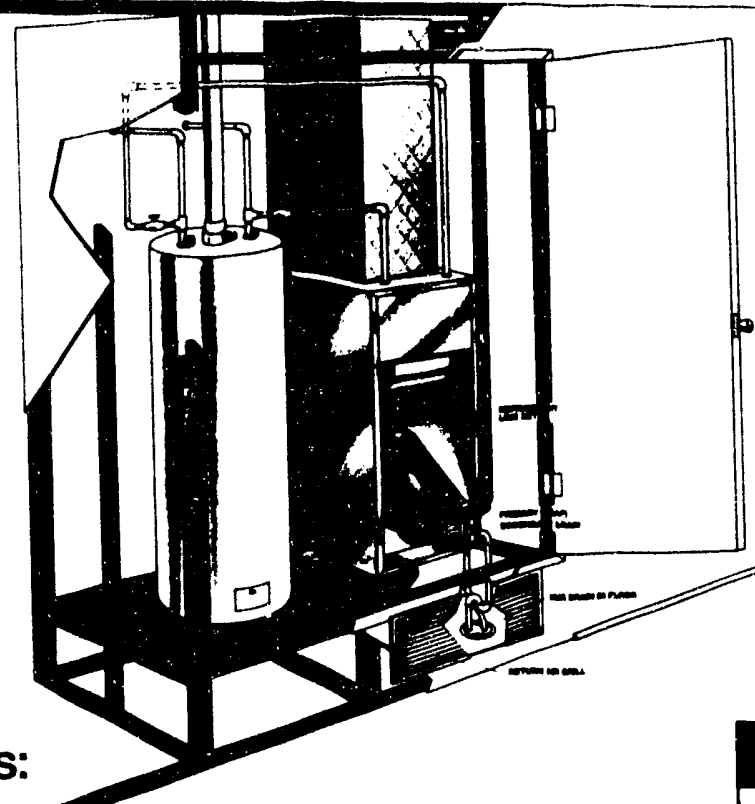

In addition to all of the above VAQ features, the MAQ Series has:

- Extra large high efficiency cooling coil for proper matching with today's higher efficiency condensing units.

- Field installable expansion valve kit for more efficient cooling performance.

- Factory installed horizontal drain pan (right to left airflow).

Slide out hot water coil assembly for easier service.
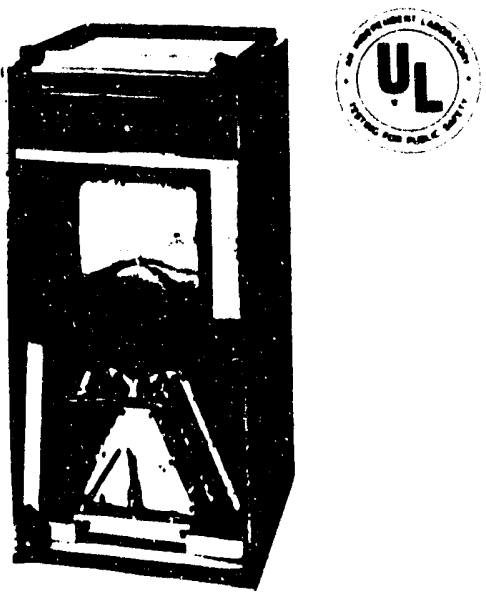

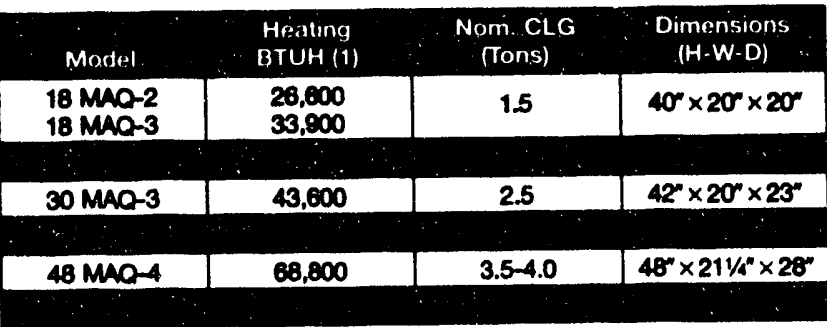

Notes:

1. BTUH capacities are based on $140^{\circ}$ EWT, $70^{\circ}$ EAT.

2. Accessories: (Field installed)

1. Expanelon valve kits - (Contact factory for Kit \#'s).

2. Freaze protector - $\# 941$ - 1 brings on pump below $38^{\circ}$. 


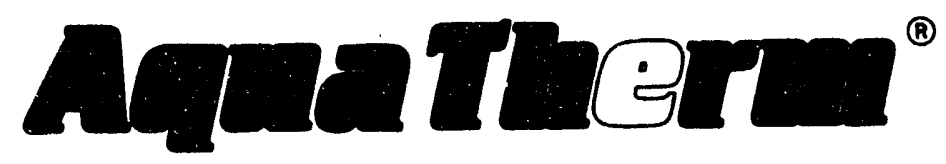

\section{RAQ Series \\ Wall or Closet Vertical Air Handler}

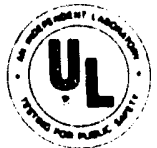

Features:

Installed circulating pump and check valve

- Large air purge valve

- Blower door safety switch

- Cap Tube metering on cooling coil (piston type optional)

- Copper tube/aluminum fin heating and cooling coils

- Optional wall panel for recessed wall mounting

- Factory installed filter

- Primary and secondary drain connections

- Manual air vent on hot water coil

- Completely serviceable from the front

\begin{tabular}{|c|c|c|c|}
\hline Model & $\begin{array}{l}\text { Heating } \\
\text { BTUH (1) }\end{array}$ & $\begin{array}{l}\text { Nom. Clg. } \\
\text { (Tons) }\end{array}$ & $\begin{array}{c}\text { Dimensions } \\
(H-W-D)\end{array}$ \\
\hline $\begin{array}{l}18 \text { RAQ - } 2 \\
18 \text { RAO - } 3\end{array}$ & $\begin{array}{l}20,200 \\
28,000\end{array}$ & 1.5 & $39 \mathrm{y}_{4}^{\prime \prime} \times 20 \mathrm{~K}^{\prime \prime} \times 16 \mathrm{~K}^{\prime \prime}$ \\
\hline 30 RAQ - 3 & 43,000 & 2.5 & $44 \mathrm{~K}^{\prime \prime} \times 24 \mathrm{~K}^{\prime \prime} \times 21 \mathrm{~K}^{\prime \prime}$ \\
\hline
\end{tabular}

Notes: 1. BTUH capacities are based on $140^{\circ} \mathrm{EWT}, 70^{\circ} \mathrm{EAT}$.

2. Consult factory for boiler applications.

3. Accessorias: (Field installed)

Wall Panels (Req'd for recessed wall mounting)

1. \#961 - Fits $18 / 24$ RAQ

2. \#962 - Fits 30/36 RAQ

Hanger Bracket - attaches to inside closet wall for air handler hanging - \#919-2

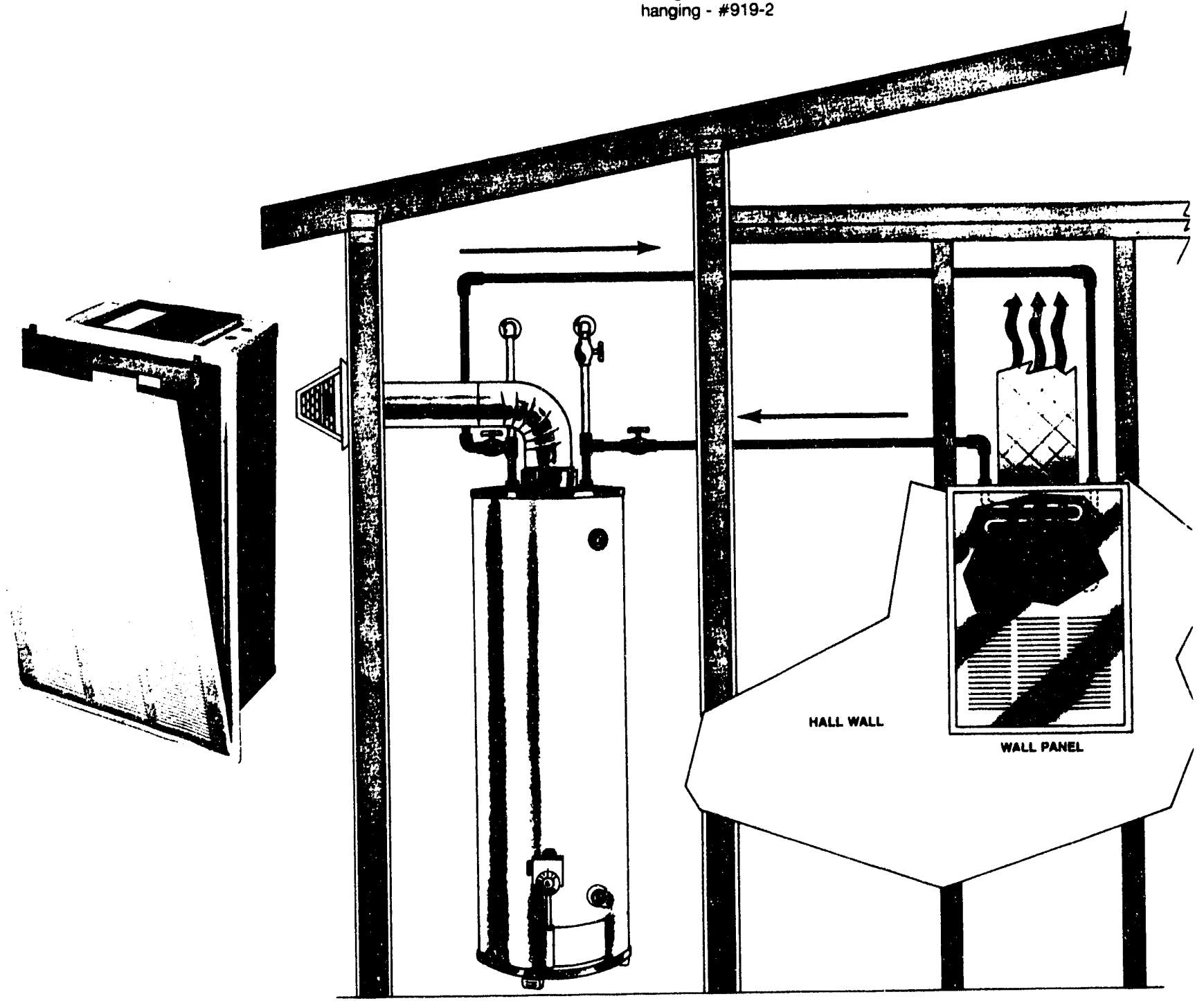




\section{RCUA-HW Series Cased Horizontal Air Handler}

\section{Features:}

- Completely cased

- Factory installed filter

- Bottom return air (Rear Return Optional)

- Completely serviceable from below the unit

- Unit shipped with access/return air panel

- Primary and secondary drain connections

- Manual air vent on hot water coil

- Compact size - only $11^{\prime \prime}$ high

- Copper tube/aluminum fin heating and cooling coils

Mounting brackets furnished with unit

- Piston-type metering device on cooling coil

- Shipped with exclusive U.L. listed "Flow Control" module

\begin{tabular}{|c|c|c|c|}
\hline Model & $\begin{array}{l}\text { Heating } \\
\text { BTUH (1) }\end{array}$ & $\begin{array}{l}\text { Nom Clg } \\
\text { (Tons) }\end{array}$ & $\begin{array}{c}\text { Dimensions } \\
\text { (H-W.D) }\end{array}$ \\
\hline 18 RCUA-2HW & 20,000 & 1.5 & $11^{\prime \prime} \times 351 / z^{\prime \prime} \times 241^{\prime \prime}$ \\
\hline
\end{tabular}

Notes:

1. BTUH capacities are based on $140^{\circ}$ EWT, $70^{\circ}$ EAT, and FIRST CO. Flow Control Module.

2. Consult factory for boiler applications

\section{HBC-HW Series Uncased Horizontal Air Handler}

\section{Features:}

Copper tube/aluminum fin heating and cooling coils

- Insulated drain pan

- Primary and secondary drain connections

a Manual air vent on hot water coil

- Compact size - only $10^{\prime \prime}$ high

- Shipped with exclusive U.L. listed "Flow Control" module

\begin{tabular}{|c|c|c|c|}
\hline Model & $\begin{array}{c}\text { Heating } \\
\text { BTUH (1) }\end{array}$ & $\begin{array}{c}\text { Nom Clg: } \\
\text { (Tons) }\end{array}$ & $\begin{array}{c}\text { Dimenisions } \\
(\text { H-W.D) }\end{array}$ \\
\hline $12 \mathrm{HBC-HW}$ & 14,600 & 1.0 & $10^{\prime \prime} \times 36 \%^{\prime \prime} \times 21^{\prime \prime}$ \\
\hline $24 \mathrm{HBC-HW}$ & 23,800 & 2.0 & $10^{\prime \prime} \times 46 \mathrm{H}^{\prime \prime} \times 21^{\prime \prime}$ \\
\hline $36 \mathrm{HBC-HW}$ & 31,600 & 3.0 & $10^{\prime \prime} \times 59 \%^{\prime \prime} \times 21^{\prime \prime}$ \\
\hline
\end{tabular}

Notes:

1. BTUH capacities are based on $140^{\circ} \mathrm{EWT}, 70^{\circ} \mathrm{EAT}$, and FIRST CO. Flow Control Module.

2. Consult factory for boiler applications

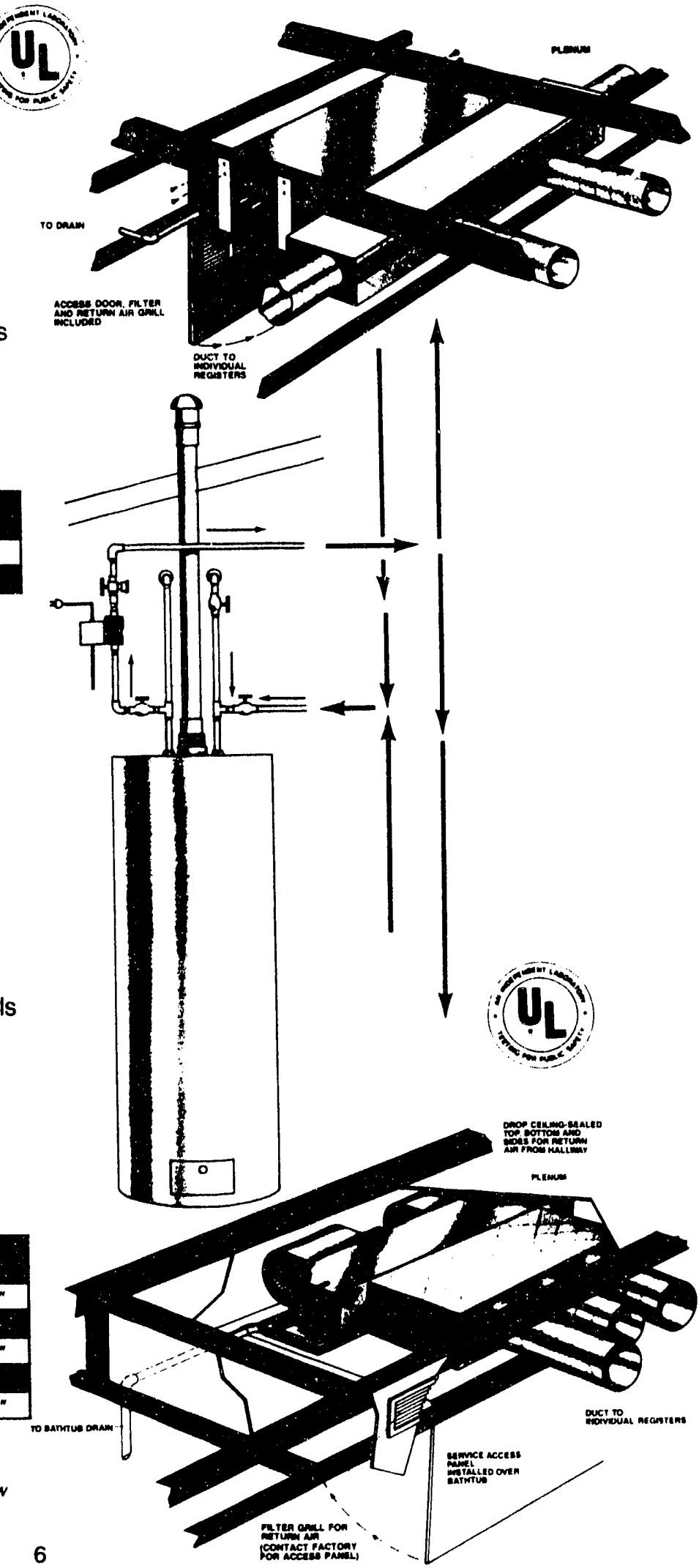


XVAQ Series Upflow, Downflow, Horizontal Heating only Air Handler

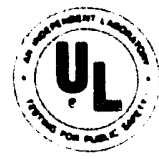

\section{Features:}

- Installed circulating pump and check valve

- Large air purge valve

- Blower door safety switch

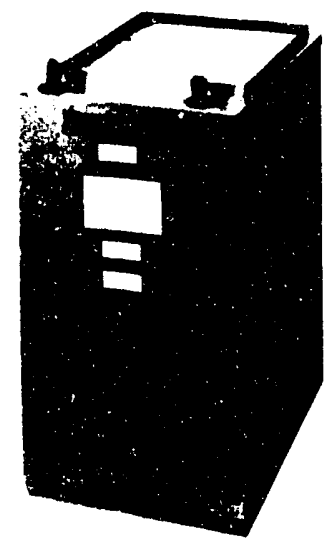

- Copper tube/aluminum fin heating coil

- Factory installed filter

- Attractive beige baked-on finish

- Compact size - $\max 27^{\prime \prime}$ tall

\begin{tabular}{|c|c|c|c|}
\hline Model & $\begin{array}{c}\text { Heating } \\
\text { BTUH (1) }\end{array}$ & $\begin{array}{c}\text { CFM } \\
((i .1 \text { ESP })\end{array}$ & $\begin{array}{c}\text { Dimensions } \\
\text { (H-W-D) }\end{array}$ \\
\hline XVAQ 22-2 & 21,800 & 710 & $25^{\prime \prime} \times 14^{\prime \prime} \times 20^{\prime \prime}$ \\
\hline & & & \\
\hline XVAQ 50-3 & 49,500 & 1320 & $27^{\prime \prime} \times 20^{\prime \prime} \times 23^{\prime \prime}$ \\
\hline
\end{tabular}

Notes:

1. BTUH capacities are hased on $140^{\circ}$ EWT and $70^{\circ}$ EAT.

HWF Series Upflow, Downflow, Horizontal Heating only Air Handler

\section{Features:}
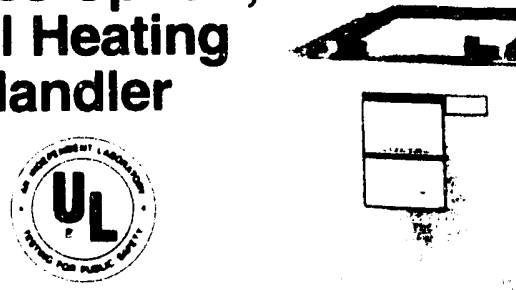

- Copper tube/aluminum fin heating coil

- Factory installed filter

- Manual air vent on hot water coil

- Attractive beige baked-on finish

- Blower door safety switch

- Shipped with exclusive U.L. listed "Flow Control" module

Blower delay relay

\begin{tabular}{|c|c|c|c|}
\hline Model & $\begin{array}{c}\text { CFM } \\
\text { Range }\end{array}$ & $\begin{array}{c}\text { Heating } \\
\text { BTUH (1) }\end{array}$ & $\begin{array}{c}\text { Dimensionis } \\
(H-W-D)\end{array}$ \\
\hline HWF 32-3 & $710-980$ & 32,000 & $2434^{\prime \prime} \times 17 \% \%^{\prime \prime} \times 201 / 4^{\prime \prime}$ \\
\hline & & $\ddots$ & \\
\hline HWF 60-4 & $1020-1780$ & 60,500 & $28 y^{\prime \prime} \times 21 \% 6^{\prime \prime} \times 281 / 4^{\prime \prime}$ \\
\hline
\end{tabular}

\section{Notes:}

1. BTUH capacities are based on $140^{\circ}$ EWT, $70^{\circ}$ EAT and FIRST CO. FIow Control Modula.

2. Consult factory for boiler applications.
HAQ Series Upflow, Downflow, Horizontal Heating only Air Handler

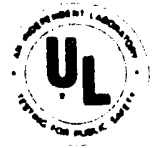

\section{Features:}

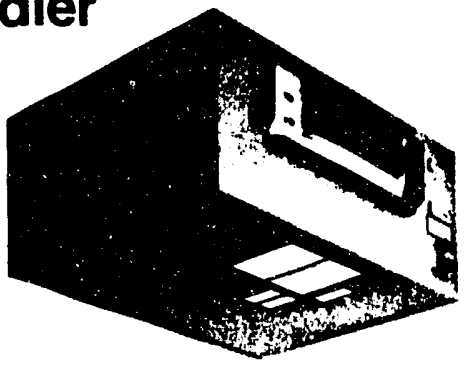

Installed circulating pump and check valve

- Large air purge valve

- Blower door safety switch

- Copper tube/aluminum fin heating coil

- Attractive beige baked-on finish

- Compact size - only $10^{\prime \prime}$ high

\begin{tabular}{|c|c|c|c|}
\hline Model & $\begin{array}{c}\text { Heating } \\
\text { BTUH (1) }\end{array}$ & $\begin{array}{c}\text { CFM } \\
((i) .1 \text { ESP) }\end{array}$ & $\begin{array}{c}\text { Dimensions } \\
(H-W-D)\end{array}$ \\
\hline HAQ 18-2 & 19,000 & 380 & $10^{\circ} \times 231^{\prime \prime} \times 1814^{\prime \prime}$ \\
\hline
\end{tabular}

Notes:

1. BTUH capacities are based on $140^{\circ}$ EWT and $70^{\circ}$ EAT.

\section{HWC Series Add-on Heating Coil} for Duct Mounting

\section{Features:}

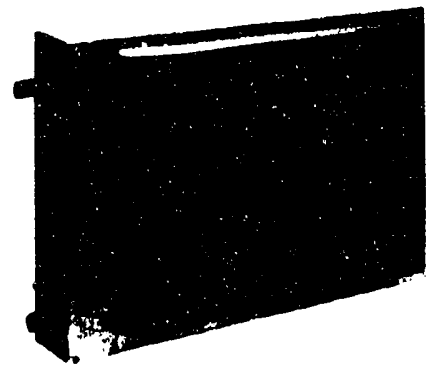

- Copper tube/aluminum fin heating coil

- Can be mounted in new or existing duct

- Vertical or horizontal mounting

- Shipped with exclusive U.L. listed "Flow Control" module

- Completely insulated cabinet

- Manual air vent on hot water coil

\begin{tabular}{|c|c|c|c|c|}
\hline Model & $\begin{array}{l}\text { CFM } \\
\text { Range }\end{array}$ & $\begin{array}{l}\text { Heating } \\
\text { BTUH (1) }\end{array}$ & $\begin{array}{l}\text { Face } \\
\text { Area }\end{array}$ & $\begin{array}{l}\text { Dimensions } \\
(H \cdot W-D)\end{array}$ \\
\hline HWC 1520 & $800-1200$ & 38,300 & $15 \times 20$ & $17^{\prime \prime} \times 37 / 6^{\prime \prime} \times 241 / 2$ \\
\hline HWC 2030 & $1800-2200$ & 64,000 & $20 \times 30$ & $222 \times 37{ }^{\prime \prime} \times 341 / 4$ \\
\hline
\end{tabular}

Notes:

1. BTUH capacities are based on $140^{\circ}$ EWT, $70^{\circ}$ EAT, FIRST CO. Flow Control module, and average air flows.

2. Consult factory for boiler applications. 

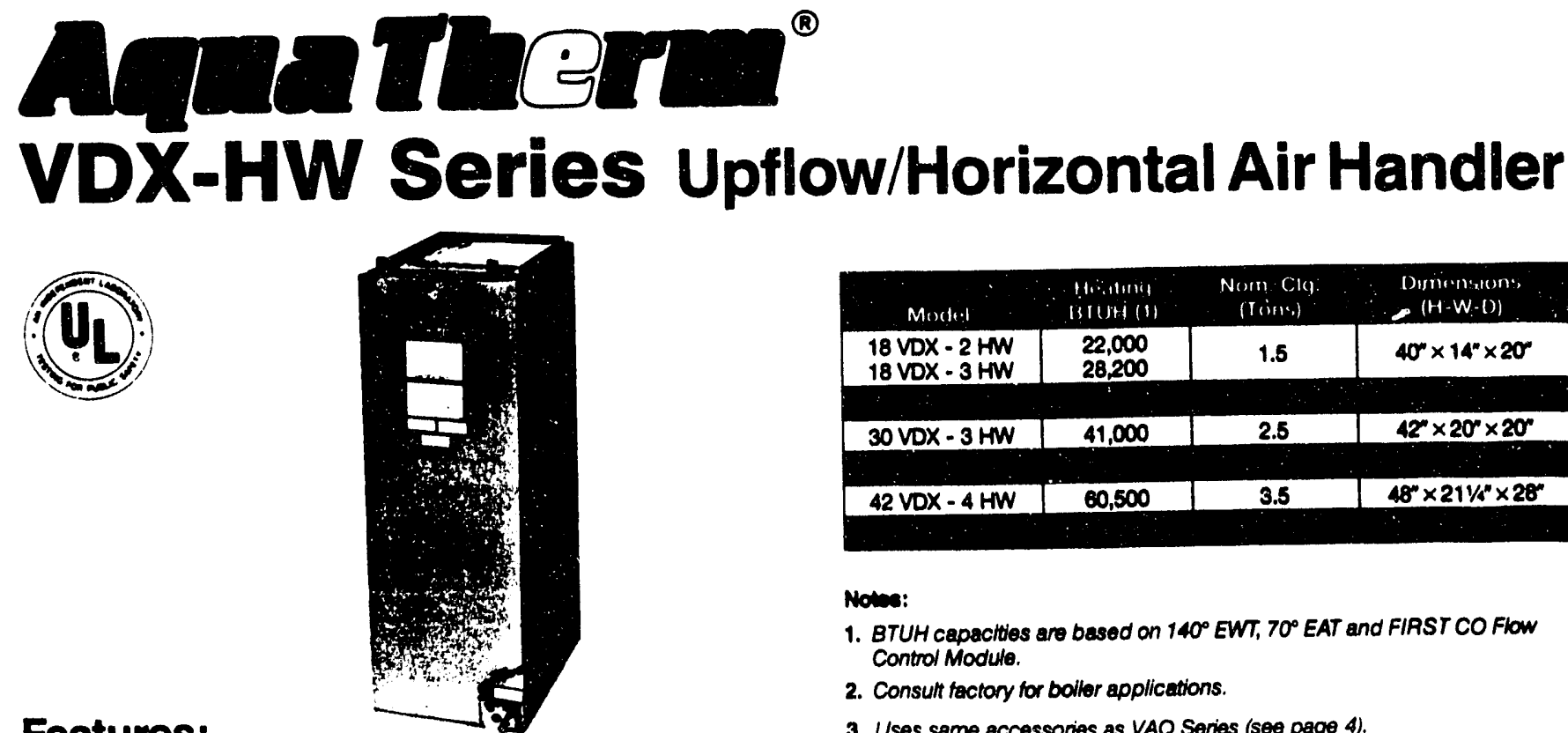

\begin{tabular}{|c|c|c|c|}
\hline Model & 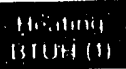 & 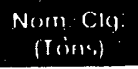 & $\begin{array}{l}\text { Dirnomisun: } \\
s(H-W-D)\end{array}$ \\
\hline $\begin{array}{l}18 \mathrm{VDX}-2 \mathrm{HW} \\
18 \mathrm{VDX}-3 \mathrm{HW}\end{array}$ & $\begin{array}{l}22,000 \\
28,200\end{array}$ & 1.5 & $40^{\circ} \times 14^{\prime \prime} \times 20^{\circ}$ \\
\hline 30 VDX - $3 \mathrm{HW}$ & 41,000 & 2.5 & $0 \times 20^{\circ}$ \\
\hline $42 \mathrm{VDX}-4 \mathrm{HW}$ & 60,500 & 3.5 & \\
\hline
\end{tabular}

Nown:

1. BTUH capactiles are based on $140^{\circ} \mathrm{EWT}, 70^{\circ}$ EAT and FIRST CO FIow Control Module.

Features:

2. Consult factory for bollor applications.

3. Uses same accessories as VAQ Series (seo page 4).

Copper tube/aluminum fin heating and cooling coils

- Factory installed filter

- Primary and secondary drain connections

- Manual air vent on hot water coil

Blower door safety switch

Attractive beige baked-on finish

- Horizontal drain pan available for 2.0 through 4.0 ton models

Shipped with exclusive U.L. listed "Flow Control" module

\section{MAX-HW Series Upflow/Horizontal Air Handler}

\section{Features:}

In addition to all of the above VDXHW features (1 through 6), the MAXHW Series has:

- Extra large high efficiency cooling coll for proper matching with today's higher efficiency condensing units.

- Field installable expansion valve kit for more efficient cooling performance. (Piston type metering is standard)

a Factory installed horizontal drain pan (right to left airflow).

- Slide out hot water coll assembly for easier service.

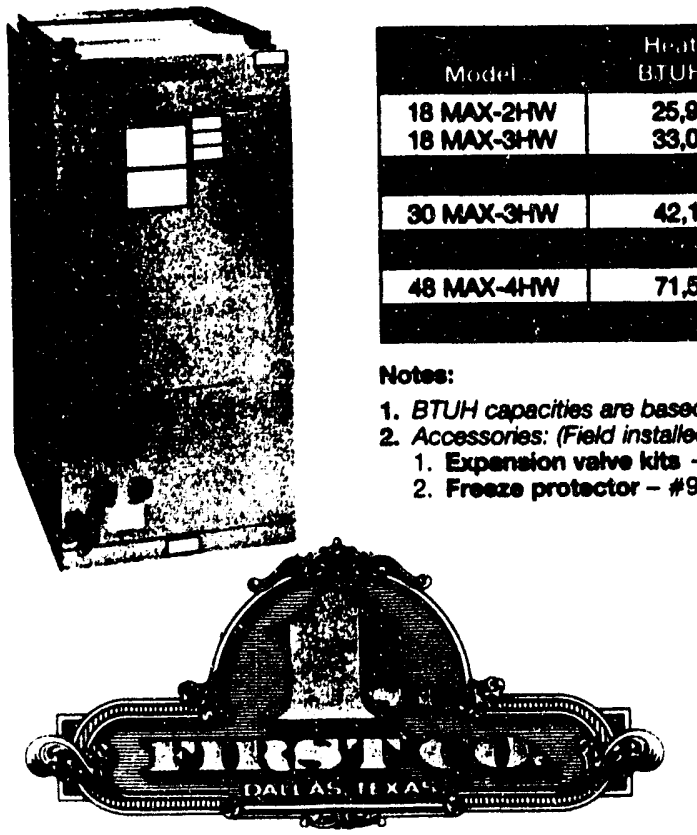

FIRST CO.

8273 Moberty Lane Dallas, Texas 75227 (214) 388-5751

FAX-214-388-2255 
APPENDIX G

APPLIANCE VENTING

G-1 


\section{AN OVERVIEW OF GRI'S VENTING RESEARCH PROGRAM AND PRACTICAL IMPLICATIONS OF REVISED APPLIANCE VENTING GUIDELINES}

R. A. Borgeson, American Gas Association Laboratories, Cleveland, Ohio

D. D. Paul, Battelle, Columbus, Ohio

and

L. R. Brand, Gas Research Institute, Chicago, Illinois

ABSTRACT

The appropriate American National standards Institute groups are currently considering substantially updating the venting guidelines in the National Fuel Gas Code including new vent sizing tables for Appendix G. These new standards are expected to include improved methods of categorization which will ensure that the vent design is consistent with the appliance operating characteristics. The technical background for these changes was developed by the Gas Research Institute's Venting/Flue Gas Management Project.

This paper will begin by providing an overview and status report of the entire Venting/Flue Gas Management Project. Then, it will illustrate the practical effects in the field that are expected to result from these revisions. First, the expected changes to appliance design will be discussed. Then, a comparison of the new and revised venting guidelines will be used to show how vent sizing and material selection will be modified. Throughout, the rationale motivating these changes will be explained.
INTRODUCTION

objective

The purpose of this paper is to provide an overall briefing on the purpose, accomplishments, and plans of the Gas Research Institute's (GRI) Venting/Flue Gas Management project("the venting project"). Additionally, a brief technical rationale for the proposed changes and their expected implications in the field will be presented.

Industry Challenge

The most significant result of the venting project thus far are improved vent sizing tables for fan-assisted, Category I appliances. These tables, along with improved, generic venting and installation instructions, have already been introduced into the field. Local servicemen, installers, and code officials need to be supplied with this information so that the transition will proceed with a minimum of confusion.

\section{VENTING PROJECT ORGANIZATION}

Purpose

The purpose of the GRI venting project is to address the need to change the methods for venting the products of combustion from modern gas appliances. Most of the current venting recommendations, as 
embodied in the National Fuel Gas Code $^{1}$ (NFGC), were developed in the 1950 's for the appliances available at that time. Since the energy crisis of the 1970's, significant changes in appliance design have occurred. In light of changing appliance technology, the ANSI subcommittee for central furnaces(Z21.47) and other gas industry groups requested GRI support to make a thorough review of all the issues concerning gas venting and recommend changes as necessary. GRI responded by funding the venting project.

\section{Principals}

The venting project was organized by GRI in 1987. The project is conducted jointly by The American Gas Association Laboratories (A.G.A.L.) and Battelle.

The venting project has a critical need for constant review and guidance from the different segments of the gas industry. For this reason, GRI organized a Technical Advisory Group(TAG) to monitor the progress of the project. The TAG includes members representing gas utilities, appliance manufacturers, and gas venting product manufacturers. Most of the members are also active in standards committees covering their area of the industry. Thus, the TAG provides an avenue for direct dialogue between the researchers, the standards bodies, and the affected industry group. The TAG has proven to be very effective in expediting industry consensus when new venting recommendations are under development.

\section{Project Tasks}

The following tasks have been active during the project:

$$
\begin{aligned}
& \text { 1. Vent oversizing, } \\
& \text { 2. Combustion Air } \\
& \text { Supply, } \\
& \text { 3. Common Venting, } \\
& \text { 4. Multistory Venting, } \\
& \text { 5. Corrosion Test } \\
& \text { Methods, } \\
& \text { 6. Categorization, } \\
& 7 \text {. F i e I d } \\
& \text { Investigations, } \\
& \text { 8. Masonry Chimneys, } \\
& \text { and Technology Transfer. } \\
& \text { 9. Techolo }
\end{aligned}
$$

Initially, the highest priorities were placed on vent oversizing, categorization, and corrosion test methods. Each of these tasks are now substantially completed. Therefore, the focus of the project is currently concentrated on a thorough investigation of masonry chimneys, combustion air. supply, and multistory venting. The remainder of the paper will concentrate on the areas of vent sizing and categorization, installation instructions, masonry chimney issues, corrosion test methods, and multistory venting.

\section{VENTING PROJECT RESULTS}

\section{Vent sizing and Appliance Categorization}

Traditional gas appliances were designed with a draft hood and depended on natural buoyancy to vent their products of combustion. The operating characteristics of many different types of appliances were quite similar. Therefore, generic venting and installation guidelines were developed "for any gas appliance" and were embodied in the NFGC. Individual 
appliances could simply refer in their installation instructions to the NFGC for detailed installation and vent sizing guidelines. The venting guidelines were structured as vent sizing tables.

The current NFGC vent sizing tables list "maximum capacities" for a given vent configuration. The maximum capacity is defined as the largest appliance input rating which can safely vent using a certain vent diameter and geometry. The maximum value is derived by requiring that no spillage will occur at the draft hood and that, the vent system will operate at a nonpositive static pressure. Naturally, the development of these tables required making general engineering assumptions about the vent gas temperatures and the amount of excess combustion air and draft hood dilution air.

The introduction of midefficiency (AFUE = 78\%-83\%) and high-efficiency (AFUE $>$ 90\%) appliances, many of which use fan-assisted combistion systems, meant that the assumptions underlying the vent sizing tables might not always be valid. For example, condensing appliances clearly are not meant to be vented with traditional venting products. It became necessary to develop a method to determine which appliances could still be vented using the NFGC. This led to the current ANSI categorization method which is schematically shown in Figure 1 . The categorization method was designed in such a way that Category I appliances could still use the generic guidelines of the NFGC. This category includes traditional, draft hood-equipped appliances as well as most midefficiency, fan-assisted models.
Appliances in the other three categories must be vented using the manufacturer's specific instructions.

After several years of field experience, the 221.47 subcommittee requested GRI support to reevaluate the categorization method. Concurrently, they requested research on eliminating the possibility of "vent oversizing", which was perceived as a possible source of vent or appliance corrosion. The initial research led to the conclusion that the categorization method could be improved and that, new vent sizing tables were needed. Most importantly, it was shown that the two separate topics should be treated as one. This makes it possible to design categorization tests and vent sizing tables using identical engineering assumptions. The recommendations for categorization ${ }^{2}$ and vent sizing tables ${ }^{3}$ are detailed in the references cited. In summary, the results and recommendations are:

$$
\begin{aligned}
& \text { 1. New vent sizing } \\
& t \text { a b } 1 \text { e s a n d } \\
& \text { categorization criteria } \\
& \text { should both use a } \\
& \text { steady-state appliance } \\
& \text { efficiency of } 83 \text { as a } \\
& \text { worst case design } \\
& \text { assumption: }
\end{aligned}
$$

2. New venting tables were developed for fanassisted appliances having both maximum and minimum capacities. The minimums are designed to reduce condensation and corrosion; and

3. The test setup for the categorization test, along with the defined boundaries of 


\section{ANSI CATEGORIZATION CRITERIA}

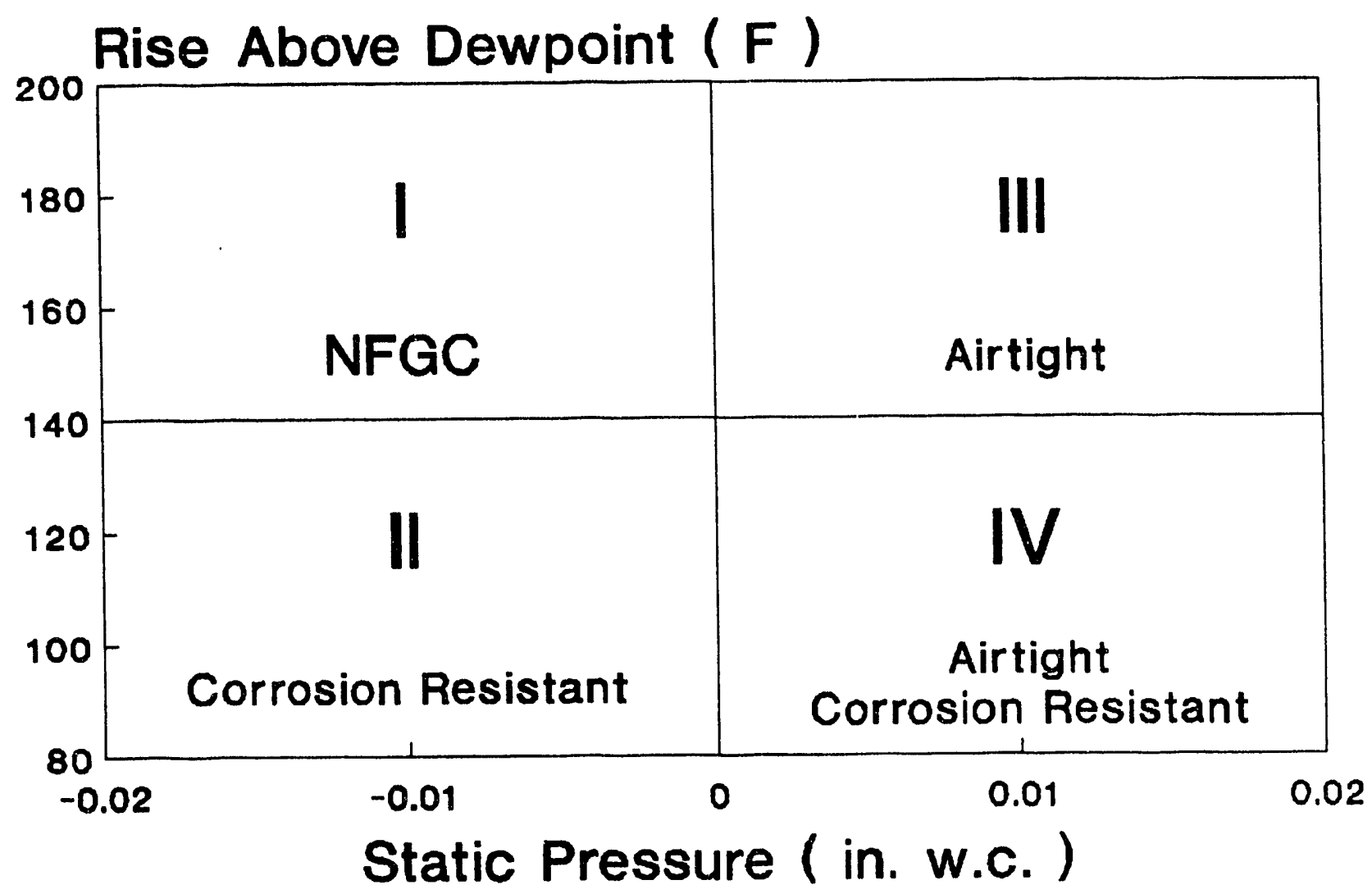

Figure 1 - Current ANSI Categorization Criteria

Category I should be altered to reflect the assumptions used for the table development.

These new tables have already been introduced into the field by members of the Gas Appliance Manufacturers Association (GAMA). An example of a portion of one table is shown in Figure 2. The column labelled "NAT MAX" is for draft hood-equipped appliances. The "FAN MIN" and "FAN MAX" columns form a range of acceptable inputs for fanassisted appliances. In 1992, the tables are expected to be incorporated into the NFGC.
Additional information about the new tables may be obtained through GAMA or A.G.A.L.

A schematic of the recommended alterations to the categorization criteria is shown in Figure 3. The change to temperature criteria is intended to make sure that appliances in Category I operate at less than 83\% steady state efficiency and are therefore compatible with the sizing tables. The categorization recommendations are expected to be adopted by the 221.47 subcommittee.

The introduction of new vent 
NEW TABLE

Example Of Common Vent Connector Table

Vent Connector Capacity

\begin{tabular}{|c|c|c|c|c|c|c|c|c|c|c|}
\hline \multirow{5}{*}{$\begin{array}{c}\text { Vent } \\
\text { Height } \\
\text { H } \\
\text { (FT) }\end{array}$} & \multirow{5}{*}{$\begin{array}{c}\text { Connector } \\
\text { Rise } \\
\mathbf{R} \\
\text { (FT) }\end{array}$} & \multicolumn{9}{|c|}{ Vent Connector Diameter - D } \\
\hline & & \multicolumn{3}{|c|}{$3^{\prime \prime}$} & \multicolumn{3}{|c|}{ 4" } & \multicolumn{3}{|c|}{$5 "$} \\
\hline & & \multicolumn{9}{|c|}{ Appliance Input Rating Limits in Thousands of Btu Per Hour } \\
\hline & & \multicolumn{2}{|c|}{ FAN } & $4 \%$ & \multicolumn{2}{|c|}{ FAN } & 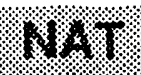 & \multicolumn{2}{|c|}{ FAN } & Natr. \\
\hline & & MIN & MAX & Wor & MIN & MAX & mor & MIN & MAX & max \\
\hline
\end{tabular}

\begin{tabular}{|r|r|r|r|rr|r|rrr|r|}
\hline 10 & 1 & 22 & 43 & 28 & 34 & 78 & 50 & 49 & 123 & 78 \\
& 2 & 23 & 47 & 33 & 36 & 86 & 59 & 51 & 136 & 93 \\
& 3 & 24 & 50 & 37 & 37 & 92 & 67 & 52 & 146 & 104 \\
\hline 15 & 1 & 21 & 50 & 30 & 33 & 89 & 53 & 47 & 142 & 83 \\
& 2 & 22 & 53 & 35 & 35 & 96 & 63 & 49 & 153 & 99 \\
& 3 & 24 & 55 & 40 & 36 & 102 & 71 & 51 & 163 & 111 \\
\hline 20 & 1 & 21 & 54 & 31 & 33 & 99 & 56 & 46 & 157 & 87 \\
& 2 & 22 & 57 & 37 & 34 & 105 & 66 & 48 & 167 & 104 \\
& 3 & 23 & 60 & 42 & 35 & 110 & 74 & 50 & 176 & 116 \\
\hline
\end{tabular}




\section{PROPOSED CATEGORIES}

\section{Flue Gas Temperature ( F )}

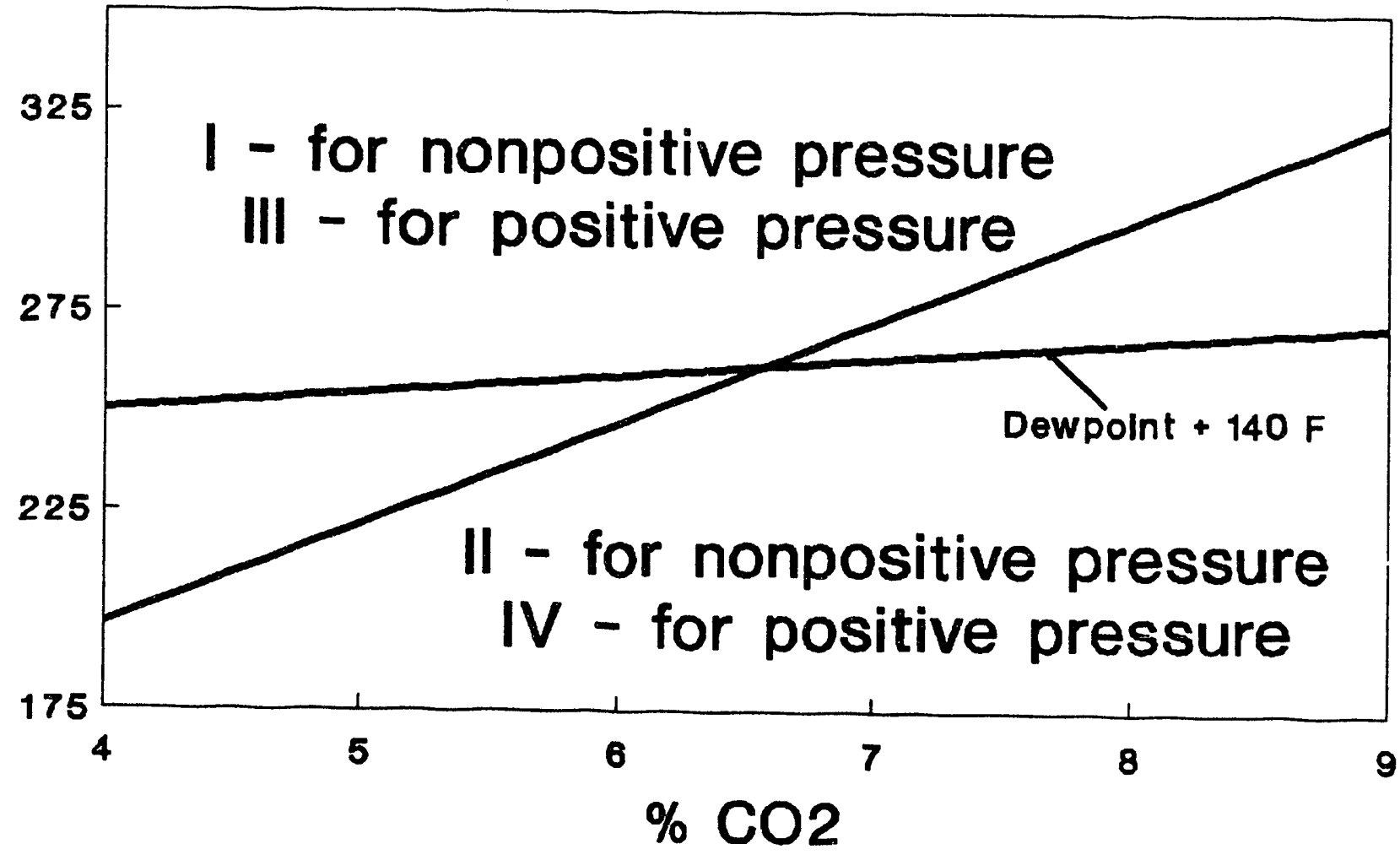

Figure 3 - Proposed Categorization Criteria

sizing and appliance categorization criteria have several implications to appliance design and installation practices. First, the modified categorization test rig will require an appliance to use a slightly larger diameter flue outlet. of course, flue outlets generally come with diameters that are multiples of one inch so that the available venting products will fit. so practically, category I appliances whose vent pressures were previously near neutral will increase their flue outlet diameters by one inch. For example, a 75,000 Btuh furnace with a 3 inch diameter will probably now use 4 inches instead. The vent sizing tables will help reduce occurrences of excessive condensation. The primary affect on installation practice will be to encourage the use of Type $B$ vent for vent connectors in preference to single wall galvanized pipe.

\section{Installation Instructions}

At the time the venting project was organized, there was a perception in the industry that the installation instructions for 
Category I fan-assisted appliances had unwarranted differences from manufacturer to manufacturer. This could potentially create confusion in the installation community. Therefore, the venting project conducted a literature review of marufacturer's installation instructions to assess the situation.

With the cooperation of GAMA, the venting project obtained samples of the installation instructions as d supplementary technical bulletins from 15 brands of Category I, fanassisted furnases. These were analyzed for eontent and scope. In all, 25 specific topics pertinent to venting were identified. Examples of these topics include, "Do the instructions define the meaning of appliance categories?" or "Do the instructicns explain the need for clean combustion air?" Each installation instruction was analyzed to catalog how the topic was coveres.

In fact, wide discrepancies in both what was covered and how it was covered were documented. These findings formed the basis for a set of recommendations ${ }^{4}$ supplied to the $\mathrm{Z21.47}$ subcommittee. This report lists recommended topics pertaining to ventincy which ought to be covered corsistently in each installation instruction.

The $\mathrm{Z} 21.47$ subcommittee is currently in the process of requiring a consistent format for furnace installation instructions. At least one major manufacturer has already rewritten their instructions in anticipation of this standards change. of course, the venting recommendations being distributed by GAMA furnace manufacturers will also help to make venting installation practice more uniform.

\section{Masonry Chimneys}

Thus far, the vent sizing tables being distributed cover metallic venting systems such as Type $B$ double wall and single wall galvanized vent pipe. However:, in some parts of the country, many homes use an existilig masonry chimney for venting. Therefore, related recommenciations for masonry chimneys are currently under development. The development has included theoretical modelling, experimental observations, and field investigations.

To obtain practical information on masonry chimney condition, over 160 chimneys were inspected. It was found that the primary mechanism for chimney damage is excessive condensation. This can be exacerbated by freeze/thaw cycles or combustion air contamination. In the course of these inspections, it was found that chimney inspection procedures vary widely depending on the knowledge and experience of the inspector. The procedures nbserved were synthesized into a consistent field inspection procedure for masonry chimneys ${ }^{5}$. This reference also includes sizing tables for flexible metalic chimney lining systems.

Initial comparisons between VENT-II6 predictions and experimental measurements made in masonry chimneys showed that the assumption of uniform flow implicit in the model was not correct. This caused the overall heat transfer in the chimney to be under-predicted. Two fullscale experiments were built to 
support the development of an improved masonry chimney model. At Battelle, an instrumented masonry chimney was built that meets the specifications of the applicable NFPA standard?. It A.G.A.L., a chimney was constructed of a transparent, high temperature thermoplastic for flow visualization. Both chimneys have confirmed that two zones of non-uniform flow exist. They are caused by jet impingement at the breaching where the flue gases enter and unsteady recirculation at the chimney top. VENT-II is being enhanced to account for these effects.

current recommendations concerning masonry chimneys are:

1. Masonry chimneys require substantial amounts of dilution air to reduce condensation. Therefore, fan-assisted appliances should not be vented using a tile-lined masonry chimney unless a source of dilution air exists; and

2. Typical common venting systems including a fanassisted appliance and a draft hood-equipped water heater can be vented into tile-lined chimneys using new sizing tables similar to those discussed above.

Research on masonry chimneys is currently the top priority of the venting project. Research areas include:

1. Materials testing to determine which damage mechanisms are most destructive,

2. The possible need for codes to regulate venting of engine-driven systems in masonry chimneys,

3. Finalizing the
sizing tables for
masonry chimneys,

4. Alternate methods for supplying dilution air, and

5. Field testing of the inspection procedure.

\section{Tests For Corrosion Resistance}

When the first higherefficiency, near-condensing appliances were introduced(some with AFUE's approaching 90\%), some problems with corrosion of heat exchangers or vents occurred. Therefore, GRI has conducted research into the causes of this corrosion since 1983. It was determined that the corrosion was caused by chlorides in the flue gas condensate. The presence of chlorides points to combustion air contamination as the ultimate source of the problem. During 1983-1985, a field survey confirmed this and produced a statistical distribution of chloride levels found in, normal field installations ${ }^{9}$.

Practically speaking, the homeowner controls (perhaps, without knowing it) the amount of combustion air contamination in the home. The appliance designer cannot rely on warnings to provide clean sources of air to the appliance. After all, this in effect asks the homeowner to alter their lifestyle. Therefore, appliances and vents need to have corrosion resistance designed to meet real-world levels of contamination. To meet this need, GRI has provided technical support to assist in the 
development of a standard ANSI performance test for corrosion resistance. This work began as a task of the Gas Appliance Technology center (GATC) ${ }^{10}$ and was later spun off into the venting project.

The corrosion test methodology under development ${ }^{11}$ is based on artificially creating corrosive flue gases in a controllable manner. The corrosivity of the flue gases is controlled by introducing trace amounts of CFC R-11 (Freon) into the fuel gas supply. In the combustion zone, the $\mathrm{R}-11$ disassociates into chloride and fluoride ions, in approximately the ratio observed in the field study. Note that the $\mathrm{R}-11$ is destroyed in the process, eliminating any environmental concerns.

The furnace under test is cycled 12,000 times on a 4 minute ON, 8 minute OFF cycle. At the end of the test, the appliance is expected to operate properly with no perforations of the heat exchanger. Thus, this is a go/nogo test, similar to the thermal cyclic test for furnaces which is already in use. Tests of this type require severe conditions to properly differentiate units which pass or fail. Therefore, the level of spiking chosen is much higher than the average found in the field study.

Thus far, 34 furnaces representing il models have been tested at different spiking levels. These furnaces include condensing and non-condensing models which may be draft hoodequipped or fan-assisted systems. The purpose of these tests is to determine through experience what spiking level will reliably differentiate between appliances which have good corrosion records, as opposed to those which do not. At the time of this writing, the recommended spiking level for appliances which use indoor combustion air is $150 \mathrm{ppm}$ $\mathrm{Cl}^{\circ}$ in fully condensed condensate. A similar test methodology for boilers which uses 4800 cycles( 10 minutes $O N, 20$ minutes OFF) is also under development.

\section{Multistory Vents}

Many low rise garden apartments feature individual gas appliances in each suite. They are typically placed in dedicated furnace rooms and are common vented into one vertical vent. There has been a need to assess whether fan-assisted appliances can be successfully retrofit into these existing installations. For this study, a full-scale experiment has been constructed at A.G.A.Z. (see Figure 4 ).

The multistory test facility ${ }^{12}$ is three stories high with separate furnaces and water heaters in each alcove. The venting system was designed to code as if 60,000 Btuh, draft hood-equipped furnaces were originally installed. However, $40,000-45,000$ Btuh, midefficiency furnaces were actually used to simulate the retrofit. The entire vent system is fully instrumented and controlled by computer. Normally the system vents into the test bay. However, the vent may be extended out through the roof of the laboratory to cause significant depressurizations with respect to the vent outlet. Facilities are also available for studying the possibility of supplying outdoor combustion air through a manifolded downcomer to relieve this depressurization.

Tests have been conducted by 


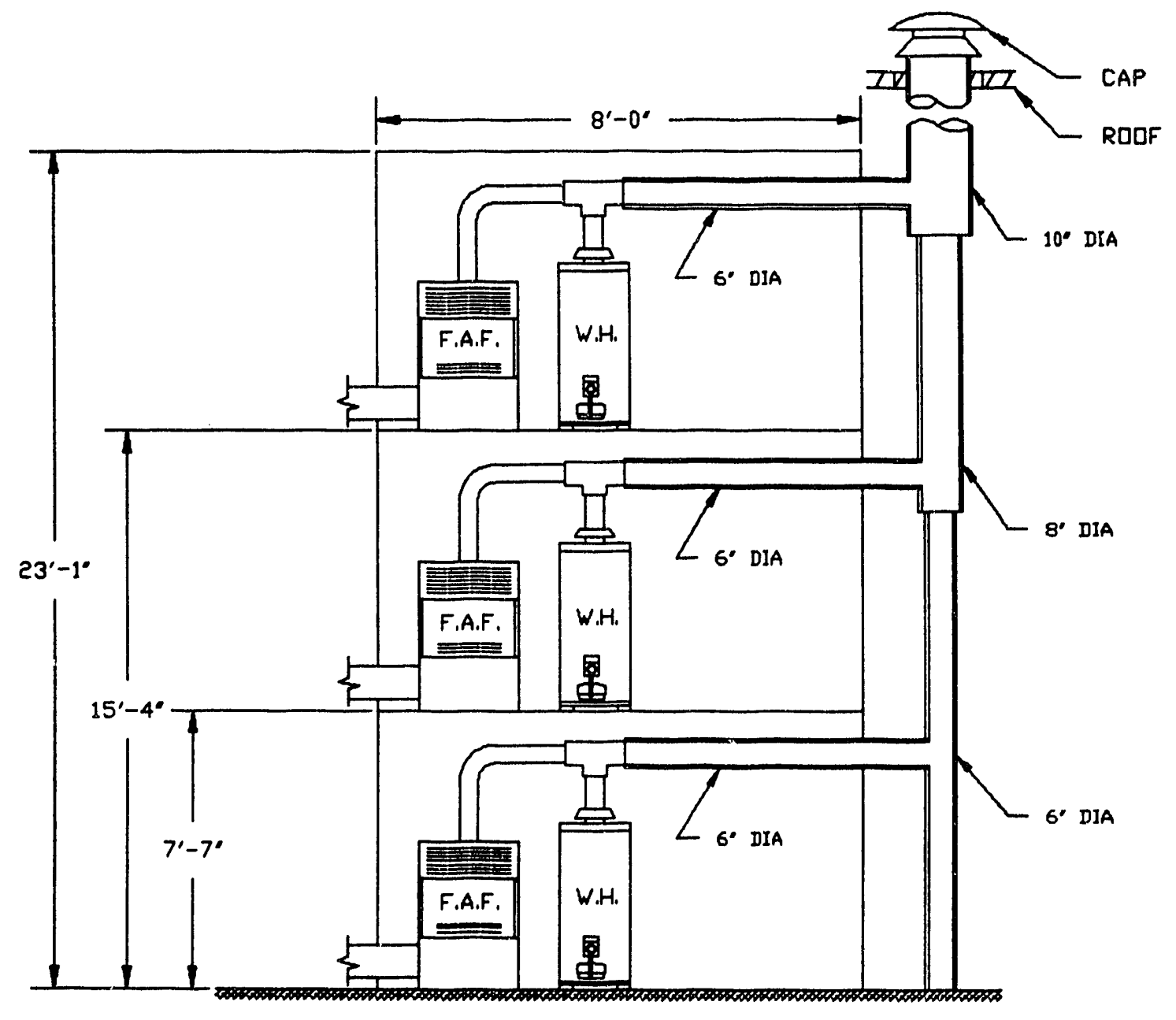

Figure 4 - Multistory Venting Facility

cycling different combinations of appliances and monitoring for any undesirable conditions. Failure modes have been studied by creating worst case situations such as total blockage. Some preliminary conclusions are:

1. The large amount of dilution air entrained by this vent system provides a good buffer against excessive condensation; and

2. The worst case failure modes applied equally to the draft hood-equipped appliances and were not caused by the retrofit operation.

Overall, our conclusion is that retrofitting fan-assisted appliances into a multistory vent which meets the code does not introduce any additional risks for venting failure.

Conclusion

The GRI venting research program has provided significant 
technical support for updating the existing venting guidelines. These guidelines are expected to help utilities and installers to practice more consistent venting methods in the field. In turn, this will promote venting system installations of uniform, high quality and safety.

\section{ACKNOWLEDGEMENTS}

The authors wish to acknowledge the guidance and support we have received from our Technical Advisory Group. The TAG has been invaluable in helping us target our research so that it will gain expedited industry acceptance. This work was supported by GRI contract \# 5088-245-1728 and 5087-245-1523. The GRI project manager is Larry Brand.

\section{REFERENCES}

1. "National Fuel Gas Code", ANSI Z223.1-1988 or NFPA 54-1988, National Fire Protection Association, Quincy, MA 1988.

2. "A Reappraisal of Categorization criteria For Venting Gas Appliances", R.A. Borgeson, et al., GRI Topical Report, GRI-90/0150, 1990.

3. "Venting Guidelines For Category I Gas Appliances", D. D. Paul, et al., GRI Topical Report, GRI-89/0016, 1990.

4 . "Recommendations For Manufacturer's Installation Instructions For Venting of Category I Fan-Assisted Combustion Furnaces", R. A. Borgeson, White Paper, American Gas Association Laboratories, Cleveland, Ohio, 1988.

5. "Masonry Chimney Inspection And Relining", E. B. Gordon et al., GRI Topical Report, GRI-
$90 / 0149,1990$.

6. "User's Manual For VENT-II (Version 4.0) With Diskette: A Dynamic Microcomputer Program For Analyzing Common Venting systems For Two Gas Appliances", A. L. Rutz, et al., GRI Topical Report, GRI-89/0094, 1989 .

7. "Standard For Chimneys, Fixeplaces, Vents, and Solid Fuel Burning Appliances", NFPA 2111988, National Fire Protection Association, Quincy, MA, 1988.

8. "Special Laboratory Facility For Venting Research", Gas Appliance And Space Conditioning Newsletter, Cleveland, Ohio, December 1989, p. 3 .

9. "Technology Development For Corrosion-Resistant Condensing Heat Exchangers", G. H. stickford, et al., GRI Final Report, GRI-85/0282, 1985.

10. "GRI's Gas Appliance Technology Center, 1987 Annual Report: Activity of A.G.A. Laboratories", C. A. Farnsworth, et al., GRI Annual Report, GRI$88 / 0008,1988$.

11. "Corrosion Test Method For Furnaces And Vents - Second Update Resulting From Industry Comments", S. G. Talbert, et al., GRI Topical Report, GRI-90/0029, 1990.

12. "Multistory Common Venting For Fan-Assisted Appliances", V. Kam, et al., GRI Topical Report, GRI-90\%0148， 1990. 

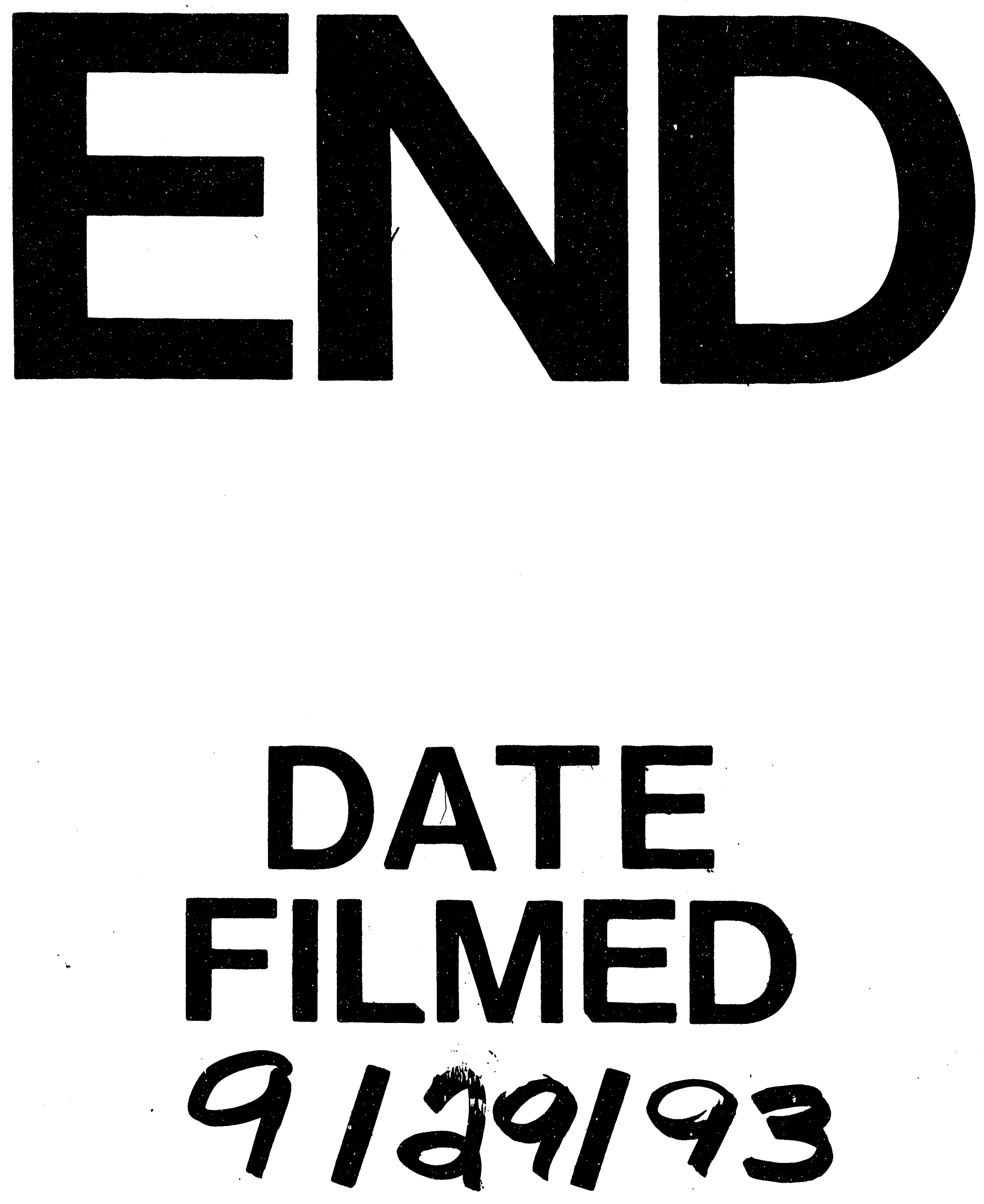

. 
